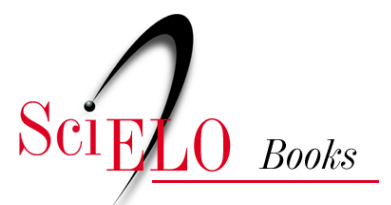

\title{
Carlos Chagas, um cientista do Brasil Carlos Chagas, scientist of Brazil
}

\author{
Simone Petraglia Kropf \\ Aline Lopes de Lacerda \\ Diane Grosklaus Whitty (trad.)
}

\section{SciELO Books / SciELO Livros / SciELO Libros}

KROPF, S.P., and LACERDA, A.L. Carlos Chagas, um cientista do Brasil = Carlos Chagas, scientist of Brazil [online]. Translated by Diane Grosklaus Whitty. Rio de Janeiro: Editora FIOCRUZ, 2009, 306 p. ISBN: 978-65-5708-000-9. https://doi.org/10.7476/9786557080009.

\section{International license.}

Todo o conteúdo deste trabalho, exceto quando houver ressalva, é publicado sob a licença Creative Commons Atribição 4.0. 



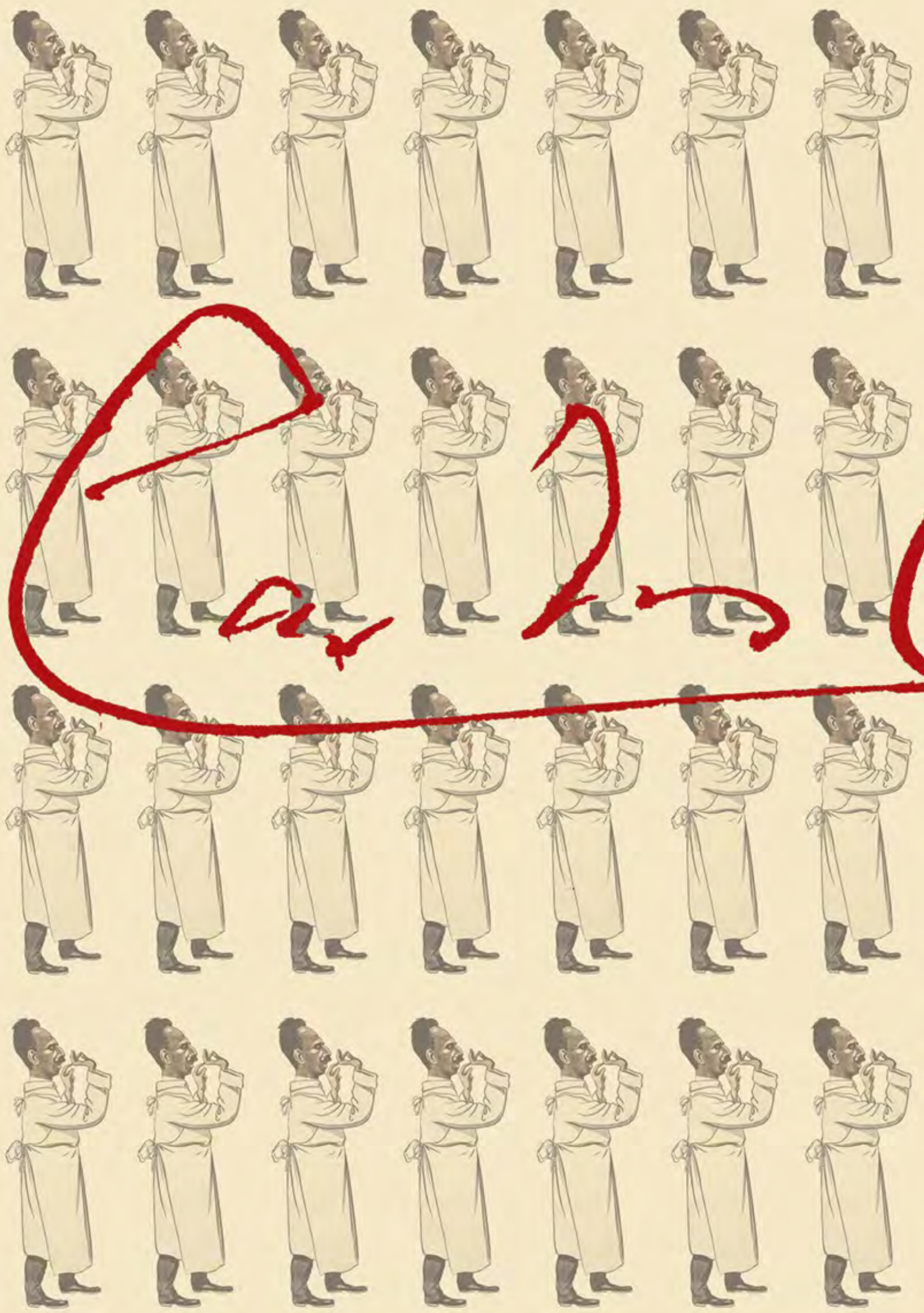



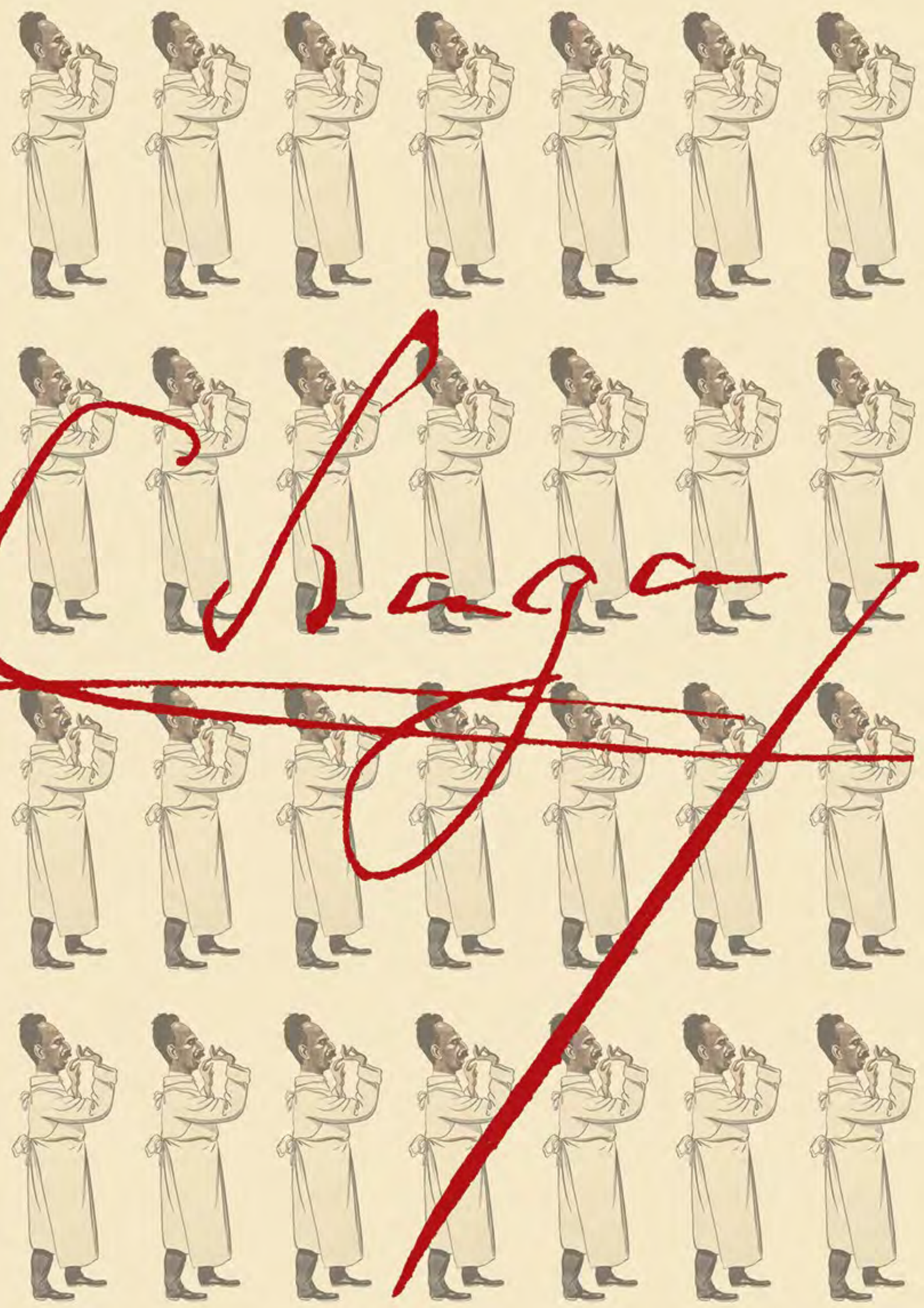


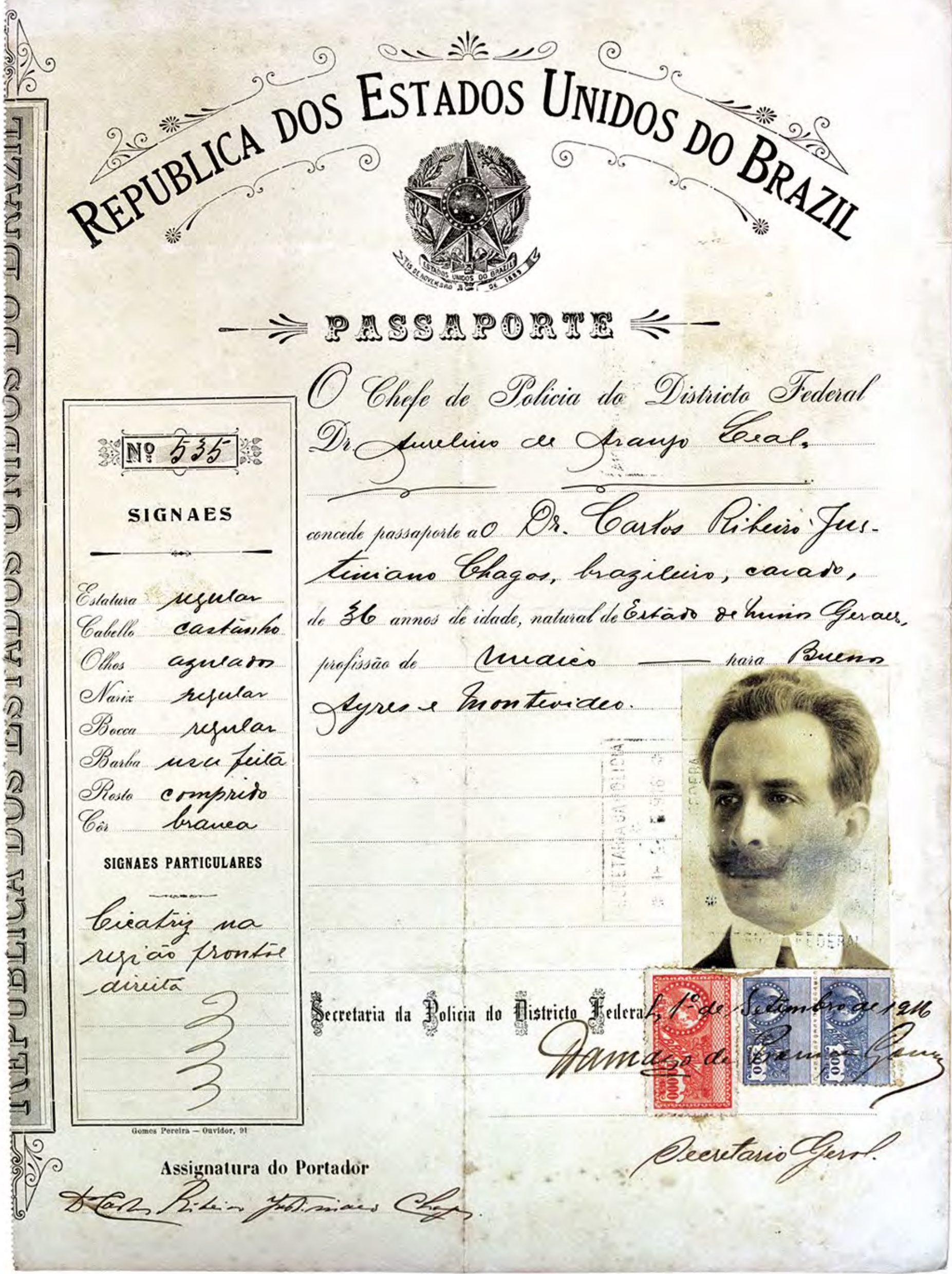




\section{Fundação Oswaldo Cruz}

Presidente

President

Paulo Gadelha

Vice-Presidente de Ensino, Informação e Comunicação

Vice President of Teaching, Information, and

Communication

Maria do Carmo Leal

\section{Editora Fiocruz}

Diretora

Director

Maria do Carmo Leal

Editor Executivo

Managing Editor

João Carlos Canossa Mendes

Editores Científicos

Science Editors

Nísia Trindade Lima

Ricardo Ventura Santos

Conselho Editorial

Editorial Board

Ana Lúcia Teles Rabello

Armando de Oliveira Schubach

Carlos E. A. Coimbra Jr.

Gerson Oliveira Penna

Gilberto Hochman

Joseli Lannes Vieira

Lígia Vieira da Silva

Maria Cecília de Souza Minayo 


\section{Carlos Chagas \\ um cientista do Brasil scientist of Brazil}

Simone Petraglia Kropf

Aline Lopes de Lacerda

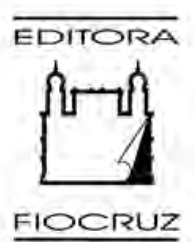


Copyright $\odot 2009$ das autoras

Copyright $\odot 2009$ by the authors

Todos os direitos desta edição reservados à

All rights reserved by

Fundação Oswaldo Cruz/Editora

ISBN: 978-85-7541-188-9

Capa, projeto gráfico e editoração eletrônica

Cover, graphic design, and electronic editing

Fernando Vasconcelos

Copidesque e revisão em português

Copyediting and proofreading

Irene Ernest Dias

Normalização de referências

Reference formatting

Clarissa Bravo

Reprodução e digitalização de imagens

Reproduction and digitization of images

Roberto Jesus Oscar

Vinicius Pequeno

Pesquisa de fontes e edição de textos

Research of sources and text editing

Luis Octavio Gomes de Souza

Assistentes de pesquisa

Research assistants

Luis Octavio Gomes de Souza

Deyse Pimenta Cacau

Demian Bezerra de Mello

Administração do projeto

Project management

Sociedade de Promoção da Casa de Oswaldo Cruz (SPCOC)

Catalogação na fonte

Cataloging in publication

Centro de Informação Científica e Tecnológica

Biblioteca da Escola Nacional de Saúde Pública Sergio Arouca

K93c Kropf, Simone Petraglia

Carlos Chagas, um cientista do Brasil = Carlos

Chagas, scientist of Brazil. / Simone Petraglia Kropf e

Aline Lopes de Lacerda ; tradução de Diane Grosklaus

Whitty. - Rio de Janeiro : Editora FIOCRUZ, 2009.

308 p., il.

Título e texto em português e inglês

1. Doença de Chagas - história. 2. História do Século 20. 3. Ciência - história. 4. Doenças Transmissíveis história. 5. Brasil. 6. Carlos Chagas. 7. Saúde pública história. 8. Iconografia I. Lacerda, Aline Lopes de. II. Título.

CDD - 22.ed. -616.93630981

Editora Fiocruz

Av. Brasil, 4036 - Térreo - sala 112 - Manguinhos

21040-361 - Rio de Janeiro/RJ

Tels.: +55 (21) 3882-9039 e 3882-9041

Fax: + 55 (21) 3882-9006

e-mail: editora@fiocruz.br

http://www.fiocruz.br/editora 


\section{Autoras/Authors}

Simone Petraglia Kropf é graduada em ciências sociais pela Pontifícia Universidade Católica do Rio de Janeiro (PUC-RJ), mestre em história social da cultura por esta mesma universidade e doutora em história social pela Universidade Federal Fluminense (UFF). É pesquisadora e professora do Programa de Pós-Graduação em História das Ciências e da Saúde da Casa de Oswaldo Cruz/Fundação Oswaldo Cruz (COC/Fiocruz). É autora, entre outras publicações, de Doença de Chagas, Doença do Brasil: ciência, saúde e nação (1909-1962), pela Editora Fiocruz (2009).

Simone Petraglia Kropf received a B.A. in Social Sciences and an M.A. in the Social History of Culture from the Pontifícia Universidade Católica do Rio de Janeiro and a Ph.D. in Social History from the Universidade Federal Fluminense. She is a Researcher and Professor at the Graduate Program in the History of the Sciences and of Health, Casa de Oswaldo Cruz/Fundação Oswaldo Cruz (COC/Fiocruz). Her publications include Doença de Chagas, Doença do Brasil: ciência, saúde e nação (1909-1962) (Editora Fiocruz: Rio de Janeiro, 2009).

Aline Lopes de Lacerda é graduada em história pela Universidade Federal do Rio de Janeiro (UFRJ), mestre em comunicação e cultura por esta mesma universidade e doutora em história social pela Universidade de São Paulo (USP). É pesquisadora do Departamento de Arquivo e Documentação da Casa de Oswaldo Cruz/Fundação Oswaldo Cruz (COC/Fiocruz) e especialista em arquivos fotográficos.

Aline Lopes de Lacerda received a B.A. in History and an M.A. in Communication and Culture from the Universidade Federal do Rio de Janeiro and a Ph.D. in Social History from the Universidade de São Paulo. She is a Researcher at the Department of Archives and Documentation, Casa de Oswaldo Cruz/Fundação Oswaldo Cruz (COC/Fiocruz), specializing in photographic archives. 
Patrocínio/Sponsorship

\section{sanofi aventis}

O essencial é a saúde 


\section{Sumário/Contents}

$\begin{array}{ll}\text { Prefácio } & 9\end{array}$

Preface

Apresentação

Introduction

$\mathrm{O}$ arquivo pessoal Carlos Chagas

Carlos Chagas's personal archive

Uma narrativa iconográfica

An iconographic narrative

1 Um menino do interior de Minas 25

A boy from rural Minas Gerais

2 Estudos médicos na capital do progresso

3 Combatendo a malária

A descoberta
The discovery

5 Estudos sobre a doença de Chagas

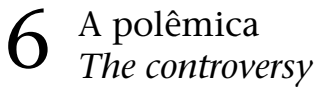

7 Expedição à Amazônia

8 Na direção de Manguinhos

9 Na saúde pública

10 No ensino médico Teaching medicine

11 Vida pessoal

12 Títulos e premiações

Bibliografia e acervos Bibliography and holdings 


\section{Prefácio}

Carlos Chagas é o detentor de um raro título na história das ciências brasileiras, por ter descoberto uma enfermidade tropical que carrega o seu nome: a doença de Chagas. Esse legado ao conhecimento biomédico é reconhecido como um fato científico ímpar, pois um mesmo pesquisador identificou não apenas a doença, mas também seu agente etiológico e o vetor de transmissão.

Esta bela obra - que reúne um conjunto iconográfico singular - é um convite para o mergulho prazeroso no legado de Carlos Chagas e da geração de médicos e sanitaristas que, liderados por Oswaldo Cruz, investiram de fortes tonalidades políticas a ciência que praticavam, destinada à construção de um futuro que redimisse a nação do que consideravam as amarras do passado colonial, visto como sinônimo de atraso. E eram muitas. Carlos Chagas e os demais membros de sua geração lançaram-se a esse desafio.

Ao afirmar que a nova enfermidade por ele identificada no sertão mineiro apresentava efeitos ampliados sobre a modernização do país, uma vez que as condições para sua ocorrência deitavam raízes na pobreza e nas más condições de vida das populações rurais, Carlos Chagas provocou perplexidade e indignação entre parte das elites da capital federal, recém-reformada como vitrine do "progresso" da jovem República brasileira. Um dos focos de resistência ocorreu na Academia Nacional de Medicina, que em 1910 o recebera como membro titular e na década de 1920 seria palco de uma acirrada polêmica. Ali o jovem cientista travou uma vigorosa batalha em defesa de suas idéias, questionadas vivamente por alguns luminares da medicina da época. Esses o acusavam de antipatriota e pessimista, pois o retrato de um país doente que Chagas ressaltava difamaria a imagem do Brasil ante as demais nações civilizadas.

Como sabemos, a história daria razão a Carlos Chagas, trazendo-lhe o reconhecimento que não alcançou de modo consensual entre os seus contemporâneos. Apesar dos avanços científicos e tecnológicos promovidos por gerações de pesquisadores que deram continuidade ao seu trabalho ao longo do século XX, a doença de Chagas permanece como um problema de saúde pública no Brasil e no continente americano. De acordo com estimativas recentes, a enfermidade atinge cerca de 12 a 14 milhões de indivíduos em 18 países endêmicos na América Latina. No Brasil, devido às migrações internas das últimas décadas, a maioria (cerca de 70\%) dos infectados vive nas cidades, sobretudo no Sudeste. Milhões de pacientes chagásicos aguardam o desenvolvimento de medicamentos mais eficazes, e nem se sabe ainda como (e se é possível) desenvolver uma vacina contra o Trypanosoma cruzi. Em 2006, o Brasil recebeu da Organização Mundial da Saúde (OMS) o certificado de interrupção da transmissão pela principal espécie vetora, o Triatoma infestans. Apesar disso, em várias regiões há espécies de triatomíneos silvestres que podem vir a domiciliar-se, criando novos focos de transmissão da doença. Os especialistas chamam a atenção para a necessidade de se manter a vigilância epidemiológica e as ações de controle e enfatizam, em particular, a importância dos aspectos socioambientais, uma vez que o convívio do vetor com os seres humanos está relacionado ao desmatamento e à precariedade das condições habitacionais.

Esta obra resultou de duas frentes de trabalho, representadas pelas autoras: a investigação sobre a história da pesquisa em doença de Chagas, desenvolvida de modo sistemático há uma década, à qual se associa a organização da documentação textual e iconográfica do arquivo pessoal de Carlos Chagas. A originalidade e a relevância desse arquivo foram reconhecidas em 2008 , quando recebeu a nominação no Registro do Programa Memória do Mundo da Organização das Nações Unidas para a Educação, a Ciência e a Cultura (Unesco), que muito nos honra e sobreleva a responsabilidade pública de sua preservação.

Para a Casa de Oswaldo Cruz é motivo de orgulho a associação com a sanofi-aventis neste empreendimento, em um momento de dupla celebração: o centenário da descoberta da doença de Chagas e o Ano da França no Brasil. Esta é mais uma das frutíferas parcerias que vimos desenvolvendo para promover ações de caráter cultural em prol da educação e da divulgação das ciências e da saúde no país.

Com esta publicação pretendemos contribuir para propagar a obra de Carlos Chagas, que, longe de situar-se em um passado distante, apresenta plena atualidade com o presente da agenda sanitária e política relacionada às chamadas doenças tropicais negligenciadas, e à sua associação com a pobreza nos países em desenvolvimento. É nessa perspectiva que há mais de vinte anos a Casa de Oswaldo Cruz trabalha para preservar a memória da ciência e da saúde brasileiras.

Nara Azevedo

Diretora da Casa de Oswaldo Cruz 


\section{Preface}

Carlos Chagas holds a rare title in the history of Brazilian science, as the discoverer of the tropical illness that bears his name: Chagas disease. This contribution to the field of biomedical knowledge is recognized as an unparalleled scientific feat, with a single researcher identifying not only a disease but also its etiological agent and transmitting vector.

Offering a unique collection of iconography, this magnificent book is an invitation to embark on an enjoyable exploration of the legacy of Carlos Chagas and of the generation of doctors and sanitarians, led by Oswaldo Cruz, who practiced a science with marked political overtones, a science aimed at building a future that would redeem the country from what they saw as the bonds of its colonial past, a burden synonymous with backwardness. And the bonds were many. Chagas and the other members of his generation took up this challenge.

When Carlos Chagas declared that the new disease he had identified in the hinterlands of Minas Gerais was having a wideranging impact on the modernization of Brazil and further argued that its incidence was rooted in rural poverty and substandard living conditions, his words both puzzled and outraged a sector of the elites in the nation's capital of Rio de Janeiro, the newly reformed showcase of progress in the fledgling Brazilian Republic. This reaction was felt in the National Academy of Medicine, which received Chagas as a fellow in 1910 and then in the 1920s became stage to a heated controversy. There the young scientist waged a fierce battle to defend his ideas, which were vigorously contested by certain luminaries of the day's medicine. The latter labeled him unpatriotic and pessimistic and accused him of giving emphasis to a portrait of a diseased country that denigrated Brazil's image among other civilized nations.

As we know, history found Carlos Chagas in the right, gaining him the recognition not accorded with unanimity by his contemporaries. Despite the scientific and technological advances achieved by the generations of researchers who lent continuity to Chagas's work during the twentieth century, Chagas disease remains a public health issue in Brazil and throughout the American continent. According to recent estimates, some twelve to fourteen million people suffer from the illness in the eighteen Latin American countries where it is endemic. In Brazil, as a consequence of internal migration in recent decades, most of those infected (about 70\%) live in cities, primarily in the Southeast. Millions of Chagas sufferers await the development of more effective drugs, and it is not even certain that a vaccine against Trypanosoma cruzi can ever be developed. In 2006, the World Health Organization awarded Brazil a certificate for interrupting transmission of the main vector, Triatoma infestans. Yet there are still a number of regions where wild triatomines may some day become domiciliated, creating new sites of disease transmission. Experts have warned about the need for continued epidemiological surveillance and control measures and have called special attention to social and environmental concerns, since interactions between the vector and human beings are related to deforestation and precarious housing conditions.

This book is the product of work on two fronts, representing its two authors: on the one hand, a decade-long systematic investigation of the history of research on Chagas disease and, on the other, the organization of textual and iconographic documentation from Carlos Chagas's personal archive. The singularity and relevance of this archive was recognized in 2008 when it was nominated for inclusion in UNESCO's Memory of the World Register, an honor that underscores a public responsibility to preserve it.

The Casa de Oswaldo Cruz is proud to join with sanofi-aventis in this endeavor, at a time when we have two reasons for celebrating: the centennial of the discovery of Chagas disease and the Year of France in Brazil. We have entered into this and other fruitful partnerships in order to foster educational outreach in science and health in Brazil through cultural initiatives.

It is our hope that this book will contribute to disseminating the work of Carlos Chagas, which is not at all part of some distant past but absolutely contemporary with today's sanitary and political agenda in the realm of neglected tropical diseases and their association with the poverty of developing nations. It is from this perspective that the Casa de Oswaldo Cruz has worked for over twenty years to preserve the memory of Brazilian science and health.

Nara Azevedo

Director, Casa de Oswaldo Cruz 


\section{Apresentação}

Carlos Chagas, um cientista do Brasil integra o conjunto de iniciativas empreendidas pela Fundação Oswaldo Cruz (Fiocruz), em 2009, para a comemoração do primeiro centenário da descoberta da doença de Chagas. Em abril de 1909, o mineiro Carlos Chagas (1878-1934), médico e pesquisador do Instituto Oswaldo Cruz (IOC), comunicou ao mundo científico a descoberta de uma nova doença humana. Seu agente causal (o protozoário que denominou de Trypanosoma cruzi, em homenagem a Oswaldo Cruz) e o inseto que o transmitia (triatomíneo conhecido como barbeiro) também haviam sido por ele identificados, ao final de 1908. A 'tripla' descoberta viria a constituir-se em um marco na história da ciência e da saúde no Brasil.

Representando uma contribuição inovadora ao campo da medicina tropical, Chagas traria a público não apenas uma nova enfermidade humana, mas a realidade sanitária e social do interior do país, assolado pelas endemias rurais. Enaltecida como uma das glórias do IOC, a descoberta conferiu imediato prestígio e projeção ao jovem cientista, que receberia várias distinções acadêmicas no Brasil e no exterior, tendo sido indicado ao Prêmio Nobel de Medicina por duas vezes.

A trajetória de Carlos Chagas foi muito além dos créditos que adquiriu por descobrir a doença que leva seu nome. Como sucessor de Oswaldo Cruz na direção do IOC (1917-1934), ampliou as fronteiras da instituição, consolidando-a como renomado centro de produção, pesquisa e ensino no campo da medicina experimental. Como diretor dos serviços federais de saúde pública do país (19191926), estendeu a ação do Estado brasileiro ao interior, promovendo importantes ações de saneamento rural e a formação de profissionais especificamente treinados para a área de saúde pública. No ensino médico, teve destacada atuação como professor da cadeira de medicina tropical da Faculdade de Medicina da Universidade do Rio de Janeiro. Defendeu a importância da pesquisa para a formação profissional dos médicos e afirmou que a associação entre o laboratório e a clínica era o caminho para que as novas gerações enfrentassem o desafio de estudar e combater as "doenças do Brasil", que atingiam, sobretudo, a população pobre das áreas rurais.

Identificando, na enfermidade que ele próprio descrevera, um dos grandes "flagelos" dos sertões brasileiros - que comprometia a vitalidade de seus trabalhadores e, conseqüentemente, o "progresso" da nação -, Carlos Chagas foi pioneiro da campanha em prol do saneamento rural do Brasil, que teve como legado a ampliação da intervenção do Estado na saúde e, sobretudo, o diagnóstico de que o atraso do país era fruto das doenças que o assolavam, profundamente associadas às más condições de vida no interior. Protagonizando importantes momentos e processos pelos quais a ciência e a saúde pública brasileiras se institucionalizavam como campos de conhecimento e de intervenção social, Chagas materializou, em sua trajetória, o projeto de uma ciência afinada com os avanços do conhecimento no cenário internacional e, ao mesmo tempo, comprometida em revelar os problemas da sociedade brasileira e indicar os caminhos para enfrentá-los.

O presente livro apresenta a trajetória biográfica de Carlos Chagas por meio, fundamentalmente, de imagens. São tanto fotografias como representações visuais de outras naturezas, como charges, caricaturas, desenhos, ilustrações científicas, e vêm acompanhadas de documentos textuais (cartas, anotações de pesquisa, matérias de jornal, publicações, diplomas) e museológicos. Nosso intuito é gerar uma composição múltipla que forneça ao leitor uma compilação dos mais expressivos documentos relativos à vida e à obra deste importante cientista. Tais registros foram selecionados, sobretudo, no vasto acervo da Casa de Oswaldo Cruz (COC), mas também em conjuntos arquivísticos de outras instituições, no Rio de Janeiro, Minas Gerais e São Paulo.

$\mathrm{O}$ arquivo pessoal de Carlos Chagas, sob a guarda da COC, expressa as múltiplas dimensões dessa trajetória que associou, de modo estreito, ciência, saúde pública e projetos/debates sobre a nação, e que, ao fazê-lo, gerou expressivos impactos não apenas no campo da medicina, mas também no universo cultural mais amplo da sociedade brasileira. Trata-se de um precioso material para historiadores e pesquisadores que busquem informações sobre a organização e a institucionalização da ciência e da saúde brasileiras em sua inserção na vida social do país e no ambiente internacional da época.

Carlos Chagas, um cientista do Brasil é composto de capítulos que abrangem: sua infância, sua formação médica, as campanhas que realizou contra a malária, a descoberta da doença que leva seu nome, os estudos sobre este assunto, a polêmica em torno da nova enfermidade, a expedição que realizou à Amazônia, sua atuação como diretor do IOC e como gestor da saúde pública federal, sua atividade como professor, alguns aspectos de sua vida pessoal e familiar e, por fim, premiações e títulos que conquistou ao longo de sua carreira. Ao início de cada capítulo, um pequeno texto apresenta os conteúdos históricos fundamentais sobre cada tema e convida o leitor a percorrê-lo através da narrativa das imagens.

Gostaríamos de agradecer àqueles que, de diversas maneiras, contribuíram para a realização deste livro. Antes de tudo, à Casa de Oswaldo Cruz, pelo amplo apoio que proporcionou à concretização do projeto, que reúne duas áreas de grande importância na 
instituição: a pesquisa em história das ciências e da saúde e a pesquisa no campo da documentação, esta associada ao trabalho de organização dos acervos arquivísticos.

A João Canossa, um registro igualmente especial: mais do que editor, ele foi um colaborador decisivo nas várias etapas de elaboração deste livro. Destacamos também nosso agradecimento aos auxiliares de pesquisa que colaboraram de modo decisivo para este trabalho, com minucioso e amplo levantamento de fontes. A Luis Octavio Gomes de Souza, que, além desse levantamento, colaborou de modo sistemático em todo o processo de elaboração do livro, desde sua concepção até a redação e revisão dos textos que o compõem, nosso reconhecimento especial. Além do trabalho de qualidade que o distingue como pesquisador, ele nos proporcionou uma agradável companhia, tornando-se, ao longo desta jornada, um querido amigo.

Deyse Pimenta Cacau, historiadora mineira, apoiou-nos na busca de documentos nos arquivos do estado natal de Carlos Chagas. Demian Bezerra de Mello, além do auxílio à pesquisa, contribuiu com a obtenção da necessária autorização para o uso das imagens aqui reunidas. A Cleice de Souza Menezes, Luciana Pinheiro, Marcela Thimoteo, Danielle Barreto e Francisco Lourenço, somos gratas pela disponibilidade em colaborar conosco em função das atividades que vinham realizando para outros projetos da COC relacionados ao centenário da descoberta da doença de Chagas, como a organização do Arquivo Carlos Chagas e a atualização da Biblioteca Virtual Carlos Chagas.

De grande importância foi o trabalho de digitalização das imagens realizado pelos fotógrafos Roberto Jesus Oscar e Vinicius Pequeno, companheiros de longa data na COC, que sempre estiveram a postos para atender nossas inúmeras solicitações, muitas vezes sob a pressão dos prazos, mas sempre com a gentileza e a eficiência que os caracterizam. A Rose Oliveira e Jean Maciel, tão importantes na missão institucional em disponibilizar a consulta pública dos documentos que integram nossos arquivos, também somos gratas pela presteza em responder às nossas demandas. Ao pesquisador Gilberto Hochman, agradecemos a leitura crítica e as sugestões que ajudaram a aprimorar o texto.

O Arquivo Carlos Chagas, que forneceu a parte mais substancial das imagens aqui publicadas (algumas delas inéditas), é resultado do empenho carinhoso e sistemático de Carlos Chagas Filho em reunir os 'papéis' de seu pai e da generosidade de doar à Casa de Oswaldo Cruz material tão precioso. Esse belo e louvável compromisso em preservar e divulgar a memória do cientista foi compartilhado por sua esposa, Anna Leopoldina de Mello Franco Chagas, que, após o falecimento de Carlos Chagas Filho em 2000, prosseguiu enviando ao nosso Departamento de Arquivo e Documentação novas remessas de documentos. Durante o processo de elaboração deste volume, contamos com a colaboração preciosa da neta de Carlos Chagas, Cristina Chagas Gouvêa Vieira, a quem manifestamos nosso agradecimento. É para nós uma grande satisfação que este livro traga, assim, de distintas maneiras, a marca da colaboração da família Chagas.

E, a propósito do acervo de Carlos Chagas, registramos nosso agradecimento a Renata Borges, que coordenou a equipe de organização desse arquivo na Casa de Oswaldo Cruz, por ter aceitado o convite para colaborar conosco com um texto sobre esse processo de organização, realizado também como parte das comemorações do centenário da descoberta da doença de Chagas.

Contar a história de Carlos Chagas, em sua múltipla atuação como pesquisador, professor e gestor, com base em imagens e outros tipos de registros, foi um desafio e um enorme prazer. Foi um processo marcado por escolhas difíceis, diante da diversidade de documentos com os quais nos deparamos, e também por lacunas inescapáveis. Foi também pontuado por momentos muito particulares, como este, que deixamos aqui registrado.

Ao pesquisar o precioso arquivo do médico Belisário Penna, responsável pelas ações de saneamento rural durante a gestão de Carlos Chagas no Departamento Nacional de Saúde Pública, pudemos perceber, nas centenas de registros fotográficos produzidos nos vários estados brasileiros, a dimensão concreta do projeto sanitarista que mobilizou esses e tantos outros médicos, cientistas e intelectuais nas primeiras décadas do século XX. E qual não foi nossa surpresa quando, entre os muitos habitantes daquelas longínquas paragens brasileiras, uma de nós (Simone) deparou-se com a imagem de sua tia-bisavó, Jandira Caldas Botelho, no balcão de um posto sanitário na pequena Quebrangulo, interior de Alagoas.

Além da extraordinária coincidência, o episódio teve um sentido que vai além de seu aspecto pitoresco e nos levou a pensar em uma importante dimensão do legado de Carlos Chagas. Essa ciência que alcançou projeção internacional e ao mesmo tempo se embrenhou pelos 'sertões' do Brasil, na trilha de Euclides da Cunha, produziu não apenas idéias e intervenções sobre a nação, mas o registro histórico de muitos brasileiros e brasileiras anônimos, gente simples e comum, sobre a qual provavelmente não haveria indícios nos arquivos correntes dos grandes centros. Junto aos tantos doentes fotografados pelo olhar médico, a expressar a triste realidade de um Brasil "imenso hospital", estiveram os muitos trabalhadores - médicos, enfermeiras, farmacêuticos - que se associaram aos médicos e cientistas vindos do 'litoral' nesse longo e coletivo processo pelo qual a medicina brasileira construiu não apenas conhecimentos e ações de saúde, mas a própria nação. Nos arquivos, e nas imagens que eles guardam, encontramos fragmentos e vestígios desse caminho. Que o leitor tenha prazer em percorrê-lo conosco. 


\section{Introduction}

Carlos Chagas, scientist of Brazil is one of several initiatives undertaken by the Oswaldo Cruz Foundation (Fiocruz) in 2009 as part of the centennial celebration of the discovery of Chagas disease. In April 1909, Minas Gerais native son Carlos Chagas (18781934), physician and Oswaldo Cruz Institute (OCI) researcher, announced to the scientific world that he had discovered a new human disease. At the end of 1908, he had also identified its causative agent (a protozoan that Chagas called Trypanosoma cruzi, in honor of Oswaldo Cruz) and the insect that transmitted the sickness (a triatomine known as the barbeiro, or barber bug). This triple discovery became a landmark in the history of science and health in Brazil.

When Chagas made this innovative contribution to the field of tropical medicine, he revealed to the public not only a new human illness but also the sanitary and social reality of Brazil's hinterlands, beset by rural endemic diseases. Lauded as one of the triumphs of the OCI, the discovery won the young Brazilian scientist immediate prominence and prestige and would earn him numerous academic awards at home and abroad, including two nominations for the Nobel Prize in Medicine.

Carlos Chagas's accomplishments went far beyond the discovery of the disease that bears his name. As Oswaldo Cruz's successor as head of the OCI (1917-1934), he expanded the Institute's borders and secured its position as a well-regarded center of production, research, and teaching in the field of experimental medicine. As director of Brazil's federal public health services (1919-1926), he extended the government's reach into the interior of the country by setting in motion important rural sanitation actions and training specialized public health personnel. In medical education, he had a notable role as chair of tropical medicine at the University of Rio de Janeiro's School of Medicine. He was a strong advocate of making research an integral part of a physician's training and believed that tying the laboratory to clinical practice was the key to ensuring that new generations could meet the challenge of studying and combating the "diseases of Brazil," whose prime victims were the poor people of rural areas.

Carlos Chagas saw the illness that he was the first to describe as one of the great "scourges" of the Brazilian hinterlands, compromising its workers' vitality and therefore the "progress" of the nation. He was a pioneer of the Brazilian rural sanitation movement, whose legacies included increased government intervention in the health field and, chiefly, the diagnosis that Brazilian backwardness stemmed from the diseases afflicting the country, which were in turn intimately bound up with poor living conditions in the interior. As a protagonist of major events and processes in the institutionalization of Brazilian science and public health as fields of knowledge and of social intervention, Chagas brought to life a brand of science attuned to international advances in knowledge and simultaneously committed to laying bare the problems of Brazilian society and pointing the paths to their solution.

This book presents Carlos Chagas's biographical trajectory fundamentally through images-photographs and other kinds of visual representations, like cartoons, caricatures, drawings, and scientific illustrations-accompanied by museological and textual documents, that is, letters, research notes, newspaper articles, publications, diplomas. Our purpose was to provide our readers with a multifaceted composition that brings together the most illuminating records about this eminent scientist's life and work. These documents were selected principally from the vast holdings belonging to the Casa de Oswaldo Cruz (COC), while still others came from the archives of institutions in the states of Rio de Janeiro, Minas Gerais, and São Paulo.

Carlos Chagas's personal archive, in the custody of the COC, reflects the multiple dimensions of his life and career, which intertwined science, public health, and projects and debates about Brazil and thus had a significant impact not just in the field of medicine but in the larger cultural universe of Brazilian society as well. This particular set of records constitutes an invaluable resource for historians and researchers seeking information on the organization and institutionalization of Brazilian science and health and their interplay with the country's social life and the global context of the past.

The chapters of Carlos Chagas, scientist of Brazil explore the scientist's childhood, his medical education, the antimalarial campaigns he led, the discovery of the disease that bears his name, his research on the topic, the controversy engulfing the new illness, his participation in the Amazon expedition, his tenures as director of the OCI and as head of federal public health, his teaching activities, and elements of his personal and family life, closing with some of the awards and titles he garnered during his career. Each chapter begins with a short text offering some historical background on the topic, inviting the reader to learn more through the images that tell this story.

We would like to acknowledge the contributions of those who in a variety of ways have helped make this book possible. First and foremost, our thanks go to the Casa de Oswaldo Cruz for its broad support in bringing to life this project, which encompasses 
two vital areas of the institution: research in the history of the sciences and health and research in the field of documentation, along with the organization of archival holdings.

Our very special thanks as well to João Canossa. More than an editor, he was a decisive contributor at many moments in the preparation of this book. We would also like to thank our research assistants for their decisive collaboration and thorough, painstaking surveying of sources. In particular, Luis Octavio Gomes de Souza, on top of his specific research tasks, rendered ongoing assistance during the entire process, from the book's conception through the actual writing and editing, and for this we owe him special recognition. Besides the quality of his work, which sets him apart as a researcher, his company was a delight and in the course of this journey he became a dear friend.

Deyse Pimenta Cacau, historian from Minas Gerais, aided in our search for records held at archives in Carlos Chagas's home state. Demian Bezerra de Mello, in addition to providing research assistance, helped in obtaining authorization for the use of the images shown in these pages. Our thanks go as well to Cleice de Souza Menezes, Luciana Pinheiro, Marcela Thimoteo, Danielle Barreto, and Francisco Lourenço, who most obligingly collaborated with us as part of their involvement in other COC projects related to the centennial celebration of the discovery of Chagas disease, such as the organization of the Carlos Chagas archive and the updating of the Carlos Chagas Virtual Library.

Photographers Roberto Jesus Oscar and Vinicius Pequeno, longtime colleagues of ours at the COC, undertook the crucial task of digitizing the majority of the book's images; they were always willing to respond to our numerous requests with their characteristic unflagging kindness and efficiency, often under the pressure of an approaching deadline.

We would also like to thank Rose Oliveira and Jean Maciel, who perform such an essential role in the COC's mission to make the records in our archives available to the public for consultation and who were so accommodating in attending to our requests. Our further thanks go to the researcher Gilberto Hochman for his critical reading and suggestions that helped refine the text.

The Carlos Chagas archive, which furnished the bulk of the images found in these pages - some never published before - is fruit of Carlos Chagas Filho's careful, systematic endeavor to gather all his father's "papers" and then generously donate this invaluable material to the Casa de Oswaldo Cruz. This fine, laudable commitment to preserve and promote the scientist's memory was shared by Chagas Filho's wife, Anna Leopoldina de Mello Franco Chagas, who, following her husband's death in 2000, continued to forward new groups of records to our Department of Archives and Documentation. Throughout the preparation of this book, we benefited from the valuable collaboration of Carlos Chagas's granddaughter, Cristina Chagas Gouvêa Vieira, to whom we extend our gratitude. We take enormous satisfaction in the fact that this book bears the touch of the Chagas family, through their various forms of collaboration.

In regard to the Carlos Chagas holdings, we would like to thank Renata Borges, coordinator of the team responsible for organizing this archive at the COC, who kindly accepted our invitation to write a text about the organizing process, another component of this year's centennial celebration of the discovery of Chagas disease.

Telling the story of Carlos Chagas and his multifaceted career as researcher, professor, and administrator through images and others types of documents has been both a challenge and a joy. It was a process filled with tough decisions, given the diversity of records we faced, but also marked by inevitable gaps. We were rewarded with some very special moments, one of which we would like to share with you.

Our research took us into the valuable archive of physician Belisário Penna, responsible for rural sanitation measures while Carlos Chagas was head of the National Department of Public Health. Containing hundreds of photographic records taken at states around Brazil, this collection made us recognize the true dimensions of the sanitation project that mobilized these and so many other doctors, scientists, and intellectuals during the early decades of the twentieth century. And much to our surprise, among the pictures of so many inhabitants of far-flung corners of Brazil, one of us (Simone) stumbled on a photograph of her great-great-aunt Jandira Caldas Botelho, at the counter of a sanitary post in the small town of Quebrangulo, in rural Alagoas.

This striking coincidence set us to thinking beyond the incident's anecdotal charm and to reflecting about an important dimension of Carlos Chagas's legacy. This approach to science, which was projected onto the world stage at the same time that it ventured into the hinterlands of Brazil on the trail of Euclides da Cunha, did more than generate ideas and spur interventions with a nationwide impact; it also bequeathed us a historical record of many anonymous Brazilian men and women, simple, ordinary people who otherwise would be unlikely to leave any traces in today's big city archives. Among the scores of diseased people photographed by the medical eye, evincing the sad reality of the "enormous hospital" of Brazil, there were likewise many workers-physicians, nurses, pharmacists-who joined with the doctors and scientists from the seacoast as part of the long, collective process through which Brazilian medicine constructed new knowledge and new public health initiatives while building the very nation. In archives and the images they hold, we find fragments and traces of this road. We hope you will find pleasure in traveling it with us. 


\section{$\mathrm{O}$ arquivo pessoal Carlos Chagas}

A primeira remessa do arquivo pessoal de Carlos Chagas foi encaminhada à Fundação Oswaldo Cruz (Fiocruz) na década de 1990 por Carlos Chagas Filho, acompanhada de documentos de seu irmão Evandro Chagas. Na época, esses registros foram unidos e organizados pela equipe do Departamento de Arquivo e Documentação da Casa de Oswaldo Cruz (DAD/COC) como um arquivo familiar, o Fundo Família Chagas.

Com a morte de Carlos Chagas Filho em 2000, sua família doou seu arquivo pessoal e foi possível identificar, em meio a esse material, vários itens cuja procedência estava diretamente relacionada aos arquivos de seu pai e de seu irmão. A equipe iniciou o trabalho de identificação, objetivando desenhar com mais precisão os contornos dos conjuntos documentais referentes a cada cientista.

O volume de documentos que pertencia a Evandro e a Carlos Chagas era tão expressivo que percebemos a necessidade de uma nova organização para cada um dos arquivos, por constituírem conjuntos orgânicos autônomos. Com o avanço do trabalho de identificação essa constatação ficou mais evidente, na medida em que a documentação dos três cientistas representava ações direcionadas para atividades distintas, realizadas por cada um em momentos e situações diversos, o que não justificava mantê-la como um arquivo familiar.

Entre 2007 e 2009, no âmbito de um projeto institucional visando à comemoração do centenário da descoberta da doença de Chagas, foi organizado o arquivo pessoal de Carlos Chagas. A documentação que compõe o arquivo desse cientista é parte significativa de um acervo mais amplo, considerando-se os documentos mantidos sob a guarda do setor de Museologia do Museu da Vida, constituído por documentos tridimensionais.

A riqueza desse acervo pode ser observada no conjunto constituído por fotografias, diplomas, artigos científicos, cadernetas de campo, anotações de pesquisa, relatórios, ilustrações científicas, livros, medalhas, entre tantos outros documentos, cujas ações que os originaram expressam a diversidade e amplitude da atuação do cientista. No campo da arquivística, um documento de arquivo é aquele que integra um "conjunto de documentos produzidos e acumulados por uma entidade coletiva, pública ou privada, pessoa ou família, no desempenho de suas atividades, independentemente da natureza do suporte" (Arquivo Nacional, 2005: 27). Nessa perspectiva, a natureza do arquivo de Chagas não deixava dúvidas sobre o caráter orgânico dos registros e sua relação com a figura do responsável pela produção do conjunto.

O conceito de arquivo pessoal se insere em uma das categorias de arquivos privados, como explica Bellotto (2007: 253): "Consideram-se arquivos privados os conjuntos de documentos produzidos ou recebidos por pessoas físicas ou jurídicas, em decorrência de suas atividades". Eles apresentam as características funcionais e administrativas comuns aos arquivos públicos, bem como a relação orgânica que os documentos de um arquivo normalmente conservam entre si.

A organização de um arquivo pessoal, assim como a de qualquer outro arquivo, requer cuidados no tratamento da documentação em seu conjunto, respeitando-se o contexto de sua produção e a lógica de sua acumulação. O arquivo de Carlos Chagas constituise em um rico acervo de fontes para a história da doença de Chagas e para a história das ciências e da saúde no Brasil na medida em que reúne, do ponto de vista das tipologias documentais, bem como das temáticas por elas veiculadas, todas as características que ajudam a definir o termo 'arquivo científico'. Segundo Silva (2006: 99), "Considera-se arquivo científico todas as fontes arquivísticas que permitem a verificação do crescimento e desenvolvimento das políticas e ensino científico, dos avanços das diferentes disciplinas e, também, da contribuição de cientistas para a sua área de atuação".

$\mathrm{O}$ arquivo foi organizado de acordo com metodologia própria para arquivos pessoais de cientistas desenvolvida pela equipe do DAD, segundo a qual o arranjo é estruturado a partir da definição das principais funções e atividades desempenhadas pelo cientista em sua vida pessoal e profissional. No caso de Chagas, grandes grupos documentais foram reunidos em torno de funções como vida pessoal, pesquisa, docência, gestão de políticas científicas, relações interinstitucionais e intergrupos e formação e administração da carreira.

Os conteúdos dos documentos remetem à atuação de Carlos Chagas como pesquisador e professor, gestor de cargos na instituição, integrante de comissões, participante nas discussões sobre políticas científicas e, por fim, à sua relação com a comunidade científica nacional e internacional, com familiares e amigos, entre outras de suas faces.

A classificação foi feita a partir da separação dos documentos de acordo com as tipologias documentais - fotografias, textos científicos, cartas, artigos científicos etc. Uma estrutura classificatória desse tipo exigiu da equipe um minucioso trabalho de 
identificação, com relação tanto à exata nominação das diversas tipologias documentais que compõe o arquivo quanto à pesquisa em outras fontes.

O trabalho de organização desse arquivo envolveu uma equipe composta por arquivistas, documentalistas e historiadores, além de colaboradores diversos. O resultado desse esforço é tornar o arquivo pessoal Carlos Chagas disponível à consulta pelos usuários do acervo sob guarda e custódia da COC.

O presente livro, ao apresentar alguns dos documentos que compõem esse rico arquivo, contribui de modo decisivo para divulgá-lo, na expectativa de que ele venha a ser amplamente visitado não apenas por especialistas, pesquisadores e estudantes, mas por todos que se interessem pela história da ciência e da saúde brasileiras, em suas interfaces com a história social do Brasil.

Renata Silva Borges

Tecnologista em saúde pública do Departamento de Arquivo e Documentação da Casa de Oswaldo Cruz e professora substituta do curso de arquivologia da Universidade Federal Fluminense

\section{Referências}

ARQUIVO NACIONAL. Dicionário Brasileiro de Terminologia Arquivística. Rio de Janeiro: Arquivo Nacional, 2005.

BELLOTTO, H. L. Arquivos Permanentes: tratamento documental. Reimpr. Rio de Janeiro: Editora FGV, 2007.

SILVA, M. C. S. M. Avaliação de documentos de interesse para a história da ciência. In: ENCONTRO DE ARQUIVOS CIENTÍFICOS, 2003, Rio de Janeiro. Trabalhos apresentados. Rio de Janeiro: Edições Casa de Rui Barbosa, 2006. 


\section{Carlos Chagas's personal archive}

The first batch of material from Carlos Chagas's personal archive was given to the Oswaldo Cruz Foundation (Fiocruz) in the 1990s by his son Carlos Chagas Filho, along with documents belonging to the scientist's other son, Evandro Chagas. At the time, the team at the Casa de Oswaldo Cruz's Department of Archives and Documentation (DAD/COC) merged both sets of records as part of a family archive called the Chagas Family Fonds.

Following the death of Carlos Chagas Filho in 2000, the family donated his personal archive as well, which proved to contain a number of items whose provenance was directly tied to his father's and brother's archives. The team then commenced the identification work that would bring the boundaries of each scientist's set of documents into sharper focus.

The volume of records belonging to Evandro and Carlos Chagas was so massive that they had to be reorganized into individual archives, each constituting an autonomous organic unit. This finding became more apparent with further progress in identification efforts, since each of the three scientists' sets of documentation reflected activities in distinct arenas, conducted at different times and in different situations, failing to justify the maintenance of a single, family archive.

The organization of Carlos Chagas's personal archive ran from 2007 to 2009, as part of an institutional project commemorating the centennial of the discovery of Chagas disease. The documentation within the scientist's archive represents a substantial portion of a broader set of holdings, including documents in the custody of the Museum of Life's Museology sector, which comprises three-dimensional objects.

These holdings offer a wealth of photographs, diplomas, scientific papers, field diaries, research notes, reports, scientific illustrations, books, medals, and various other documents, all products of activities that signal the scope and diversity of Chagas's career. In the field of archival science, an archival record is defined as one of a "set of records created and accumulated by a public or private organization, person, or family in the conduct of their affairs, whatever the nature of the medium" (Arquivo Nacional, 2005: 27). From this perspective, the nature of Chagas's archive left no doubts as to the organic character of its records and their relation to the individual responsible for their creation.

Conceptually, a personal archive is a subset of private archives, as Bellotto explains (2007: 253): "A private archive is defined as a set of records created or received by private individuals or legal entities in the conduct of their affairs." They display the same functional, administrative features as public archives and the same organic relationship usually true of documents within an archive.

As with any other archive, the organization of a personal archive requires careful treatment of the material as a whole, respecting the context in which it was created and the logic behind how it was accumulated. The Carlos Chagas archive provides a rich set of sources on the history of Chagas disease and the history of the sciences and health in Brazil, combining all the features that help to define the term "scientific archive," as regards both documental typologies and their themes. According to Silva (2006: 99): "A scientific archive is defined as any archival source that permits verification of the growth and development of scientific policies and teaching, of advances in different fields, and, furthermore, of scientists' contributions within their spheres of action."

Organization of the Carlos Chagas archive followed methodology appropriate to the personal archives of scientists, as developed by the DAD team, which means the arrangement is structured around a definition of the scientist's main functions and activities during his personal and professional life. In the case of Chagas, large groups of records were compiled according to functions such as personal life, research, teaching, scientific policy management, inter-institutional and inter-group relations, and education and career administration.

The content of these documents addresses Carlos Chagas's pursuits as a researcher and professor, institutional administrator, member of commissions, participant in discussions on scientific policy, and, lastly, his relation with the Brazilian and worldwide scientific communities and with family and friends, among other facets.

The classification was also based on separation of records according to documental typology: photographs, scientific texts, letters, scientific papers, and so on. This kind of classification structure demanded painstaking identification work by the team, entailing precise designation of the diverse documental typologies within the archive, along with research into other sources.

A team of archivists, documentalists, and historians, together with various other collaborators, joined in organizing the archive. Thanks to their efforts, the Carlos Chagas personal archive, held in the custody of the Casa de Oswaldo Cruz, is now available for consultation by users. 
In presenting some of the documents that make up this rich archive, this book plays a decisive part in making it known to a larger public. It is our hope that the archive will receive a broad range of visitors, not only specialists, researchers, and students but everyone curious to learn more about the history of Brazilian science and health and their interplay with the country's social history.

Renata Silva Borges

Technologist in public health with the Department of Archives and Documentation, Casa de Oswaldo Cruz/Fiocruz, and substitute professor of Archival Science at the Universidade Federal Fluminense

\section{References}

ARQUIVO NACIONAL. Dicionário Brasileiro de Terminologia Arquivística. Rio de Janeiro: Arquivo Nacional, 2005.

BELLOTTO, H. L. Arquivos Permanentes: tratamento documental. Reimpr. Rio de Janeiro: Editora FGV, 2007.

SILVA, M. C. S. M. Avaliação de documentos de interesse para a história da ciência. In: ENCONTRO DE ARQUIVOS CIENTíFICOS, 2003, Rio de Janeiro. Trabalhos apresentados. Rio de Janeiro: Edições Casa de Rui Barbosa, 2006. 


\section{Uma narrativa iconográfica}

Com as imagens aqui reunidas, queremos apresentar uma narrativa visual sobre a trajetória de vida do médico e cientista Carlos Chagas. Elas são resultado de pesquisa, identificação, seleção, edição e tratamento gráfico; além das legendas, vêm acompanhadas de trechos de depoimentos e citações de época.

Pesquisar e reunir imagens, tendo como objetivo criar um quadro que permita compreender a trajetória de um indivíduo no seu tempo e espaço, manifesta a intenção de utilizar as representações visuais como instrumento cognitivo. As fotografias, entre outros tipos de imagens, constituem realizações materiais das formas de ver e de representar características de uma época. Além disso, a partir do universo dos documentos iconográficos a que se tem acesso hoje, somos levados a problematizar o espaço ocupado pela visualidade em diferentes sociedades, em distintos momentos.

O primeiro passo para a realização dessa empreitada consistiu na localização de acervos que apresentassem conexões expressivas com a vida de Carlos Chagas. Ao mesmo tempo, mantínhamos a atenção voltada para a pesquisa de registros que pudessem, em alguns casos, representar contextos relativos a períodos da vida do biografado, estratégia presente no capítulo dedicado à sua infância, por exemplo. Nessa busca, vários acervos foram considerados de interesse, e o livro conta com uma gama variada de documentos deles provenientes. Contamos, fundamentalmente, com o arquivo histórico do Instituto Oswaldo Cruz (IOC) local de formação e atuação profissional de Chagas, cujos laços com o cientista foram por ele mesmo ressaltados como mais do que simples laços profissionais - e com o seu arquivo pessoal. Esses dois conjuntos documentais fornecem as principais fontes a partir das quais construímos a 'espinha dorsal' desta narrativa, e não por acaso.

Os arquivos, de modo geral, possuem características muito peculiares, na medida em que encontram a sua unidade e a razão mesma de sua existência na figura de quem os produziu, seja uma instituição ou um indivíduo. Essa relação única entre os documentos e seu produtor está na origem de um tipo de vínculo específico que só os documentos de arquivo apresentam, capaz de transformar uma massa de documentos de conteúdos e formatos diversos em um todo organicamente significante. Cada documento, e todos no seu agrupamento, guardam o seu sentido original naquela relação. É por isso que costumamos encontrar, na sequência serial da documentação que caracteriza os arquivos, uma densidade de informações, uma organicidade de relações que dificilmente se apresenta da mesma forma em outros tipos de acervos.

Foi no arquivo pessoal de Chagas e no da instituição à qual devotou sua vida que encontramos as pedras fundamentais que sustentam a narrativa sobre a trajetória do cientista. Com base nesses universos documentais e na compreensão atual que temos de sua vida, numa perspectiva histórica, fomos escolhendo os episódios que queríamos abordar, as imagens que poderiam expressálos, e as sequências que, 'costurando' esses elementos, lhes conferissem sentido. Nesse processo, o conhecimento histórico ia tecendo a trama que envolveria os elementos aparentemente dispersos da documentação, ao mesmo tempo que os próprios registros nos sugeriam, de diferentes maneiras, novos percursos narrativos.

A importância e a riqueza do caráter serial - que marca a produção documental em arquivos - para a pesquisa com imagens fica exemplificada no tratamento que dedicamos a um tema relacionado à vida de Chagas: a série de retratos de doentes produzida pelo IOC durante as primeiras décadas do século XX. Trata-se de uma extensa documentação fotográfica que registra as várias manifestações clínicas de uma gama de enfermidades estudadas pelos médicos e cientistas de Manguinhos, incluindo a doença de Chagas. A qualidade estética dos retratos e o volume do material nos permitiram uma seleção das imagens que, naquela época, eram reconhecidas como provas dos sinais que atestavam a existência das enfermidades. O fato de que esses retratos se multiplicam nos arquivos médicos criou condições para que pudéssemos tratá-los, no livro, não como registros singulares da doença, mas, ao contrário, como uma série de individualidades indistintas, unidas pela classificação da moléstia que se descortinava como fato médico.

No capítulo dedicado ao tempo de Carlos Chagas na direção de Manguinhos utilizamos diversas imagens que, do ponto de vista de construção formal, são bastante semelhantes. Referimo-nos àquelas em que o diretor figura entre visitantes nas varandas do castelo mourisco. No arquivo do IOC, essa série de fotografias é característica do período de Chagas na direção do instituto: antes e depois de sua gestão encontram-se, no arquivo, imagens semelhantes, mas o volume e a concentração não se repetem mais. Se a produção rotineira desse tipo de fotografias foi uma diretriz da própria gestão de Carlos Chagas é hipótese a ser analisada, mas, de todo modo, essa série nos permite refletir sobre as práticas institucionais de produção de imagens e seu valor para uma investigação acerca de linguagens e usos da produção institucional fotográfica nos anos 1920 e 1930 . Esse é um dos sentidos que as imagens podem nos sugerir. 
Os registros pertencentes a outros acervos foram buscados para ampliar as possibilidades informativas, mas, sobretudo, para estabelecer relações entre Chagas e o universo em que atuou e circulou. Imagens e registros de personagens contemporâneos ao cientista e com os quais se relacionou, além de arquivos de jornais e revistas, podem oferecer uma base para se refletir sobre suas relações sociais, sua imagem pública, a amplitude e os canais de circulação de suas idéias, os momentos de consagração e também de críticas e polêmicas.

A opção por inserir citações históricas na narrativa foi estratégia de contextualização dos documentos visuais e de estabelecimento de conexões entre as imagens e visões de mundo de diferentes atores sociais que, de alguma maneira, estabeleceram relações com os temas retratados. Além disso, documentos textuais foram transformados em iconografia e editados junto às imagens, no intuito de multiplicar as diferentes 'vozes' a serviço dessa narrativa. Assim, a apresentação das imagens de velhas cartas e bilhetes, de recortes de jornais ou relatórios contendo grifos, cortes, rasgos foi uma opção não apenas estética mas também dotada de sentido para a compreensão dos próprios atributos físicos dos documentos: eles são igualmente vetores de conteúdo, contribuindo para ampliar a compreensão e leitura do registro. A multiplicidade documental contida no livro atesta o nosso propósito de valorizar diferentes enunciados, iluminando a lógica discursiva de distintos gêneros documentais.

Por trás de cada imagem devemos considerar as práticas e padrões que orientaram e permitiram a sua produção, circulação e usos, no intuito de nos indagar acerca do papel social desempenhado pela visão. Hoje responsáveis por representar a cultura visual de épocas variadas, as imagens nos desafiam a proceder a uma leitura diferenciada, baseada numa operação de percepção. A materialidade do objeto visual e o conhecimento dos contextos de seu aparecimento, somados às deduções que a operação perceptiva acarreta, são elementos que concorrem para a sua leitura.

Nossa intenção foi, portanto, construir uma biografia visual de Carlos Chagas que, ao utilizar imagens e outros tipos de documentos - associados a uma representação 'objetiva' do real - não pretende ser menos autoral do que qualquer outra narrativa biográfica. Ao contrário, através da nossa narrativa, construímos 'um' percurso para o cientista, elegemos contextos e fatos, perseguindo sempre o desafio de ultrapassar os temas retratados em direção a um exame da natureza visual bem como da função social desses documentos.

Ao leitor caberá estabelecer outras conexões, indagar os registros a partir de novas perspectivas, construindo, ele também, a sua narrativa. As imagens são terreno fértil para as interpretações e, polissêmicas, estimulam o leitor a conhecer o passado trilhando uma infinidade de caminhos. 


\section{An iconographic narrative}

Through the images found on these pages, we have endeavored to craft a visual narrative of the life trajectory of physician and scientist Carlos Chagas. The images are the product of research, identification, selection, editing, and graphic treatment. In addition to textual captions, the reader will find excerpts of testimonies and historical quotations.

In researching and assembling these images in order to paint a picture that provides an understanding of an individual's journey through his time and space, we opted to use visual representations as a cognitive tool. Photographs, like other types of images, are concrete realizations of how people typically see and represent things during a given era. Moreover, considering the volume of today's universe of accessible iconographic documents, we are led to reflect on the space occupied by visual culture in different societies at different moments.

Our first step in this enterprise was to locate archives that had significant connections to Carlos Chagas's life. Concomitantly, we were attentive to researching records that might be representative of contextual settings within our subject's lifetime-a strategy used in the chapter on Chagas's childhood, for instance. A number of holdings were deemed of interest in this search, and the book includes a wide gamut of documents from these. Our main sources were Chagas's personal archive and the historical archive belonging to the institution where he trained and spent most of his career-the Oswaldo Cruz Institute (OCI)-and where he forged bonds that went deeper than mere professional ties, as he himself affirmed more than once. The backbone of our narrative was constructed from these two sets of records-and this is no accident.

Every archive tends to display its own distinctive characteristics, since it derives its very unity and raison d'être from the personality that produced it, whether this was an institutional entity or an individual. This unique relationship between records and their creator lies at the heart of a kind of connection peculiar to archival records, a connection capable of taking a mass of documents of varied content and format and transforming them into an organically significant whole. Every record in itself, and all of them within their grouping, traces its original meaning to this relationship. This is why the characteristically serial nature of an archive's documentation offers us densely packed information and organic relationships rarely observed in the same way in other kinds of holdings.

The cornerstones of this narrative of the scientist's life and career were found in his personal archive and the archive of the institution to which he devoted his life. Grounded in this universe of documents and in our current understanding of his life from a historical perspective, we selected the episodes we wanted to address, the images that could express them, and the sequence in which they could be stitched together in a meaningful way. In the process, historical knowledge served to weave apparently disparate elements of documentation into a web, while we also discovered that the records themselves had their own ways of suggesting new narrative paths.

The serial nature of archival documentation makes this material particularly valuable when researching images, as exemplified in our processing of one topic related to Chagas's life: the series of portraits of diseased people produced by the Oswaldo Cruz Institute during the early decades of the twentieth century. This extensive photographic documentation has left a record of the different clinical presentations of a gamut of illnesses studied by Manguinhos physicians and scientists, including Chagas disease. The aesthetic quality of the portraits and their very quantity afforded us a selection of the images that in their day had been recognized as proof of the clinical signs confirming the existence of these illnesses. The fact that the medical archives contained a multitude of such pictures let us process them in the book not as singular records of this disease but, to the contrary, as a series of indistinguishable individualities, unified by the classification of the malady then revealing itself as a medical fact.

In the chapter on Carlos Chagas's time as director of Manguinhos, we used a number of images of quite similar formal construction, in which the director is seen among visitors on the verandahs of the Moorish-style castle. Within the OCI archive, this series of photographs is characteristic of the period when Chagas headed the Institute; comparable images from before and after his tenure can be found in the archive, but they are neither as numerous nor as concentrated. Whether or not he had put in place under his directorship a standing guideline to take this type of picture is a hypothesis to be analyzed, but in any case, this series lets us ponder institutional practices concerning the production of images and what their import might be in an investigation of the language and use of photographic production by institutions in the 1920s and 1930s. This is one of the meanings images can impart to us.

We looked for records within other holdings not only to expand the scope of information but primarily to anchor Chagas to the universe where he worked and lived. Images and records of his contemporaries and colleagues, in addition to newspaper and 
magazine archives, form a background against which we can ponder his social relationships, his public image, how his ideas circulated and how far they reached, his moments of glory, and his experiences with criticism and controversy as well.

Quotations were added to the narrative as a strategy for contextualizing the visual documents and for drawing links between the images and the worldviews of the various social actors who in one way or another were engaged with the themes portrayed. Textual records in iconographic format were similarly included with the images as a means of multiplying the various voices at the service of this narrative. In other words, our inclusion of images of old letters and notes and of newspaper clippings or reports with rips, tears, and markings was not merely an aesthetic choice but was intended to imbue the physical attributes of these records with meaning as well, for they too are vectors of content that help enhance our understanding and interpretation of the records. The book's multiplicity of documents attests to our wish to value manifold utterances, illuminating the discursive logic of distinct genres of documents.

We must take into account the practices and norms that guided and allowed for the creation, circulation, and uses of every image, so we can contemplate the social role played by vision. Images today are responsible for representing the visual cultures of different eras, and they challenge us to undertake differentiated interpretations, based on a perceptual operation. The materiality of the visual object and our knowledge of the contexts in which it appeared, together with the deductions derived from our perceptual operation, all have a say in this interpretation.

Using images and other types of records - all of which are associated with an "objective" representation of reality - our aim was thus to create a visual biography of Carlos Chagas that would be no less authorial than any other biographical narrative. To the contrary, through our narrative, we have laid out one possible path to understanding the scientist, choosing contexts and facts, always striving to reach beyond the themes portrayed and into an exploration of the visual nature and social function of these records.

It is up to the reader to make other connections and to contemplate these records from other angles, creating his or her own narrative too. These images lay fertile ground for different interpretations and, in their polysemy, can encourage the reader to learn about the past by pursuing an infinity of roads. 


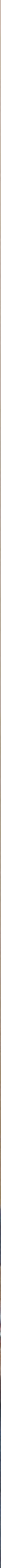


arlos Ribeiro Justiniano Chagas nasceu aos 9 de julho de 1878, na Fazenda Bom Retiro, a cerca de vinte quilômetros da cidade de Oliveira, Minas Gerais.

No século XVIII, a busca pelo ouro abriu muitas veredas no oeste mineiro. A "nova picada de Goiás" passava pelo local onde, à beira do rio Maracanã, iria se estabelecer Oliveira, em um cruzamento de vários caminhos. A origem do nome é atribuída ao português que, por volta de 1730, instalou uma pousada para descanso de tropeiros e viajantes. Duas décadas depois, os que ficaram na região erigiram um cruzeiro e, mais tarde, a capela de Nossa Senhora de Oliveira. Foi o núcleo do povoado que, em 1860, transformou-se em cidade.

Construída na segunda metade do século XVIII, a Fazenda Bom Retiro foi uma das primeiras propriedades estabelecidas em Oliveira, anterior ao povoado que daria origem à cidade. Com cerca de 7.700 hectares de extensão, tinha como atividades principais a pecuária de corte e leiteira e o cultivo de cana-de-açúcar e café. Possuía ainda plantações de milho e feijão e grande variedade de árvores frutíferas.

O bisavô de Carlos Chagas, Francisco das Chagas de Andrade, era natural dos Açores e chegou à região em meados do século XVIII. Dos muitos filhos que teve com Mariana Josefa Lobato, a primogênita, Romualda Chagas de Andrade, casou-se com um tenente português, Serafim Justiniano de Figueiredo. Tiveram muitos filhos, entre os quais José Justiniano Chagas, que seria pai de Carlos Chagas. A primeira esposa de José Justiniano faleceu precocemente e ele casou-se novamente, com Mariana Candida Ribeiro de Castro, cujo pai, Carlos Ribeiro de Castro, possuía fazendas na região, entre as quais a Bom Retiro.

Carlos Chagas foi o primeiro dos quatro filhos do casal. Tinha 4 anos quando o pai faleceu. A mãe assumiu, então, a administração do cultivo do café na Fazenda Bom Retiro e também na Fazenda Bela Vista, que José Justiniano havia adquirido nas proximidades de Juiz de Fora.

A convivência do menino com seus tios maternos, Cícero, Olegário e Carlos - o "tio Calito" era médico formado no Rio de Janeiro e dono de uma casa de saúde em Oliveira -, fez com que ele manifestasse, desde cedo, vontade de avançar nos estudos, com particular interesse pela medicina. Aos 8 anos, já alfabetizado, foi matriculado no Colégio São Luís, dirigido por jesuítas em Itu, interior de São Paulo. Fundado em maio de 1867, foi o segundo colégio criado por essa ordem religiosa no país - o primeiro havia sido fundado em Santa Catarina. Era um dos mais importantes estabelecimentos de ensino do Brasil no século XIX.

A rígida disciplina do internato não agradou ao menino. Em maio de 1888, ao ter notícias de que os escravos recém-libertados estariam depredando fazendas, fugiu para ir ao encontro de sua mãe. A indisciplina foi punida com a expulsão e Carlos foi transferido para o Ginásio São Francisco, em São João del-Rei, Minas Gerais.

Fundado pelo padre João Batista do Sacramento (1852-1907), o Ginásio São Francisco era uma renomada instituição de ensino e seu corpo docente reunia importantes nomes da intelectualidade são-joanense. Professor de latim e de história natural, o padre Sacramento foi uma figura marcante na formação do menino vindo de Oliveira.

Concluídos os estudos, Mariana decidiu que seu filho deveria formar-se em engenharia. Em 1895, Chagas ingressou no curso preparatório da Escola de Minas de Ouro Preto, tradicional centro de ensino superior. Os excessos da vida boêmia, contudo, custaram-lhe a reprovação nos exames e o retorno a Oliveira. Com a ajuda do tio médico e do avô, o jovem venceu a resistência da mãe e mudou-se para o Rio de Janeiro, capital federal, para estudar medicina. 
arlos Ribeiro Justiniano Chagas was born on July 9, 1878, on Bom Retiro Farm, about twenty kilometers from the city of Oliveira, Minas Gerais.

The eighteenth-century quest for gold opened many new routes in western Minas Gerais. The Goiás trail passed through the spot along the Maracanã River where Oliveira would be founded, at a point of many crossroads. The city is said to be named after a Portuguese man who started an inn around 1730 , where drovers and travelers could rest. Two decades later, those who had stayed behind erected a cross and later built Nossa Senhora de Oliveira chapel. This was the heart of the settlement that became a city in 1860.

Built in the latter half of the eighteenth century, Bom Retiro Farm was one of the first pieces of property established in Oliveira, even before the birth of the village that would later blossom into a city. Most of the farm's 7,700 hectares went to beef and dairy herds and sugarcane and coffee crops. Corn and beans were also planted, and there was a large variety of fruit trees.

Carlos Chagas's great-grandfather, Francisco das Chagas de Andrade, came to the region from his native Azores in the mid-eighteenth century. Romualda Chagas de Andrade was the oldest of the many children he had with his wife, Mariana Josefa Lobato. This daughter wed the Portuguese lieutenant Serafim Justiniano de Figueiredo, and they too had many children, one of whom was Carlos Chagas's father, José Justiniano Chagas. José Justiniano's first wife died early and he then married Mariana Candida Ribeiro de Castro, whose father, Carlos Ribeiro de Castro, owned a number of farms in the area, one of which was Bom Retiro.

Carlos Chagas was the oldest of the couple's four children. He was 4 when his father passed away. His mother took over the coffee crops on Bom Retiro and Bela Vista farms, the latter purchased by José Justiniano near the Minas city of Juiz de Fora.

Thanks to Carlos's close ties with his maternal uncles Cícero, Olegário, and Carlos_- "Uncle Calito" was a physician trained in Rio de Janeiro, with a clinic in Oliveira-he was an eager student from early on, with a keen interest in medicine. Eight-year-old Carlos knew how to read and write when he entered Colégio de São Luís, a boarding school run by Jesuits in Itu, rural São Paulo. Founded in May 1867, it was the religious order's second school in the country (the first was in Santa Catarina) and one of the most important teaching institutions in nineteenth-century Brazil.

The young boy did not take well to the boarding school's strict discipline. In May 1888, when he learned that recently freed slaves were going around laying siege to farms, he ran away from school to be with his mother. Expelled as a result, he was transferred to São Francisco School in São João del-Rei, Minas Gerais.

Founded by Father João Batista do Sacramento (1852-1907), São Francisco School was another prominent teaching institution, with important members of the local intelligentsia on its staff. Father Sacramento, a teacher of Latin and natural history, was an influential figure in the education of the lad from Oliveira.

Once Carlos had completed his studies, his mother Mariana decided he should go to college to study engineering. In 1895, he enrolled in the preparatory course at the Ouro Preto School of Mines, a traditional institute of higher education. But Carlos paid a price for living a bohemian lifestyle: he failed his final exams and had to return to Oliveira. With the help of his physician uncle and his grandfather, the young man prevailed over his mother's objections and moved to Rio de Janeiro, then the nation's capital, in order to study medicine. 

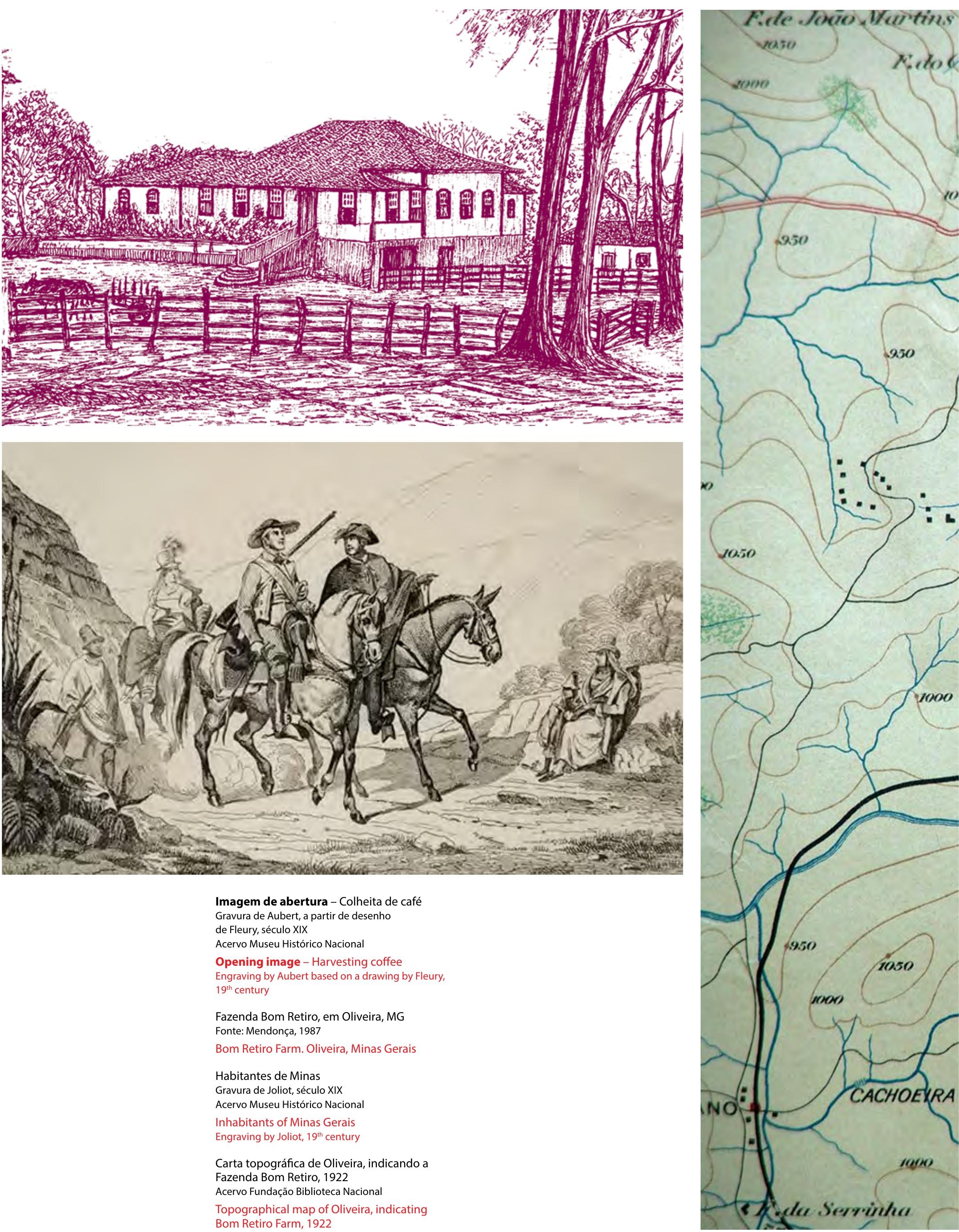

Imagem de abertura - Colheita de café

Gravura de Aubert, a partir de desenho

de Fleury, século XIX

Acervo Museu Histórico Nacional

Opening image - Harvesting coffee

Engraving by Aubert based on a drawing by Fleury,

$19^{\text {th }}$ century

Fazenda Bom Retiro, em Oliveira, MG

Fonte: Mendonça, 1987

Bom Retiro Farm. Oliveira, Minas Gerais

Habitantes de Minas

Gravura de Joliot, século XIX

Acervo Museu Histórico Nacional

Inhabitants of Minas Gerais

Engraving by Joliot, $19^{\text {th }}$ century

Carta topográfica de Oliveira, indicando a

Fazenda Bom Retiro, 1922

Acervo Fundação Biblioteca Nacional

Topographical map of Oliveira, indicating

Bom Retiro Farm, 1922
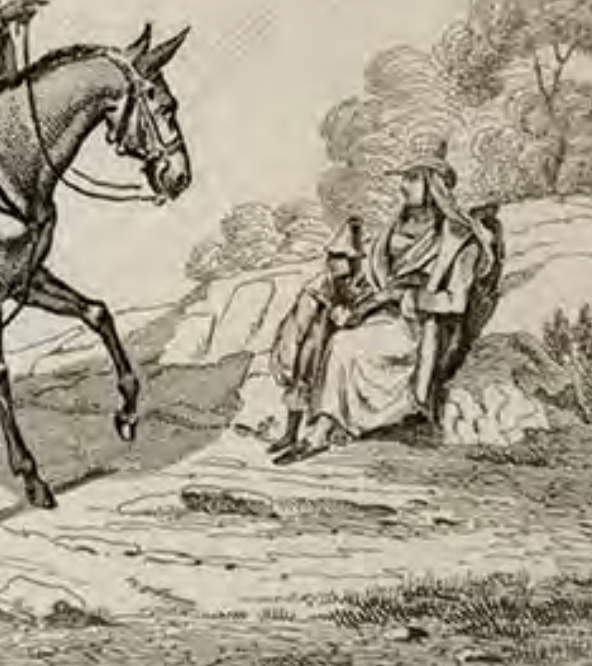


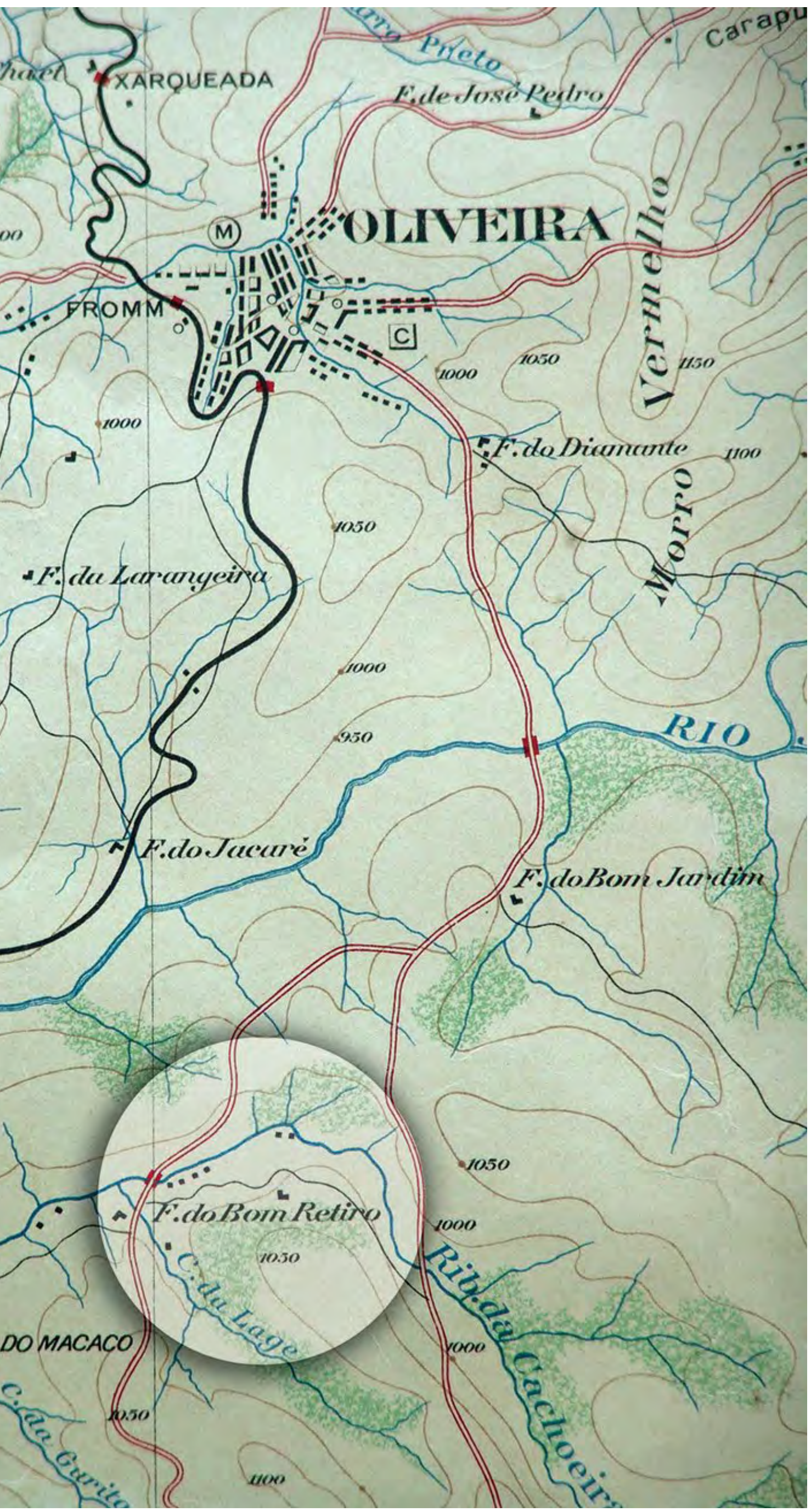

Oliveira ou Nossa Senhora da Oliveira (...) é uma das sucursais de São José, pequena cidade situada (...) a duas léguas de São João delRei. Pertence ao pequeno número das que não devem sua fundação à presença do ouro; deve-a unicamente às vantagens de posição. Com efeito, diversas estradas importantes passam por este ponto: a que vai de Barbacena à vila de Formiga, a do distrito de Rio Grande à cidade de Pitangui, de Rio de Janeiro e São João del-Rei a Goiás, de Vila de Campanha a Formiga etc. A vila de Oliveira está situada no meio de morros sobre o dorso de uma colina cujo cume é muito achatado.

Auguste de Saint-Hilaire

Oliveira, or Nossa Senhora da Oliveira (...), is part of the parish of São José, a small town lying (...) two leagues from São João del-Rei. It is among the few villages that does not owe its formation to the presence of gold; it owes it solely to the advantages of location. Indeed, several important roads pass through the place: the one from Barbacena to the village of Formiga, the one from the district of Rio Grande to the town of Pitangui, from Rio de Janeiro and São João del-Rei to Goiás, from Vila de Campanha to Formiga, etc. The village of Oliveira lies in the midst of hills, straddling a very flat-topped one. Auguste de Saint-Hilaire 


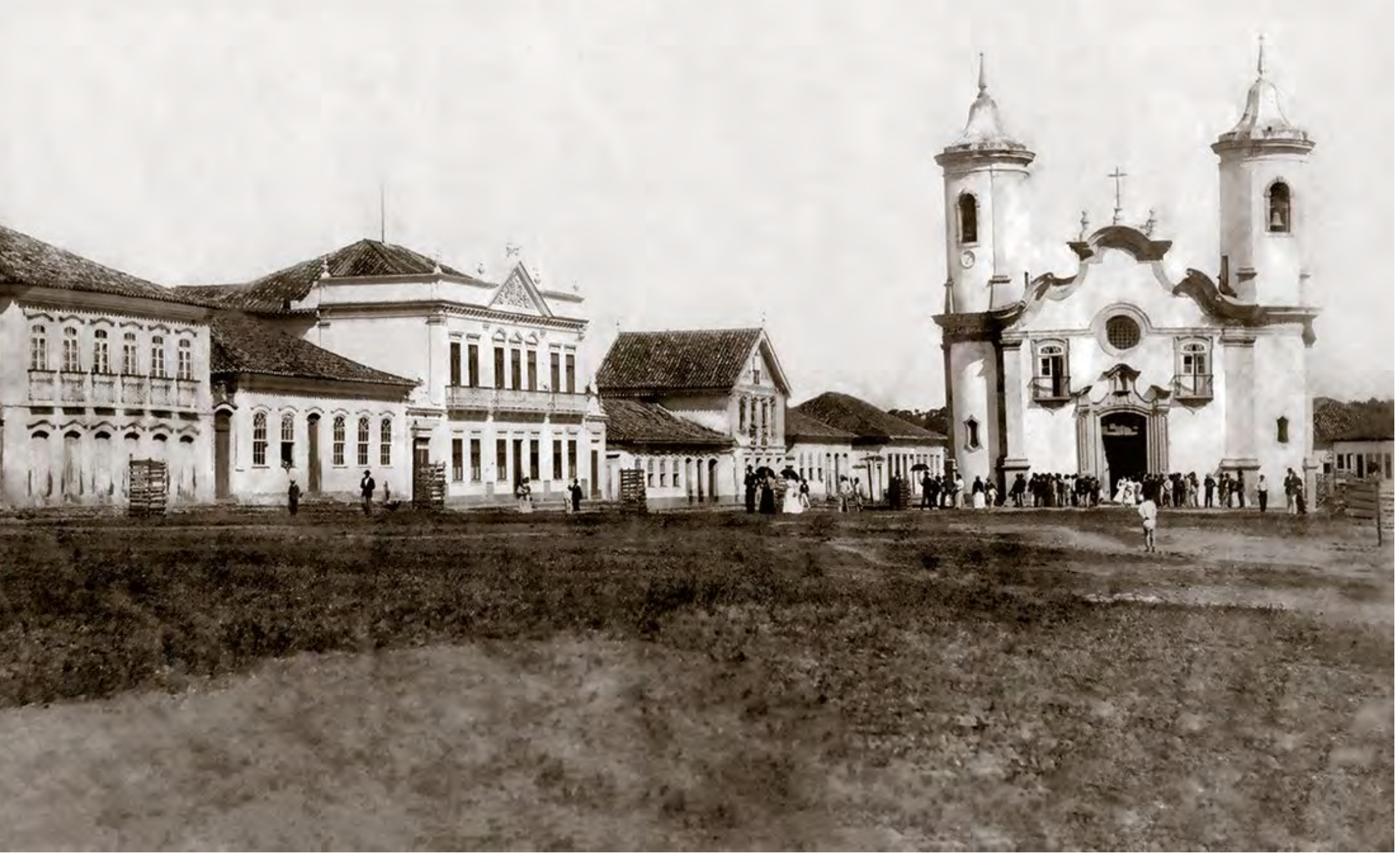

Matriz de Nossa Senhora de Oliveira, 1900 Acervo Fundaçăo Casa de Cultura Carlos Chagas

Nossa Senhora de Oliveira Cathedral, 1900 

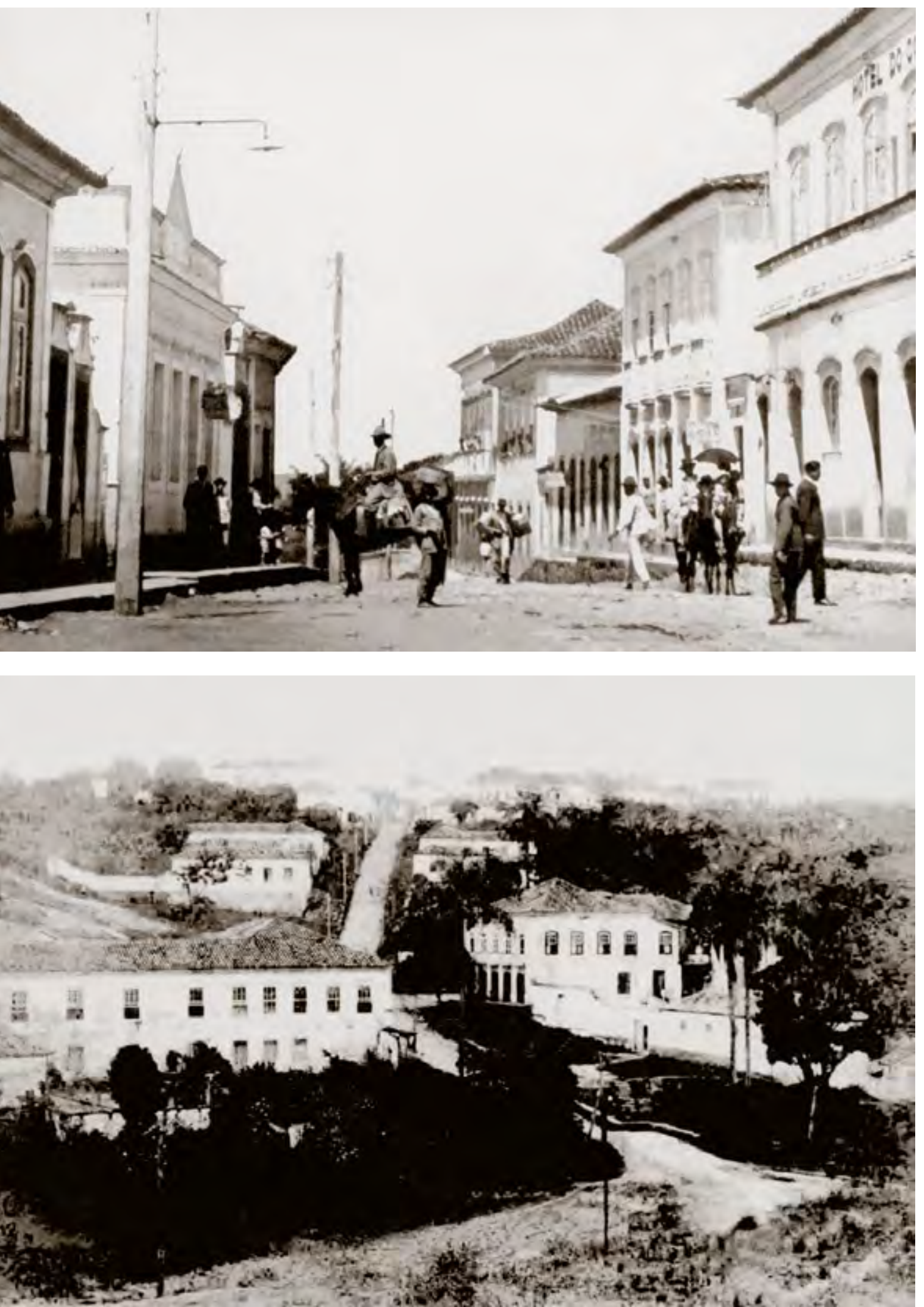

Rua Direita. Oliveira, década de 1910

Acervo Fundação Casa de Cultura Carlos Chagas

Direita Street, in Oliveira, 1910s

Ladeira dos Frades. Oliveira, década de 1920

Acervo Fundação Casa de Cultura Carlos Chagas

Ladeira dos Frades, a street in Oliveira, 1920s

Oliveira possui duas igrejas, das quais a principal foi construída no cume da colina, no meio da rua larga, e a igual distância das duas ordens de casas; é bastante bela no interior. Empregaram, para orná-la, uma pedra de um belo verde-maçã, que o mineralogista Pohl afirma ser, talvez, talco endurecido. Vêem-se em Oliveira diversas lojas de fazendas e mercearia que são bem sortidas, tavernas, uma farmácia e dois albergues, cada qual com seu rancho. Há aí também alfaiates, cordoeiros, serralheiros etc.

Auguste de Saint-Hilaire

Oliveira has two churches, the main one built at the crest of the hill, halfway along the main street and equidistant from two rows of houses; it is quite lovely inside. It is decorated with a beautiful apple-green stone, which mineralogist Pohl identifies as mineral talc. In Oliveira, one finds a number of very well-stocked fabric and grocery stores, some taverns, a pharmacy, and two inns, each with its own rancho [rustic building]. There are also tailors, rope makers, locksmiths, etc.

Auguste de Saint-Hilaire 


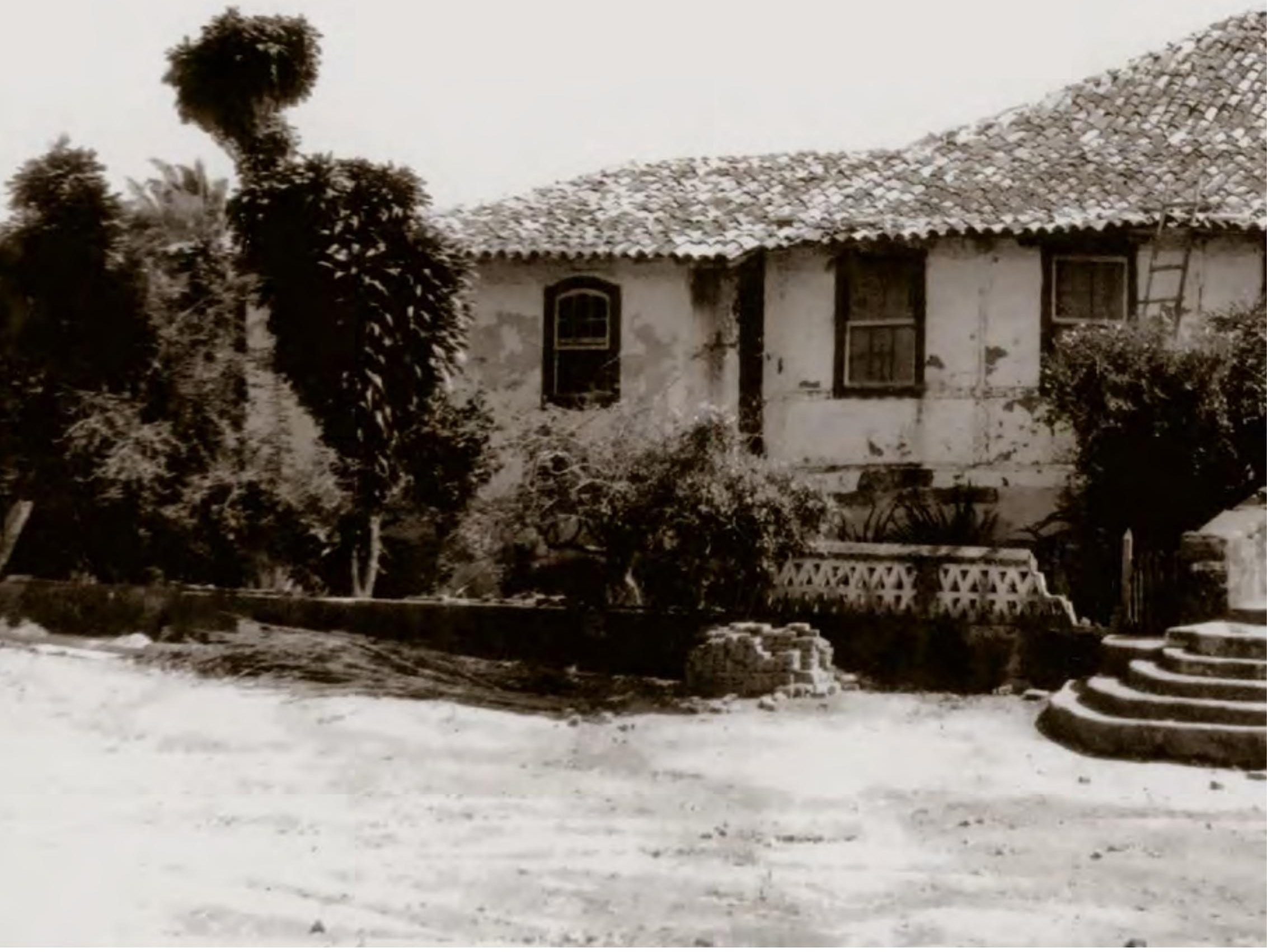




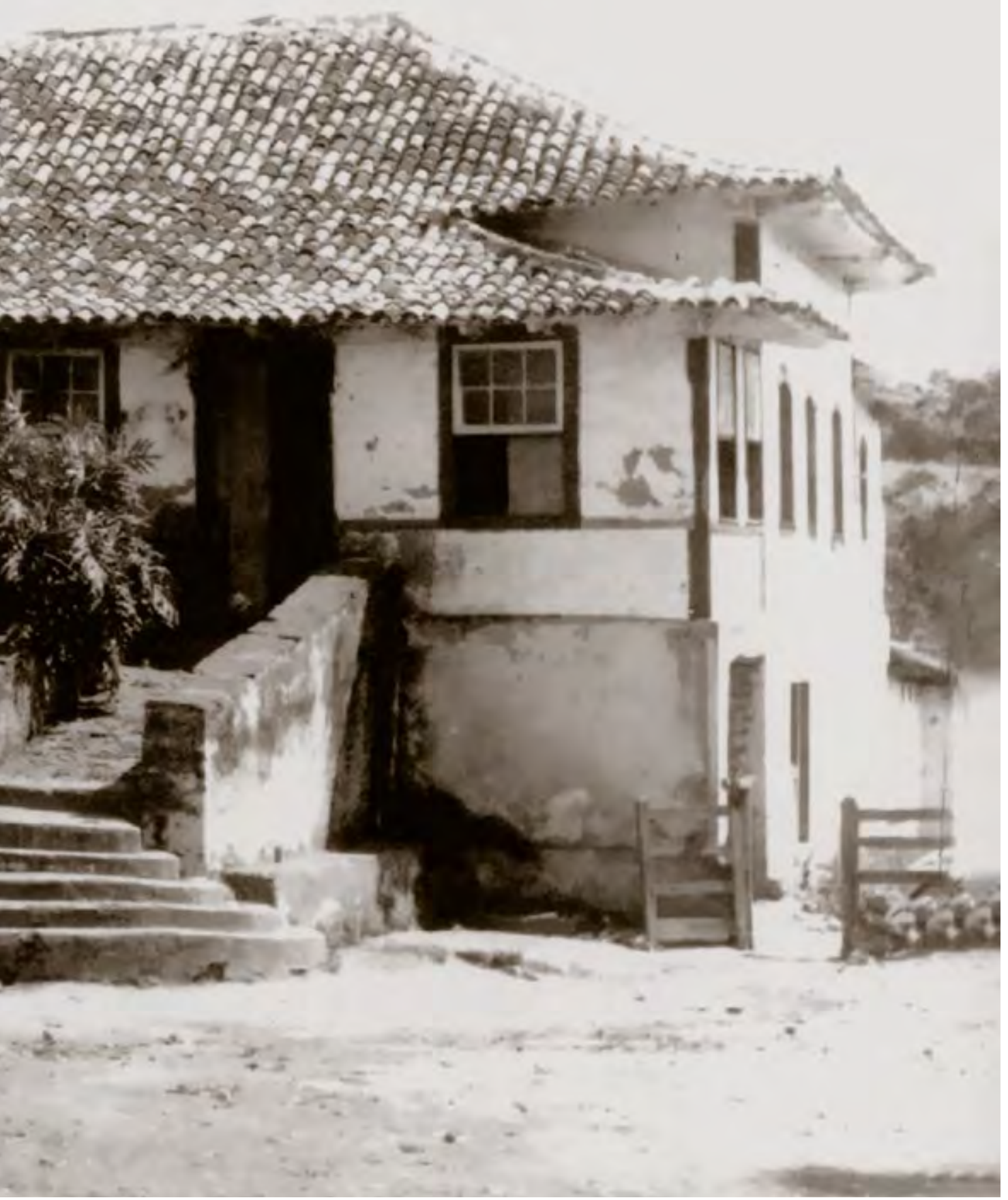

A rotina alimentar diária era respeitada rigorosamente. $\grave{A}$ alvorada, buscava-se o leite de ordenha recente, ainda tépido, cabendo ao visitante o privilégio de o saborear. Seguia-se o desjejum. Café, broa de milho e mingaus entretinham o estômago até a hora do almoço, servido ali pelas dez e meia. Merenda, fartamente acompanhada de deliciosos doces, dividia a segunda parte do dia. Após o jantar, semelhante ao almoço, o terço era puxado pelo patrão, a quem cabia sempre declamar os mistérios. Uma pequena ceia noturna preparava, para o leito, a gente cansada do trabalho diário.

Carlos Chagas Filho

The daily meals obeyed a strict routine. Fresh milk, still warm, was fetched at dawn, and the privilege of savoring it fell to visitors. Next came breakfast. Coffee, sweet cornbread, and porridges tided one over till lunch, which was served around ten thirty. A snack, generously accompanied by delicious sweets, divided the second part of the day. After supper, similar to lunch, the chaplet would be led by the master, who always prayed the Mysteries. A light evening meal got people who were tired from the day's work ready for bed.

Carlos Chagas Filho 


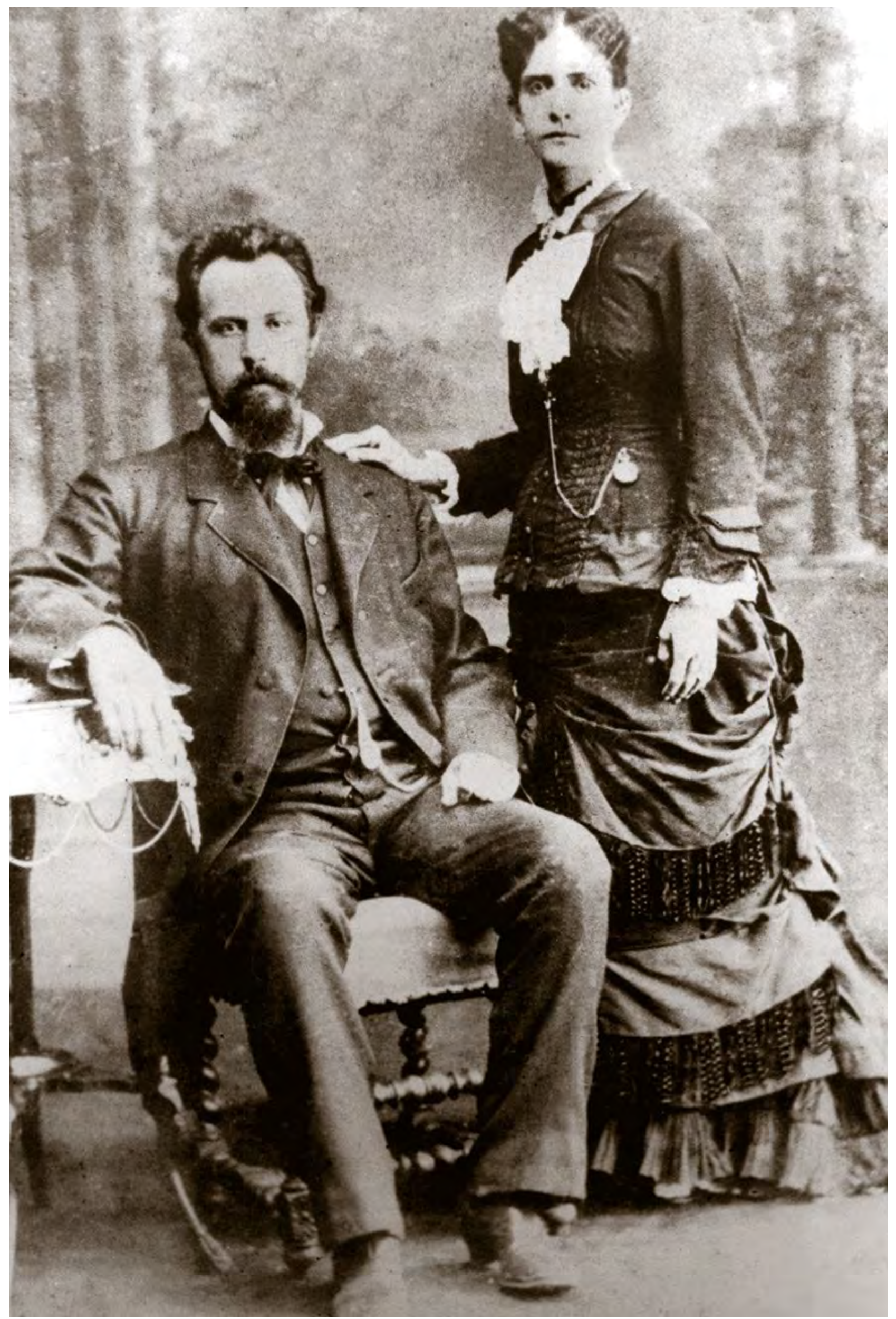

José Justiniano Chagas e Mariana Candida Ribeiro

de Castro Chagas, pais de Carlos Chagas

Acervo Casa de Oswaldo Cruz

Carlos Chagas's parents, José Justiniano Chagas and

Mariana Candida Ribeiro de Castro Chagas 


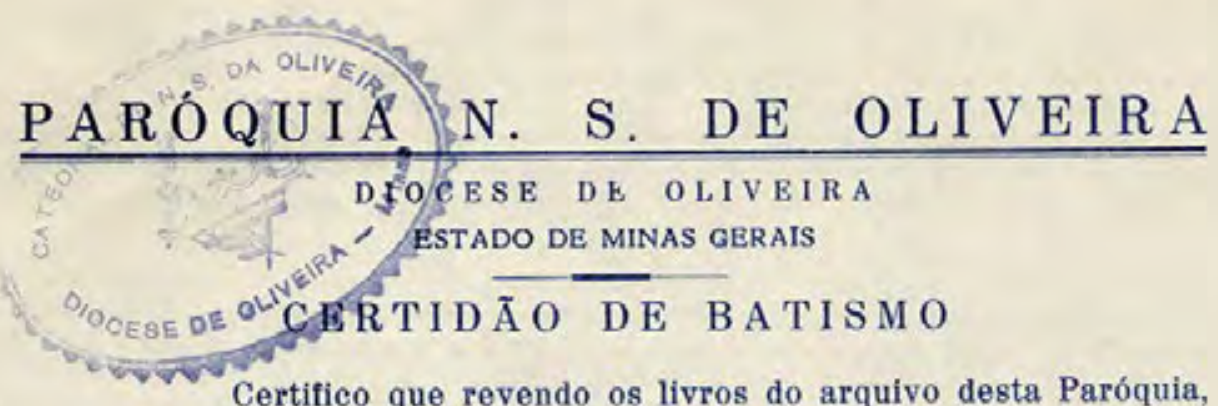
encontrei o teor seguinte:

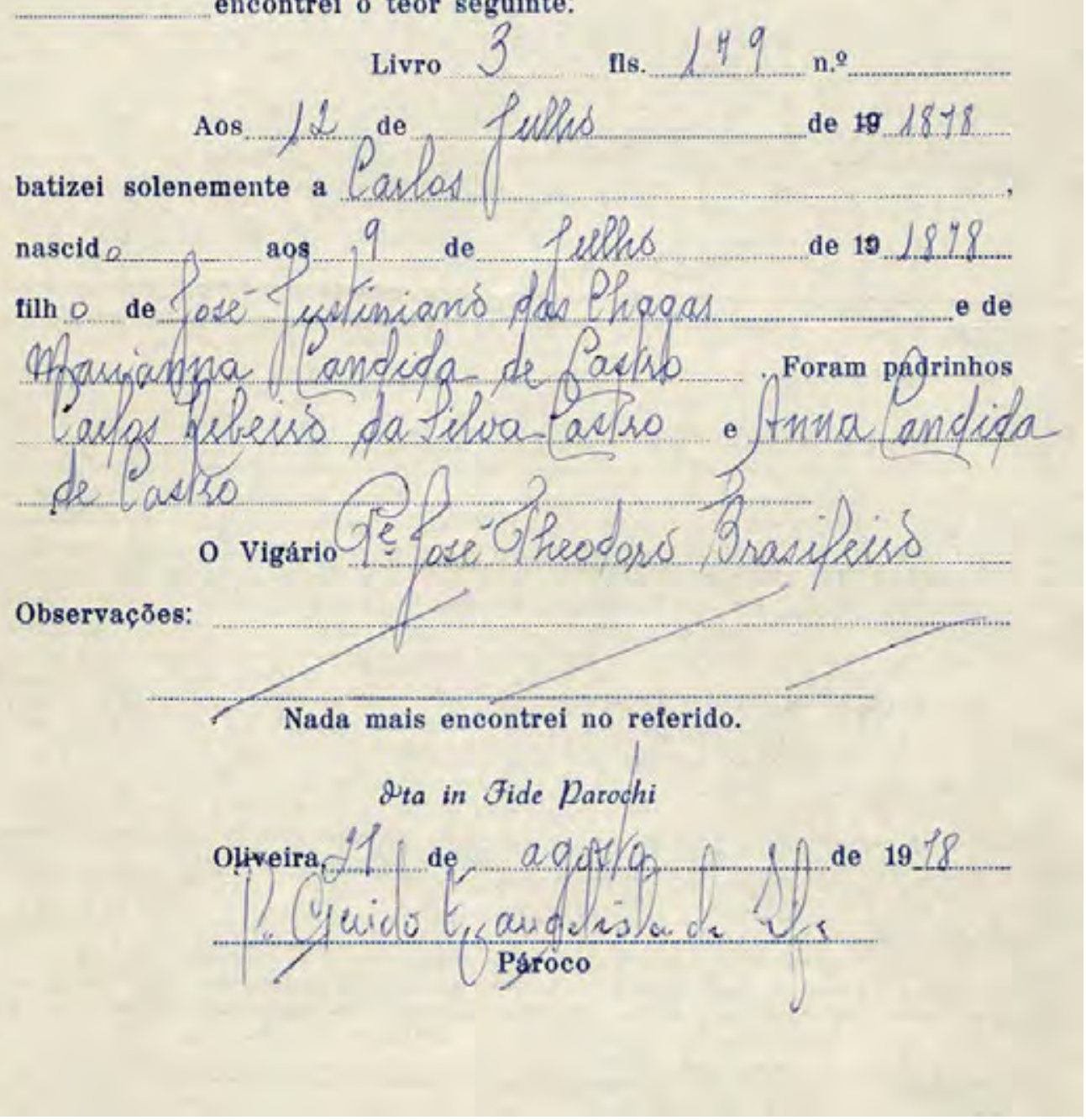

Certidão de batismo. Oliveira, 1878. Em 1979,

quando se comemorou o centenário de

nascimento de Carlos Chagas, Carlos Chagas Filho

recebeu de um primo de Oliveira esta certidão

que informava ter seu pai nascido em 1878 e

não em 1879, como era considerado até então Acervo Casa de Oswaldo Cruz

Baptismal certificate. Oliveira, 1878. In 1979,

during commemorations of the centennial of

Carlos Chagas's birth, Carlos Chagas Filho received

this certificate from a cousin in Oliveira; it states

that the scientist was born in 1878 , not 1879 ,

as previously believed

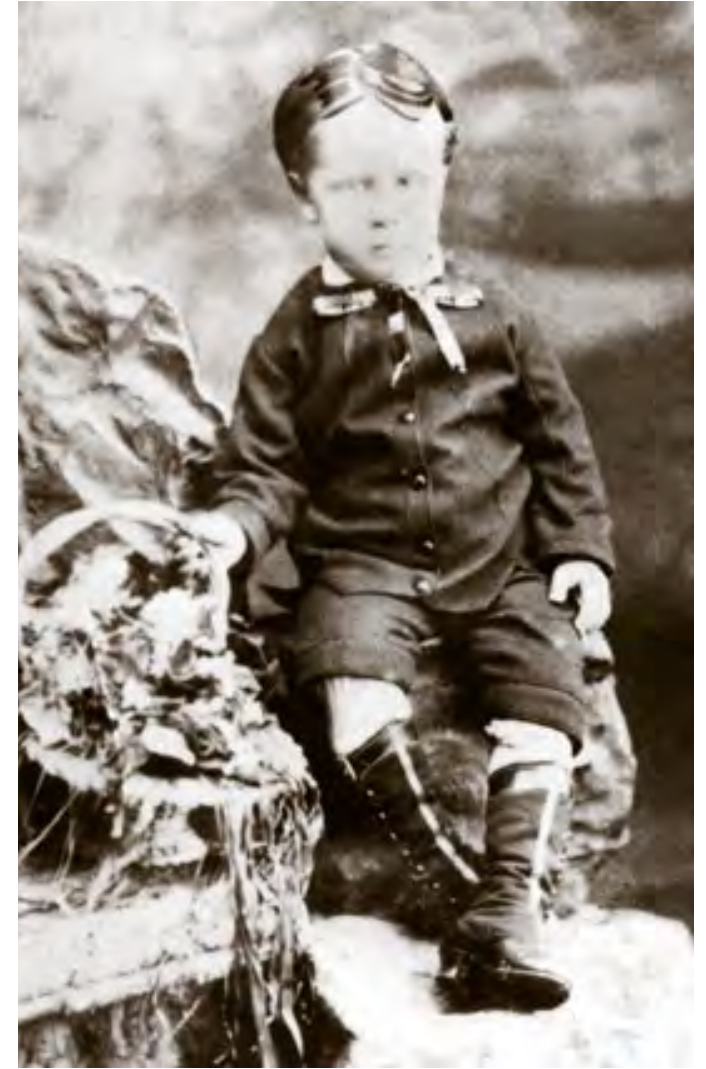

Carlos Chagas aos 4 anos Acervo Casa de Oswaldo Cruz Carlos Chagas at the age of 4 


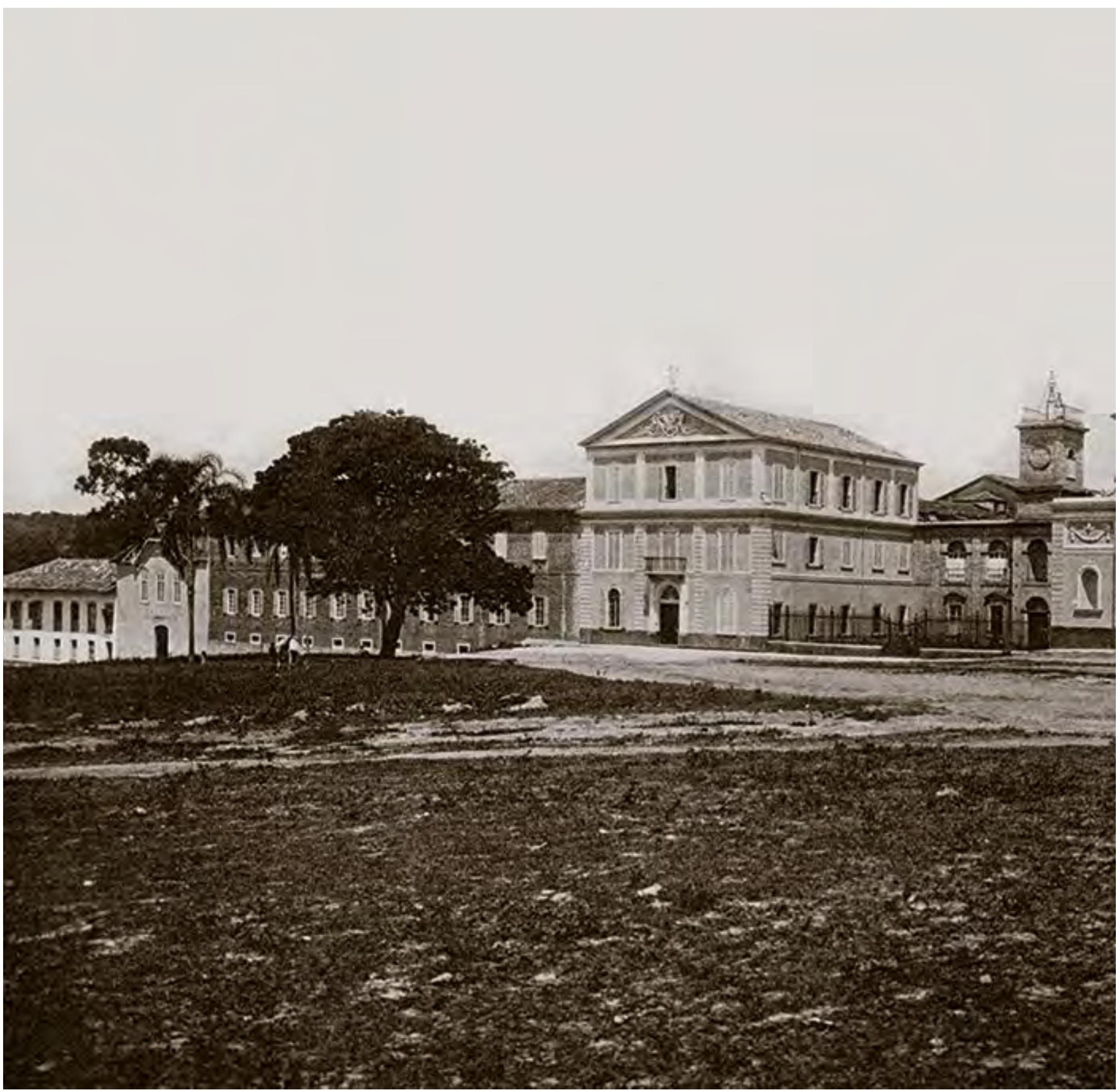

Colégio São Luís em Itu, SP, 1903

Acervo Associação dos Antigos Alunos da Companhia de Jesus

São Luís School in Itu, São Paulo, 1903 


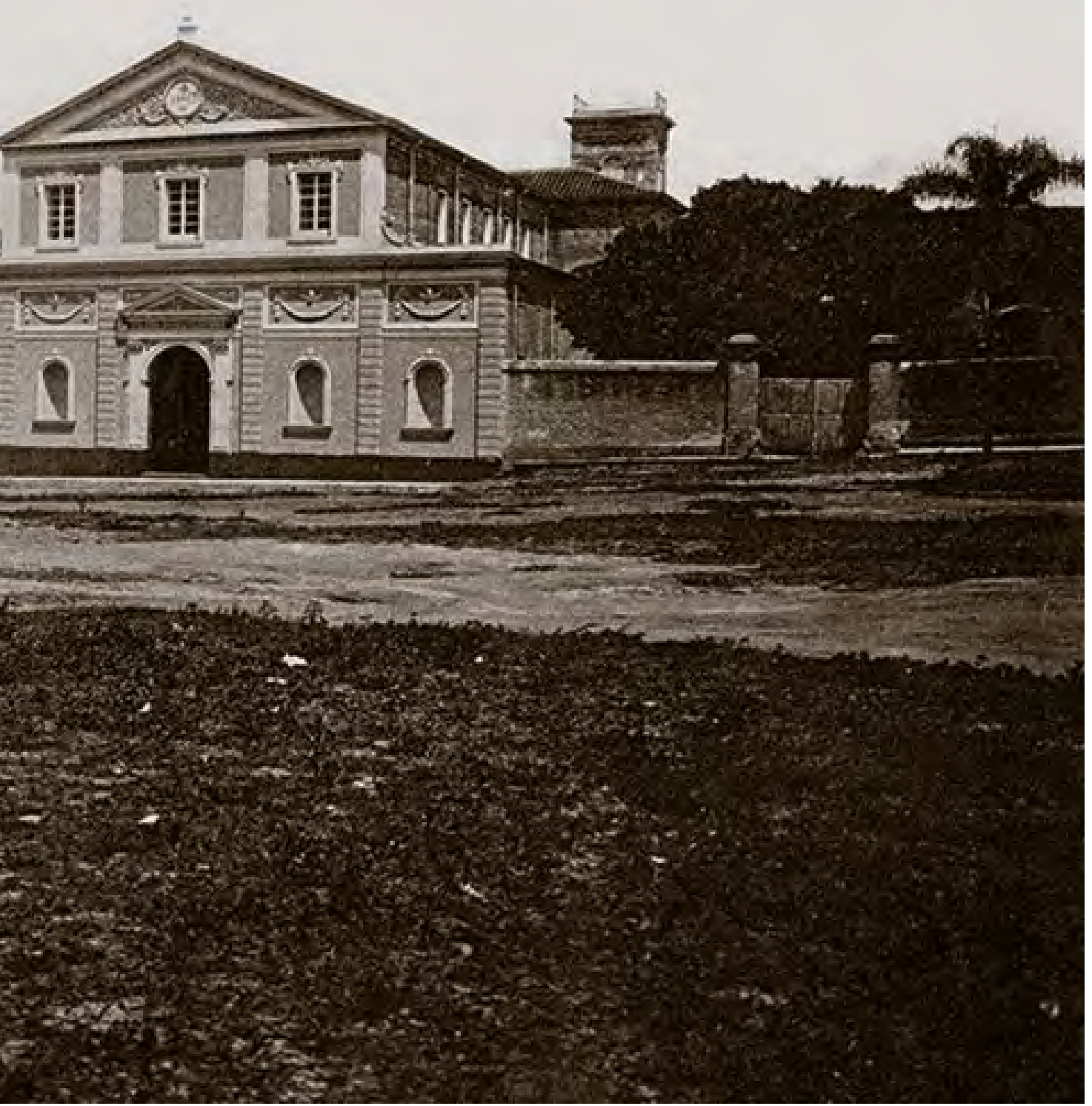

O Colégio de São Luís abrigava-se em vestuto casarão, que mais tarde (...) veio a servir de quartel da Força Pública do estado. As salas de aula eram grandes, o recreio aprazível, os dormitórios amplos e bem mantidos, mas a disciplina dos jesuítas não sabia bem ao menino de fazenda, acostumado à liberdade.

Carlos Chagas Filho

São Luís School was housed in a traditional old mansion, which later (...) came to serve as the barracks for the state Police Force. The classrooms were large, the recess area pleasant, the dormitories roomy and neat, but the Jesuit discipline did not sit well with the farm boy, accustomed to his freedom.

Carlos Chagas Filho 
... a alvorada às cinco horas, seguindo-se a missa, sempre longa. Do desjejum, servido somente às sete e meia, passava-se às aulas das oito às 12 e trinta, quando se servia o almoço, que, como o jantar, era frugal e, mais ainda, a merenda, dada às cinco e meia da tarde. Depois do recreio (...) continuava-se a estudar até as oito e meia da noite. Antes de dormir, os meninos tinham direito a uma xícara de chá, sem nada. (...) Mesmo sem apreciá-la, Chagas procurou integrar-se na vida do colégio. Participou das atividades da Arcádia Gregoriana, fundada em 1882, associação destinada ao fomento das letras clássicas, onde os alunos de maior pendor podiam dedicar-se à leitura de seus escritos em prosa e verso ou ao exercício da expressão oral (...).

Carlos Chagas Filho

(...) sunrise at five o'clock, followed by mass, always long. From breakfast, served only at seven thirty, one went on to classes from eight until twelvethirty, when lunch was served, meager like dinner, and, more meager still, the afternoon snack, which came at five thirty. After recess, (...) the studying continued until eight thirty at night. Before bed, the boys had the right to a cup of tea, with nothing else. (...) Even though he didn't enjoy it, Chagas tried to join in school life. He took part in the activities of the Gregorian Arcady, founded in 1882, an association that fostered the classics and where the more inclined pupils could dedicate themselves to reading their writings in prose and verse or to practicing verbal expression (...).
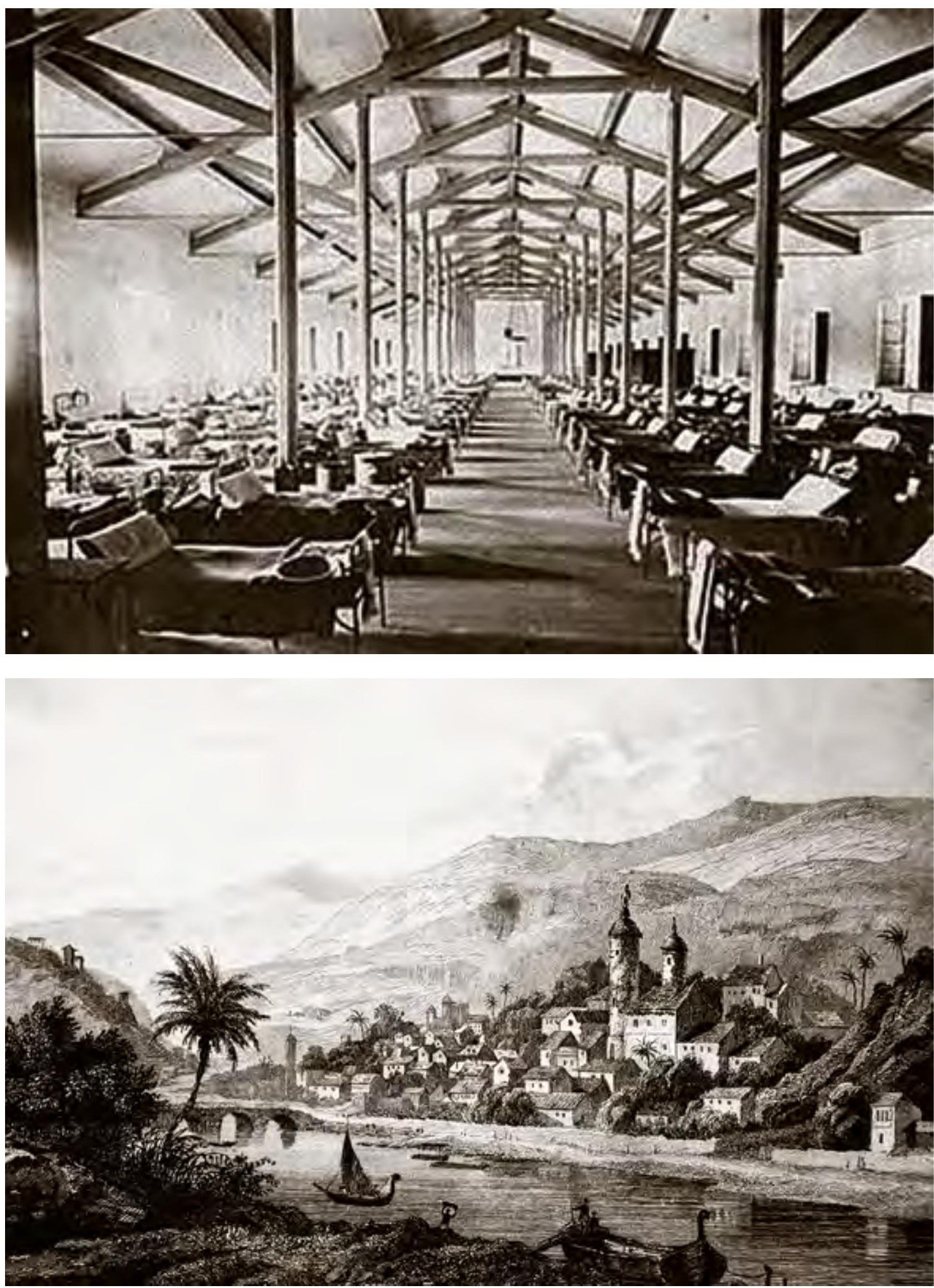

Dormitório dos alunos no Colégio São Luís. Itu, 1903

Acervo Associação dos Antigos Alunos da Companhia de Jesus

Student dormitory, São Luís School. Itu, 1903

Vista de São João del-Rei, MG

Gravura de François Hippolyte Lalaisse a partir de desenho de Van der Burch, século XIX

Acervo Museu Histórico Nacional

View of São João del-Rei, Minas Gerais

Engraving by François Hippolyte Lalaisse based on a drawing by Van der Burch, $19^{\text {th }}$ century 

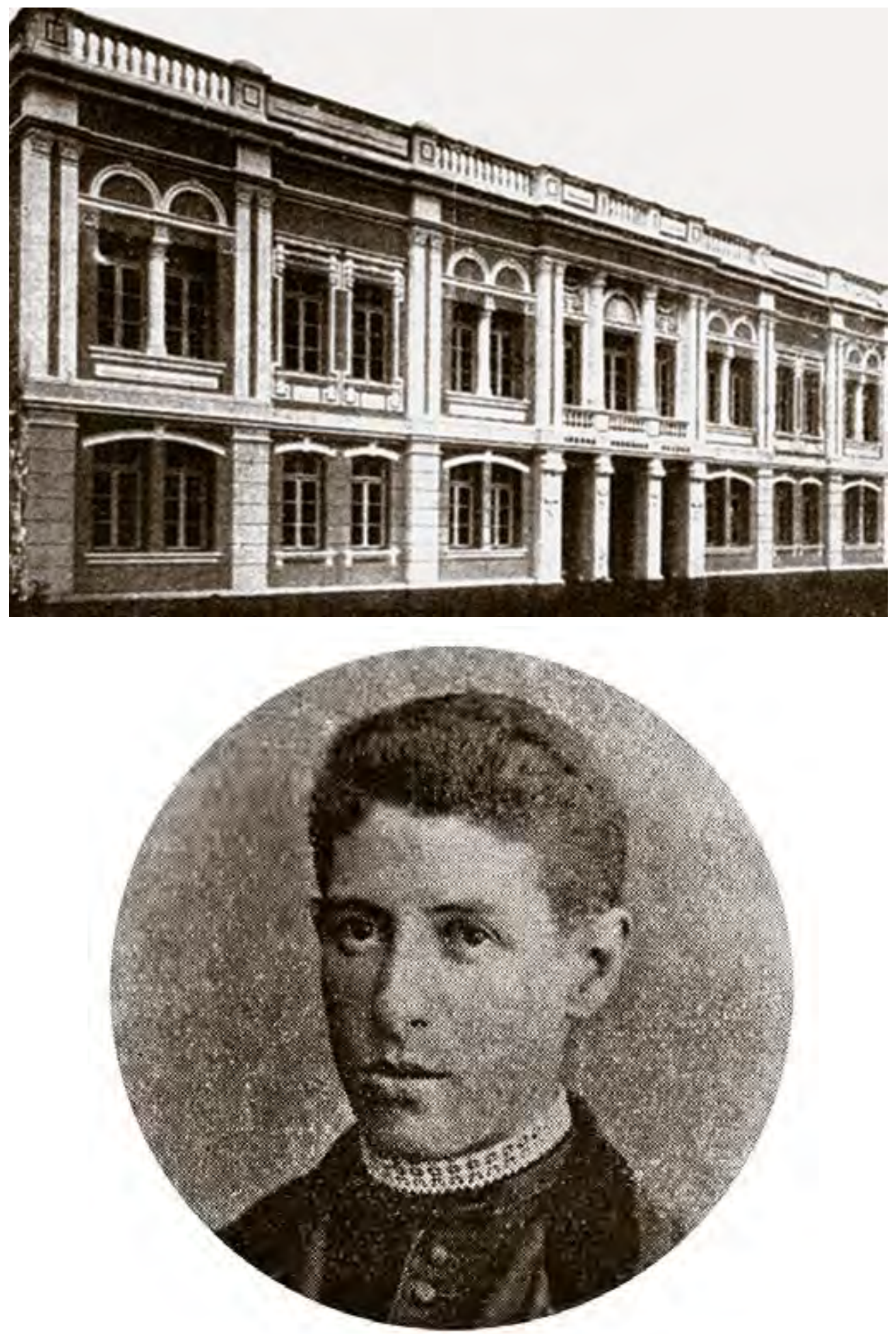

Foi em São João que Chagas ouviu falar, pela primeira vez, em Machado de Assis. Sacramento dava aos seus estudantes uma semente de estímulo intelectual e de amor pelas coisas brasileiras que iria segui-los pela vida afora. Foi assim com Chagas. (...) Marca a vida no Colégio São Francisco as páginas mais alegres da adolescência de meu pai.

Carlos Chagas Filho

It was in São João that Chagas first heard of Machado de Assis. Sacramento instilled in his students the seed of intellectual motivation and love for what is Brazilian, something that would stay with them throughout their lives. That's how it was with Chagas. (...) My father's life at São Francisco School marked the happiest pages of his adolescence.

Carlos Chagas Filho

Ginásio São Francisco, em São João del-Rei Acervo Universidade Federal de São João del-Rei São Francisco School, in São João del-Rei

Padre João Batista do Sacramento, fundador e diretor do Ginásio São Francisco Fonte: Braga, 1913

Acervo Fundação Biblioteca Nacional

Father João Batista do Sacramento, founder and director of São Francisco School 
Carta de Carlos Chagas para sua mãe

Acervo Casa de Oswaldo Cruz Letter from Carlos Chagas to his mother

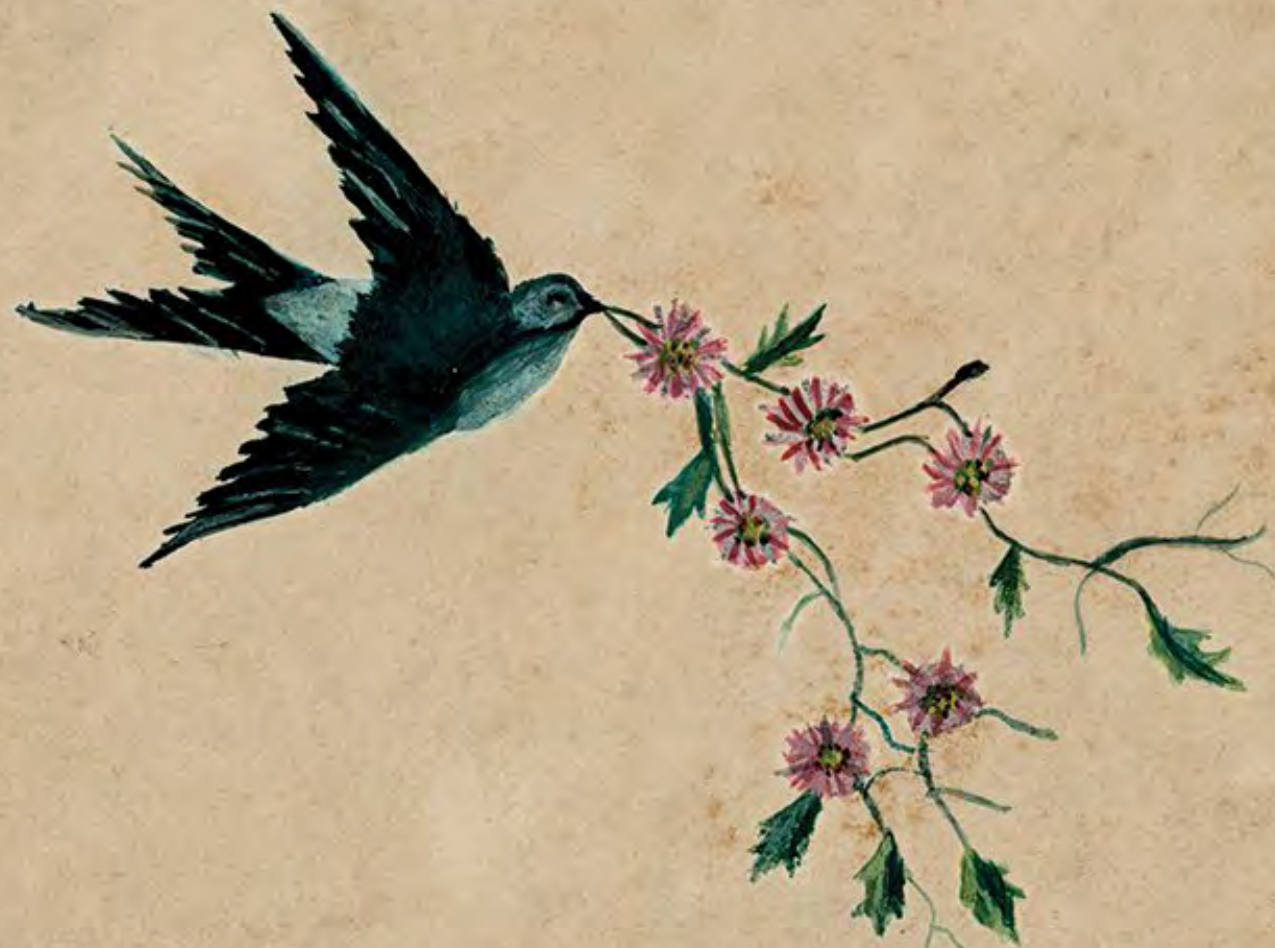

$\xi_{x}: h^{2}$

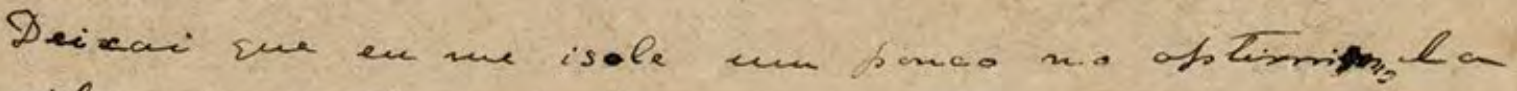

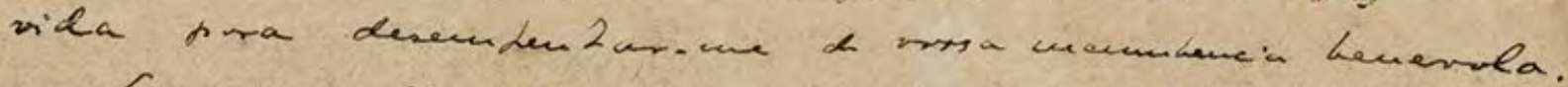
Gs encautas de una munt = Fotrieal, en ghe o

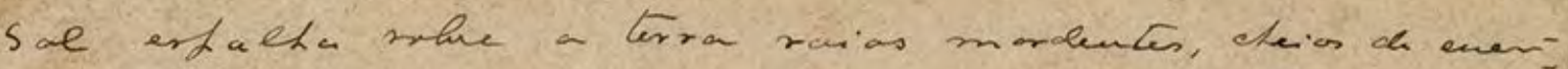
sia creacora, un sue o merde naturale bubra a

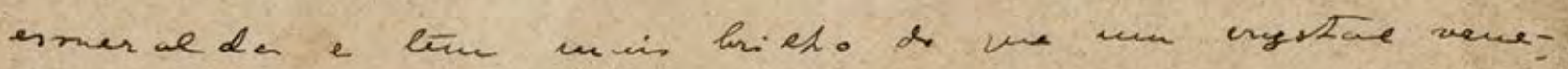

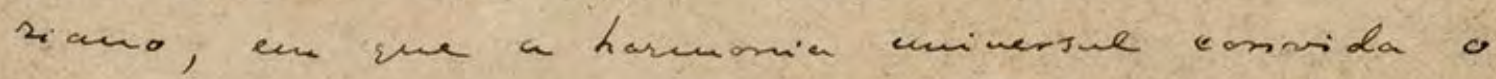

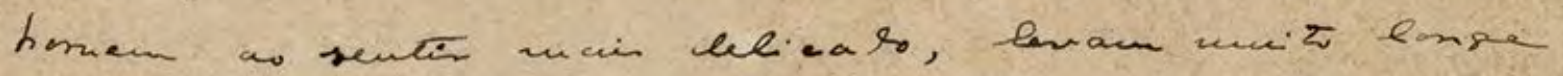
- Leusanento, suando illunina-o clarilad intansa Le un uffers, as soro de renctuas suil, easintosa:

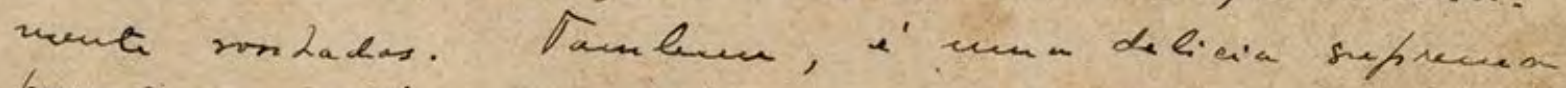

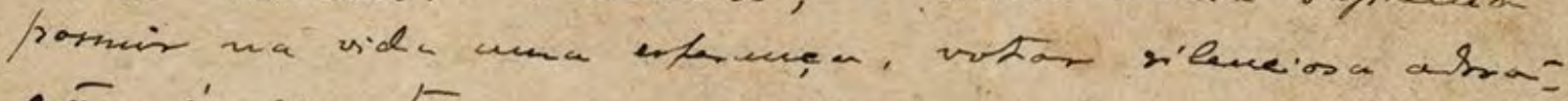

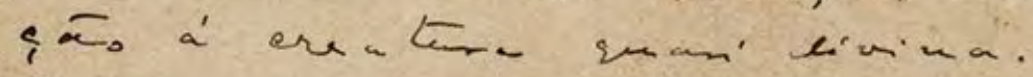

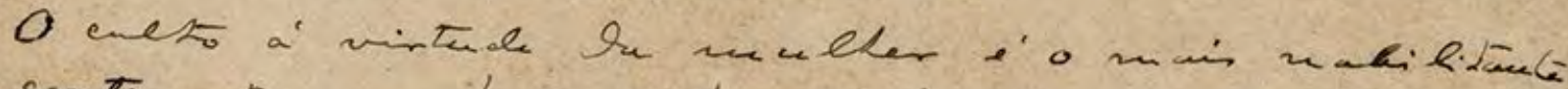
surtiment sue hoch o hamen Lamin, a surele whe unfindo a alena o misiticas ersenerin, illumerima a

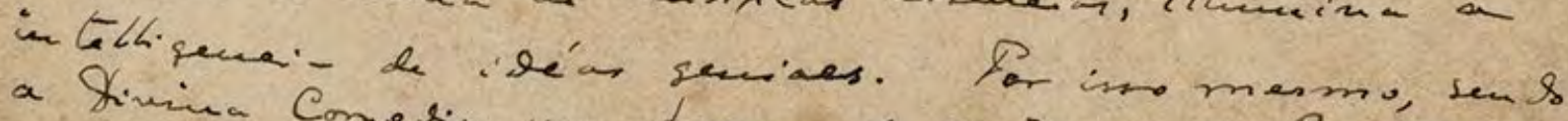

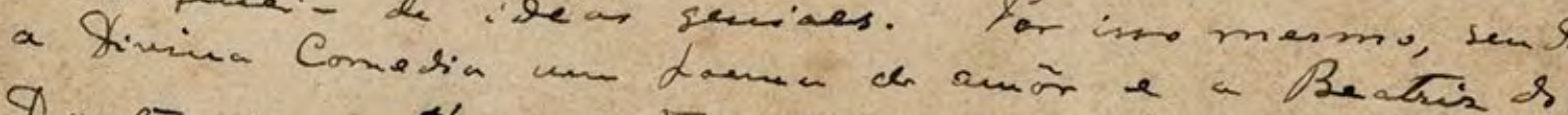

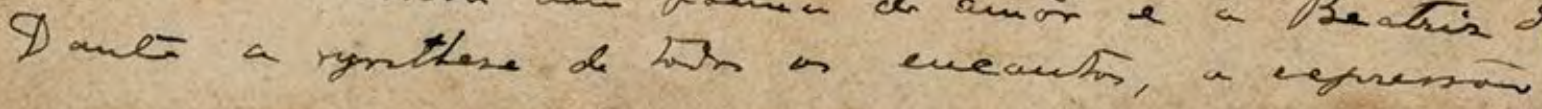


1- UM MENINO DO INTERIOR DE MINAS | A BOY FROM RURAL MINAS GERAIS

de un sorriso la Divindade, metka insfirarm-se

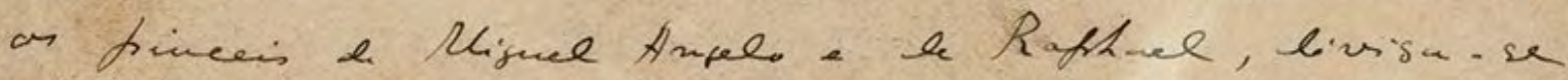

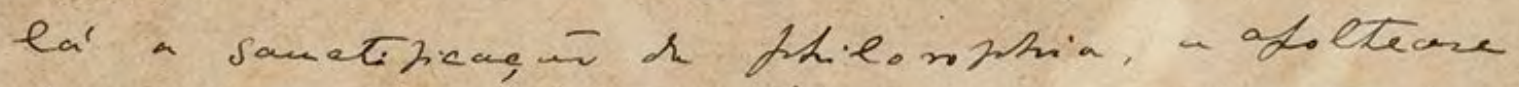

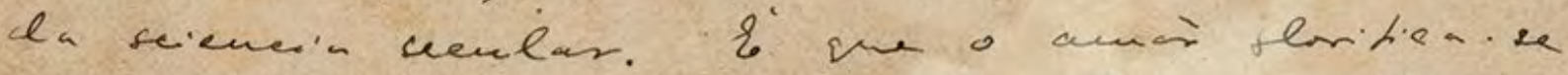

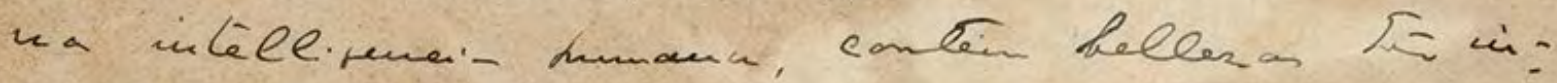

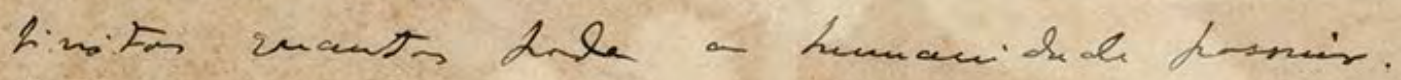

Le alguma mes, na pratica ob heen, o domen leixare

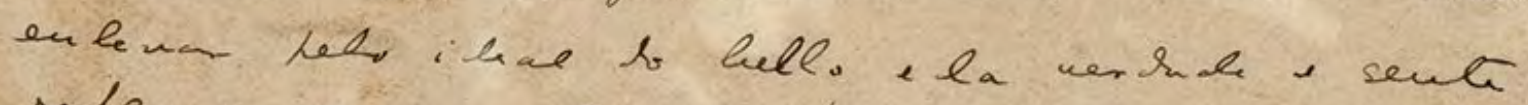

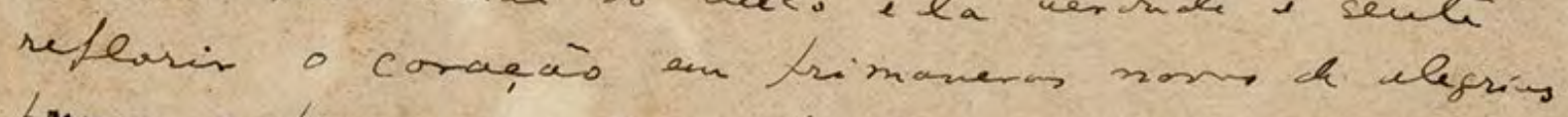
fress e prazeres suaves, $e^{\prime}$ see ra is th acomdanta.

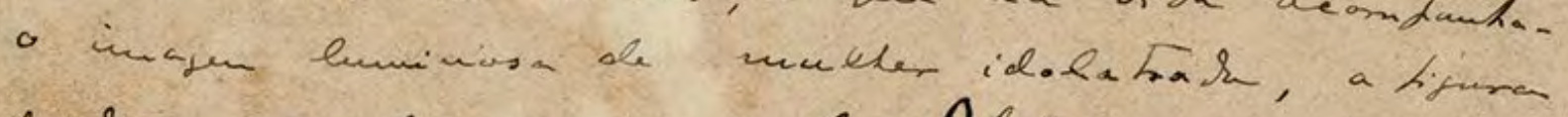
ratias e diminsisina de Mläe.

tearlas teasas.

41 


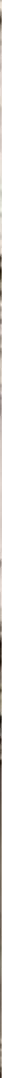

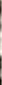

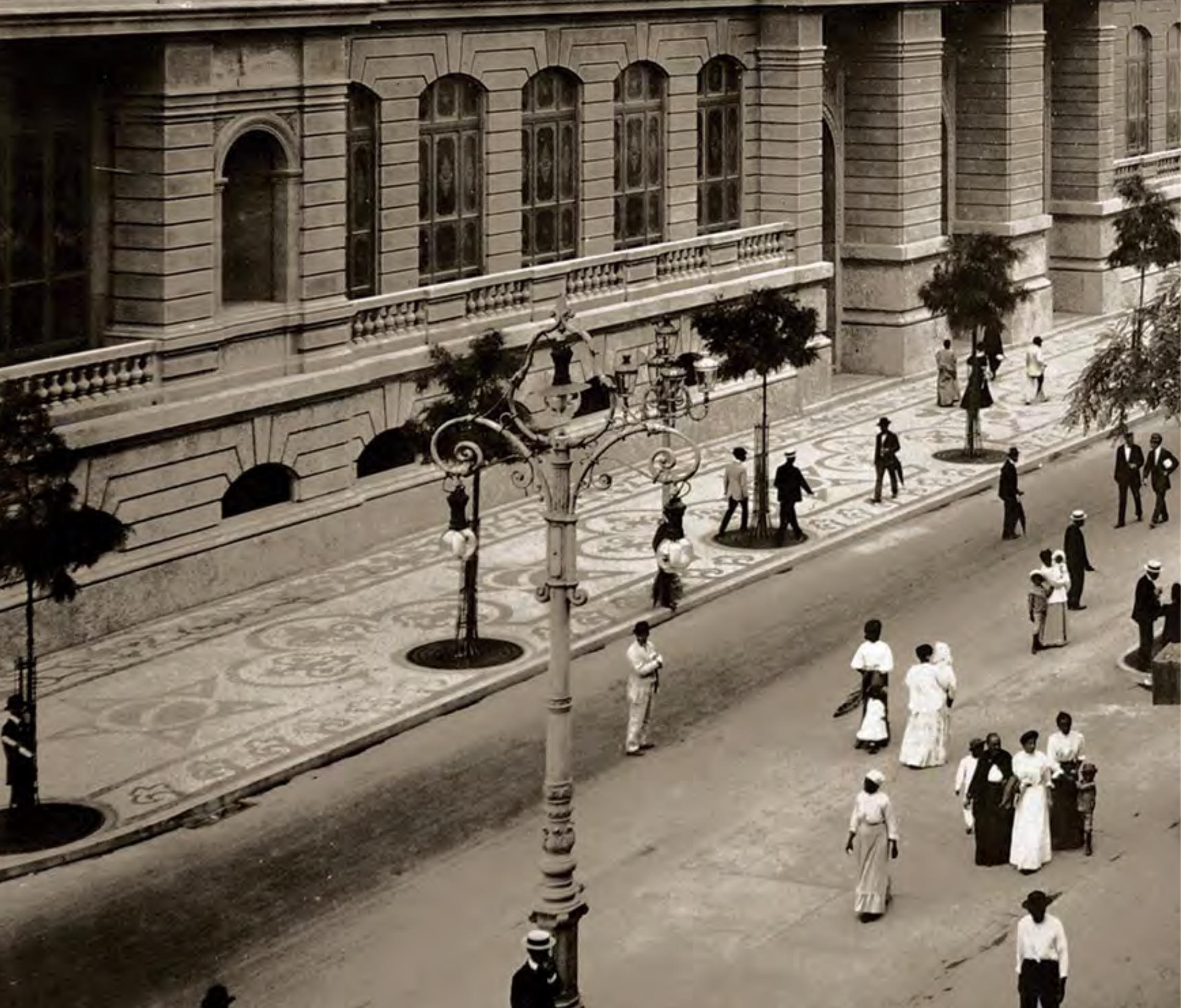


E m abril de 1897, Carlos Chagas matriculou-se na Faculdade de Medicina do Rio de Janeiro. A capital federal vivia dias de grande efervescência. A proximidade do novo século intensificava a crença em um novo tempo, em que o Brasil, guiado pela ciência, se tornaria, enfim, uma nação "civilizada". A "vida vertiginosa" da cidade, para usar a expressão do cronista João do Rio, fazia-se sentir no cotidiano, com a eletricidade, o telégrafo, o telefone e as ferrovias.

O ambiente de renovação ocorria também na Faculdade de Medicina, que buscava acompanhar as teorias de Louis Pasteur (1822-1895) e Robert Koch (1843-1910) sobre a ação dos microorganismos como causas de doenças e dominar os novos recursos, como soros e vacinas, para combatê-las. Desde a década de 1880, vários professores da faculdade defendiam que o ensino médico deveria incorporar os preceitos e práticas da medicina experimental, ou seja, da pesquisa no laboratório visando à produção de novos conhecimentos.

Era um período de proeminência internacional também da chamada medicina tropical. Desde a conquista e exploração de outros continentes, os europeus preocupavam-se com as doenças dos trópicos. Naquela virada de século, a "medicina dos climas quentes" vivia um momento de particular desenvolvimento, com as descobertas sobre o papel dos insetos na transmissão de enfermidades. Em 1898-1899, médicos ingleses e italianos estabeleceram que a malária era transmitida não por "miasmas", mas por mosquitos. Em 1900, os norte-americanos comprovaram o mesmo para a febre amarela. O mundo viveria, a partir de então, uma grande confiança na vitória sobre esses e outros 'males'. Além da teoria do inseto vetor, a preocupação dos europeus em enfrentar as doenças que ocorriam em suas colônias levou à criação, em 1899, na Inglaterra, das primeiras escolas dedicadas ao ensino e ao estudo da medicina tropical. Os conhecimentos e práticas da nova especialidade seriam decisivos na formação e na vida profissional de Chagas.

Dois professores marcaram em especial o seu curso médico, realizado entre 1897 e 1903 . Com Miguel Couto (1865-1934), de quem se tornaria amigo pessoal, aprendeu os métodos e princípios da experimentação, visando ao diagnóstico e ao estudo clínico das doenças que compunham a nosologia brasileira, bem como a concepção de que a clínica médica deveria ser renovada pelos saberes e técnicas propiciados pelo laboratório. Com Francisco Fajardo (1864-1906), pioneiro da microbiologia no Brasil e dos estudos sobre o parasito e o vetor da malária, tomou contato com os temas da medicina tropical. Em seu laboratório, na Santa Casa de Misericórdia, Chagas iniciou-se nas pesquisas sobre essa doença.

Com o objetivo de elaborar sua tese de doutoramento, pré-requisito para a conclusão do curso médico, dirigiu-se em 1902 ao Instituto Soroterápico Federal (também conhecido como Instituto de Manguinhos), criado dois anos antes para fabricar soro e vacina contra a peste bubônica; tendo irrompido em Santos em 1899, a doença ameaçava a capital federal. Oswaldo Gonçalves Cruz (1872-1917), jovem microbiologista treinado no Instituto Pasteur de Paris, havia sido designado para comandar os trabalhos técnicos de Manguinhos. Em fins de 1902, assumiria a direção integral do instituto, que, em 1908, passaria a levar seu nome. Decidido a torná-lo um renomado centro de medicina experimental, Oswaldo Cruz costumava receber estudantes de medicina interessados em desenvolver ali suas pesquisas. Sob sua orientação, Chagas passou a frequentar o Soroterápico diariamente. Em maio de 1903, defendeu sua tese, sobre os aspectos hematológicos da malária.

Apesar do convite feito por Oswaldo Cruz para integrar a equipe de pesquisadores de Manguinhos, optou pela clínica. Em março de 1904, foi nomeado médico da Diretoria-Geral de Saúde Pública e passou a trabalhar no Hospital Paula Cândido, em Jurujuba, Niterói. Ao mesmo tempo, instalou seu consultório particular no centro do Rio, na rua da Assembléia. Naquele mesmo ano casou-se com Iris Lobo, filha do senador mineiro Fernando Lobo Leite Pereira (1851-1918), e que conhecera por intermédio de Miguel Couto. 
$\mathrm{I}^{\mathrm{n}}$ n April 1897, Carlos Chagas entered the Rio de Janeiro School of Medicine. This was a time of cultural effervescence in the federal capital of Rio. The approach of a new century fueled the belief that a new era was dawning, when Brazil, guided by science, would finally become a "civilized" nation. The "dizzying life" of the city, in the words of writer João do Rio, could be felt in the daily march of events, in electric power, the telegraph, the telephone, and the railroad.

This spirit of revitalization was evinced at the School of Medicine as well, where efforts were made to keep step with Louis Pasteur's (1822-1895) and Robert Koch's (1843-1910) theories on the action of microorganisms as disease agents and to master new resources for fighting them, like serums and vaccines. In the 1880s, a number of the school's faculty members had begun arguing that medical teaching should incorporate the precepts and practices of experimental medicine, that is, of laboratory research aimed at producing new knowledge.

It was also the international heyday of so-called tropical medicine. Ever since the Europeans had begun exploring and conquering other continents, they had been worried about the diseases of the tropics. At the turn of the century, "warm-climate medicine" was enjoying a growth spurt, which brought discoveries about the role of insects as disease transmitters. In 1898-1899, British and Italian physicians ascertained that malaria is transmitted not by miasmas but by mosquitoes. In 1900, scientists from the United States proved the same about yellow fever. From that moment on, the world was quite confident in the prospect of victory over these and other illnesses. European concern over the diseases afflicting their colonies led not only to development of the insect vector theory but also to the 1899 creation of the first schools of tropical medicine, in England. Chagas's knowledge of this new specialty and its practices would prove decisive in his training and career.

Two professors were especially influential in Chagas's medical schooling, which extended from 1897 to 1903. One was Miguel Couto (1865-1934), who eventually became his personal friend and who taught him the methods and principles of experimental medicine and their application to the diagnosis and clinical study of Brazilian diseases. Couto further instilled in him the idea that medical practice should be constantly renewed through knowledge and techniques derived from the laboratory. The other teacher was Francisco Fajardo (1864-1906), a pioneer of both microbiology in Brazil and of studies on the malaria parasite and vector, who introduced Chagas to the subjects specific to tropical medicine. Chagas began his investigations of malaria in Fajardo's laboratory at Santa Casa de Misericórdia hospital.

In 1902, Chagas started work on his medical school thesis - a prerequisite for obtaining a degree - at the Federal Serum Therapy Institute. Also known as Manguinhos, the Institute had been established two years earlier to manufacture serum and vaccine against the bubonic plague that had broken out in Santos in 1899 and was threatening the nation's capital. Oswaldo Gonçalves Cruz (1872-1917), a young microbiologist trained at the Pasteur Institute in Paris, had been appointed to oversee technical work at Manguinhos. In late 1902, he was assigned to head the entire Institute, which would come to bear his name in 1908. Determined to mold the Serum Therapy Institute into a respected center of experimental medicine, Oswaldo Cruz welcomed medical students interested in conducting their research there. Under his guidance, Chagas became a daily presence. In May 1903, he defended his medical thesis on hematological aspects of malaria.

Although Oswaldo Cruz invited Chagas to join Manguinhos' research team, he opted instead to take up the practice of medicine. In March 1904, he was appointed to a post as a physician with the General Directorship of Public Health and was assigned to the Paula Cândido Hospital in Jurujuba, Niterói. At the same time, he opened a private practice in downtown Rio, on Assembléia Street. Also in 1904, he married Iris Lobo, daughter of Minas Gerais senator Fernando Lobo Leite Pereira (1851-1918), whom he had met through Miguel Couto. 


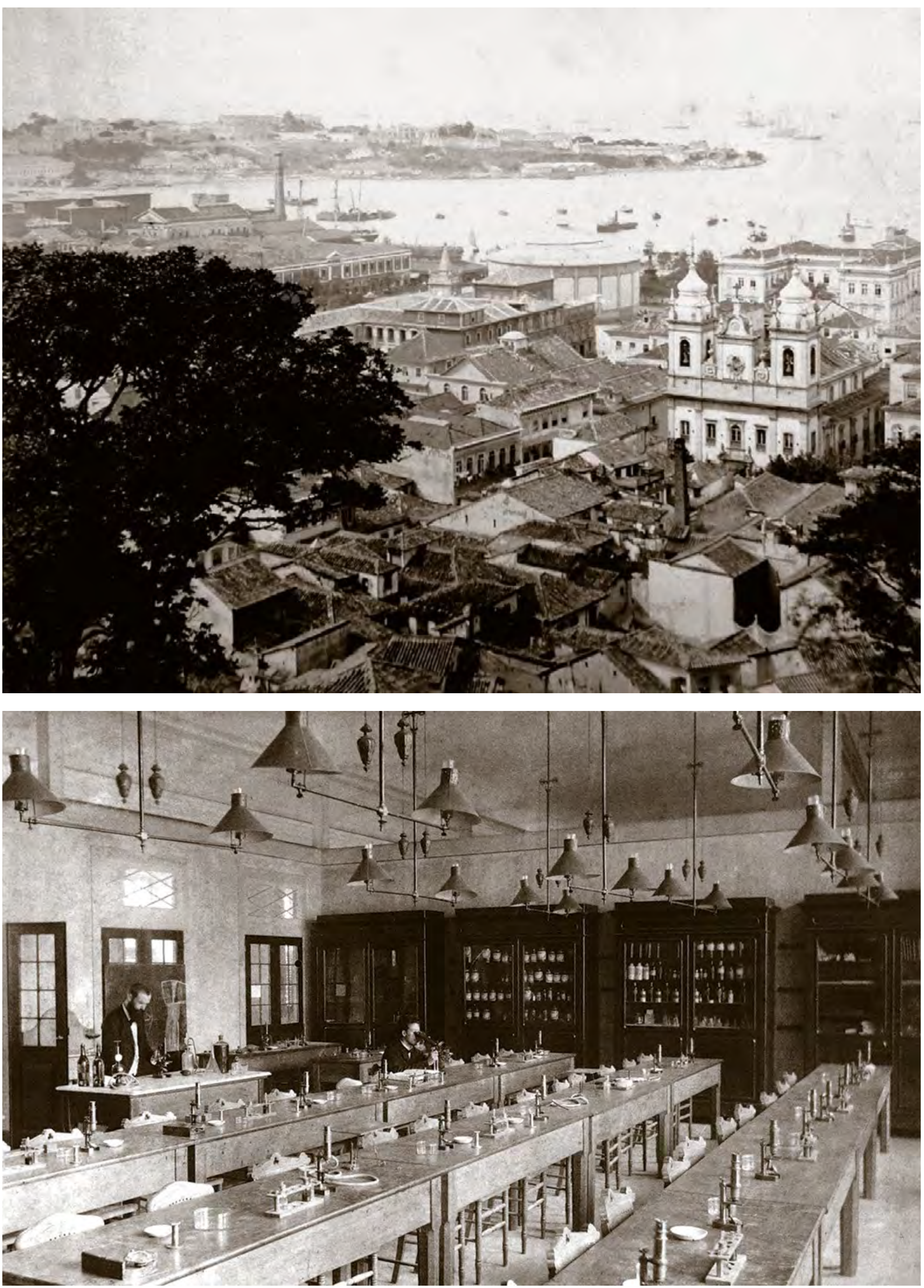


Imagem de abertura - Vista da avenida

Central, vendo-se a Escola de Belas Artes (atual Museu Nacional de Belas Artes). Rio de Janeiro,

c. 1906. Chagas testemunharia a reforma urbana comandada pelo prefeito Francisco Pereira Passos no Rio de Janeiro. A abertura da avenida Central (atual Rio Branco), em 1904-1905, foi o símbolo maior da Belle Époque vivida na capital federal

Foto Augusto Malta

Acervo Museu Histórico Nacional

Opening image - View of Central Avenue, showing the Fine Arts School (now the National Fine Arts Museum). Rio de Janeiro, c. 1906. Chagas would witness Mayor Francisco Pereira Passos's urban reform of Rio de Janeiro. Opened in 1904-1905, Central Avenue (now called Rio Branco) was the premier emblem of the Belle Époque in the nation's capital

Photograph by Augusto Malta

Vista do centro do Rio de Janeiro, tomada do morro do Castelo para a ilha das Cobras, década de 1890. Em destaque, a Igreja de São José; à esquerda, o Paço Imperial

Foto Juan Gutierrez

Acervo Museu Histórico Naciona

View of downtown Rio de Janeiro taken from Morro do Castelo, looking towards Ilha das Cobras, 1890s. São José Church in the foreground, with the Imperial Palace to the left Photograph by Juan Gutierrez

Laboratório para ensino médico, década de 1880

Foto Marc Ferrez

Acervo Fundação Biblioteca Nacional

Medical teaching laboratory, 1880s

Photograph by Marc Ferrez

Recibo de matrícula na Faculdade de Medicina. Rio de Janeiro, 13 abr. 1897 Acervo Casa de Oswaldo Cruz

Enrollment receipt from the School of Medicine. Rio de Janeiro, Apr. 13, 1897

Santa Casa de Misericórdia do Rio de Janeiro, c. 1895 . Situada na antiga praia de Santa Luzia, abrigou, entre 1813 e 1918, o ensino médico na capital

Foto Marc Ferrez

Acervo Instituto Moreira Salles

Santa Casa de Misericórdia Hospital in Rio de Janeiro, c. 1895. Located on former Santa Luzia Beach, the hospital was used for medical $t$ eaching purposes in Rio de Janeiro from 1813 1918

Photograph by Marc Ferrez
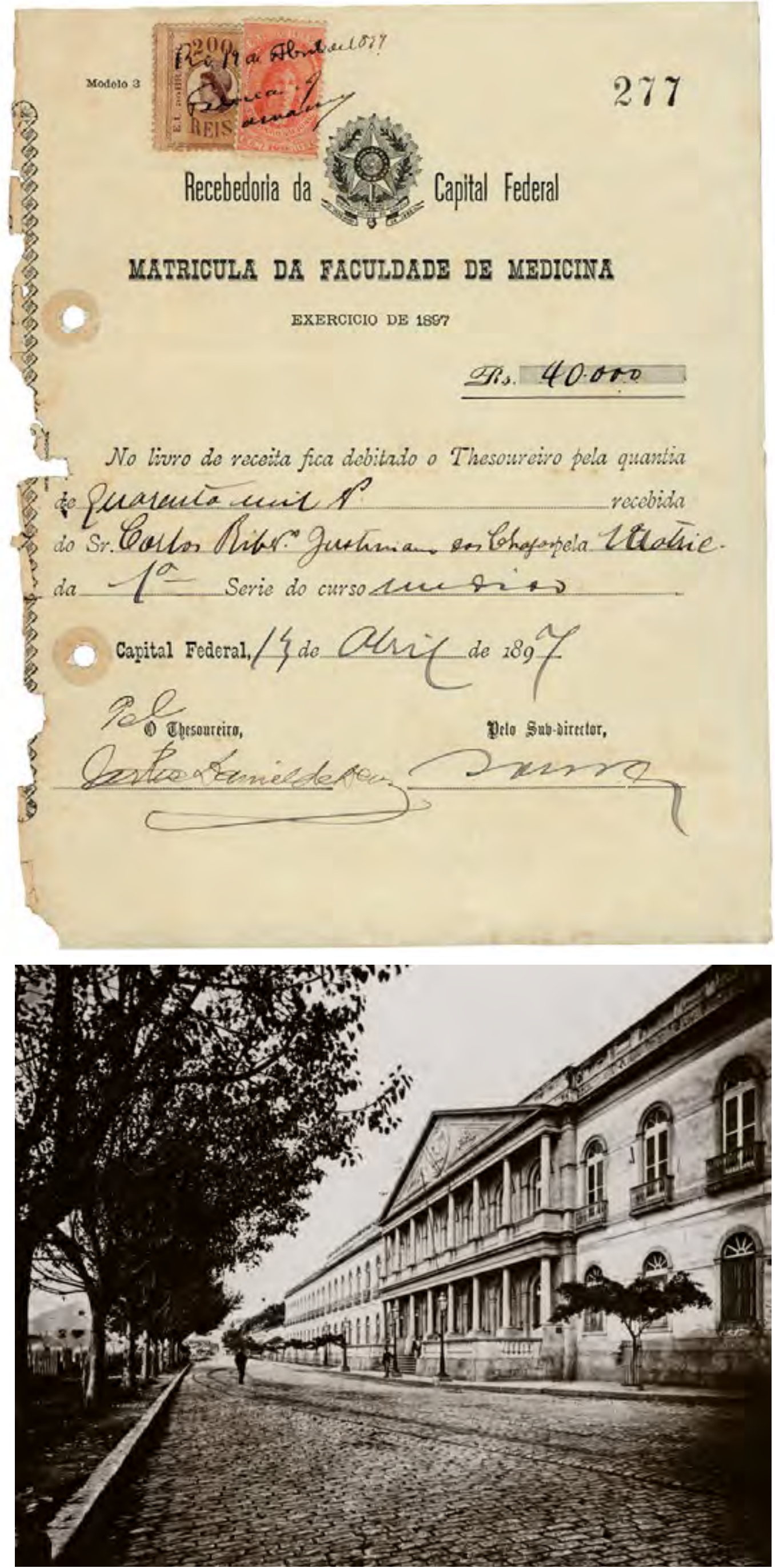

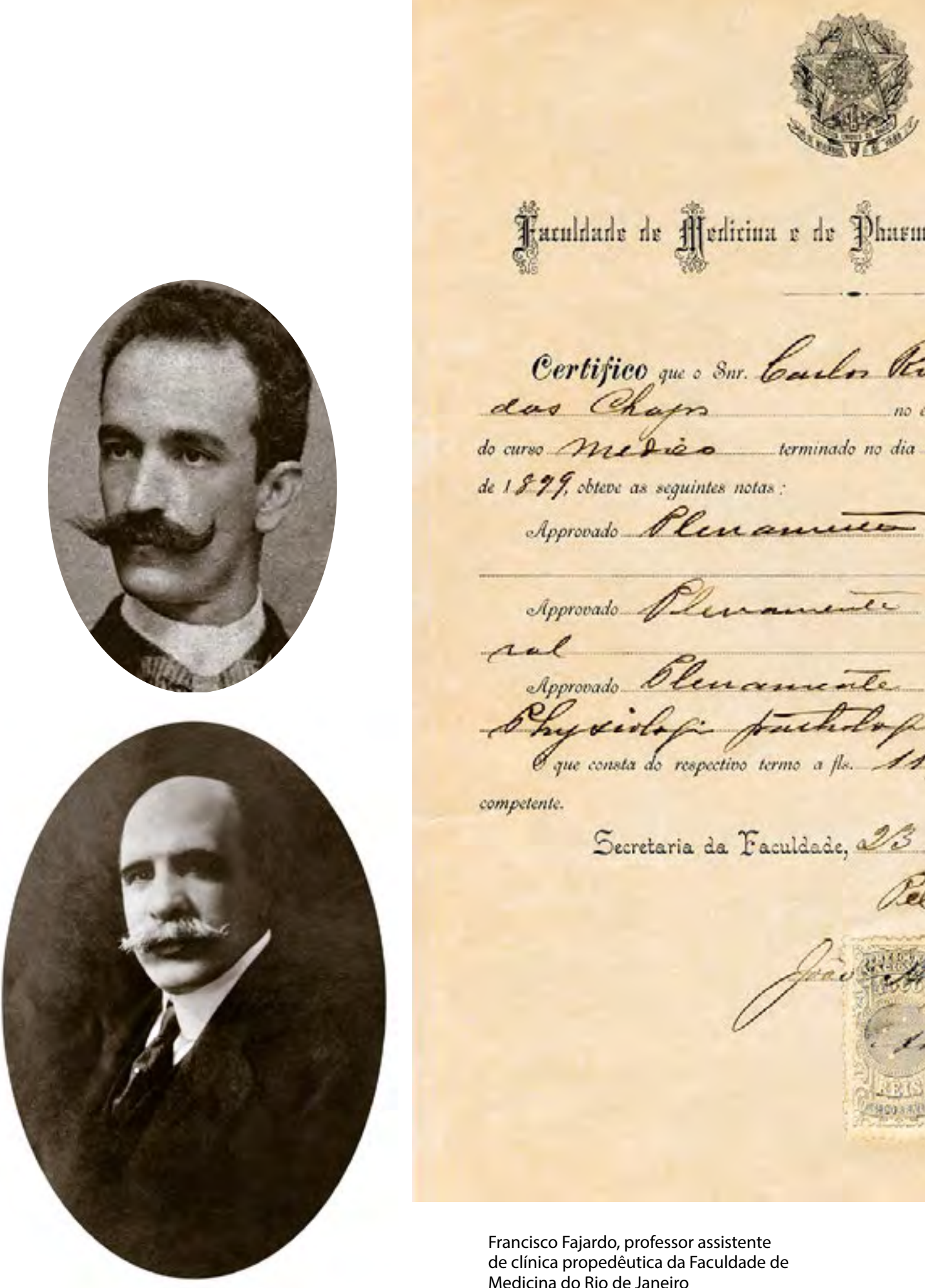

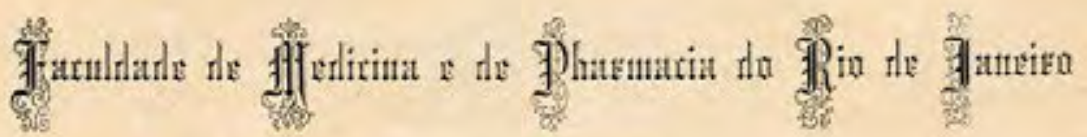

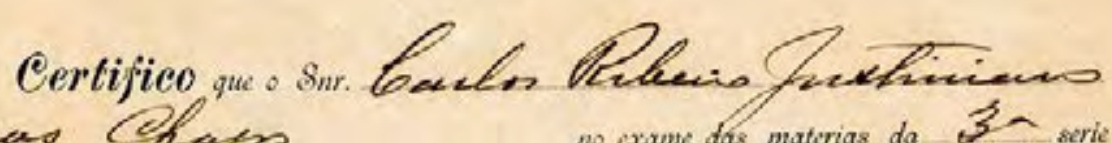
cas Chafos no cxame das matcrias da 3 - serie

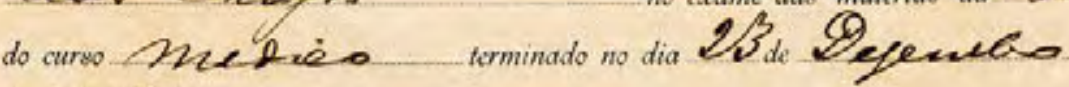
de 1899 , obteve as seguintes notas:

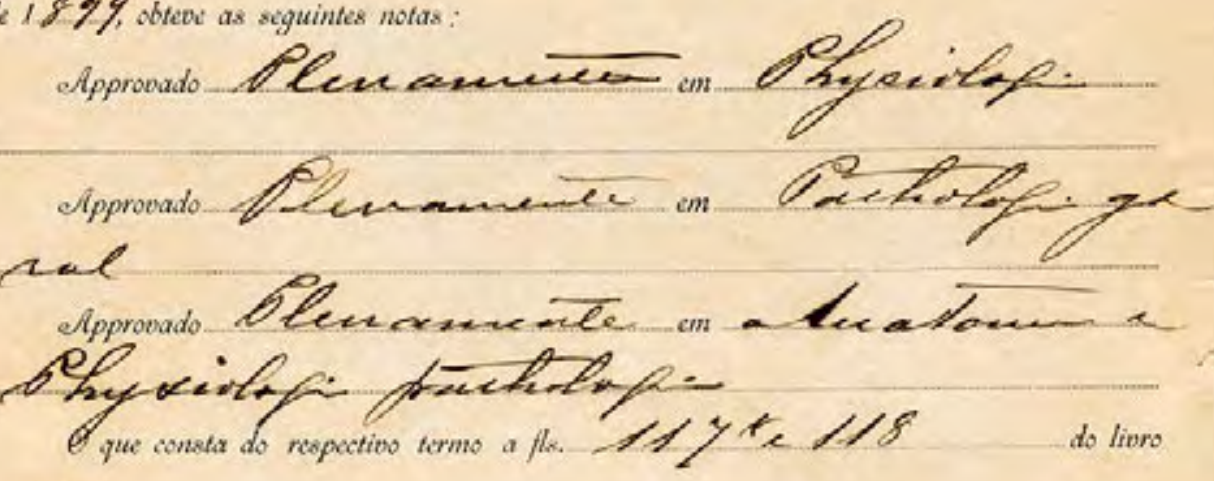
compotente.

$$
\begin{aligned}
& \text { Secretaria da Faculdade, a\% afecerio de } 1 \% 0 \\
& \text { Welo Secretario, }
\end{aligned}
$$

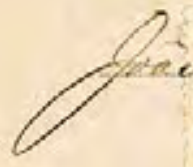

Francisco Fajardo, professor assistente

de clínica propedêutica da Faculdade de Medicina do Rio de Janeiro

Fonte: Benchimol \& Sá, 2005

Francisco Fajardo, assistant professor of

clinical propaedeutics at the Rio de Janeiro

School of Medicine

Miguel Couto, catedrático de clínica médica da Faculdade de Medicina do Rio de Janeiro Acervo Academia Nacional de Medicina

Miguel Couto, chair of clinical practice at the Rio de Janeiro School of Medicine

Certificado de aprovação em disciplinas do curso médico. Rio de Janeiro, 23 maio 1900 Acervo Casa de Oswaldo Cruz

Certificate stating that Chagas passed his third year medical school classes. Rio de Janeiro, May 23, 1900 


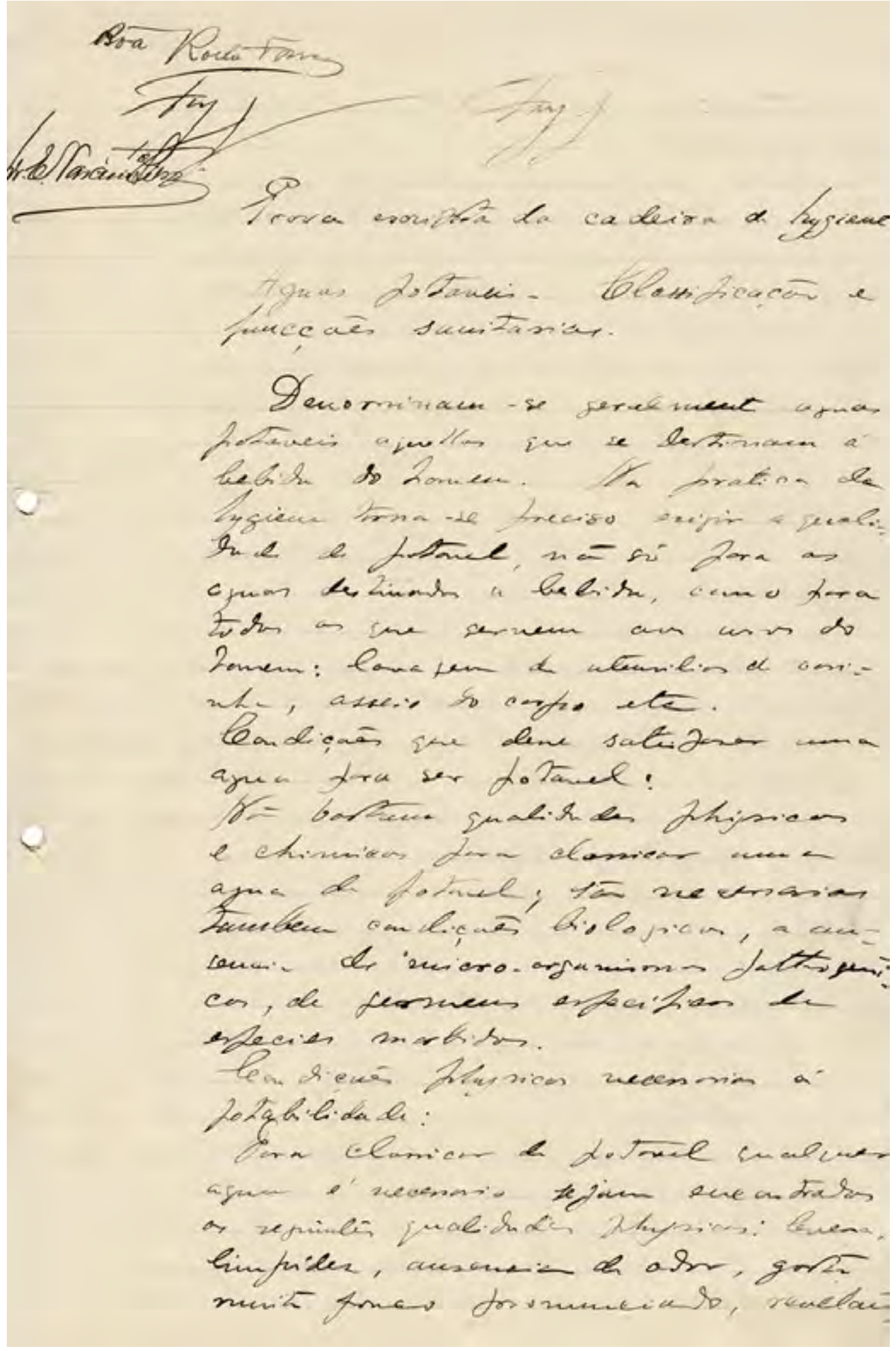

Prova da cadeira de higiene. Rio de Janeiro, 4 dez. 1902

Acervo Casa de Oswaldo Cruz

Hygiene class exam. Rio de Janeiro, Dec. 4, 1902

Oswaldo Cruz, diretor do Instituto

de Manguinhos, aos 29 anos

Acervo Casa de Oswaldo Cruz

Oswaldo Cruz, director of the Manguinhos Institute, at the age of 29

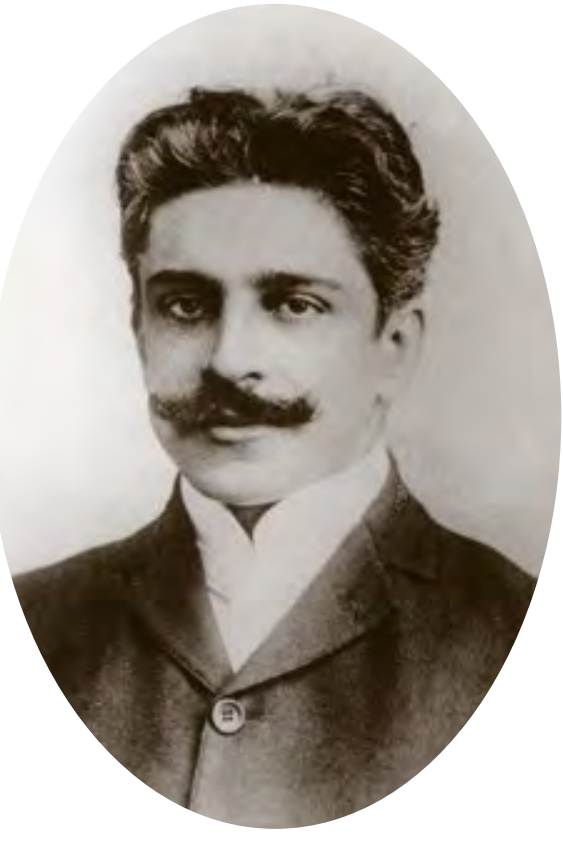

Recebeu-me o querido mestre com a singeleza habitual de suas maneiras e dele ouvi poucas palavras, que apenas expressaram o agrado em acolher aspirações de trabalho, no ambiente de sua incansável atividade. Foi aquele o momento decisivo do meu destino profissional. Do mestre nunca mais eu me afastei e pude apreciar, em 15 anos de amistosa convivência, toda a evolução de seu luminoso espírito.

Carlos Chagas

The esteemed master received me with the simplicity characteristic of his demeanor, and I heard but a few words from him, which simply expressed his pleasure in welcoming someone aspiring to engage in work, within the arena of his tireless activity. This was the decisive moment in my professional destiny. From that point on, I never left my master, and during our fifteen years of congenial fellowship, I had the opportunity to bear witness to the whole evolution of his luminous spirit.

Carlos Chagas 
Sentiam todos que em

Manguinhos cultivava-se a ciência em moldes até então desconhecidos em nosso ambiente e, por esse motivo, não é para surpreender que novos elementos dotados de interesse e curiosidade científica fossem, irresistivelmente, sendo atraídos para aquele modesto laboratório distante e de difícil acesso, no qual Oswaldo Cruz imprimia, em grande estilo, novos rumos à ciência experimental, no Brasil (...). Começou então a estabelecer-se verdadeira romaria de médicos, professores, e de simples estudantes que vinham a Manguinhos à procura do Mestre, desejosos de fazerem sua iniciação científica ou elaborar teses de doutoramento.

Henrique Aragão

Everyone felt that science as cultivated at Manguinhos fit molds wholly novel to our environment, and thus it is no surprise that new individuals displaying scientific interest and curiosity were irresistibly drawn to that modest laboratory, far off and hard to reach, where in grand style Oswaldo Cruz pushed experimental science in Brazil in new directions (...). This set in motion a veritable pilgrimage of physicians, teachers, and ordinary students, who came to Manguinhos seeking the Master, wanting to learn how to do scientific research or write their medical theses.

Henrique Aragão

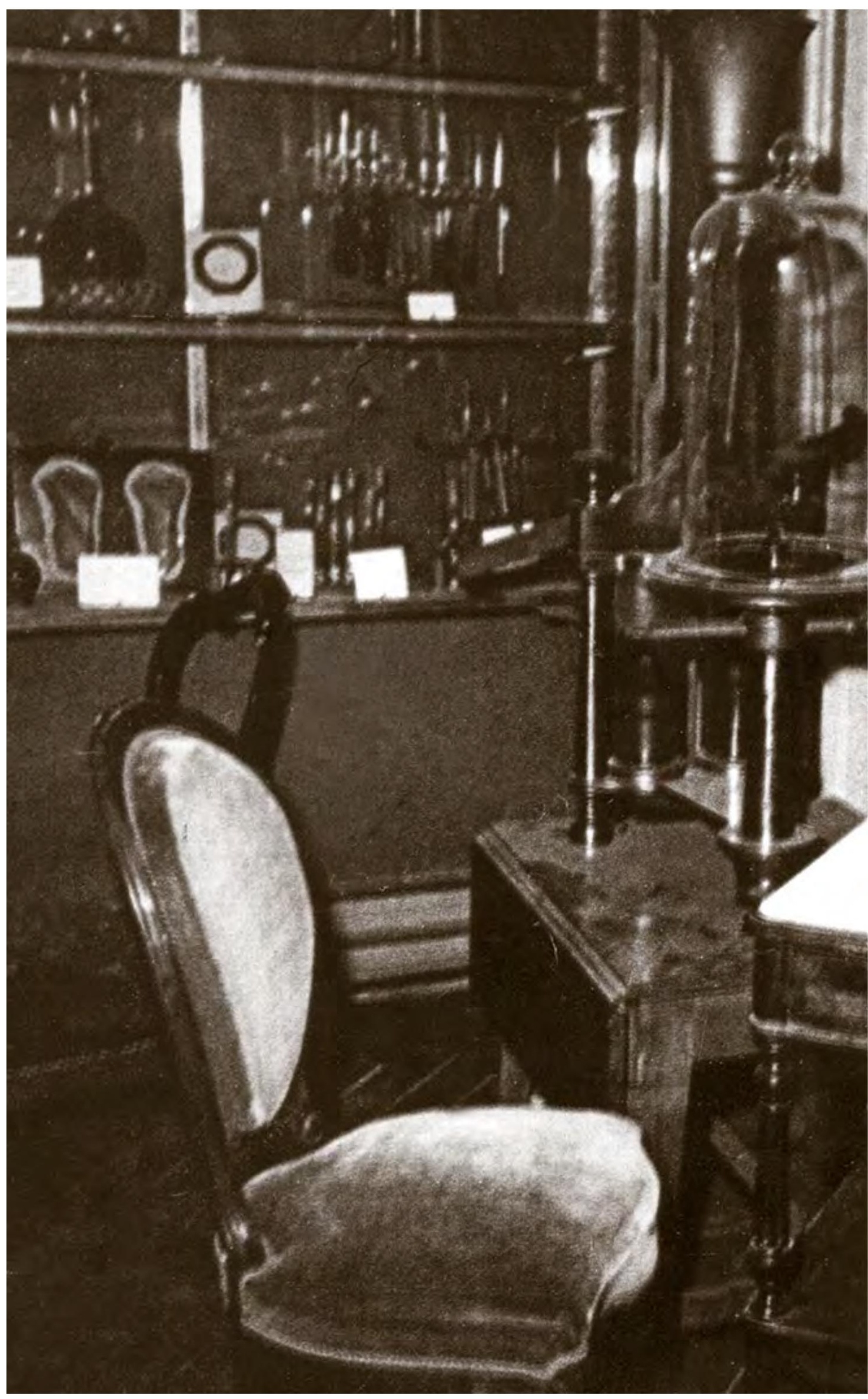

Laboratório do Instituto de

Manguinhos em seus primeiros anos Acervo Casa de Oswaldo Cruz

The Manguinhos Institute laboratory in its early years 
Cais original que servia ao Instituto de Manguinhos. Na época, a baía de Guanabara estendia-se até a região onde posteriormente seria

construída a avenida Brasil. Além do acesso marítimo, o transporte até o local podia ser feito pela Estrada de Ferro Leopoldina, até a parada do Amorim (posteriormente denominada Carlos Chagas, atual estação de Manguinhos) Acervo Casa de Oswaldo Cruz Original pier serving the Manguinhos Institute. At that time, Guanabara Bay stretched back into the area where the metropolitan artery known as Avenida Brasil was later built. In addition to this sea access, the Institute could also be reached by taking the Leopoldina Railroad to Amorim, a stop later renamed Carlos Chagas and now known as Manguinhos

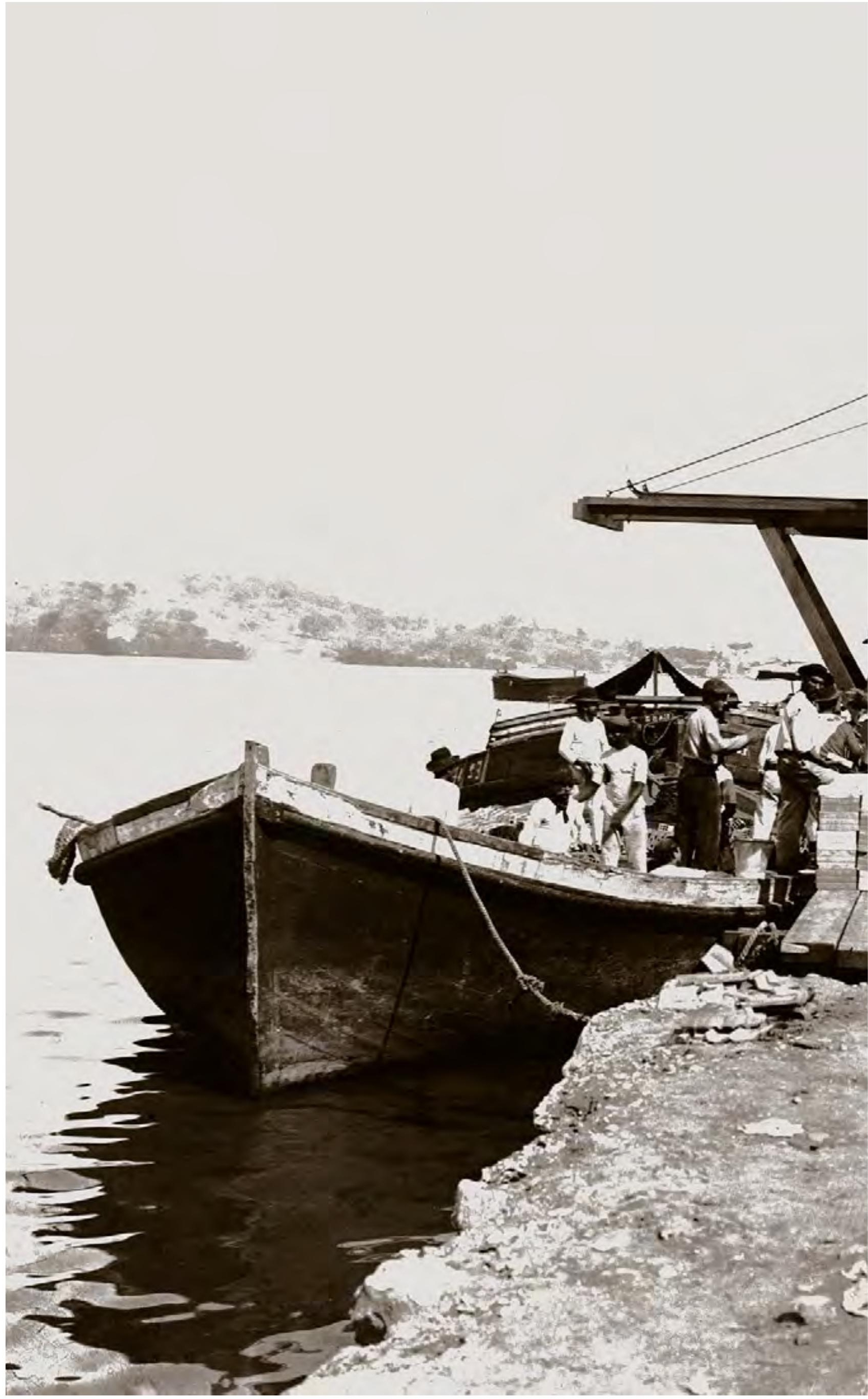




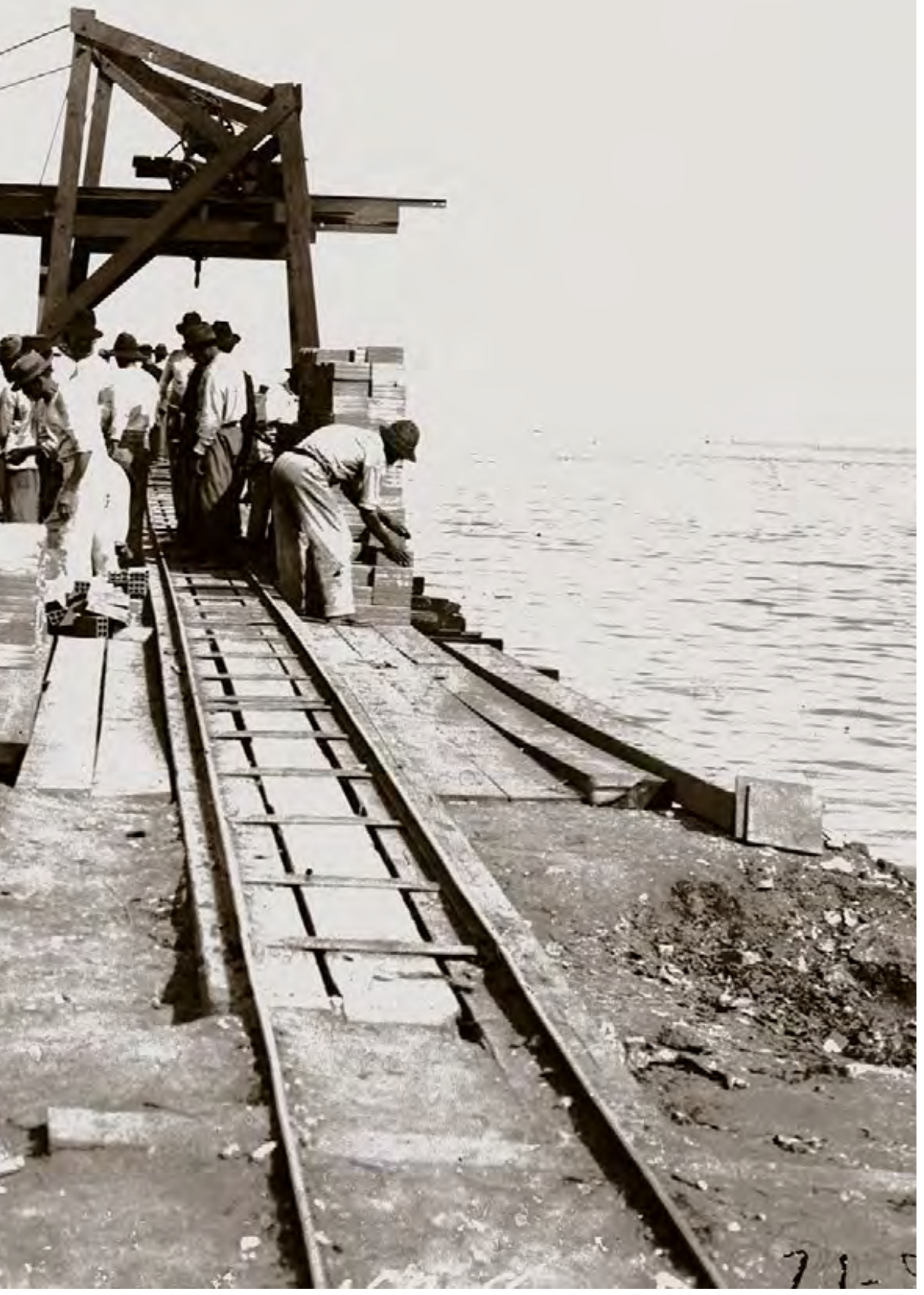

Diariamente tomava-se o trem das 10:30 hs na praça da República, o qual em 20 minutos ia até 'São Francisco Xavier', (...) cujo comboio suburbano ia em 10 minutos à parada do 'Amorim'. Aí esperavam os médicos um servente com 2 cavalos de sela; para estudantes não havia condução.

Ezequiel Dias

Every day one would catch the 10:30 morning train at Praça da República, arriving at São Francisco Xavier in 20 minutes, (...) where the train to the outskirts would reach the Amorim stop in 10 minutes. There the doctors would wait for an attendant with two saddled horses; there was no transportation for students.

Ezequiel Dias 
Nada se podia conceber de mais simples e modesto, mas ali havia o que era absolutamente essencial a qualquer organização científica: um cérebro capaz de dar orientação segura todo voltado para um nobre ideal e um grande entusiasmo de todos pelo trabalho e pelas investigações científicas.

Henrique Aragão

One could imagine nothing simpler nor humbler, yet that which is absolutely vital to any scientific organization was found there: a mind capable of providing sound guidance, thoroughly focused on a noble ideal, and tremendous enthusiasm for work and scientific research on everyone's part.

Henrique Aragão

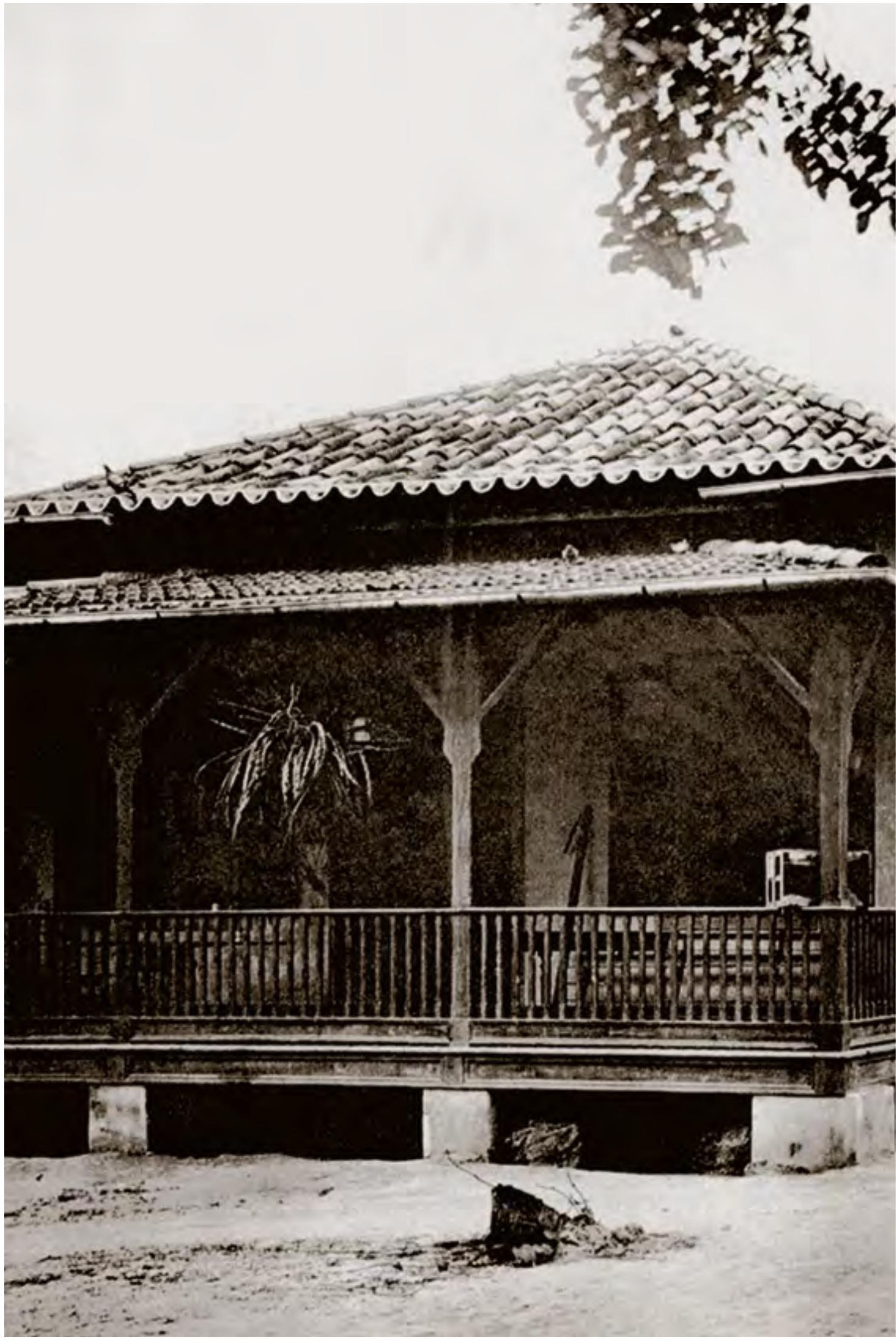

Construção principal da antiga fazenda de Manguinhos, adaptada para o funcionamento dos laboratórios do Instituto Soroterápico Federal nos primeiros anos (1900-1904). Na varanda, havia uma mesa para refeição dos funcionários. A casa branca ao lado abrigava duas salas para laboratórios e uma saleta de lavagem e de esterilização entre elas. O castelo mourisco da atual Fundação Oswaldo Cruz seria construído nesse local a partir de 1905 Acervo Casa de Oswaldo Cruz

Main building on the Manguinhos farm, adapted to house the Federal Serum Therapy Institute's first laboratories (1900-1904). The staff had a dining table on the verandah. Inside the nearby white house were two laboratory rooms, with a smaller room in between them for washing and sterilization. Construction of the Moorish-style castle at today's Oswaldo Cruz Foundation would begin on this spot in 1905 

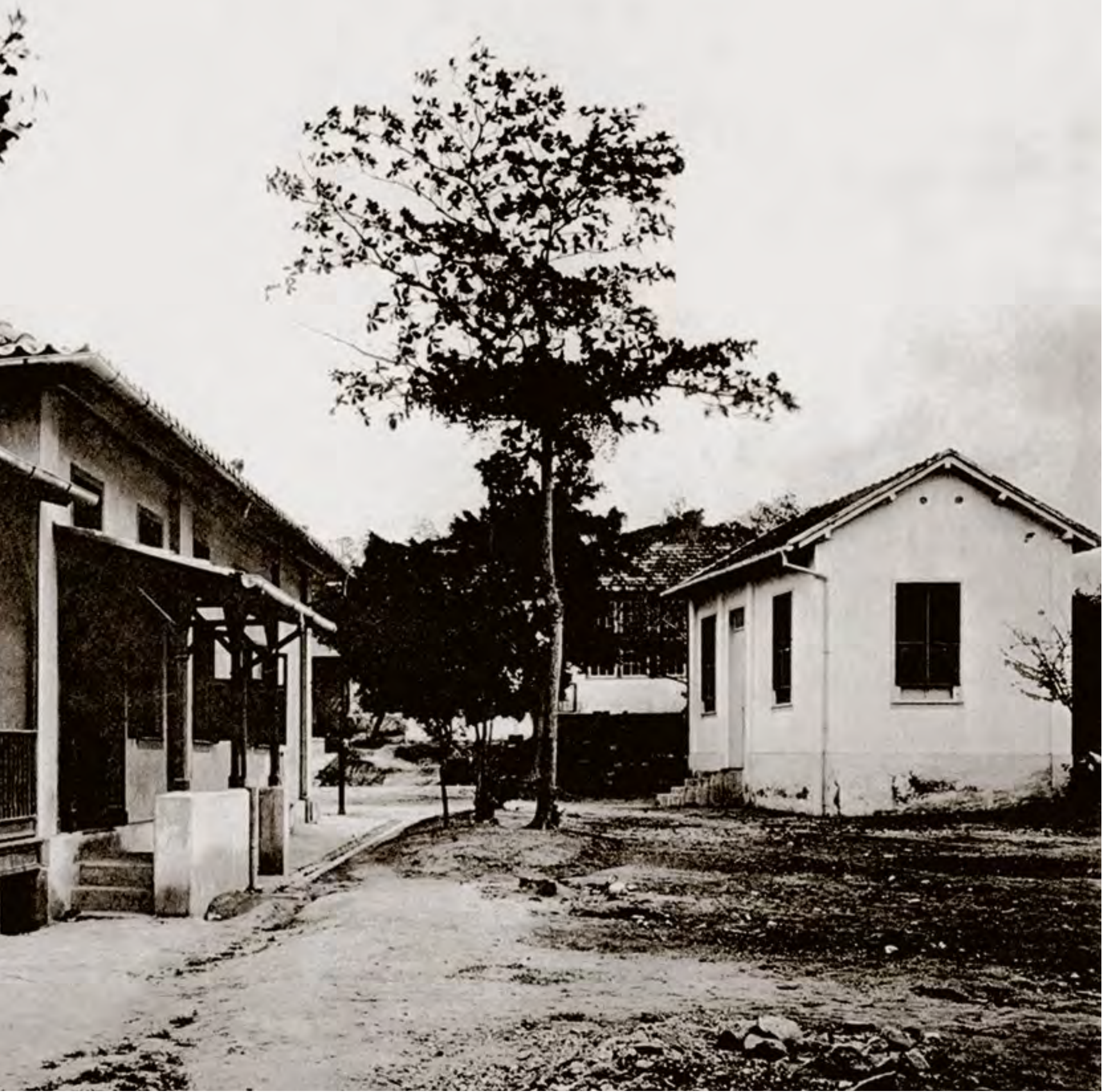

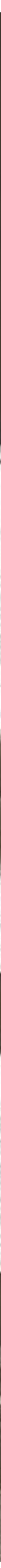

Sessão científica coordenada por Oswaldo Cruz no Instituto de

Manguinhos, 1904

De costas, Alcides Godoy. À sua direita: Antonio Cardoso Fontes,

Henrique da Rocha Lima, Oswaldo Cruz, Henrique Marques

Lisboa, Carlos Chagas, Ezequiel Dias, Rodolpho de Abreu Filho,

Paulo Parreiras Horta, Henrique Aragão e Afonso MacDowell

Acervo Casa de Oswaldo Cruz

Scientific session at the Manguinhos Institute, with Oswaldo

Cruz acting as coordinator, 1904. Facing away from the camera:

Alcides Godoy; to his right: Antonio Cardoso Fontes, Henrique da

Rocha Lima, Oswaldo Cruz, Henrique Marques Lisboa, Carlos

Chagas, Ezequiel Dias, Rodolpho de Abreu Filho, Paulo Parreiras

Horta, Henrique Aragão, and Afonso MacDowell 


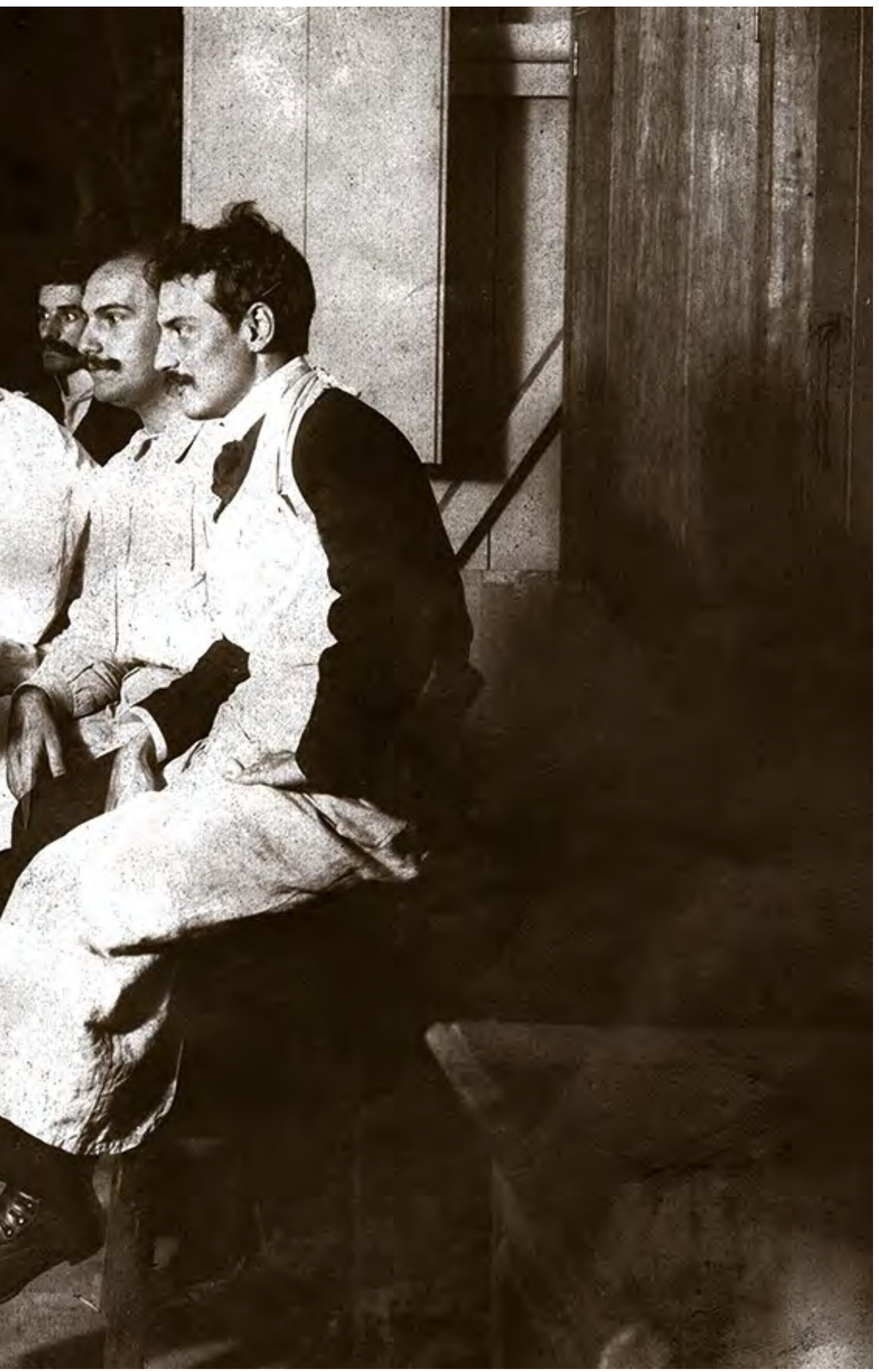

Tinha Oswaldo Cruz o trabalho de marcar, em cada revista, as publicações mais importantes assinalando o nome daquele que as deveria ler para resumi-las na sessão a realizar-se, semanalmente. $E$, neste mister, ia também orientando $o$ assunto conforme as tendências e predileções que observava em seus discípulos.

Henrique Aragão

It was Oswaldo Cruz's job to mark the more important articles in each journal and indicate the name of whomever should read and then summarize them at the weekly session. And in discharging this duty, he would also go about guiding the topic in accord with the inclinations and penchants he observed in his disciples. 


\section{Reise-Berichte}

über

Rinderpest, Bubonenpest in Indien und Alrika, Tsetse- oder Surrakrankheit, Texasfieber, tropische Malaria, Schwarzwasserlieber.

Von

Robert Koch.

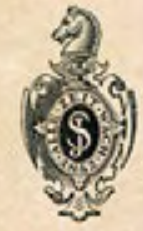

Berlin.

Verlag von Julius Springer. 1898.

\section{ETUDES}

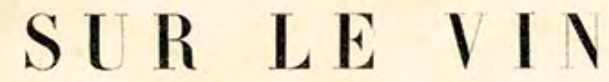

SES MALADIES

CAUSES QQU LES PROVOQUENT

PROCÉDÉS VOIVEAIX

POUR LE CONSERVR ET POUR LE VIEILLII

PAR M. L. PASTEUR

MEMeEE DK LINSTHYT

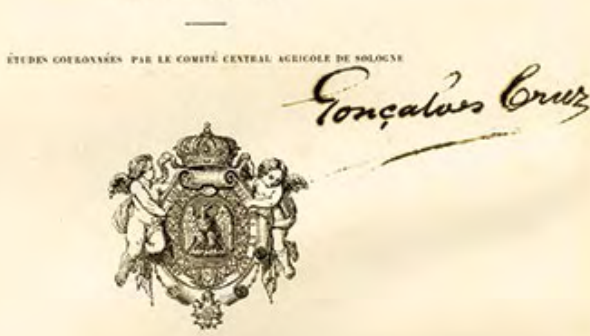

PARIS

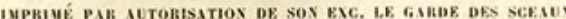

I L'IMPRIMERIE IMPÉRIALE

M DCCC: LVI
COURS DE MÉDECINE

DU COLLÉGE DE FRANCE

LECONS

$D E$

\section{PHISIOLOGIE OPÉRATOIRE}

\section{CLAUDE BERNARD}

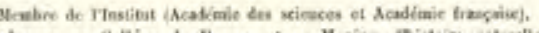

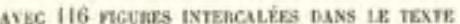

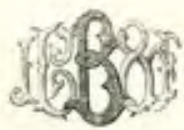

PARIS

LIBRAIRIE J.-B. BAILLIERE ET FII.S

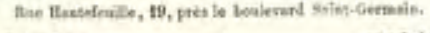

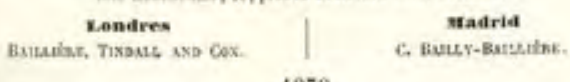

1879

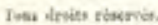

B.ATTISTA GRASSI

STUDI DI UNO ZOOLOGO

SULLA MALARIA

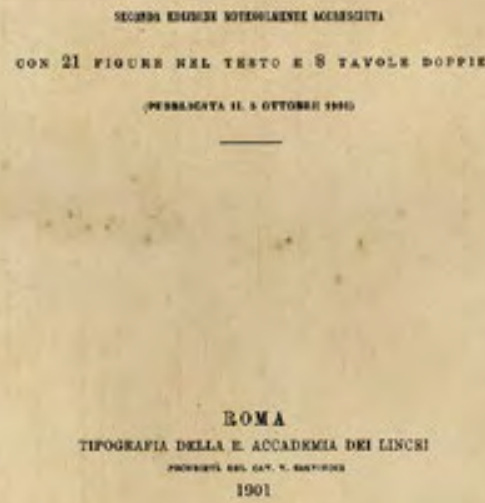




\title{
Tropical DISEASES
}

\author{
A Manual of the Diseases of Warm Climates
}

BY

\section{PATRICK MANSON C.M.G., M.D., LL.D. (ABERD.)}

Fellow of the Royal College of Physicians, London; Fellow of the Royal Society; Foreign Associate of the Académie de Médecine, France; Honorary

Member of the Société de Médecine de Sand: Physician to the Seamen's

Hospital Society; Lecturer on Tropical Diseases at St. George's

Hospital, Charing Cross Hospital Medical Schools; Lecturer in the London School of Tropical Medicine; Medical Adviser to the Colonial Office and to the Crown Agents for the Colonies
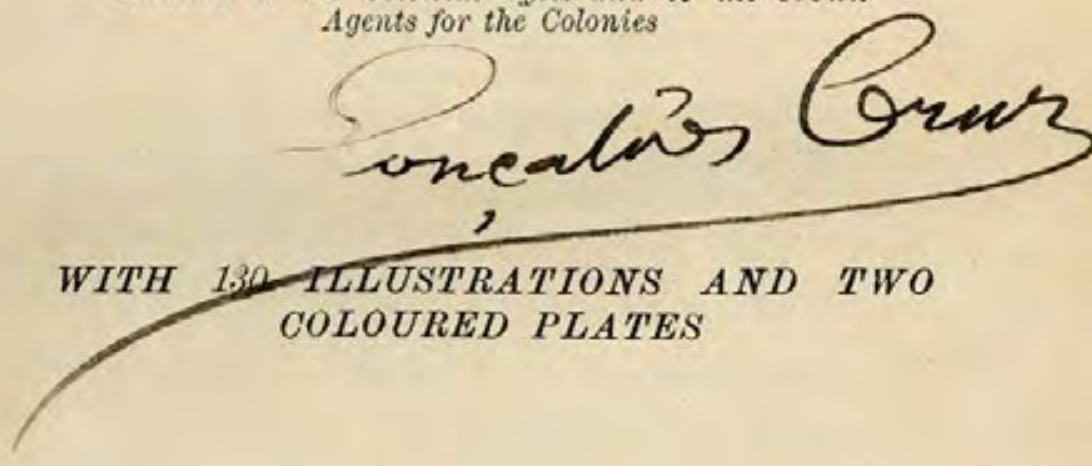

Riebised Edition

CASSELL AND COMPANY, Limited LONDON, PARIS, NEW YORK\& MELBOURNE. MCMIII

ALL RIGHTY RESERVED

Alguns dos principais autores no campo da medicina experimental. Livros

que pertenceram a Oswaldo Cruz e a Carlos Chagas

Acervo Casa de Oswaldo Cruz

Some of the main authors from the

field of experimental medicine. Books

that belonged to Oswaldo Cruz and

Carlos Chagas 


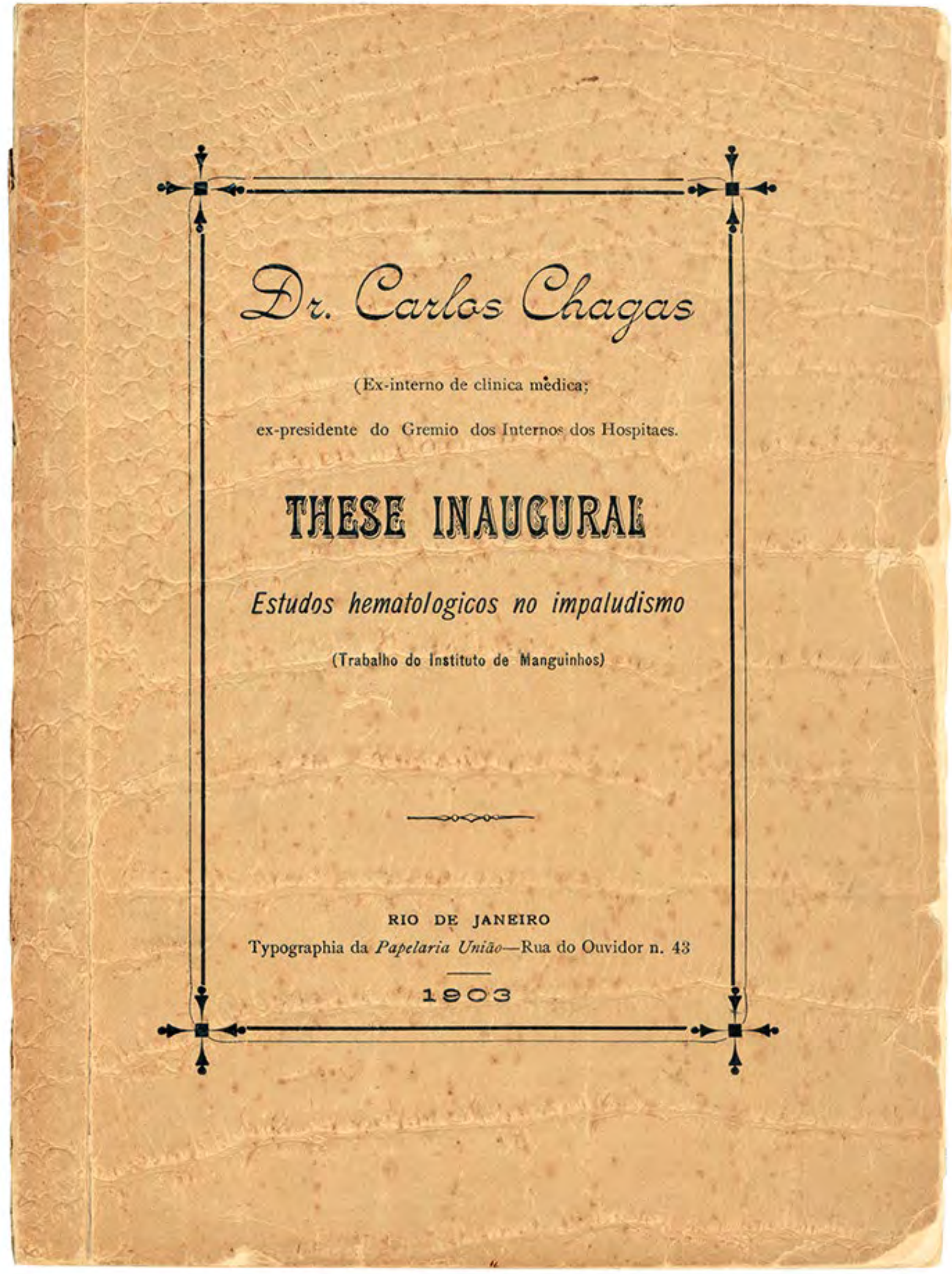

Tese de doutoramento na Faculdade de

Medicina. Rio de Janeiro, maio 1903

Acervo Casa de Oswaldo Cruz

Medical thesis. Rio de Janeiro, May 1903 


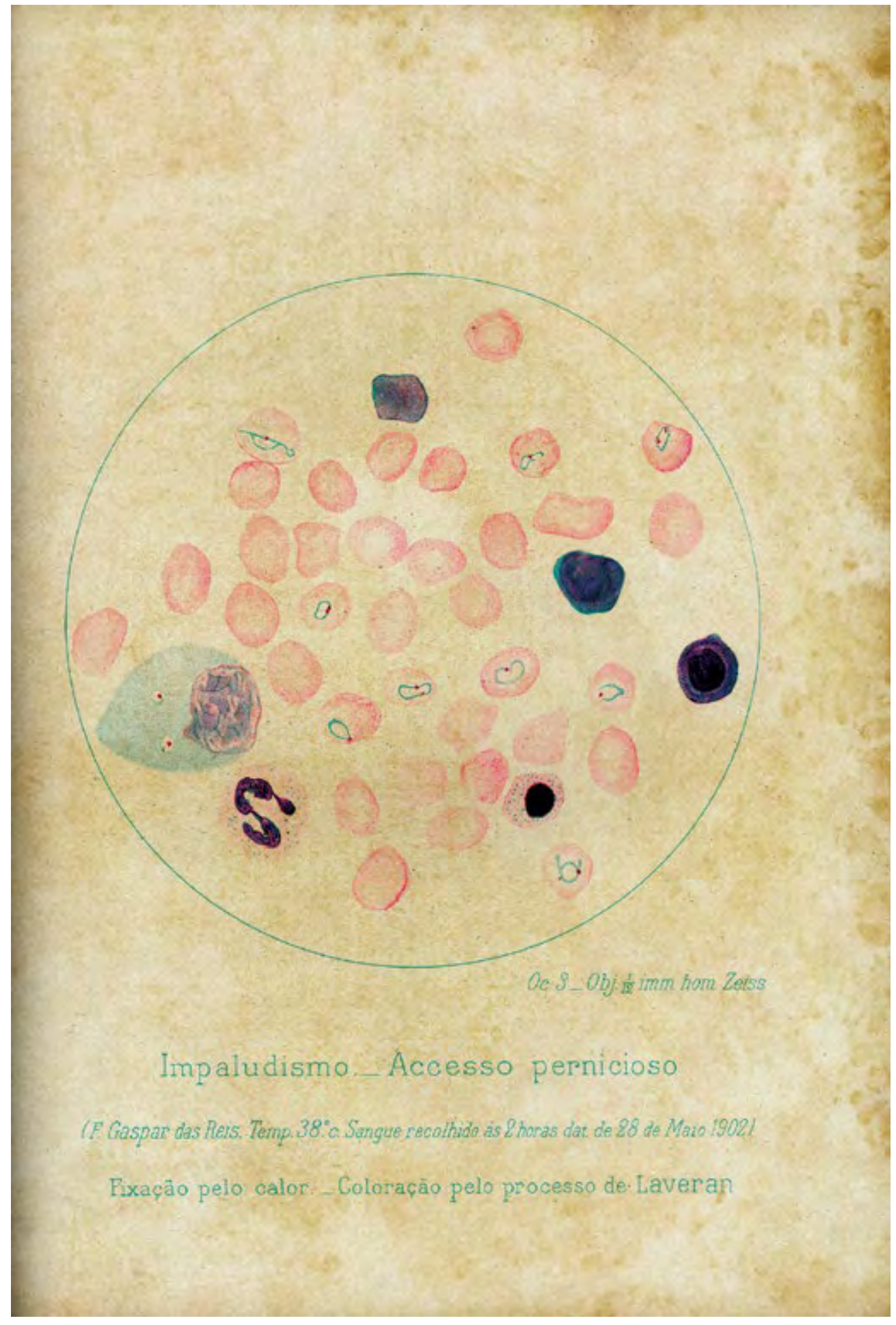

... o laboratório representa em nossa terra uma esperança.

Dele esperamos esclarecidos os inúmeros problemas de patologia tropical, que por aí prevalecem obscuros, zombando da sagacidade dos observadores e cujas incógnitas estão repletas das ilações as mais benéficas ao nosso bem-estar.

\section{Carlos Chagas}

(...) in our land, the laboratory represents hope. We hope it will clarify the countless issues in tropical pathology that still reign obscure among us, ridiculing the observer's wisdom, while these very unknowns abound with deductions that would greatly benefit our well-being.

Carlos Chagas

Preparação de sangue de um caso de malária. Figura publicada por Chagas em sua tese de doutoramento, em 1903 Acervo Casa de Oswaldo Cruz

Blood preparation from a malaria case.

Figure published by Chagas in his

medical thesis, in 1903 


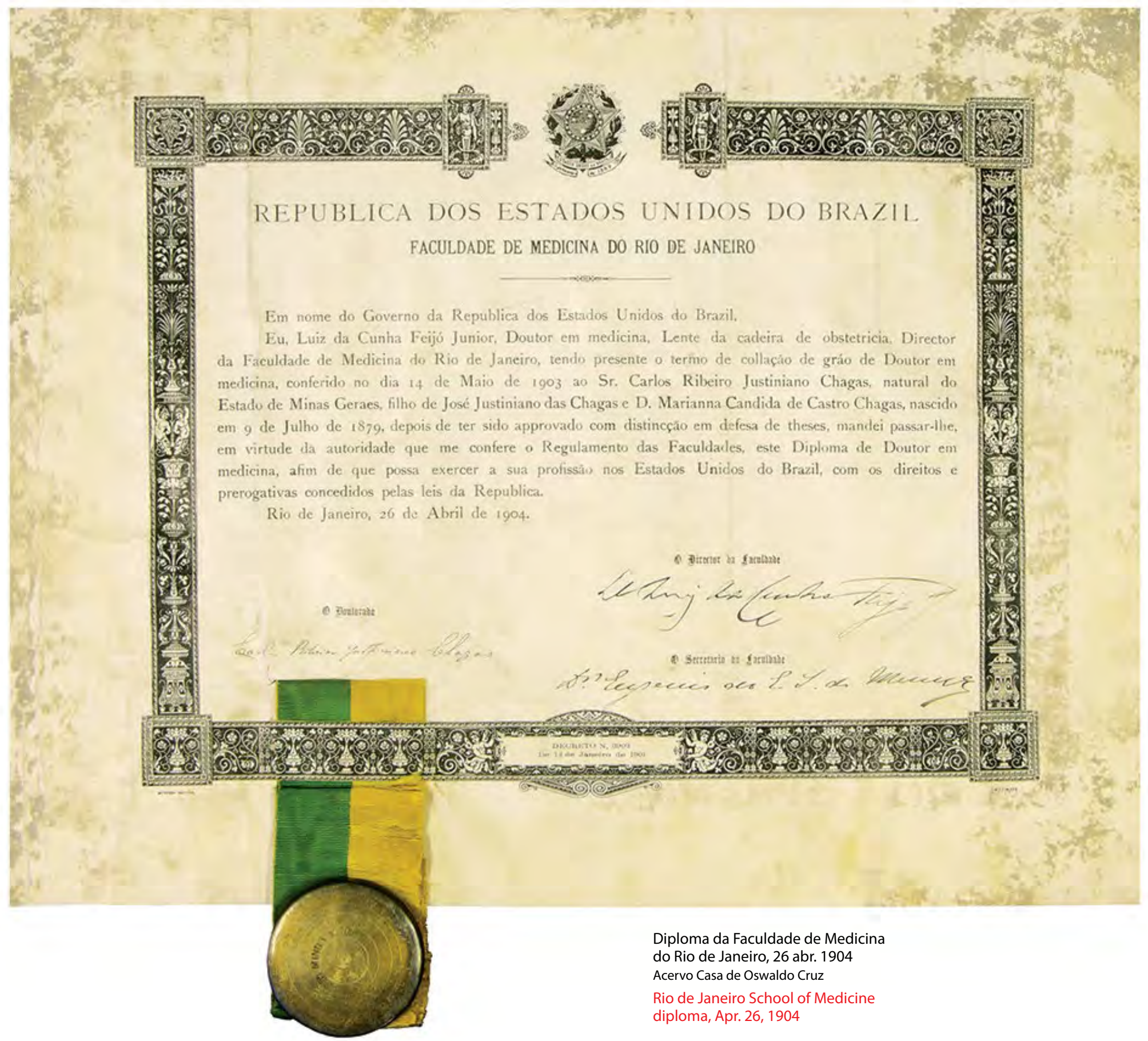




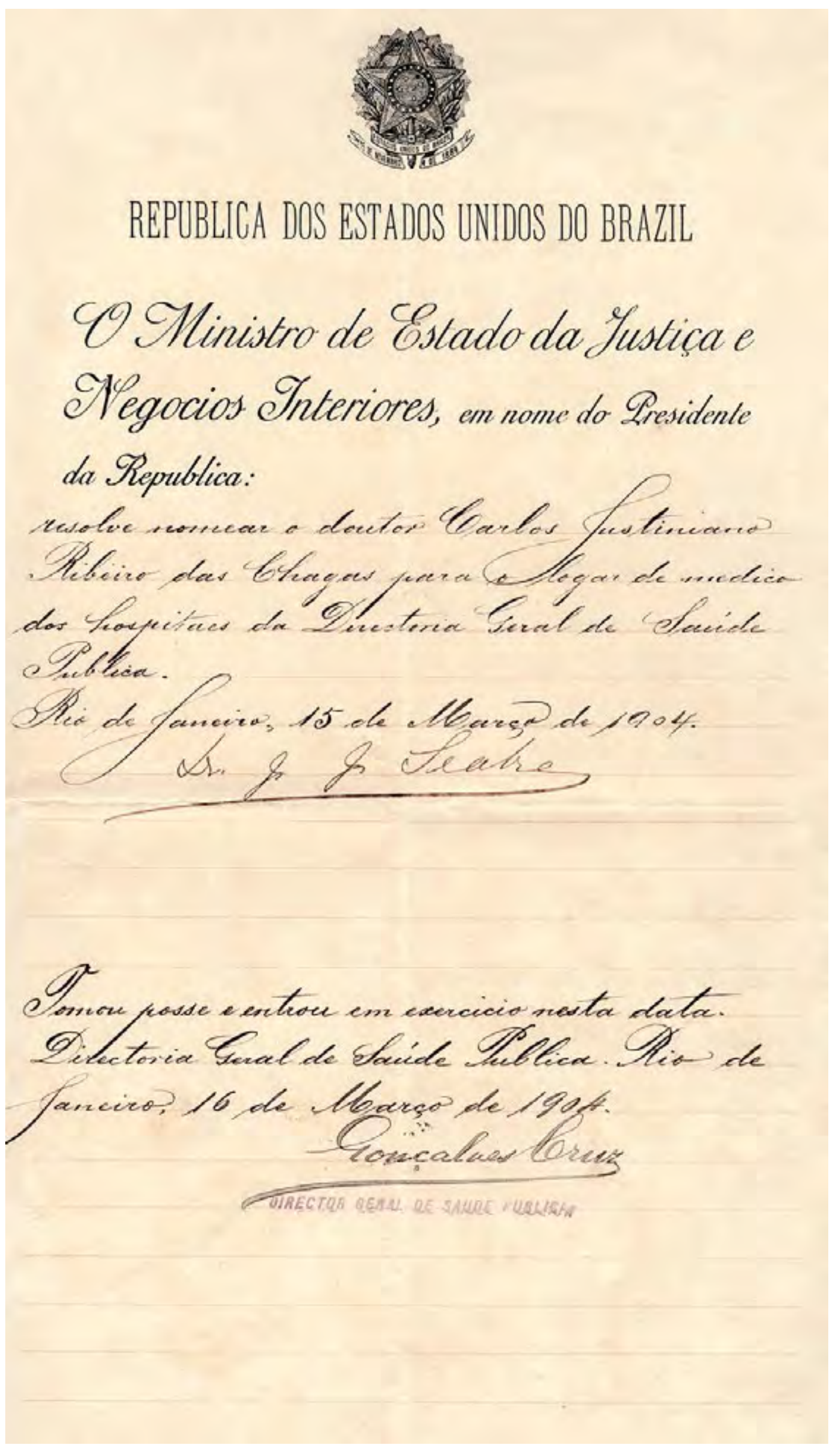

Nomeação para médico da Diretoria-Geral de Saúde Pública. Rio de Janeiro, 15 mar. 1904 Acervo Casa de Oswaldo Cruz

Official appointment as a physician with the General Directorship of Public Health. Rio de Janeiro, Mar. 15, 1904 


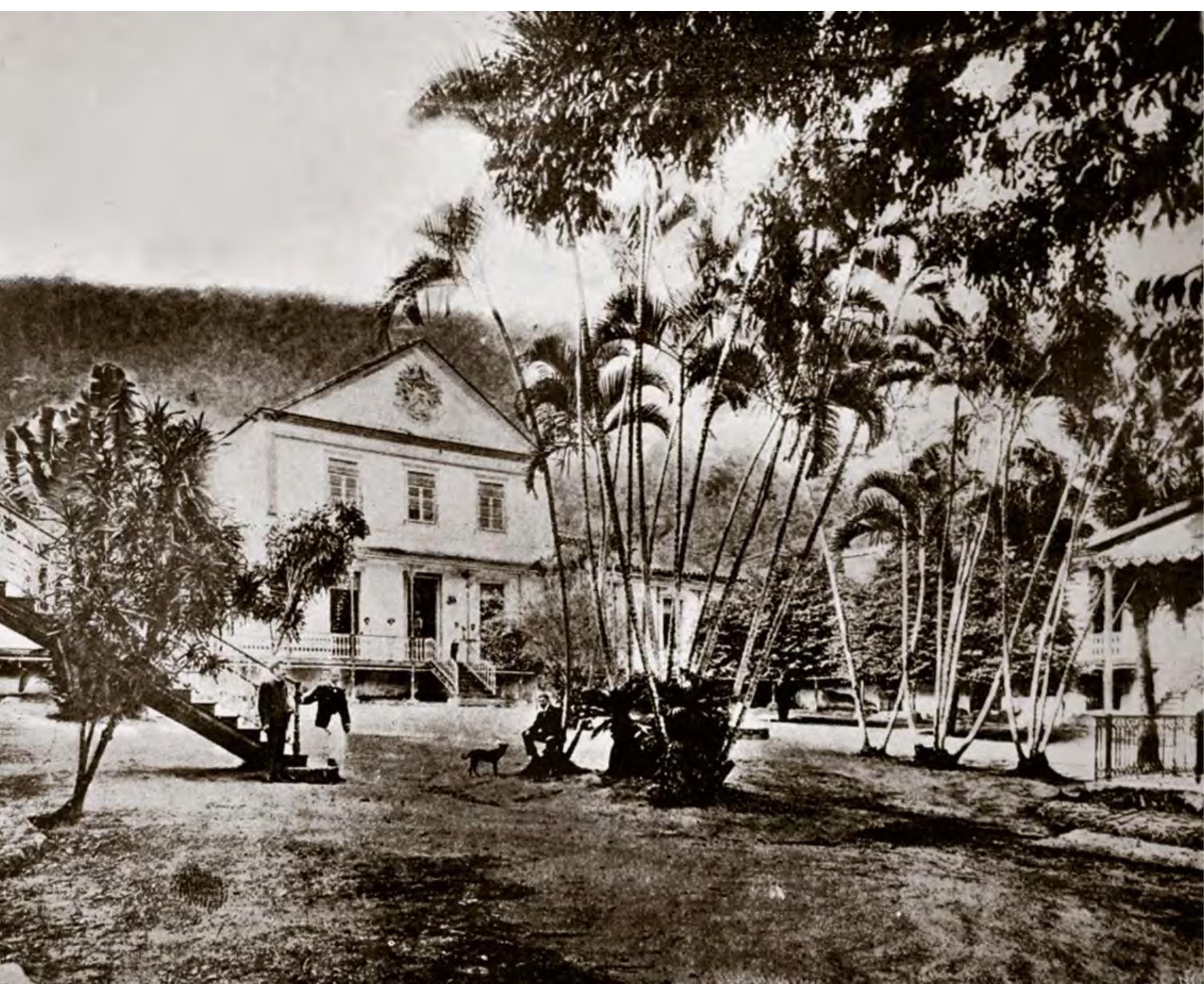

Hospital Paula Cândido, em Jurujuba, Niterói Fonte: Diretoria-Geral de Saúde Pública, 1909

Paula Cândido Hospital, in the neighborhood of Jurujuba, Niterói 

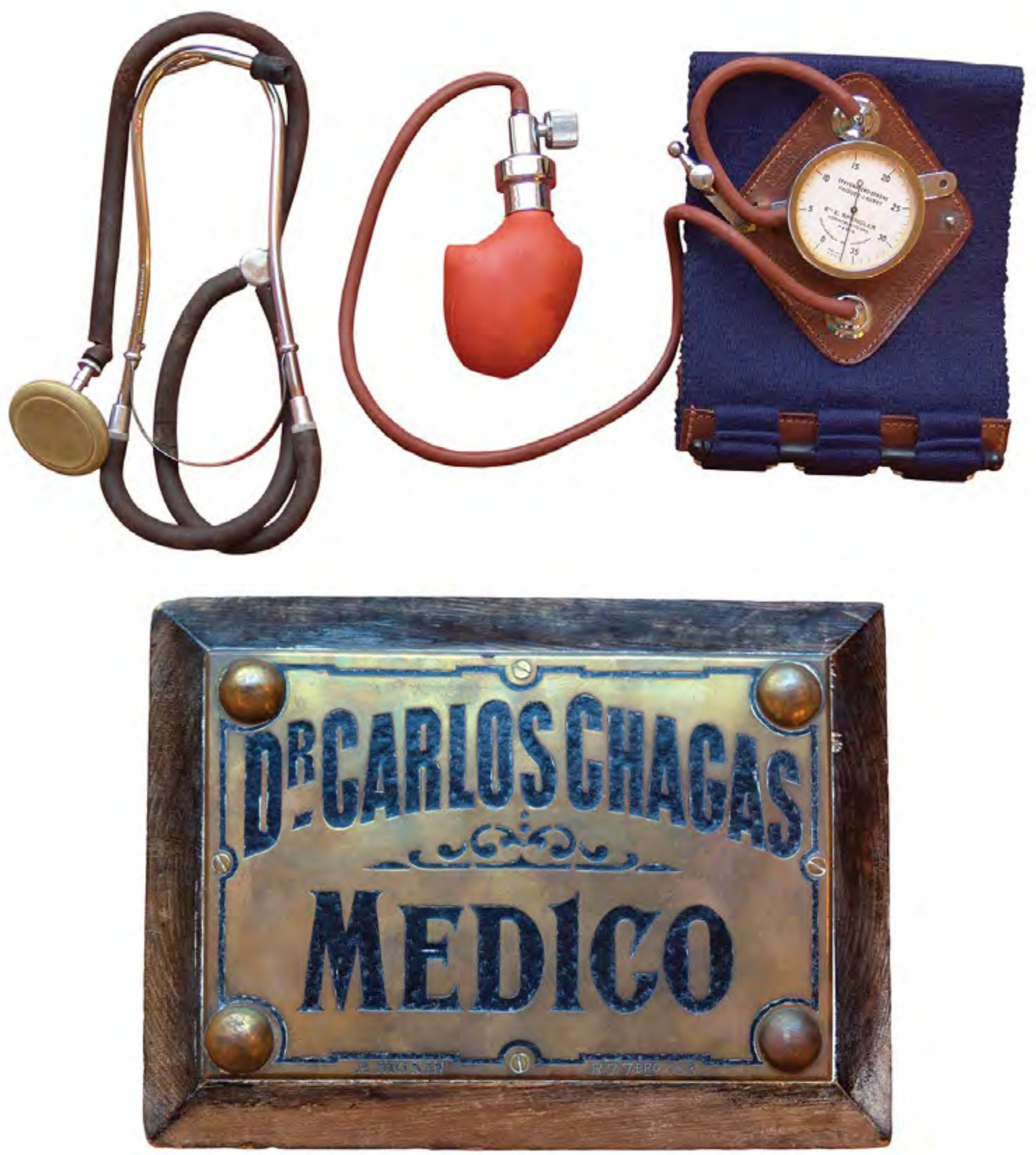

Estetoscópio e aparelho de pressão arterial que pertenceram

a Carlos Chagas

Acervo Casa de Oswaldo Cruz

Carlos Chagas's stethoscope and

blood pressure gauge

Placa de seu consultório médico,

instalado em 1904 na rua da

Assembléia, centro da cidade

do Rio de Janeiro

Acervo Casa de Oswaldo Cruz

Sign on Carlos Chagas's medical office

on Assembléia Street, downtown

Rio de Janeiro, established in 1904 
$\mathrm{N}$ o início do século XX, a entomologia médica - estudo dos insetos transmissores de doenças - estava em grande desenvolvimento em todo o mundo. No Instituto de Manguinhos, vários pesquisadores dedicavam-se a investigações nesse campo. Um fator importante para impulsioná-las eram as expedições feitas a várias regiões do Brasil. Além de proporcionar a coleta de materiais para estudo (como novas espécies de mosquitos), tais viagens serviam para experimentar métodos de profilaxia, pois entre seus objetivos estava o de debelar epidemias (especialmente de malária) que ocorriam quando obras de modernização, como a construção de ferrovias, adentravam matas e regiões não habitadas.

Em 1905, a Companhia Docas de Santos solicitou a Oswaldo Cruz, diretor-geral de Saúde Pública, providências para combater uma epidemia de malária entre os trabalhadores que construíam uma hidrelétrica em Itatinga, São Paulo. Carlos Chagas foi comissionado para coordenar a campanha.

No início de 1907, iniciou missão semelhante com Arthur Neiva (1880-1943), também pesquisador de Manguinhos, em Xerém, Baixada Fluminense, onde a doença prejudicava a captação de água para a capital federal, realizada pela Inspetoria Geral de Obras Públicas.

Em junho, Chagas partiu para o norte de Minas Gerais, em uma terceira campanha contra a malária, junto com Belisário Penna (1868-1939), também médico da Diretoria-Geral de Saúde Pública. Uma epidemia paralisava as obras de prolongamento da Estrada de Ferro Central do Brasil no trecho entre Corinto e Pirapora. Desde sua inauguração em 1855, essa ferrovia era vista como um dos principais meios de integração do território nacional, daí o projeto de estendê-la da capital federal até Belém do Pará. Em 1904, havia sido inaugurada a estação de Curvelo e, dois anos depois, a estação de Corinto. No verão de 1906-1907, contudo, as "febres" paralisaram as obras na ponte do rio Bicudo, impedindo a construçã̃o do ramal para Pirapora.

$\mathrm{Na}$ época, a profilaxia da malária, testada por pesquisadores em todo o mundo, abrangia diversas estratégias. O combate aos vetores era feito mediante a aplicação de substâncias tóxicas (como o petróleo) nas coleções de água, visando a destruir as larvas dos insetos que ali se reproduziam. Outra medida era a proteção dos indivíduos com cortinados nas camas e telas nas portas e janelas das casas. O ataque ao parasito, por sua vez, dava-se pela ingestão de quinina (produto extraído da casca da árvore quina), tanto para prevenir quanto para tratar a infecção.

Já desde a primeira campanha, Chagas observou que, depois de picarem suas 'vítimas' no interior das habitações, os mosquitos adquiriam um peso que os fazia permanecer ali por longo tempo, digerindo o sangue e maturando os ovos. Por isso, preconizou que eles deveriam ser atacados não apenas em sua fase larval, aquática, mas sobretudo em sua fase adulta, alada, nesses ambientes, mediante aplicação de substâncias inseticidas (como enxofre ou piretro). Esse método, décadas mais tarde utilizado em larga escala, com o advento do DDT, foi aplicado em Itatinga em conjugação com outras medidas, como a quininização. A contribuição de Chagas para os estudos e a profilaxia da malária foi reconhecida no I Congresso Internacional de Paludismo, realizado em Roma em 1925. 
$\mathrm{n}$ the early twentieth century, great advances in medical entomology (the study of disease-transmitting insects) were being made all around the world. A number of researchers at the Manguinhos Institute were conducting investigations in this field, with important impetus added to their efforts by expeditions to various regions of Brazil. These trips yielded material for study (like new mosquito species) and also served as opportunities for trying out prophylactic measures, since one of the goals of the missions was to quash the epidemics (especially malaria) that erupted when modernization works like railroad construction moved into forests and uninhabited areas.

In 1905, the Santos Port Authority asked Oswaldo Cruz, then director general of Public Health, to take measures to combat a malaria epidemic among workers who were building a hydroelectric power plant in Itatinga, São Paulo. Carlos Chagas was commissioned to coordinate the campaign.

In early 1907, this time in partnership with Arthur Neiva (1880-1943), likewise a Manguinhos researcher, Chagas initiated a similar endeavor in Xerém, a town in the lowland area of Rio de Janeiro known as the Baixada Fluminense, where the disease was hampering a General Office of Public Works project to source water for the nation's capital.

In June, Chagas headed to northern Minas Gerais on a third anti-malaria campaign, this time with Belisário Penna (1868-1939), another physician with the General Directorship of Public Health. An epidemic had halted work on a new stretch of the Central do Brasil Railroad, between Corinto and Pirapora. Inaugurated in 1855 , the railway had always been viewed as one of the key elements of national integrationhence the project to link the Brazilian capital to far northern Belém do Pará. Curvelo station was inaugurated in 1904 and Corinto station two years later. In the summer of 1906-1907, however, so-called fevers shut down works on the bridge over the Bicudo River, hindering construction of the line to Pirapora.

Investigators around the globe had already tested out a gamut of malaria prevention strategies. Toxic substances like petroleum were added to standing waters to destroy the insect larvae that reproduced there, thus combating the vector. Bed nets or screened doors and windows afforded individual protection. Quinine extracted from the bark of the cinchona tree was used to fight the parasite itself, both preventing and treating the infection.

Right from the first campaign, Chagas had noted that once mosquitoes had bitten their victims inside a dwelling, they grew so heavy that they would remain there a long time, digesting the blood and letting their eggs mature. Because of this, he recommended that the insects be attacked not just during their aquatic larval stage but primarily as winged adults inside of houses, with the use of insecticides like sulfur and pyrethrum. This method, which came into widespread use with the later advent of DDT, was adopted in Itatinga in conjunction with other measures, like quininization. Chagas's contribution to studies on malaria and its prevention was recognized at the First International Malaria Congress, held in Rome in 1925. 

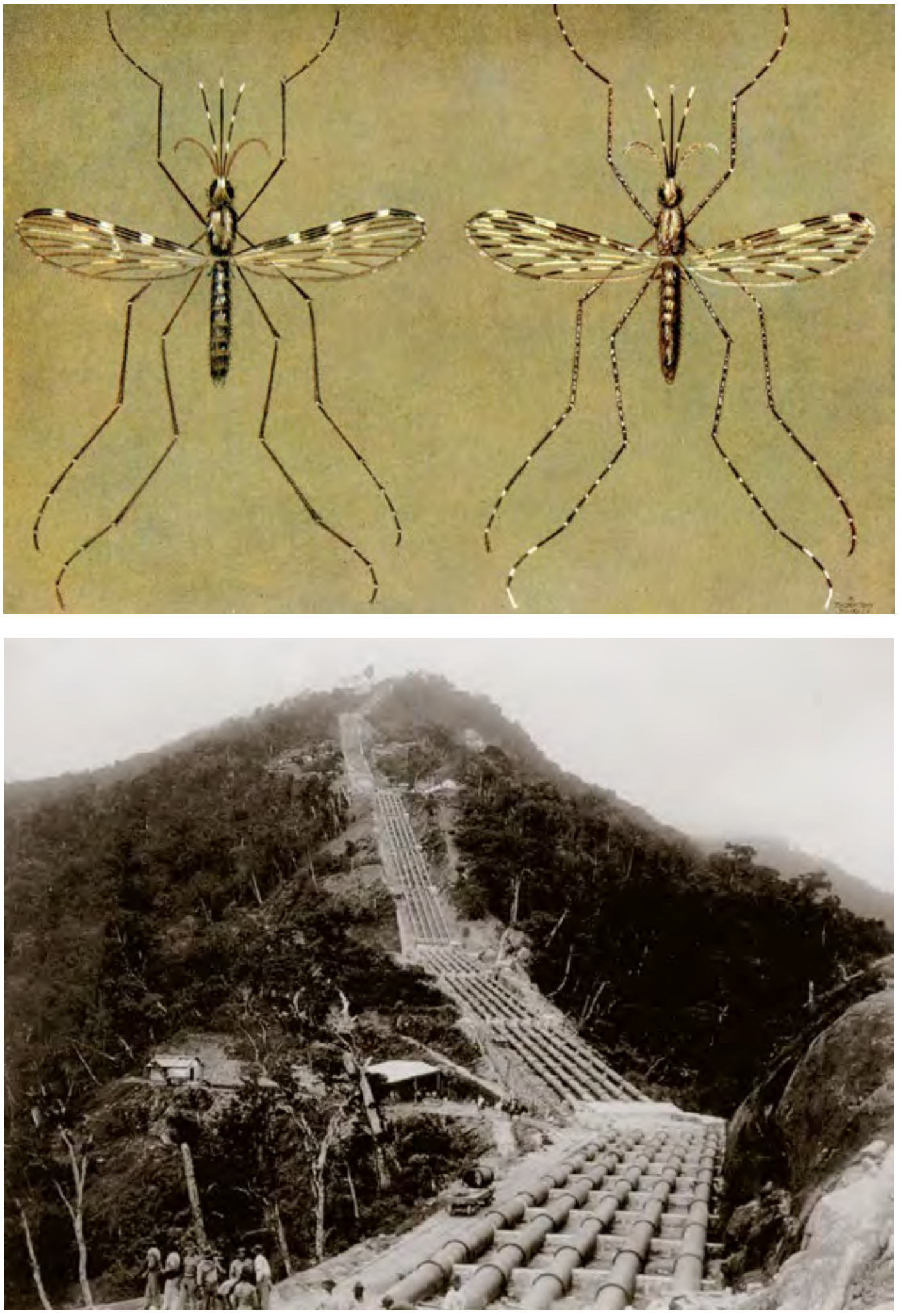

Imagem de abertura - Mosquito transmissor de malária Acervo Museu Nacional

Opening image - Malaria-transmitting mosquitoe

Mosquitos transmissores de malária

Fonte: Manson-Bahr, 1924

Malaria-transmitting mosquitoes

Tubos condutores de água para as turbinas da

usina hidrelétrica construída para fornecer energia ao

Porto de Santos. Itatinga, c. 1905

Acervo Família Paula Machado

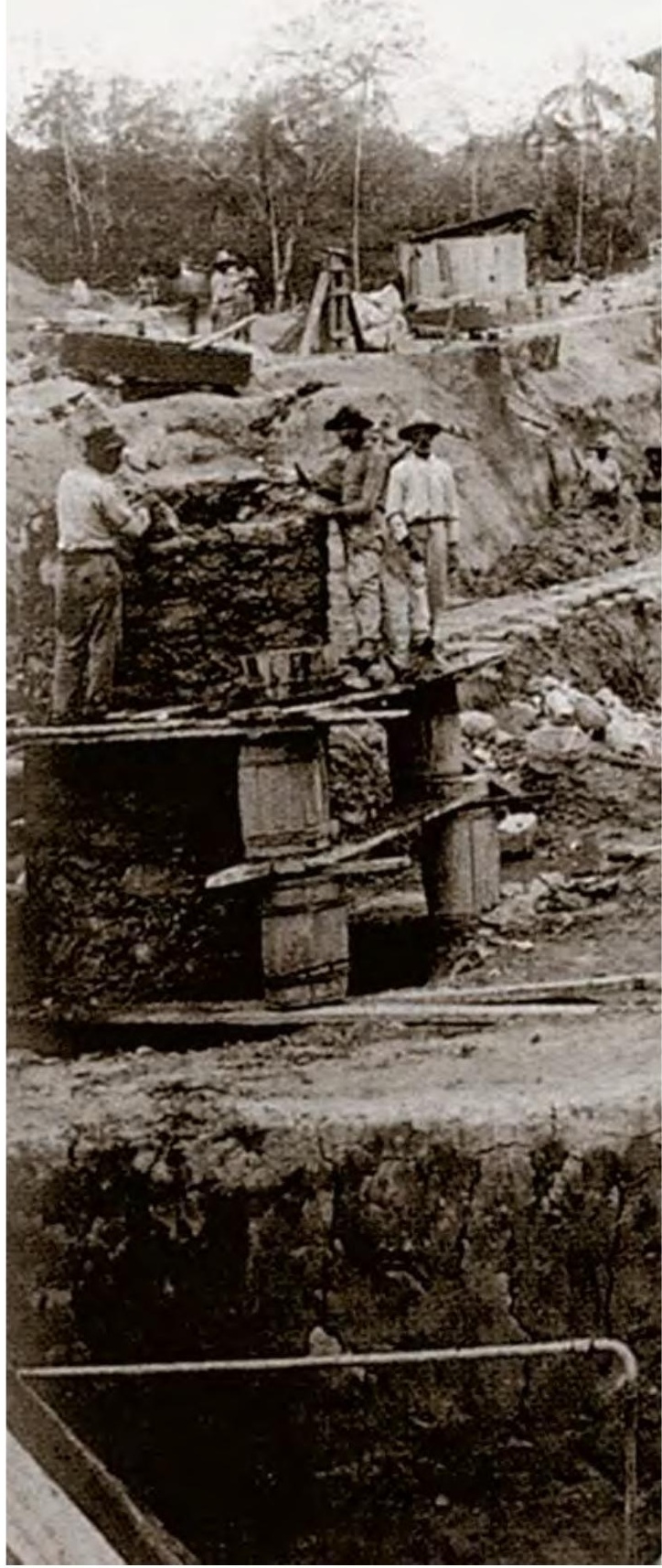

Penstocks to the hydroelectric power plant built to supply

energy to the port of Santos. Itatinga, c. 1905

Construção de hidrelétrica pela Companhia

Docas de Santos. Itatinga, C. 1905

Acervo Família Paula Machado

Construction of hydroelectric power plant by the

Docas Port Authority. Itatinga, c. 1905 


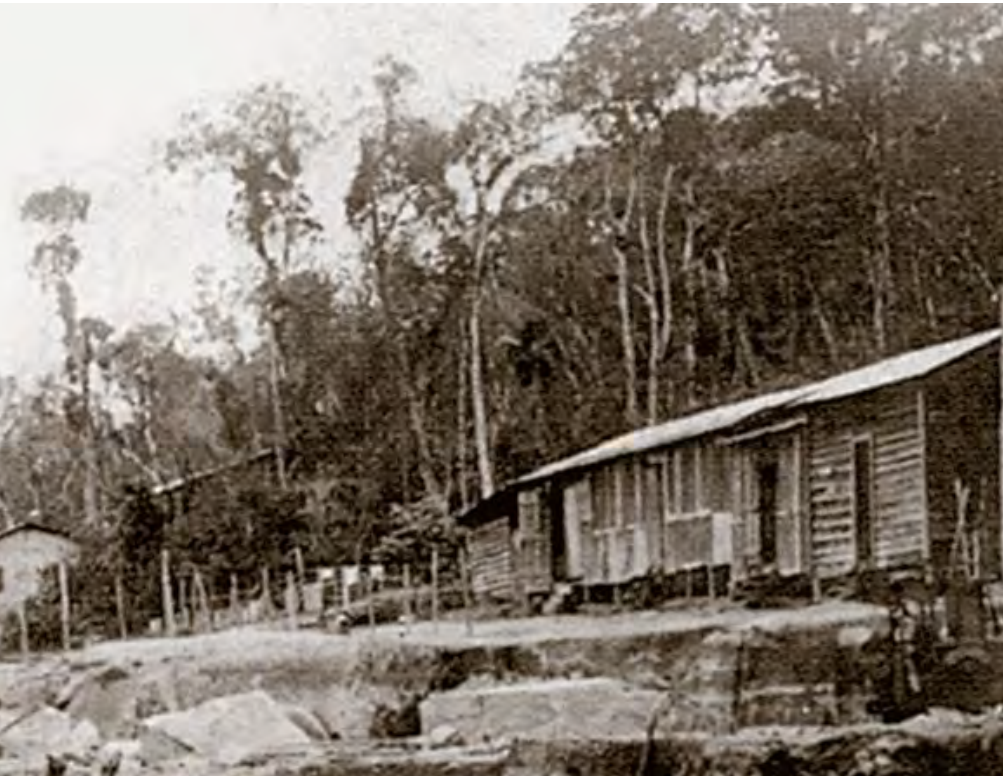

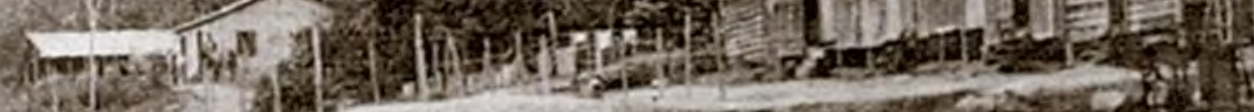

F. 1 (n)

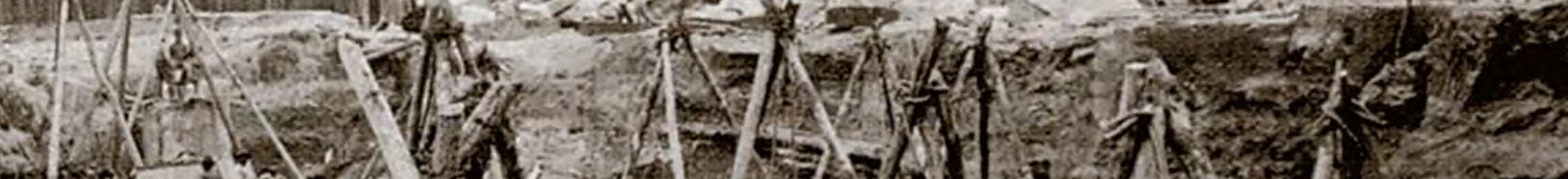
(2) (3) 20.2 $3{ }^{2}$.

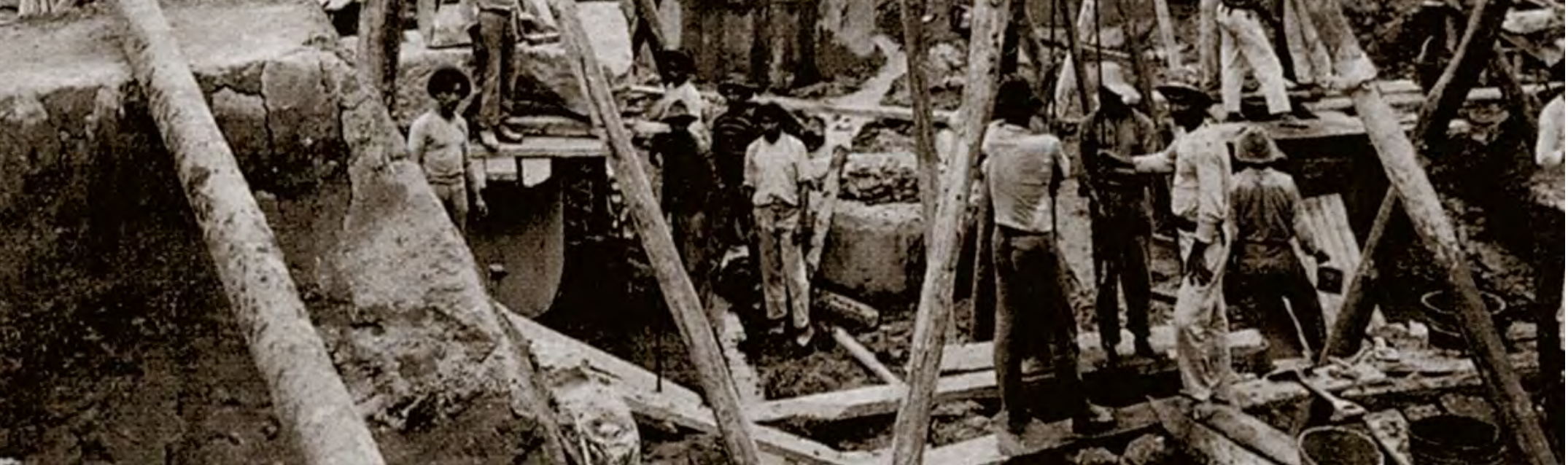




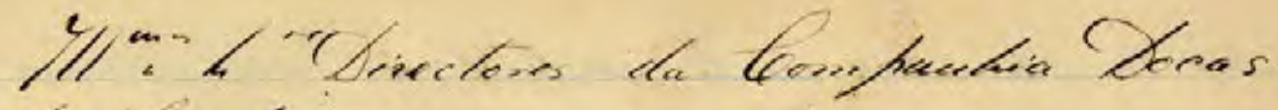
de Pearlor.

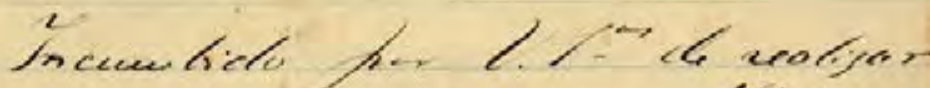

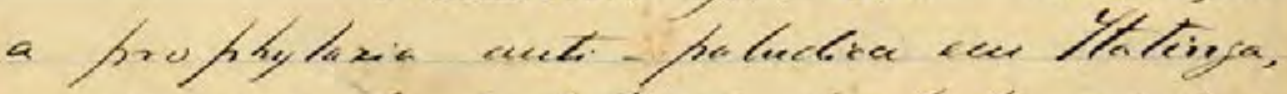

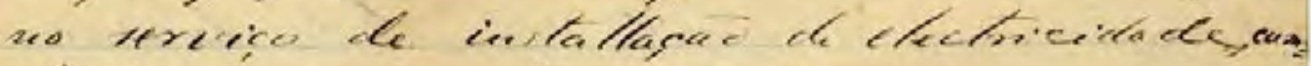

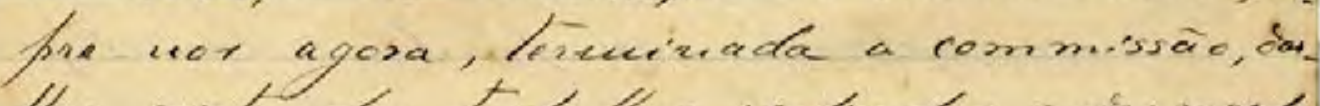

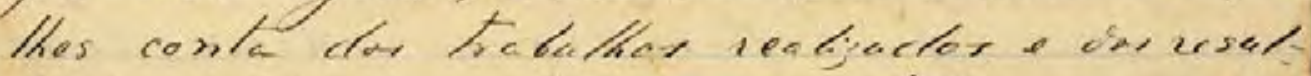
tados oblidos, neforis o we ferlyauras indis. bevevarel observas was fuluesas thocas efi:

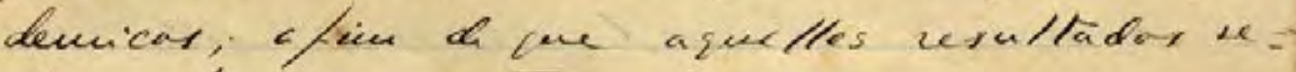
jam perencusenles.

toomecarenos protistando woxp agradecineuts ao illutado $h: X^{2}$ Ulbico

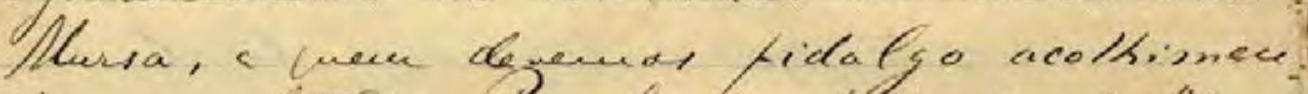

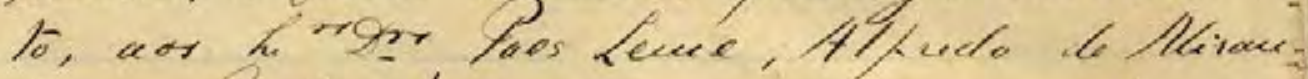

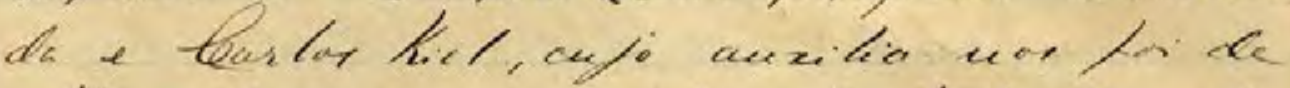
alta velia ua execucáo do tratatho, de cuja convivencia wer zear a reuplie grato temarar)

\section{lesdade scientifiere}

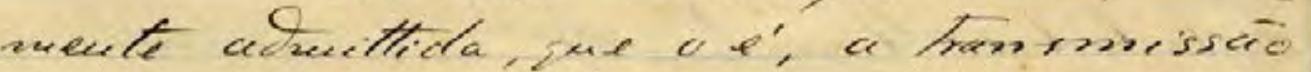

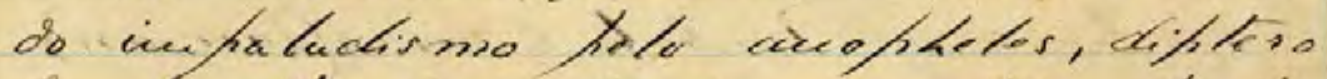
Sa facertia dar celicidios, convtiter linfe a bave unica pacional da brofilylaerá zer hectiva \& ene contecinento, cula ma

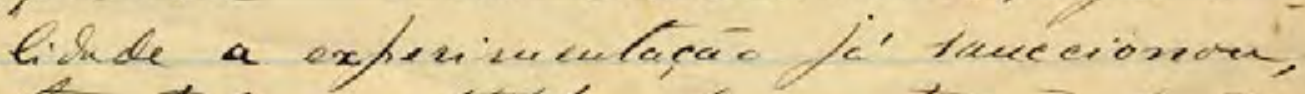

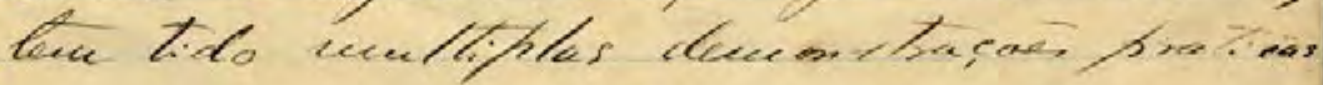




\section{Brazil-Medico}

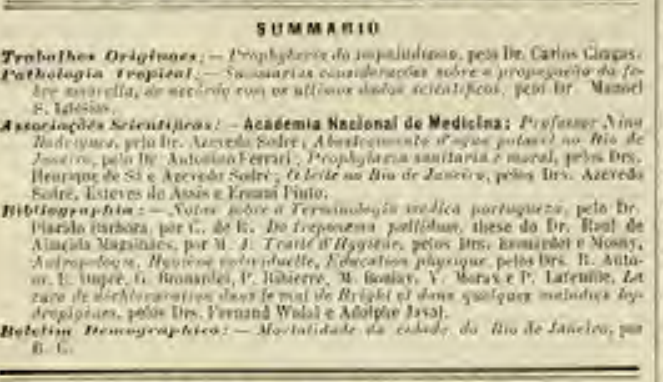

\section{TRABALHOS ORIGINAES}

Prophylaxia do impaludismo

Prao De. Castos Cinscas

Tratalbo do lestitato de Manguinhos

\section{I}

Mosquilo

Impressoes recentes de uma campanha prophy. latica contra o impaludismo constiluem a lase deste pequeno trahallo. E nâo se veja ahi o intuito de doutrinar ou o de innovar, sinaso esse, perfeitamente acceitavel, de registrar factos zelosamente observados, delles aproveitando as illaçoes naturaes. Nesles assumptos, de ordem pratica, os cnsinamentos dos livres, seja dos mais sabios, deisam sempre at maryem, esquecidos, pequenos defallos, cuja importancia 806 a repetiç̃o de experiencias vem salieotar. Alóm de que, nos estudos experimentaes, de regra es surgir, numa experiencia repetida, outra verdade at registrar. Dahi algum possivel interesse, certo pequeno, para a aprendizagem que nos propor ciona a pratica de conhecimentos seientificos amplamente sanecionados.

0 progredir dos estudos eliologicos tem trazido á luygiene moderna, na prophylaxia especiliea das mo. lestias infectuosas, o melhor de seus elementos de aeç̃o. Mais uma conquista do laberatorio, no campo da parasitotogia, novo ensinamenlo pratico, applicavel á prophylaxia, que vae assim fugindo do empirisono para cotrar no dominio pleno das sciencias experimentaes. $\boldsymbol{E}$ os processos geraes de hygiene, aquelles que traduziam a ignorancia da verdade no contagio das inferçoes, váo eedendo terreno a praticas especialisadas, expressisas agora de noçes cliologicas noyas, adquiridas com o determinismo experimental que as forva irrecusaveis.

Entre aquellas noçoes figura o culicidio, evjo papel epideminologico constitue uma das mais benclieas couquistas da medieina moderaa. Nem pair: mais, respcito á importancia deste agente de transmissain das especies morbidas, a divergencia doutrinaria dos estudiosos, ás vezes tão demorada em des. apparecer uas serdades que a sciencia vae conquistando. E: que, para varrer daqui a jossibilidade de duvidar, existem factos multiplos, de ordem experimental edecordem pratica, sempre coherente sem allirmar a realidade dir theoria. Exemplilicam essa verdade a febre amarella e o impaludismo, molestias hoje evitaveis, cujos processos prophylaticos poderse-hio reduzir a formulas alzebricas, de applicaço lâo posiliva guanto o éa daquellas que a mathema. tica nos offerece.

Exporemos as regras classicas, estabelecidas para uma campanha anti-paludica. E abi, quando opportunu, traremos os dados de nossa observacaio piessôal. Necessario é, porém, rapido estado prévio, 110 que interesza nosxo ponto de vista, dos dous ele mentos epidemiologicos do impaludismo, $\rightarrow$ anophe. lina e o doente impaladado, - bases da prophylaxia resplectiva.

0 eulicidio trasmissor do impaludismo perteuce a sub-fanilia anophelina, que se divide em 18 generos, uuitos delles com especies brazileirs. Diversas anophelinas tèm sido responsabilisadas, experimentatmente, pela transmissão da molestia; possivel é, porim, $e$ até provavel, dada a identidade de condiçoes biologicas entre ellas, possam todas re. presentar aquelle papel, na etiologia da especie morbida.

Sáo conhecidas no Brazil as seguintes anophelinas: 2 cellia (1) (Argyrotarsis albipes); 2 my;omyias, - Myzomyia Litzi e a Myzomyia tibia-maculata (re. cem-descriptas em Manguiuhos pelo Dr. A. Nraxs; e 2 pyrelophorus, o Pyretophorus Lome e uma outra esjecie năo descripta, cujos exemplares pertencem ao Instifuto de Manguinbos, onde vito ser estudados. Noso genero foi creado ha pouco pelo Dr. Oswatvo Caux, com una especie brazileira, a mesma a que - Dr. A. Lotz deu a denominacâo de Pyrelophorils. Fusaba. Sobre este ponlo, para resolvel-0, é esperada a opiniza de Tremens.

A distribuicăo destas anophelinas pelas diversas zonas do raiz é pouco conhecida, merecendo a altenço dos pesquizadores. Segundo Gi:.un predominam na Norte em todo o littoral representantes do genero cellia, especialmente o celli (Argyrotarsis albipes). Tambem aqui na cidade do hio de Janeiro e pontos visinhos sâo os 2 cellia as especies que mais abundam.

Tivemos oprortunidade de fazer colheita de culicidios em Mimas Geraes, em pontos diversos do Estado, ealli encontramos representadas todas as pspecies brazileiras, excepễo uniea do Nyzomyia Lutzi. Predomimates sino naquella zona as duas especies de purelophorus e o novo genero estudado em Manguinhos, e tal e a abuudaucia destas anophelinas por todo o Estado que acreditamos sejum ellas as principaes Iransmissoras do impstudismo nas margens do firo S. Erancisco, onde as epidemias stio extensissimas $\mathrm{e} \mathrm{em}$ extremo mortiferas. Nas margens do Rio Itapanbaum, em Itatinga, onde realizamos nossa campauha prophylatica, encontramos tres anopheliuas: Cellia (Arg.

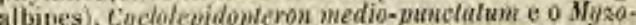
mana Lora. Alli prodomina o albipes, vindo depois o Myzomy Lura euja importancia ua transmissio do Myzomyia Lera, euja importancia ua transmissáo do impaludismo das montanhas, em virtude da evolucto
delle nas bromilias, vamos em breve salientar, tendo a referir facio curioso.

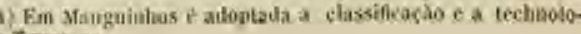
gia de Treosis.o.
Poder-se-á sintetizar num duplo intuito a profilaxia do impaludismo: impedir que o homem doente contamine o culicídio transmissor, evitar que o culicídio parasitado infecte o homem são.

Carlos Chagas

Paludism prophylaxis can be summed up in a twofold purpose: preventing the diseased man from contaminating the transmitting Culicidae, and preventing the parasite-infected Culicidae from infecting the healthy man.

Carlos Chagas

Primeiro trabalho de Chagas sobre profilaxia da malária Brazil-Medico, 15 ago. 1906

Acervo Casa de Oswaldo Cruz

Chagas's first article on malaria

prevention

Brazil-Medico, Aug. 15, 1906 


\section{NOVAS ESPECIES DE GULICIDIOS BRAZILEIROS}

DR. CARLOS CHAGAS

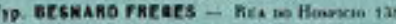

$$
\text { roo } 7
$$

\section{$x \div 1956$}

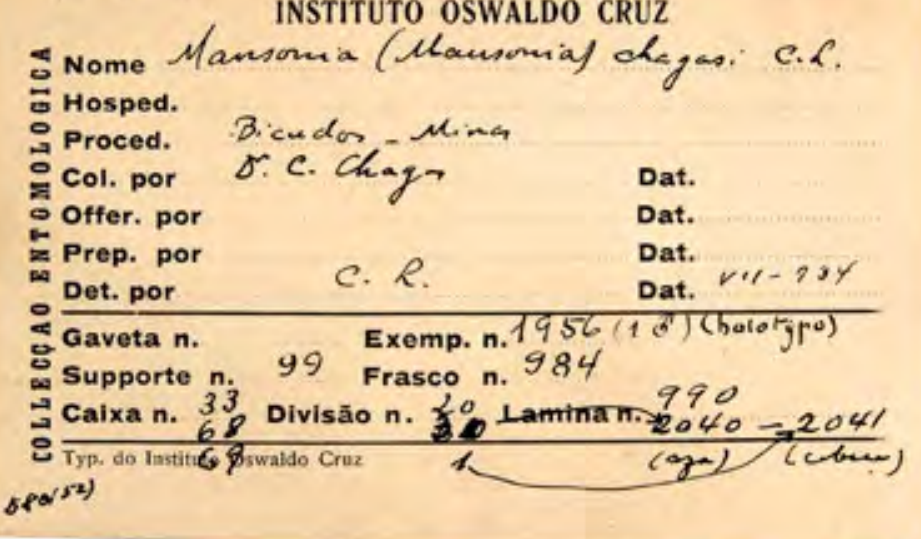

Em 1907, Chagas descreveu novas espécies

de mosquitos

Acervo Casa de Oswaldo Cruz

In 1907, Chagas described new species of mosquitoes

Ficha de registro do mosquito Mansonia chagasi.

Espécie descrita em 1935 por Angelo da Costa Lima,

renomado entomologista do Instituto Oswaldo Cruz,

em homenagem a Carlos Chagas, a partir de material

coletado por este em Bicudo, MG

Acervo Coleção Entomológica do Instituto Oswaldo Cruz

Laboratory index card for the mosquito Mansonia

chagasi. Species described in 1935 by Angelo da Costa

Lima, distinguished entomologist from the Oswaldo

Cruz Institute. Named in honor of Carlos Chagas, who

collected the material in Bicudo, Minas Gerais

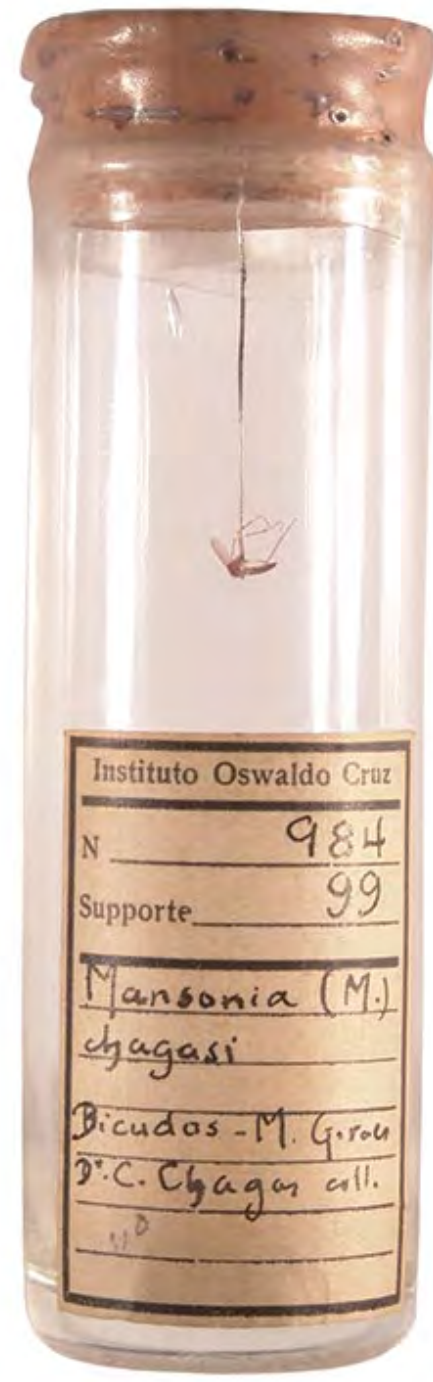

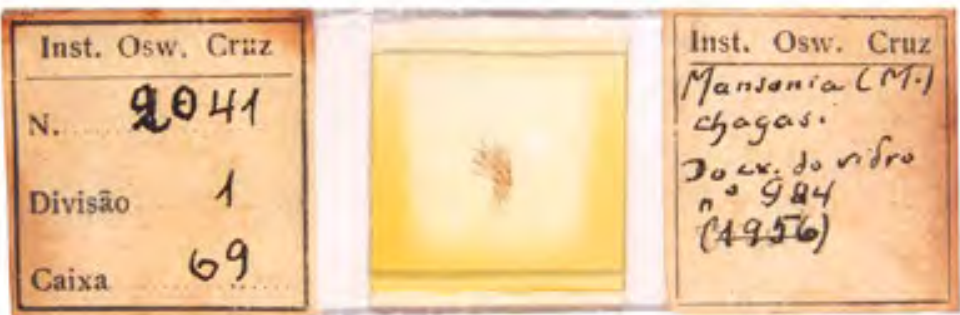

Exemplar de Mansonia chagasi (holótipo), coletado por Carlos Chagas. Holótipo é o espécime designado pelo pesquisador como padrão da espécie por ele descrita, que é usado para futuras comparações com outros espécimes Acervo Coleção Entomológica do Instituto Oswaldo Cruz

Holotype of Mansonia chagasi, collected by Carlos Chagas. A holotype is the specimen that a researcher designates as the standard for the species he describes; it is used in comparing future specimens

Lâmina com cabeça do mosquito Mansonia chagasi (holótipo)

Acervo Coleção Entomológica do Instituto Oswaldo Cruz

Slide of the head of a Mansonia chagasi mosquito (holotype) 


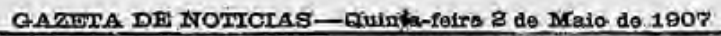

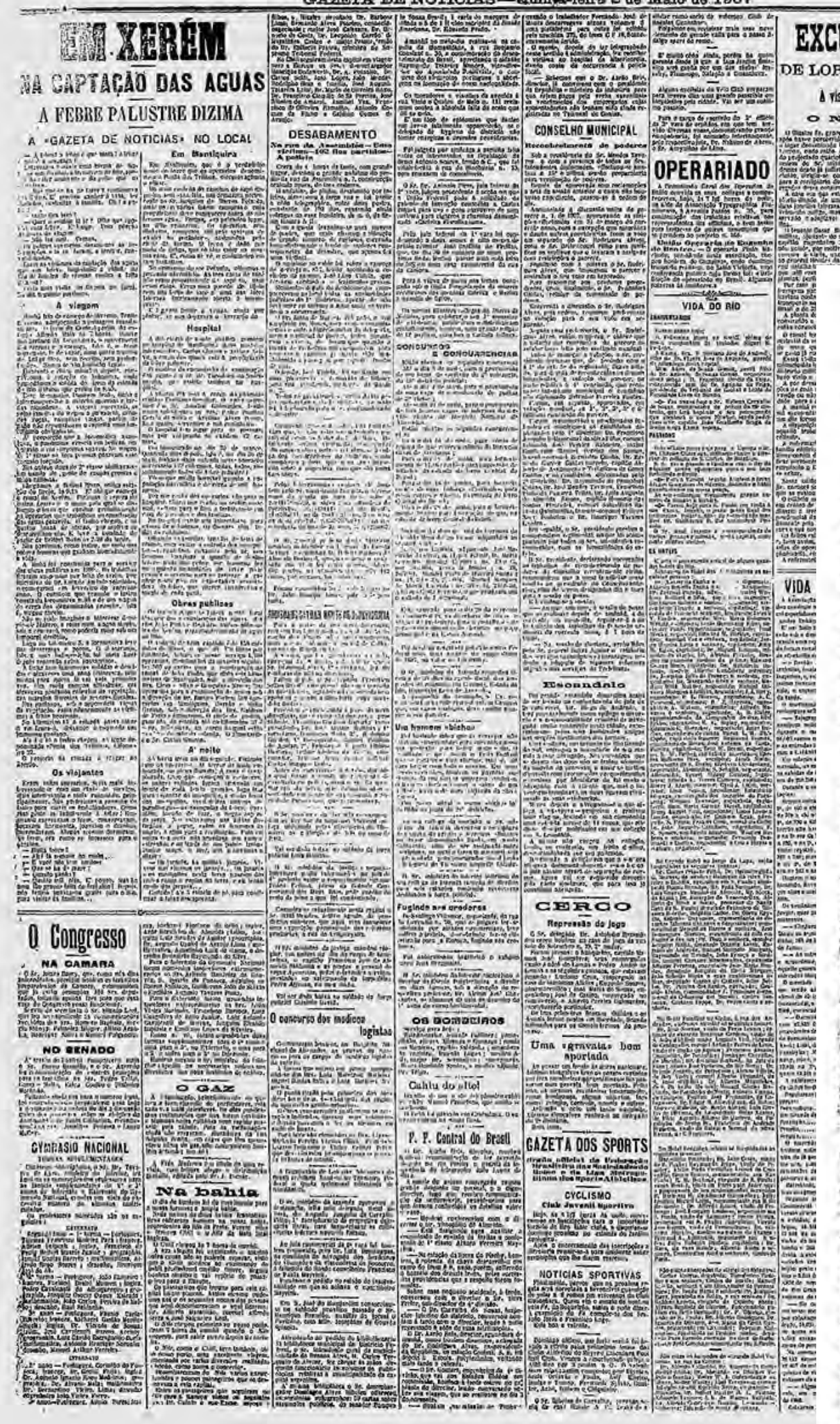

Em Xerém: na captação das águas a

febre palustre dizima

Gazeta de Noticias, 2 maio 1907

Acervo Fundação Biblioteca Nacional

"In Xerém: paludism decimates as

water works progress"
3

EXCURSĀO MILITAR

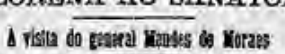

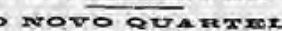

A

1.

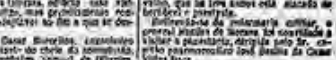

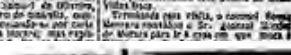

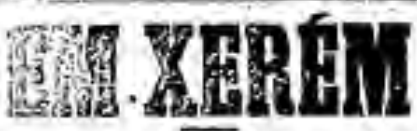

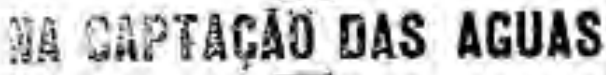

\section{A REBRE PALLISTRE DIZIMA}

a pgazeta de noticias. no local

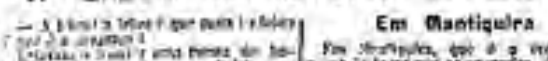

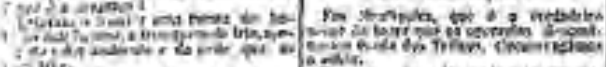

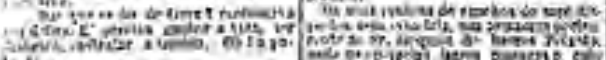

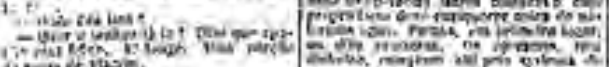
ond

(6)

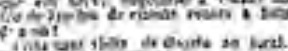

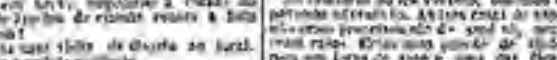

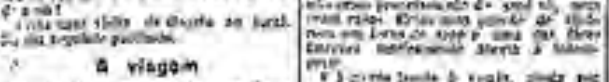

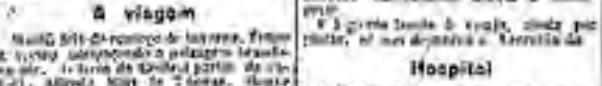

20.

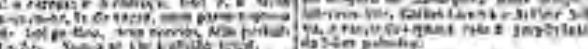

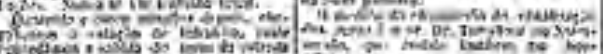

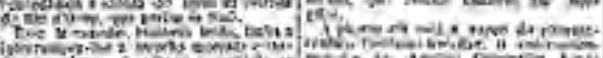
4.

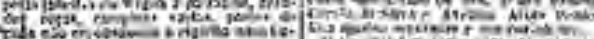

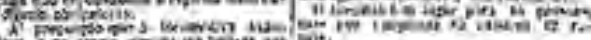
Fin

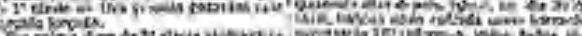
6I A

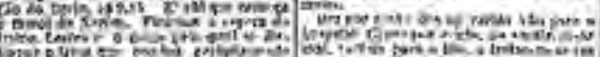

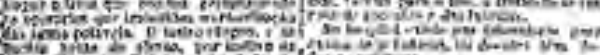
mathing

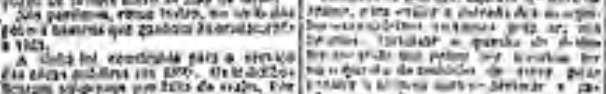

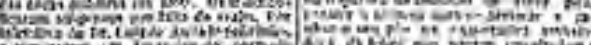
100 ond

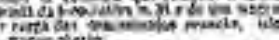
Obres pothlises

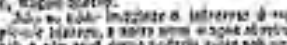

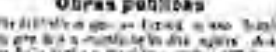

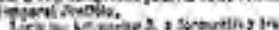
thy wat

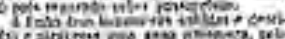

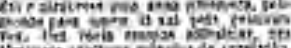

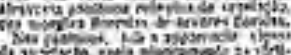

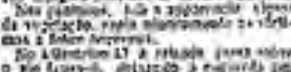

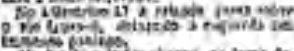
Mis in

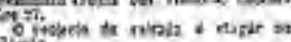
Q2 vis!antos.

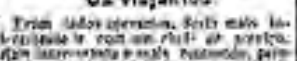

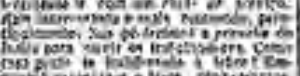

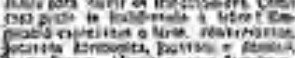
ning

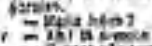
, Elowan

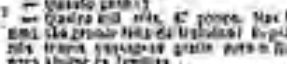

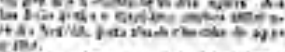
4 . to

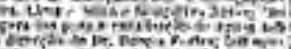

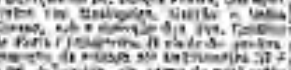
The con a'nolite mand and rinterts

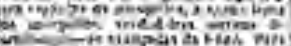
- 50 ond wir

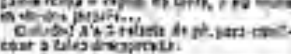




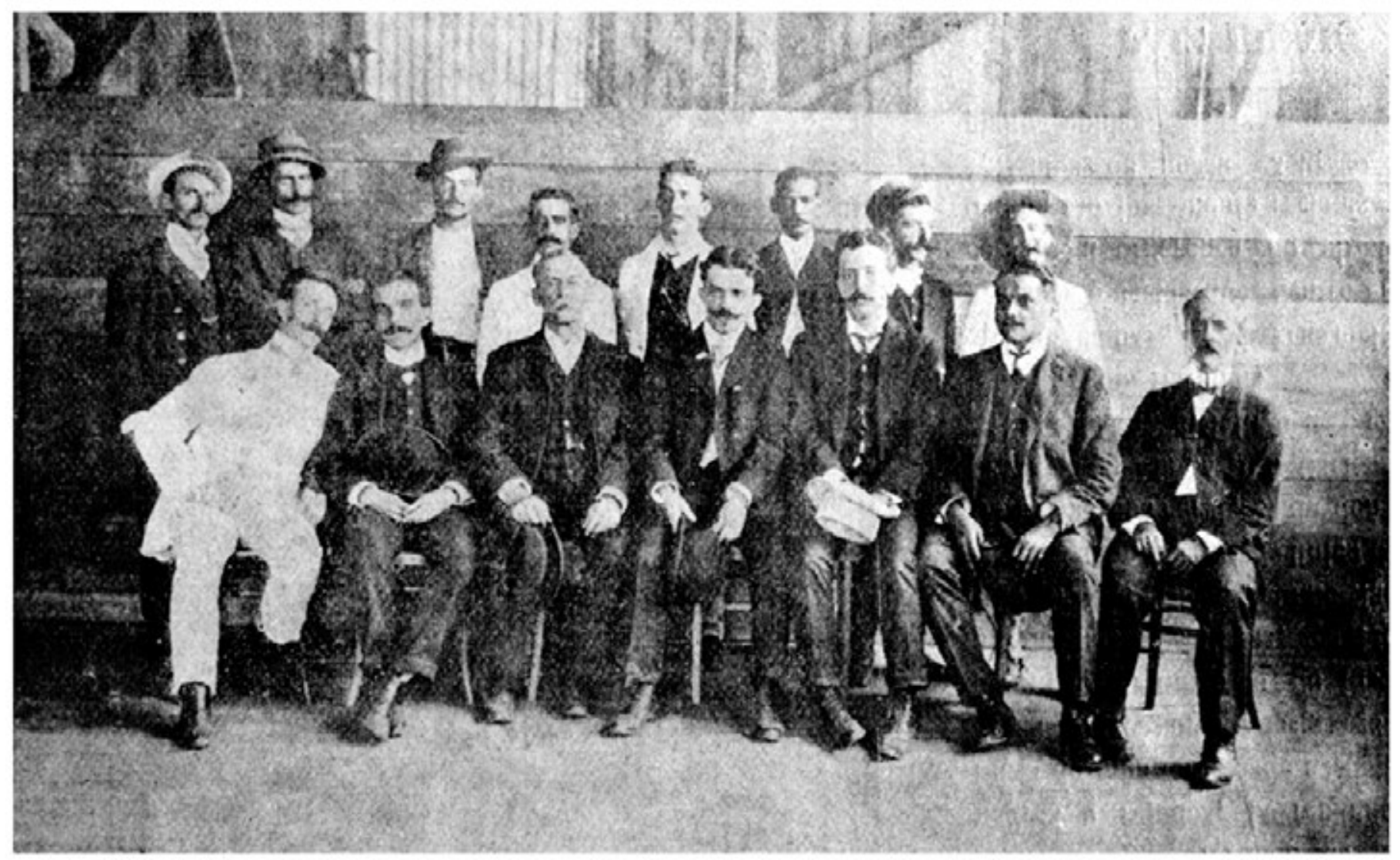

Um grupo de medicos e auxiliares dos serviços clinicos, de defe a e prophylaxia exigidos pela insalubridade local - Sentados da esquerda para direita Dr . Carlos Chagas, chefe do serviço prophylatico; Alvaro Ramos Valladares, Afranio Peixoto, Rocha Vaz, Theodureto do Nascimento, do serviço clinico e Emiliano Bacellar, pharmaceutico. Por traz os auxiliares dos serviços medicos.

\section{SANEAMENTO DA BAIXADA DO HIO}

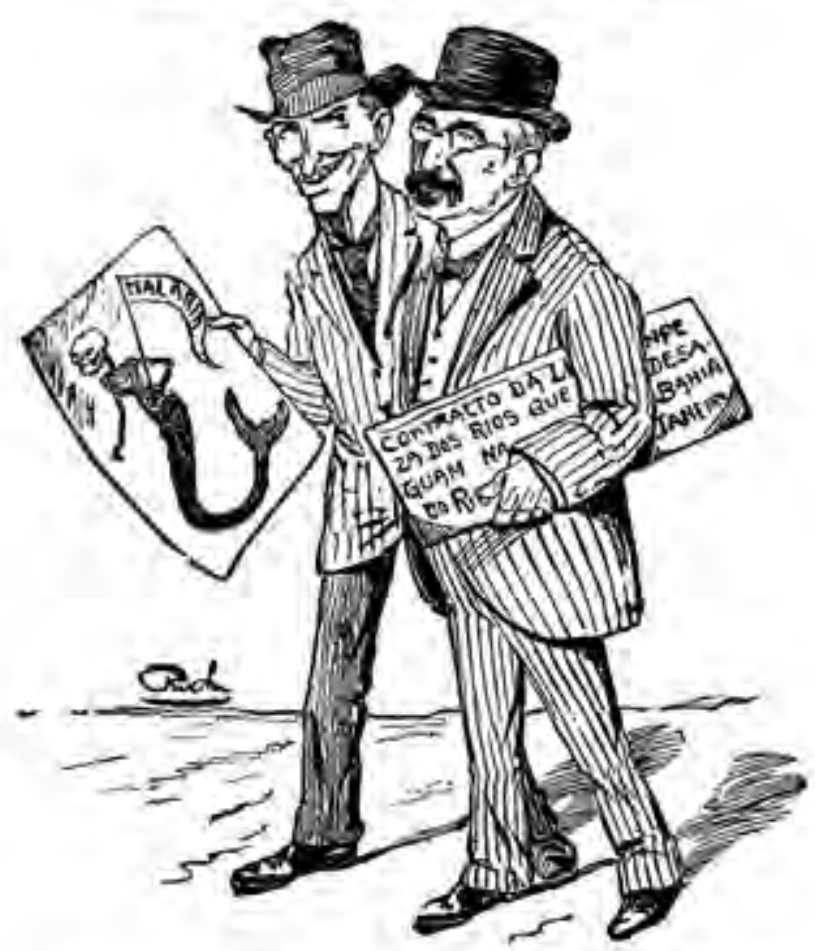

CAfco SA: - Ha de ir ávante a limpeza de todos os rios que desaguam na babie do Rio de Janeiro e a dragagem do fundo d'essa thahia, etc., etc. E a complemento indispensavel is obras do porto e ao saneamento da Capital pensavel.

$Z$ é PONo:- Ea queo digal Os taes Mos e riachos, obE.ruidos como estấo ha longos annos, șío a causa do interminavel impaludismo que toe a vida de milhares e milhares de creaturas. A proposito: aqui está a sereia que canta, $n^{\prime}$ esses paptanaes... Por honra do bom nome hy gienico, arranjado com tantos sacrificjos para a Cepital Federal, e preciso acabar com esta bichat
Chagas em Xerém, RJ, com grupo de médicos e auxiliares que atuaram na profilaxia da malária Revista da Semana, 26 maio 1907

Acervo Fundação Biblioteca Nacional

Chagas in Xerém, Rio de Janeiro, with a group of physicians and assistants who participated in malaria prevention initiatives

Revista da Semana, May 26, 1907

Saneamento da baixada do Rio

OMalho, 3 set. 1910

Francisco Sá era ministro da Viação e Obras Públicas Acervo Fundação Biblioteca Nacional

"Sanitation of the Rio lowlands"

OMalho, Sep. 3, 1910

Francisco Sá was minister of Transportation and Public Works

Trecho da Estrada de Ferro Central do Brasil entre Belo Horizonte e Pirapora

Detalhe do mapa produzido pelo Ministério da Viação e Obras Públicas. Inspetoria Federal das Estradas, 1913 A Estação de Pirapora seria inaugurada em 1910 . O projeto de prolongar a ferrovia do Rio de Janeiro até Belém do Pará não se concretizou

Acervo Fundação Biblioteca Nacional

Central do Brasil line from Belo Horizonte to Pirapora Detail of map made by the Ministry of Transportation and Public Works. Federal Inspectorship of Roads, 1913 Pirapora station would be inaugurated in 1910. Plans to extend the railway from Rio de Janeiro to far-northern Belém do Pará never came to fruition 

Eu comparo o Brasil a uma criança que está engatinhando; só começará a andar quando tiver muitas estradas de ferro.

Inácio, personagem de Relíquias de Casa Velha de Machado de Assis

I liken Brazil to a child who is crawling; it will only start to walk once we have many railroads.

Inácio, character from Brazilian writer Machado de Assis's Relíquias de Casa Vellha
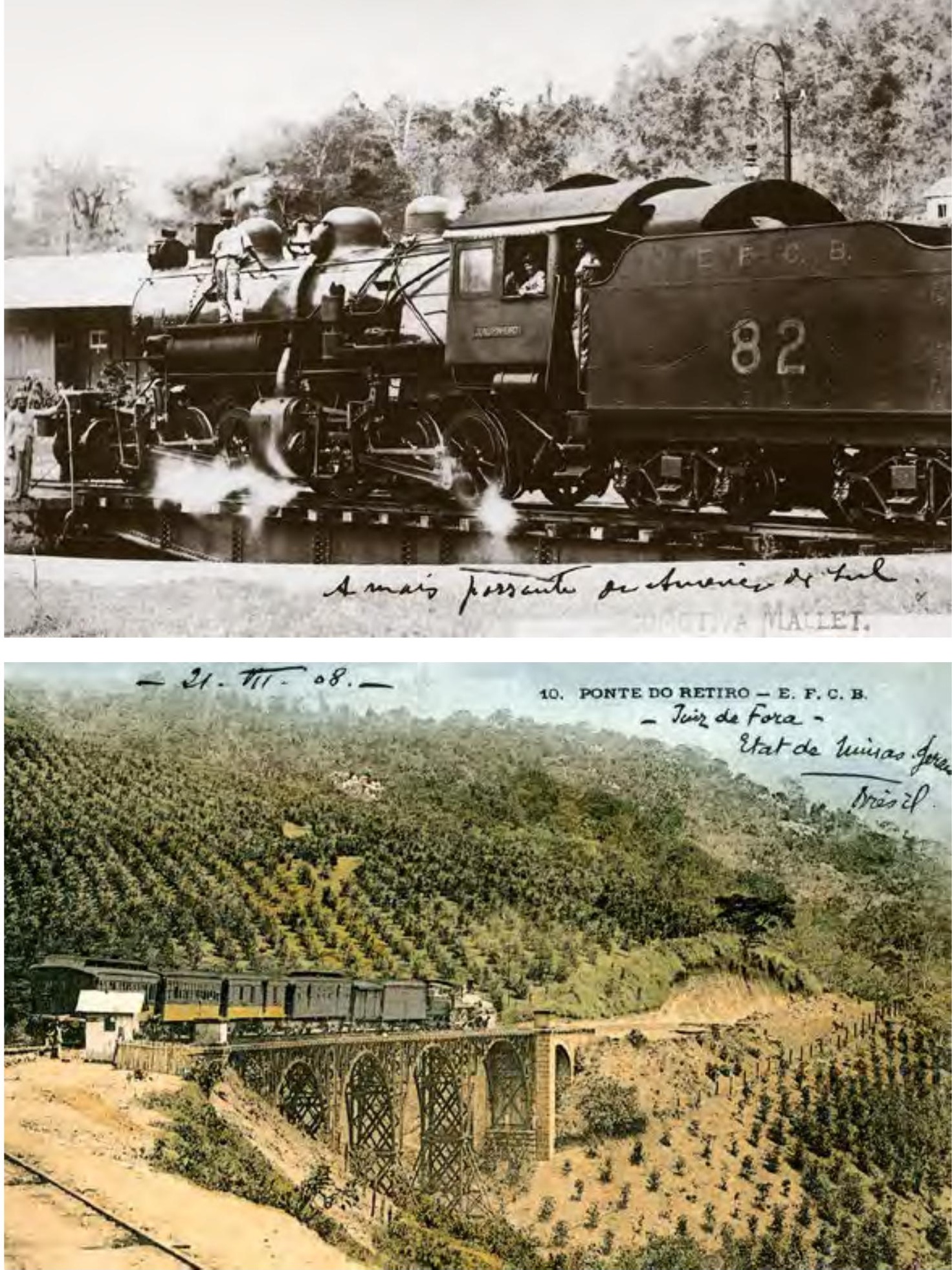

Locomotiva a vapor tipo Mallet batizada "João

Pinheiro", da Estrada de Ferro Central do Brasil,

fabricada pela American Locomotive Co. dos Estados

Unidos, em 1907, provavelmente na estação de

Lafaiete, em Minas Gerais

Fonte: Gerodetti \& Cornejo, 2005

Mallet locomotive named the "João Pinheiro"

purchased by the Central do Brasil Railroad from the American Locomotive Co. (U.S.), in 1907, probably at Lafaiete station in Minas Gerais

Viaduto do Retiro, situado numa região de cafezais nas proximidades de Juiz de Fora, MG, sendo atravessado por uma composição da Estrada de Ferro Central do Brasil, c. 1905

Fonte: Gerodetti \& Cornejo, 2005

Central do Brasil train, crossing the Retiro Viaduct, located in a coffee-growing region near Juiz de Fora, Minas Gerais, c. 1905

O progresso do norte OPorvir, 29 jun. 1904

Reportagem comemorando a chegada da Estrada de

Ferro Central do Brasil a Curvelo, MG

Acervo Biblioteca Pública Estadual Luiz de Bessa

"Progress in the north"

O Porvir, Jun. 29, 1904

Article commemorating the arrival of the Central do

Brasil Railroad in Curvelo, Minas Gerais 


\section{OPROGRE SS, DANORTE}

Com a data de hoje vae. se registrar para este munt. cipio e, em geral, para o Norte de áinas o mais importante acontecimento, piecursor de novo periodo que firmará a prosperidade de uma vasta, riquissima e lortil zona.

A primeira locomotiva da E.F. Central do Brasil, ao entrar a ser recebida festivamente nesta cidade, nảovim despertér, com 'o seu pcs. sante silvo, a uma popula. çà em torpor, mas $\mathrm{sim}$ chamar a noves postos de actividade a um povo que sempre notabilisou se pala sura of erosidade nos diversos ramos da industria, si bu:m que, a:é entāo privado À distanicisdo de faceis meios de trinsporte.

0 trafego, que em breves dias serầ uma realidade concuscendo parn o fasil e rapido escoarnento da ploJucçis, estabolecerń, poln permata, as multipias relaçôes do commercio, nug. mentundo considersvalmt:nte, nesta ciáade a sta pra. ca. it zouindis sem duvi. da uma das primeiras, devido stu 530 movimerto e a bonorabuidade dos seus $o$. perosus representantes.

Já era iempo. A $\mathbb{Z}, \mathrm{F}$. C. da Brasil, cujo contracto assignado em Londres $\mathrm{mm}$ 185.3 , teve como escopo 0 estabelecimento da mais ra. pida communicaçño entre o Rio de Janeıro o Minas Geraes, vindo della tambem nuferir incontestaveis van. tagens o Estado de S.Paulo.

lless longo perion, pir: mais de quareaca annos, é para se nitar a serie ie beneficios que tèm resultado para o territcrio servido por esse importante factur do progresso.

Agora, pọis, que a Cen. tral approxima-se do seu obejectivo, demandando, no derradeiro municipio a per. correr, o magestoso Rio S. Francisco, grande impulso văo ter as cidades do Norte e até onde chegarem \&s agues desse Mississipe Brasileiro, no inspirado dizer de uт notavel mineiro, năc se fará esperar, antes será uma realidads, a prosperidade para alguns milhōes de ha. bitantes de mais do um Estado.

Foi um distincto minciro o inesquecivel Mariann Procopio, que tambom lançou em terra mineira o primeiro tritho e so lada de outros patriotas como Christiano Uttoni e o Barão de Camargos, que se recommendem á posteridade, esforçou.se pelo prolongamento da E.F. D. ledro I I, hoje Central do Bresil, em direcçto au Nurte de Minas.

Assim, corresponder.do nos 1. uvaveis intuitos de quanos se empenhtran nesso grande corrmettimento, a. cora que a bem orienteda Jministrsçăo do Giverno de Minas precura a aimar os di. versos ramos da ind sstria, saibam os habitantes desta ciarade e os do Norte, mineiros que sin todos, Ho proveitar recelvendo a pri. meira locomutiva, a grande elemento de progressis no qual desiançam of futaro a prisperidade de-tr notusel parte da teria mineirn.

Sằ us nossos vatres,

c. 2 - VI-idi.

\section{i). $\mathrm{E}$}

\section{Salve?}

Setá hoje festivamente ouvido psia mossa sidade o silso da locomosiva parsante, coirtanda as nocsis plagas sertanejas, invadinda or nos oua coraçoss de un grande e gz(a) rexosijo e contents nento e tansformutido en reaifled: o nusso tăo ambiciuna:o Jesidaratum! Este dia assignalara pora nos ot serl tinejis uma reva era, que nunca mais deverá ser esquecto. pelus amantes do progressos e por todos acuelles que, de coraçio an:bicionam o engrand:cinerito macrial da nossa bos s querida ter:a : liste dia deve ser solem-isado com estrepitosos vivis ans pmpitgnsdnres da trausfor naçãc da nosan cijade e das missas terras serta. nejas, porzue forats efles que com os seus eriziços alcanzaram os nieios sulficientes para que pujessemos huje, dia d: satisfijajo o de contentamento -ara os ucssos coraçóes, ouvir o silvo da loconiosiva, que marcaiá para nossa :erra um que marcaia para noss

Salvel

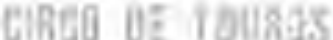

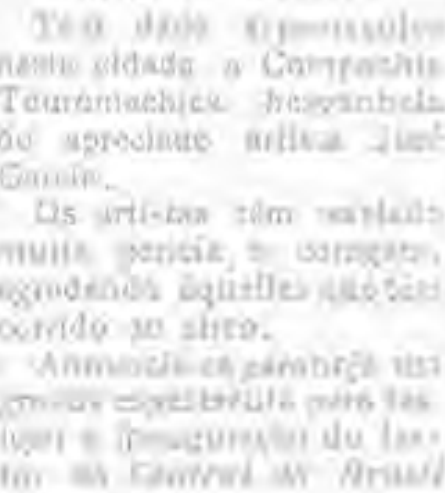

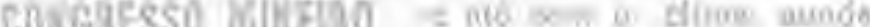

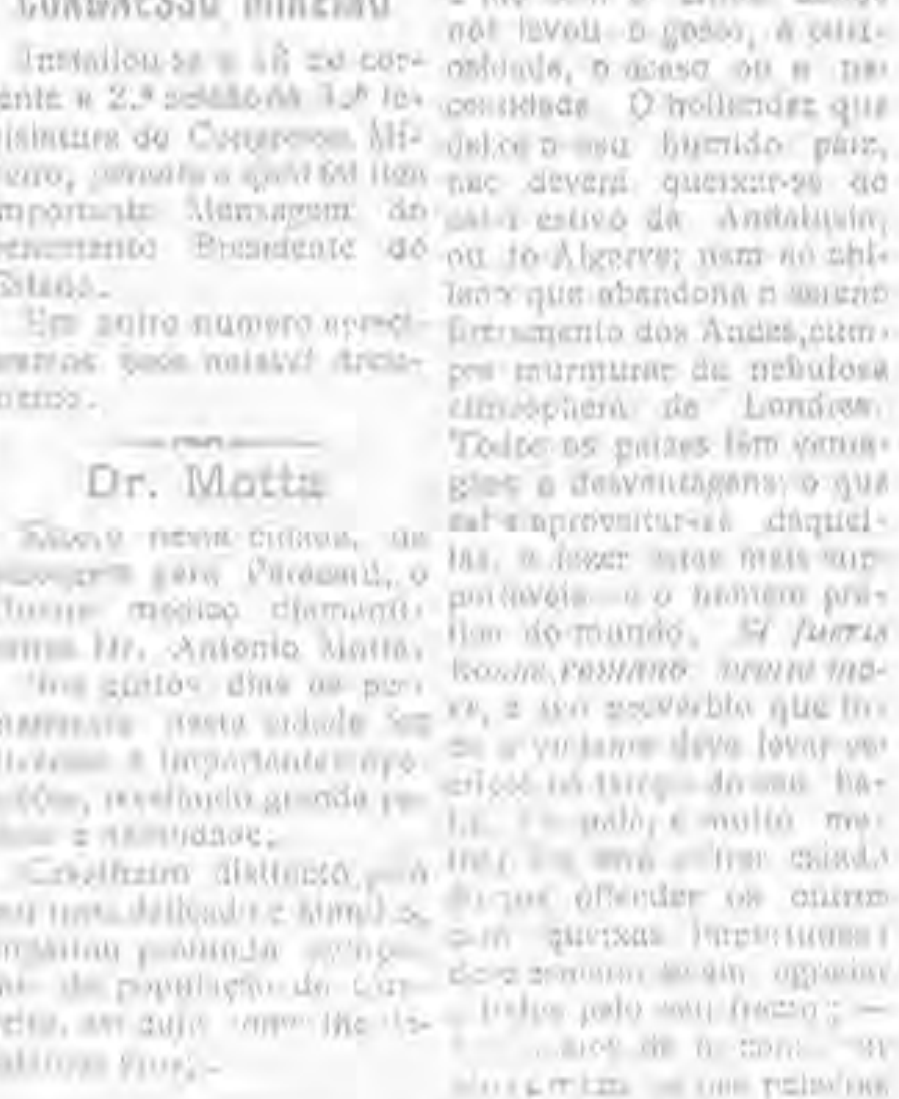

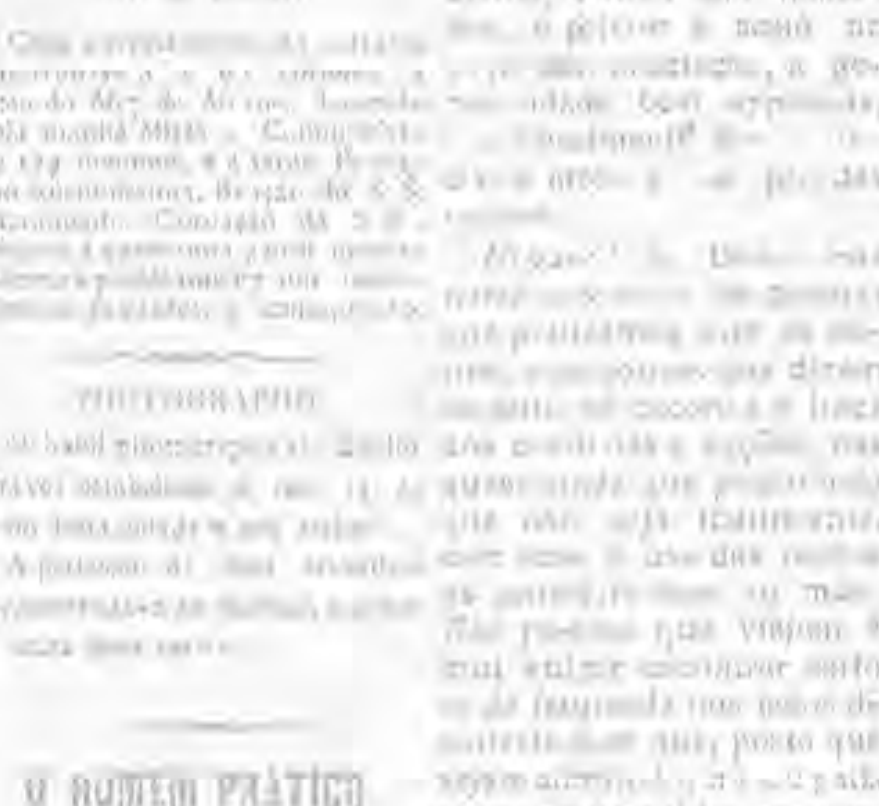

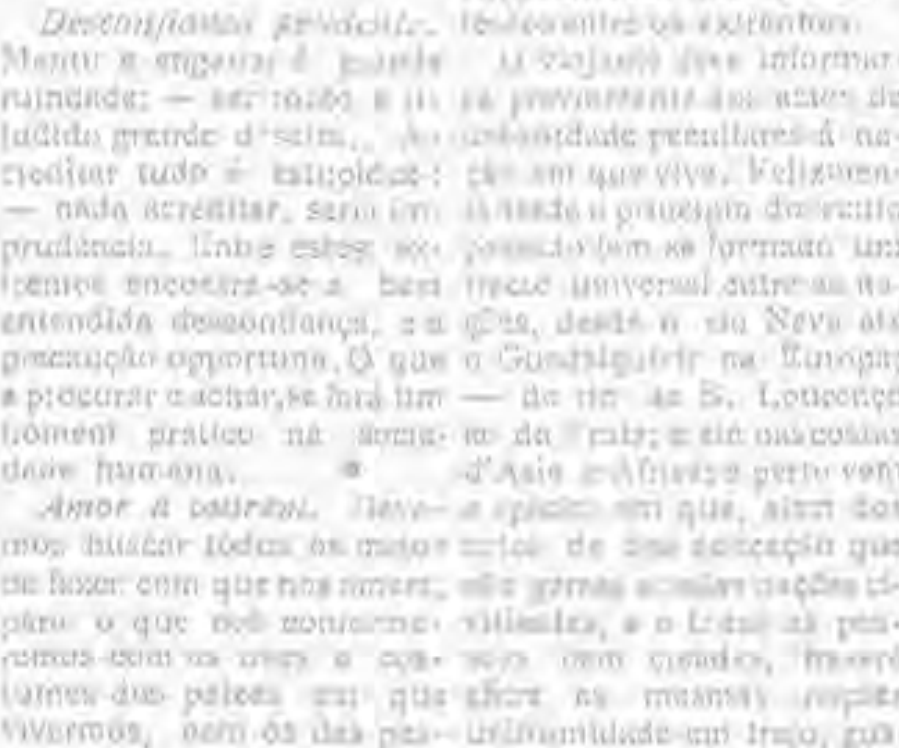


O rio das Velhas deriva seu nome, diz a tradição local, de três velhas encontradas acocoradas nas suas margens pelo explorador paulista Bartolomeu Bueno da Silva, o 'Diabo Velho' (...). A etimologia é um tanto fraca e manca. Os vermelhos, ensina o Sr. Rodrigues Valério (...), chamavam-no Guyaxim, e uma corruptela dessa palavra, Guacuí, ainda se encontra em mapas obsoletos. Isto significaria rio da Velha e, provavelmente, os primeiros exploradores traduziram erroneamente para o plural e, em seguida, seus descendentes inventaram as agora clássicas três velhas.

Richard Burton

The Rio das Velhas, River of the Old Women, derives its name, says local history, from the three old squaws found squatting upon its banks by the Paulista explorer 'Old Devil,' Bartolomeu Bueno da Silva (...). The etymology is somewhat loose and lame. The red men, we are told by Sr. Rodrigues Valerio (...), called it 'Guyaxim,' and a corruption of this word becomes Guaicuhy, still found on obsolete maps. This would mean the 'old squaw's stream' and probably the early explorers mistranslated it into a plural, whilst their descendants invented the now classical three old women.

Sir Richard Burton

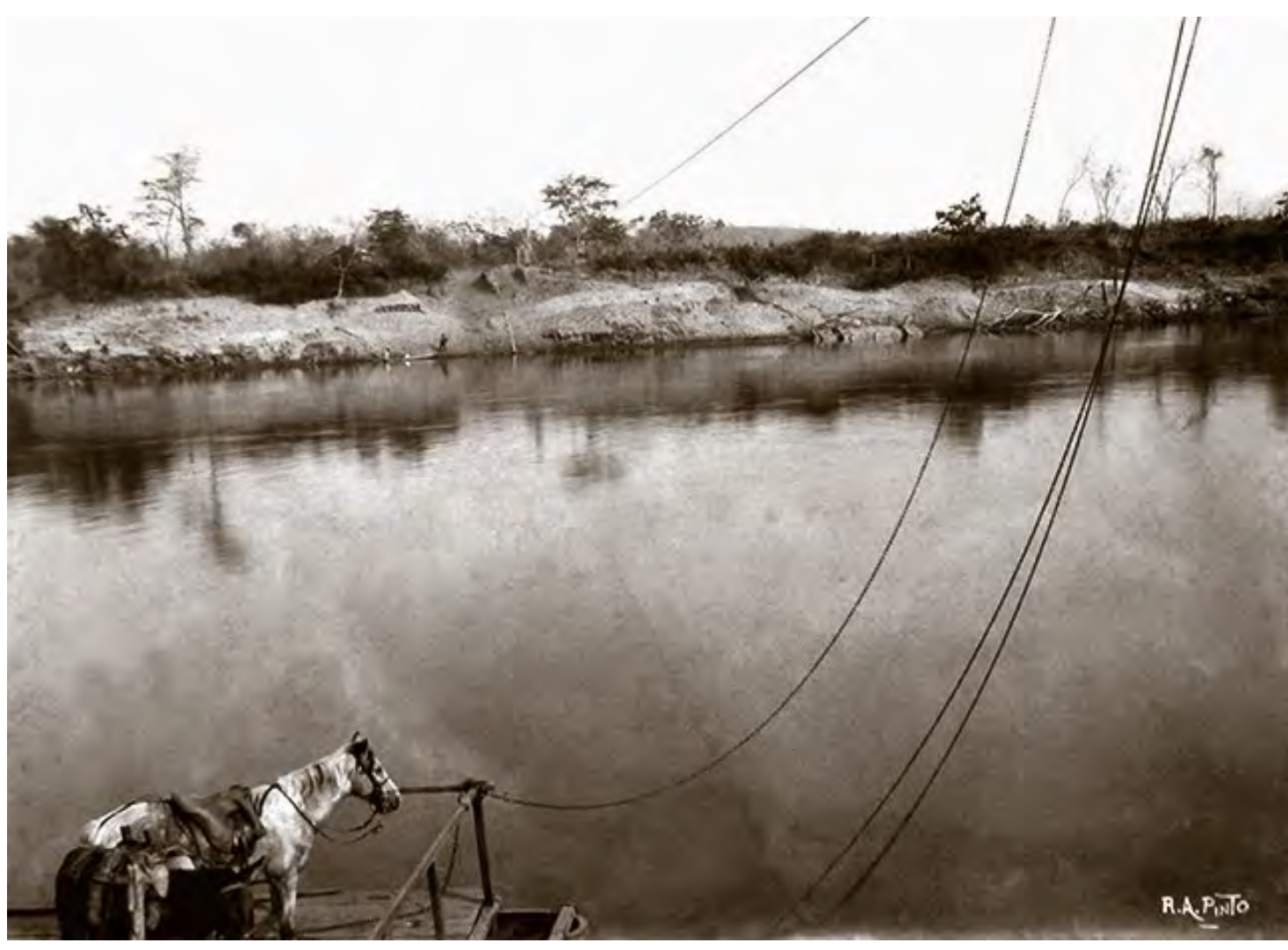

Vista do rio das Velhas em Curvelo, década de 1900

Foto Raimundo Alves Pinto

Acervo Arquivo Público Mineiro

View of the Rio das Velhas in Curvelo, 1900s

Photograph by Raimundo Alves Pinto

Estrada de Ferro Central

O Paiz, 6 jun. 1907

Nota anunciando o embarque de Carlos

Chagas e Belisário Penna para o norte de Minas

Acervo Fundação Biblioteca Nacional

"Central do Brasil Railroad"

O Paiz, Jun. 6, 1907

Note announcing Carlos Chagas and Belisário

Penna's departure for northern Minas Gerais 


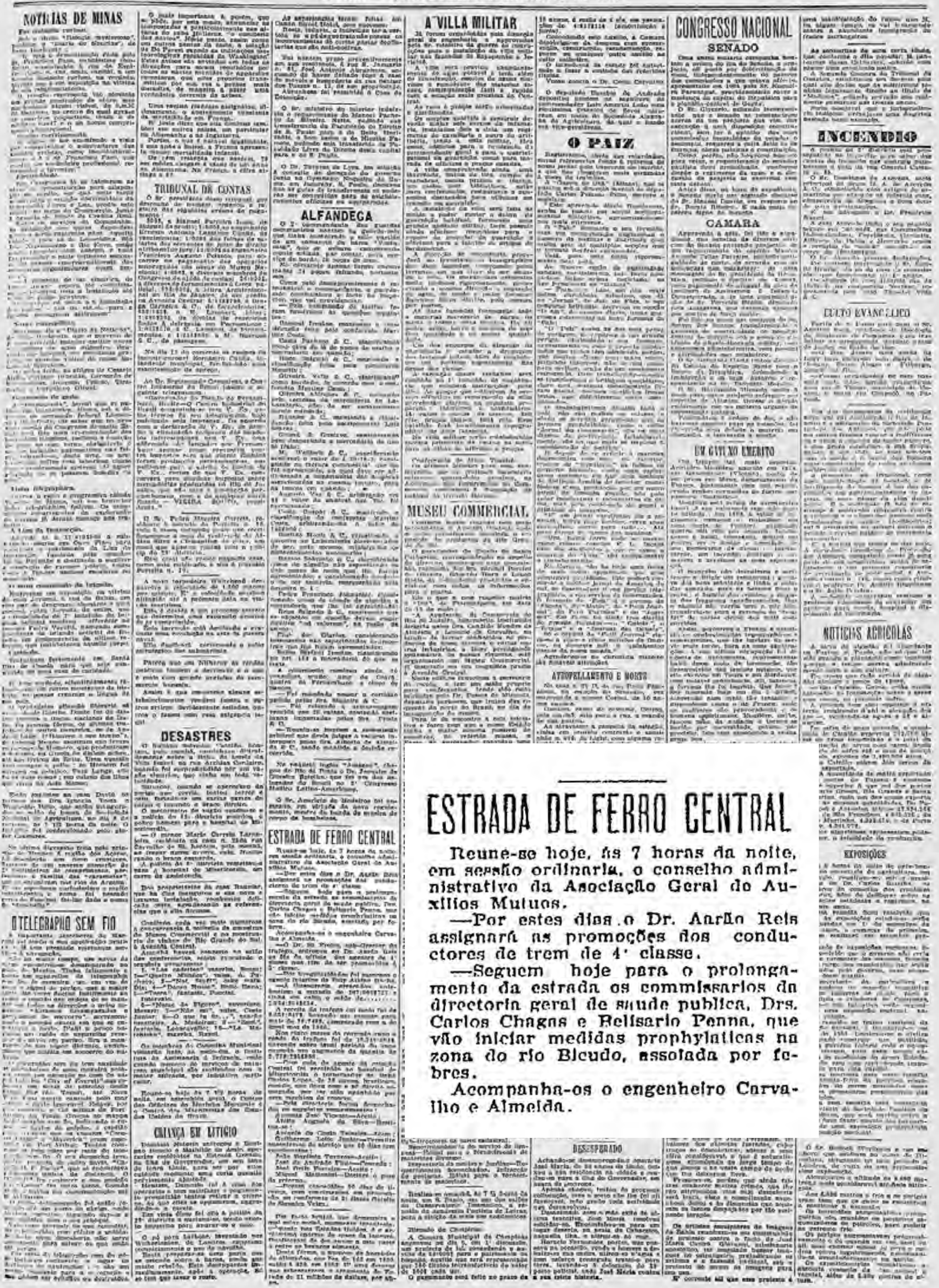




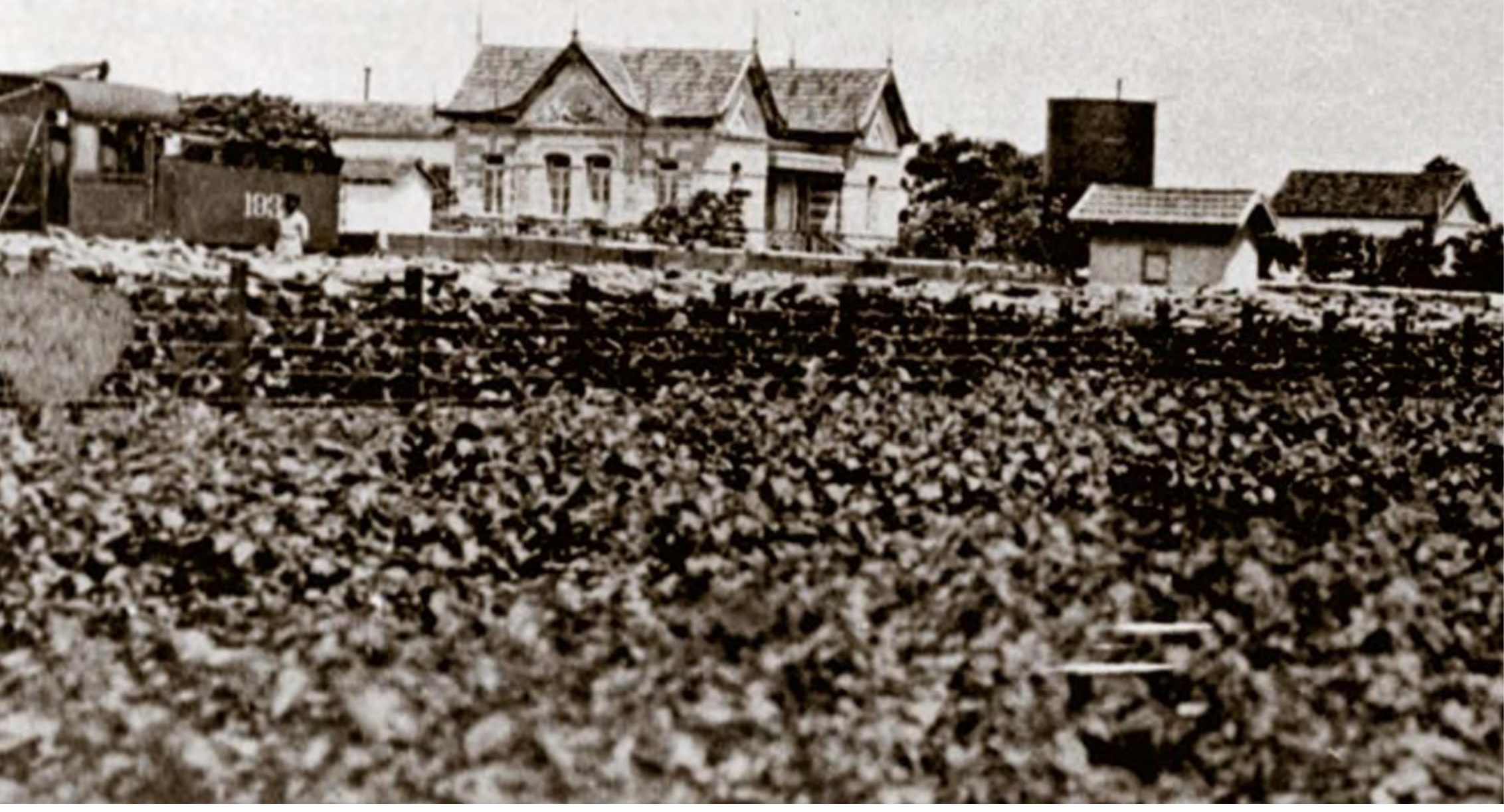

Vista de Lassance, MG. À direita, a estação ferroviária, inaugurada em fevereiro de 1908. À esquerda, vê-se locomotiva do trem da Central do Brasil. A região de Lassance formava uma área praticamente desabitada em meados do século XIX, suas terras servindo como pouso de descanso para os tropeiros que cortavam o sertão mineiro. Foi nessa época que um desses viajantes resolveu fixar-se no local e construir um rancho à beira do córrego São Gonçalo, dando origem a um primitivo aldeamento às margens do rio das Velhas. São Gonçalo das Tabocas foi o nome escolhido para o modesto vilarejo. O nome Lassance só seria adotado em fevereiro de 1908, como homenagem ao engenheirochefe das obras de construção da ferrovia Ernesto Antônio Lassance Cunha. Em 1911, o povoado passaria a integrar o recém-criado município de Pirapora e em 1953 assumiria a condição de cidade Acervo Casa de Oswaldo Cruz

View of Lassance, Minas Gerais. To the right, the train station, inaugurated in February 1908. To the left, a Central do Brasil locomotive. Practically uninhabited in the mid-1 $19^{\text {th }}$ century, the Lassance region offered a resting place to drovers crossing the hinterlands of Minas. It was around then that one of these travelers decided to settle there and build a hut alongside the São Gonçalo s tream: this became the start of a primitive village on the banks of the Rio das Velhas. The modest little town was first named São Gonçalo das Tabocas and later rechristened Lassance, in February 1908, in honor of Ernesto Antônio Lassance Cunha, head engineer of railway construction works. In 1911, the settlement became part of the newly created municipality of Pirapora and in 1953 it gained the status of city

Vista de Lassance tomada do alto de um vagão ferroviário Acervo Casa de Oswaldo Cruz

View of Lassance from atop a train car 


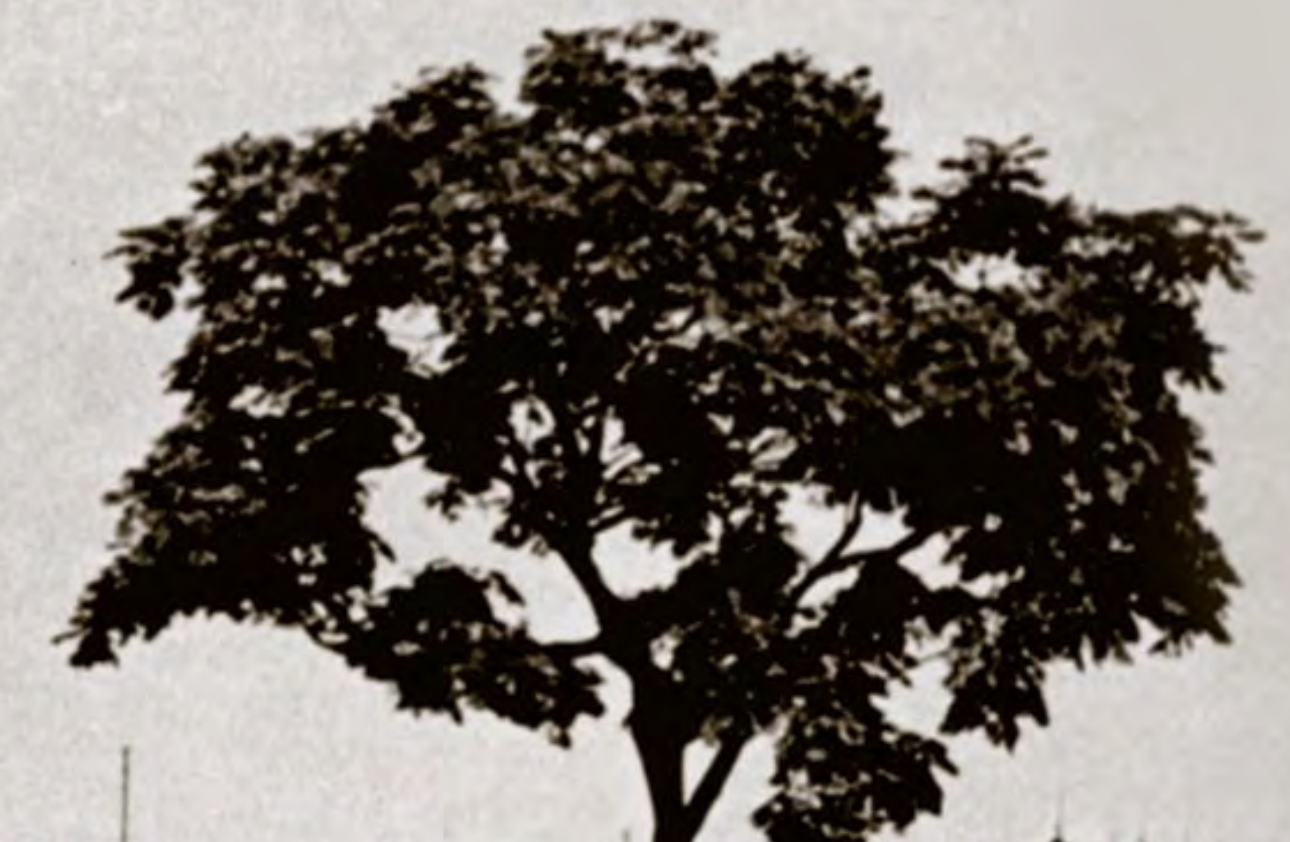
Af

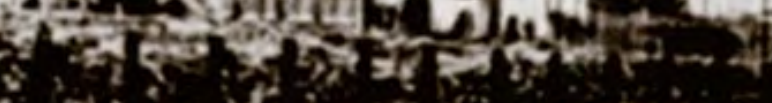

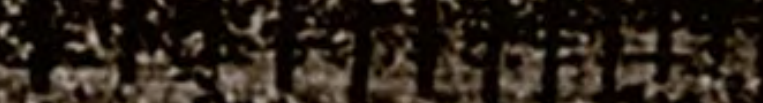

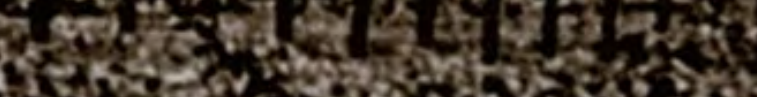

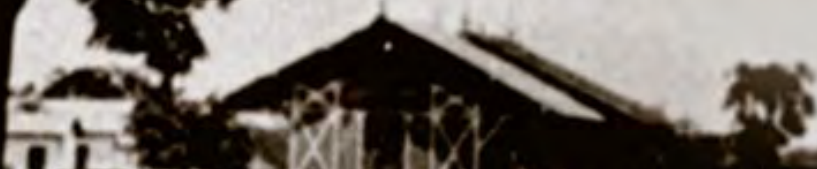

ing

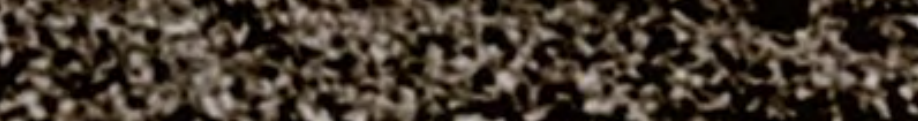

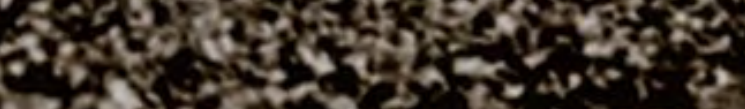

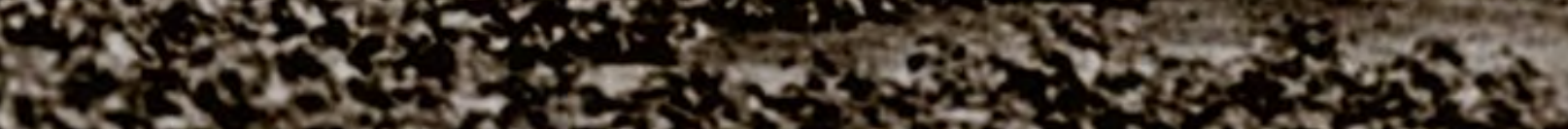

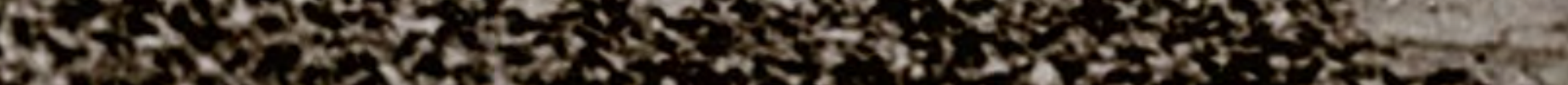

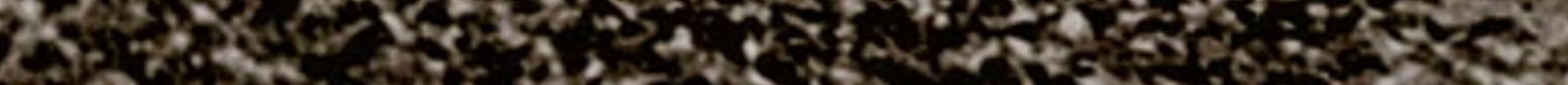

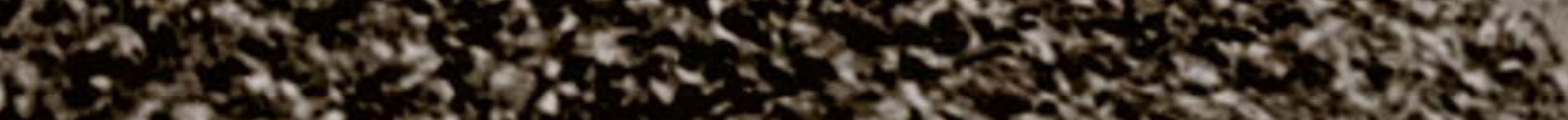

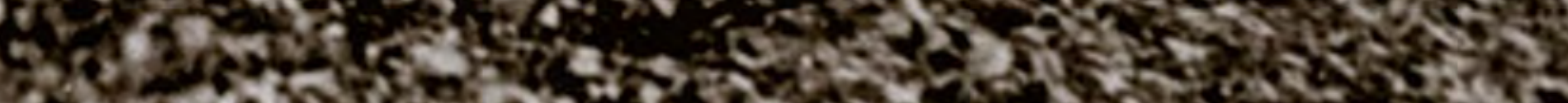
atromas

9- -7 -

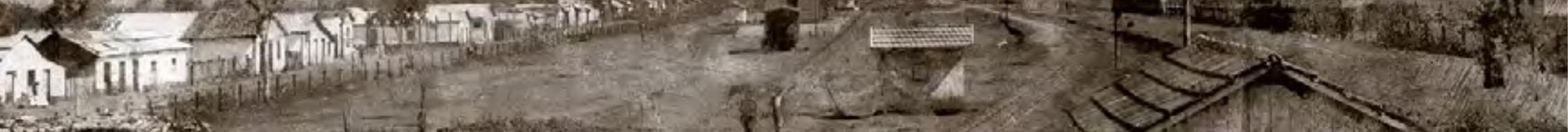

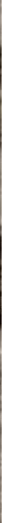




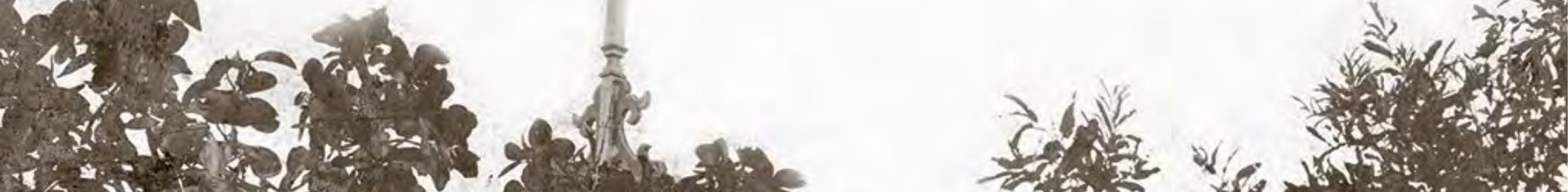

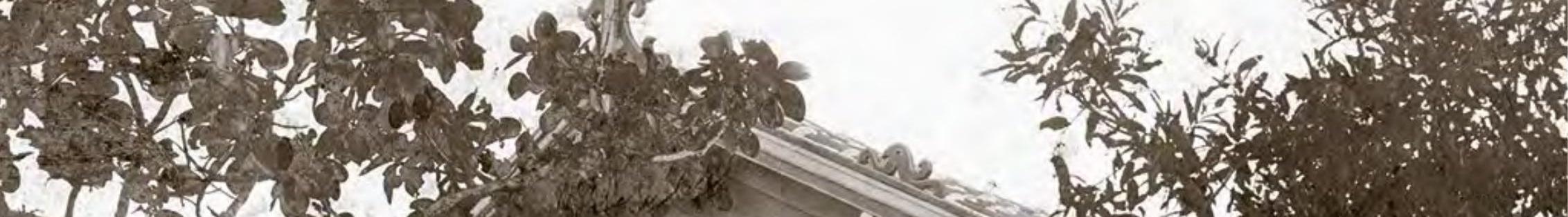
W.

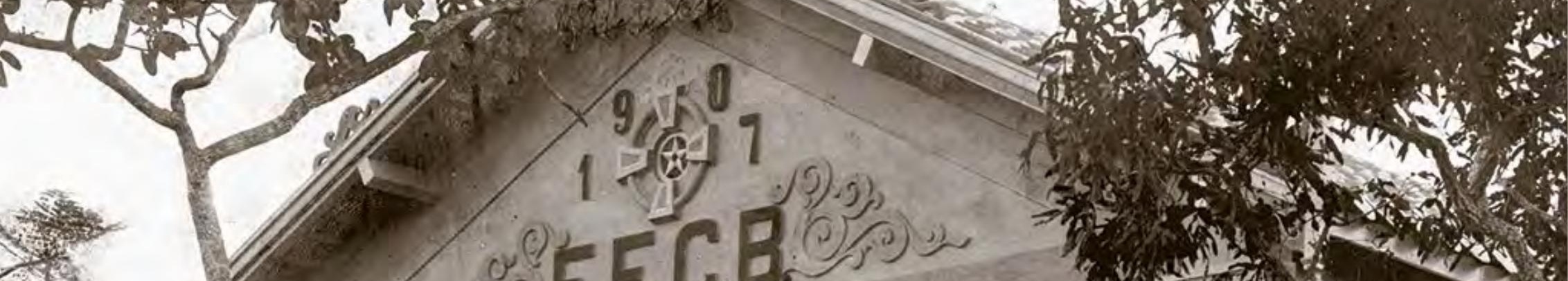

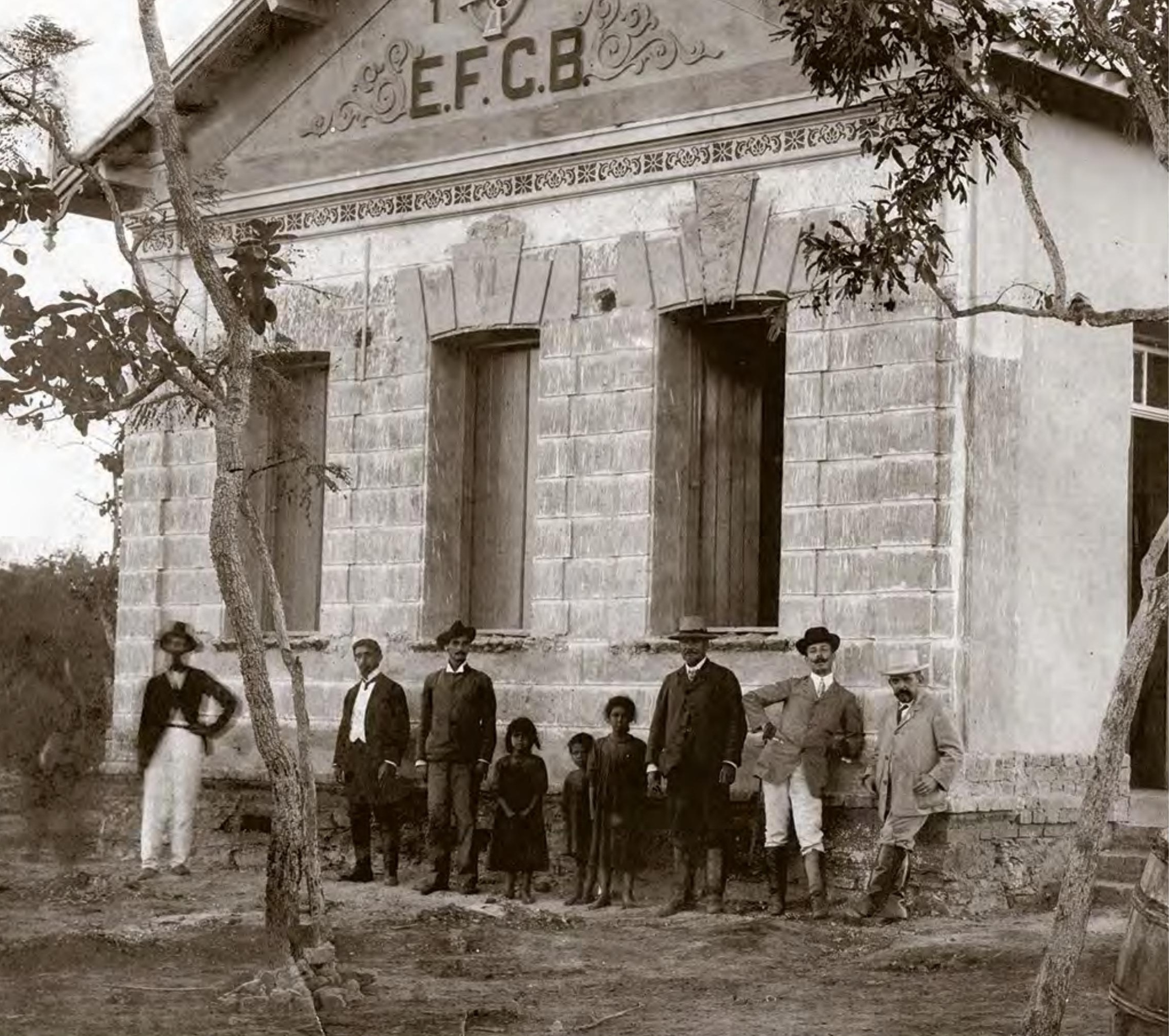




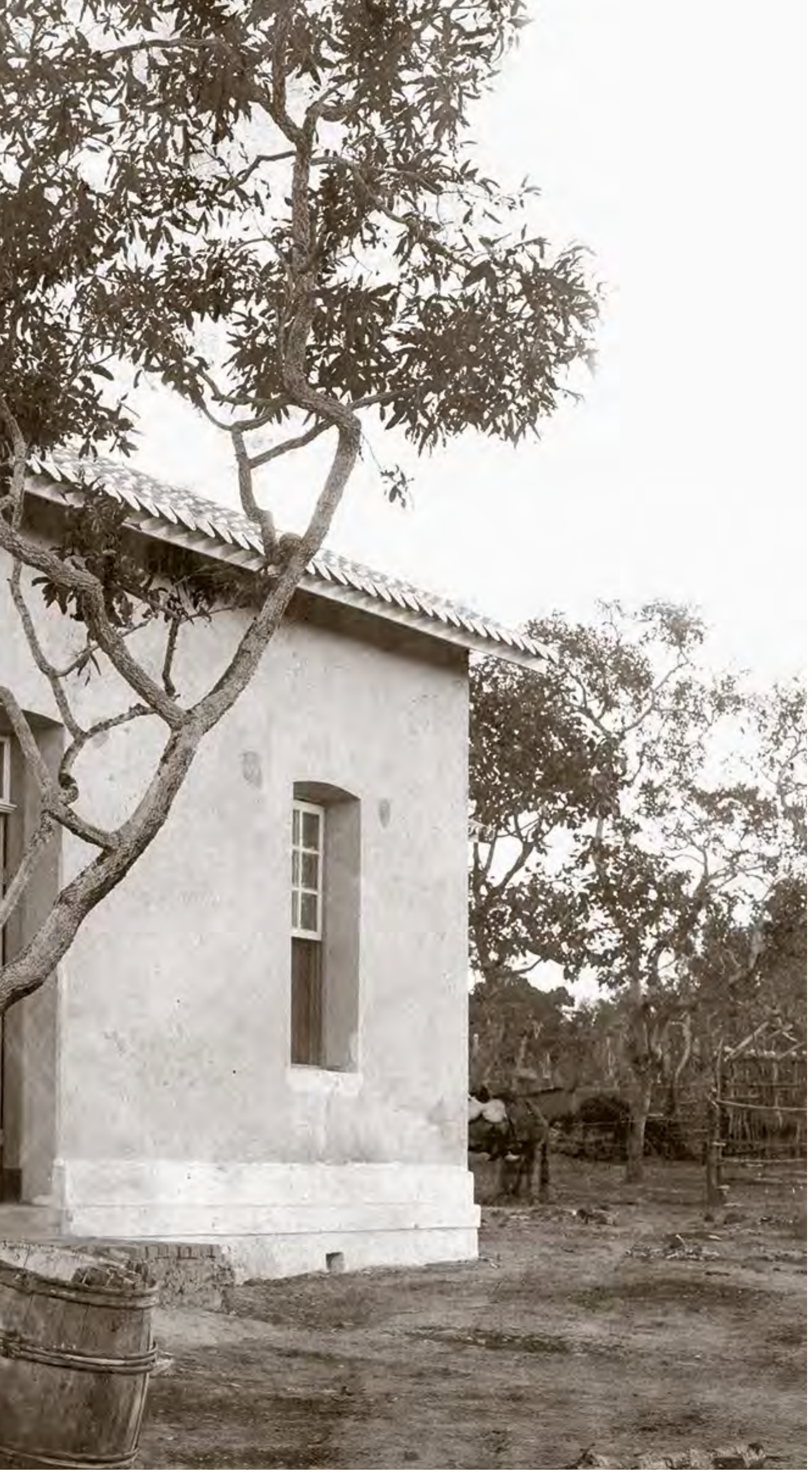

Estabelecemos (...) a quininização diária para os infectados e a quininização de três em três dias para os indivíduos indenes. Depois de uma propaganda bem dirigida sobre a conveniência da medida profilática e devido também à autoridade dos chefes de serviço, nem uma dificuldade encontramos em praticar os meios indicados. (...) Depressa vieram aparecendo os benefícios desta regra, na diminuição considerável dos casos de recaídas, na ausência absoluta de novas infecções. A saúde geral do operariado melhorou notavelmente, desaparecendo a dificuldade trazida pelo mau estado sanitário à regularidade dos trabalhos.

Carlos Chagas

We established (...) a regimen of daily quinine treatment for those who were infected and treatment every three days for those who were not. Subsequent to a wellaimed information campaign on the suitability of this prophylactic measure, and likewise owing to the foremen's authority, we encountered no trouble putting the prescribed actions into practice. (...) The benefits of this approach were soon evident, as cases of relapse decreased substantially and there were absolutely no new infections. The laborers' general health improved noticeably, eliminating negative effects on the smooth progress of work occasioned by poor sanitary conditions. 


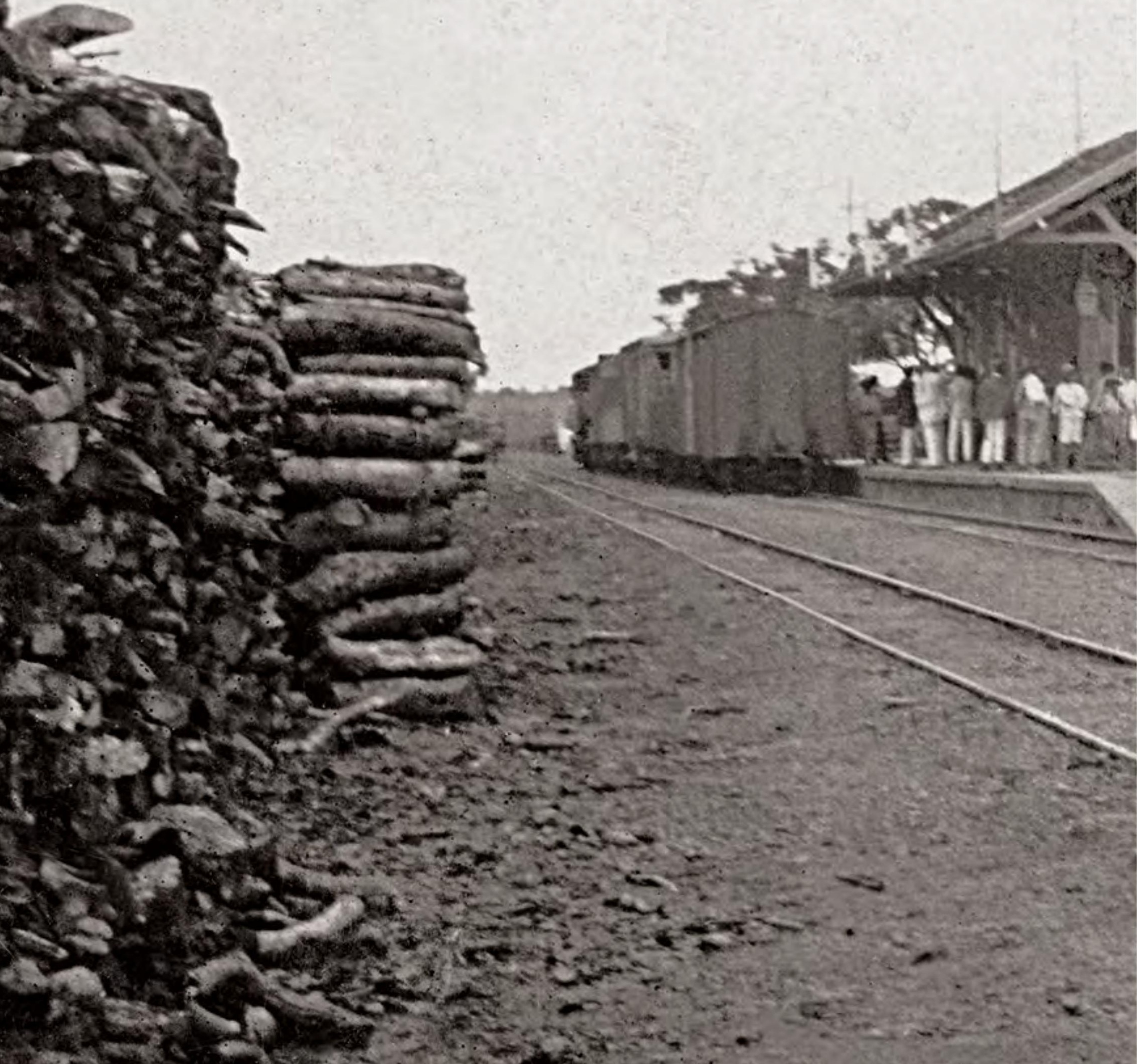




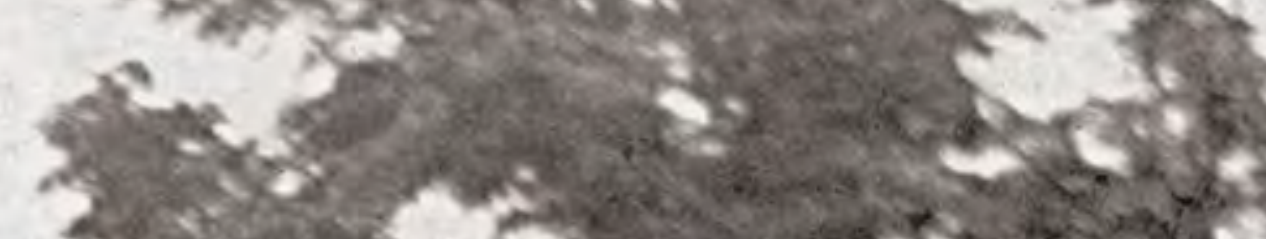

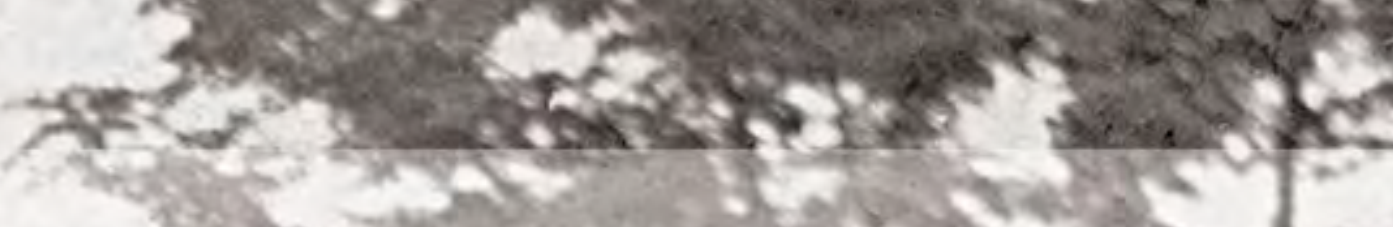
ats $\quad 4$ A descoberta Wherent 4 the discovery

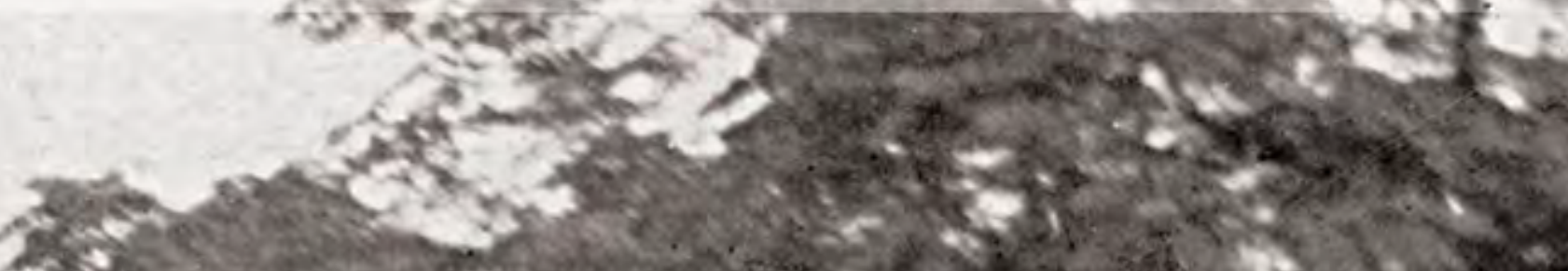

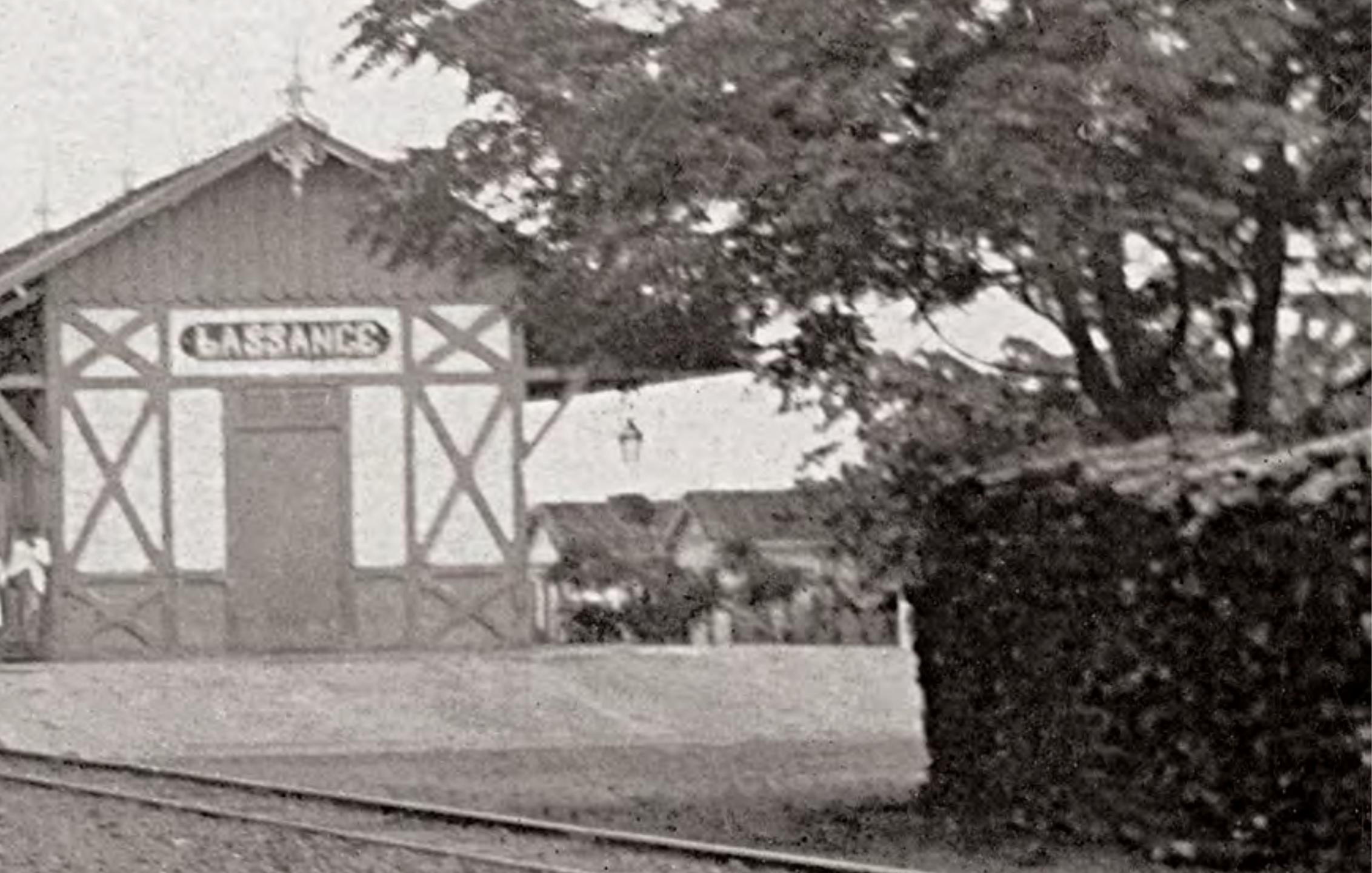

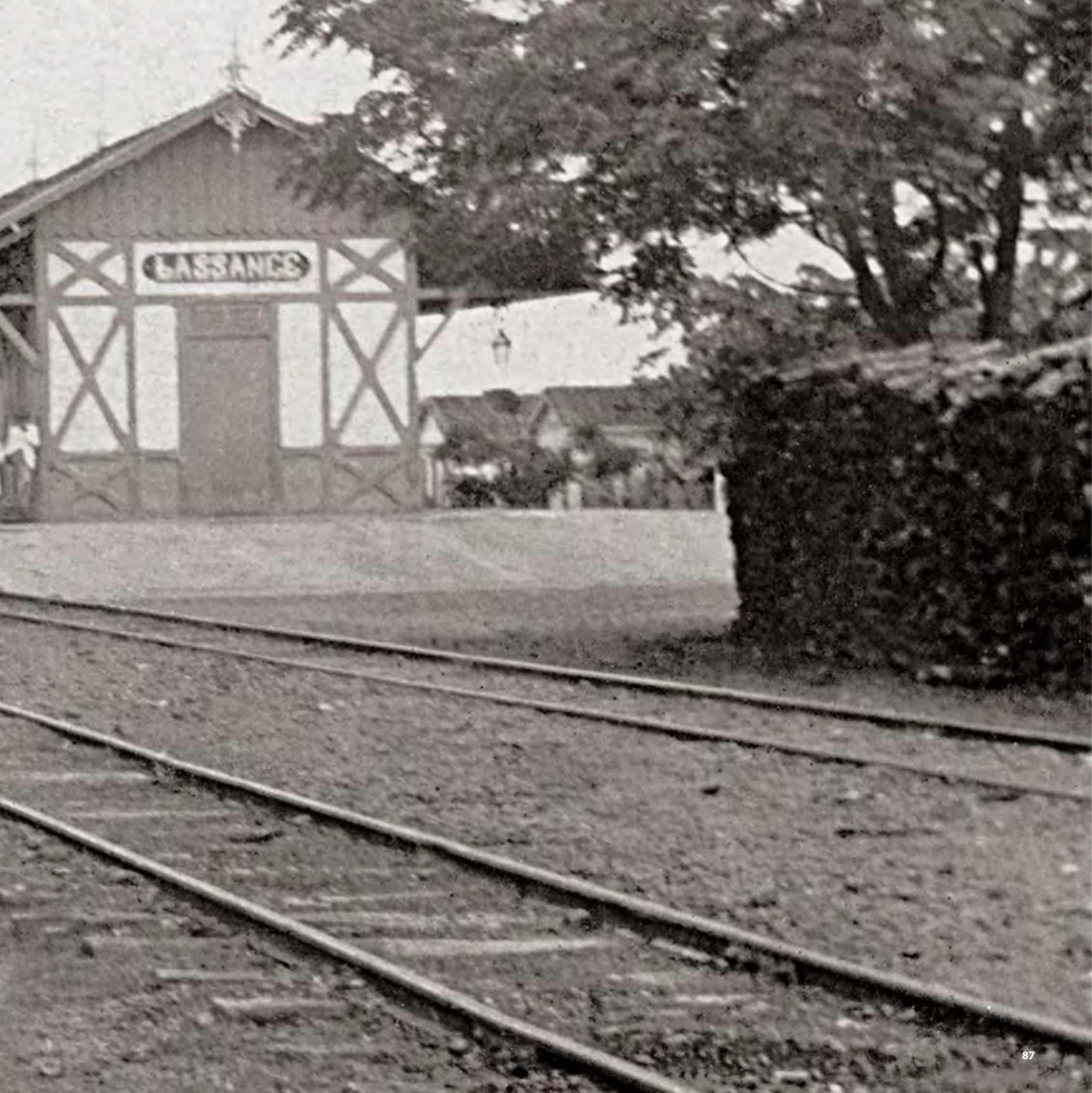


- m Lassance, norte de Minas Gerais, enquanto coordenava as atividades de combate à malária, Carlos 4 Chagas montou um pequeno laboratório em um vagão de trem da Estrada de Ferro Central do Brasil. Motivado por seu crescente interesse pela entomologia e pela protozoologia, ele costumava coletar e examinar espécies da fauna brasileira.

Em 1908, Chagas, que em março havia sido nomeado pesquisador do Instituto Oswaldo Cruz (IOC), identificou, no sangue de um sagui muito comum na região de Lassance, uma nova espécie de tripanossoma, a qual batizou de Trypanosoma minasense. Era um parasito natural, não patogênico, do macaco. A vinda, em meados daquele ano, de pesquisadores alemães - como Stanislas von Prowazek (1875-1915), discípulo do descobridor do agente causal da sífilis, o renomado Fritz Schaudinn (1871-1906) - para estágio no IOC colocou os cientistas brasileiros a par das novidades no estudo dos tripanossomas na Europa e foi decisiva para as investigações realizadas por Chagas. O estudo daquele tipo de protozoário estava na ordem do dia da medicina tropical européia, desde que se demonstrara que, além de doenças animais, eles também causavam enfermidades humanas, como a tripanossomíase africana ou doença do sono.

Ainda em 1908, em viagem a Pirapora, Chagas e Belisário Penna pernoitaram em um rancho. Ali, Penna capturou exemplares de um inseto sugador de sangue, sobre o qual lhes havia falado Cornélio Homem de Cantarino Motta (1869-1959), chefe dos engenheiros da Estrada de Ferro Central do Brasil. Era conhecido popularmente como barbeiro, pelo fato de picar suas vítimas preferencialmente no rosto, enquanto dormem. Como descreveu Chagas, proliferava "nas habitações pobres, nas choupanas de paredes não rebocadas e cobertas de capim", atacando o homem à noite, "depois de apagadas as luzes, e ocultando-se, durante o dia, nas frestas das paredes, nas coberturas das casas, em todos os esconderijos".

Sabendo da importância de insetos que se alimentam de sangue como transmissores de doenças, Chagas examinou alguns barbeiros em seu vagão-laboratório e encontrou, em seu intestino, um protozoário em forma de tripanossoma. Pensou que poderia tratar-se de um parasito do inseto ou de um tripanossoma de vertebrados. Neste último caso, poderia ser o próprio T. minasense identificado nos macacos da região.

Por não dispor, em Lassance, de condições laboratoriais para avançar na pesquisa, Chagas enviou barbeiros a Oswaldo Cruz, em Manguinhos. Depois de colocá-los em contato com macacos criados em laboratório, este percebeu que um animal havia adoecido e apresentava tripanossomas no sangue. Chagas foi informado dos resultados das experiências. Voltando a Manguinhos, concluiu que o protozoário não era o minasense, mas uma nova espécie de tripanossoma, a qual batizou de Trypanosoma cruzi em homenagem a Oswaldo Cruz. A nota anunciando a descoberta do parasito foi redigida em 17 de dezembro de 1908 e publicada em 1909 na revista alemã Archiv für Schiffs- und Tropen-Hygiene.

Depois de estudar o ciclo evolutivo do T. cruzi, Chagas retornou a Lassance para averiguar se este era um parasito patogênico para o homem. Realizou exames de sangue nos moradores da região. Depois de encontrar o protozoário em um gato, evidenciando um reservatório doméstico do parasito, identificou, finalmente, no dia 14 de abril de 1909, o T. cruzi no sangue de uma criança febril. Em nota enviada ao Brazil-Medico, uma das principais revistas médicas do país, anunciou a descoberta que o consagraria. Berenice, uma menina de 2 anos, era o primeiro caso do que seria considerado uma nova doença humana.

O fato foi divulgado também entre a comunidade científica internacional, mediante publicações na Alemanha e na França. Oswaldo Cruz anunciou pessoalmente o feito de seu discípulo no dia 22 de abril, na Academia Nacional de Medicina.

Em 26 de outubro de 1910, Chagas foi recebido como membro dessa prestigiosa associação médicocientífica, que abriu exceção a suas regras admitindo um novo titular sem que houvesse vaga disponível. Apresentou, então, suas pesquisas sobre a nova tripanossomíase, que, por sugestão de Miguel Couto, passou a ser chamada também de "moléstia de Chagas". 
W hile he was coordinating anti-malaria efforts in Lassance, in northern Minas Gerais, Carlos Chagas set up a small laboratory in a Central do Brasil Railroad wagon. Spurred by a growing interest in entomology and protozoology, he had acquired the habit of collecting and examining species of Brazilian fauna.

In 1908, after his appointment in March of that year as a researcher at the Oswaldo Cruz Institute (OCI), Chagas was examining the blood of a marmoset quite common in the Lassance region when he identified a new species of trypanosome, which he named Trypanosoma minasense. It was a natural nonpathogenic parasite of the monkey. In the middle of the year, some German researchers came to do internships at the OCI - for instance, Stanislas von Prowazek (1875-1915), disciple of the renowned discoverer of the causative agent of syphilis, Fritz Schaudinn (1871-1906). They brought Brazilian investigators abreast of Europe's newest studies of trypanosomes, making a fundamental impact on Chagas's research in the area. The study of this type of protozoan had been on the agenda of European tropical medicine ever since it was shown that it caused not just animal diseases but human ones as well, like African trypanosomiasis, also known as sleeping sickness.

It was in the same year of 1908, on a trip to Pirapora, that Chagas and Belisário Penna spent the night in a rustic home. There, Penna captured specimens of a bloodsucking insect that they had heard about from Cornélio Homem de Cantarino Motta (1869-1959), chief engineer for the Central do Brasil Railroad. It was popularly called a barbeiro, or "barber bug" (sometimes referred to as a kissing bug in English), since it liked to bite its victims on the face while they were sleeping. As Chagas described it, the insect grew in abundance "in primitive, grass-thatched huts with unplastered walls," where it would attack people at night, "after the lights have been turned off, disappearing during daytime in the cracks of walls, the roofs of houses, and all sorts of hiding places."

Chagas was aware that bloodsucking insects play an important role in disease transmission and so he examined some of the bugs in his laboratory car. He found a trypanosome protozoan in their guts, and thought it might be a parasite of the insect or a trypanosome of vertebrate hosts. In the latter case, it might be the same T. minasense identified in the region's monkeys.

Since Lassance lacked adequate laboratory facilities for further research progress, Chagas sent some specimens of the insects to Oswaldo Cruz at Manguinhos. After the barbeiros had been placed in contact with laboratory-raised monkeys, Cruz saw that one of the animals fell ill and presented trypanosomes in their blood. Chagas was informed of the findings. Upon his return to Manguinhos, he concluded that the protozoan was not the minasense but a new species of trypanosome, which he named Trypanosoma cruzi in honor of Oswaldo Cruz. The note announcing discovery of the parasite was written up on December 17, 1908, and published in 1909 in the German journal Archiv für Schiffs- und Tropen-Hygiene.

After studying the life cycle of $T$. cruzi, Chagas went back to Lassance to ascertain whether this parasite was pathogenic to humans. He did blood tests on residents there. After finding the protozoan in a cat, which indicated the parasite had a domiciliary reservoir, he eventually identified $T$. cruzi in the blood of a feverish child, on April 14, 1909. In a note to Brazil-Medico, one of Brazil's top medical journals of the day, he announced the discovery that would earn him renown. Berenice, a 2-year-old girl, was the first case of what was considered a new human disease.

The international scientific community learned of Chagas's feat through German and French publications. Oswaldo Cruz personally announced his disciple's accomplishment on April 22 at Brazil's most prestigious medical and scientific association, the National Academy of Medicine.

On October 26, 1910, Chagas was inducted into the Academy, which had made an exception to its rule about accepting a new member only when a seat opened up. There he presented his research on the new trypanosomiasis, which also became known as "Chagas disease," at the suggestion of Miguel Couto. 
Imagem de abertura - Estação da Estrada de Ferro Central do Brasil em Lassance Acervo Casa de Oswaldo Cruz

Opening image - Central do Brasil

Railroad station in Lassance

Em 1999, por ocasião da celebração dos 90 anos da descoberta da doença de Chagas, a Casa de Oswaldo Cruz contratou o desenhista Carlos Chagas para reproduzir, em uma narrativa iconográfica, o processo que levou à descrição da nova enfermidade. Para isso, o homônimo do cientista realizou extensa pesquisa no acervo da instituição e, com base em fotografias, textos de época e conversas com os historiadores, criou estas ilustrações

In 1999, during commemorations of the ninetieth anniversary of the discovery of Chagas disease, the Casa de Oswaldo Cruz hired the illustrator Carlos Chagas to create an iconographic narrative reconstructing the process that led to description of the new illness. As part of this task, the scientist's namesake undertook detailed research of the Casa de Oswaldo Cruz archives and then designed his illustrations based on photographs, historical texts, and conversations with historians

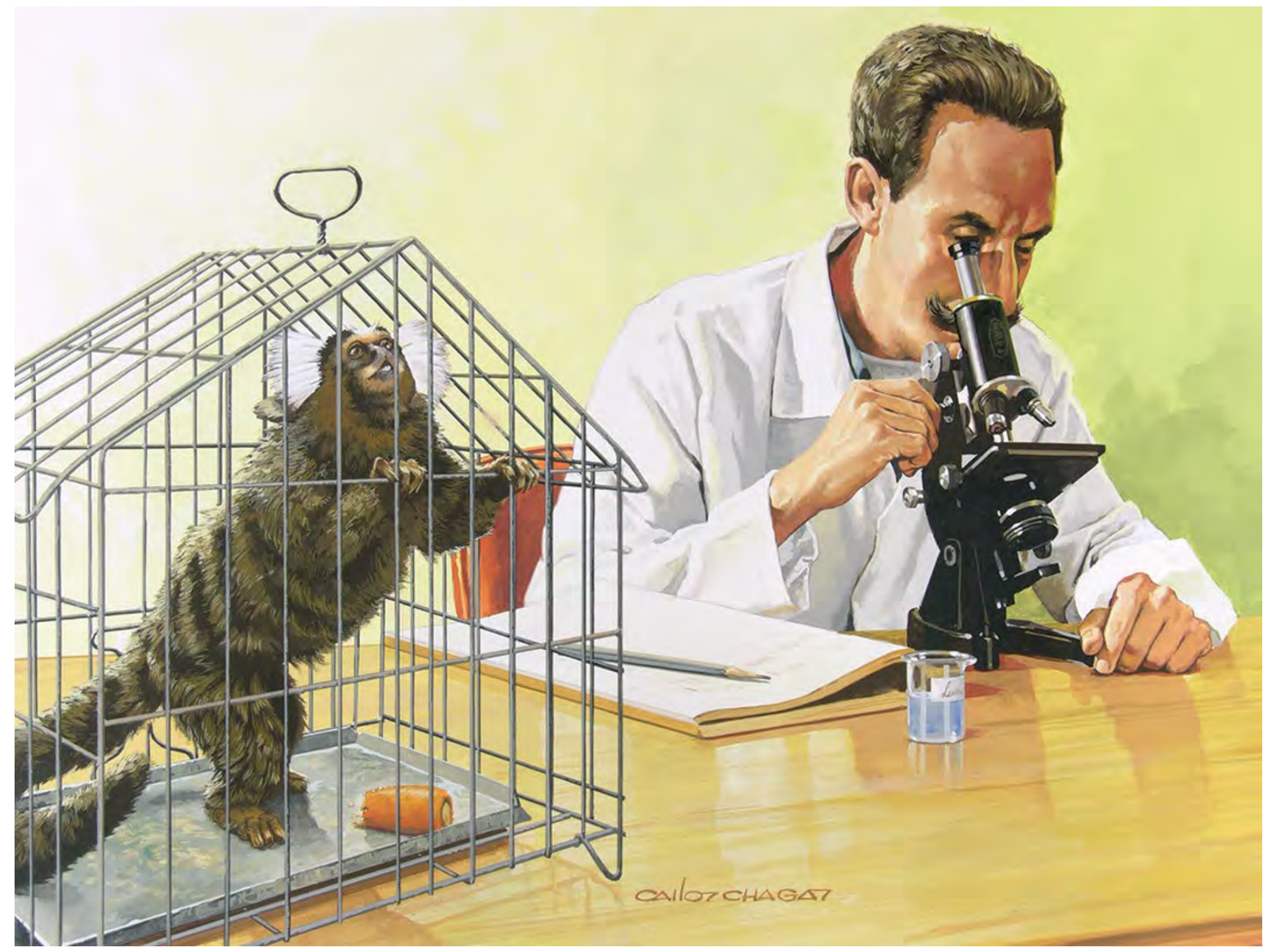

Em Lassance, Carlos Chagas identifica, em saguis, o Trypanosoma minasense

In Lassance, Carlos Chagas identifies Trypanosoma minasense in marmosets 


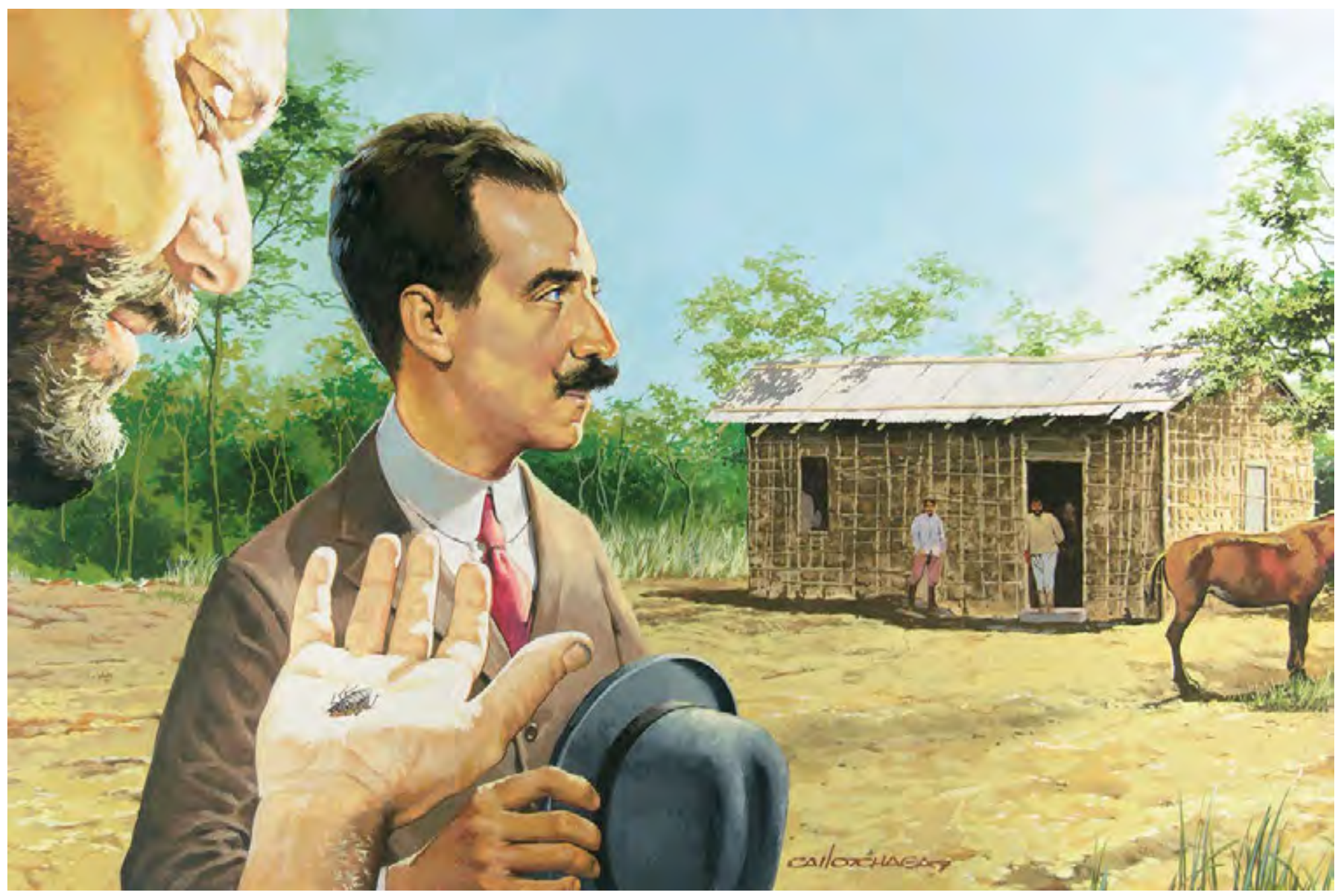

Chagas toma conhecimento da existência dos barbeiros nas casas de pau a pique da região

Chagas learns of the existence of barbeiros in the region's wood and mud houses 


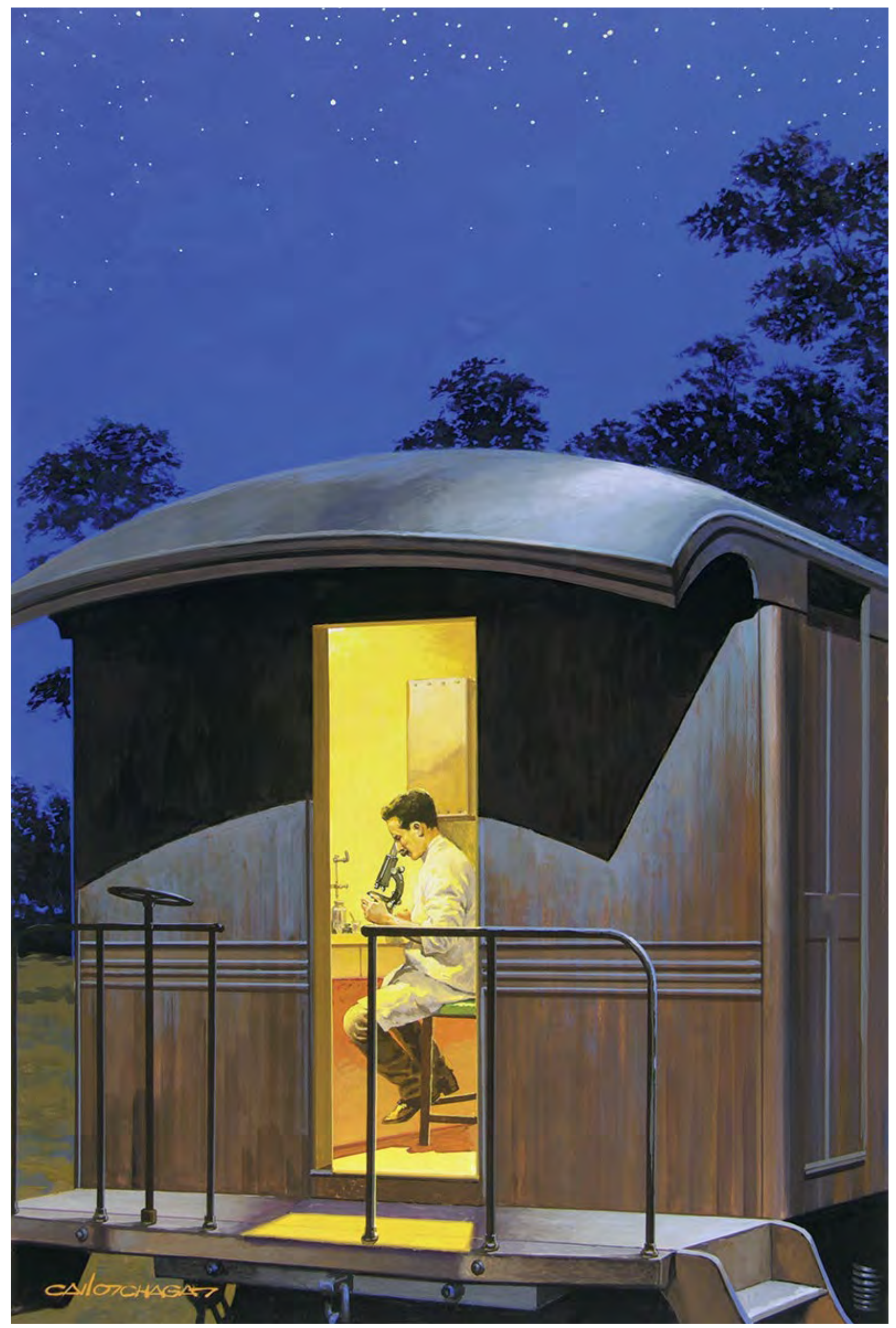

Ao examinar alguns barbeiros, encontra um protozoário em forma de tripanossoma

While examining some of the bugs, Chagas finds a protozoan in the form of a trypanosome 


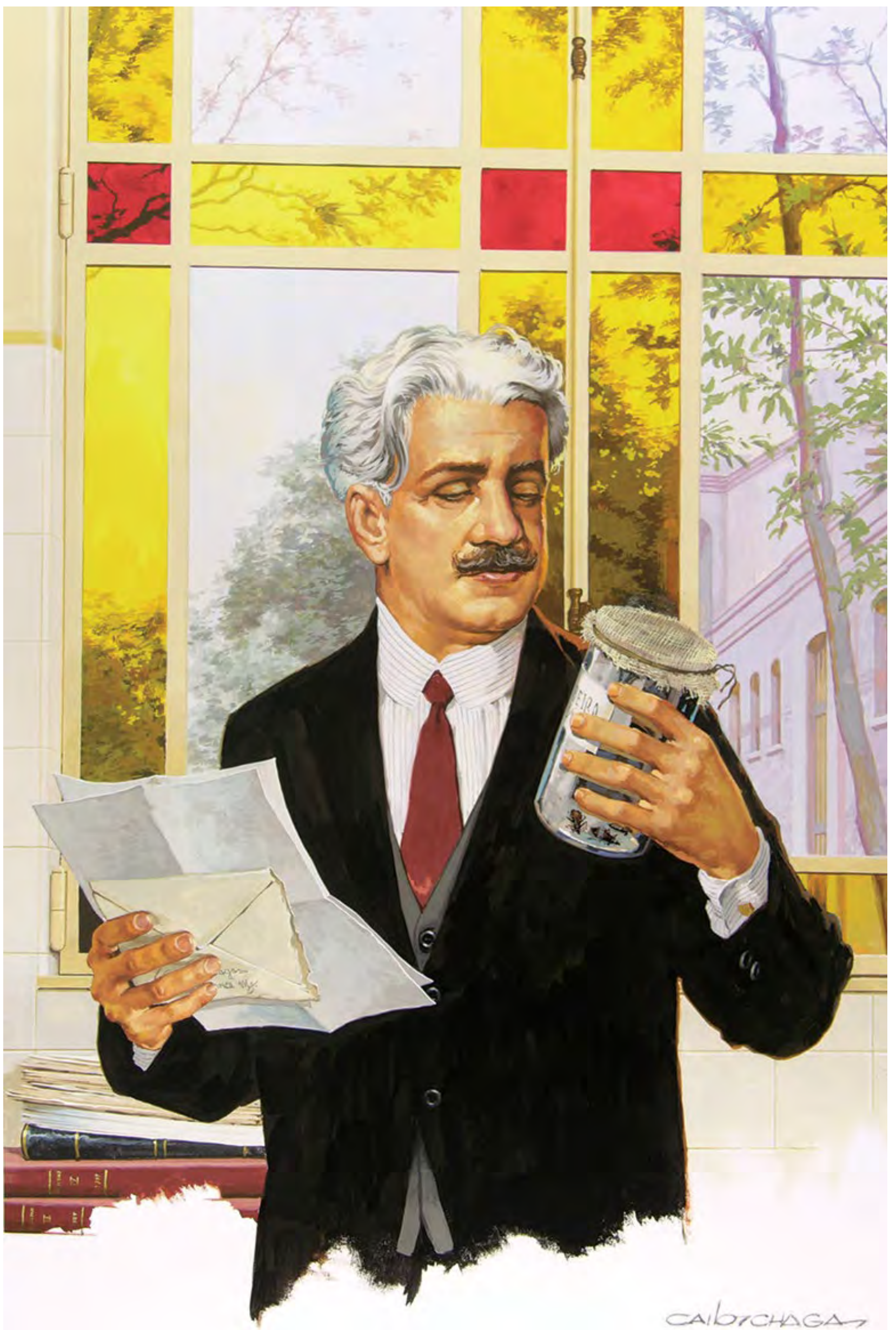

Oswaldo Cruz recebe alguns barbeiros enviados por Chagas de Lassance para experiências com macacos criados nos laboratórios de Manguinhos

Oswaldo Cruz receives some barbeiros that Chagas sent from Lassance to be used in experiments with Manguinhos laboratory monkeys 


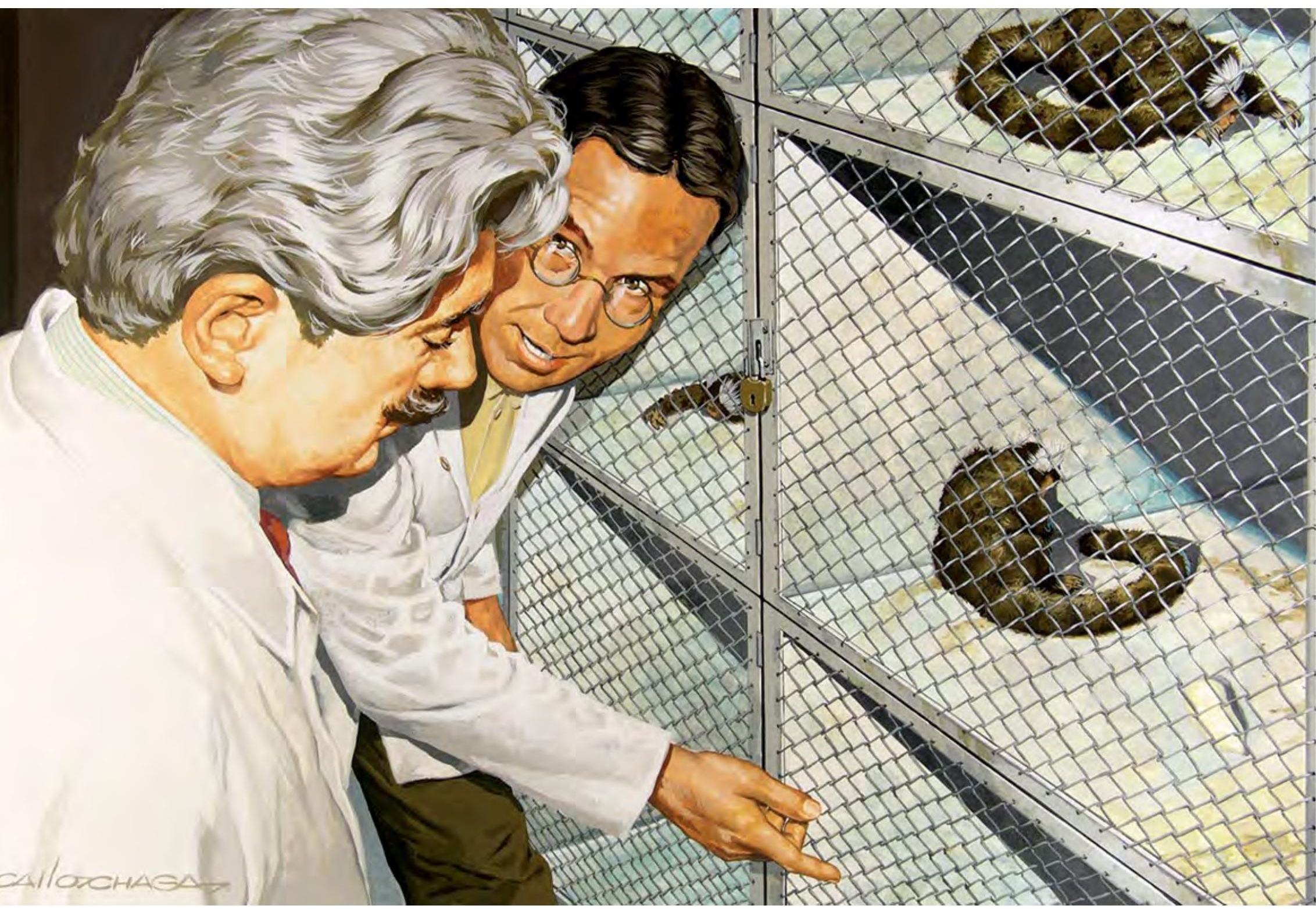

Oswaldo Cruz percebe que um dos macacos adoeceu, apresentando tripanossomas no sangue

Oswaldo Cruz notes that one of the monkeys has fallen

ill and presents trypanosomes in its blood 


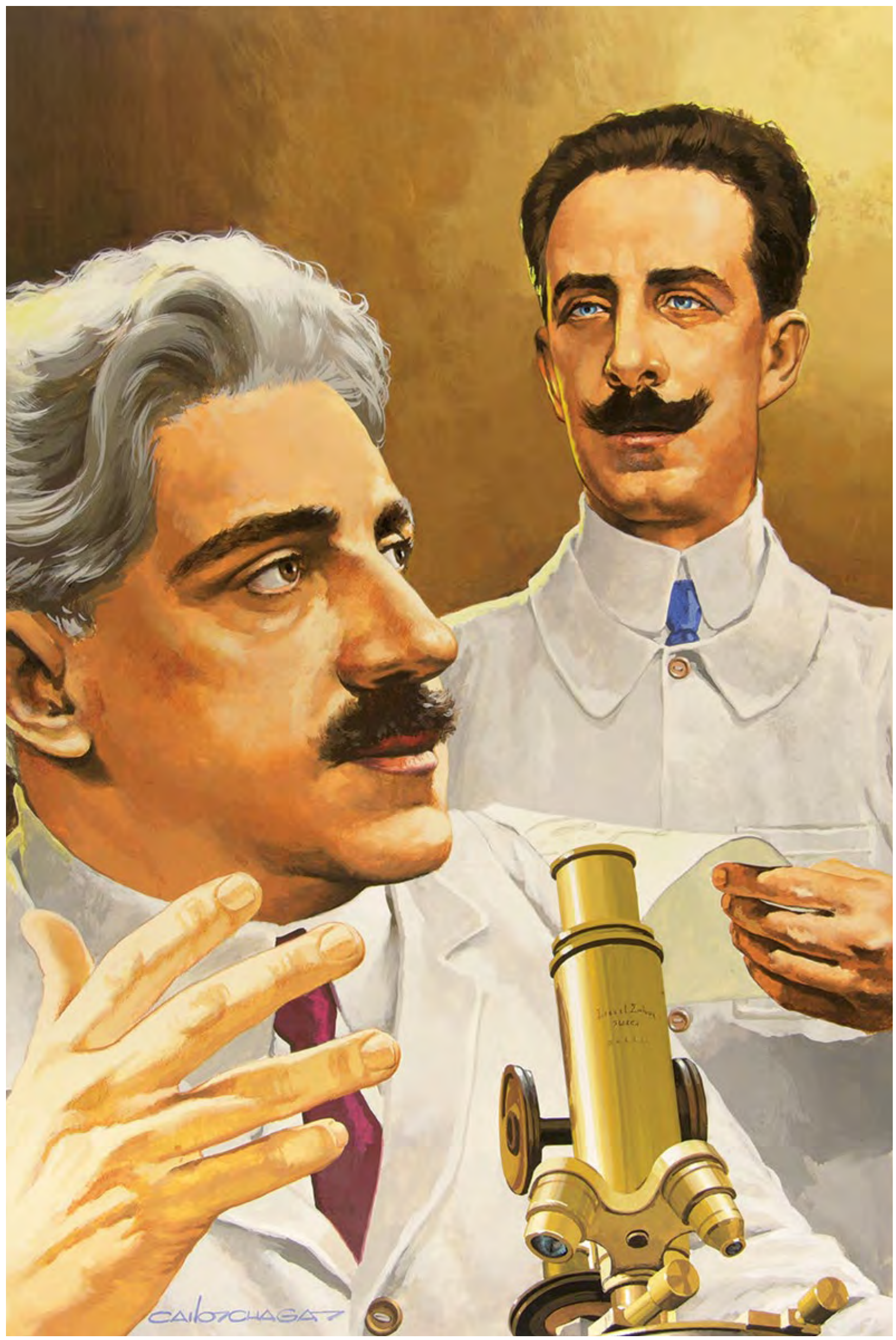

Chagas conclui que se trata de uma nova espécie de

tripanossoma, a qual denomina de Trypanosoma cruzi

Chagas concludes that this is a new species of

trypanosome, which he calls Trypanosoma cruzi 


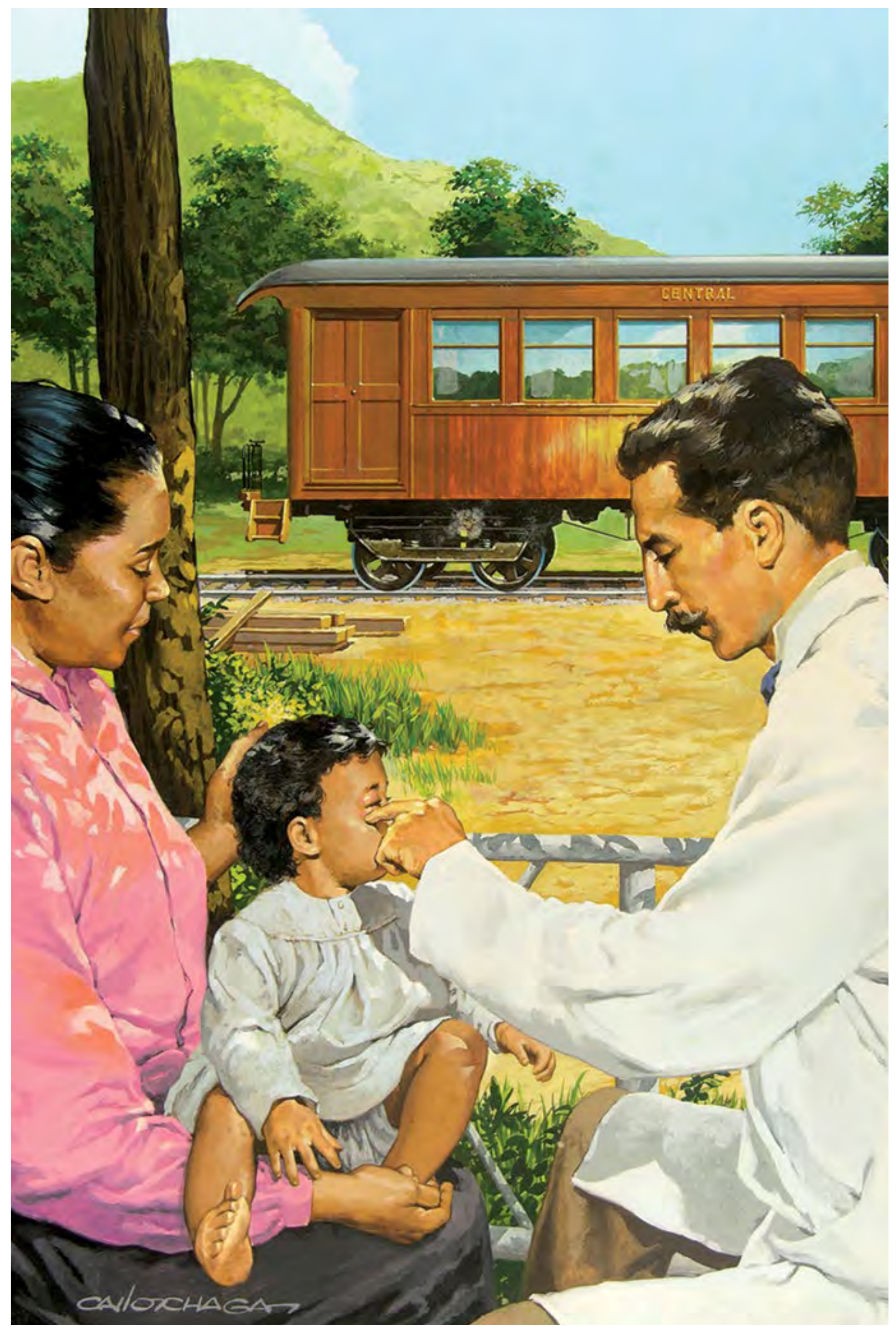

Em 14 de abril de 1909, Chagas encontra o T. cruzi no sangue de uma menina chamada Berenice e conclui estar diante de uma nova doença humana

On April 14, 1909, Chagas finds T. cruzi in the blood of a young girl named Berenice and concludes that this is a new human disease 


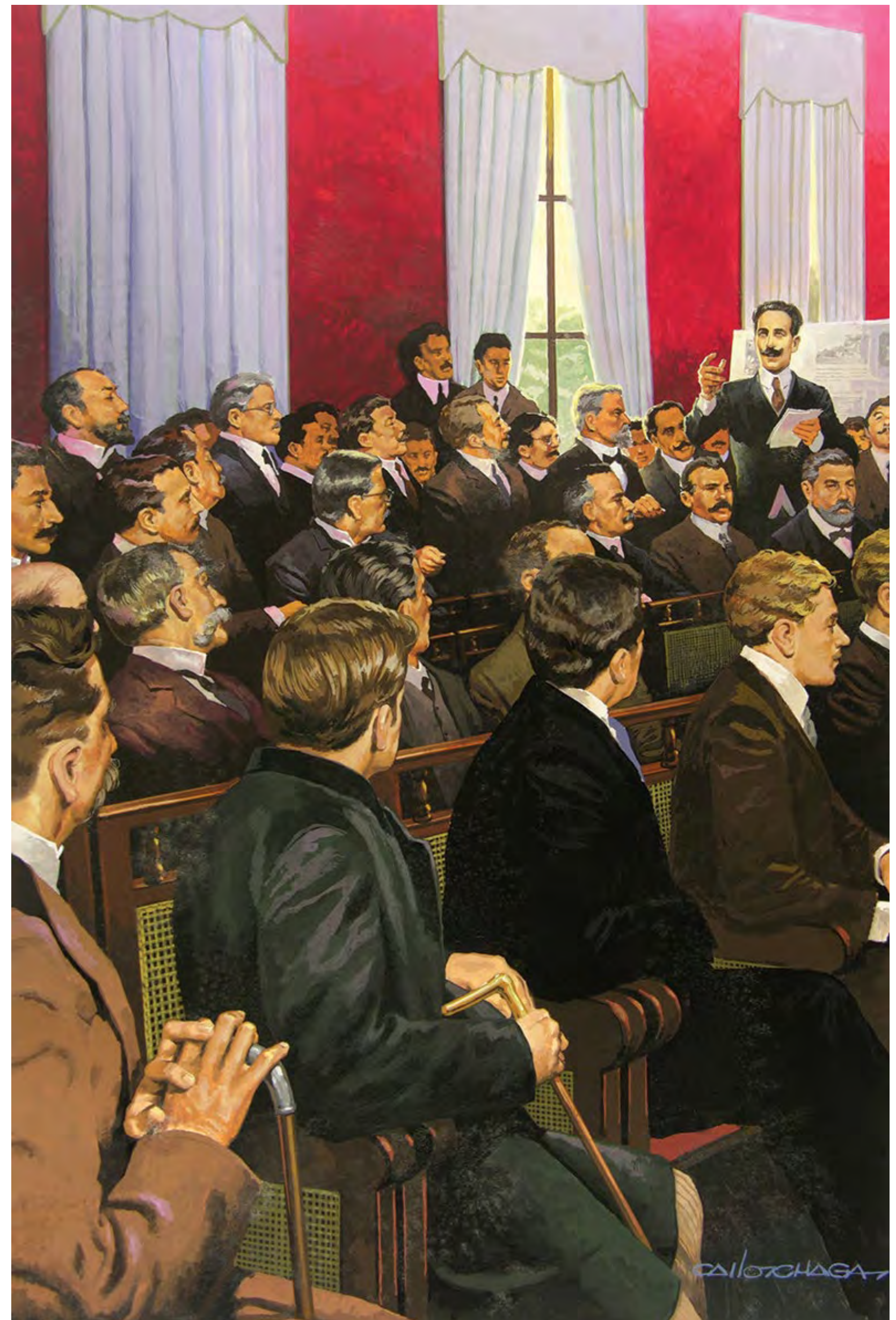

Em outubro de 1910, Chagas torna-se membro da Academia Nacional de Medicina e apresenta suas pesquisas sobre a nova doença

In October 1910, Chagas is made a fellow of the National Academy of Medicine and presents his findings on the new disease 


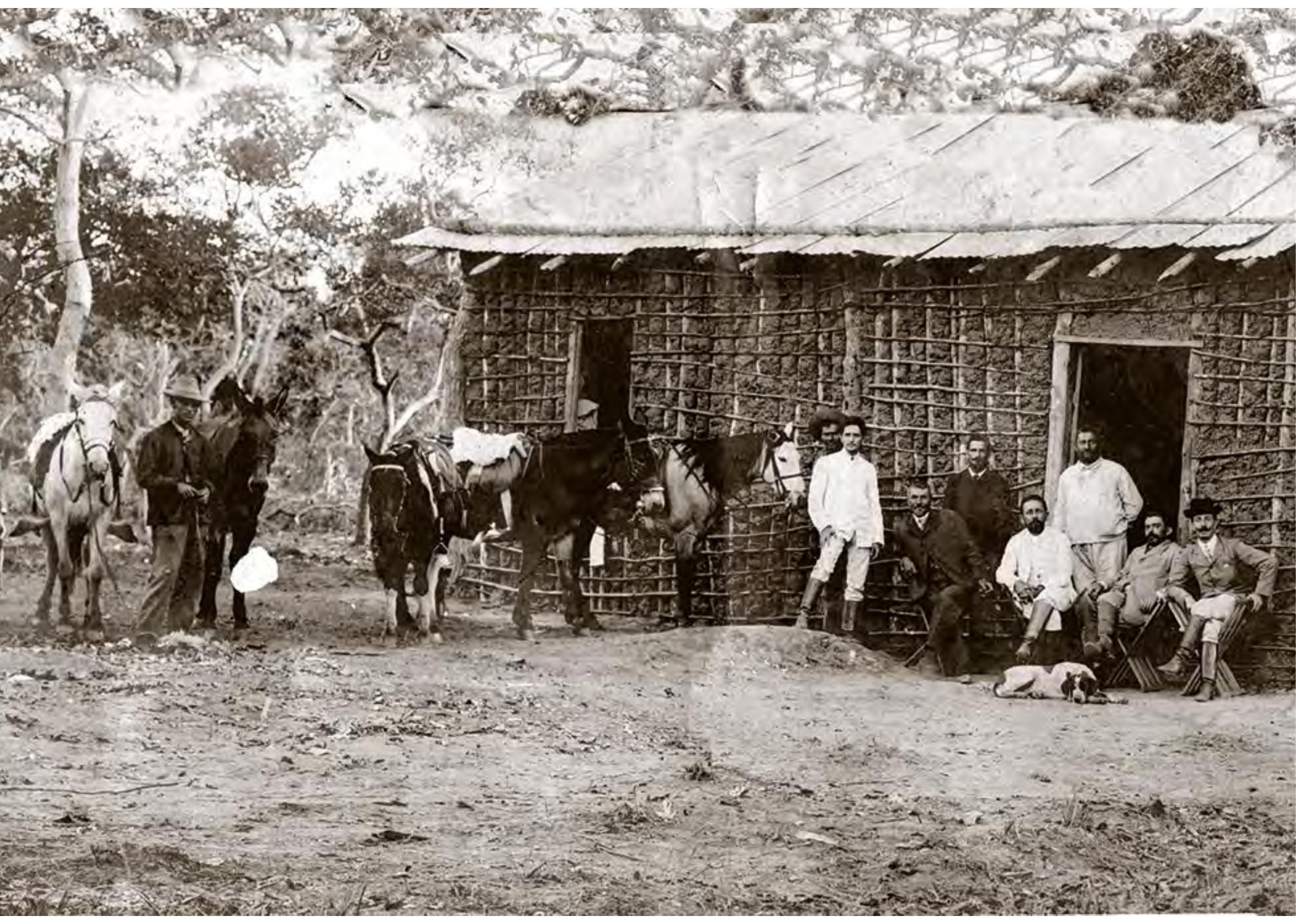

Chagas e a equipe que trabalhava no prolongamento da Estrada de

Ferro Central do Brasil no norte de Minas Gerais. Teria sido nesse

rancho, no caminho para Pirapora, que Belisário Penna capturou os

primeiros barbeiros examinados por Chagas. Sentados, da direita

para a esquerda: Carlos Chagas, Belisário Penna, Cornélio Homem

Cantarino Motta (chefe da comissão de engenheiros) e o médico

Bahia da Rocha. Em pé, os engenheiros Amaral Teborge, José de

Oliveira Fonseca e Joaquim Silvério de Castro Barbosa

Acervo Casa de Oswaldo Cruz

Chagas with the team working to extend the Central do Brasil

Railroad in northern Minas Gerais. Located on the way to Pirapora,

this is said to be the house where Belisário Penna captured the first barbeiro bugs examined by Chagas. Seated from right to left: Carlos

Chagas, Belisário Penna, Cornélio Homem Cantarino Motta (head

of the engineers commission), and physician Bahia da Rocha.

Standing: engineers Amaral Teborge, José de Oliveira Fonseca, and Joaquim Silvério de Castro Barbosa 


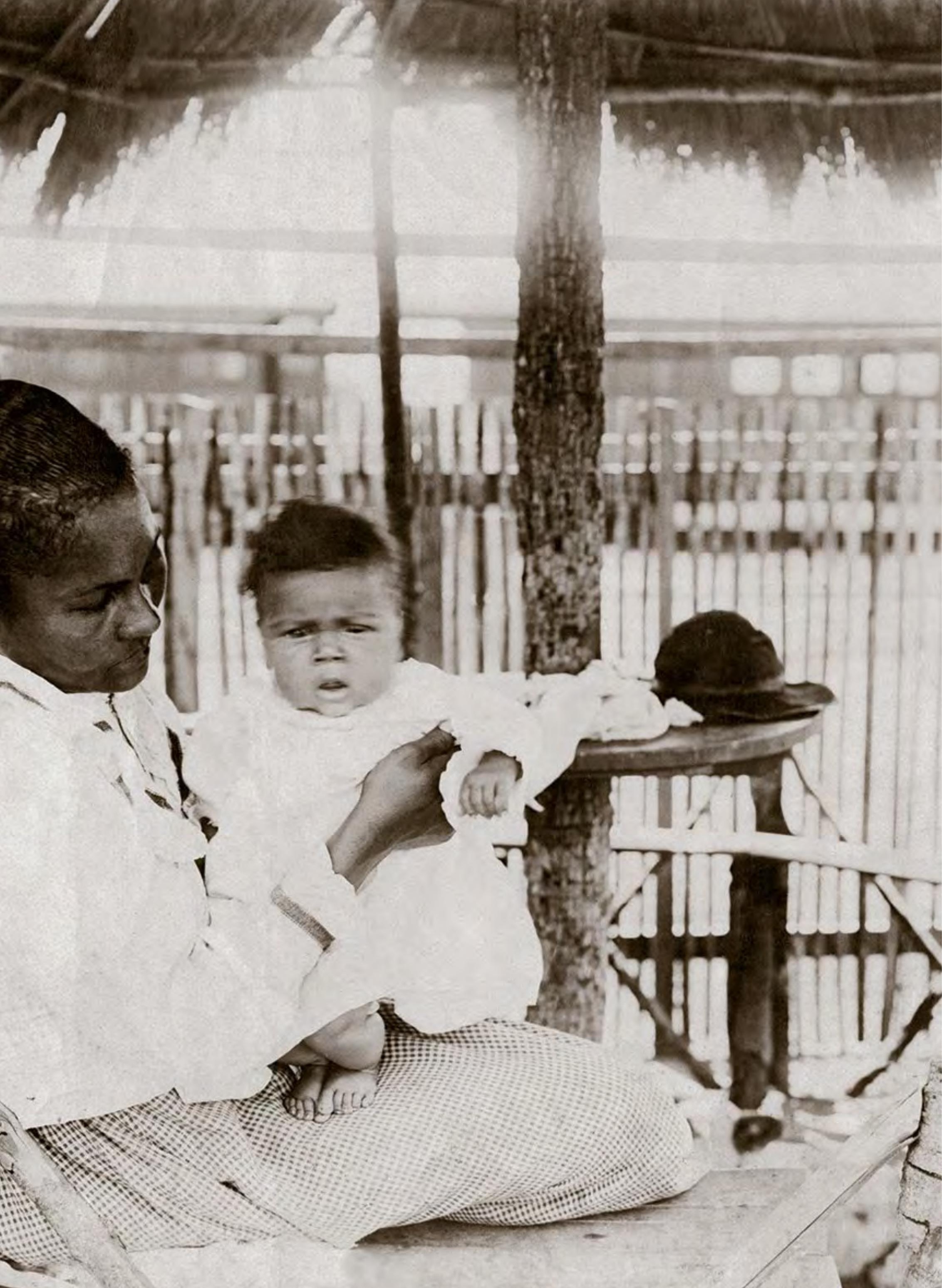


Carlos Chagas observa a menina Rita, um dos primeiros casos da doença de Chagas. Lassance, década de 1910. Por muito tempo, pensou-se que esta criança era Berenice, o primeiro caso identificado em abril de 1909

Acervo Casa de Oswaldo Cruz

Carlos Chagas observing the young girl Rita, one of the first cases of Chagas disease. Lassance, 1910s. It was long believed that this child was Berenice, the first case, identified in April 1909

Berenice em 1979. Quase sessenta anos depois da descoberta, ela passou a ser acompanhada por pesquisadores mineiros e submetida a diversos exames. Levava uma vida normal e apresentava manifestações clínicas compatíveis com as de pessoas de sua idade, mesmo sendo verificada a presença do T. cruzi. Berenice contava que, apesar das poucas lembranças que tinha de Carlos Chagas, havia guardado os presentes que ele lhe dera, como uma medalha e uma boneca. Contou ainda que o cientista propôs levá-la para ser educada no Rio de Janeiro, mas seus pais se opuseram à idéia. Faleceu em 1981, aos 73 anos, de insuficiência cardíaca

Acervo Casa de Oswaldo Cruz

Berenice in 1979. Almost sixty years after the discovery of Chagas disease, researchers in Minas Gerais began monitoring her and submitted her to a number of tests. She was leading a normal life and presented clinical signs compatible with people her age, even though the presence of $T$. cruzi was detected. Berenice said she remembered little about Carlos Chagas but had kept the gifts he gave her, such as a medal and a doll. She also said the scientist had proposed to take her to Rio de Janeiro for schooling, but her parents were against it. She died of congestive heart failure in 1981 at the age of 73

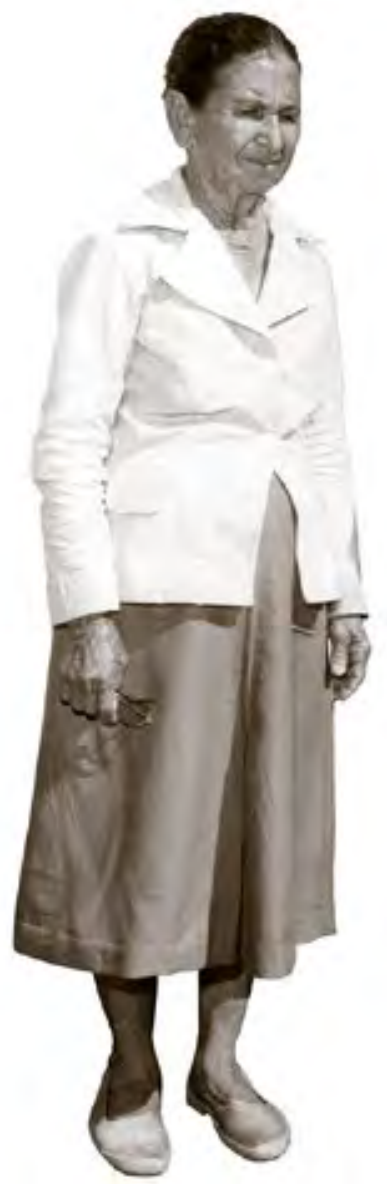




\section{Brazil-Medico

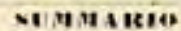

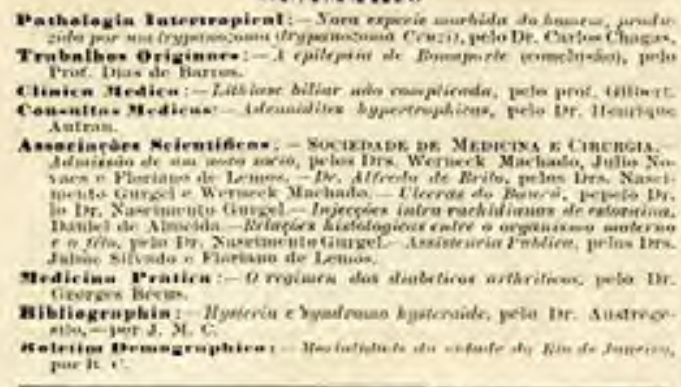

PATHOLOGIA INTERTROPICAL

Nova especie morbida do homem, produzida por um trypanozoma trypanozoma Cruzi

$$
\text { Notor prexian }
$$

Tratultio do trastiluto Orsuas Gare

P'Elo Da. Callos Chagas

$$
\text { As istentr sto Institele }
$$

Vimos, lesde mezes, estadaulos a cvela exolu. tivo de an hemo-flagellado, o trypanozoma erwai que tem para tospedeiro intermediario am hemalo. phago, o cosorrtonus sanguisergu ?. Fizemos, de nossah pesclusas ainda nao concluitlas, uma pulticaçán privia 1], aguardando opportunidade, apus esclarecimento de alguns pontos, jara publicacto definitive. Alnfecgao que serviu de inicio a bossos estudos rora obtida experimentalanente pelo Dr. Oswalde Crez, lazetulo jicar por alguns conorrhihos, levarlos de Minas, um sagui hapalle peniciltata . Por inoculaçoes de samguc e aimda por pieada de conorrhinos obtivemos a infeceño etm inversos animaes, taes como a colaya, o cao, o coello, sendo ella sempre motial para alguns destes vertelirados. lgnoravamos, porem, quaí fosse n hospraleiro habi. tual do fry parizonna o o esclarecimento deste pouto levou-jos a realizar novas jestuisas, na zonta onde lavianos collhido o hematophago, pesquisas cujo resultado essencial, pela sua iniportancia, increcem immediata publicidade.

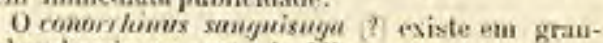
de abundancia no norte de Minas, nas zonas percorridas pelo prolongamento da $\mathrm{F}$. de $\mathrm{F}$. Central do Brazil. E um hematoplago, conbecito pelo nome

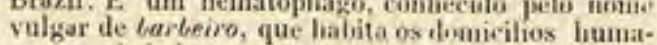
nos, preferinto sempre o sangue do lomem para suas refeiçees. Nas easas o nonorrkimus habila as cavidades das paredes, cheontranto guarida favoravel nas parcoles nâ reloecadas, esís ataca o lomem a noite, depois der apagadas as luzes. Constitue un terrivel flagello, em extremo inconmodo ao lomem, cujo repouso nocturno elle difliculta. Ontros animaes dousesticos, aquelles que permoitam no inlerior

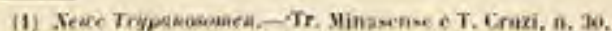
in -Ardiv. L Adiff a Tropentygiene, $1909,102,120$. dos domicilios, sim lambem pivarlos jeeto conorrhe nus. No gato verificamos a infeceto natural pelo trypanozoma rue arpelle licmatoplago transmitte. Daula a juefereucia do conorytimus jelo xangou

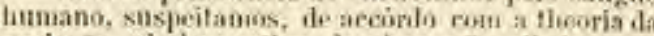

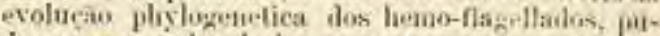
desse ser parasita do homen e try paurza inia meontrado no apparelle digestivo daquelle hematophago.

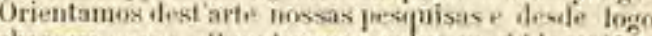
chamou urasa atlengato um quadro mortido uniforme, apreciayol em guast toulas as criancas da zona oute alminla u invertelmado.

Daquelle quadro, presente as vrzes ral a alullos. porem mais frequente nas criancas, ox elromentus imais salientes kâ os suguintes: grande anemis, decidencia orkanica acrentuada, edema sab paijuthral ef frequentemente edemas gemeralisalos, engurgitamento "anglionar consideravel, lavendu volumows zanglios nas pleiades peripharivas axil-

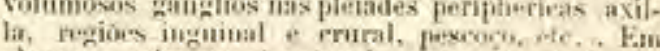
algumas criamess, of molavel a atropibis div desern. volvineato. W una coudica morbida permanente, com incidenites agudos. que se expressam em reacrato feliril e ontros elementos morlidens. is nogies clinicas que temos da molestia sio ainda muito incompletas, estando apenas inficiadas, hesssi sentido, noxsas ohservaróes. New salemos muito solire o prognostion, parecendo, pelas informacies colhidas, ser molestia is vezes mortal. veristinito

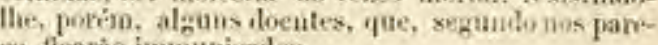
e, flicarán imumunisalos.

Reputulos exames de sangue, om crioneas ua condicano morbida cluonica, forram necativos. Nuu

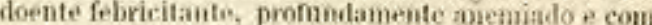

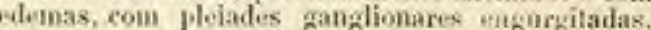
cheontramos try panozouas, cuja morgholon ia f identiea di do tryjpenzomer Crwzi. Xa ausencia de qualquer outra eliologia jara os symptomas morbidos observadox e ainda de acciondo com a experimentacao anterior en animaes, jul gainns tratarese de uma irysanozomiaso lumana, molestia oceasionatla pelo

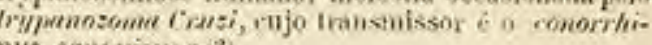
nus santgrisugal??

Em nossis pesquisas temos sula vantajosa-

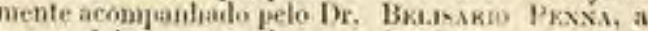
quem deixanos aqui os mais sincems agralect. mentos.

Latsanee, K. de F. Central, is te Wirit de I909.

\section{TRABALHOS OIIGINALS}

A epilepsia de Bonaparte

(Nuile de paychologien morbida)

Pelo Pien: A. Diss de Barron (Conclusèto)

Apraz-me exporr, antes de manifestaçós outrax dessa amestesia moral á qual me refiro, e para contraste com ella, antes que analogos factos no simples dominio das relacoes sociaes que passo a oxper. o opposto ilessi eruetdade, o verdadeiru reverso da imedalla cujo anverso se acabon de vêr.

Oecorre-me leminar a serie de attencous de toda a especie, pratenteadas para com a velhice e a dex,
Trabalho publicado na revista Brazil-Medico anunciando a descoberta da nova doença, 1909 Acervo Casa de Oswaldo Cruz

Article published in the journal Brazil-Medico announcing the discovery of the new disease, 1909
IIIL WOVI IIOHSTIL

\section{Na Academia Tacional de Timedicina}

\section{IHPORTAYTE COHHIWLCGCÕO \\ A (trypanozoma Cruzi)}

Em sessão hontem realisara, na Academia Nacional de Medicina, á qual compareceram, além de muitos membros, os Srs. marechal ministro da guerra, general Mendes de Moraes e grande numero de pessoas gradas, o ilhustre director geral de Saude Publica, Sr. Dr. Oswaldo Cruz, apresentou uma importante e vabiosa communicacão, que despertou vivo interesse no seio da douta corporação. Trata-se de um nova entidade morbida, que um dos mais bellos ornamentos do Instituto Oswaldo Cruz, - Dr. Carlos Chagas, conseguiu isolar, após pacientes e cuidadosos estudos.

Essa nova molestia, completamente desconhecida do mundo mexlieo. é uma "trypanozomiase", produzida por um novo trypanozoma, que o joven e talentoso bacteriologista, como homenagem ao seu sabio mestre, denaminou "trypanozoma Cruzi". Essa molestia é muito frequente no Estado de Minas, em que 0 povo canfunde com a opilação (ankyłostomiase), sendo, no embanto, como ficon evirlenciado com os estudos do Dr. Carlos Chagas, uma molestia inteiramente diversa, cujo cortejo symptomatologico lhe confere um logar, á parte, na pathologia intertropical.

Uma nova molestia [trecho]

Gazeta de Noticias, 23 abr. 1909

Acervo Casa de Oswaldo Cruz

"A new illness" [excerpt]

Gazeta de Noticias, Apr. 23, 1909 
Sociedade do Medecina o Covingia do Sin de OHnciro.

$$
\text { en } 11 \text { a Daiv de } 1909
$$

Exuro. Fur. Ars barbs funtinians ons Chages.

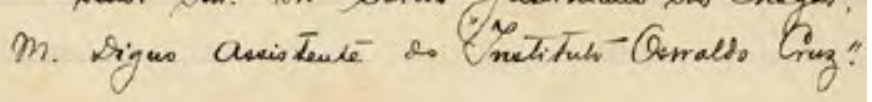

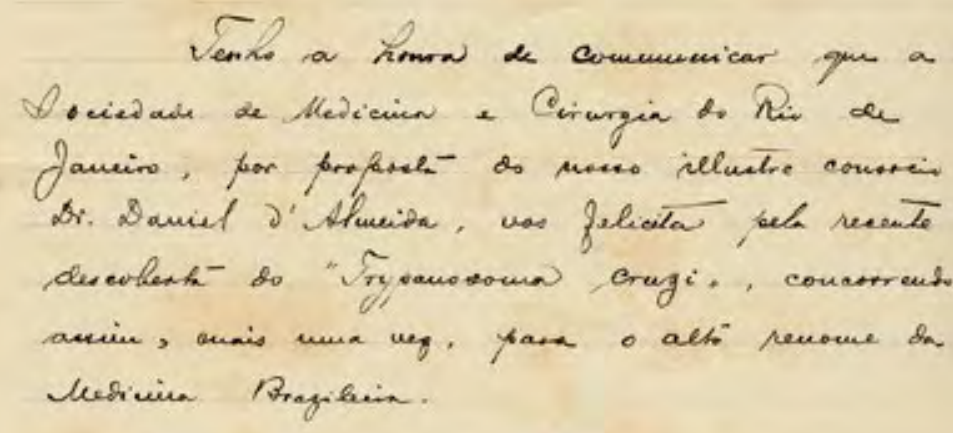

$$
\begin{aligned}
& \text { Sausesares } \\
& \text { Thiedegavo de Nomubr }
\end{aligned}
$$

Carta da Sociedade de Medicina e Cirurgia do Rio de Janeiro felicitando Chagas pela descoberta do Trypanosoma cruzi. Rio de Janeiro, 11 maio 1909

Acervo Casa de Oswaldo Cruz

Letter from the Rio de Janeiro Society of Medicine and Surgery congratulating Chagas on the discovery of Trypanosoma cruzi. Rio de Janeiro, May 11, 1909

Carta de Oswaldo Cruz a Henrique da Rocha Lima, pesquisador de Manguinhos, comentando a nova doença descoberta por Carlos Chagas, 1 jun. 1909 Acervo Casa de Oswaldo Cruz

Letter from Oswaldo Cruz to Manguinhos researcher Henrique da Rocha Lima, commenting on the new disease discovered by Carlos Chagas, Jun. 1, 1909

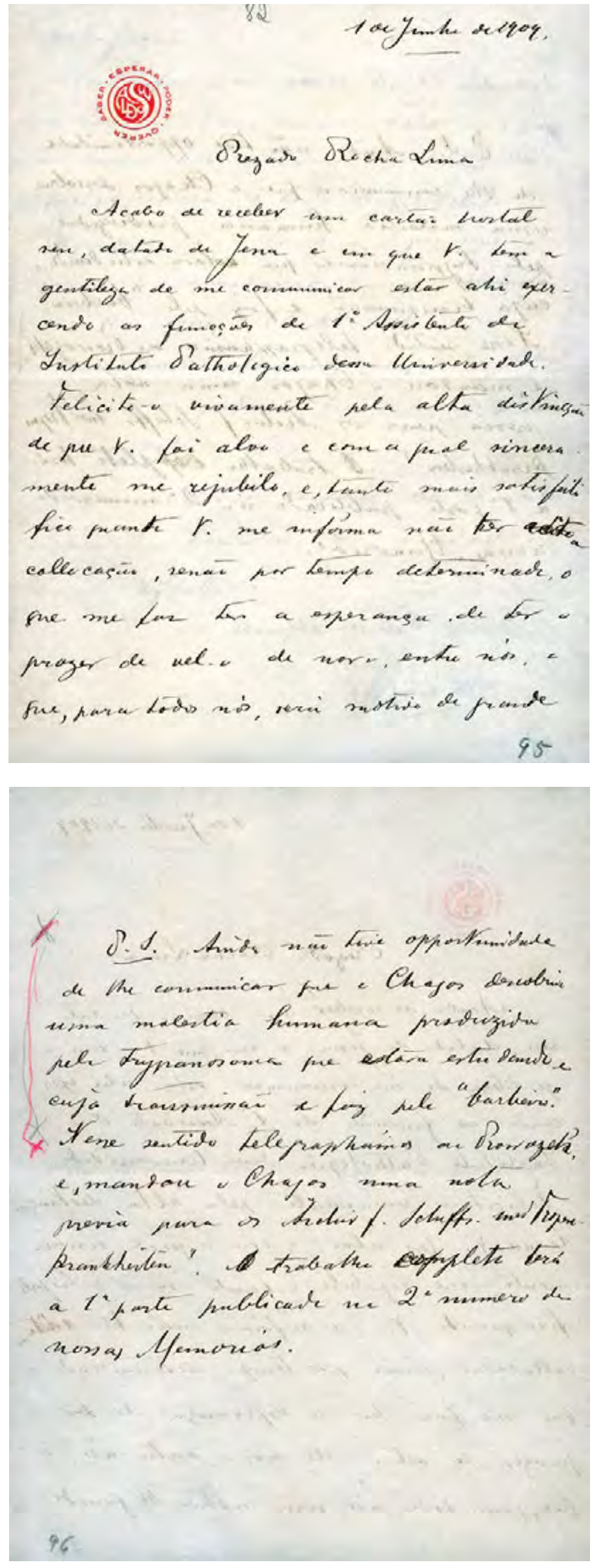


Nunca, até agora, nos dominios das pesquisas etiológicas, se tinha feito descoberta tão completa e tão brilhante em tão curto prazo, e, o que é mais, por um só experimentador. A descoberta da moléstia de Chagas, tal como foi feita, é a demonstração prática e brilhante do axioma do imortal Francisco de Castro, que pontificava: só é ciência por fora o que é lógica por dentro.

\section{Oswaldo Cruz}

Never before in the realm of etiological research had such a comprehensive and brilliant discovery been made in such a short space of time and, moreover, by one single experimenter. Given how it was achieved, the discovery of Chagas disease stands as a brilliant, practical demonstration of the axiom of the immortal Francisco de Castro, who pontificated: it's only science on the outside if it's logic on the inside.

Oswaldo Cruz
SOCIÉTÉ

\section{DE PATHOLOQIE EXOTIQUE}

Paris, le 13 Janver 1910

Siżoe Social :

INSTITUT PASTEUR

PARIS

Monexeur ę orès honozó Gohiègue,

The 2"honneur de rous anformer que J.8.

Société de Pethologie exotfque, dans se séance

au 12 yanrurlq10, tous a élu mecobre conres/rontante

Ie. Soctétś espère ģue pous poudrez bien

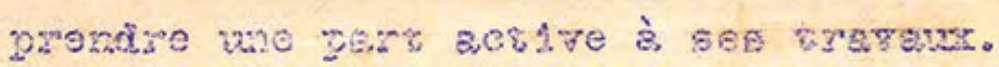

veudilez egréer, Plonsieur et très honosé

Coliègue, I'essurance de me considération trèz

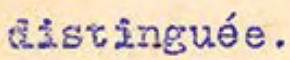

\section{Le Président de la Société}

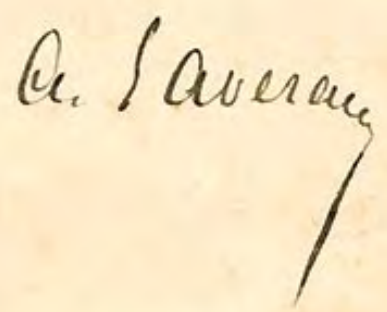

llonsium C. Chagas.

Carta de Alphonse Laveran - parasitologista

francês que identificou o microorganismo

causador da malária em 1880 - comunicando a

eleição de Chagas como membro

correspondente da Sociedade de Patologia

Exótica de Paris, 13 jan. 1910

Acervo Casa de Oswaldo Cruz

Letter from Alphonse Laveran - the French parasitologist who in 1880 identified the microorganism that causes malaria - advising that Chagas had been elected a Corresponding Member of the Society of Exotic Pathology of Paris, Jan. 13, 1910 


$$
\begin{aligned}
& \text { or Gadou Cotiogas } \\
& \text { Lassere 6.:6.83. llimas- }
\end{aligned}
$$

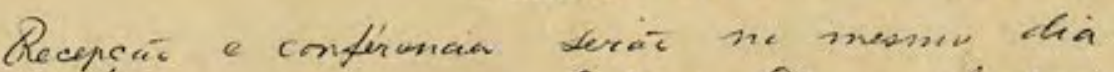

$$
\begin{aligned}
& \text { thinel Derena excren-me: Entrada Chagas Scadennia } \\
& \text { al fy contra todas as regras e at' sem rentionia vagabia }
\end{aligned}
$$

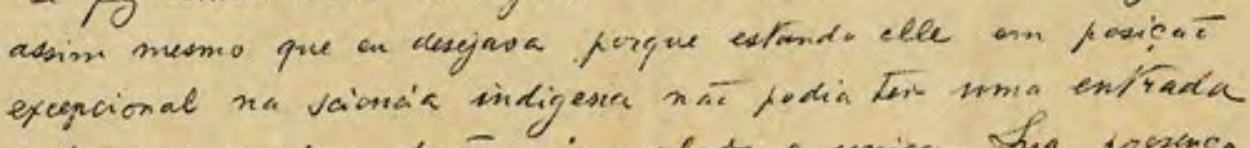

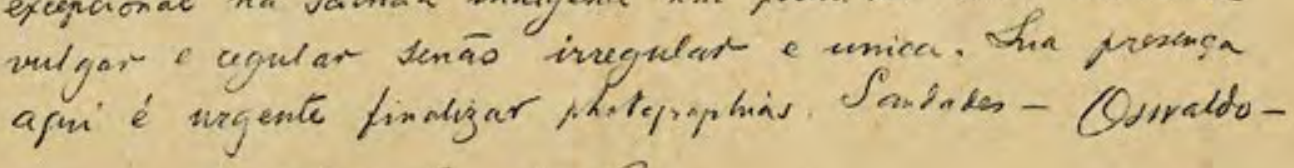

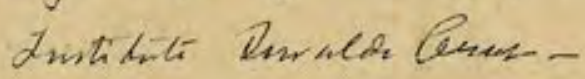

Telegrama de Oswaldo Cruz sobre a nomeação de Chagas como membro titular da Academia Nacional de Medicina; destaca a excepcionalidade da admissão, diante da inexistência de vaga. Rio de Janeiro, 1910 Acervo Casa de Oswaldo Cruz

Telegram from Oswaldo Cruz about Chagas being named a fellow of the National Academy of Medicine. It highlights the exceptional nature of the Academy's decision to welcome a new member even though no seats were open. Rio de Janeiro, 1910

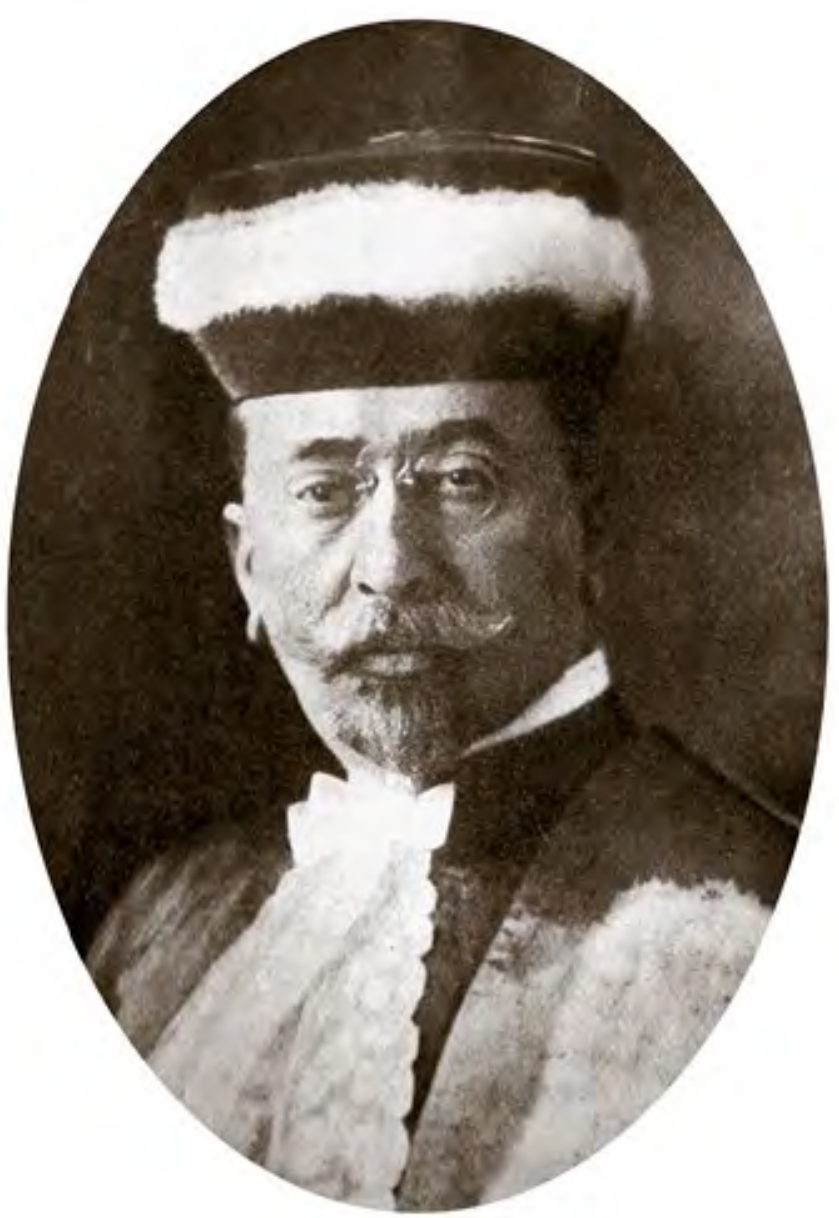

Miguel Pereira, presidente da Academia Nacional de Medicina em 1910 e 1911

Acervo Academia Nacional de Medicina

Miguel Pereira, president of the National Academy of Medicine in 1910 and 191
A Academia que tenho a honra de presidir não quis ficar indiferente quando sentiu a medicina nacional dignificada e enaltecida por um descobrimento de que o mais sábio dos sábios que lidam com coisas da ciência se ufanaria de ser o notável autor e por isso, ao mesmo tempo em que creditou a $V$. Ex. a homenagem de uma sessão extraordinária, prevaleceu-se do ensejo para inaugurar a sua instalação elétrica inspirado pela delicada atenção de que não fosse a $V$. Ex. faltar a apoteose dessa luz triunfante que, inseparável do progresso, é a predileta da inteligência.

Miguel Pereira

The Academy over which I have the honor of presiding did not wish to stand by impassive as it witnessed Brazilian medicine distinguished and aggrandized by a discovery that would make the wisest of the wise among those who address matters of science proud to claim its noteworthy authorship. Therefore, at the same time that [the Academy] pays tribute to you with this extraordinary session, it has seized the opportunity to inaugurate its electrical installations, moved by the attentive consideration that you might not be absent from the brilliant explosion of this triumphant light, inseparable from progress and most beloved by intelligence.

Miguel Pereira 


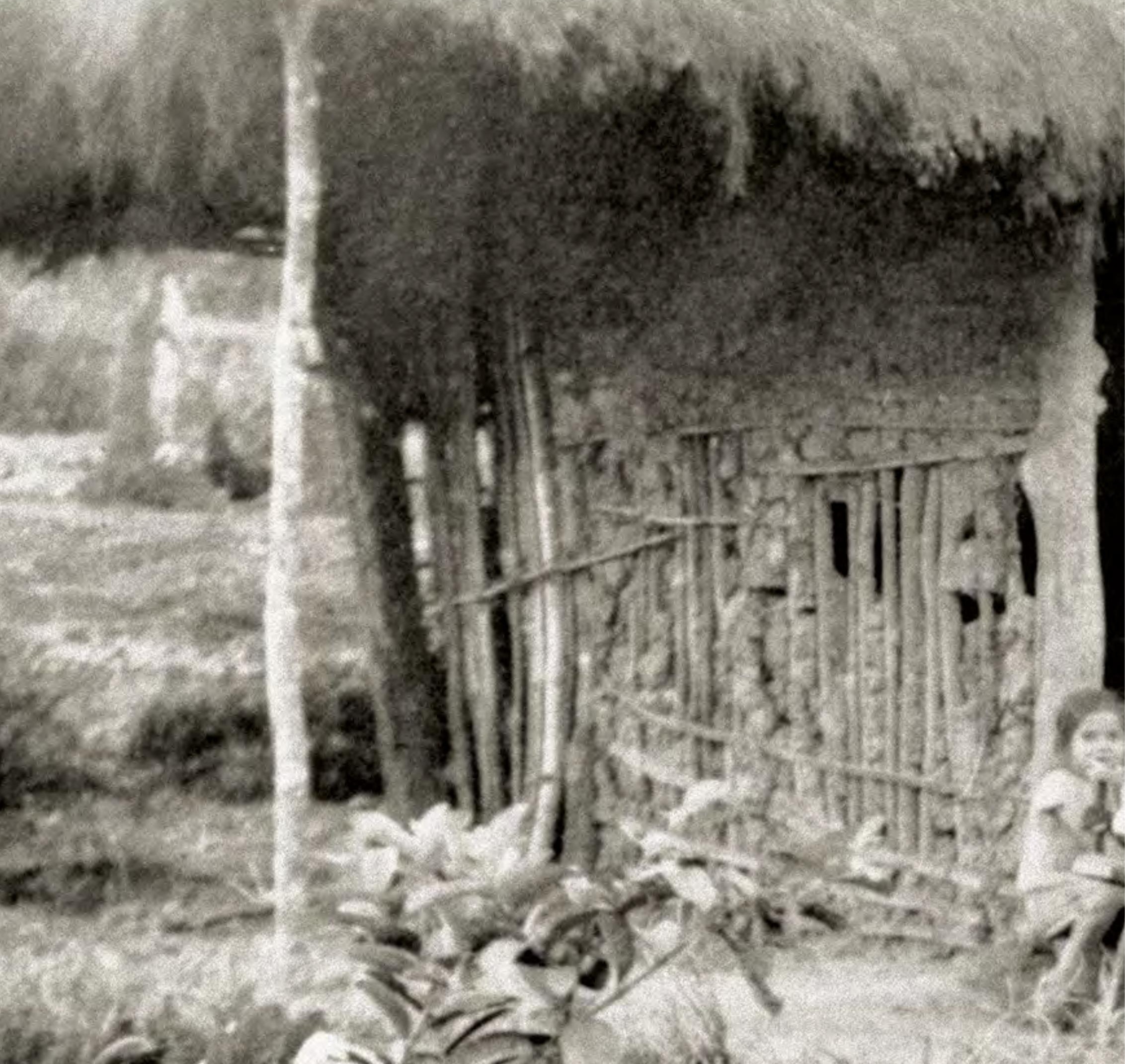

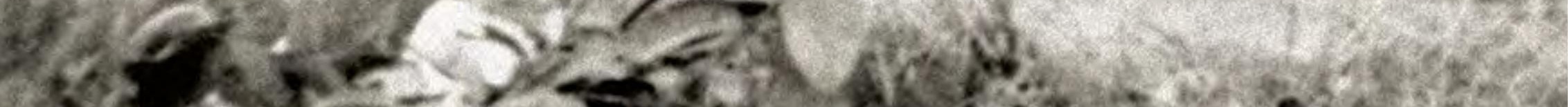

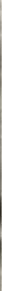




\section{Estudos sobre a doença de Chagas Researching Chagas disease}

(s)

\section{nownty}

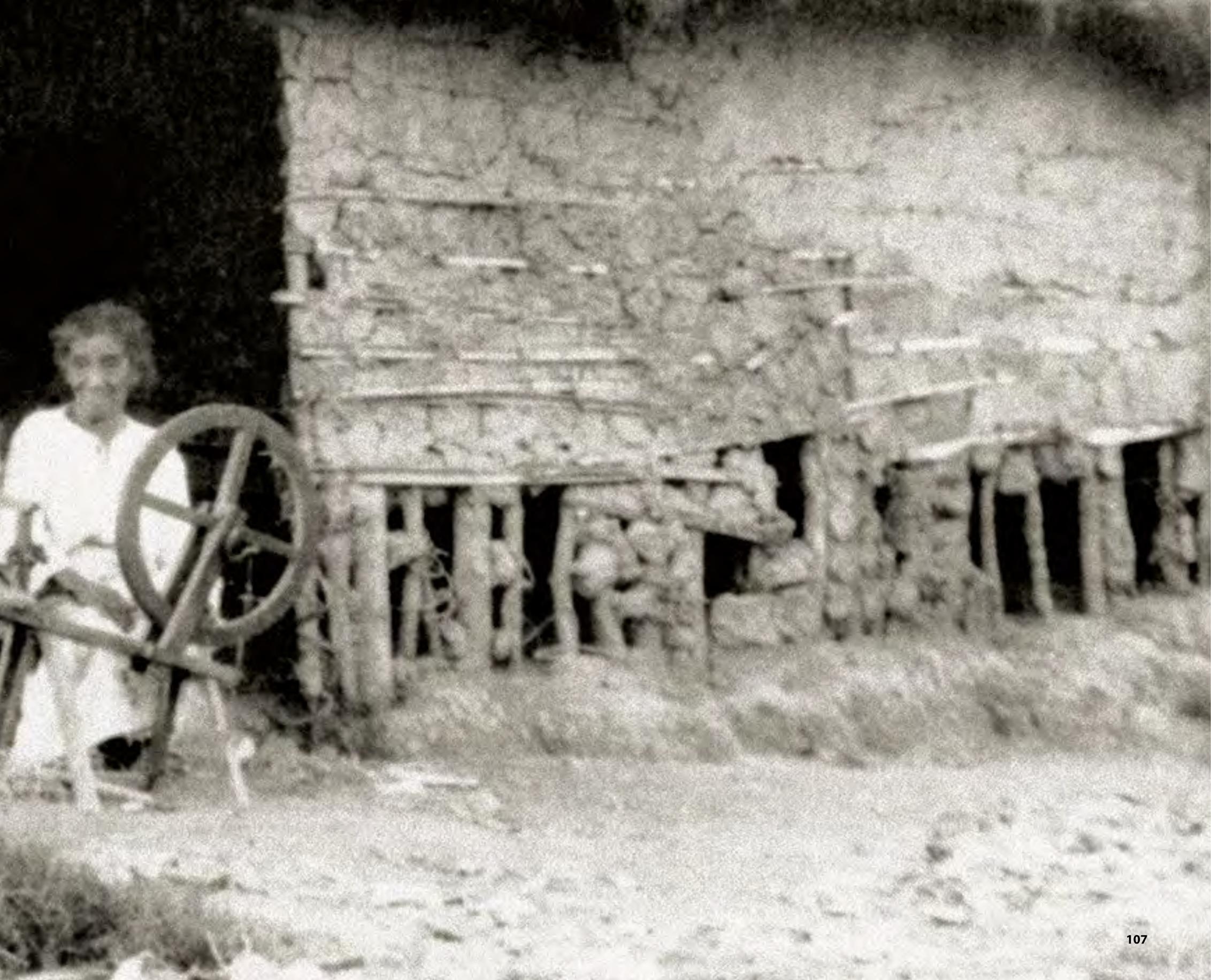


A doença de Chagas tornou-se um dos principais temas na agenda de investigação do Instituto Oswaldo Cruz. Com a colaboração de outros pesquisadores, Carlos Chagas dedicou-se a estudá-la em seus vários aspectos: as características biológicas do vetor e do parasito, os reservatórios do Trypanosoma cruzi, as manifestações clínicas e a evolução da doença, os métodos de diagnóstico e possíveis formas de terapêutica.

Seus trabalhos sobre a doença foram apresentados nas principais associações médicas do país. Em 1911, na Exposição Internacional de Higiene e Demografia, em Dresden, Alemanha, a nova enfermidade despertou grande interesse. Em 1912, Chagas recebeu do Instituto de Doenças Marítimas e Tropicais de Hamburgo o Prêmio Schaudinn de protozoologia. No ano seguinte, foi indicado ao Prêmio Nobel de Medicina. Na época, o governo federal garantiu recursos para a construção, em Lassance e em Manguinhos, de hospitais destinados a investigar a doença.

Segundo os primeiros estudos de Chagas, o período inicial da infecção pelo T. cruzi tinha como principais sintomas febre, aumento do fígado, do baço e dos gânglios, e inchaço no rosto indicativo de comprometimento tireoidiano. Chagas dividiu a fase aguda em duas formas: casos com graves distúrbios cerebrais (geralmente crianças com menos de 1 ano, que quase nunca sobreviviam) e casos mais frequentes, sem tais manifestações, que logo evoluíam para o estado crônico.

$\mathrm{Na}$ fase crônica, haveria distúrbios endócrinos, cardíacos e neurológicos. Nesse momento inicial das investigações, Chagas considerou como sinal clínico mais característico da doença a hipertrofia da tireóide (bócio), expressa em aumento de volume do pescoço. Para ele, nas localidades onde havia a tripanossomíase, o bócio endêmico não era o mesmo que ocorria na Europa (que muitos já atribuíam à carência de iodo), mas o resultado da ação do T. cruzi na tireóide. Por isso a designação "tireoidite parasitária", proposta pelo médico Miguel Pereira (1871-1918).

Desde os primeiros estudos, Chagas afirmou que a nova enfermidade, que atingia os moradores de casas infestadas por barbeiros a partir das primeiras idades, produzia danos permanentes em seu desenvolvimento físico e mental; tratava-se, portanto, de uma endemia rural que prejudicava seriamente a modernização do país e deveria ser firmemente combatida pelos poderes públicos. Num momento em que o Brasil comemorava o progresso em sua capital litorânea recém-reformada, a ciência de Manguinhos revelava um 'outro país', marcado pela pobreza e pelo abandono: o Brasil do interior.

A nova moléstia tropical, assumindo contornos particulares como endemia dos sertões, passou a ser vista como 'doença do Brasil', em vários sentidos além do geográfico: símbolo de um 'país doente' e da ciência que indicaria os meios para sua 'redenção'.

Em meados da década de 1910, pesquisadores na Argentina questionaram as hipóteses de Chagas sobre as formas crônicas, afirmando que o bócio endêmico não tinha nenhuma relação com a tripanossomíase. Chagas reviu, então, alguns aspectos de sua concepção inicial. Mesmo mantendo a convicção sobre a etiologia parasitária do bócio endêmico, passou a tratá-lo como questão sujeita a discussão; ao mesmo tempo, reforçou a importância dos elementos cardíacos.

Depois de sua morte, suas hipóteses sobre os problemas endócrinos e neurológicos atribuídos à infecção pelo T. cruzi foram abandonadas, mas a forma cardíaca crônica foi amplamente confirmada. Distúrbios do trato digestivo, assinalados por Chagas sem maior aprofundamento, seriam também comprovados posteriormente.

Atualmente, considera-se que a doença de Chagas, em sua fase crônica, abrange a forma indeterminada (em que não se manifestam sintomas), a forma cardíaca e a forma digestiva. 

the collaboration of other researchers, Carlos Chagas explored a wide gamut of its features: the biological characteristics of the vector and parasite, Trypanosoma cruzi reservoirs, the disease's clinical presentation and evolution, diagnostic methods, and possible treatment options.

His papers on the disease were presented at Brazil's leading medical associations. In 1911, at the International Exposition on Hygiene and Demography in Dresden, Germany, the new illness drew intense interest. In 1912, Chagas received the Schaudinn prize in protozoology from the Hamburg Institute for Maritime and Tropical Diseases. The following year he was nominated for the Nobel Prize in medicine. It was then that the federal government pledged funds to build hospitals in Lassance and at Manguinhos where the disease would be investigated.

According to Chagas's earliest studies, the main symptoms of the first phase of infection by T. cruzi were fever; enlarged liver, spleen, and lymph nodes; and facial swelling, the latter a sign of a compromised thyroid. Chagas divided the acute phase into two forms: cases entailing serious brain disorders (generally involving children under the age of one, who almost never survived) and more common cases, devoid of such manifestations, which soon evolved to the chronic phase.

The chronic phase was characterized by endocrinological, cardiac, and neurological disturbances. When he first started his investigations, Chagas believed the most notable clinical characteristic of the disease was hypertrophy of the thyroid (goiter), manifested in increased neck size. For him, where trypanosomiasis was found in Brazil, the accompanying endemic goiter was not the same as in Europe (which many were already attributing to iodine deficiency) but was instead the result of T. cruzi's effect on the thyroid. Ergo the name parasitic thyroiditis, proposed by physician Miguel Pereira (1871-1918).

Right from the outset of his studies, Chagas held that the new illness, which struck people living in barbeiro-infested housing at very early ages, caused permanent damage to physical and mental development. He felt this rural endemic disease was a serious roadblock to the modernization of Brazil and that the public authorities should therefore combat it with a firm hand. At a time when the country was commemorating progress in its newly reformed seaside capital, science at Manguinhos was revealing "another country", marked by poverty and abandonment: rural Brazil.

The new tropical illness assumed specific features as a disease endemic to the country's hinterlands. Thus it came to be seen as "the disease of Brazil," and not just in the geographic sense: it was the symbol of a "diseased country" and of the science that would point the way to "redemption."

In the mid-1910s, researchers in Argentina began questioning Chagas's hypotheses about the chronic forms of the disease, arguing that endemic goiter had nothing to do with trypanosomiasis. Chagas then revised some elements of his initial conception. Although he still held that endemic goiter was of parasitic etiology, he began addressing it as a matter open to discussion, while reinforcing the importance of cardiac elements.

Chagas's hypotheses about the endocrinological and neurological disorders he had attributed to infection by $T$. cruzi were discarded after his death, whereas the chronic cardiac form was amply confirmed. Disorders of the digestive tract - which Chagas had pointed out but had not studied in detail - were later shown to be part of the disease as well.

The chronic phase of Chagas disease is now seen as encompassing the indeterminate form (asymptomatic), the cardiac form, and the digestive form. 


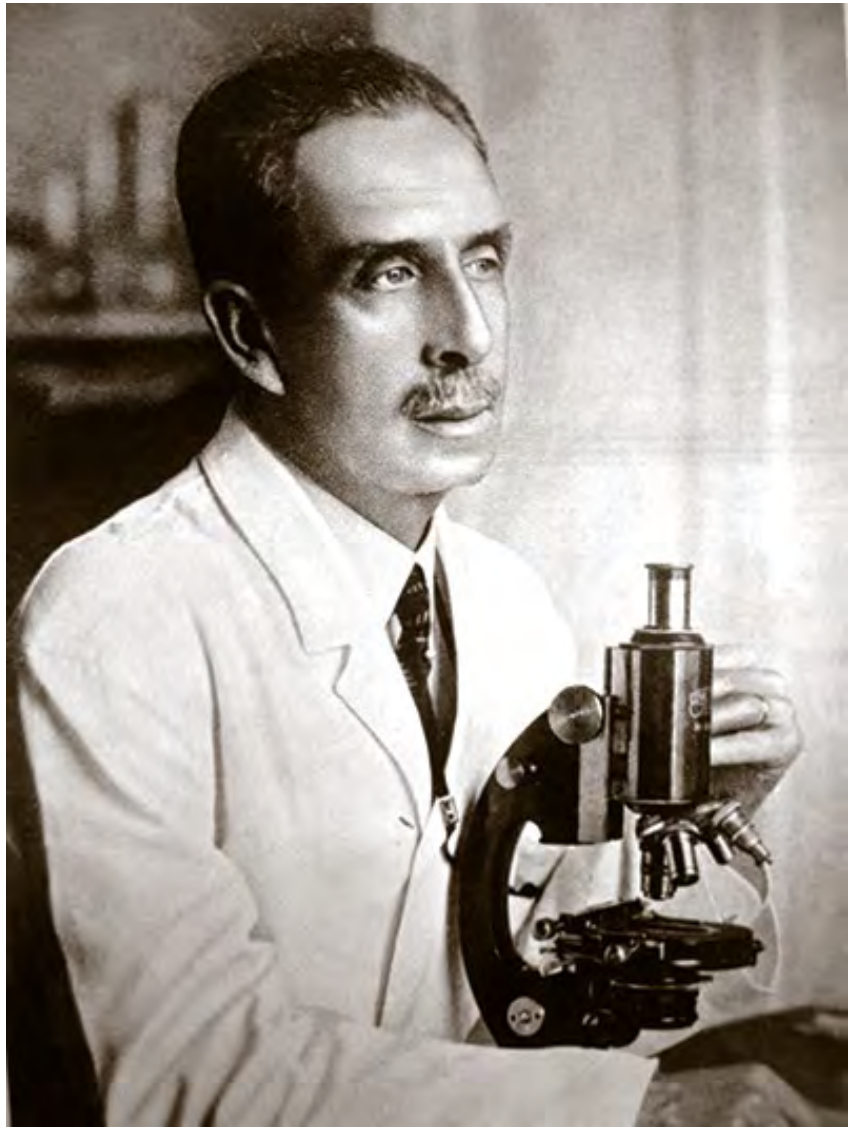

Imagem de abertura - Cafua em Lassance

Acervo Casa de Oswaldo Cruz

Opening image - Thatched wood and mud hut in Lassance

Carlos Chagas em seu laboratório no Instituto de Manguinhos

Acervo Casa de Oswaldo Cruz

Carlos Chagas in his laboratory at the Manguinhos Institute

Trabalho publicado por Chagas no primeiro volume das Memórias do Instituto Oswaldo Cruz, em agosto de 1909

Acervo Casa de Oswaldo Cruz

Paper published by Chagas in the first volume of Memórias do Instituto Oswaldo Cruz, in August 1909

\section{NOVA TRIPANOZOMIAZE HUMANA}

Estudos sobre a morfolojia e o ciclo evolutivo do Schizotrypanum cruzi n. gen., n. sp, ajente etiolojico de nova entidade morbida do homem

\section{UEBER EINE NEUE TRYPANOSOMIASIS DES MENSCHEN}

Studien über Morphologie und Entwicklungszyklus des Schizotrypanum cruzi n. gen., n. sp., Erreger einer neuen Krankheit des Menschen

VON

DR. CARLOS CHAGAS

Reimpresso das "MEMORIAS DO INSTITUTO OSWALDO CRUZ" Vol. I - Fac. II - Agosto 1909

Sonderabdruck aus den "MEMORIAS DO INSTITUTO OSWALDO CRUZ" Band I - Heft II - August 1909 

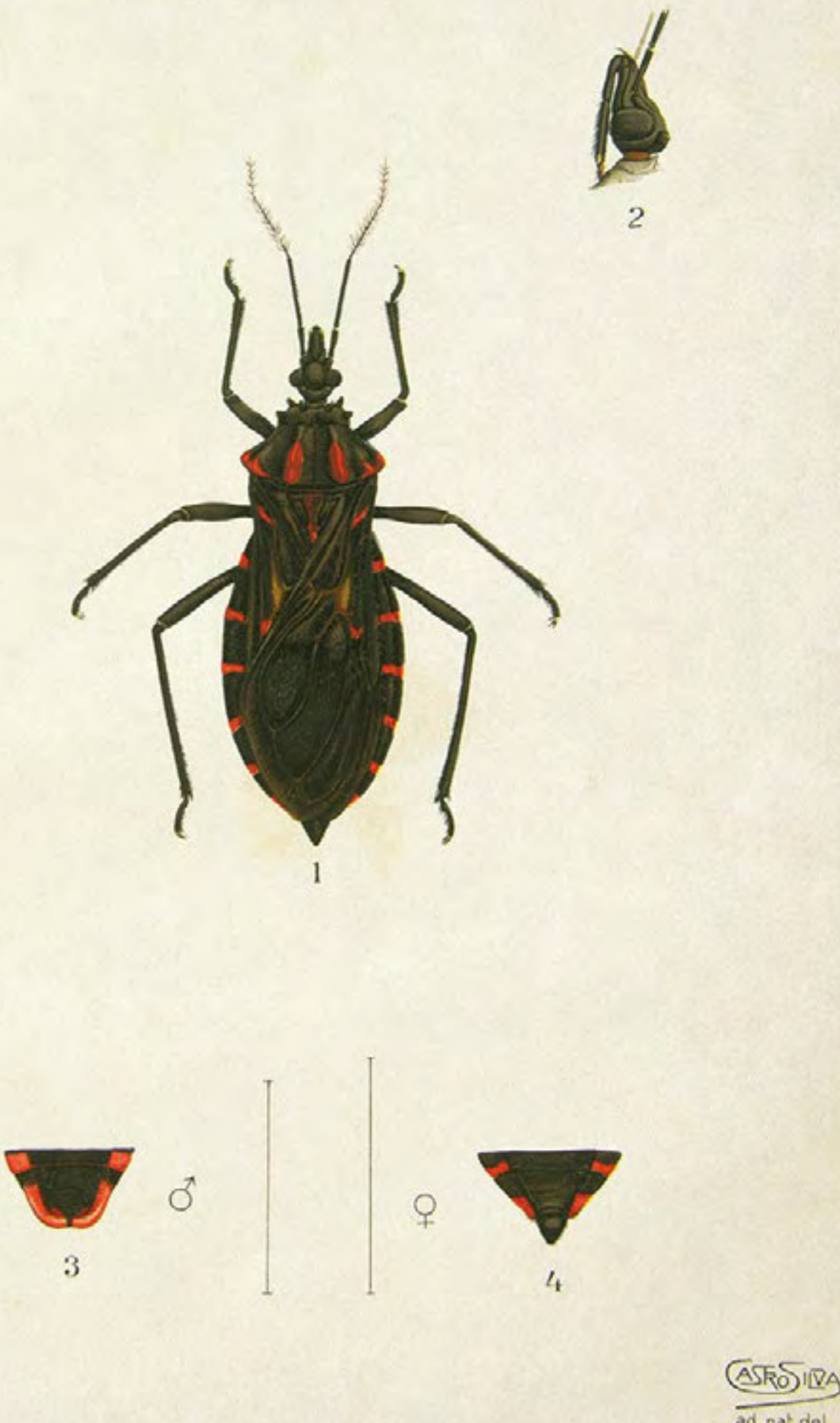

Conorhinus megistus, espécie de barbeiro encontrada em Lassance Prancha de Castro Silva publicada em artigo de Chagas nas

Memórias do Instituto Oswaldo Cruz, em agosto de 1909

Acervo Casa de Oswaldo Cruz

Conorhinus megistus, species of barbeiro found in Lassance

Engraved plate by Castro Silva, published in an article by Chagas in

Memórias do Instituto Oswaldo Cruz, in August 1909 
MEMORIAS DO INSTITUTO OSWALDO CRUZ Tомо I - 1909
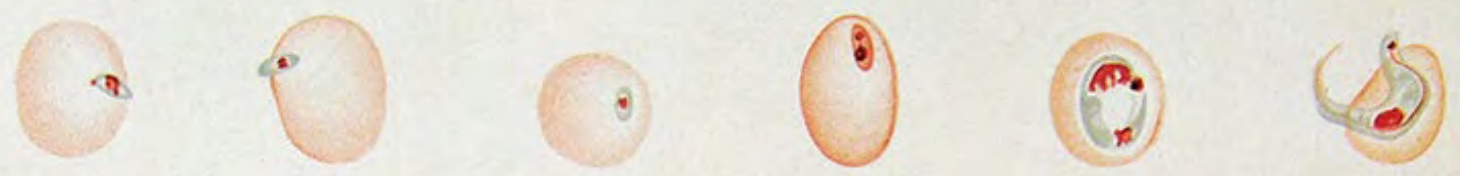

2

3

4

5

6

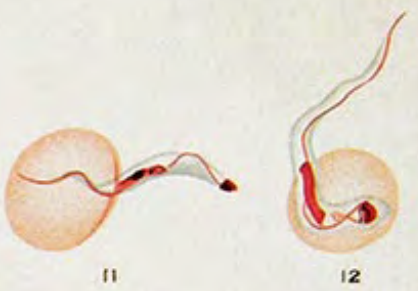

10

2
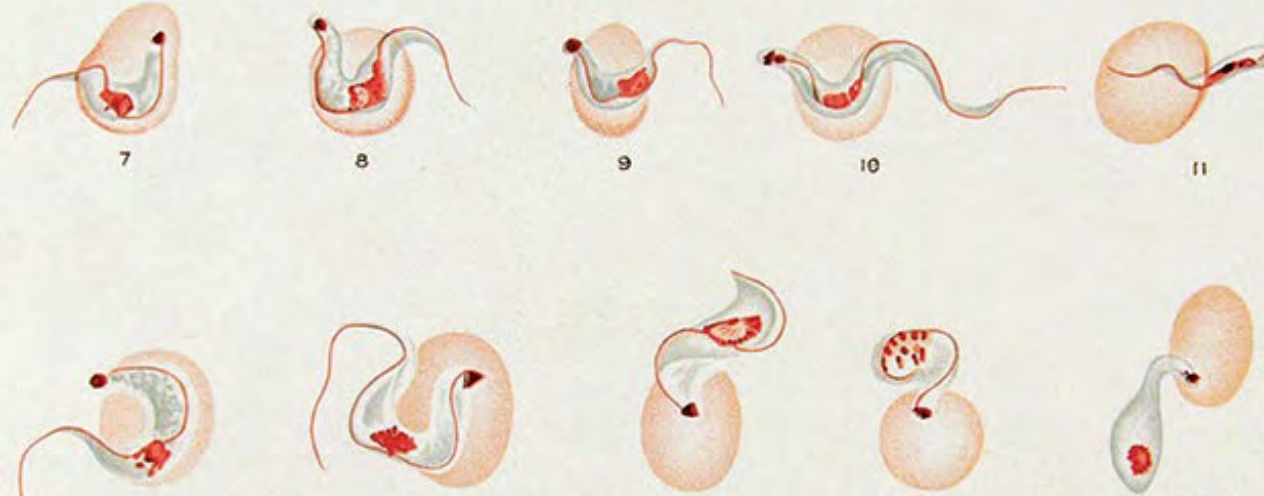

17

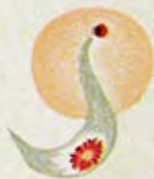

14

16

18

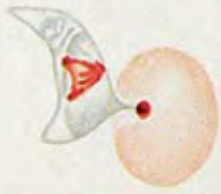

19

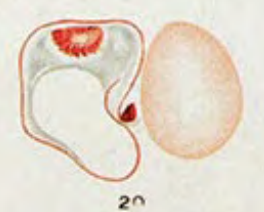

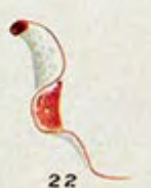
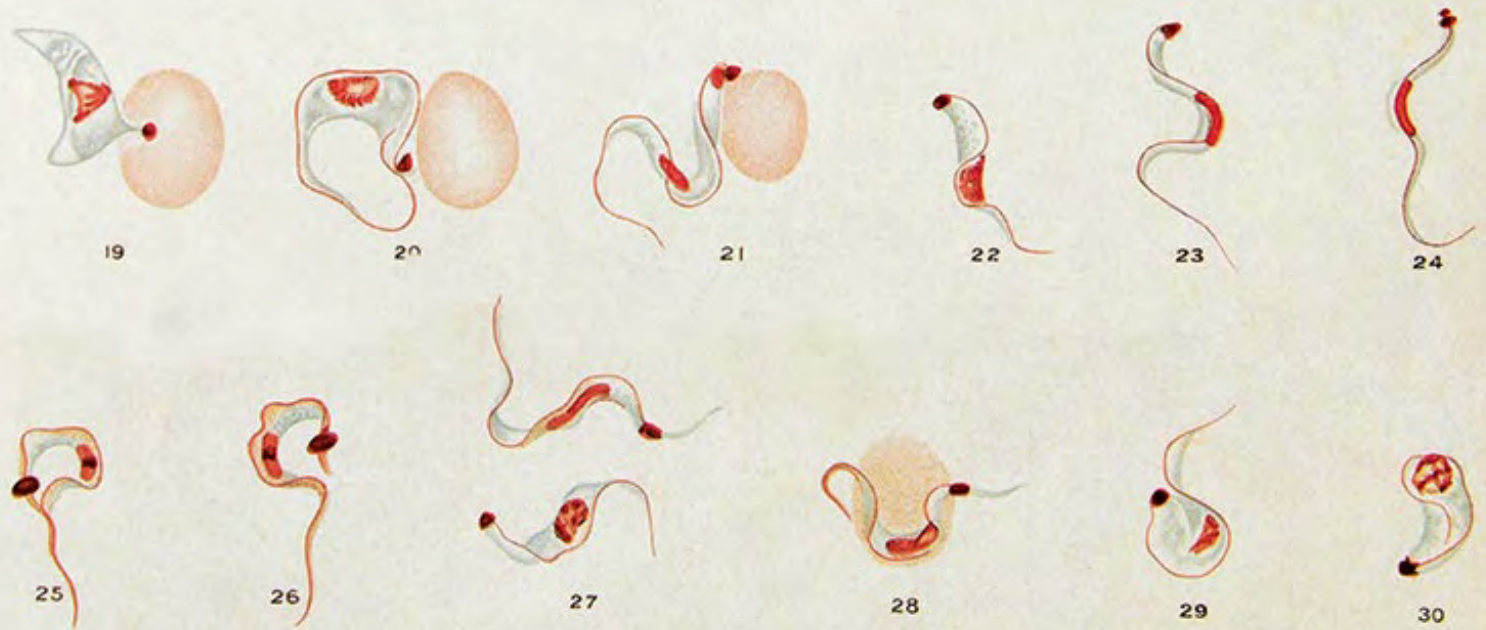

30

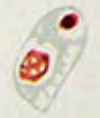

$(8$

31

32
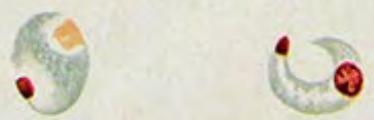

34
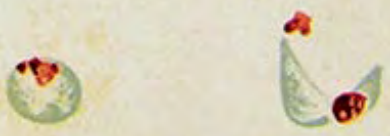

36

(ASTOSID

Estágios evolutivos do T. cruzi

Pranchas de Castro Silva publicadas em artigo de Chagas nas

Memórias do Instituto Oswaldo Cruz, em agosto de 1909

Acervo Casa de Oswaldo Cruz

Life cycle of Trypanosoma cruzi

Engraved plates by Castro Silva, published in an article by Chagas

in Memórias do Instituto Oswaldo Cruz, in August 1909 
MEMORIAS dO INSTITUTO OSWALdo CRUz Томо I - 1909

(3) $i$

3

Ei:?

25

$\because ;$

$a^{3} x$

$\therefore$

40

41

43

44

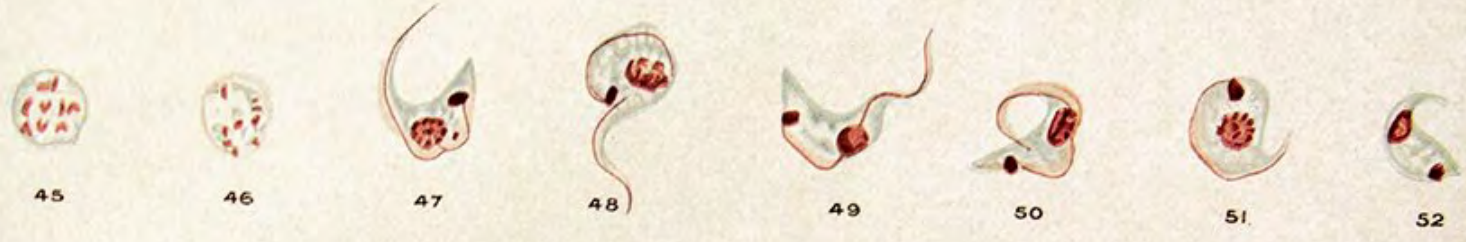

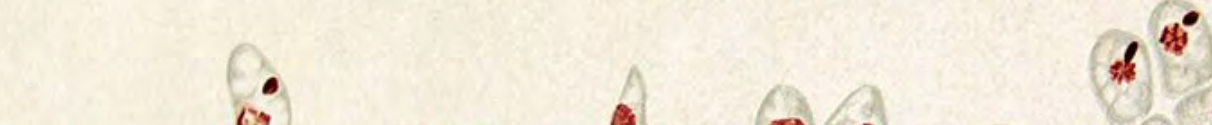

- II

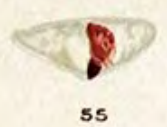

$\because 2$

1.

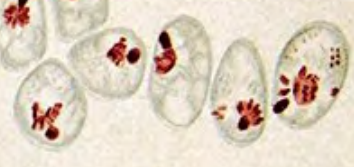

53

54

$56 \quad 57$

59
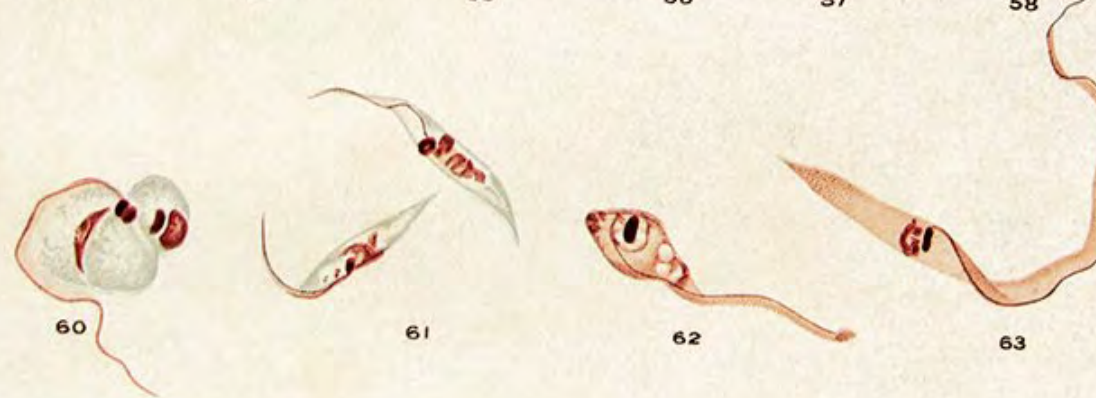

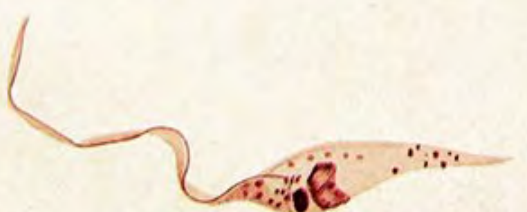

65

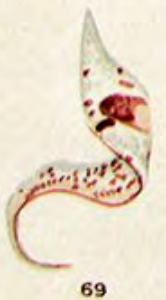

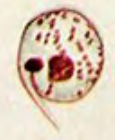

70
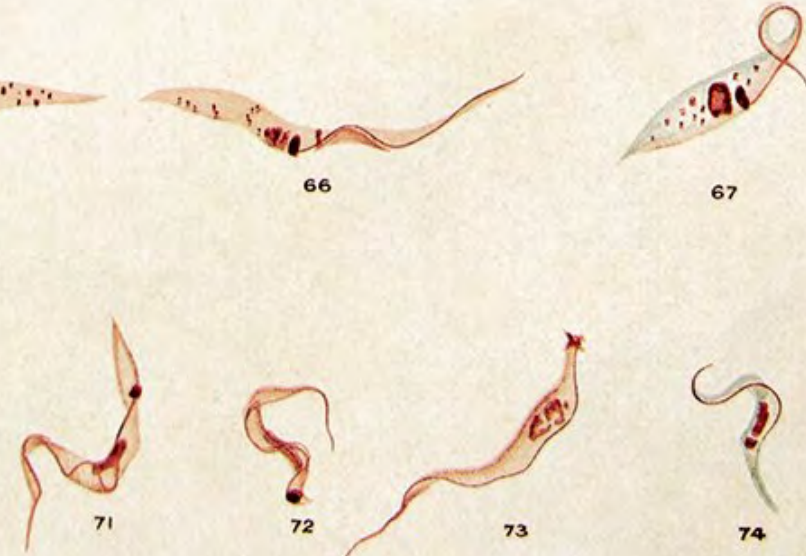

67

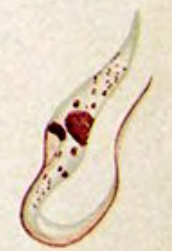

68
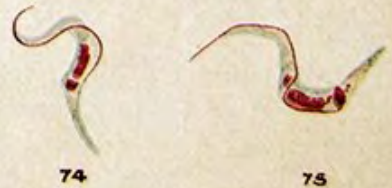

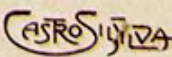


MEMORIAS DO INSTITUTO OSWALDO CRUZ Tомо I - 1909

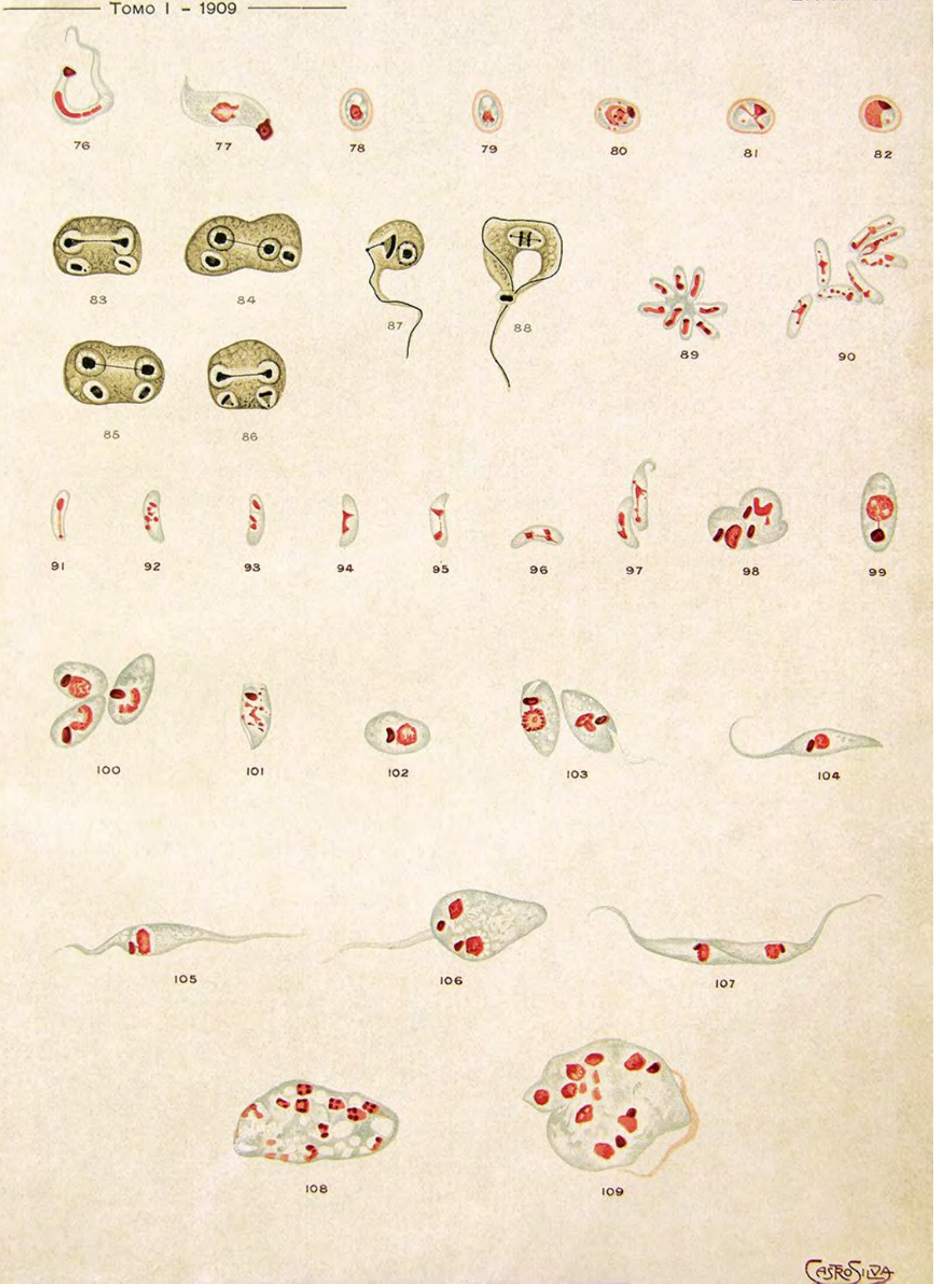




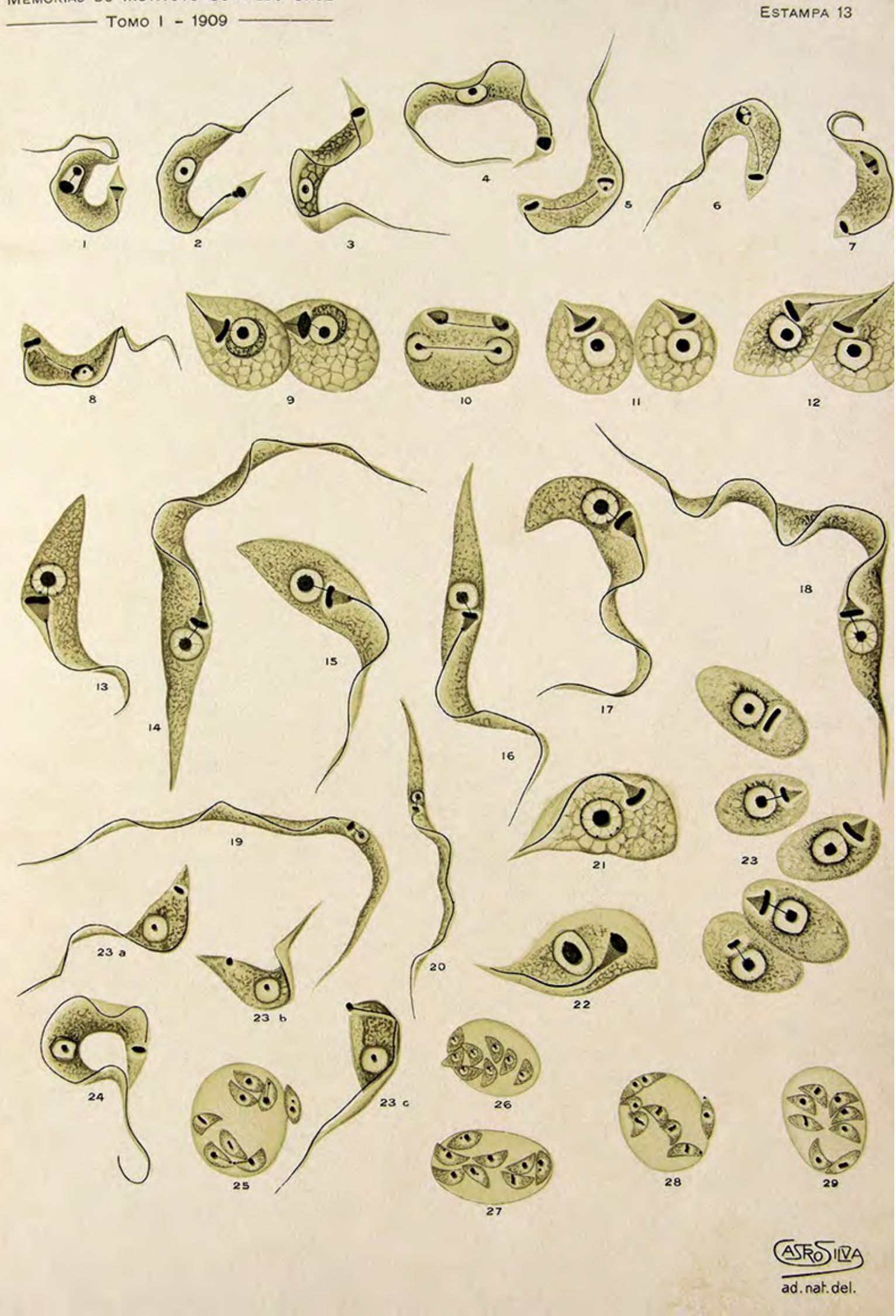




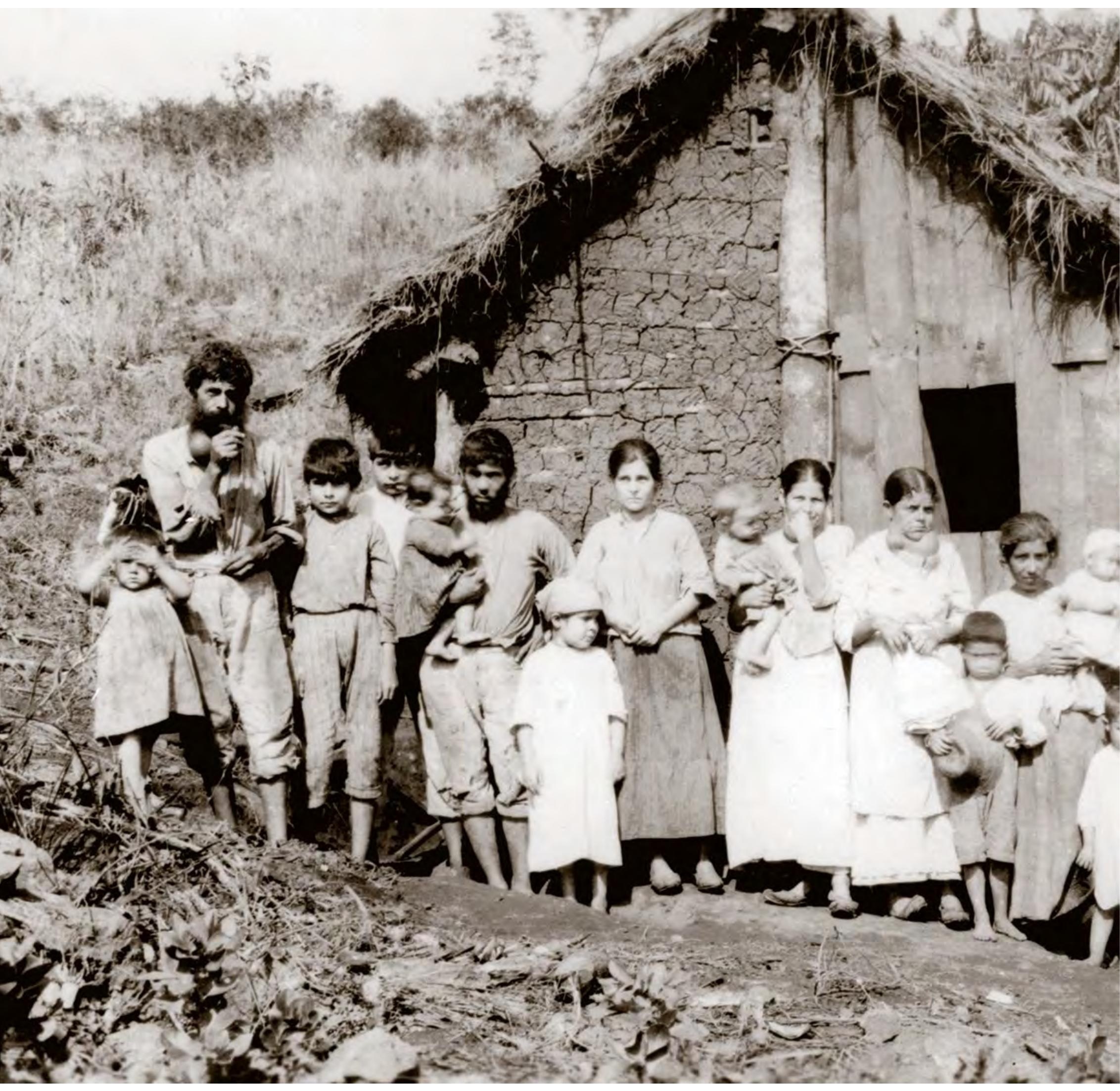

Grupo em Lassance, em habitação típica das

populações rurais, com paredes de barro e

cobertura de capim ou palha, conhecida como

cafua

Acervo Casa de Oswaldo Cruz

Group in Lassance in a typical rural home, with

mud walls and grass-or straw-thatched roof

known as a cafua 


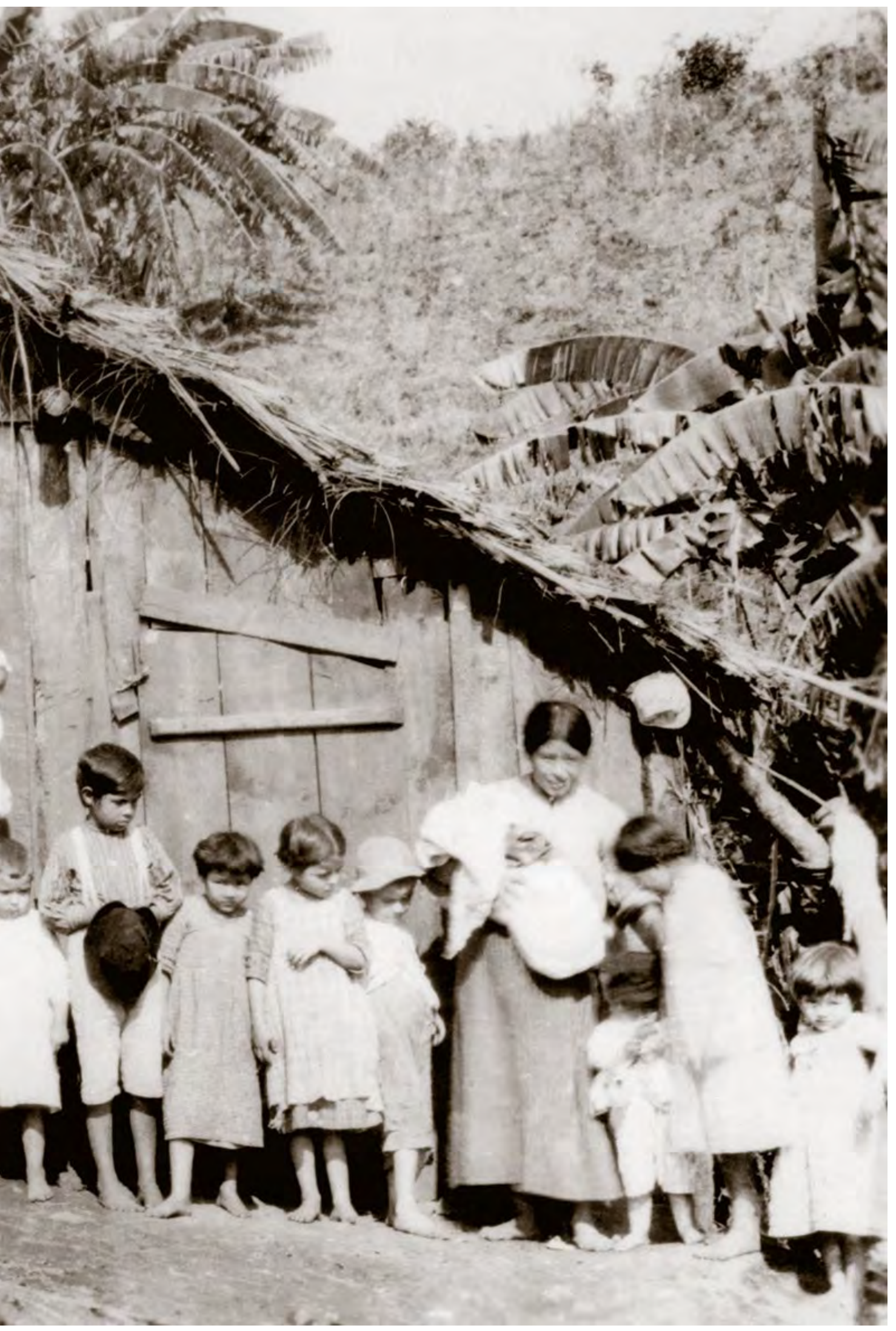

... lá pelo interior do país, nas zonas da moléstia, a população pobre habita choupanas nas mais precárias condições, tendo as paredes cheias de numerosas fendas, que constituem ninhos colossais de Conorhinus.

Carlos Chagas

(...) there in the interior of the country, in the regions of the disease, the poor population dwells under the most precarious conditions, in huts whose walls are filled with many cracks, forming enormous nests of Conorhinus.

Carlos Chagas 

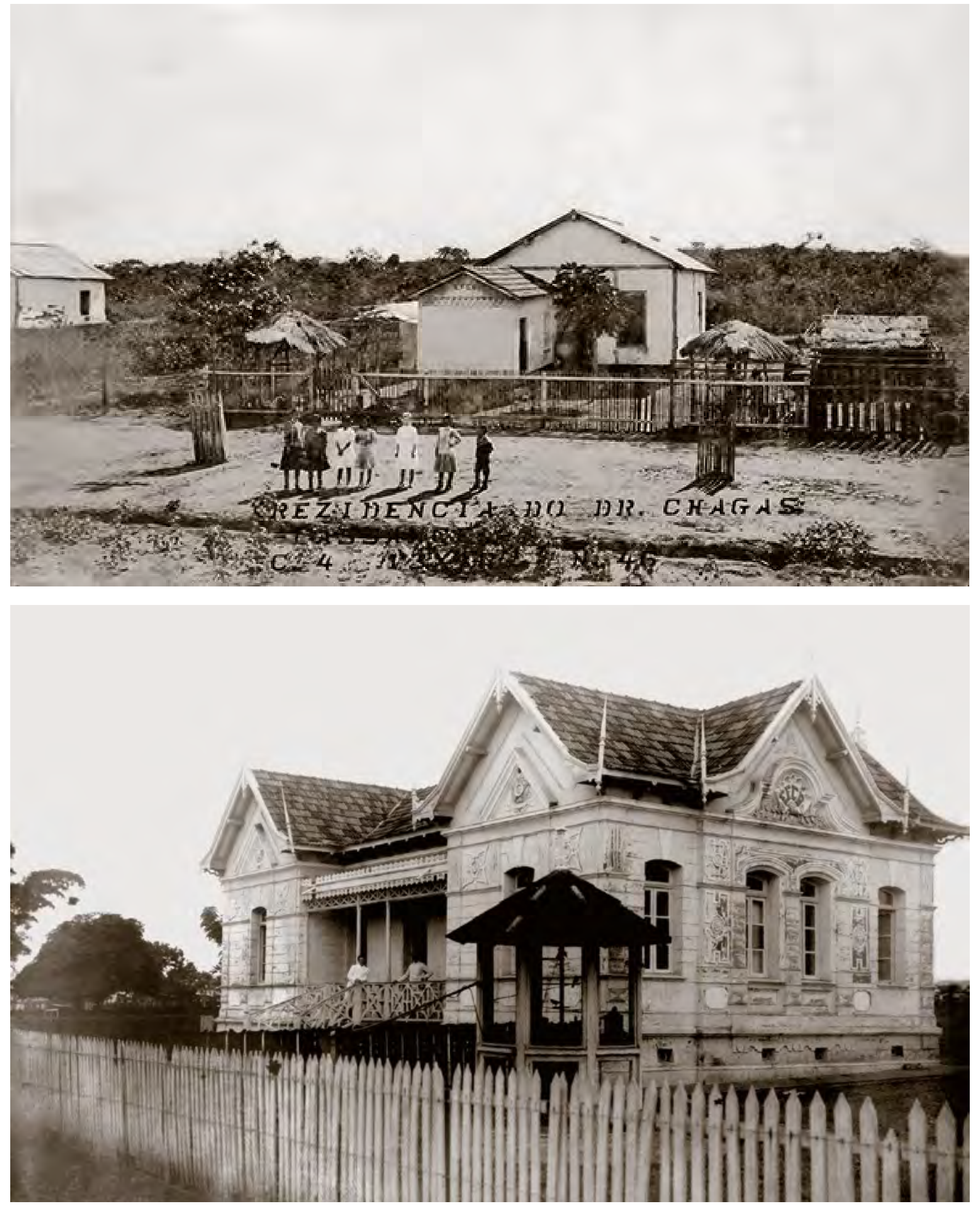

Residência de Chagas em Lassance Acervo Casa de Oswaldo Cruz

Chagas's residence in Lassance

Hospital regional de Lassance Acervo Casa de Oswaldo Cruz

Lassance regional hospital 


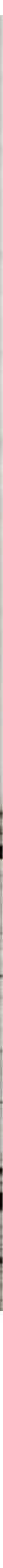



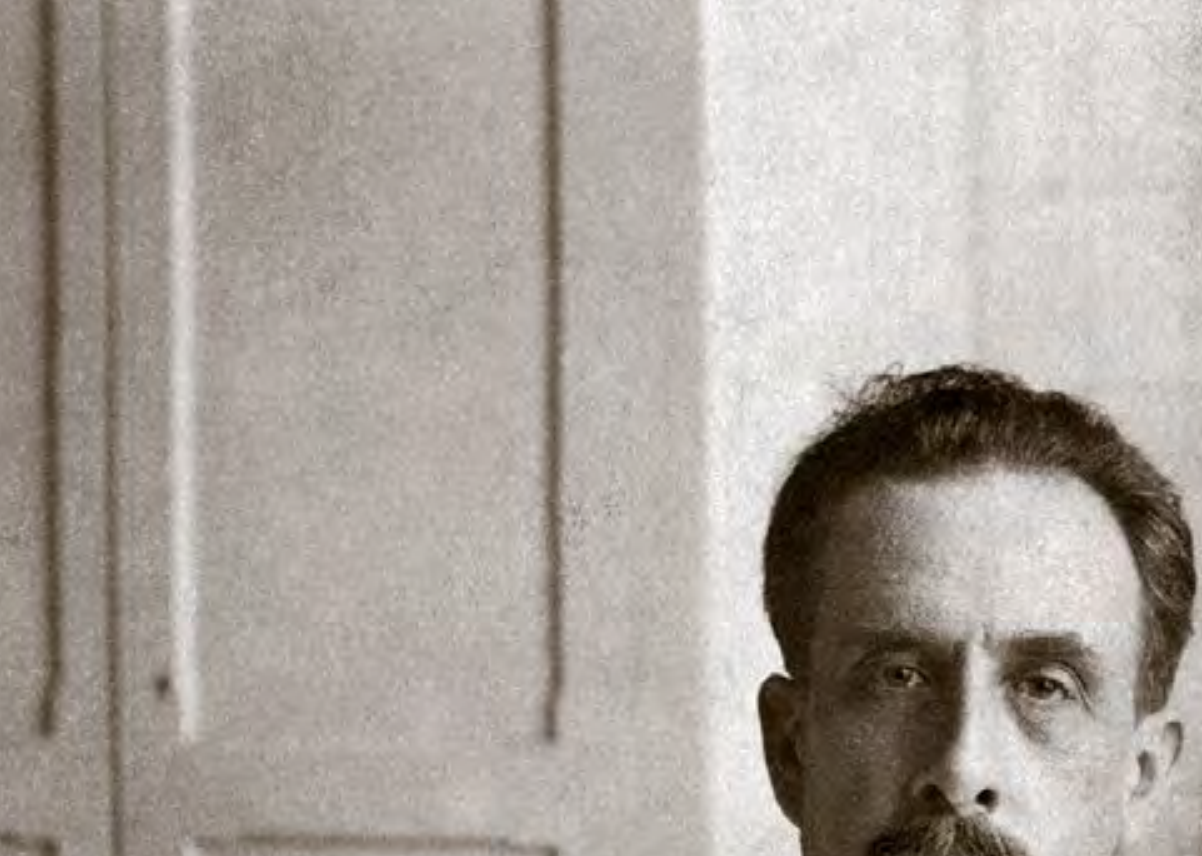
Chagas em seu laboratório no Instituto de Manguinhos Acervo Casa de Oswaldo Cruz

Chagas in his Manguinhos Institute laboratory

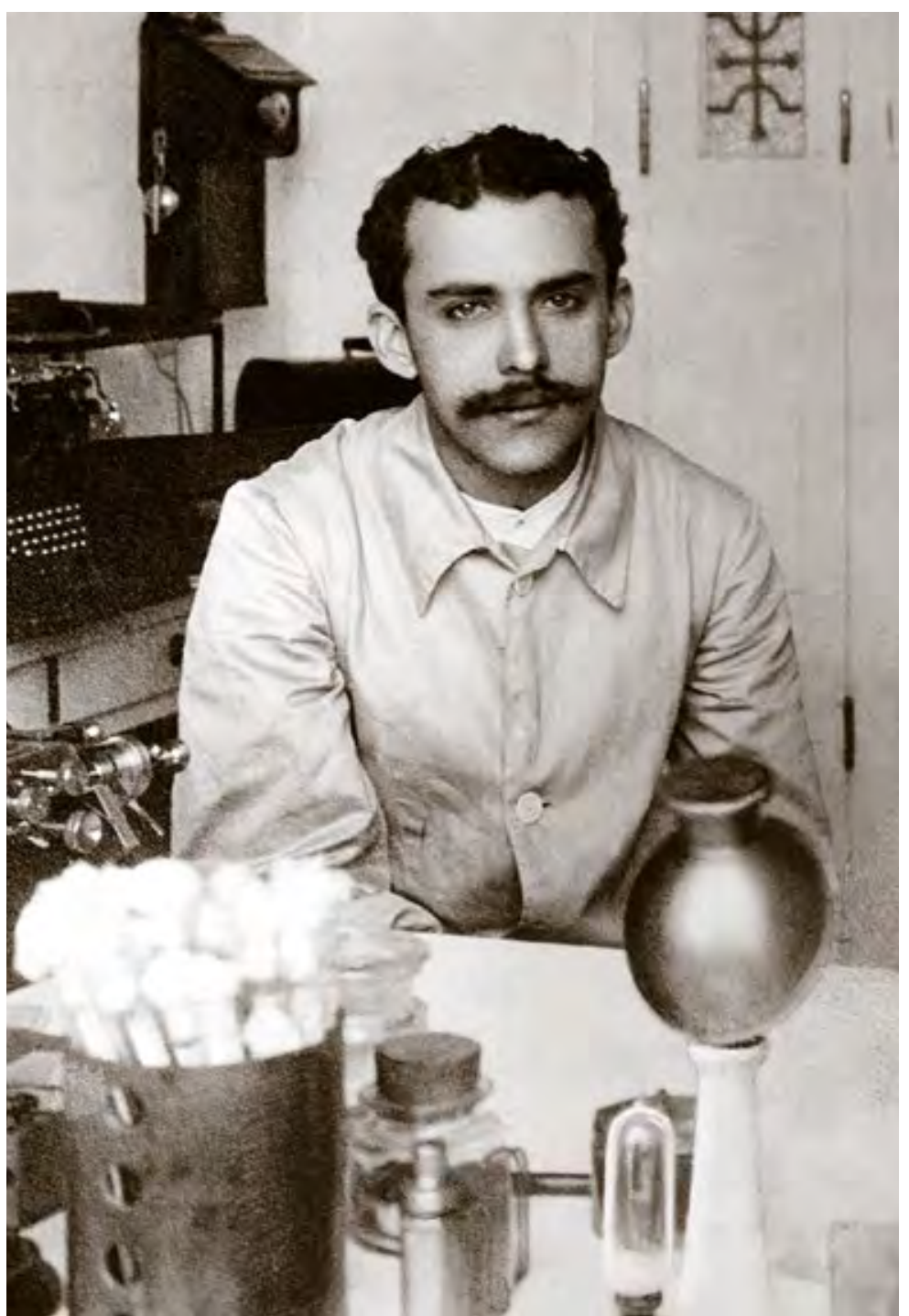

Os estudos de anatomia patológica de Gaspar Vianna (1885-1914) foram decisivos para a compreensão da ação patogênica do $T$. cruz

Acervo Casa de Oswaldo Cruz

Gaspar Vianna's (1885-1914) studies in pathological anatomy made a decisive contribution to understanding the pathogenic action of Trypanosoma cruzi

Arthur Neiva (1880-1943) estudou as diferentes espécies de barbeiros

Acervo Casa de Oswaldo Cruz

Arthur Neiva (1880-1943) studied the various species of barbeiros

Astrogildo Machado (1885-1945) desenvolveu, em 1913, em parceria com César Guerreiro (1885-1949), o primeiro método sorológico de diagnóstico para a doença de Chagas e realizou estudos em busca de um medicamento para a doença Acervo Casa de Oswaldo Cruz

In 1913, in collaboration with César Guerreiro (1885-1949), Astrogildo Machado (1885-1945) developed the first serological technique for diagnosing Chagas disease and did research to try to find a drug treatment
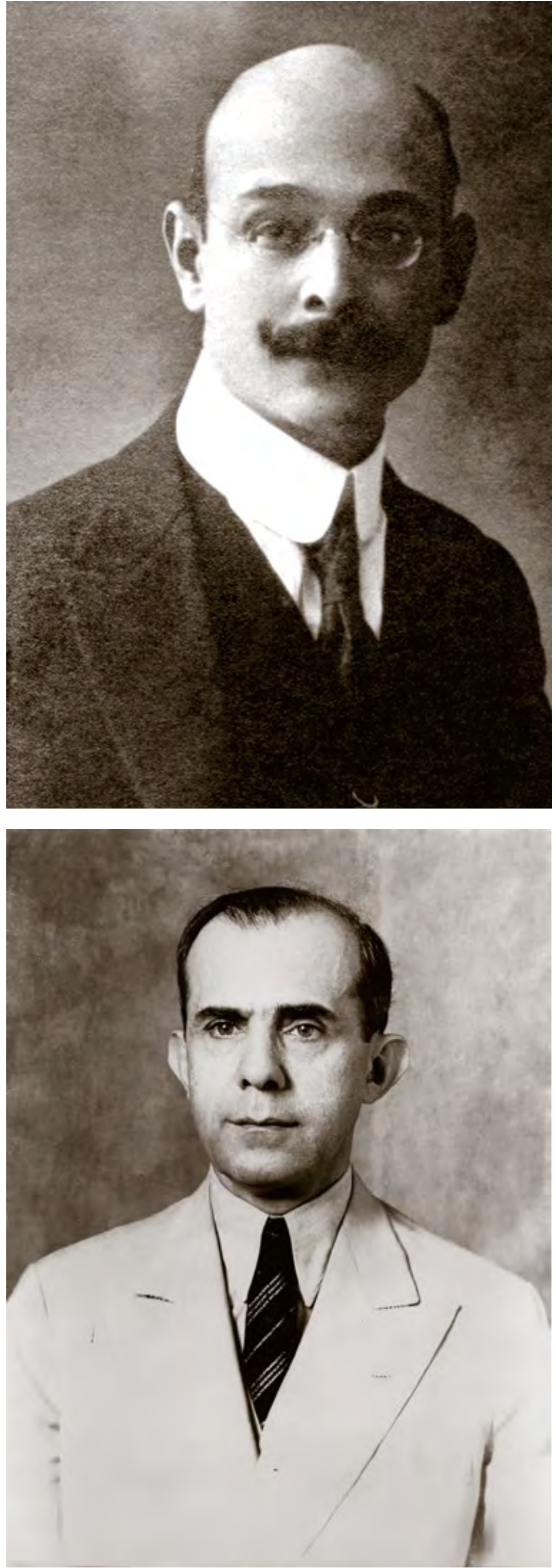

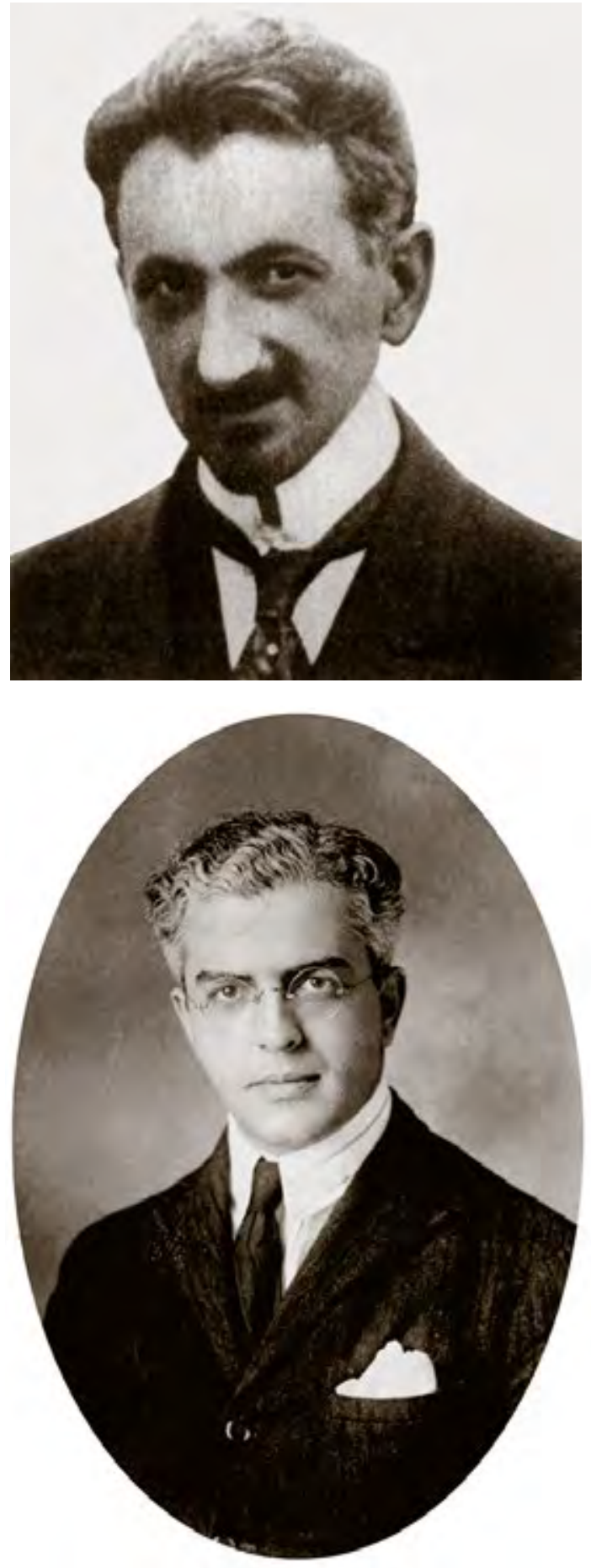

Ezequiel Dias (1880-1927) realizou pesquisas sobre os aspectos hematológicos da doença de Chagas e testou inseticidas contra os barbeiros

Acervo Casa de Oswaldo Cruz

Ezequiel Dias (1880-1927) conducted research on hematological aspects of Chagas disease and tested insecticides for use against barbeiros

Carlos Bastos de Magarinos Torres (1891-1984) empreendeu importantes estudos sobre a patologia da tripanossomíase americana

Acervo Casa de Oswaldo Cruz

Carlos Bastos de Magarinos Torres (1891-1984)

undertook important studies on the pathology of

American trypanosomiasis

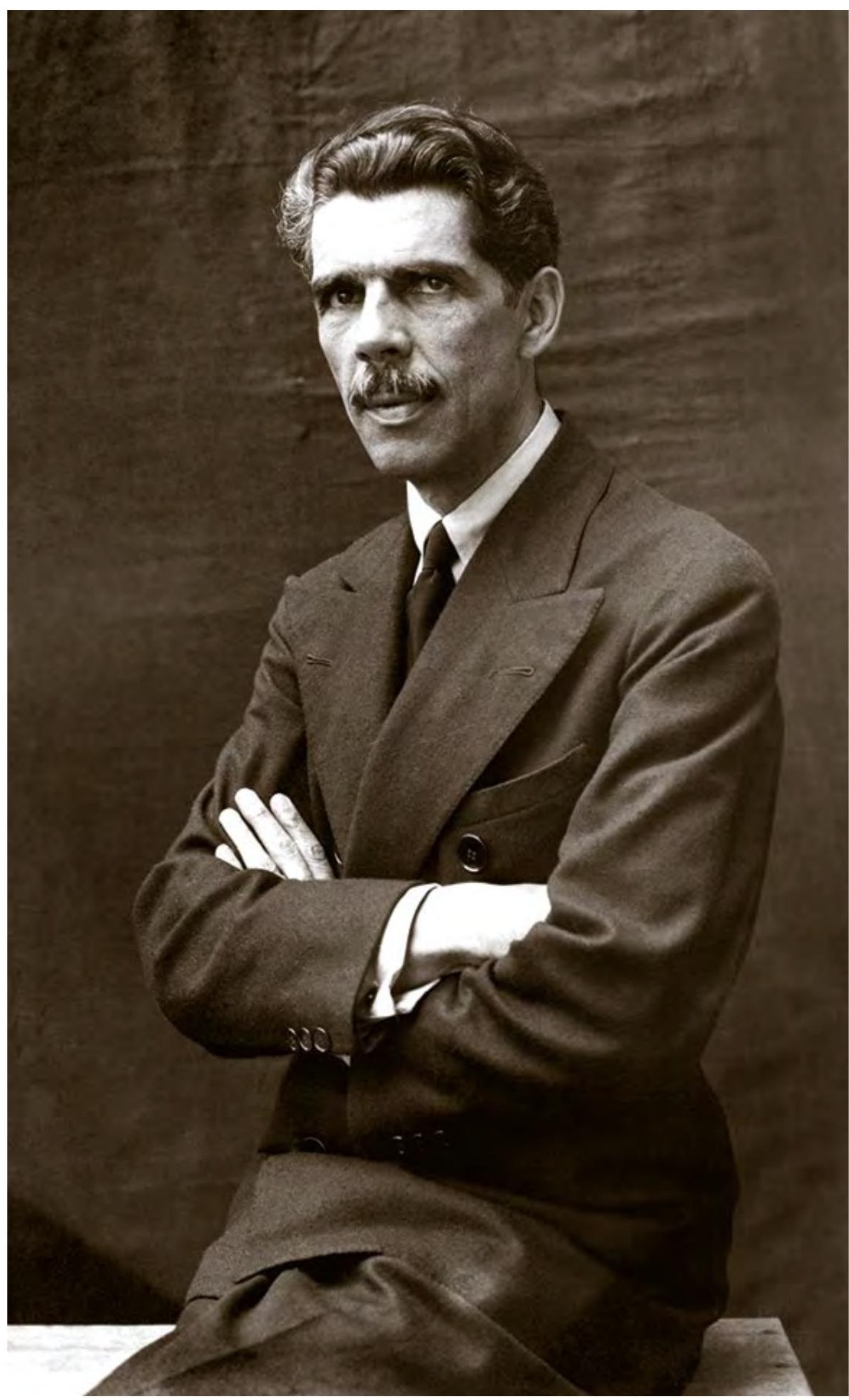

Eurico Villela (1883-1962), primeiro diretor do Hospital Oswaldo Cruz, foi importante colaborador no estudo da forma

cardíaca da tripanossomíase americana

Acervo Casa de Oswaldo Cruz

Eurico Villela (1883-1962), first director of the Oswaldo Cruz Hospital, was an important collaborator in research into the cardiac form of American trypanosomiasis

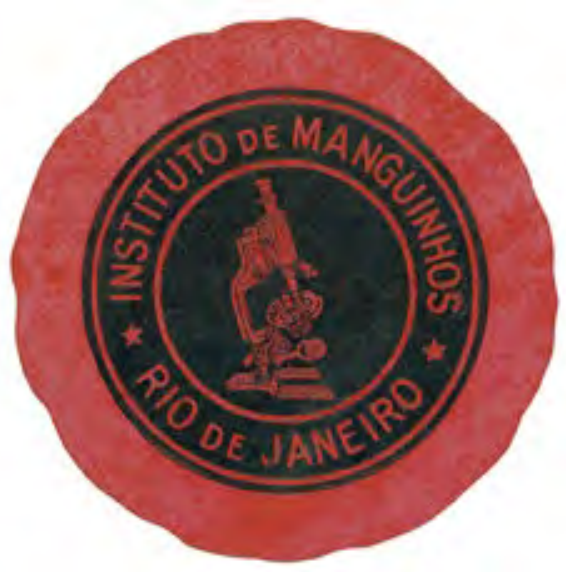



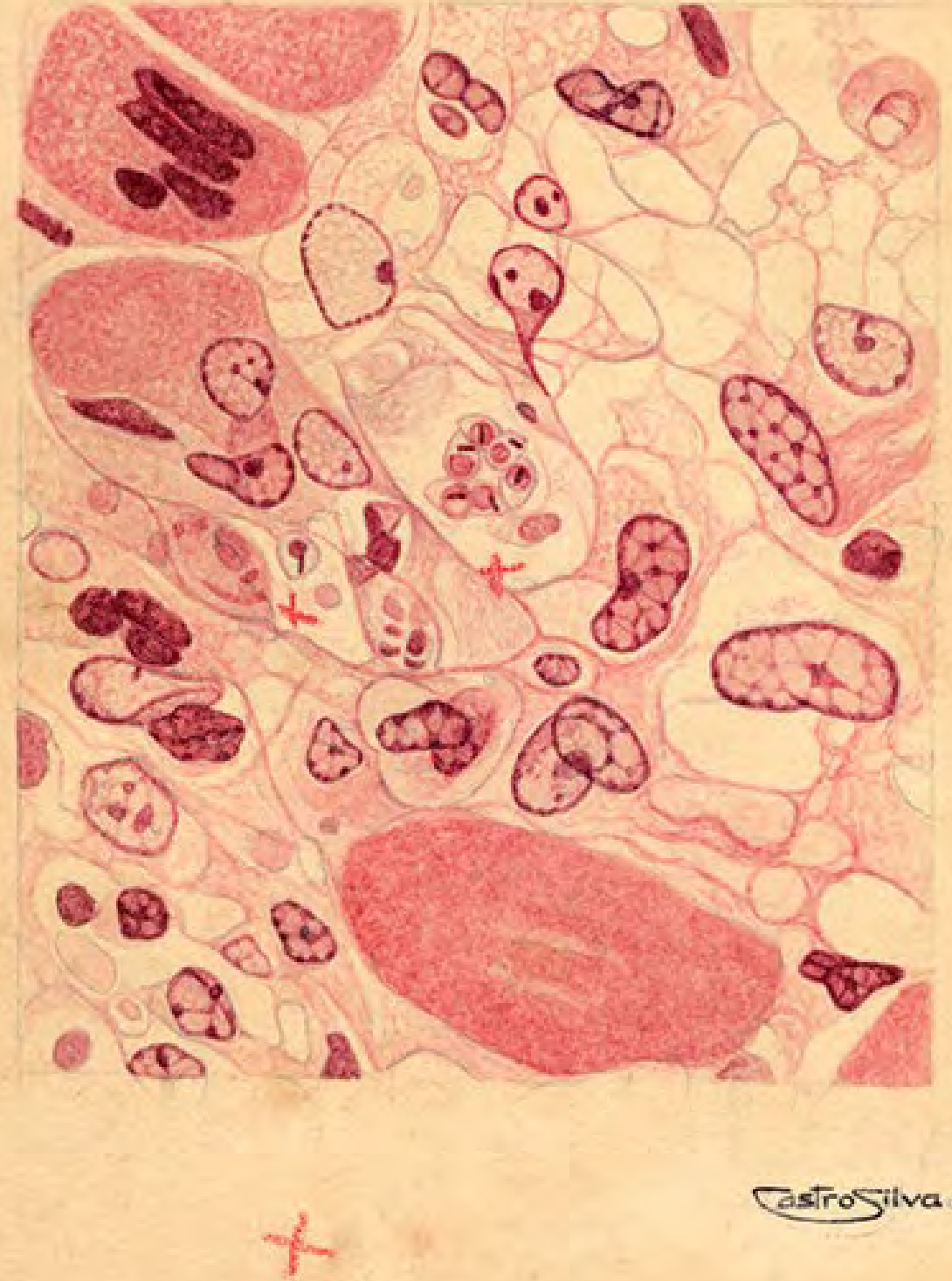

Castrositva del.

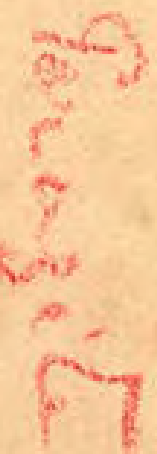

Ao patrimônio da escola de Oswaldo Cruz, muita vez o tenho afirmado, pertencem os trabalhos relativos à tripanossomíase americana; $e$ se glórias neles pudessem ser proclamadas, delas partilhariam todos os trabalhadores de Manguinhos.

Carlos Chagas

\section{Studies on American}

trypanosomiasis stand among the assets of the Oswaldo Cruz school, as I have often stated; and if any glory may be attributed to them, all workers at Manguinhos share in it.

Carlos Chagas 
MEMORIAS DO INSTITUTO OSWALDO CRUZ
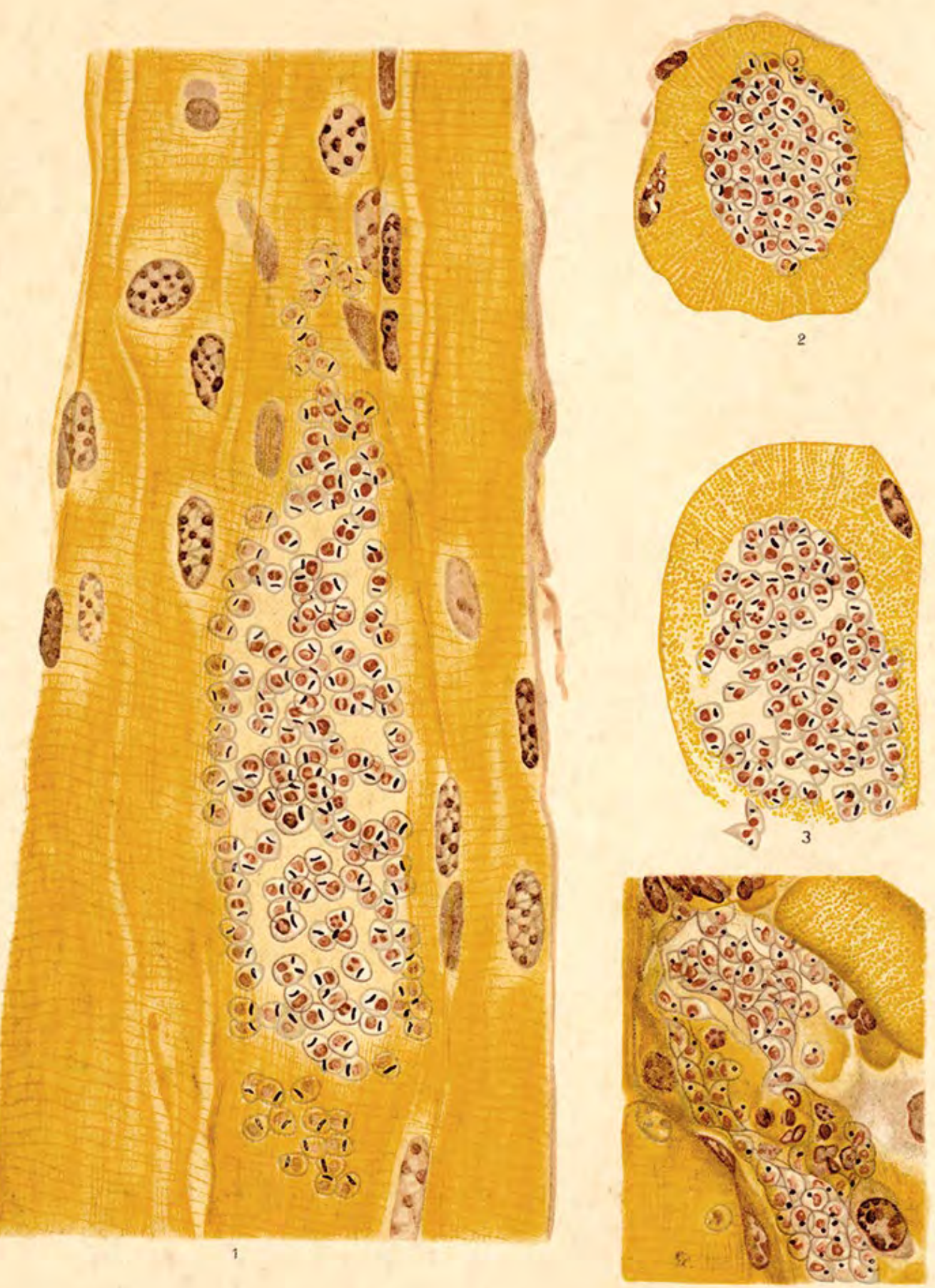

CastroSilva del.

Cortes histológicos indicando a presença do T. cruzi nos tecidos,

publicados em artigo de Gaspar Vianna nas Memórias do Instituto Oswaldo Cruz, em 1911

Prancha de Castro Silva

Acervo Casa de Oswaldo Cruz

Histological sections indicating the presence of T. cruzi in tissues, published in an article by Gaspar Vianna in Memórias do Instituto Oswaldo Cruz, in 1911

Engraved plate by Castro Silva

Folhas iniciais de manuscrito de Carlos Chagas sobre a nova tripanossomíase

Acervo Casa de Oswaldo Cruz

First pages of a manuscript by Carlos Chagas on the new trypanosomiasis 
5 - ESTUDOS SOBRE A DOENÇA DE CHAGAS | RESEARCHING CHAGAS DISEASE

reypousomian bazile: Mova merbitia Luma

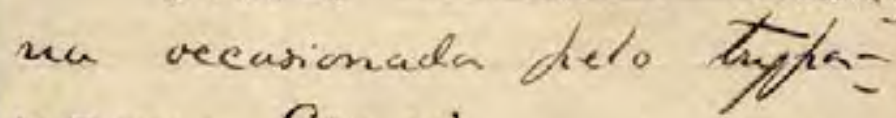
nozme Cruzi.

Trabalho realiade sab a diveciaio ob dr. Comald Cruz felo -

- Ir Cantor Chag chefe de cersico of in Z.tato Qsralds Cing. Snorymi:

Schizatrefounge. Shimes: lite paragitaria.

Defimicas.

4 thyfiangomiase braplaira $i$ unua nublt. \& in symbtomatosic ens. hera, ore de evrlacal agnah, o mais das vegs de evvluça Chonica, grassand entancicamena nas fmon contamenaly, onde recarima un eleven caefficiente da lethatihle

Ueu is elementh eundibs seacis

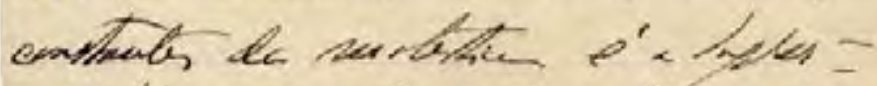
Fythic la flewdol tisrende, an formaci- frewert de xulueses decion.

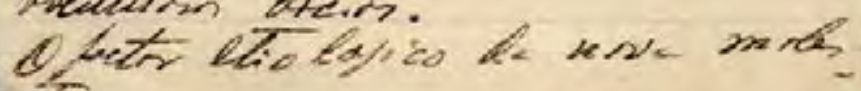

t' un hewo-thagellas, deceminas dy heroposma cruzici, Haus som tito sota picada de une quantle hematophago, o Préato ma negistal prumean= Fras vas Smicitios las. manes abigass mas peases on hacedes a atacaras o han wen á usite, a mota ds

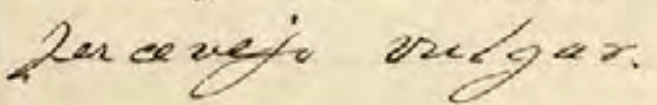

Systhematica do parazita. A haveng-, no cyclo biologico do pungit Q now mebtio, de nua divisán multigle egular no pulmer on vertebras e a curmeai de divisa. engitulinal hinasia no sangue ferifherico levaram was à creaceas a un novo geners, o genero schizothypa:

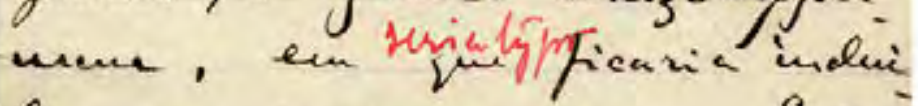
da a nova trecie. Estu: dos porterious, provin, ualigaos no Litituto de Slanguicwher (Traballon de A. Rachado ef. Vianua) vieram dermy tran a enistencia de una divisa. multipla no trypa

125 

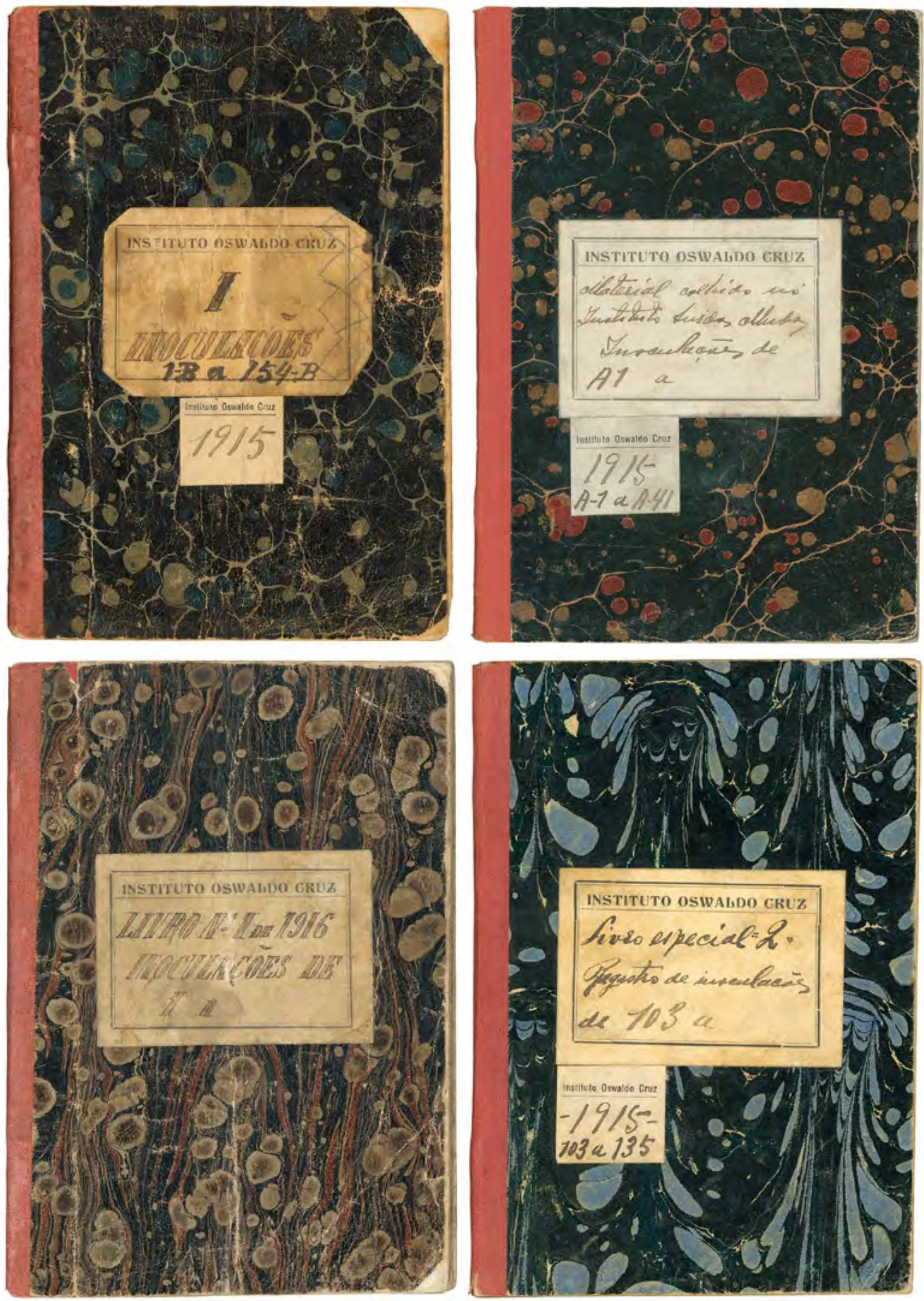
5 - ESTUDOS SOBRE A DOENÇA DE CHAGAS I RESEARCHING CHAGAS DISEASE

$$
\text { Din ted juch a } 1 s / s
$$

3sutis, un cat a un ondit invala:

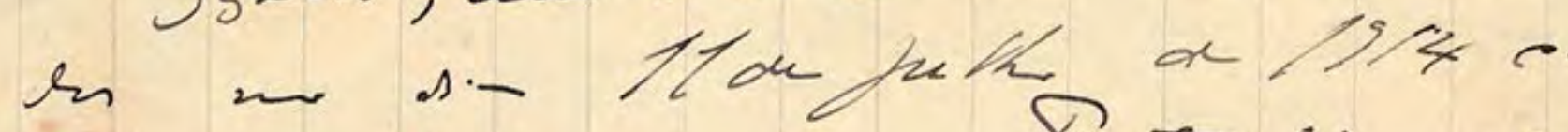
rangur $\alpha$ menin- Setzeki-, Sangy

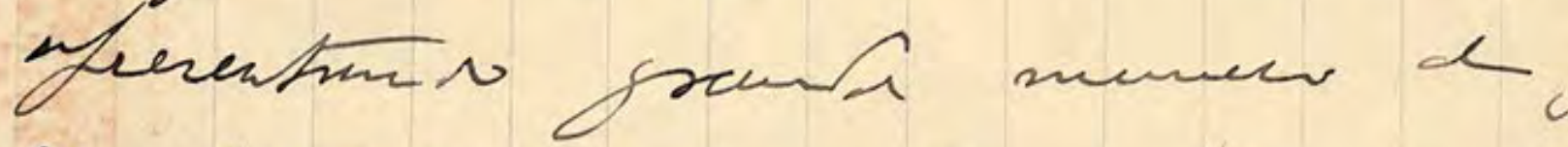
Qn ansuria afureut $\alpha$ format tinas Gaial 12 - as grotur - gavila IIC cuchorritho. 8.14 a jiek.

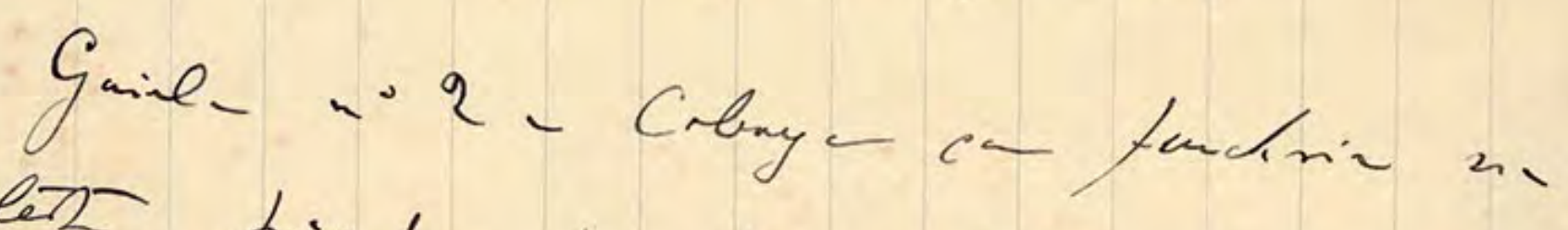

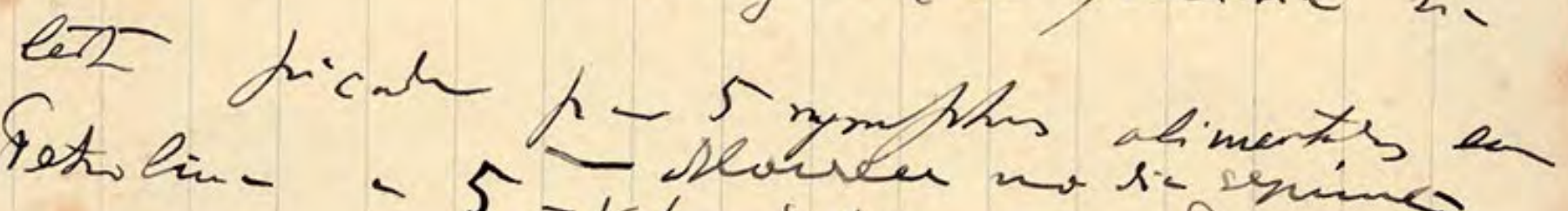

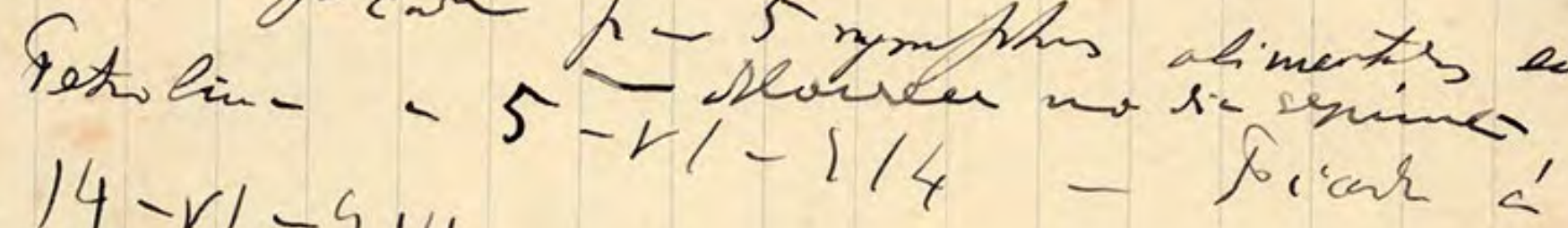
$14-11-914$.

Di- Is e gich,

Cobuy- inocular can ramme of we-

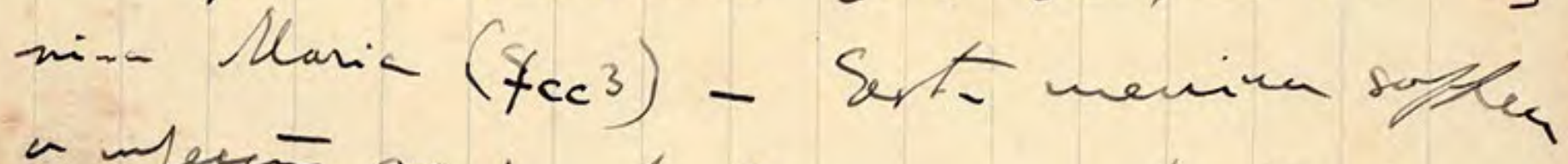

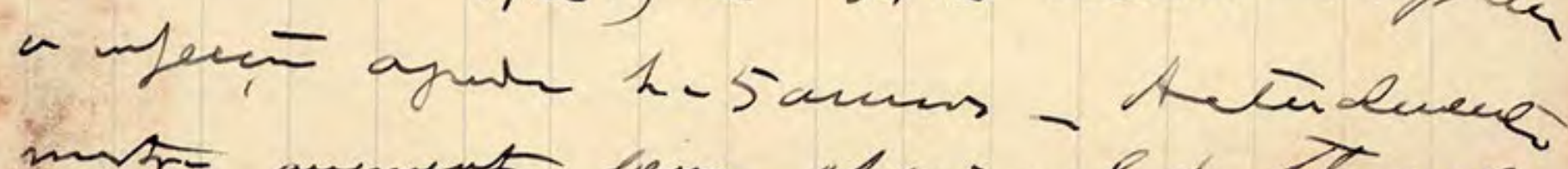

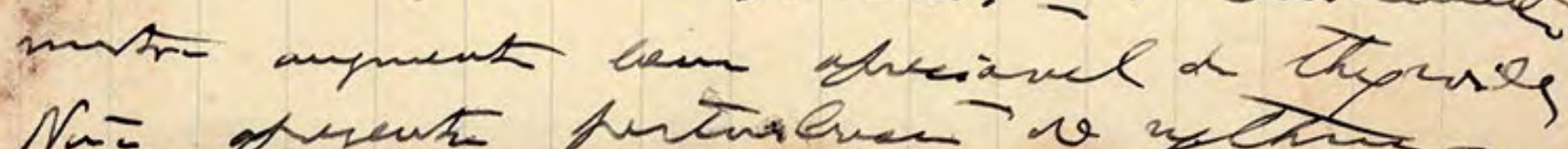

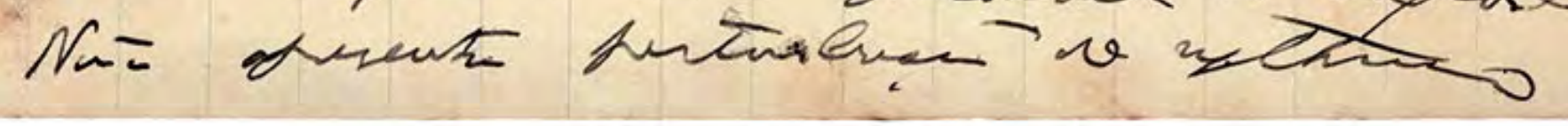

Anotações de Carlos Chagas sobre experiências de inoculação do
em julho de 1914 Acervo Casa de Oswaldo Cruz

Carlos Chagas's notes on experiments in which

Trypanosoma cruzi was inoculated in
experimental animals, conducted in July 1914

127 


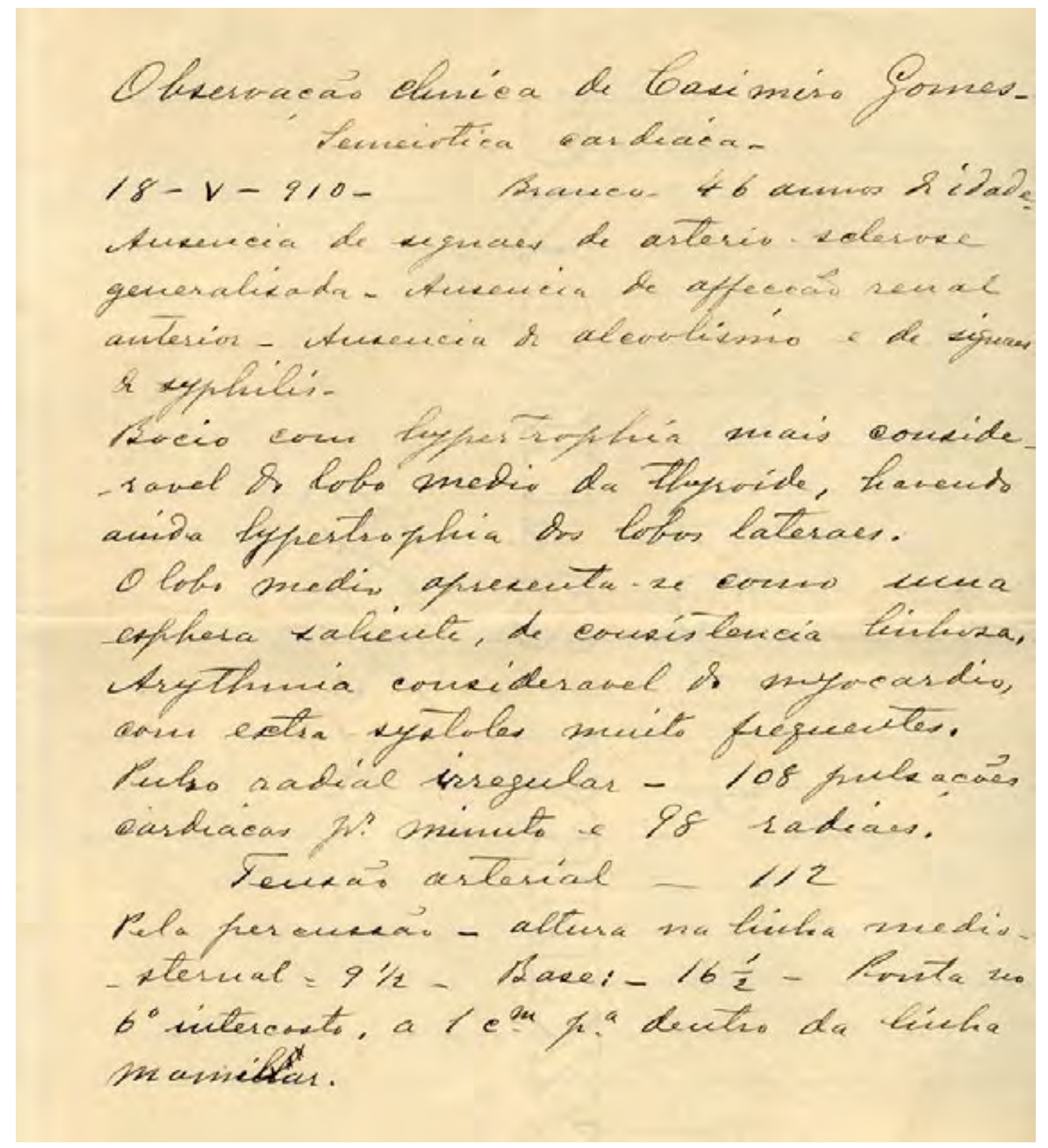

Observações sobre os sintomas cardíacos

de um paciente, em 18 de maio de 1910

Acervo Casa de Oswaldo Cruz

Observations on a patient's cardiac

symptoms, May 18, 1910

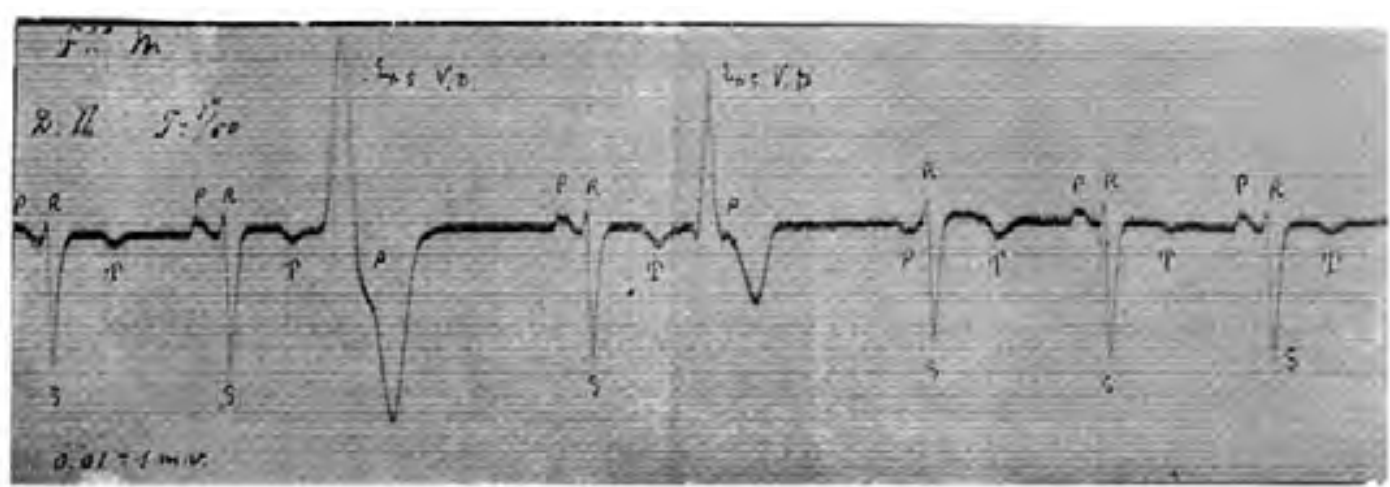

Traçado eletrocardiográfico de morador de Lassance com a forma cardíaca da doença. Chagas foi pioneiro no uso do eletrocardiógrafo no Brasil

Publicado em artigo de Carlos Chagas e Eurico Villela

nas Memórias do Instituto Oswaldo Cruz em 1922

Acervo Casa de Oswaldo Cruz

Electrocardiographic tracing of a resident of Lassance

presenting the cardiac form of the disease. Chagas

pioneered the use of electrocardiography in Brazil

Published in an article by Carlos Chagas and Eurico

Villela in Memórias do Instituto Oswaldo Cruz in 1922 

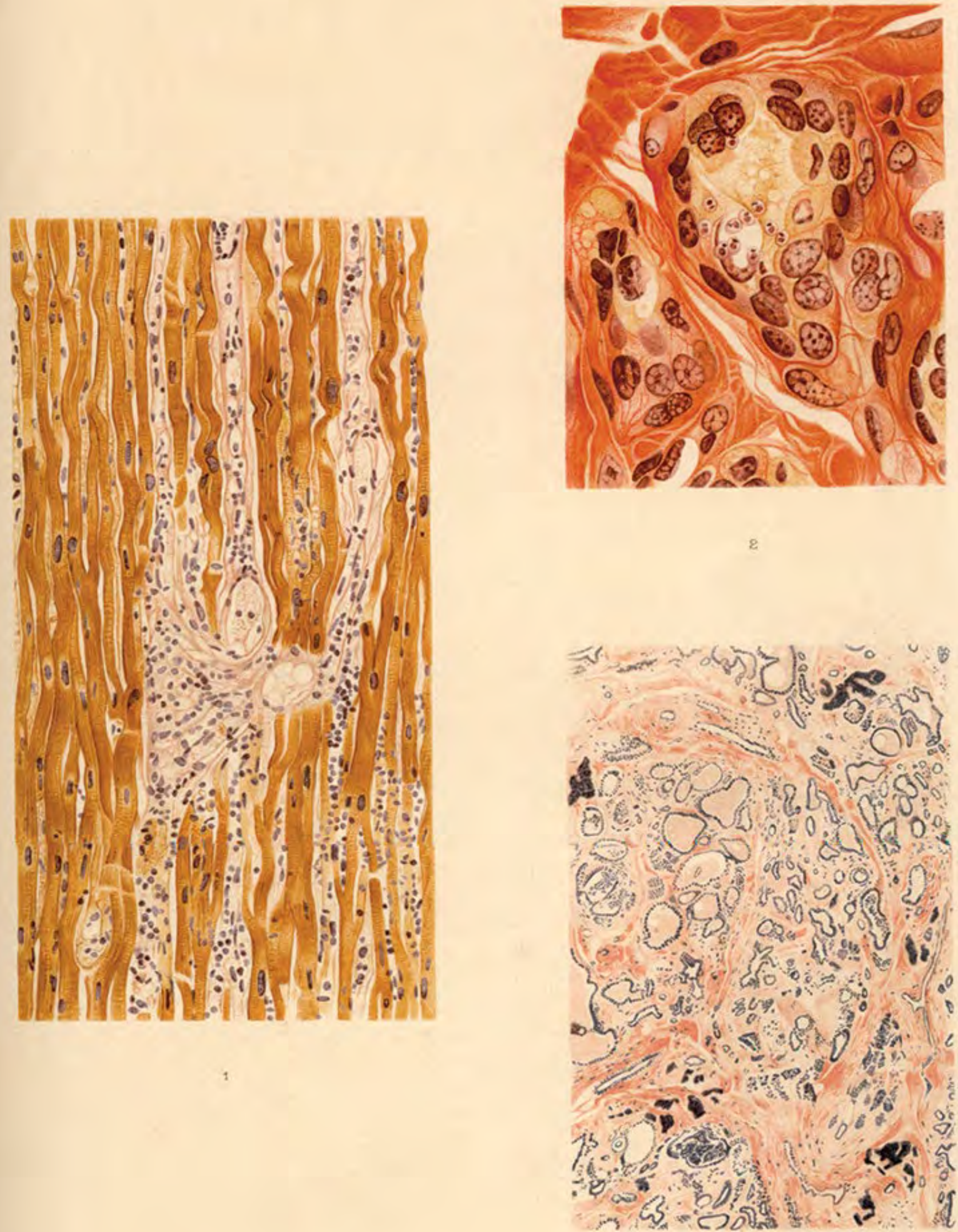

3

Castrosilva del.

Cortes histológicos publicados em artigo de Chagas nas Memórias do Instituto Oswaldo Cruz em 1916 


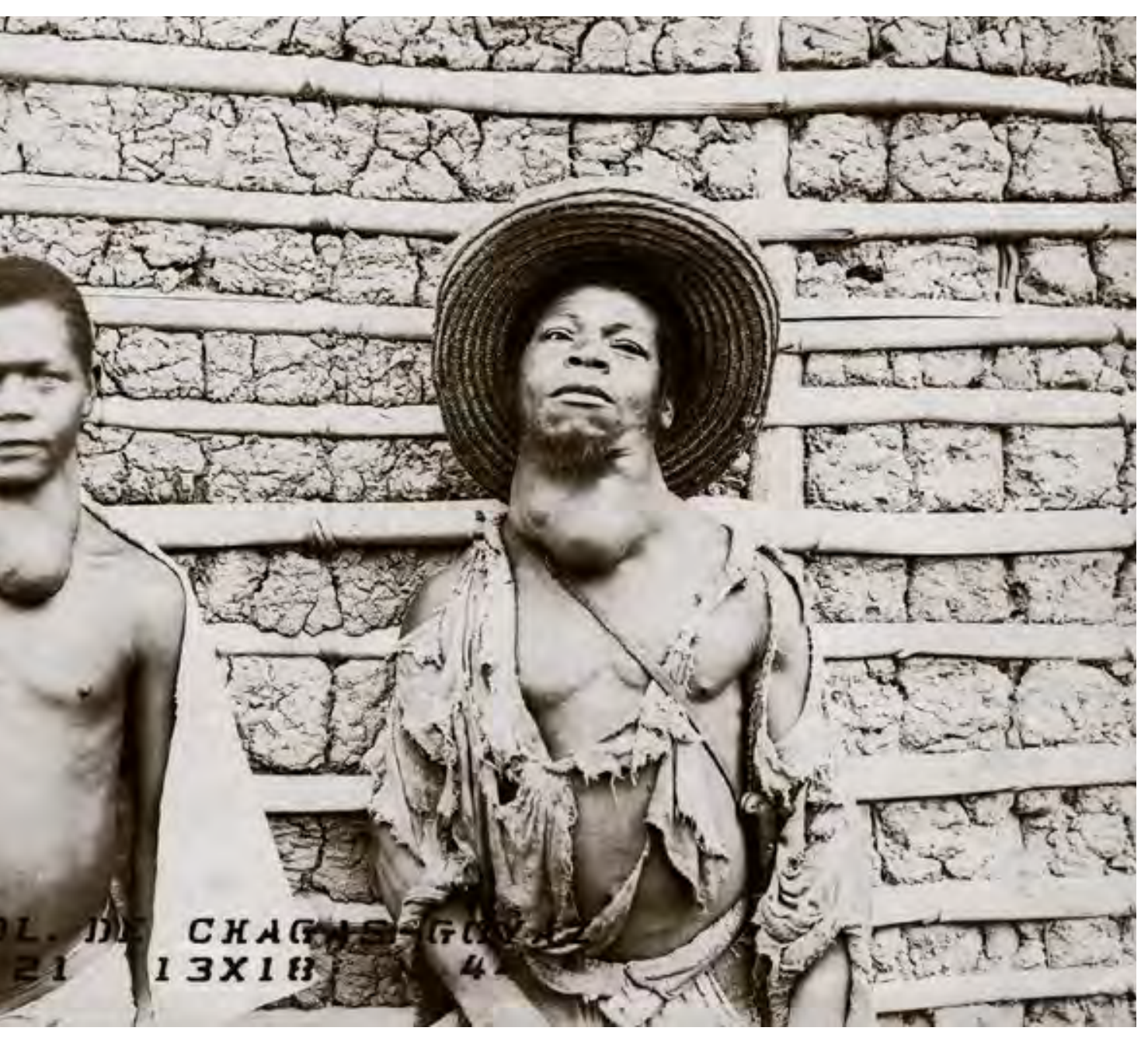

É habitual dizer-se, e nós mesmos já temos cometido esse pecado, que o povo sertanejo é indolente e sem iniciativa. A verdade, porém, é outra. A ausência de esforço e iniciativa dessa pobre gente é proveniente do abandono em que vive, e da incapacidade fisica e intelectual resultante de moléstias deprimentes e aniquiladoras, cabendo nessas regiões à moléstia de Chagas a primazia desse malefício.

Arthur Neiva e Belisário Penna

It is usually said - and we ourselves have committed this sin - that the sertanejos are lazy and lack initiative. Yet the truth is otherwise. These poor people's lack of drive and initiative derives from the state of abandonment in which they live, and from their physical and intellectual incapacity, which results from depressing, destructive sicknesses, with Chagas disease the worst such evil in these regions.

Arthur Neiva and Belisário Penna 



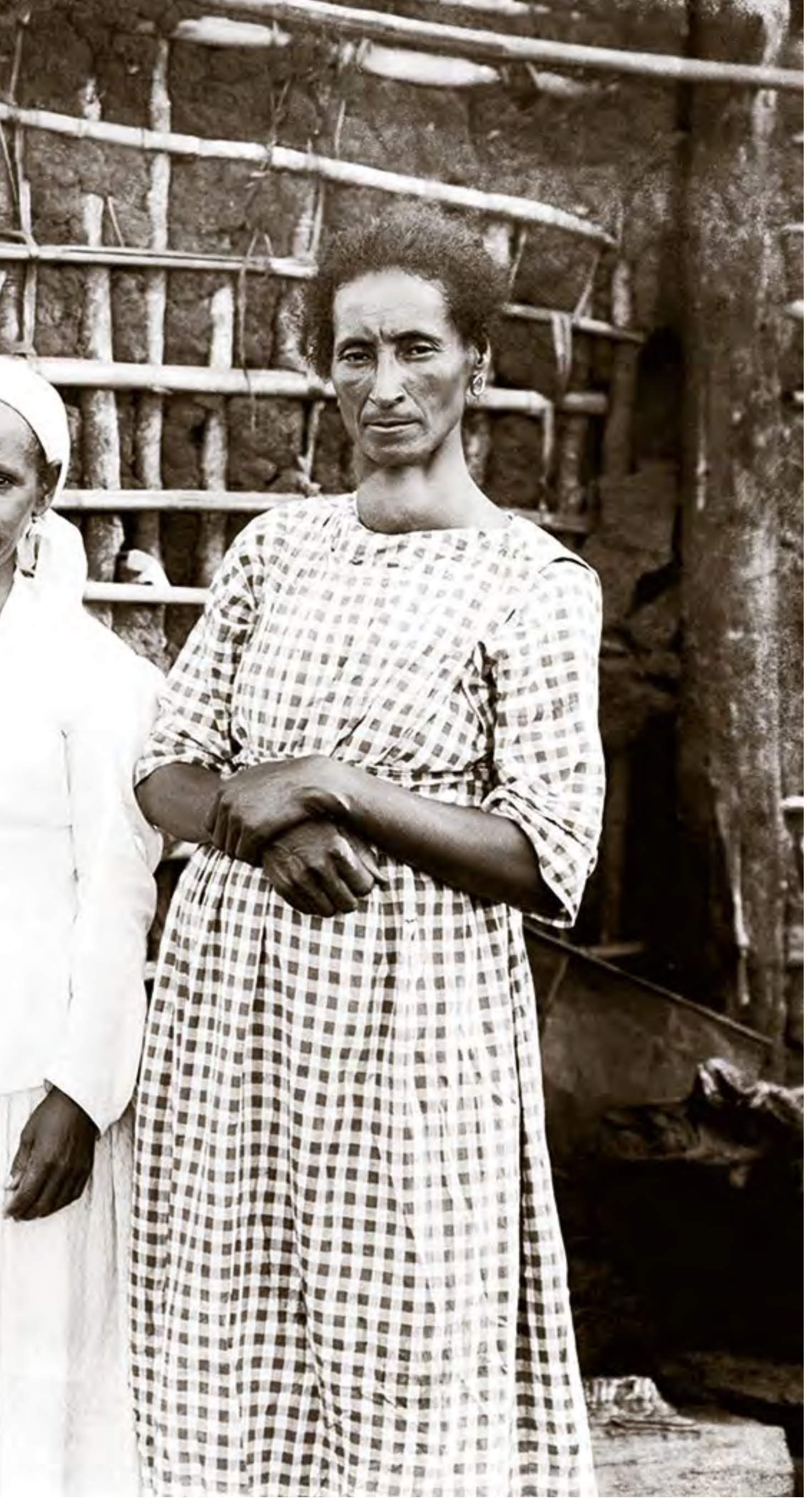

Vi tudo isso, vi, talvez, mais do que isto, mas nem tudo sei exprimir na forte impressão que me causaram os fatos observados. E, quando vendo ainda passar diante de minha retina mental a figura da miséria humana que a moléstia identificou corporizada e semimorta na imensidade de sua desdita, só consigo voltar a mim mesmo considerando o trabalho científico que visa à redenção daquele povo, e, num natural desvelo patriótico, descanso aos acenos da esperança de uma profilaxia inadiável, em trabalho fecundo e salvador.

Clementino Fraga

I saw all this - all this and perhaps more - but what I observed left such a deep impression that I do not know how to express it all. And when, moving across my mind's eye, I still see that figure of human misery made manifest and embodied in the disease, halfdead in the enormity of its misfortune, I am only able to return to my senses if I remember the scientific work that seeks to redeem these people and, with natural patriotic fervor, I place my trust in the hopeful signs of urgently needed prophylaxis through fruitful, salvational work.

Clementino Fraga 

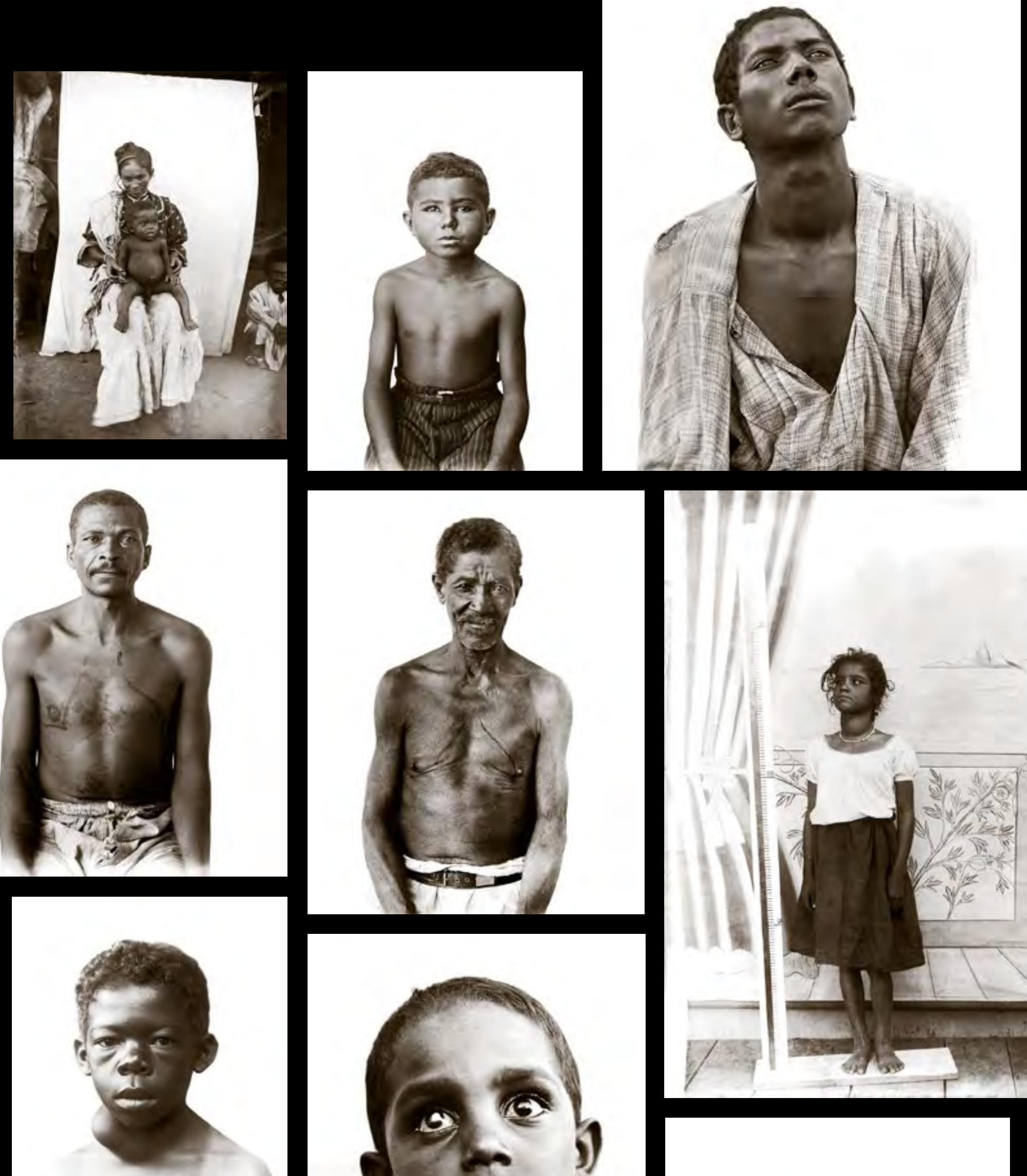

Casos descritos como portadores

da doença de Chagas

Acervo Casa de Oswaldo Cruz

Cases described as carriers of Chagas disease
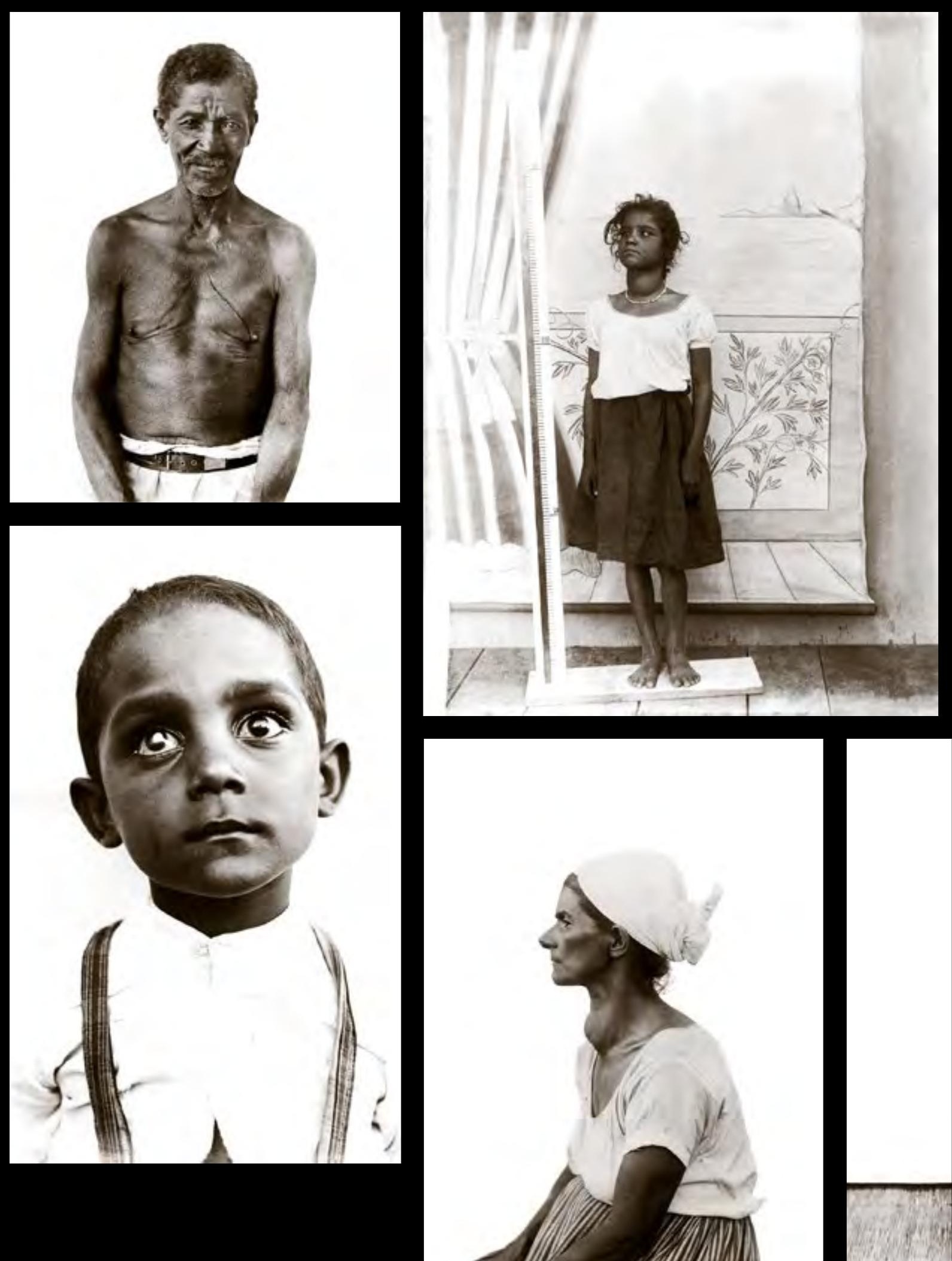


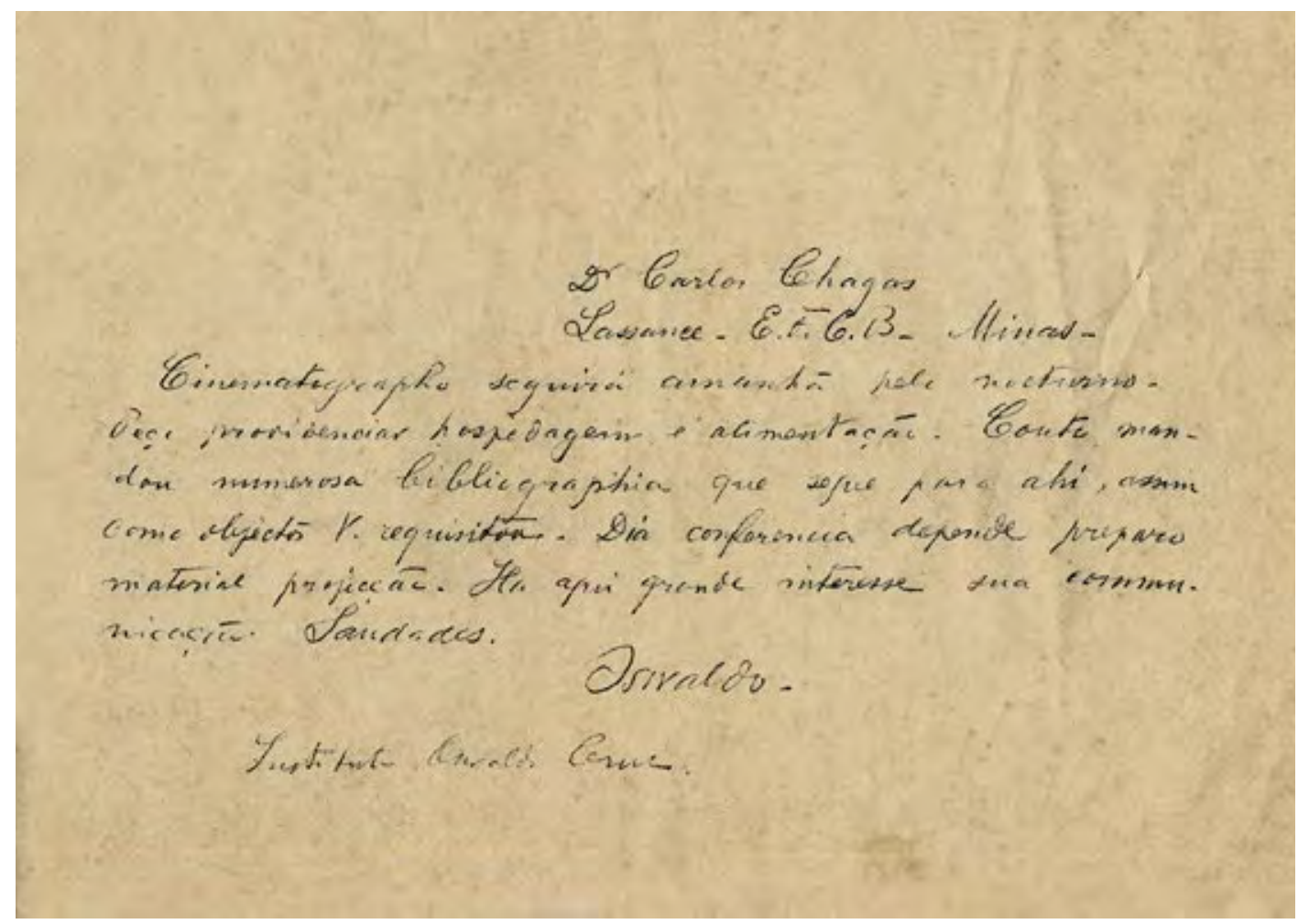

\section{MOLESTIA "C.ARLOS CHAGAS"}

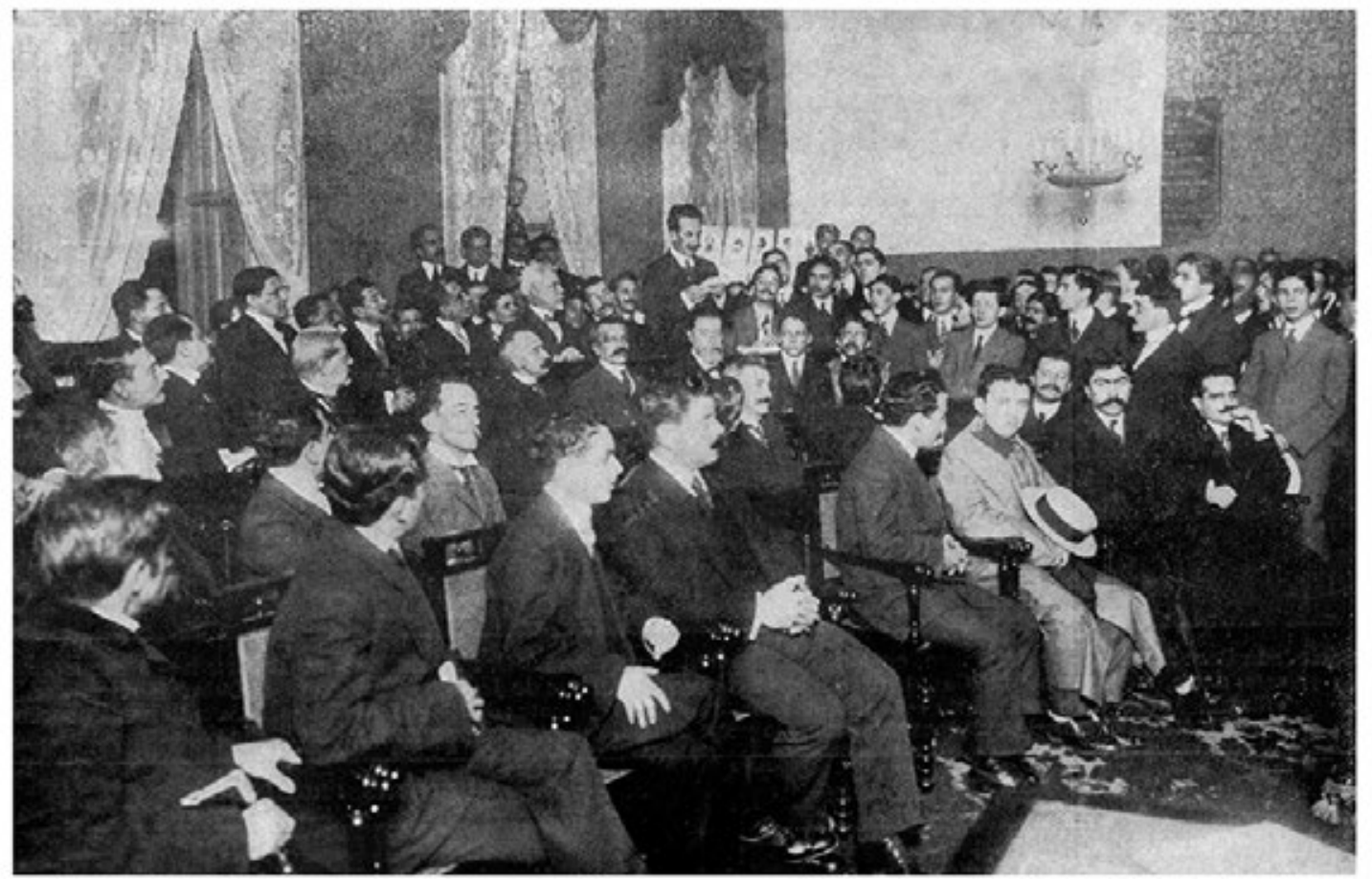

O Dr. Carlos Chagas, lendo a sua conferencia na Academia Nacional de Medicina sobre a đcscobcrta da molestia que tem - seu nome e que e preduzida por uma especie de carrapato a que chamam barbeiro - molestia terrivel que ataca geralmente os que residem em casas de taipa, cobertas de sage, isto é, grasule parte da populaçáo pobre do interior dos Estados. Essa conferencia feita na prescnça do presidente da kepublica e de numeroso e selec:o auditorio fol illustrada com projeçóes luminosas e causou profunda impressão.

Telegrama de Oswaldo Cruz a Carlos Chagas sobre o envio de cinematógrafo para Lassance, a fim de preparar imagens a serem apresentadas na Academia Nacional de Medicina. Rio de Janeiro, 1910 Acervo da Casa de Oswaldo Cruz

Telegram from Oswaldo Cruz to Carlos Chagas about dispatching a filmmaker to Lassance to capture images for presentation at the National Academy of Medicine. Rio de Janeiro, 1910

Moléstia 'Carlos Chagas'

OMalho, 12 ago. 1911

Segunda conferência de Chagas na Academia Nacional de Medicina Acervo Fundação Biblioteca Nacional

"'Carlos Chagas' Disease"

O Malho, Aug. 12, 1911

Chagas's second conference at the National Academy of Medicine 


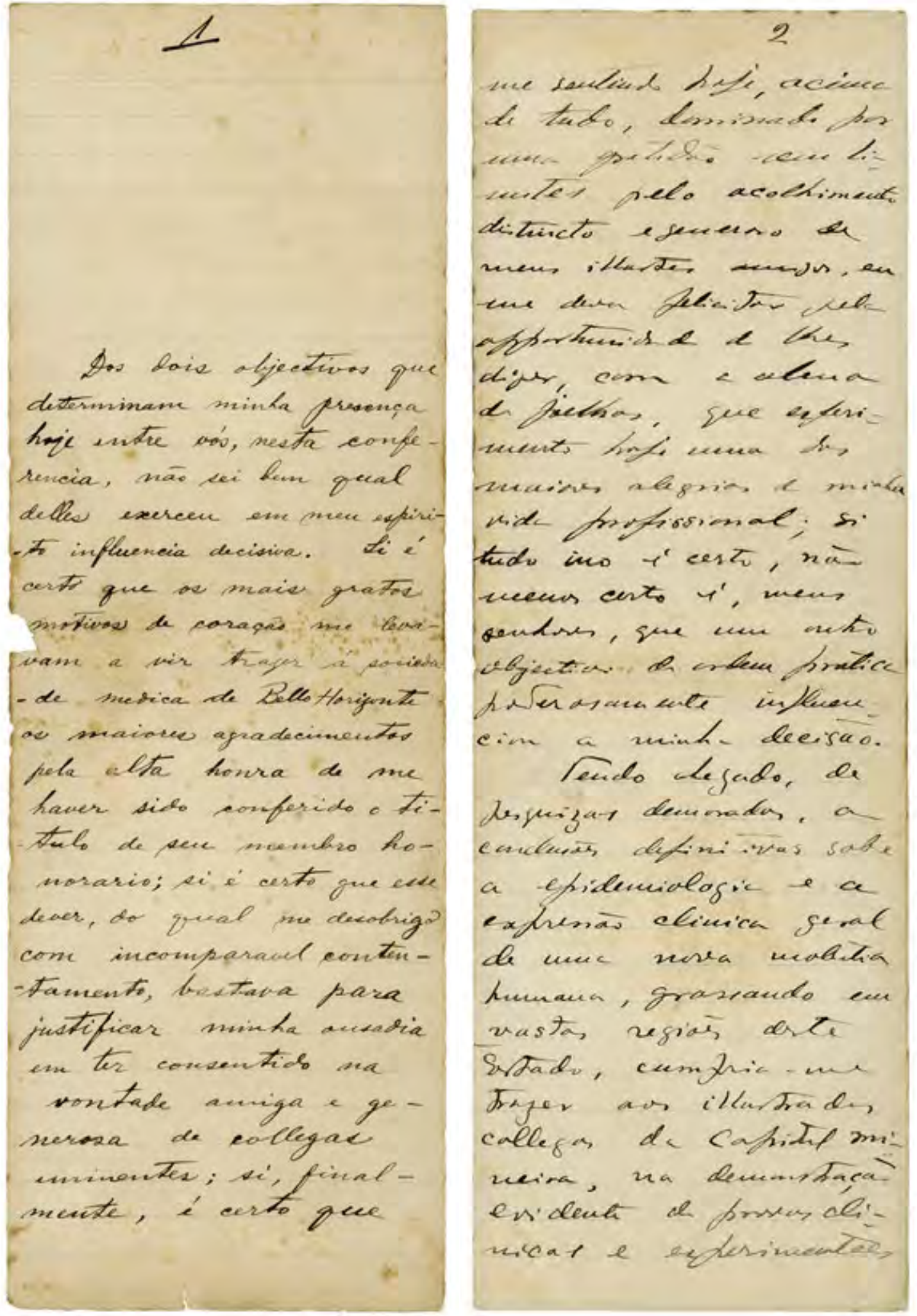

Calcule (...) quais são os resultados sociais de semelhante flagelo, no nosso país. É dever patriótico divulgar essas noções pelo Brasil inteiro, que deve estar alerta contra esse inimigo terribilíssimo!

Carlos Chagas

Just calculate (...) the social consequences of such a scourge within our country. It is our patriotic duty to disseminate these notions across all Brazil, which must be on its guard against this most terrible enemy! Carlos Chagas

Folhas iniciais de manuscrito da conferência proferida em 1911 por Carlos Chagas em Belo Horizonte Acervo Casa de Oswaldo Cruz

First pages of the manuscript of Carlos Chagas's conference in Belo Horizonte, 1911 


\title{
NOVA ENTIDADE MORBIDA DO HOMEM
}

PELO

\author{
Dr. CARLOS CHAGAS.
}

Reimpresso do * BRAZIL MEDICO * N. 43 de

15 de Novembro de 19 ro.

RIO DE JANEIRO - MANGUINHOS

66

1911

Separata de trabalho publicado por Chagas no

Brazil-Medico, relativo a sua primeira

conferência na Academia Nacional de

Medicina, realizada em outubro de 1910

Acervo Casa de Oswaldo Cruz

Reprint of Chagas's first conference before the

National Academy of Medicine, in October

1910, published in Brazil-Medico 


\section{A DOENGI DE CARLLS CHAGAS|}

Ưma sessão memoracel na Academia Nacional de Bietheiua

(....au Brésil, certaines sources qui donnent le cot. rie, $n$ out plits d'action de ce gene, lorsiquelles arrivent canalisćes dans la vil. le"... - Bozviez, Géogra. phic Médicals.)

Todos os que assistiram, e era legiáo - auditorio, á sessáo da Academia Nacio nal de Medicina, no set salẫo do Syllo geu Brazileiro, năo puderan reprimir a maior expressăo de tristeza, reconliecen do, pelas projecçōes luminosas e pela fita cinematographica que illustruram a demonstraçâo scientifica do Dr. Chagas, que ha, em una vasta zona central do Brazil, "m arande flagello, inclemente como patudisno de certas regiōes amazonicas, cruel como a febre amarela ora felizmente banida desta cidade. Aquella procisșio de desgraçados, que só o cinematogratiho podia nos deixar apreciar na sua vida actual; aquelle bando de infelizes, que vivem sofírendo ou nascem morrendo, sio as victimas de uma endenta, cuja causa arimada Carlos Chagas desvendou, e que todo o mundo scientífico confirmou e applaudiu.

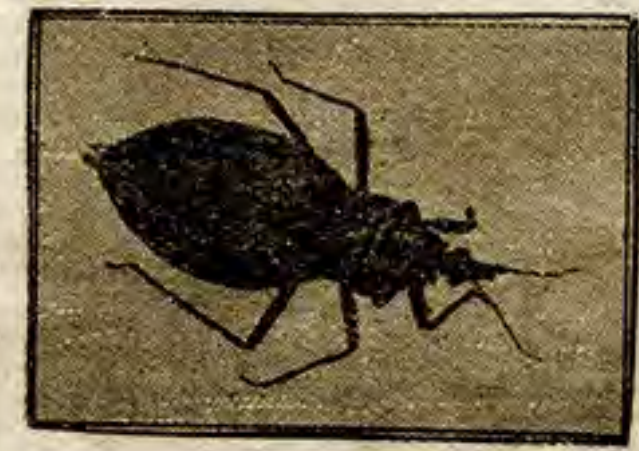

BARBEIRO

Inoculador da docnça

A doença de Carlos Chagas

O Paiz, 31 out 1910

Trecho de reportagem de Ismael da Rocha sobre a sessão da Academia Nacional de Medicina em que Chagas apresentou seus estudos sobre a

tripanossomíase americana

Acervo Casa de Oswaldo Cruz

"Carlos Chagas's disease"

O Paiz, Oct. 31, 1910

Excerpt from an article by Ismael da Rocha on the session of the National Academy of Medicine in

which Chagas presented his

studies on American trypanosomiasis

Um terrivel flagello que assola os sertões centraes do Brasil [trecho]

A Imprensa, 6 ago. 1911

Acervo Casa de Oswaldo Cruz

"A terrible scourge lays waste to Brazil's central hinterlands" [excerpt]

A Imprensa, Aug. 6, 1911

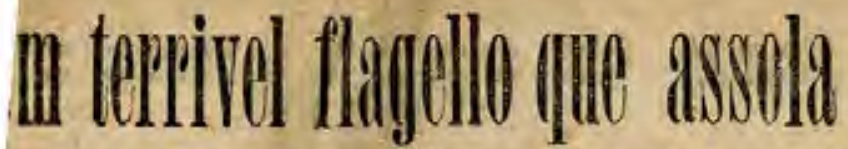
as sertices pentraers do Brasil

Uinas, Bahia, Goyaz, Mato-Grosso e parte de São Paulo presas do horrivel morbus

\section{Entrevista com o dr. Carlos Chagas, o sabio descobridor do temivel microbio}

Aquella Avenida Izabel de Pinho, lar-1 . - A distribuiç̌o geographica da moles.

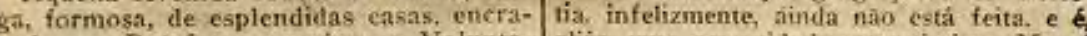
vadis em Botafogo, proximo a Volunta- alias, tma necessidade argentissima. Mas é rios, tem, no set1 numero 21 , a atoradia muito vasta a zona coutaminada: mais de de um dos mais eminentes brasileiros, o um terco de Minins. grande parte de Goyaz dr. Carlos Chagas. Este conhecido medi- e Mato Grosso, o sul da Bahia, e talvez co e scientista patrio, salbio bacietiolo- 8 . Paulo. Nas souals contaminadas - eis gista, vai para tres annos descobriu o mi- a tristissima verdacle - a populaçá inteire crobio de uma molestia que $e^{\text {a }}$ a uniea que

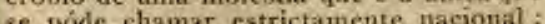
se póde chamar estrictamente nacional : e a "Sehizotripanose de Schizotripanum, que e o microbio que the es causa. Este é o nome scientifico, mas 3 denominaç̄o pratica \& "thyroidite parasitaria". sendo gue nos circulos medicos de uso appelíidal-a "molestia de Chagas", em gloria ao set benemerito investigatior:

O dr. Carios Chagas estava felizmente O dr. Carios Chagas estays for

Fez-nos conduzir á sala de visitas, que arranjadia cont arte e boni gosto.

- Dr. Chagas, sabendo que vai fazes uma conferencia no sablatio...

- Náo, a minha conferencia fícon transferida para segunda-feira.

Como salic, jă, sobre o assumipto, fiz, ha mezes uma conferencia na Academia de Medicina.

Foi apenas un ligeiro eshoco clinico Foi apenas un ligeiro estaco clinico logares infeccionados onde passei cerca logares infecciemados onde passei cerca
de 8 mezes estudando, e tive ocesisia de de 8 mezes estudando, $e$ tive occasiaso de
ohter novos conlecimentos, porque sáo infinitas as faces queapresenta essat molestia. Tem constantemente para o estudioso campo vastissimo de interesse sempre novo.

$A$ conferencia que agora vou fazer ${ }^{2}$ um complemento da primeira e desta vez com demonstraços praticas, gracas ao com demonstraçoes praticas, gracas an

elemento elinico que trouxe de Mmas.
$O$ que irei dizer segunda-feira sera. pois, um resumo geral da parasitologia da molestia $e$ da cliniea

$\mathrm{E}$ encararei o assumpto tambem no ponto de vista social, mostrando a praticahilidade de meios applicaveis de prophylaxia.

Illustrarei a seseão com novas projeIllustrarei a sessăo com novas proje-
ceóes luminosas e nova fita cinematographica de casos clinicos.

- $\mathrm{O}$ doutor trouxe alguns doenies. - Sim. 14 doentes das principaes fór. mas clinicas.

Nesta occasiăo entrou pela sala uma crianca de pelle escurecida e cabellos de caboclo.

de caboclo.
-Olhe, este $\varepsilon$ um dos atracalos da - Olhe, este \& um dos atacalos
molestia, disse-nos o dr. Chagas.

De facto, a crianca êmpletamente aplrasica e, si bem tenha 8 asyos de ida. de, nāo apparenta mais que um menino de cinco.

Tem um ofhar maito vivo, vinha rodeada de brinquedos, c fazia carinhos as dr. Chagas.

dr. Trouxe-o conmigo, continuou este. porque é muito intelligente.

porque muito intelligente. Mudos. - Nāo nos poderia o dontor dar umas
idés, geraes que fossem, sobre a moles tin?

- Pois năo. O parasita ten localiza-

- Eb antes do doutor, ninguem tínha, stquet, noticia deste flagello?

- Ninguem, absolutamente

- Cabe-lhe, pois, inuegavelmente a glor...

Nĩo, interrompeu mokiesto o grande medico, cabe-me apenas at sorte de ter sido a primeiro. E foi interessante o facto da minhat descoberta. $O$ senhor sahe que a molestia se transmitte por meio do "barbeiro", que é am insecto que vive com o homem a habita as casas cuja construcçáo é primitiva, out mal cniclakla, como as da poptalaça pobre e de muitas hatitacues em nossos Estulos. Pois bem, nos intestinos do "barbetro" fui encontrar um parasita desconhecido. Fiz picar, entấ, animaes do Jaloratorio, que adoeceram. Dahi comciei mislias pesquizas.

$\mathrm{Im}$ Minas pude verificar que, em todas as casas onic havia o "barbeiro", as pessoas apresentavaun aspecto doentio. Estudando o sangue das pessoas gute offereciam os typos mais agudos da molestia, nellas fui encontrar exactamente o selisofrifonam. Dahi por diante tenho de continuo estudado esta molestia, retdadeiramente terrivel. e que, para o estudioso tem sempre aspectos novos, nois $\hat{\varepsilon}$, talvez, mais variadat que a syphilis, que ế, aliás, do mesmo grtipo zoologica da thyroidite parasitaria de que estamos falando.

- I. a cura deste horror?

- Ah! por emguant, nenhum meio theraveutico se conhece com efficacia, pelo menos, no periodo agudo... A prophylaxia, sim, tenho-a estudado com vantacem e a clla me referirei na proxima conferencia de segunda-feira. Como meio de cura, já mpregtei o " 606 ", mas sem resultado. Em gualđade de condiçốes com a molestia de ue the falo, so existe a molestia do somno, ná Árica, e que já está muito bem estudada pelos europeus.

Aliăs, a molestia brasileira tambem tem preoccupado o Velho Mundo, cujas revistas echnicis ou leigas tèm dedicado columnas inteiras a "schizotripanose".

Tem mesmo preoccupado mais a Europa que o nosso meio, não obstante a neninuma diffictldade que encontrei em me fazer acreditado. Nas regióes flagelladas, todos os medicos immediatamente acolheram,com grande curiosidade e interesse, o resultado de minhas experimentaçöes, Sim, porque a causa ć de uma horrivel evidencia e estí udo perfeitamente estudado, tanto que nảo temo a minima contestaçầo a tudo quanto tenlio dito e vou dizer.

Nesta ultima viagem, commigo foi una conmissăo doutissima, composta dos drs. Couto. Anstregesilo aswaldo Crinz, que Couto, Ausiregesilo e Oswaldo Cruz, que o mea mestre. Viram mass de 150 doentes 
CORRETo DA MANHa - Sexta-feira, 11 de Agosto de 1911

\section{A "doença Carlos Chagas"}

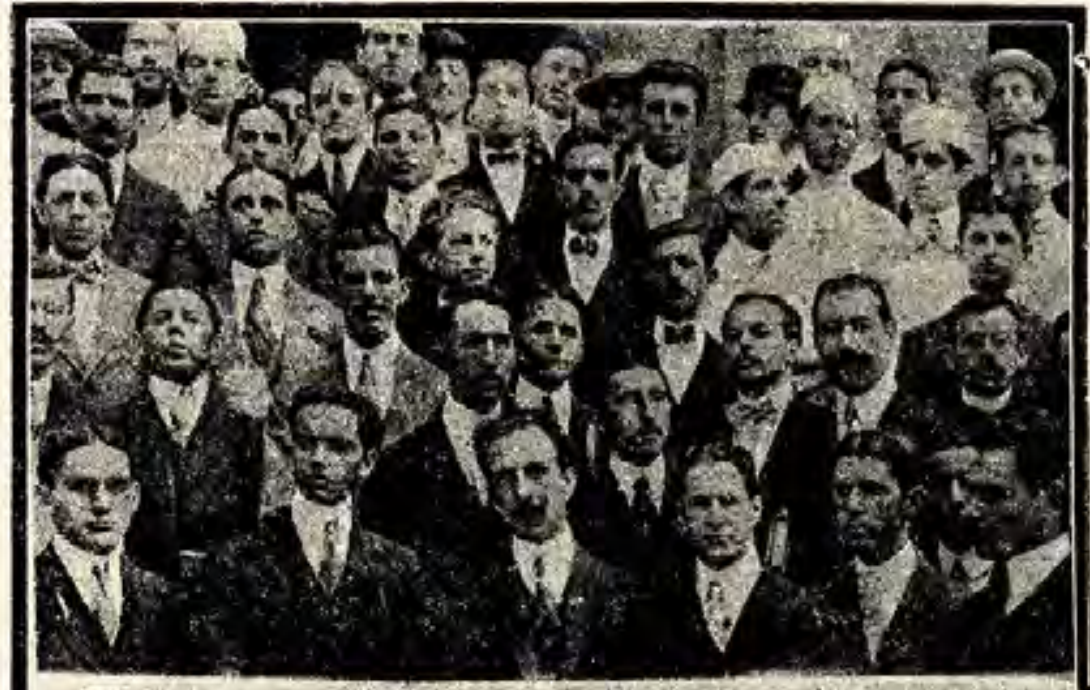

\section{A sessão de hontem}

no hospital da Misericordia

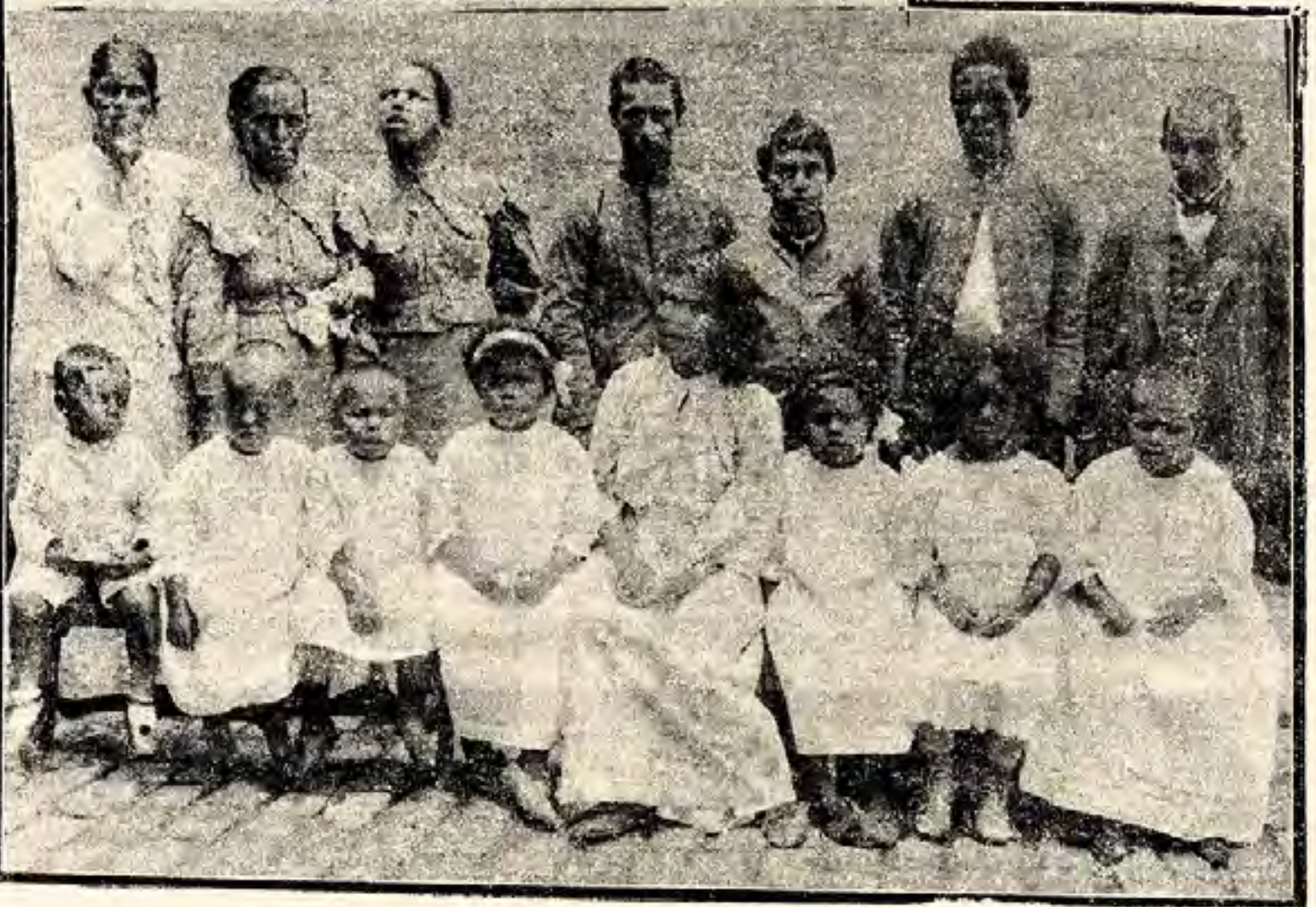

0 di. Carlus Chagre, rodeado por grande numero dos academicos que ascistiram a sun pretercio de hontem. Grupo de enfermos da edoenca Curlos Chagas

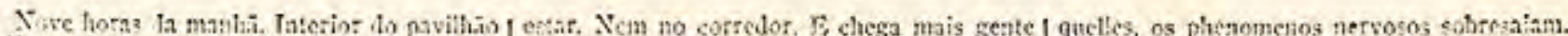

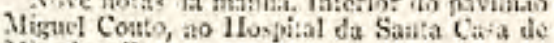
Miferisontit. Aingutem se pide nexe:. Teo: que um for-

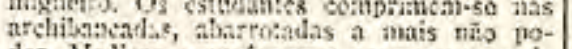
der. Misitsos o professonsts cone ervam-se de

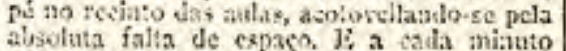
qtis se ession, é mais ketate ntic chega. Vialros

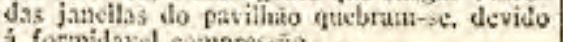

a formidavel eompressio...
is mais gente. ji is portas ninguem póde Questes, a fórma cardiaca dominara; na-

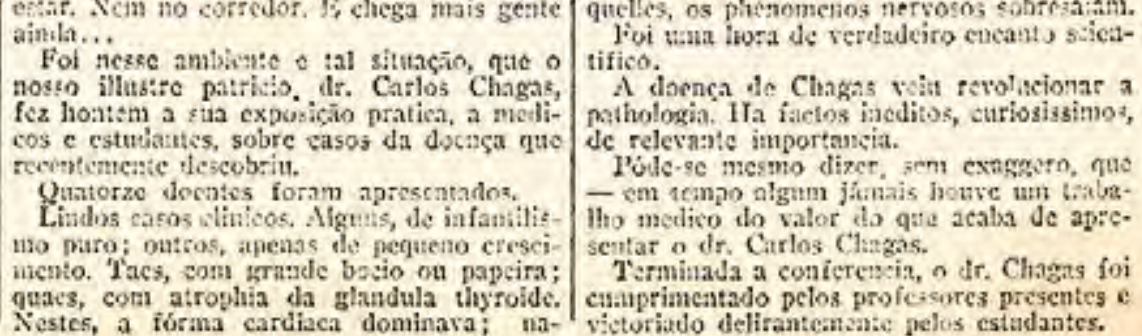




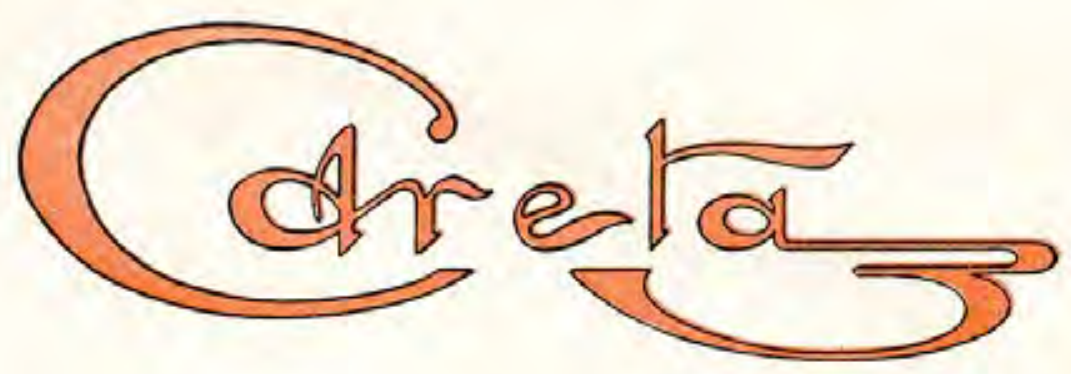

\section{REDACÇÃO E OFFICINAS: RUA DA ASSEMBLÉA, 70 - RIO DE JANEIRO}

\author{
ASSIGNATURAS \\ ANNO ...... $15 \$ 000$ | SEMESTRE . . . \$ \$ \$ $\$ 000$
}

NUMERO AVULSO

CAPITAL. .... 300 Rs. | ESTADOS. ... $400 \mathrm{Rs}$

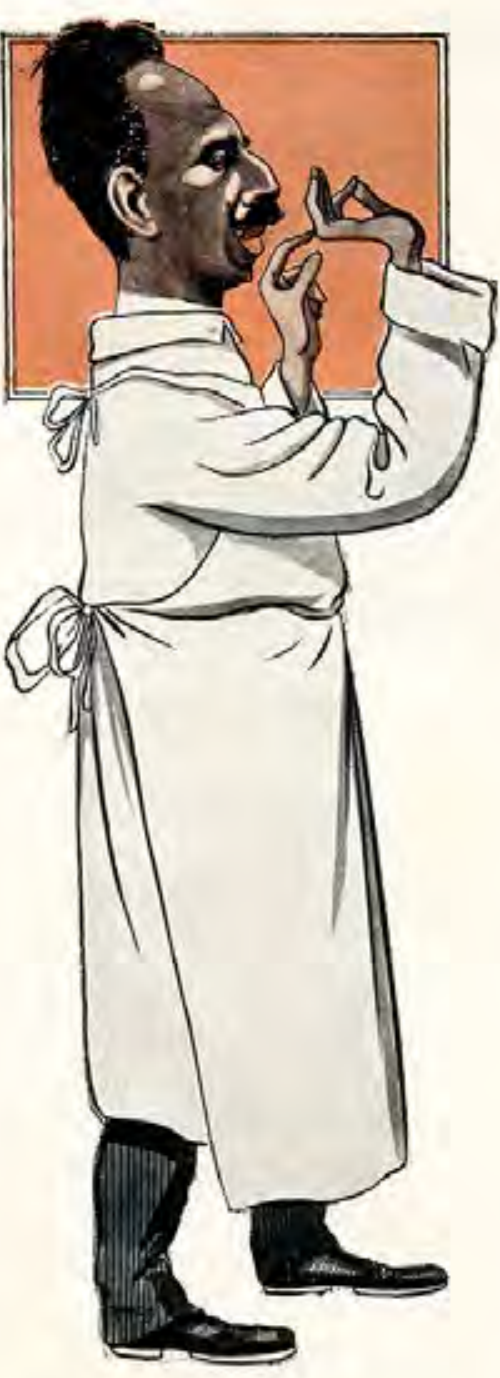

Dr. Carlos Chagas

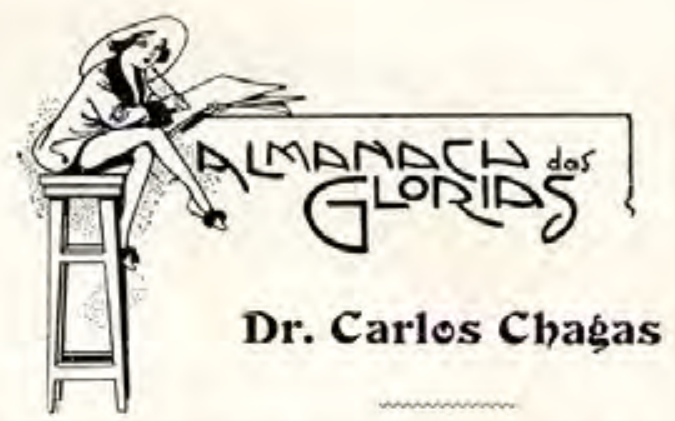

O Dr. Carlos Chagas, do nosso nacional Instituto de Manguinhos, é o benemerito descobridor da molestia que recebeu o seu nome na pia baptismal da sciencia.

A doença de Chagas, a thyroidite parasitaria, atacando a quinta parte das nossas indolentes populacões sertanejas, transmittida pelo abundante insecto denominado barbeiro, atrophia a glandula thyroide $\mathrm{e}$ produz, além de outros muitos males, o papo, o idiotismo, a desvirilisação, a paralysia geral.

O grande scientista, com a tenacidade modesta peculiar aos sabios, descobrio as causas e os meios de transmissão, o desenvolvimento $\mathrm{e}$ as modalidades, os effeitos $\mathrm{e}$ as consequencias, bem como o tratamento dessa, em verdade, terrivel molestia.

Emquanto, por entre alas de povo deslumbrado, os generaes, fulgurando na pompa dos seus uniformes, exercitam as guapas hostes destinadas ao serviço patriotico da morte, e os artistas recebem retumbantes applausos e todos, alegres ou tristes, somos vistos no turbilhão ondeante da vida, o homem de sciencia olvidado e invisivel, trabalha $\mathrm{em}$ silencio obscuro; jámais a sua gloria se reveste de aspectos brilhantes e nunca é proclamada com enthusiasmo no delirio das expansões populares, e quando, por ventura, o exito completo não é o remate das suas pesquizas, o sabio desapparece do mundo sem que ao coração dos homens chegue o conhecimento de seus longos esforcos improficuos. Sabio, merecedor de todas as glorificaçốes, o benemerito Dr. Carlos Chagas continúa a ser um distincto moço obscuro. 


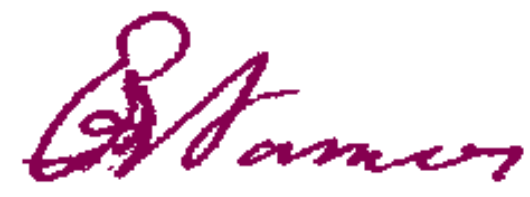

$20<$
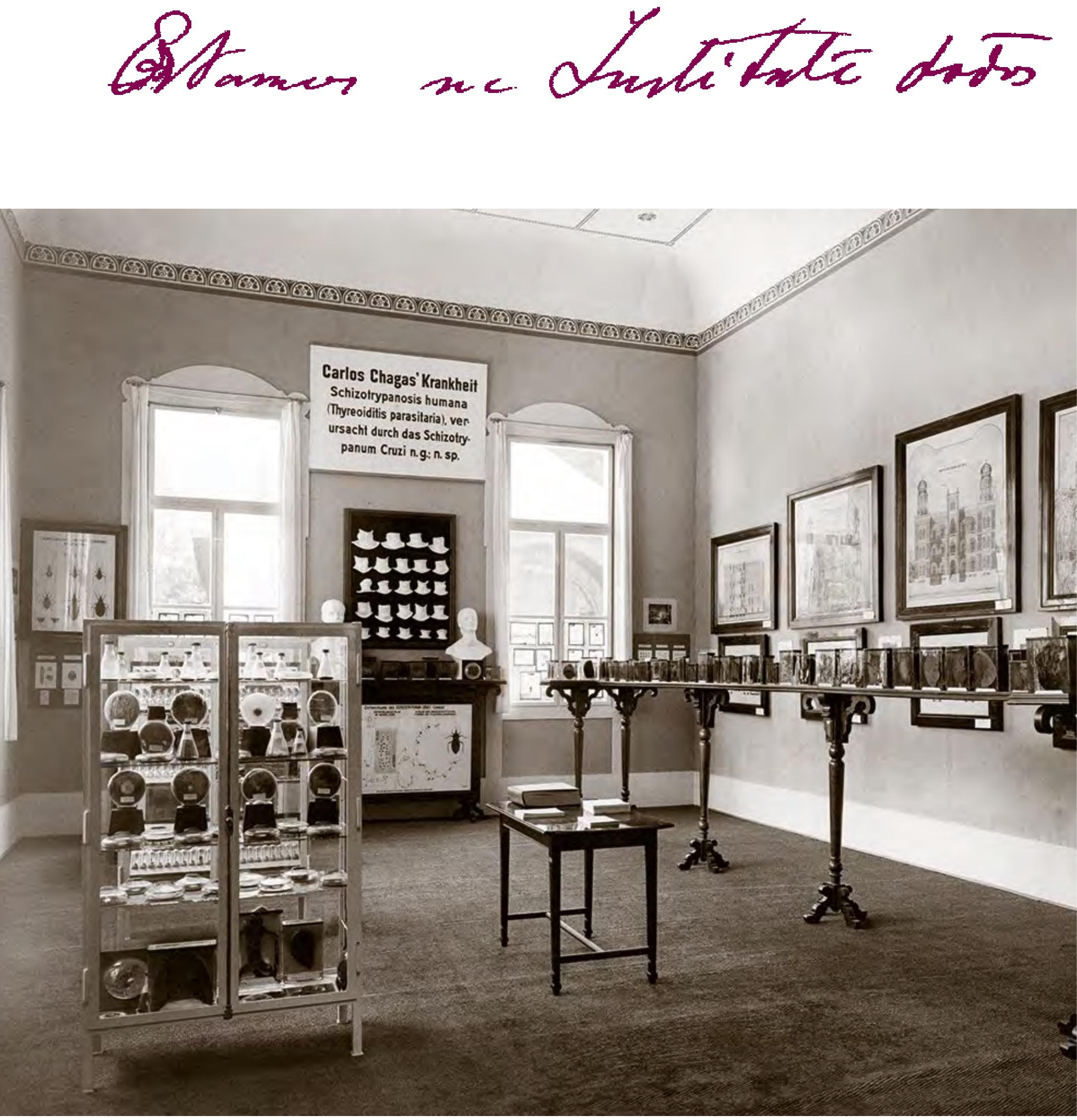

Materiais relativos à doença de Chagas em sala do pavilhão brasileiro na Exposição de Dresden, Alemanha, em junho de 1911

Acervo Casa de Oswaldo Cruz

Materials about Chagas disease on display at the Brazilian pavilion at the Dresden Exhibition, Germany, June 1911

Pavilhão brasileiro na Exposição Internacional de Higiene e Demografia realizada em Dresden

Acervo Casa de Oswaldo Cruz

Brazilian pavilion at the International Exposition on Hygiene and Demography, held in Dresden 


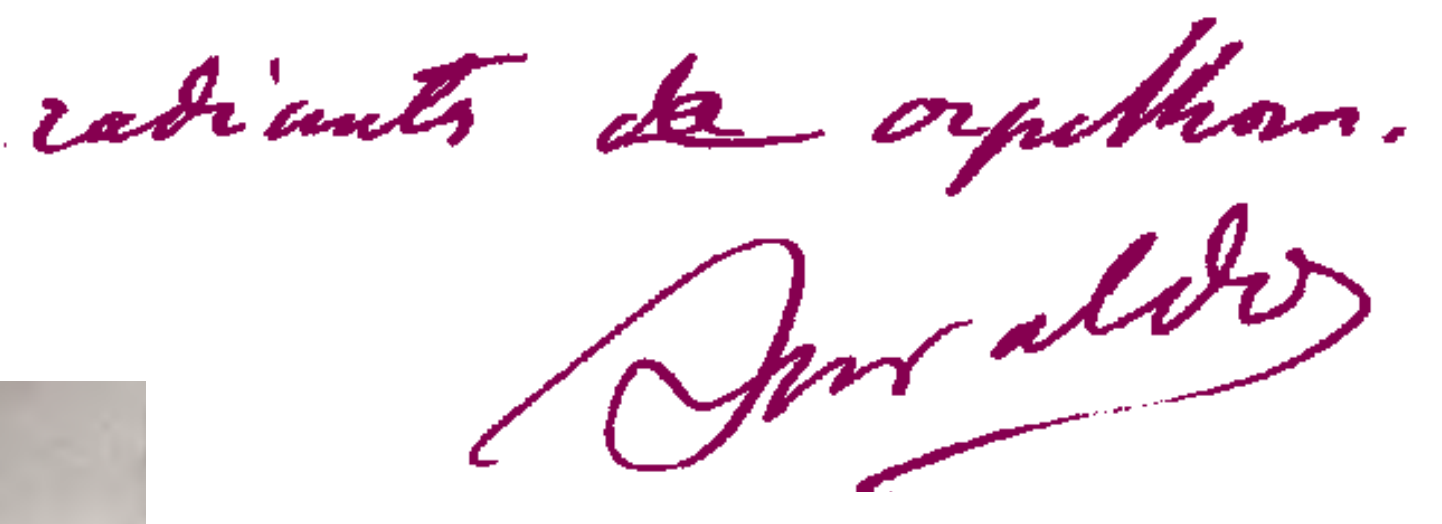

All of us at the Institute are bursting with pride Oswaldo

O material que levamos é abundante e importante: a moléstia de Chagas vai prender a atenção; levamos preparados, peças anatômicas, fotografias, moldagens em gesso, bustos de doentes.

Oswaldo Cruz

We are taking an abundant amount of important material: Chagas disease will capture attention; we are taking preparations, anatomical parts, photographs, plaster molds, busts of the ill.

Oswaldo Cruz 


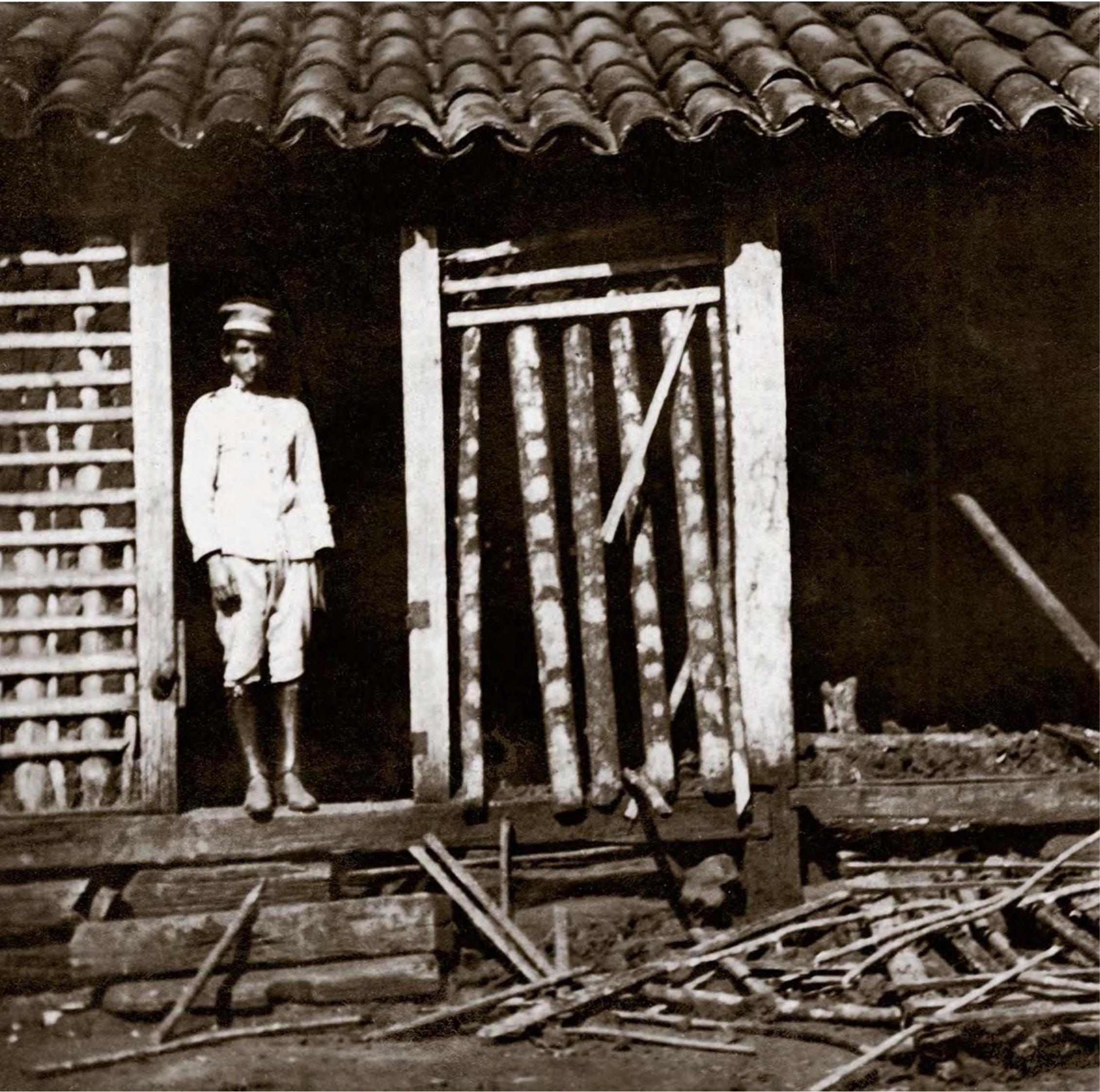

Demolição de casa para combate ao barbeiro. Jataí, PR, 1919. Para Chagas, o combate à

"doença do barbeiro" deveria ser feito pela melhoria nas habitações rurais. Em 1918, o

Serviço de Saneamento Rural do Paraná foi pioneiro em estabelecer normas para a

construção de casas visando a impedir a proliferação de barbeiros. Os inseticidas foram

utilizados somente a partir da década de 1950

Acervo Casa de Oswaldo Cruz

Razing a house in the battle against the barbeiro. Jataí, Paraná, 1919. For Chagas, the

"barbeiro disease" should be fought by upgrading rural housing. In 1918, the state of Paraná's

Rural Sanitation Service was the first to enact standards on home construction with

the intent of preventing the proliferation of barbeiros. It was only in the 1950s that insecticides

came into use 


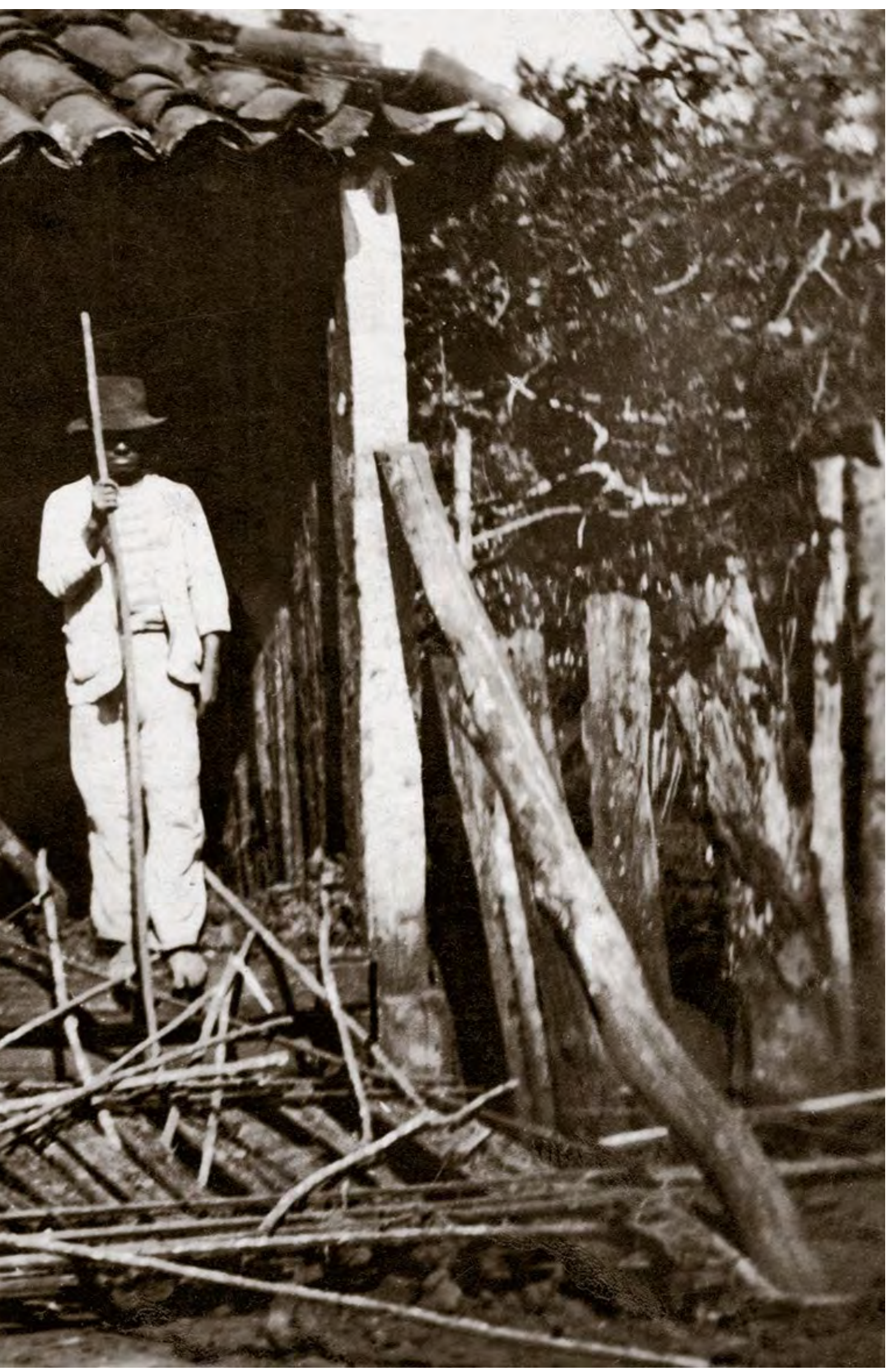

Poder-se-há, na higiene pública, encontrar meios eficazes de atenuação do mal? Acreditamos que sim, se tal problema, seguramente problema de Estado e de humanidade, se tornar preocupação de um estadista cientificamente bem orientado.

Carlos Chagas

Will it be possible, within public hygiene, to find efficacious ways of attenuating this affliction? We believe so, if this problem-most surely a problem of the State and of humanity - becomes the concern of a scientifically welladvised statesman.

Carlos Chagas 


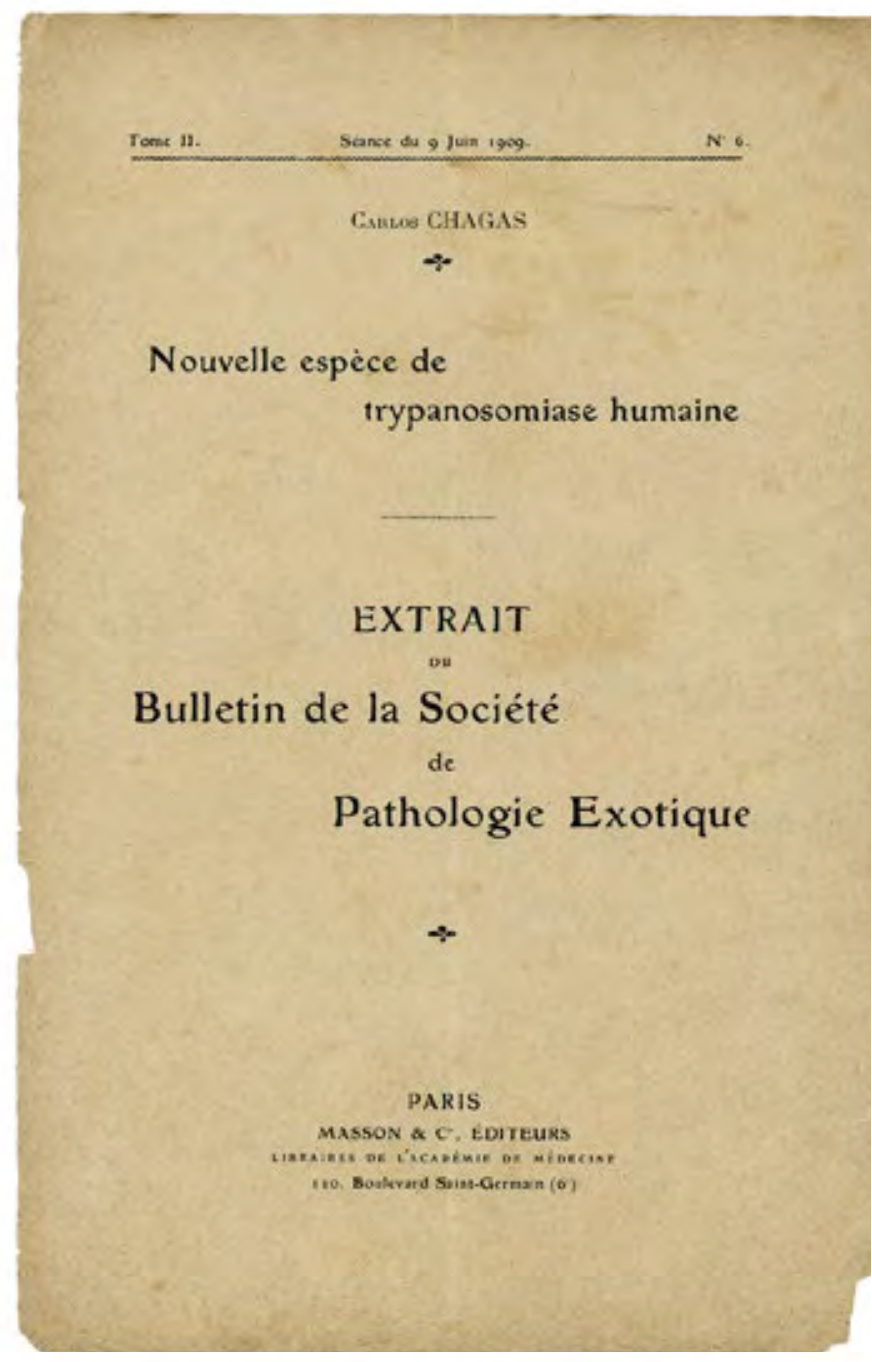

\section{NOVA ENTIDADE MORBHA DO HOMEM} neto

Dk. CARLOS CHAGAS.

trypanosomiase humaine
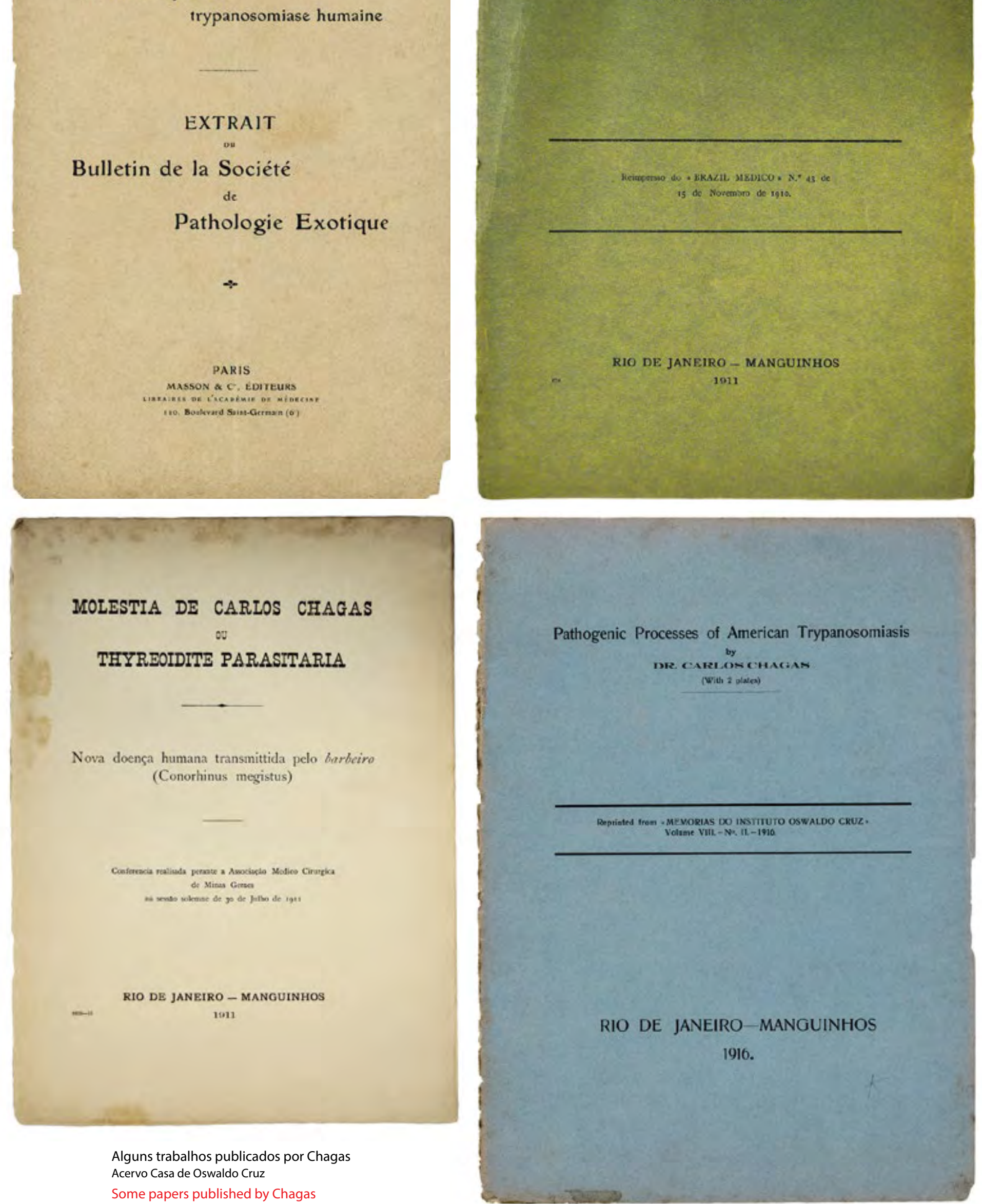

Acervo Casa de Oswaldo Cruz

Some papers published by Chagas 
ASPECTO CLINICO GERAL DA NOVA ENTIDADE MORBIDA PRODUZIDA PELO SCHIZOTRYPANUM CRUZI.

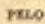

Dr. CARLOS CHAGAS.

Reimpareso do . BRAZIL. MEDICO, N* 19 de is de Jullho de rg10.

RIO DE JANEIRO - MANGUINHOS

1910

\section{ARCHIVES \\ oEs \\ NALADIES DU CCER \\ DES VAISSEAUX ET DU SANG

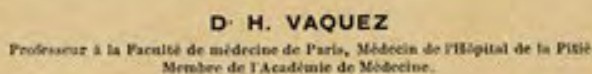 \\ racadkmie do scodocine.}

\section{SUR LES ALTERATIONS DU CCEUR DANS LA \\ TRYPANOSOMIASE AMÉRICAINE \\ (MALADIE DE CHAGAS) \\ 10 Profesanue CHAOAs (Rio-de Janeiro)}

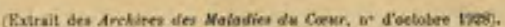

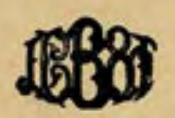

PARIS

LIBRAIRIE J,-B. BAILLIBRE ET FILS

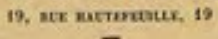

\section{Amerikanische Trypanosomiasis} (Chargasmohe Krankheit) Kurso atsologisohe und klinimohe Botrachtunges.

\section{Dr. GaRLOB CRAGas}
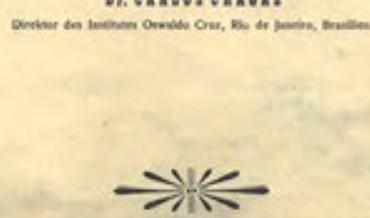

1925

\section{FORME CARDIAOUE DE LA TRYPANOSOMUASE AMÉRICANE}

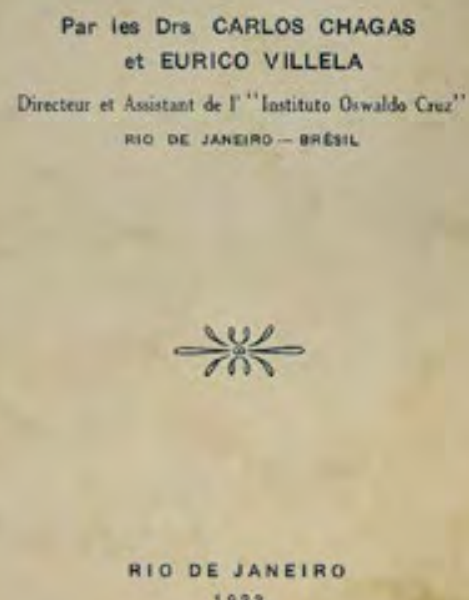

1923 


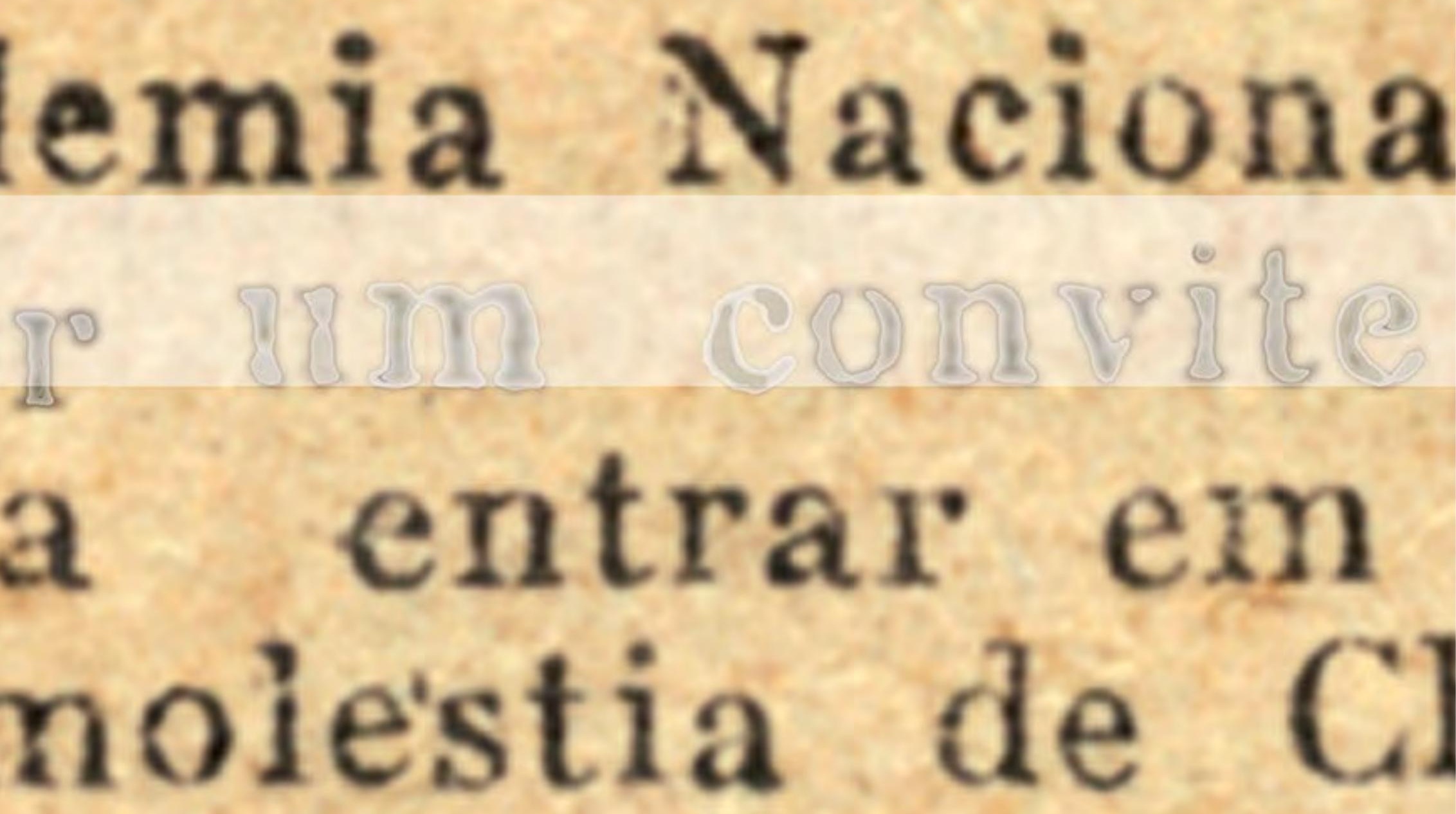



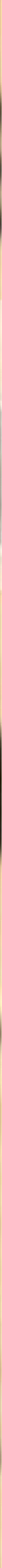
edicas e as
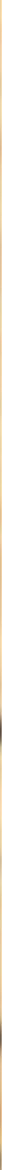
A

partir de 1915, pesquisadores na Argentina, liderados pelo microbiologista austríaco Rudolf Kraus

(1868-1932), puseram em dúvida alguns aspectos centrais da definição clínica da doença de Chagas. Para eles, as manifestações tireoidianas e neurológicas atribuídas a essa enfermidade em sua fase crônica corresponderiam, na realidade, ao bócio e ao cretinismo endêmicos tal como havia na Europa; ou seja, tratava-se de endemias distintas e sobrepostas.

Tal alegação gerou dúvidas sobre a extensão da tripanossomíase e, consequentemente, sobre sua importância médico-social, pois era a partir do bócio - muito comum em Minas e outras regiões do interior do Brasil que se estimava a vasta distribuição da endemia no país. Debatendo com Kraus em congresso médico realizado em Buenos Aires, em 1916, Chagas reiterou que a doença por ele descoberta não se restringia aos aspectos tireoidianos; enfatizando a importância dos distúrbios cardíacos, passou a tratar a questão do bócio endêmico como aberta a discussões.

Em 1919, alguns pesquisadores brasileiros retomaram as contestações feitas na Argentina. Questionaram a definição clínica e, sobretudo, a importância social da tripanossomíase americana. A polêmica intensificouse em fins de 1922 e no decorrer de 1923, na Academia Nacional de Medicina. Liderados por Julio Afrânio Peixoto (1876-1947), literato e catedrático de higiene da Faculdade de Medicina da Universidade do Rio de Janeiro, os críticos de Chagas afirmaram que aquela era uma doença rara, restrita à região de Lassance, e não um flagelo nacional. Segundo eles, a visão de 'Brasil doente' - disseminada por Chagas e pelos partidários do movimento pelo saneamento rural - era exagerada e pessimista, trazia descrédito sobre o país e afugentava imigrantes e capitais.

Foram questionadas também a patogenicidade do Trypanosoma cruzi e a autoria de sua descoberta, que, segundo alguns, caberia não a Chagas mas a Oswaldo Cruz, por ter sido este o autor das experiências que permitiram identificar que se tratava de um novo parasito. Com grande repercussão na imprensa, a polêmica envolvia questões científicas e políticas, estas referidas ao intenso debate nacionalista da época. Foi nutrida também por rivalidades e disputas pessoais com Chagas, relativas a sua atuação como diretor do Instituto Oswaldo Cruz e do Departamento Nacional de Saúde Pública.

O parecer oficial da Academia Nacional de Medicina reiterou os méritos de Chagas e sua autoria na descoberta do T. cruzi. Contudo, não se posicionou sobre as questões da definição clínica e da extensão geográfica da doença, declarando não possuir condições para tanto. Na conferência com que encerrou a polêmica, em dezembro de 1923, o cientista defendeu suas convicções e rebateu com veemência os que acusavam de antipatriótica sua visão do país.

A polêmica gerou um ambiente de dúvidas em torno da doença. Apesar disso, Chagas prosseguiu em suas pesquisas, reforçando o caminho que já privilegiava desde 1916, relacionado ao estudo da forma cardíaca. Tais dúvidas seriam superadas ao longo das duas décadas que se seguiram à sua morte, ocorrida em 1934 . Estudos realizados por médicos argentinos e por discípulos de Chagas em Manguinhos - entre os quais seu filho, Evandro Chagas (1905-1940), e seu afilhado, Emmanuel Dias (1908-1962) - levariam ao consenso sobre a enfermidade como problema médico específico e socialmente relevante no Brasil e no continente americano. 
n 1915, researchers in Argentina, led by Austrian microbiologist Rudolf Kraus (1868-1932), cast doubts on some of the central aspects of the clinical definition of Chagas disease. For them, the thyroidal and neurological manifestations assigned to the chronic phase of this sickness in fact represented the endemic goiter and cretinism found in Europe - in other words, they were distinct yet overlapping endemic illnesses.

This allegation stirred doubt about the scope of trypanosomiasis and therefore about its medical and social import, because the notion that this endemic disease was vastly distributed across Brazil was based on cases of goiter, which was very common in Minas Gerais and other interior regions of the country. Contesting Kraus at a medical congress in Buenos Aires in 1916, Chagas reiterated that the disease he had discovered was not restricted to thyroid aspects; while accentuating the weight of cardiac disturbances, he left the question of endemic goiter open to discussion.

In 1919, some Brazilian researchers again took up the arguments presented in Argentina. They questioned the clinical definition and especially the social importance of American trypanosomiasis. The controversy grew more heated in late 1922 and 1923, within the National Academy of Medicine. Led by Julio Afrânio Peixoto (1876-1947), a man of letters who held the chair in hygiene at the University of Rio de Janeiro's School of Medicine (formerly the Rio de Janeiro School of Medicine), Chagas's critics asserted that this was a rare disease restricted to the region of Lassance and not a national scourge. According to them, the notion of a "diseased Brazil" disseminated by Chagas and followers of the rural sanitation movement was exaggerated and pessimistic and, furthermore, it discredited Brazil and scared off immigrants and foreign capital.

They also questioned the pathogenicity of Trypanosoma cruzi and the authorship of its discovery, which, some argued, fell not to Chagas but to Oswaldo Cruz, since the latter had conducted the experiments that made it possible to identify the new parasite. There was much press coverage of the clash, which involved not just scientific matters but political ones as well, tied to the era's passionate nationalist debate. This discord was further fed by personal rivalries and conflicts with Chagas involving his work as director of both the Oswaldo Cruz Institute and the National Department of Public Health.

In its official affidavit, the National Academy of Medicine endorsed Chagas's merits and his authorship of the discovery of $T$. cruzi. However, it took no stance when it came to the disease's clinical definition or geographical range, claiming it was unable to do so. The controversy was brought to an end at a conference in December 1923, where Chagas defended his convictions and vehemently rebutted those who accused him of holding an unpatriotic view of his country.

The controversy left the disease surrounded in a cloud of doubts. Chagas nevertheless moved ahead with his research, emphasizing the path he had prioritized since 1916, that is, study of the cardiac form. These questions would be resolved over the course of the two decades following his death in 1934. Studies by Argentinean physicians and by disciples of Chagas at Manguinhos - including his son Evandro Chagas (1905-1940) and his godson Emmanuel Dias (1908-1962) - led to the consensus that the sickness is a specific, socially relevant medical issue in Brazil and the American continent. 
Imagem de abertura - Os debates da sciencia [trecho]

A Noite, $11 \mathrm{dez} .1922$

Acervo Casa de Oswaldo Cruz

Opening image - "Science's debates" [excerpt]

A Noite, Dec. 11, 1922

Em carta a sua esposa Iris, Chagas comenta a conferência que proferiu em congresso médico em Buenos Aires, na qual rebateu as críticas de Rudolf Kraus a seus trabalhos. Buenos Aires, set. 1916

Acervo Casa de Oswaldo Cruz

In a letter to his wife Iris, Chagas remarks on the conference he gave at the medical congress in Buenos Aires, in which he rebutted Rudolf Kraus's criticisms of his work. Buenos Aires, Sep.

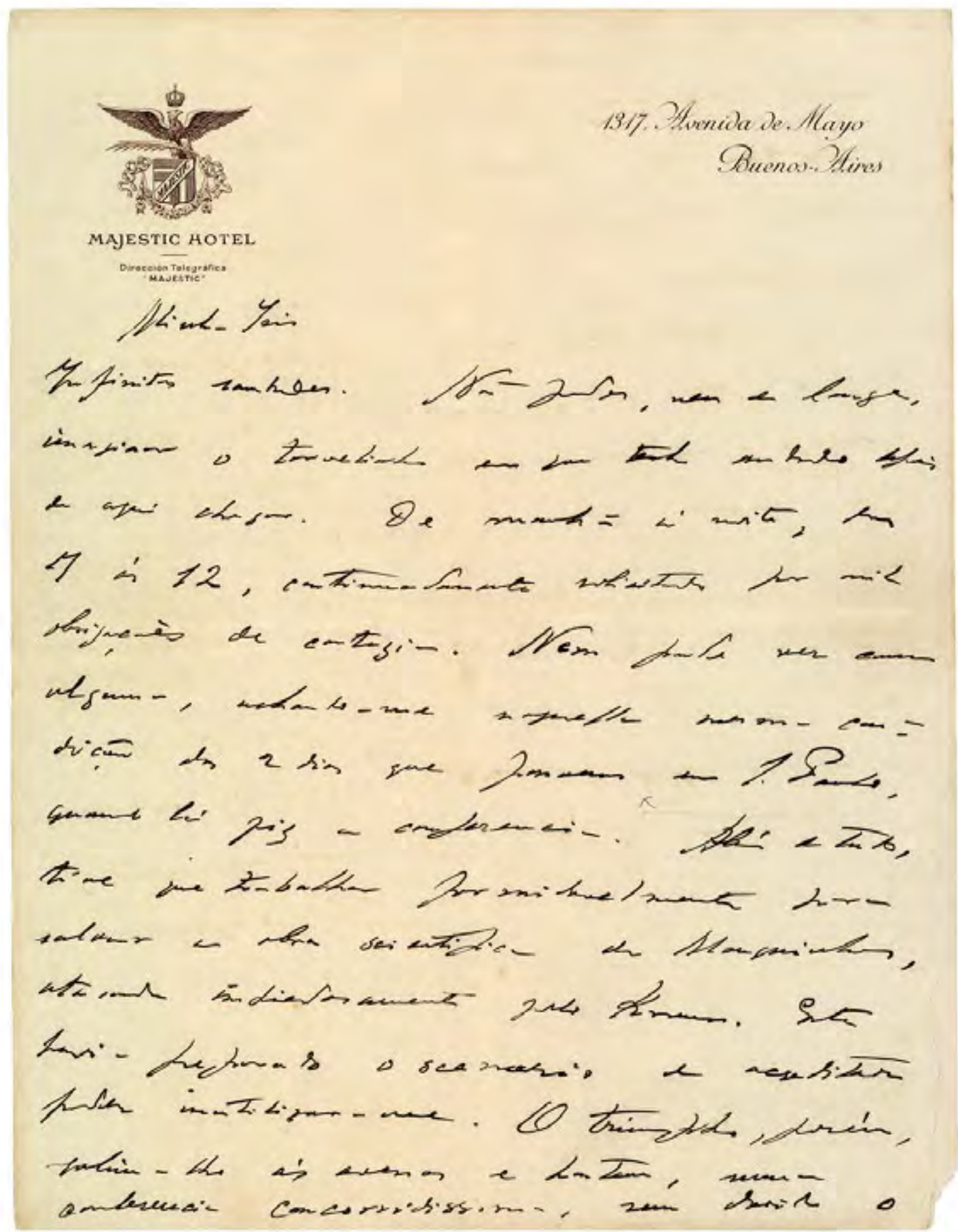


13) OHonida de. Mayo Buenar. Ptives

MAJESTIC HOTEL

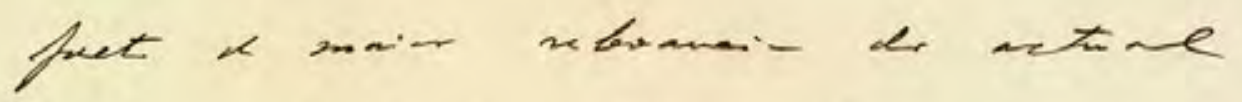

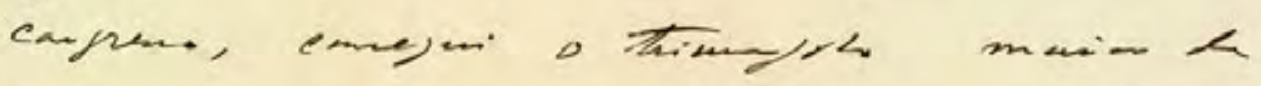
tak a mish curein- melica. tsi

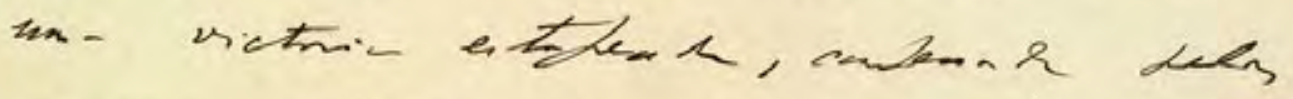

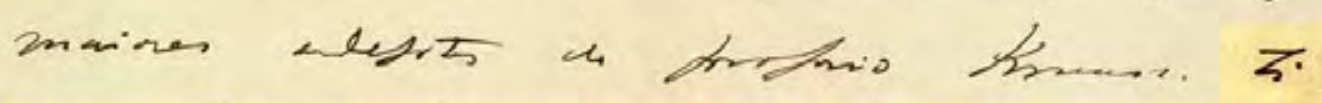

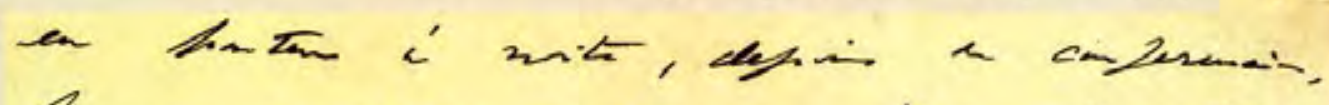

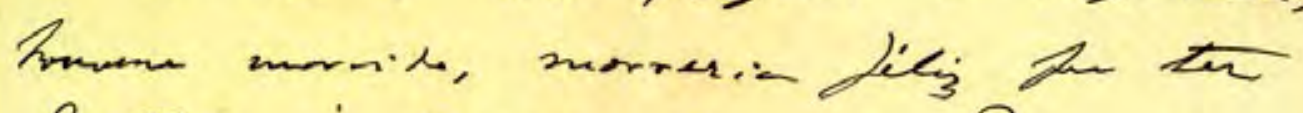

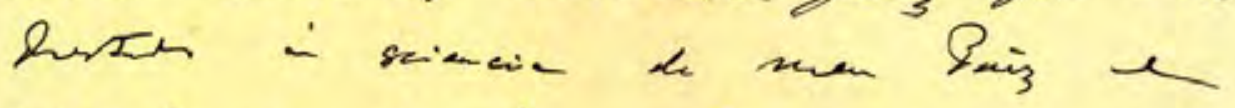

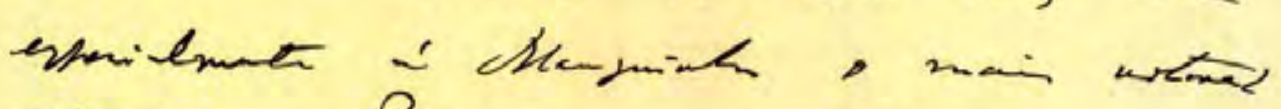

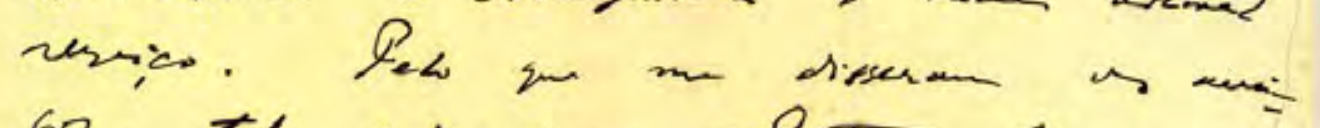

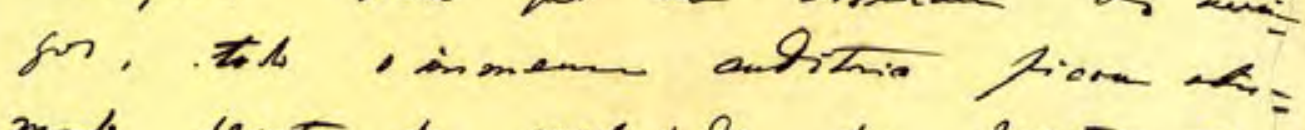

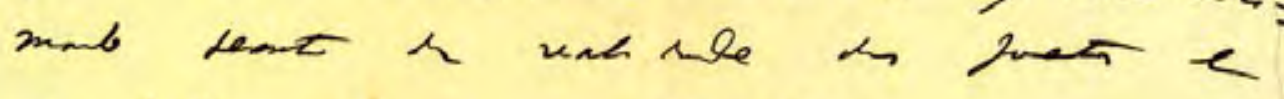

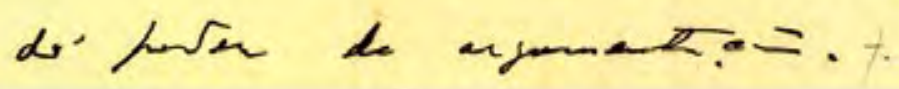

Minha Iris,

Se eu ontem à noite, depois da conferência, houvesse morrido, morreria feliz por ter prestado à ciência de meu País e especialmente a Manguinhos o mais notável serviço. Pelo que me disseram os amigos, todo o imenso auditório ficou entusiasmado diante da realidade dos fatos e do poder de argumentação.

Carlos Chagas

My Iris,

If I had died last night after the conference, I would have died happy for having rendered outstanding service to my Country's science and especially to Manguinhos. From what my friends have told me, the entire enormous audience was excited about the reality of the facts and the power of argumentation.

Carlos Chagas

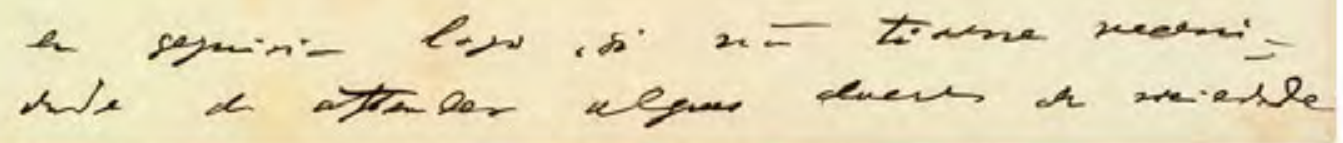




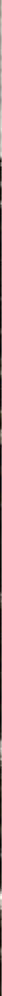

Academia Nacional de Medicina no prédio do Silogeu

Brasileiro, situado no centro da cidade do Rio de Janeiro

Acervo Academia Brasileira de Letras

National Academy of Medicine, at the Silogeu Brasileiro

building, located in downtown Rio de Janeiro
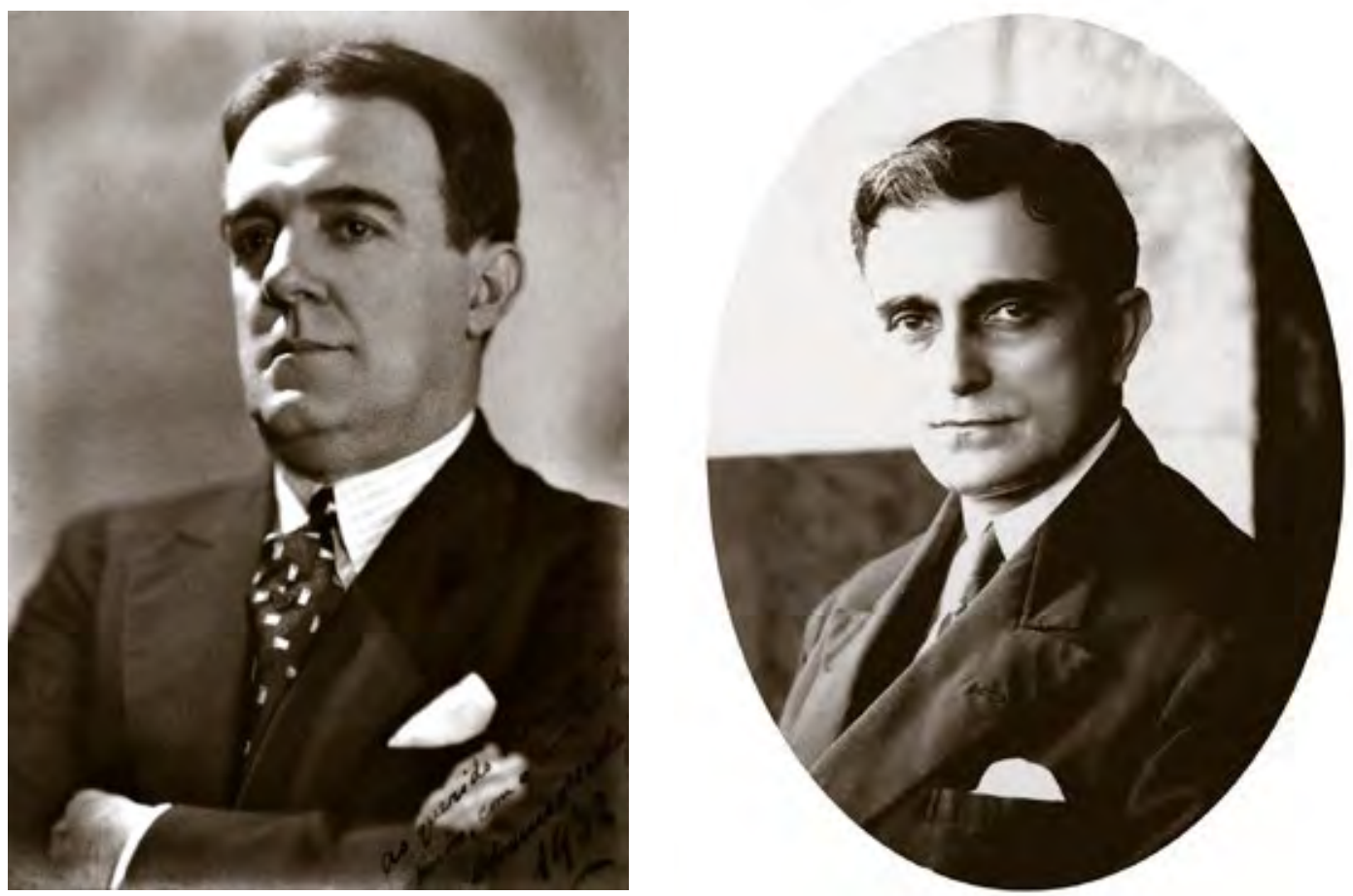

Afrânio Peixoto, principal opositor de Chagas na polêmica na

Academia Nacional de Medicina

Acervo Academia Nacional de Medicina

Afrânio Peixoto, Chagas's chief opponent in the controversy within

the National Academy of Medicine

Clementino Fraga, professor da Faculdade de Medicina de Salvador

foi o principal defensor de Chagas na polêmica

Acervo Casa de Oswaldo Cruz

Clementino Fraga, professor at Salvador's School of Medicine and

Chagas's biggest champion during the controversy 

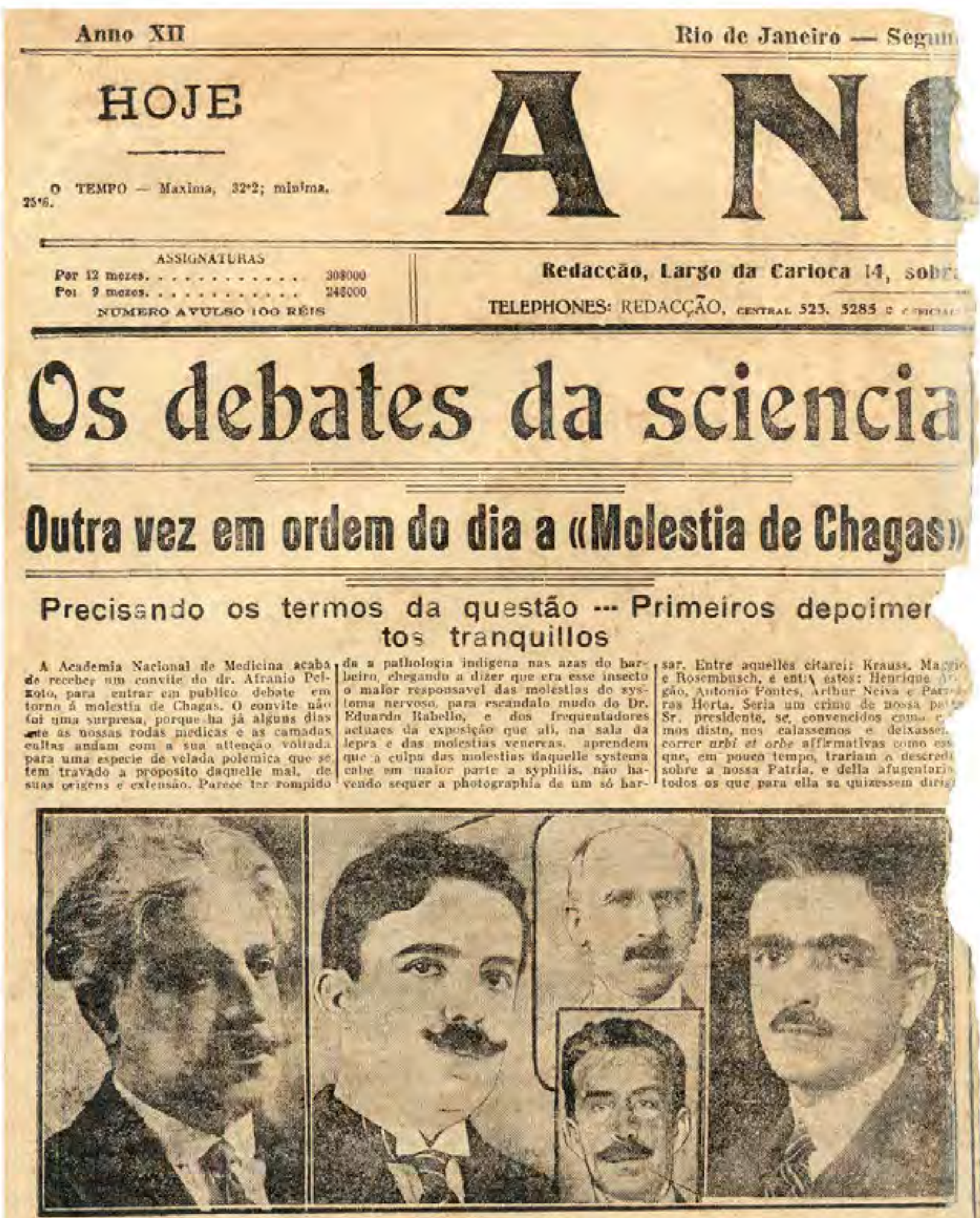

Os debates da sciencia [trecho]

A Noite, 11 dez. 1922

Acervo Casa de Oswaldo Cruz "Science's debates"

[excerpt]

A Noite, Dec. 11, 1922

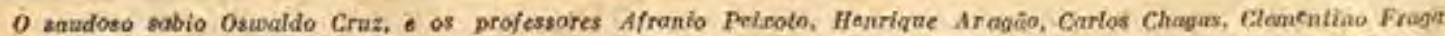
este particular dobate o proprio Dr. Afranio teiro naquelle mundo de quadros e de fi- a menos que nâo viessem vivor apenas aas

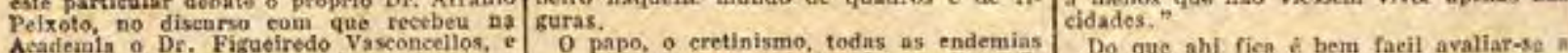
onde ha evldentes allusóes $a$ doença a que e as modalidades morbidas da ankylostomise ligou o nome do actual director do De- se ou opilaşio, e até a malaria ot impaln. partamento Nacional de Saude Pablica o do dismo. passaram a complicar-se sob a lenInstituto de Narguinhos, que, por signal, ja te do Dr. Garlos Chajas eotn visóes do triSe empenhou tambem no debate, a que ailu- panozoma, Cruz-Chagas, ou apenas tripadif em discurso de homenugem que seceneineste fex.

pozoma Chagas, sekundo a proposta que

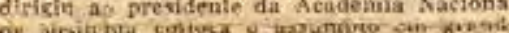
- forcada svidiogia, nato interessando muts apenas ans medicos é ás rodas de alta cuitura, a sim a toclas as camadas soctars.

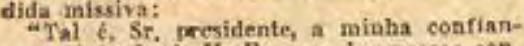
ca na isenção dé $V$. Ex. na dos nossos confrades, na das classes cultas do paiz que nos to publleo do assumpto, na Aeademía Nacional de Medicina, eapaz de permiltir a revisha de problema que tanto affecta o hom nome do Brasil," fez $\mathrm{em}$ tempo o Dr. Austregesilo.
Collocado mas deridas proporgàex en nada fica comtudo diminuido o valor sci. Resalva porim, e ahi esta a metisa do debate, o bom nome do Brasil junto ao es. trangeiro, e corrige-se um gravissiliu erro

pidemialogieo.
Vem aqui a proposito uma allusâo ao parecer do Dr. Henrique Aragšo, tambem de Manguinhos, e acatada entre os que mals aif pesquizaram, contido nam discurso deste especialista, proferido em 1910, na Sociedade de Medicita e Cirtirgia, por occastáo de sua posse. Eis o que diz o Dr. Aragáo. no seu juixo insuspeito, por isto que nío ê

Nessas condicōes, para maior esclarecimessas cosolado o bocio e a eretinismo endemt Do que ahi fiea of bern facil avaliar-se on

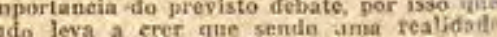
a molestia de Chalas. năo săo begutenos al jerigos soclaes que decorrem din fendencto de confundil-a com oulcos matêl das nossnpupulaçues do intorior. Exakgerty as propog. fós do um mal para smptar o valor din

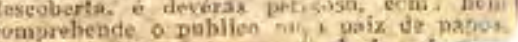

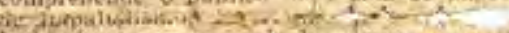

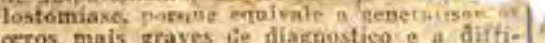
cultar a curá de mflhares de cofermos. Nontros termost om doente de papo, ou cpilacto. delixa de recorver ás fnsplescers da proplylaxis adequads, de proctarar ou melhor droga indicadia, esta ou aquetid injecsẫo, porque os partillarios da theori do bagas dizem que o mal dell e verien petas reaçón da propria natureza, núo sibe aintia eomo.

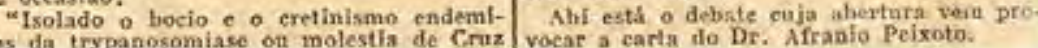




\section{INSTITUTO OSWALDO CRUZ}

CAIXA POSTAL 926

BRAZIL - RIO DE JANEIRO
Hio de Janeiro, 6 de Dezenbro de 1922
Carta de Chagas a

Miguel Couto,

presidente da Academia Nacional de Medicina, em que

reage às declarações de Afrânio Peixoto e solicita formação de comissão para avaliar seus estudos. Rio de Janeiro, 6 dez. 1922

Acervo Casa de Oswaldo Cruz

Letter from Chagas to Miguel Couto, president of the National Academy of Medicine, in which he responds to Afrânio Peixoto's statements and asks that a

commission be formed to evaluate his

research. Rio de Janeiro, Dec. 6, 1922
Bxme Snr. Professor tiguel couto

D. D. Presidente da Acadenia Nacionel de tedicina.

Rn discurso pronunciado na ul tima sessão dessa Academia,o Sr. Professor de hygiene da Baculdade de Ledicina do Rio de Janeiro,fez slluaões, fucilante interpretavois, aos trabainos do Instituto Oswaldo Cruz,por min realizados, sobre una nova doença huakna. I cono, ea taes allusões, procura-se depreciar a valis daquelles trabahos e recusar probidade soientifica a quen os executou,julgo sttender á dele2a. de ninha dignidade profisaional vindo requerer a V. Bxoia, requeise, conourfencia, a designaģzo de una connisez̃o de acadenicos, experiaentadostos en assumptos de pathologia seral e de cilnica, afia de enitir parecer sobre a verdade de meus estudos.

Assumo, desde logo, o comproniaso de subnetter-ae á deciaão dos collegas designados poe V. Bxcia, que saberão fundanentar seu parecer ea razões scientificas irrecusaveis. 3 una vez decidido que actuei coa improbidade, e não nerecen credito ainhas conclusđes, considerar-ne-el innediutanente exone rado desвa hadenia, cuja dignidade näo poderá tolerar, entre os seue menbros, alsun estignatisado pela pratica do asis revoltante erabuete.

Caso contrario,e verificado que os aeus trabalnos foran realizedoe coa absoluto rigor bcientifico, aerecencio ar minhas conclueð̃es essencitaes o veredictua dossa Acadenia, caberí 10 ji- 


\section{INSTITUTO OSWALDO CRUZ}

CAIXA POSTAL 926

BRAZIL - RIO DE JANEIRO

camente ao Sr. professor de hygiene actuar de accordo co:a o que the indicar sua consciencia de aedico.

Kundamenta, acias de tudo, esee aeu proceder, Sr. Presidente, 0 respeito devido a clesse nedioa brasileira e aos srandes centros de scienoia de todo o mundo, onde foras applaudidos, e an= plasente sanceionados, os estudos sobre a trypunozonicse anericana. 8 pernitbo-ae aquí tranecrever uas parte do honroso officio con que o Sr. Becretorio Ceral da Acudenia ge dignou coanunicor-ae a minha acceitaḡo, coao seu aerabo titular: L 6 A Acudends Vecionel de Kedicina, ns gua sesstio de 13 do corrente, resolveu, por un soto inteirazente excepoional, attendendo aos relevantes servig̨os por vós prestudos á sciencia, acclaaar-voa nenbro titular da Corporaģ̃o. \$3

Claro esté,Sr. Fresidente, que ne não aesiste o direito de corresponder a tanto apreģo coa a ignoajnia de unu attitude na quel seria sacrificados aeus aelindres pesooses e a attenq̧o dovids. a meus eainentes collegss brasileiros.

Sdnittido na Acedenia, en virtude de relevantes vervigoo preptados é Eolencia, 0111 nz̃o poderei peraanecer dibnaiente, uns. vez que o concelto desaa nobre corporagão haja sido aodiIlcado, no que respeita a abie iaportunte de ainhas contribuiçōes scientifics.

Devo binds coraunacar a V. sxeja que es nüo puder ser attendido meu desejo, porque venha decidir a Acadeaia tratar-se de una questito pessoel, nessa hypothese eu ne desobriso de neus deveres e do neu procedente escrupulo, considerstido-ne despido, desde 10 so, da alta dignidade que os aeus nobres collegas resolveran conferitrne.

Conmunico finblnente, a V. 3xoia, que ne promptifico a fornecer a connissถ̆o, seaso designads, todos os eleantos de veriricackio, tanto de ordea experiaental auanto de ordea cilnica. afin de que posse ella amplanente ajuizar si fui impudente como se pernitte classificar-te o Sr. professor, ou si ne assistiria o direito, obscurecido ea aia o senso aoral, de detaivaric Ihe intacte a gentileza. 
97, Pais audu', 8 de deviem bro de 1922

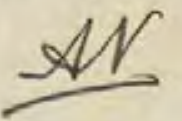

Enwo.Ons Prot. Dr Niguel conto, mevi

digno Presidente da Acallmea Hacio. nal de llediciua :

Twe o praser de ler, nas colemes do "errral de comvercio" de ortem, a can ta ve a vexcia divigive cun en Demeares acadenicos, owicesial interes. tado na questat da drenca de Creve. chagar.

Felizmente, olus dès minkas, - aliás heskidas, forgre ras ercervi "ingudente", 20 que ve weha seo use origrwal, cons nos topies das devas foLhas que preblicarone suen discurso,

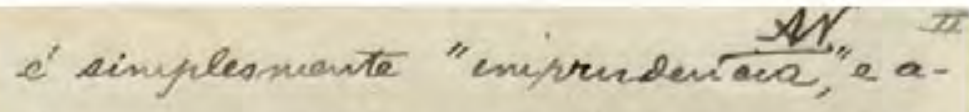
lude a qualificacáo dúl revocacseos que reule dofrends for cause dever devergancia scientifica ... - felizman te, reputo, destois de tautor ataque a for haulos domeres de respeitaull catacidade grofissional, $e^{\prime}$ o do hunil de academico trofresar de kigiene. que despenta un Dexio revide, errio que, funilmente, desejore da completa slucidacas do assento. Noô enith durida, Deuler Previdente, de expirtencei de tarasitore excontrade un Lavaance, eveade quarenta casoy fir for site subli. cado. Powers mais da, reaturen. te comprovados, fora deste iuveiro.

Carta de Afrânio Peixoto a Miguel Couto em que responde a Chagas. Rio de Janeiro, 8 dez. 1922

Acervo Academia Nacional de Medicina Letter from Afrânio Peixoto to Miguel Couto, responding to Chagas. Rio de Janeiro, Dec. 8, 1922 
O que afirmo nas mmiles lecies, so men kiro, no mevo escritor, é gue informacies que tarks, de consticun Colegar, de Lomenes responuscries de to da categoria sbcial, é gee, wa goveralidade Las zonas de vlluias gerces, nato exista dequer coso que ke akeor. tha ver entrel âló a desgraca ire me riavel de 4.500 .000 desser calu. niados minevos, quaxi todos degenecados a cretuis.

Una deploracul facilidade tarece queres confundir factos gue ráó têne a preteudide relacáo: éo caso do bócio endenico, assinuilado a'tal trifanozomiare, bócio ender mico gre espiste for tode a baste do nueudo, e que, só en levias, no Arasil, peria tarasitario, tarao mister inpatriotes de gratificar crua fama tescoal con una calamidade publica.

E'esse ponto a eleccider, sesa éa ascimelacás a ver dis cutedr, ,ronas ua vás, conelueses lagitivas a terar de factos pecentificomente cmeporados.

Talé, Deulor Dresidente, a nirck. contianca na issucás de VExcia, na do rosen contrades, wa das eles ses culfar do saix gue wr consideram, que desijasia un anplo

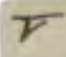
Lebate peblico do asento, wa Mce denia Racional de cledicina, cafar de vemicter a revisáo de groblema gev tanto afecta o lom no. one vacional.

Le a concluato que rese deliate twasper - debate a aelecta on credi. tos dessa cisteteicas e da cuspaso. ciedade-for gue tel ravidade notografica, a drenca de Laesance. l'ken una chaga nacional, tere; en, o humilde swofesor de higione, 2 conigo tavtes nuis brasileivar nigos de cua terra lat. Lifamale. de we redurios, de un rederioncr $a$ eres nessa Desgraca; ne ná,
AN

ná se dizá nais que munorot michoés de concestor e laborianos, Lignor e sabios fatricios nosso, de clevias beraes, das cretuirs e degeverador: Uma gloria imprulente se redusirzá, mos gauhará - Hove norve racional. gue ela sa. erificiu. Esera' uma Gerliza piantefica que farenes gara rós.

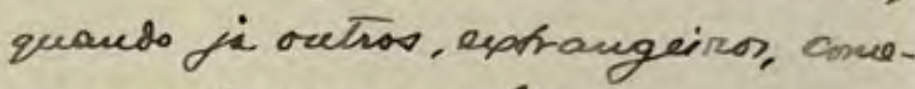
cue a fever, for nós.

Cria, Orxia, Hechor Presidente, na dedi cacaís de nevs peutiven to cuais abrahs, da seu menos criad Aranio seix oroy 


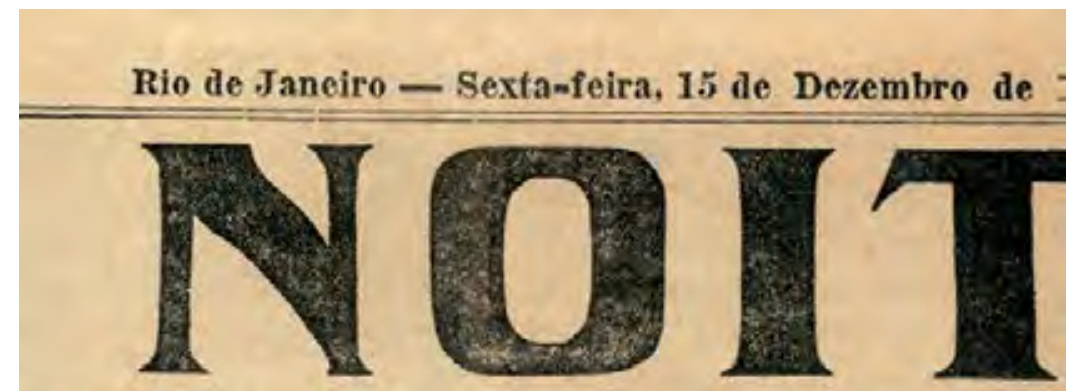

Larso da Carioca 14, sobrado - officinas, rua do Carano

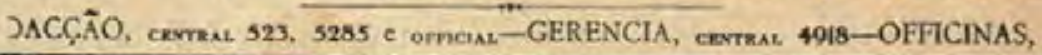

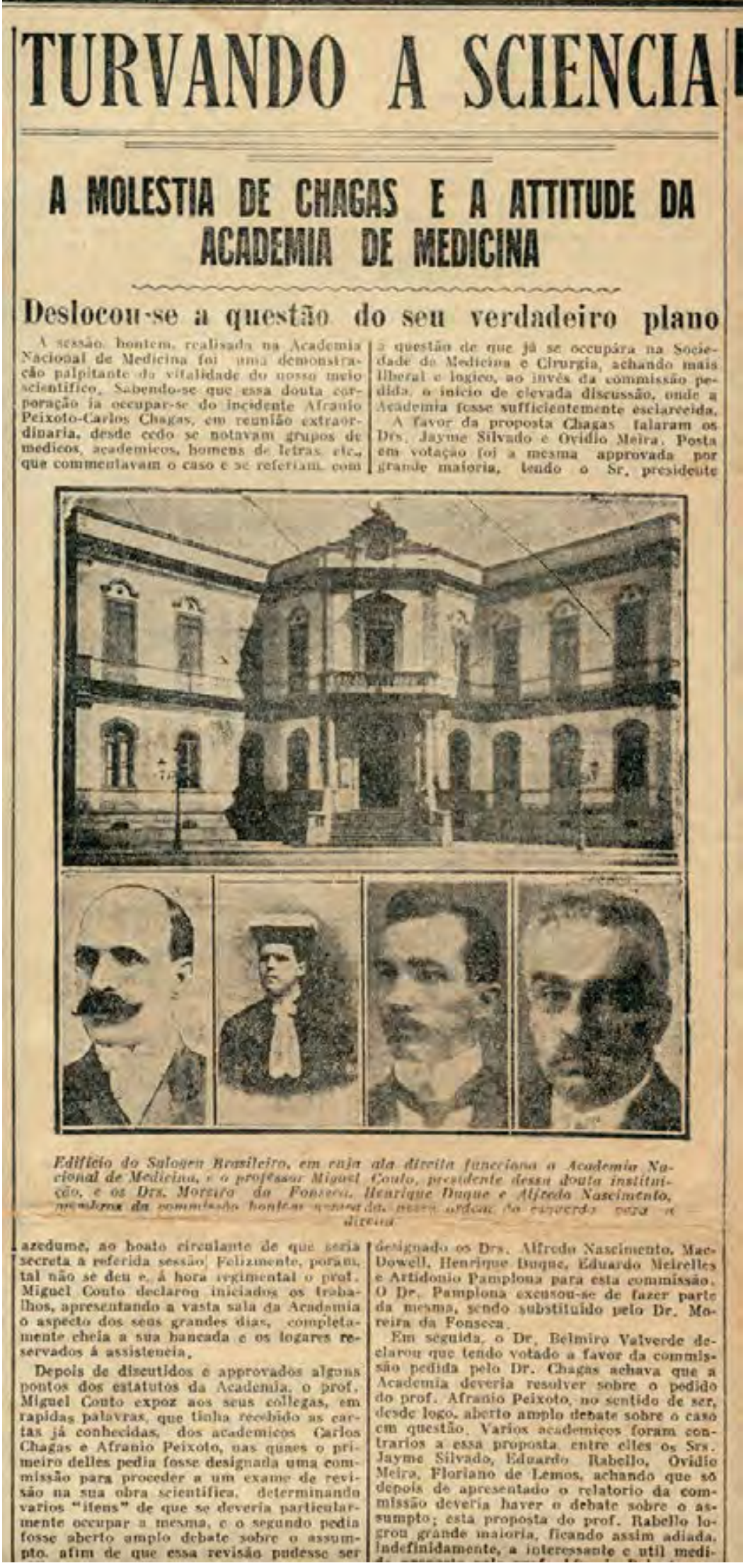

Turvando a sciencia [trecho]

A Noite, 15 dez. 1922

Acervo Casa de Oswaldo Cruz

"Muddying science" [excerpt] A Noite, Dec. 15, 1922 


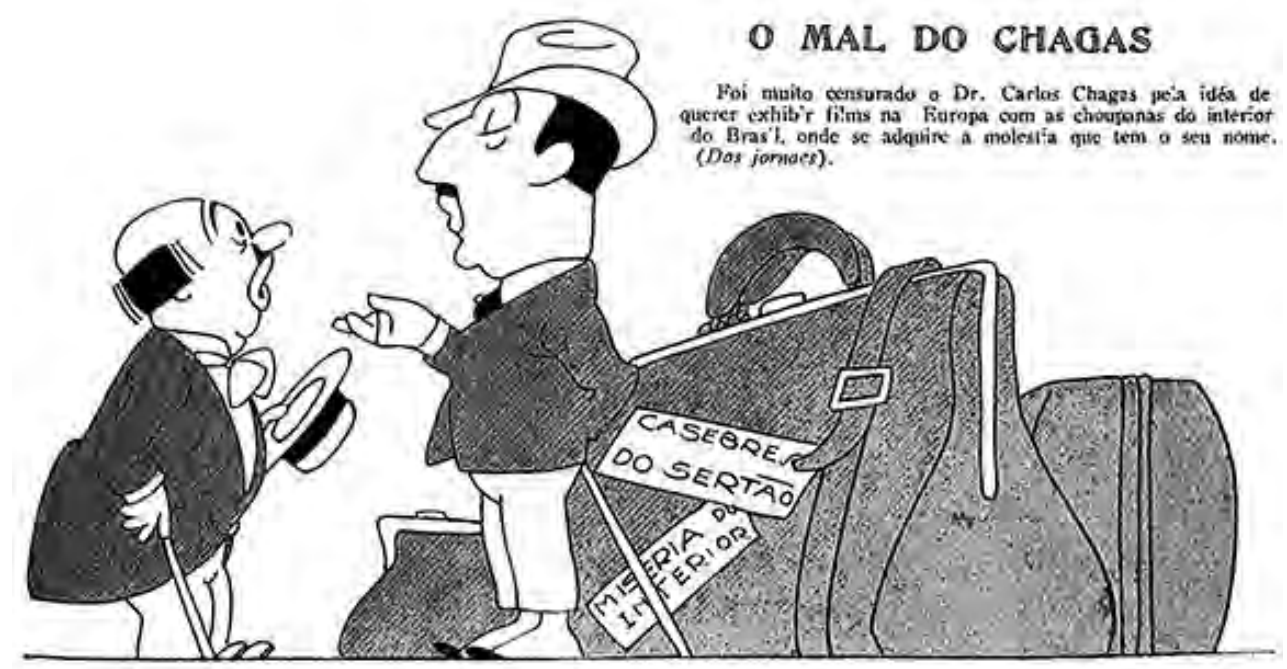

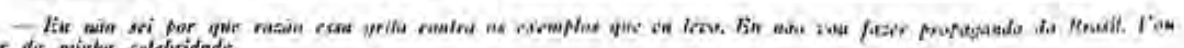
tratur do minter selebridnde.
O mal do Chagas

OMalho, 2 jun. 1923

Charge de J. Carlos (José Carlos de Brito e

Cunha, 1884-1950)

Acervo Fundação Biblioteca Nacional

"The problem of Chagas"

O Malho Jun. 2, 1923

Cartoon by J. Carlos

Uma questão que empolga o mundo medico

Revista da Semana, 15 dez. 1923

Ao centro, Chagas em sua conferência na Academia Nacional de Medicina em 6 de dezembro de 1923 e, no detalhe, a mesa presidida por Miguel Couto

Acervo Casa de Oswaldo Cruz

"An issue stirs up the medical world"

Revista da Semana, Dec. 15, 1923

In the center: Chagas presenting his

conference at the National Academy of

Medicine on December 6, 1923; detail

shows the table presided over by Miguel Couto

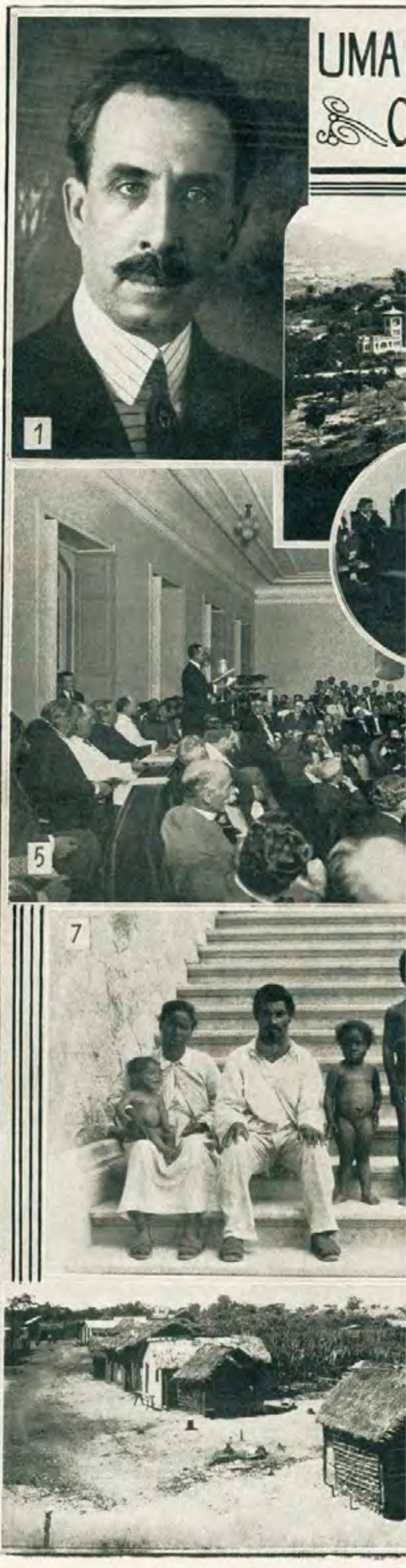




\section{QUESTÃO QUE EMPOLGA MUNDO MEDICO}

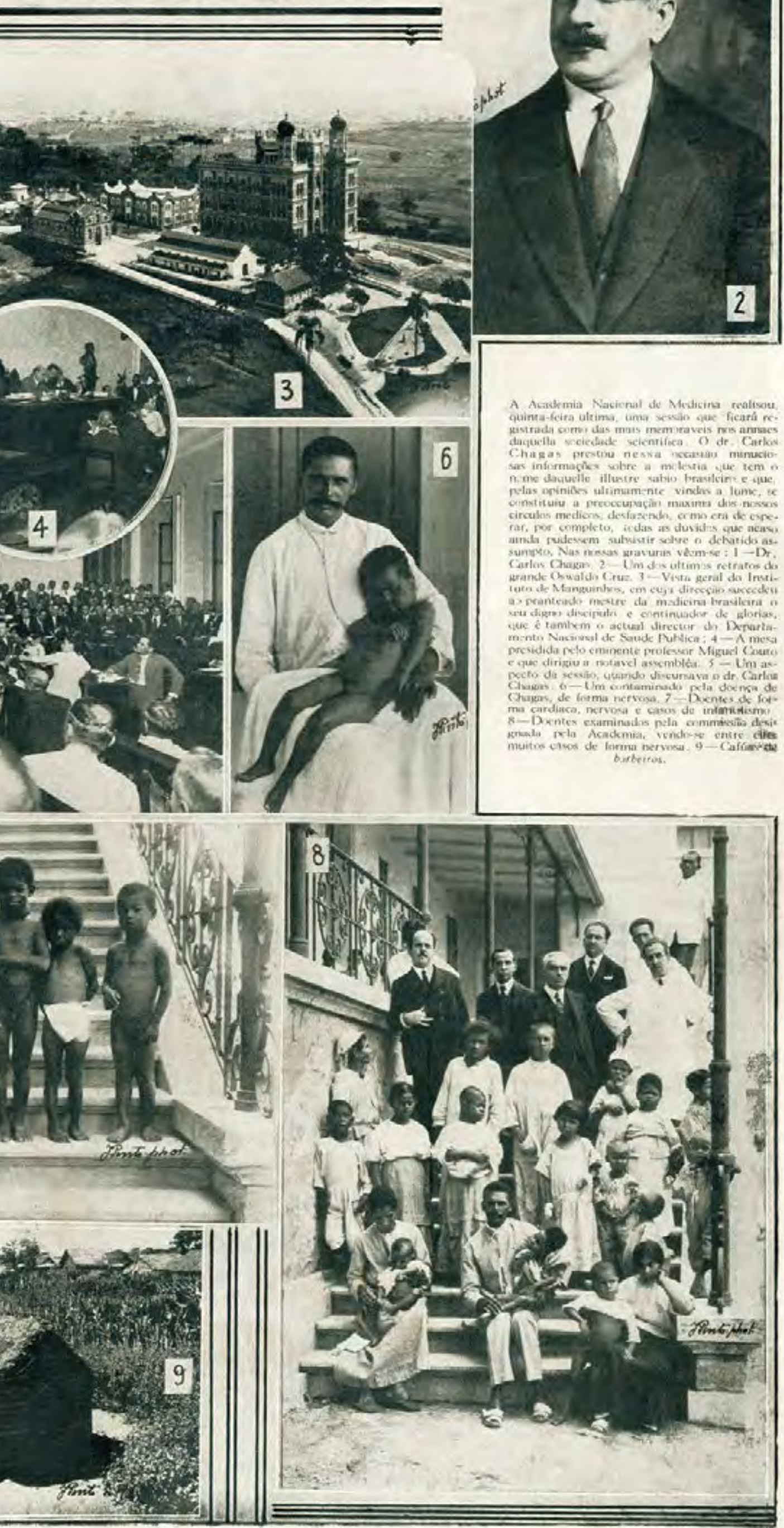

De pé está, Exm. Sr.

Presidente, a minha dúvida, que é a certeza de todos nós... Oito ou oitenta, não vai muito além o perigo social do mal de Lassance.

Afrânio Peixoto

Continuarei resoluto nas minhas convicções científicas, e nem um dia me afastarei dos sentimentos de zelo pela vida e pela saúde de meus patrícios. É o meu dever de médico, é a solidariedade humana que me orienta.

Carlos Chagas

Mr. President, my doubt still stands, and it is the certainty of us all... Eight [cases] or eighty, the social danger of the sickness of Lassance does not go much beyond this.

Afrânio Peixoto

I shall remain firm in my scientific convictions, and not for one day shall I abandon my desire to safeguard the lives and health of my compatriots. It is my duty as a physician; it is human solidarity that guides me. 


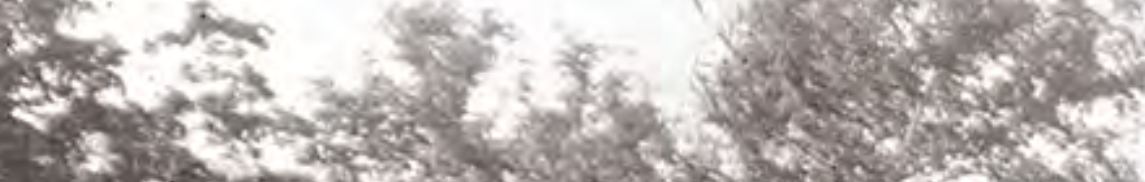

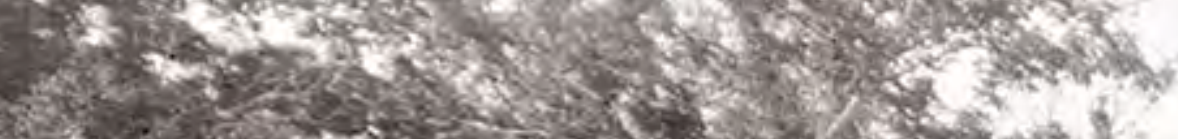

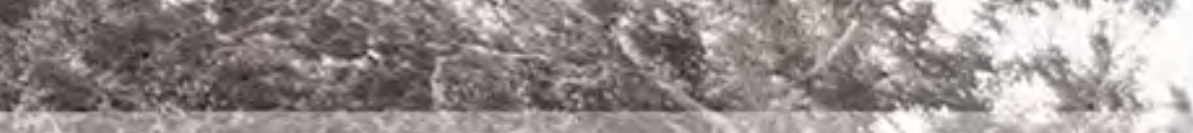

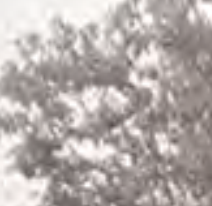

2.t. 20. Vif

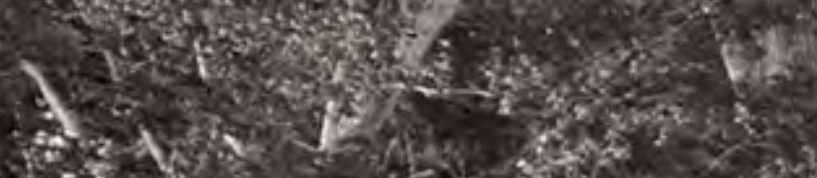

(i)

(-

rew 9

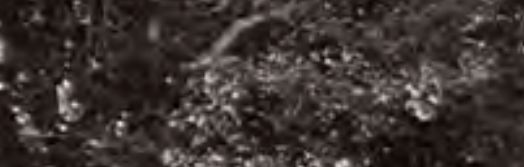

20.5.

4.

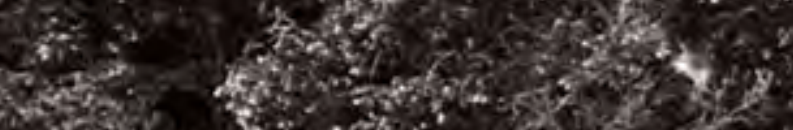

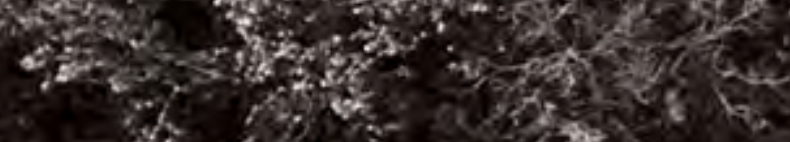

of 60 s.

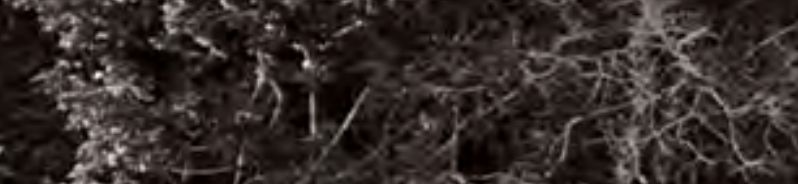

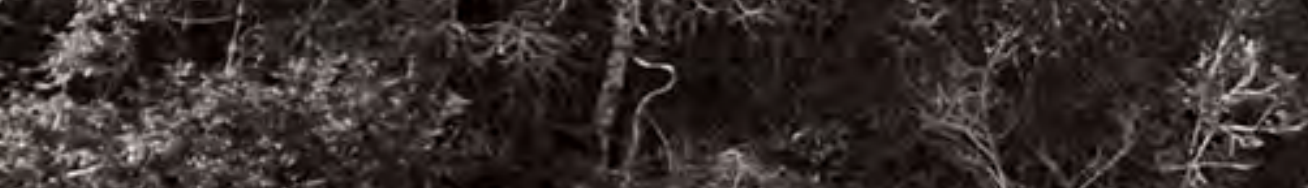

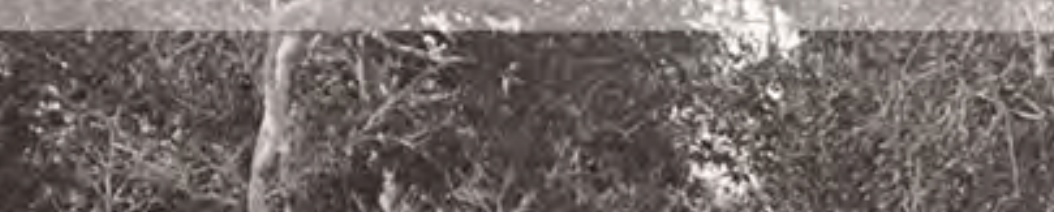

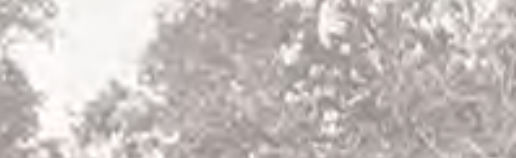

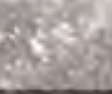
5. 
D esde os primeiros anos do Instituto de Manguinhos, seus pesquisadores eram requisitados a empreender viagens científicas a diversas localidades do território brasileiro, com o objetivo de realizar estudos e atividades que auxiliassem órgãos públicos e privados envolvidos com a modernização do país. As campanhas que Carlos Chagas empreendeu contra a malária em Itatinga, São Paulo, em Xerém, Rio de Janeiro, e no norte de Minas Gerais foram um exemplo desse movimento pelo qual a ciência afirmava seu papel de importante instrumento de progresso e de construção da nação.

Em agosto de 1912, em função da crise do extrativismo da borracha amazônica, o governo federal firmou contrato com o Instituto Oswaldo Cruz para o estudo das condições de salubridade do vale do rio Amazonas, tendo em vista a elaboração de um plano que permitisse a exploração racional de seus recursos. Entre outubro daquele ano e março de 1913, Chagas percorreu os rios Solimões, Purus e Negro e seus principais afluentes, acompanhado de Antonio Pacheco Leão, da Faculdade de Medicina do Rio de Janeiro, João Pedroso, da Diretoria-Geral de Saúde Pública, e um fotógrafo.

A comissão visitou seringais e povoados ribeirinhos, examinando as condições de vida da população e analisando fatores como abastecimento de água, esgoto, moradia, alimentação, trabalho e assistência médica. Além disso, realizou observações clínicas sobre diversas doenças, sobretudo a malária, que atingia a maior parte dos habitantes. Levantou também informações sobre as principais epidemias ocorridas na região, registrou as práticas medicinais locais, capturou insetos suspeitos de transmitirem doenças e colheu plantas de possível valor medicinal. No laboratório improvisado a bordo da pequena embarcação que lhe servia de transporte, Chagas examinou animais em busca de parasitos e observou ao microscópio amostras e materiais colhidos entre a população.

Em outubro de 1913, Chagas expôs os resultados da expedição na Conferência Nacional da Borracha, no Senado Federal, no Rio de Janeiro. Sua conferência, bem como o relatório apresentado por Oswaldo Cruz ao Ministério da Agricultura, Indústria e Comércio, ofereceu um amplo inventário da situação de abandono médico e social em que viviam as populações da Amazônia e enfatizou a necessidade de medidas sanitárias para viabilizar o desenvolvimento econômico da região.

A grande repercussão das expedições científicas realizadas pelo Instituto Oswaldo Cruz contribuiu para fortalecer o movimento que, a partir de meados da década de 1910, buscaria alertar a sociedade brasileira e, sobretudo, o governo para a importância do saneamento rural do país e para a urgência de uma ampla reforma dos serviços de saúde pública brasileiros. 
Trom the earliest years of the Manguinhos Institute, its researchers had been commissioned to make scientific journeys to various parts of the Brazilian territory, where they carried out studies and activities to aid with government and private interventions to modernize the country. The campaigns against malaria led by Carlos Chagas in Itatinga, São Paulo; Xerém, Rio de Janeiro; and northern Minas Gerais stand as examples of this movement through which science affirmed its role as a vital instrument of progress and nation-building.

In August 1912, in response to a crisis in the Amazon rubber sector, the federal government signed a contract commissioning the Oswaldo Cruz Institute to survey health conditions in the Amazon Valley so that a plan could be devised for the rational use of its resources. From October of that year through March 1913, Chagas traveled the Solimões, Purus, and Negro rivers and their main branches in the company of Antonio Pacheco Leão, of Rio de Janeiro's School of Medicine; João Pedroso, of the General Directorship of Public Health; and a photographer.

The commission visited native rubber stands and riverside settlements, where they assessed living conditions and analyzed such factors as water supply, sewerage, housing, food, work, and health care. They made clinical observations of different diseases, especially malaria, which afflicted most of the region's inhabitants, and also gathered information on the main epidemics, recorded local medical practices, captured suspected disease-transmitting insects, and gathered plants of potential medical value. At the makeshift laboratory set up on their small transport vessel, Chagas examined animals for parasites and used his microscope to look at samples and other material collected from people.

In October 1913, Chagas presented the expedition's findings before the National Rubber Conference, held at the Federal Senate in Rio de Janeiro. His talk, along with Oswaldo Cruz's report to the Ministry of Agriculture, Industry, and Commerce, painted a clear picture of the state of medical and social oblivion to which people of the Amazon had been relegated and underlined how the region's economic development depended on sanitary measures.

The impact of the Oswaldo Cruz Institute's scientific expeditions lent strength to the movement that had been working since the mid-1910s to alert Brazilian society, and especially the government, to the importance of rural sanitation in Brazil and the urgent need for a broad reform of the country's public health services. 
CARLOS CHAGAS, UM CIENTISTA DO BRASIL I CARLOS CHAGAS, SCIENTIST OF BRAZIL

Imagem de abertura - Aspecto da região amazônica visitada por Chagas Casa de Oswaldo Cruz Opening image - View of the Amazon region visited by Chagas

Estrudas realyadow on Shiecteon?

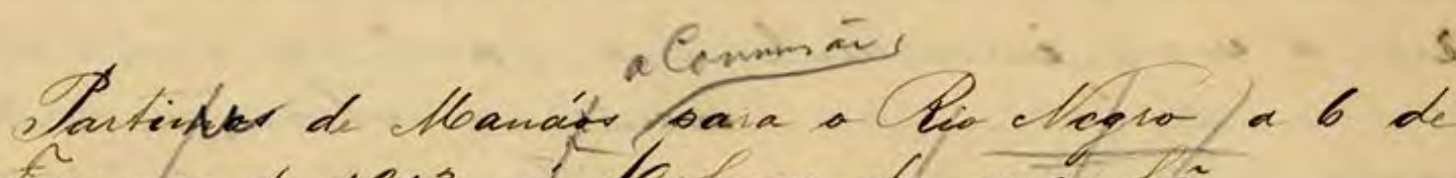

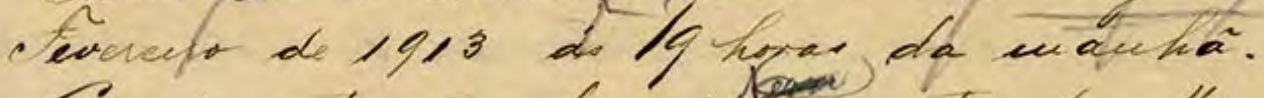

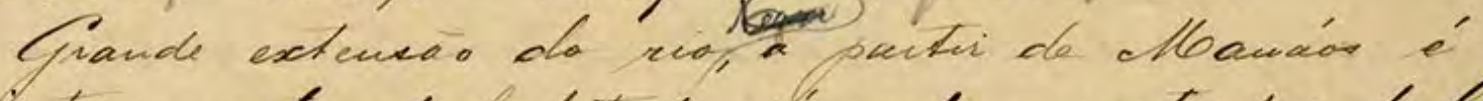
inteiramente dechabitada, to senda veoutradar de lon qe en longe jequevar choupanas nar uargens. Nen

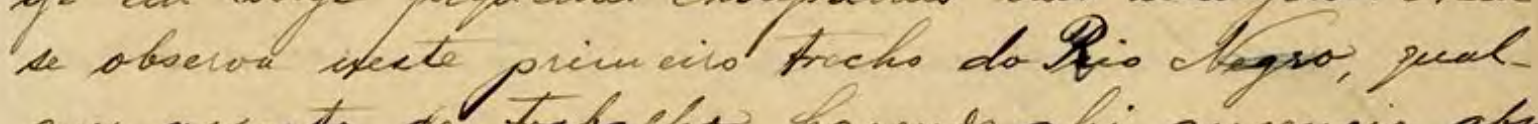
quer aspecto de trabalins, havend ahi acesececia abos luta de culture.

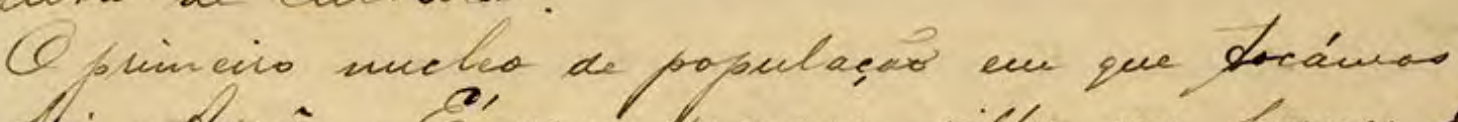

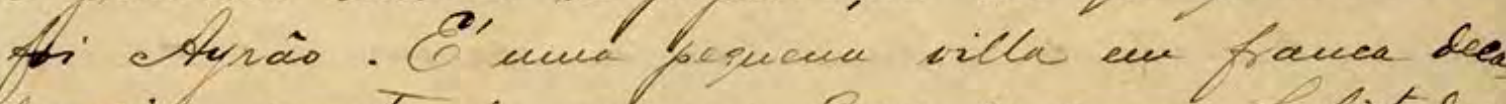
dencil, coutand apenas 8 on 10 caxas habitador

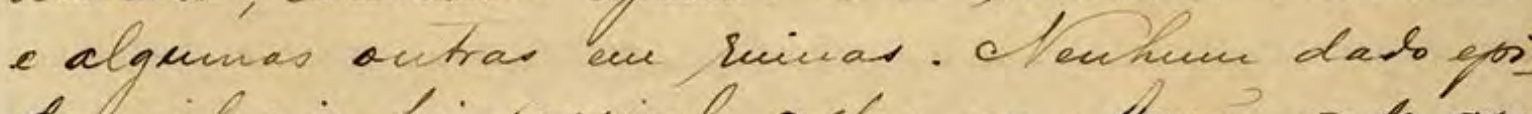

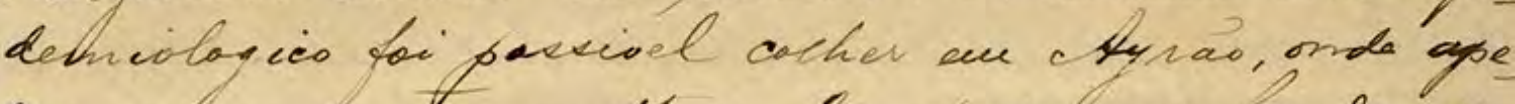

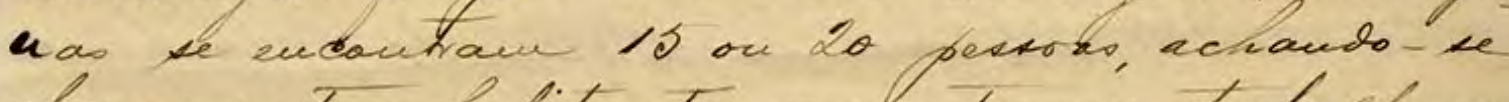
alquer autros nabitantes acesentes en trabalno nos

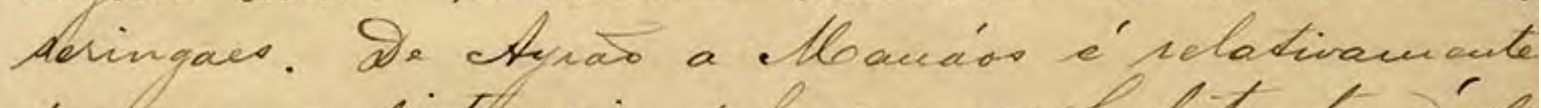
fequena a dietbuei, peto pue as ha bitaules o alvi, quacel doentes, pollen procurar recukos ceedios norba cidade.

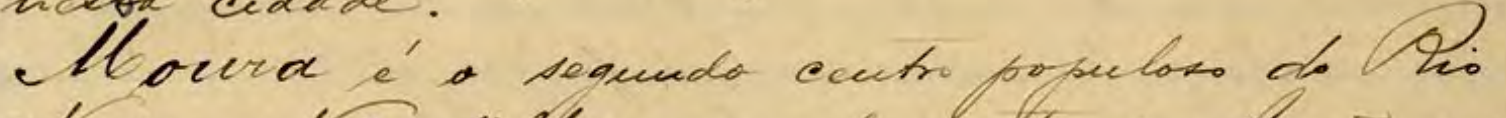

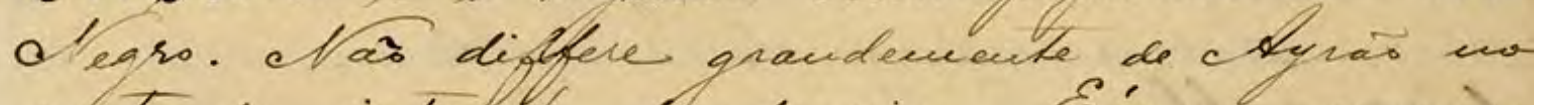

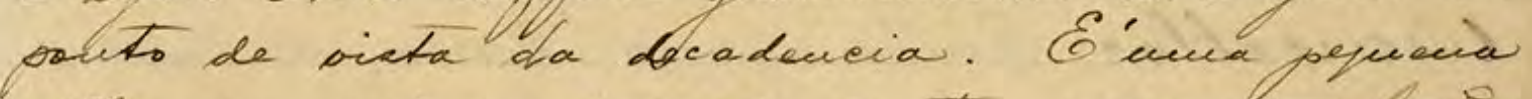

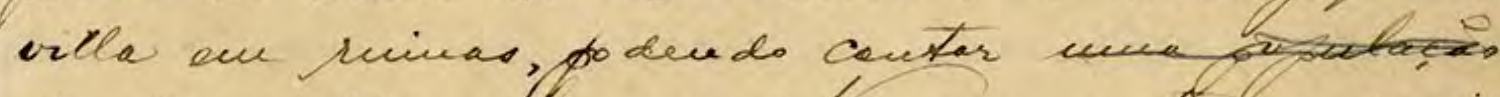

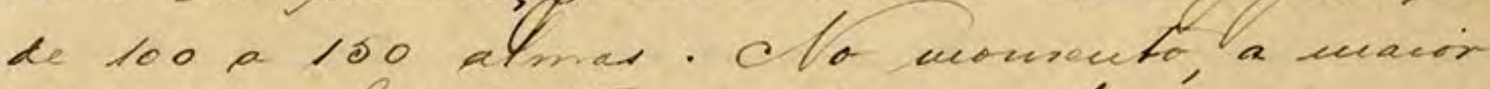
parte dos rabitaules da villa achava te duren

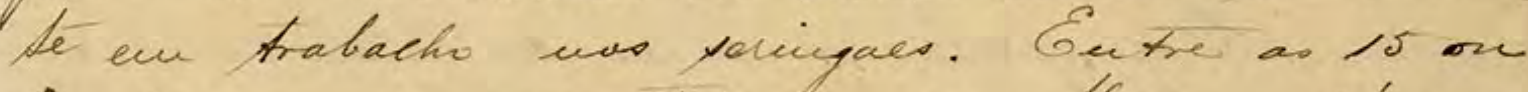

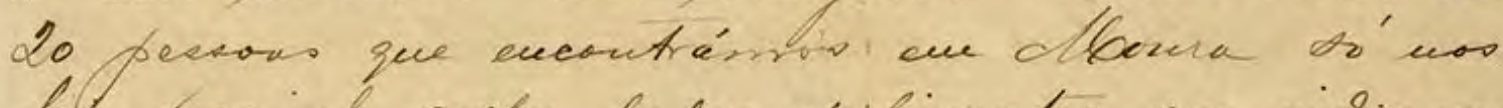

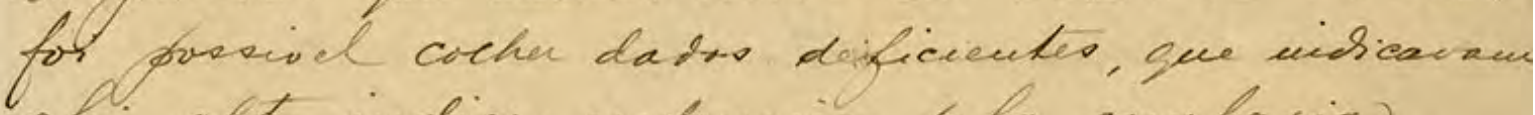
ahi alto indice euderesin beta ecedaria.

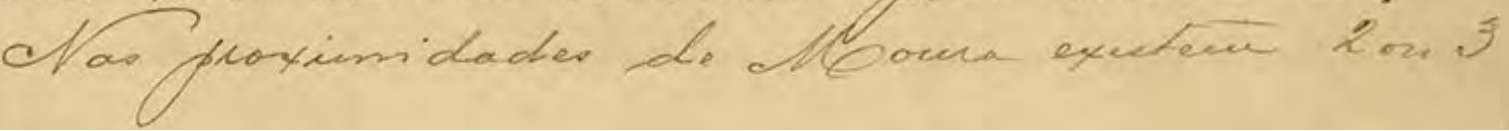

Trecho do relatório da expedição ao vale do rio Amazonas realizada entre 1912 e 1913 por Carlos João Pedroso Acervo Casa de Oswaldo Cruz Excerpt from the report on the 1912-1913 expedition to the Amazon Valley by Carlos Chagas, Pacheco Leão, and João
Pedroso

168 

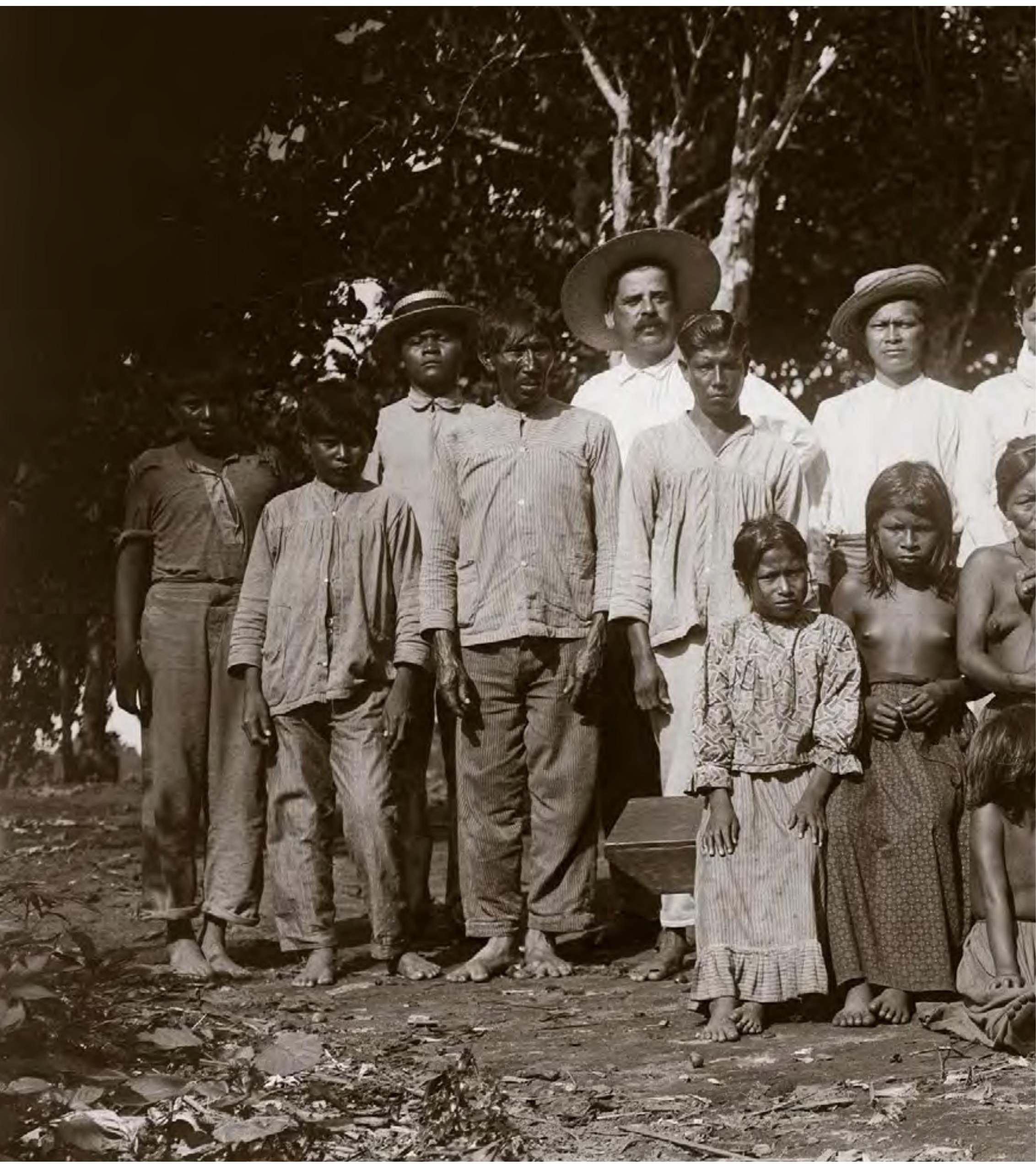


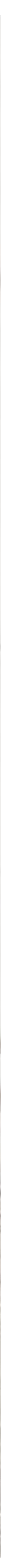




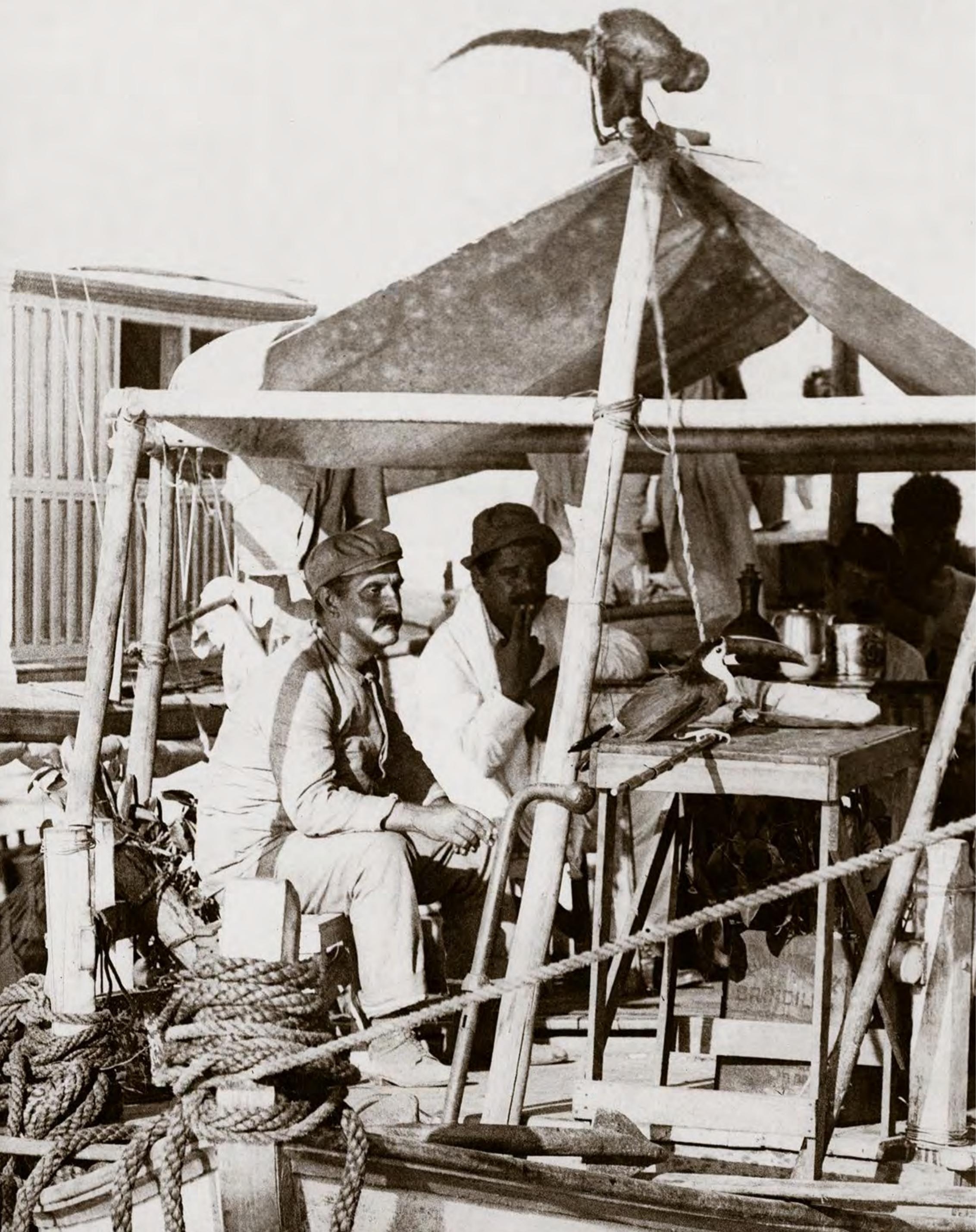



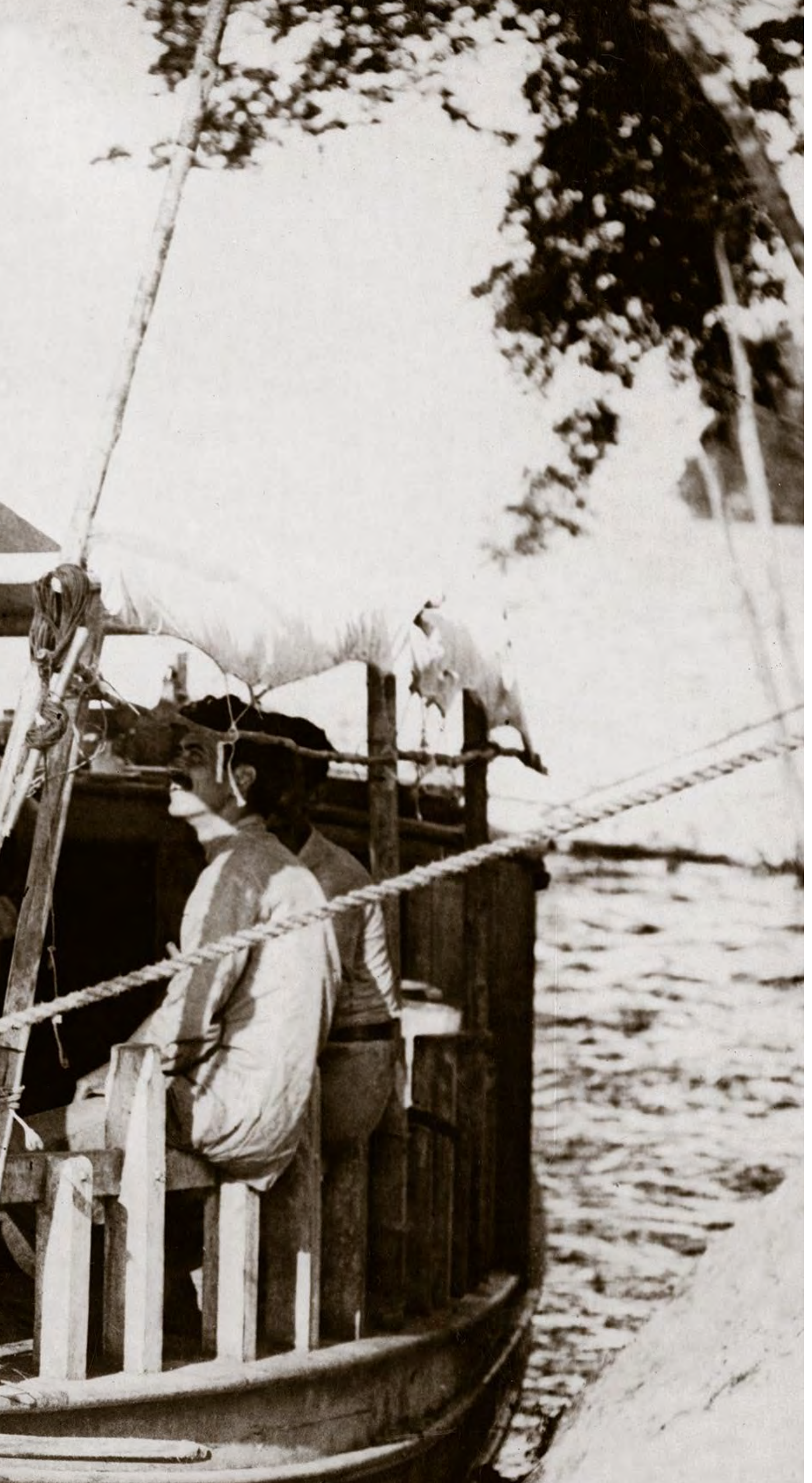

Membros da expedição. Chagas (ao fundo) e Pacheco Leão (à sua direita) 


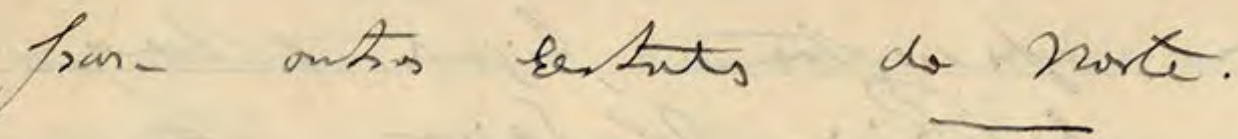

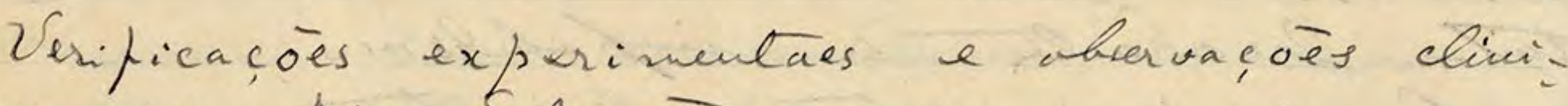
cur w hio Solimats:

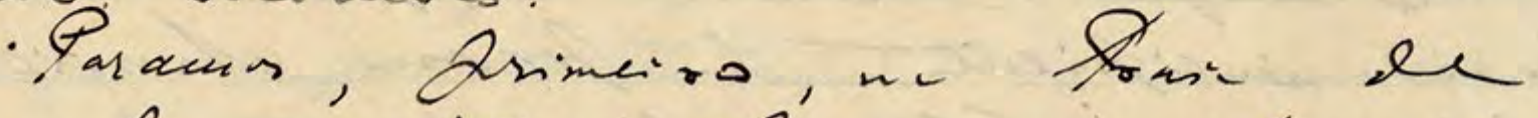

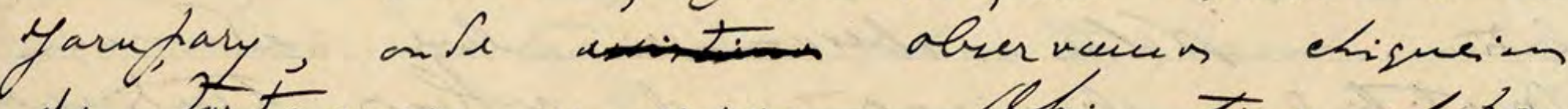
de tortarugs mumersm. Ch. the rass.

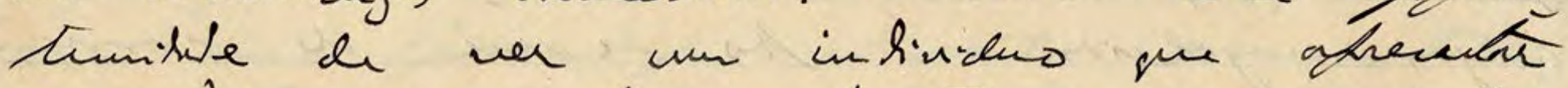
n- free un - frimentiming vegra, swh

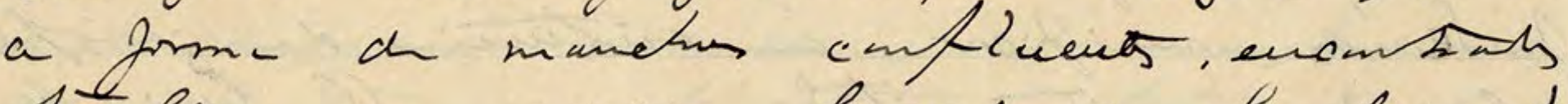

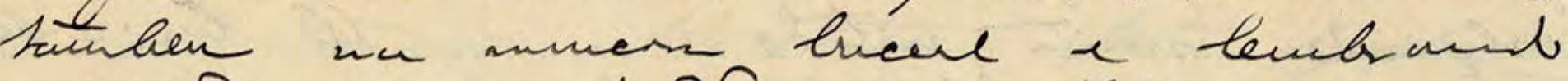

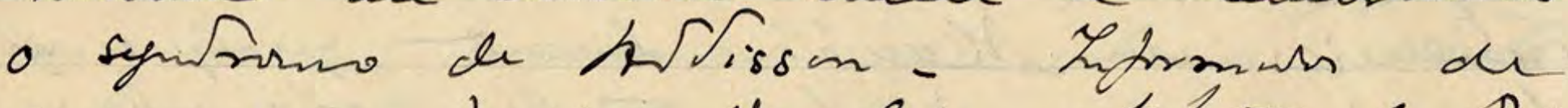

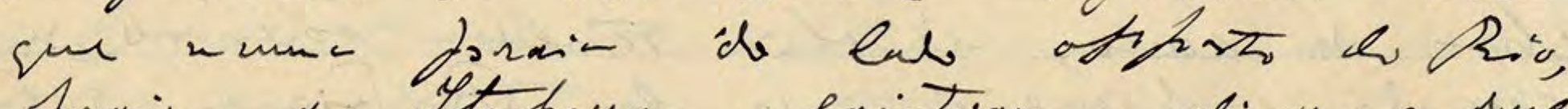

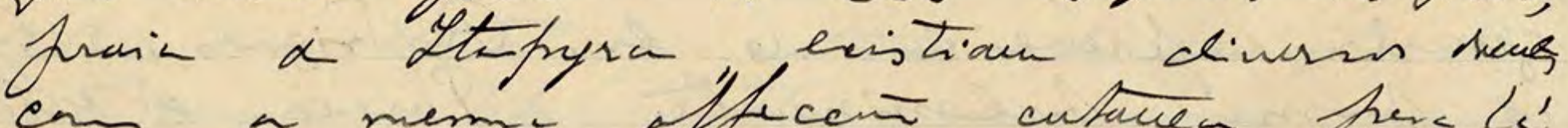

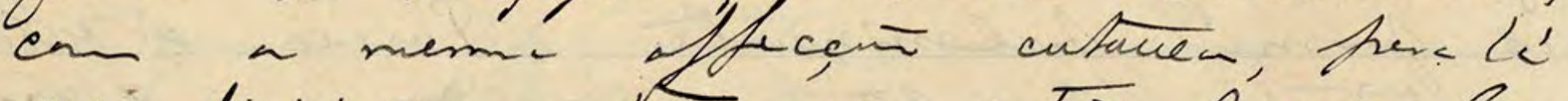
un divigims. Foi - un entin Risivel

Caderneta da expedição ao vale do rio Amazonas, 1912-1913

Acervo Casa de Oswaldo Cruz

Notebook from the Amazon Valley expedition, 1912-1913

Boca do Acre, rio Purus, AM Acervo Casa de Oswaldo Cruz

Municipality of Boca do Acre, located on the Purus River, Amazonas

Cachoeiras no rio Negro, na região de Massarabi, AM, 1912

Acervo Casa de Oswaldo Cruz

Rapids on the Negro River, in the region of Massarabi, Amazonas, 1912

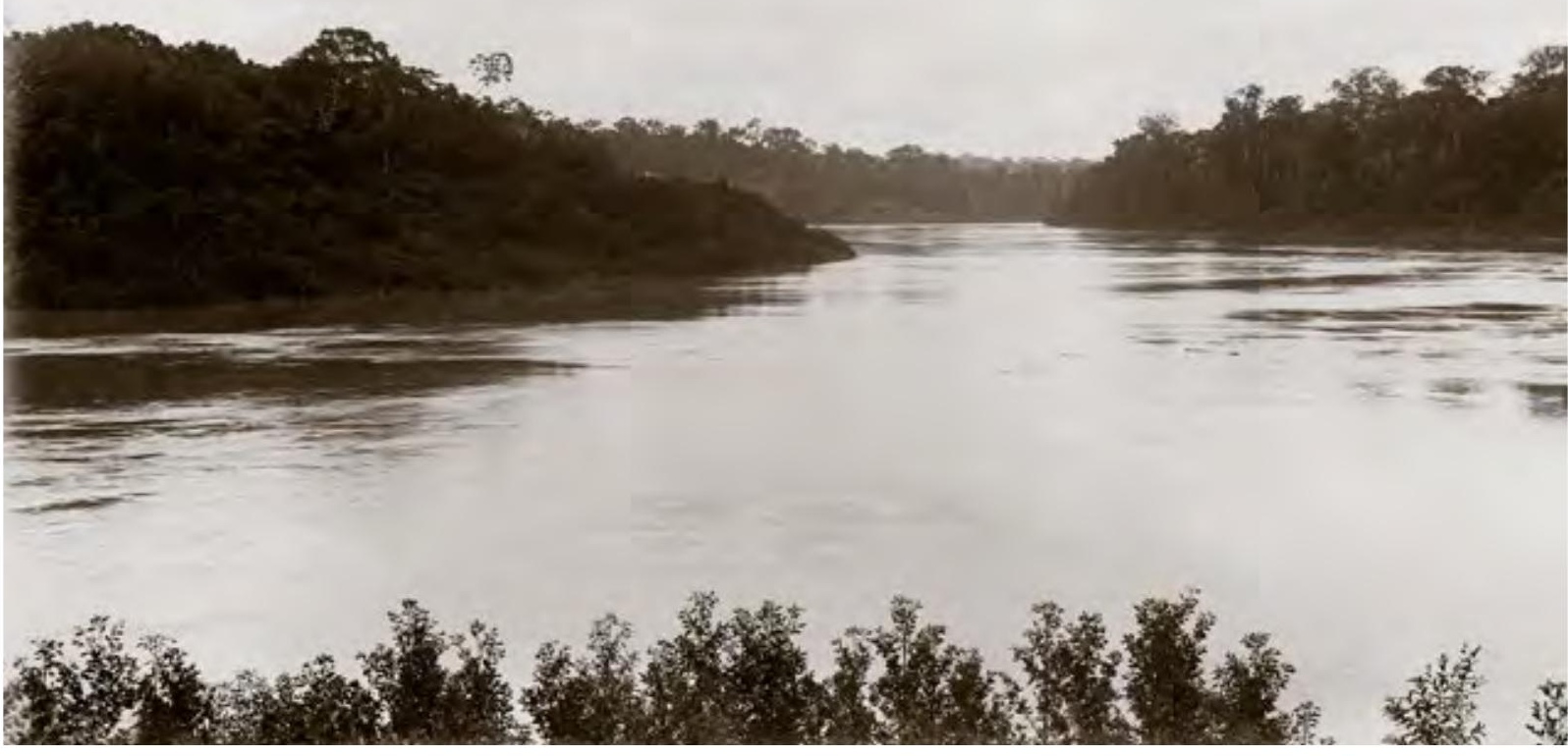




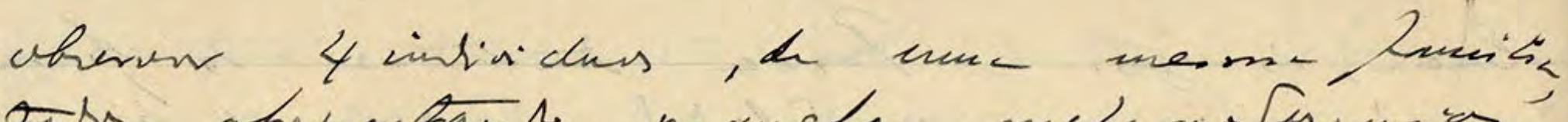

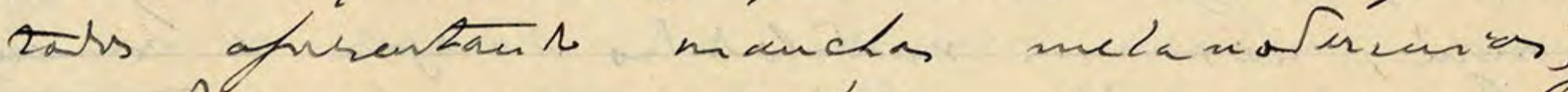

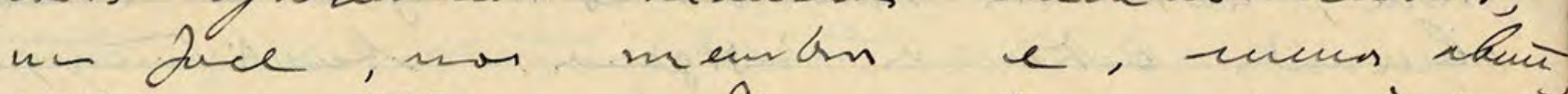

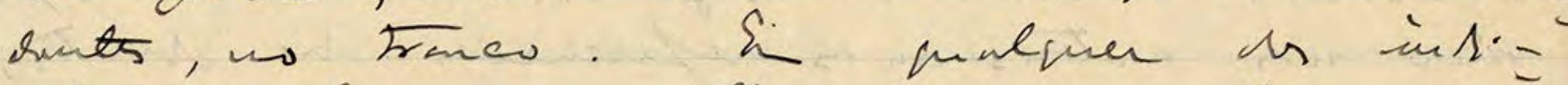

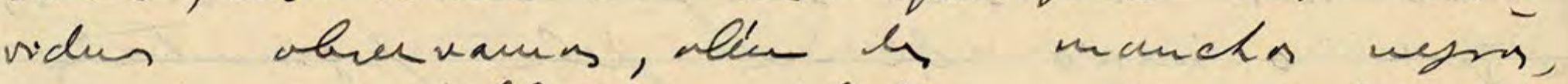

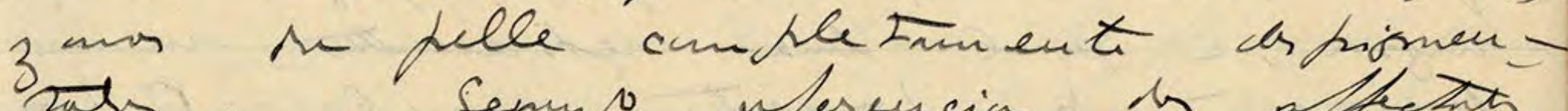

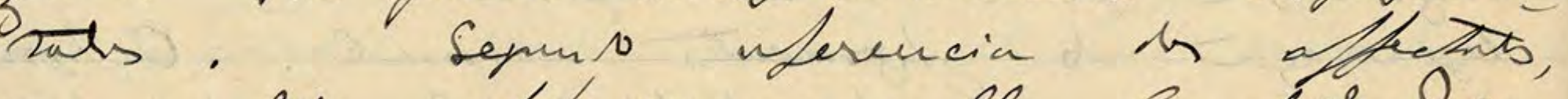

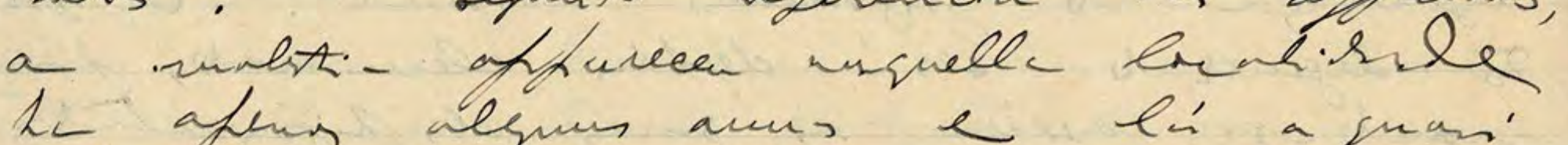

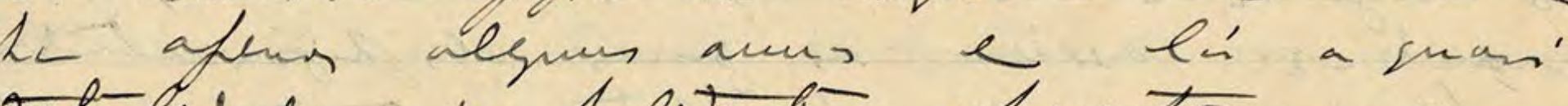

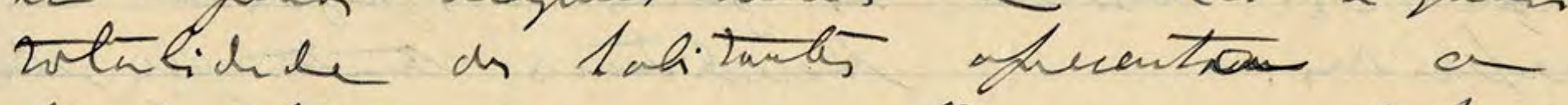

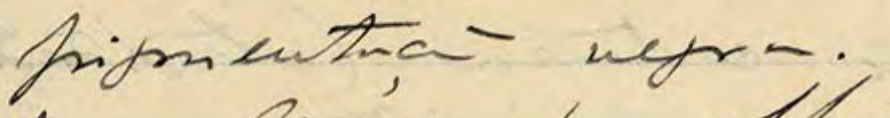

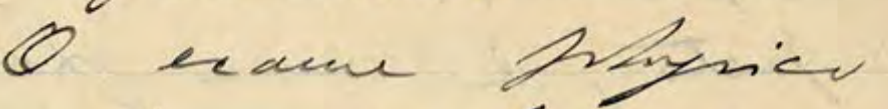

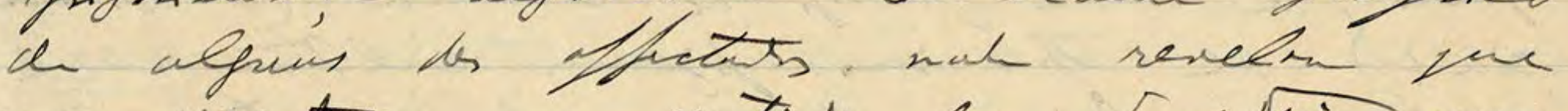

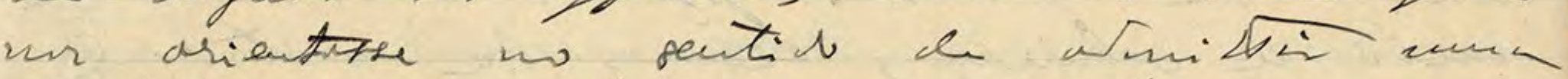
molst seral, wtacme $b$ nfins un les dentas npere

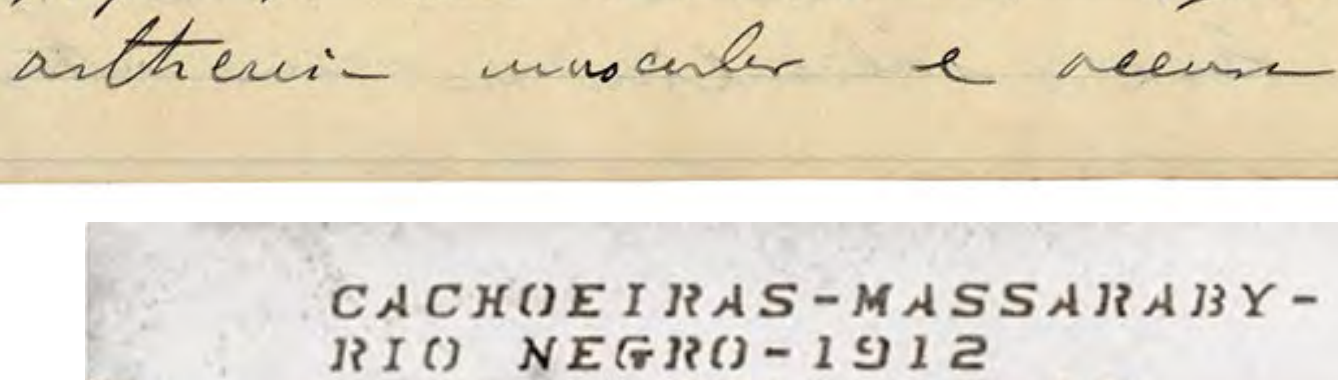

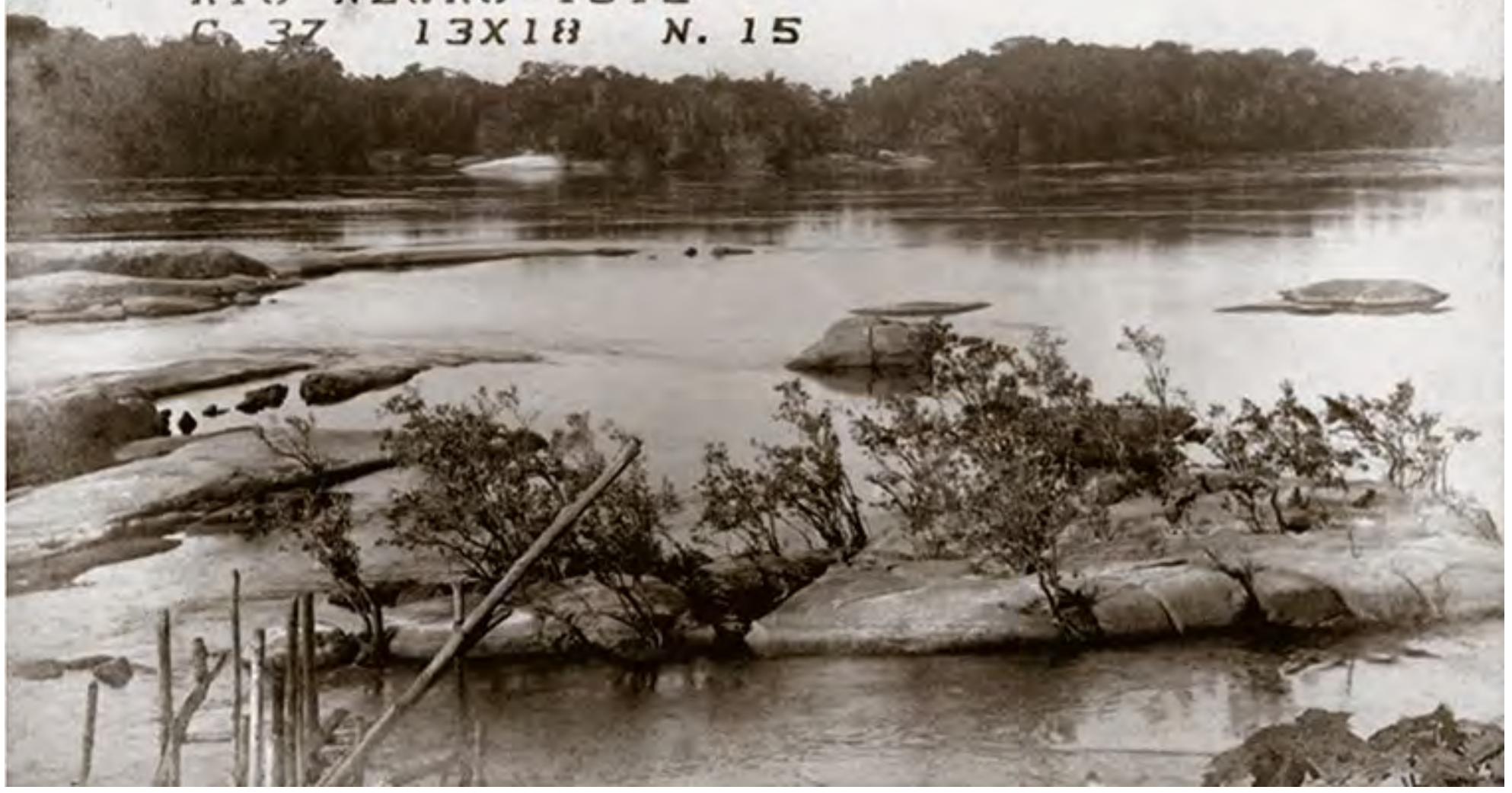




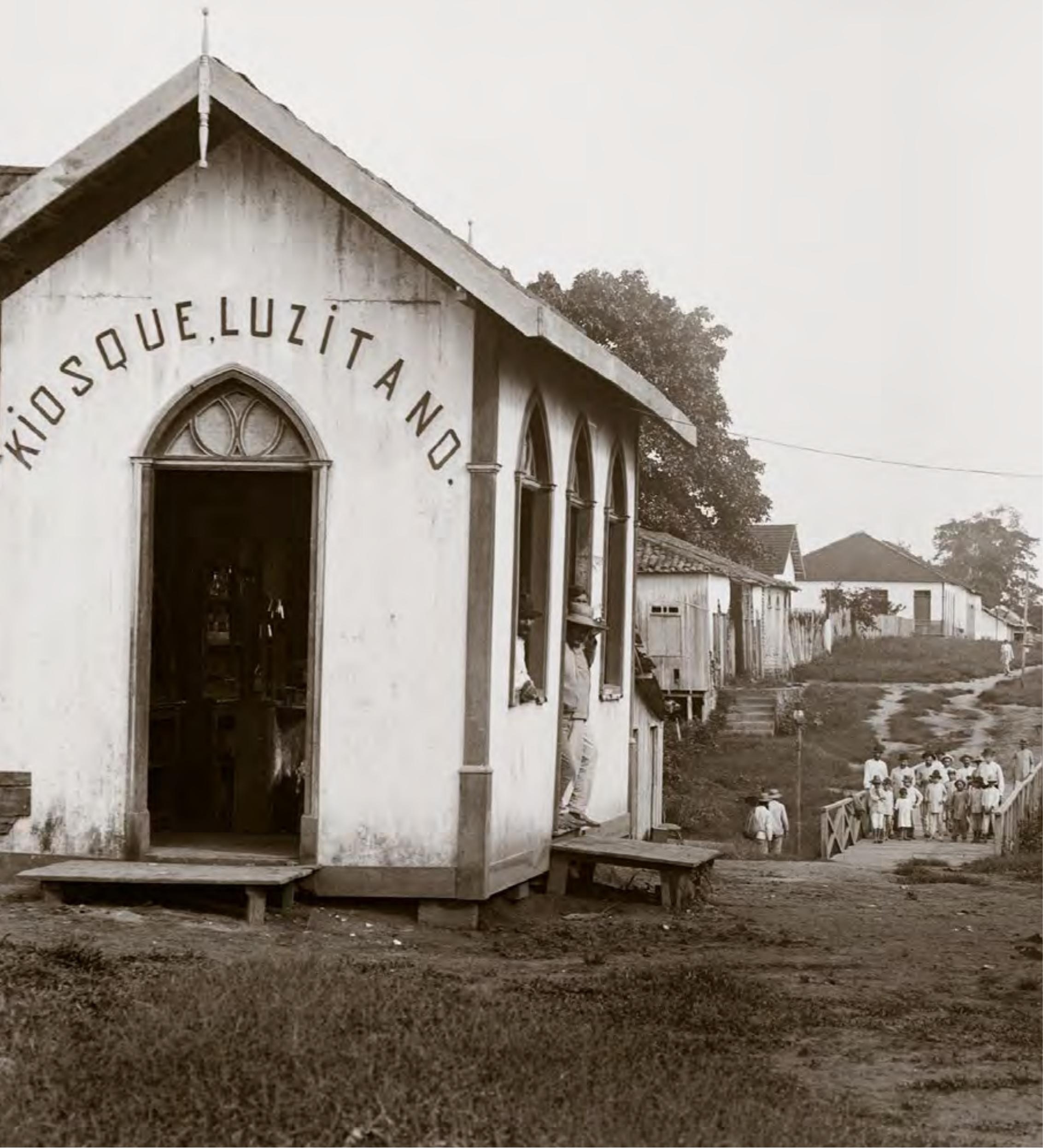

São Felipe, AM, nov. 1912 


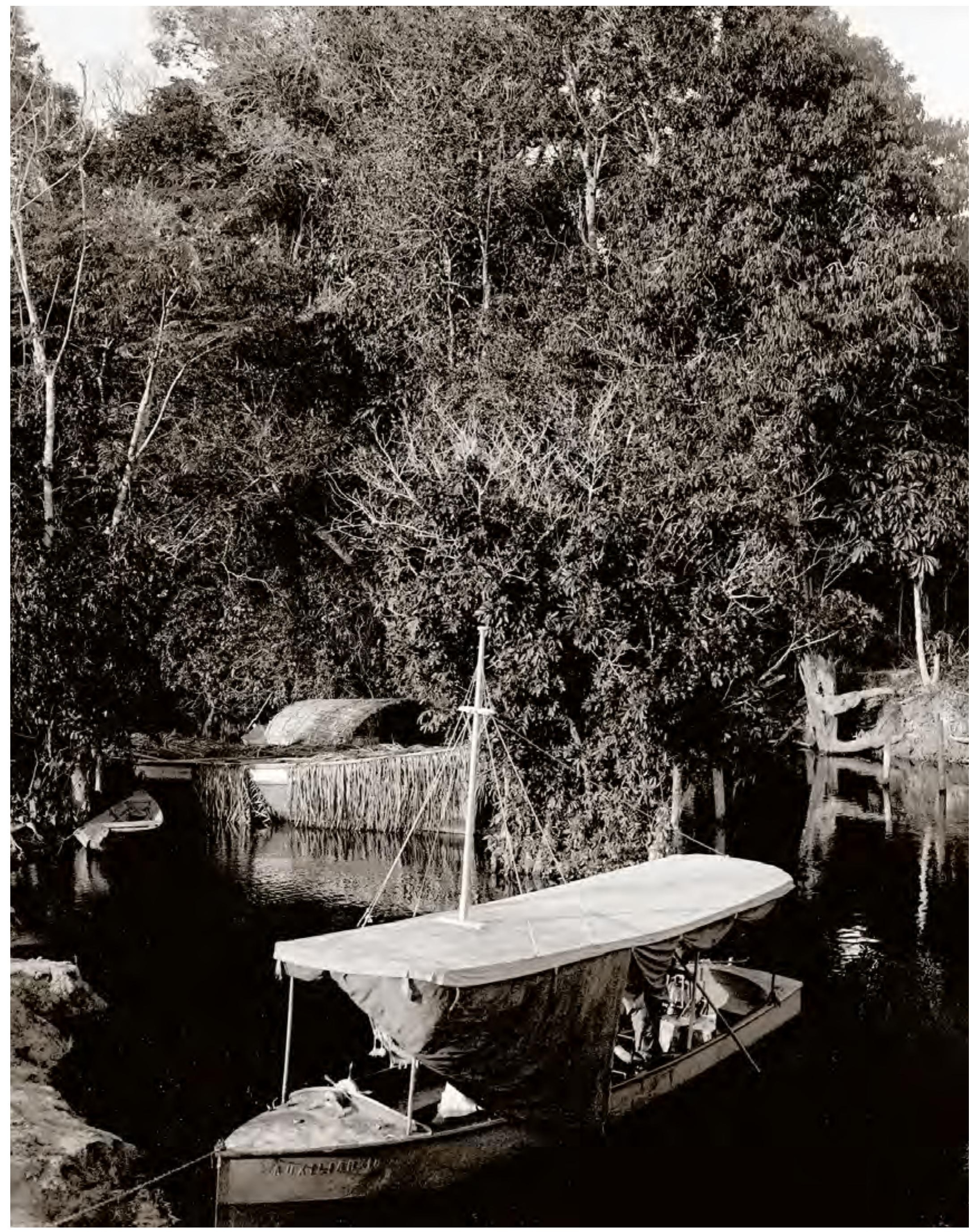




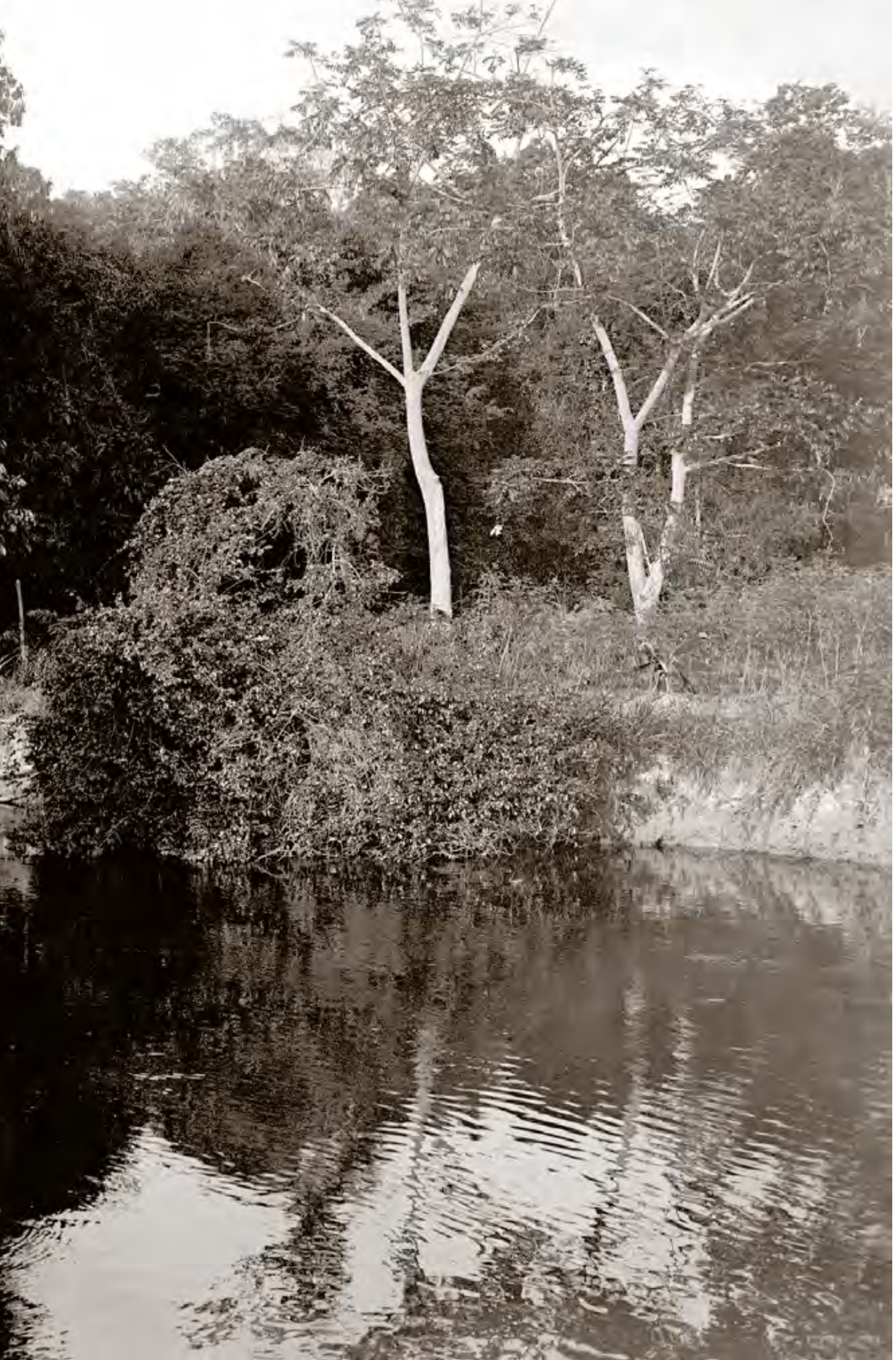

Aspecto da região

percorrida por Carlos Chagas

durante expedição ao vale do rio

Amazonas, 1912-1913

Acervo Casa de Oswaldo Cruz

View of the region visited by

Carlos Chagas during the Amazon

Valley expedition, 1912-1913 
a $a$

res, mod
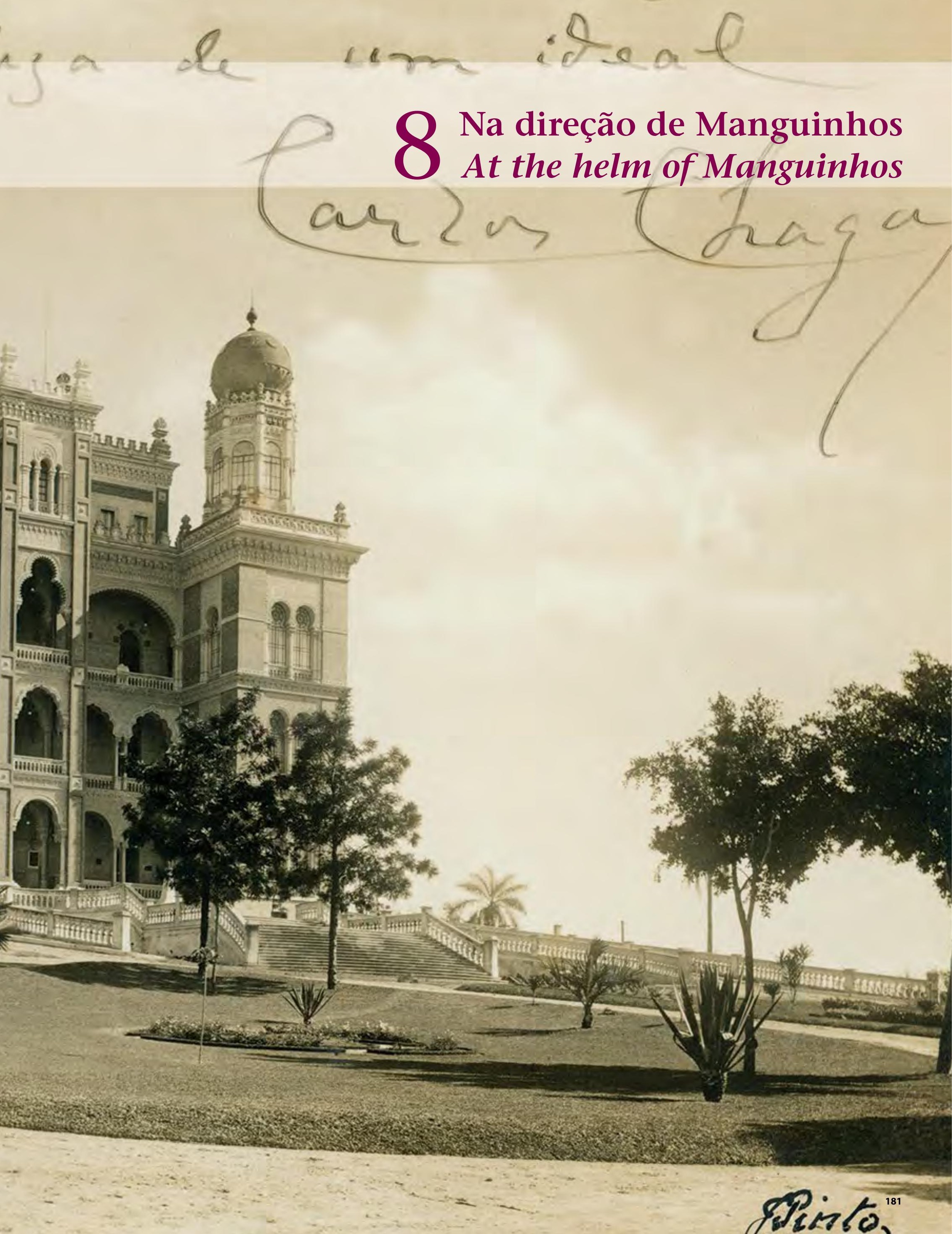
$\mathrm{E}$ m 14 de fevereiro de 1917, três dias após a morte de Oswaldo Cruz, Chagas foi nomeado, pelo presidente da República Wenceslau Braz (1868-1966), diretor do Instituto de Manguinhos, cargo que ocuparia até o fim de sua vida. Seguindo o modelo implantado por Cruz, inspirado no Instituto Pasteur de Paris, as atividades de pesquisa, ensino e produção continuaram em estreita vinculação com as demandas da saúde pública.

Chagas ampliou a estrutura laboratorial e o quadro de pesquisadores do instituto, enviando vários deles ao exterior para aperfeiçoamento. A fim de conferir maior formalidade às áreas de trabalho, estabeleceu seções científicas: Bacteriologia e Imunidade, Zoologia Médica, Micologia e Fitopatologia, Anatomia Patológica, Hospitais, Química Aplicada. Em 1918, inaugurou o Hospital Oswaldo Cruz, destinado à internação de portadores de doenças infecciosas (entre elas a tripanossomíase americana) e a pesquisas clínicas.

No campo do ensino, Chagas ampliou o Curso de Aplicação de Manguinhos, oferecido desde 1908 para a formação de pesquisadores em microbiologia e zoologia médica.

$\mathrm{Na}$ área de produção, diversificou a pauta de medicamentos e produtos biológicos fabricados em Manguinhos, entre eles alguns desenvolvidos pelos próprios pesquisadores. Estimulou a comercialização desses produtos, ampliando assim a renda própria que, desde o período de Oswaldo Cruz, era fundamental ao funcionamento do instituto. Dentre tais produtos, destacava-se a vacina desenvolvida por Alcides Godoy (1880-1950) para combater o carbúnculo sintomático ou "peste da manqueira", que atacava o rebanho bovino. Uma medida fundamental para a expansão da área de produção foi a organização, em 1918, do Serviço de Medicamentos Oficiais, criado pelo governo federal com o objetivo de produzir e fornecer, gratuitamente ou a preços subsidiados, a quinina (profilático e terapêutico para a malária) e outros medicamentos. A partir de 1920, o instituto assumiu também a responsabilidade pelo controle da qualidade dos imunobiológicos fabricados ou importados pelos laboratórios nacionais.

Chagas recebeu em Manguinhos, durante sua gestão, inúmeras personalidades do mundo científico e político do Brasil e do exterior. Estabeleceu importante rede de relações com pesquisadores e instituições científicas de vários países, promovendo intercâmbios e cooperações. Em 1923, por exemplo, promoveu a criação do Instituto Franco-Brasileiro de Alta Cultura e a fundação da Sociedade de Biologia do Rio de Janeiro, filiada à Sociedade de Biologia de Paris.

Apesar do prestígio como 'herdeiro' de Oswaldo Cruz, Chagas foi alvo de muitas críticas, resultantes, sobretudo, da crise vivida pelo instituto ao longo da conturbada década de 1920, no cenário de turbulências por que passava a sociedade brasileira. $\mathrm{O}$ estrangulamento financeiro - provocado pela concorrência com outros produtores de imunobiológicos, a insuficiência das dotações orçamentárias do instituto e a inflação, intensificada com a Primeira Guerra Mundial - levou ao desgaste de sua infraestrutura e ao declínio dos vencimentos de seus funcionários. Ainda assim, Chagas conseguiu manter alguns dispositivos fundamentais do modelo firmado por Oswaldo Cruz, como a autonomia financeira face ao orçamento federal, propiciada pela venda de produtos fabricados na instituição.

Seu falecimento, em 1934, deu-se no mesmo ano em que tinha início a gestão de Gustavo Capanema (1900-1985) no Ministério da Educação e Saúde (criado em 1930), que iria promover mudanças substantivas na administração do instituto e em seus vínculos com a saúde pública. O sucessor de Chagas na direção de Manguinhos foi Antonio Cardoso Fontes (1879-1943), que havia sido seu colega na Faculdade de Medicina do Rio de Janeiro. 
$\mathrm{O}$ n February 14, 1917, three days after Oswaldo Cruz passed away, Brazilian president Wenceslau Braz (1868-1966) appointed Chagas director of the Manguinhos Institute, a position he was to hold for the rest of his life. Consonant with the model put in place by Cruz under the inspiration of the Pasteur Institute in Paris, research, teaching, and production remained tightly aligned with public health needs.

Chagas enlarged the Institute's laboratory structure and staff of researchers, sending several of them abroad for further specialization. He strengthened the formal structure of each work area by establishing specific scientific sections: Bacteriology and Immunity, Medical Zoology, Mycology and Phytopathology, Pathological Anatomy, Hospitals, and Applied Chemistry. In 1918, he inaugurated the Oswaldo Cruz Hospital, which took in patients with infectious diseases, like American trypanosomiasis, and conducted clinical research.

In the realm of teaching, he expanded the Institute's program of specialization courses that had been training researchers in microbiology and medical zoology since 1908.

In production, he diversified the roll of drugs and biological products produced at Manguinhos, including some developed by the Institute's own investigators. He bolstered marketing of these products to bring in more of the direct income that had been vital to the Institute's operations ever since the days of Oswaldo Cruz. One of the more noteworthy products was the vaccine developed by Alcides Godoy (1880-1950) to combat symptomatic carbuncle, which attacked cattle. The production area received a big boost in 1918, when the federal government organized the Official Drug Service, which was to produce medications like the quinine used to prevent and treat malaria and to supply these free or at reduced prices. Starting in 1920, the Institute also assumed responsibility for quality control of the immunobiological products made or imported by other Brazilian laboratories.

During his tenure in office at Manguinhos, Chagas received countless public figures from the scientific and political world in Brazil and abroad. He shaped a valuable network of relations with researchers and scientific institutions from different countries, stimulating exchange and cooperation. In 1923, for instance, he fostered creation of the French-Brazilian Institute for High Culture and of Rio de Janeiro's Society of Biology, affiliated with the Society of Biology in Paris.

Despite his prestige as Oswaldo Cruz's "heir," Chagas was the target of much criticism, primarily as a result of the crisis facing the Institute throughout the turbulent 1920s, when Brazilian society was experiencing a period of turmoil. The financial crunch triggered by competition from other laboratories that manufactured immunobiological products, an ever-tighter budget, and inflation, which climbed during World War I, wore away at the Institute's infrastructure and pushed down staff wages. Chagas nonetheless managed to keep in place some of the vital components of Oswaldo Cruz's model, such as the financial autonomy in relation to the federal budget afforded by the sale of products made at the Institute.

Chagas passed away in 1934, the same year that Gustavo Capanema (1900-1985) began his administration of the Ministry of Education and Health, created in 1930. The new minister would substantively alter the Institute's administrative structure and its ties with public health. Chagas's successor at Manguinhos was Antonio Cardoso Fontes (1879-1943), his former classmate at the School of Medicine in Rio de Janeiro. 
Logo que tivemos notícia da nomeação do ilustre sábio, que foi dos discípulos mais fieis e distintos do $\mathrm{dr}$. Oswaldo Cruz, procuramos obter de S.S. algumas declarações sobre seu programa. Disse-nos o dr. Carlos Chagas - o único programa possível para quem é chamado a dirigir o Instituto Oswaldo Cruz consiste no seguinte: continuar o programa do $\mathrm{dr}$. Oswaldo Cruz.

O Imparcial, 1917

So soon as we heard of the appointment of the illustrious sage, who was one of Dr. Oswaldo Cruz's most loyal and distinguished disciples, we sought to obtain some statements about his program from Carlos Chagas. The honorable doctor told us: "the only program possible for whoever is called upon to head the Oswaldo Cruz Institute is the following: the continuation of Dr. Oswaldo Cruz's program."

O Imparcial, 1917

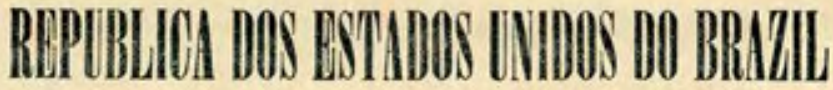
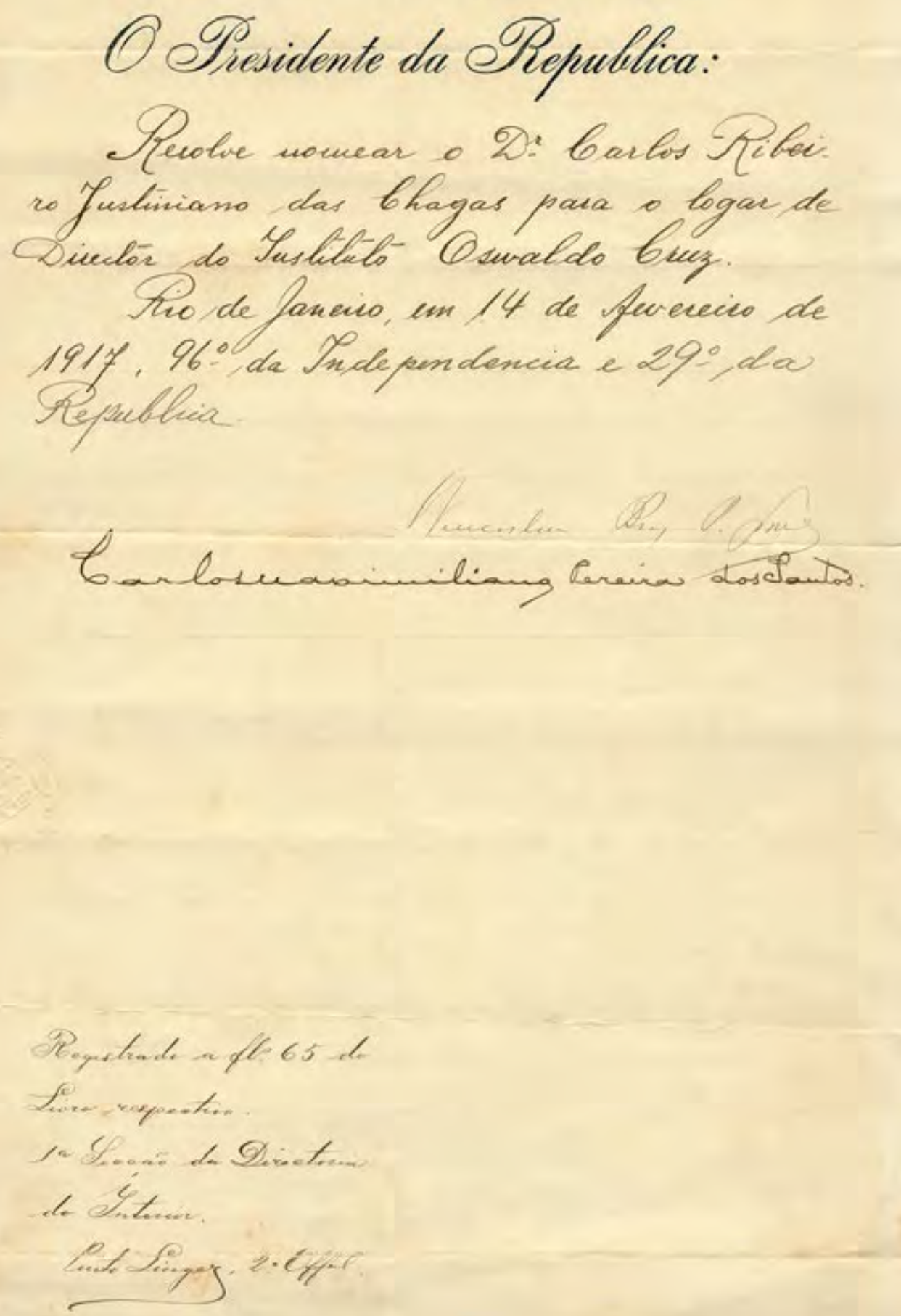

Imagem de abertura - Castelo mourisco

do Instituto Oswaldo Cruz

Foto J. Pinto

Acervo Casa de Oswaldo Cruz

Opening image - Moorish-style castle at

the Oswaldo Cruz Institute

Photograph by J. Pinto

Nomeação para diretor do Instituto

Oswaldo Cruz. Rio de Janeiro, 14 fev. 1917

Acervo Casa de Oswaldo Cruz

Appointment as director of

the Oswaldo Cruz Institute. Rio de Janeiro,

Feb. 14, 1917 


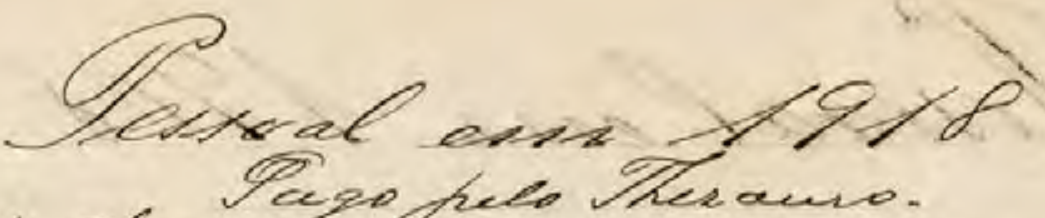

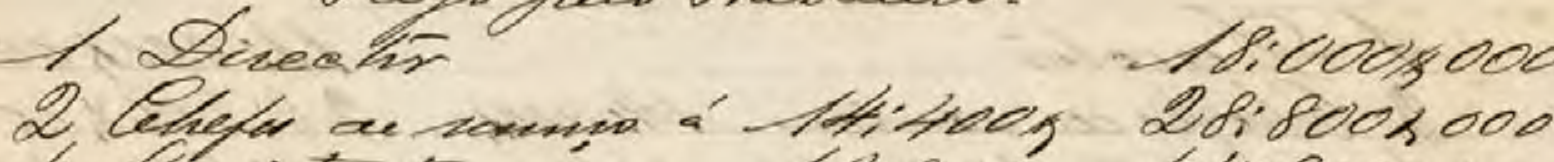

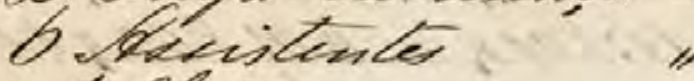

$\rightarrow$ nelader

Ibemonawile

$\rightarrow$ Qenewhila

1 beokivita esciblewano - li.foos blíb0ordoo \%.2008000 bif $\mathrm{OCO}_{3} \mathrm{CO}$ tis 008000 3: 6008000 3. 6007000 izefe de coedaces

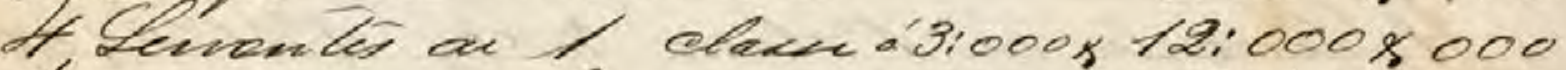

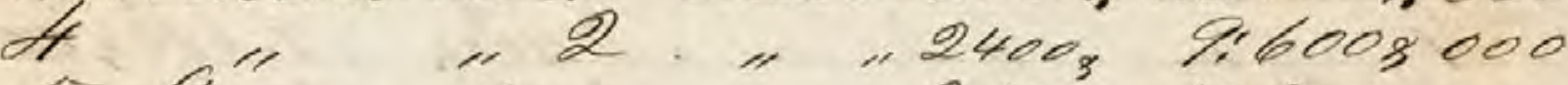
5 beedenter 1 Shertar

2 Prachicis la 2 Arevestar

sag. $2160 x$ loif00\% 000 5. 1008000 a' biloos 12.5201 lo.800\%000 $\frac{5: 0408000}{191: 2408000}$ hela zenida aoderbut.

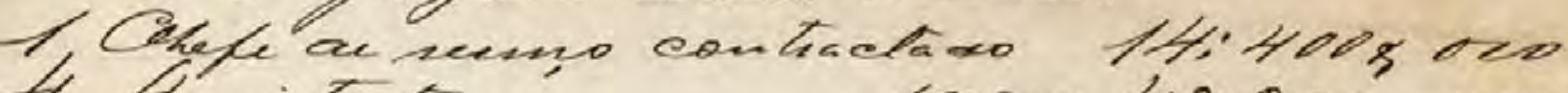

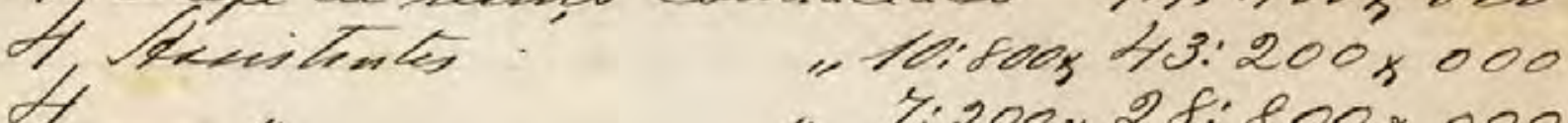
"I" "\%.2005 28.8005000 1 Geripturavio $13: 6005$ 3:6008000 "3:600\% 3:600\% 000

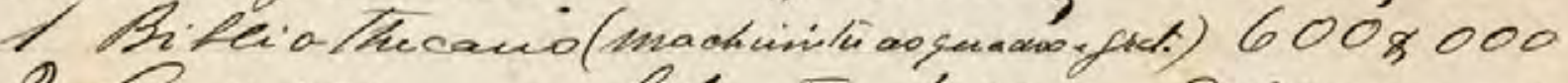

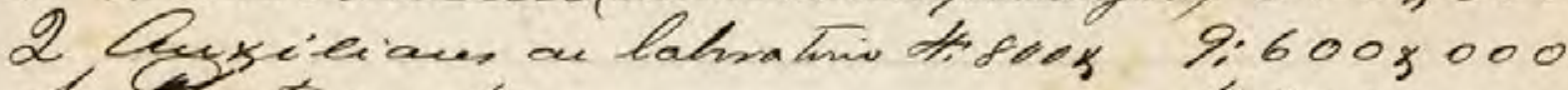
Siltera hteo Quenteria

I Cercarepaxo ara iraductor

$\rightarrow$ H, $200 \% 000$ 3. $000 \% 000$ 3. $600 \% 000$ 3. $600 y 000$

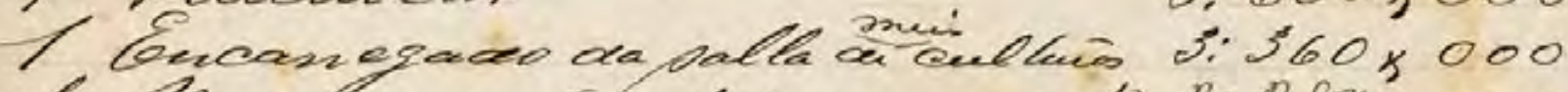

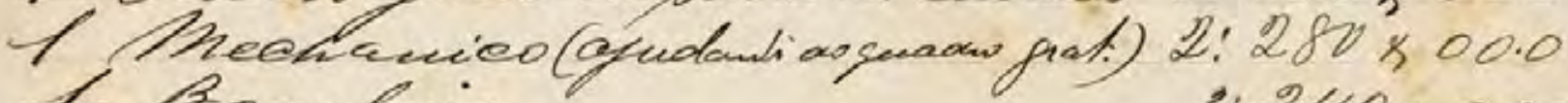
Ponatear
Remuneração de pessoal do Instituto Oswaldo Cruz em 1918. A'renda do Instituto' advinha da venda dos produtos fabricados pela

instituição

Acervo Casa de Oswaldo Cruz Personnel budget for the Oswaldo Cruz Institute in 1918. Part of payroll expenditures were covered by income from the sale of Institute products 


\section{INSTIVUTO OSWAIDO CRUZ.}

Tabella, das despezas \& serem effectuadas pela renda propria do Instituto Oswsido Cruz, de sccordo com o Art.l1 do Regulemento approvado pelo Decreto Ne 13.527 de 26 de larço de 1919 , no exercicio de 1919.

Custeio e conclusão das obras do hospital Oswaldo Cruz. $80: 000 \$ 000$ Custeio do Hospital Regional 12:000\$000

Pessoal contractado, inclusive um professor estrangeiro 156:000\$000 Excursões scientificas 15:000\$000

Impressão das memoria, bolletins, rotulos,bulas etc 28:000\$000 Acquisição de livros e jornses scientificos 12:000\$000 Droges e Utensilios de laboratorio 24:000\$000

Custeio de carros e automoveis

24:000\$000

Viciraria e preparo de ampolas

40:000\$000

Gaz e accessorios

22:000\$000

Ladeiras, ferragens, combustivel, lubrificantes, tintas accessorios de electricidade, etc.

$36: 000 \$ 000$

Alimentação

15:000\$000

Acquisição e sustento de grandes e pequenos animass 36:000\$000

Laterial photographico, encardeneção, publicações, limpeza, despezas miudas e eventuaes 


$$
\begin{gathered}
\text { INSTITUTO OSWaLdo CRUz. } \\
\text { Relação dos productos fornecidos } 8.0 \text { serviço de }
\end{gathered}
$$

Industria Pastoril, do dinioterio da hgricultura, Industria e Commercio.

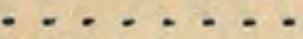

2928.

Fornecido por conta da subvenção de 48:000\$000

550.000 Dóses de vac.anti-carbunculosa......275:000\$000

4.030 Dóses de vac. contre a espirzllose...... 1:209\$000

4.000 Dóses de malleina diluida ......... 4:000\$000

630 Vidros de tubercuina bruta........ 4:095\$000

1.100 Vidros de sôro a-estreptococcico...... 8:800\$000

1.500 Vidros de sôro a-tetanico........... 7:5005000

$300: 6048000$

1.300.000 Dóses de vaccina contra a peste da manqueira $189 ; 000 \$ 000$

Soma.

$489: 604 \$ 000$

1919

Bornecimento feito de accordo com o contracto feito entre

este Instituto e o Linisterio de Agricultura, Industria e

Commercio, de 1 de Janeiro \& 31 de Outubro.

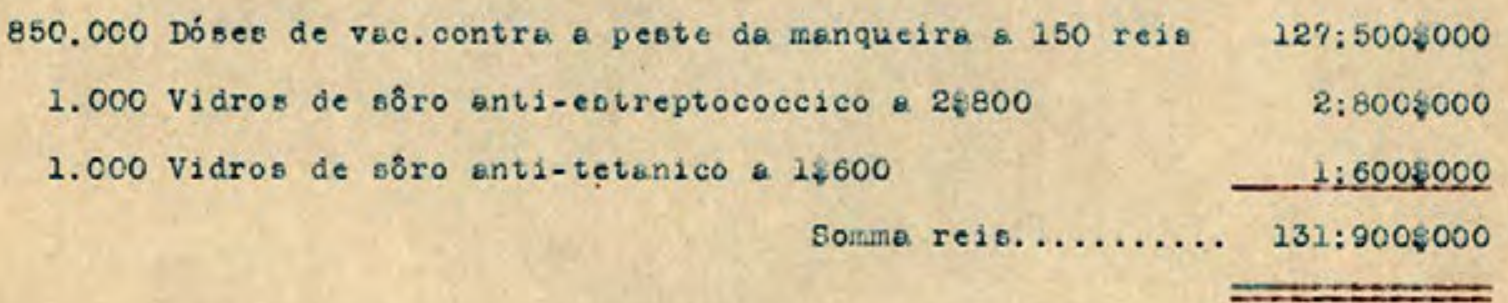


Carlos Chagas recepciona a

rainha Elizabeth da Bélgica em

sua visita ao Instituto Oswaldo

Cruz, em 27 de setembro de

1920

Foto J. Pinto

Acervo Casa de Oswaldo Cruz

Carlos Chagas receives

Belgium's Queen Elizabeth

during her visit to the Oswaldo

Cruz Institute, on September

27, 1920

Photograph by J. Pinto

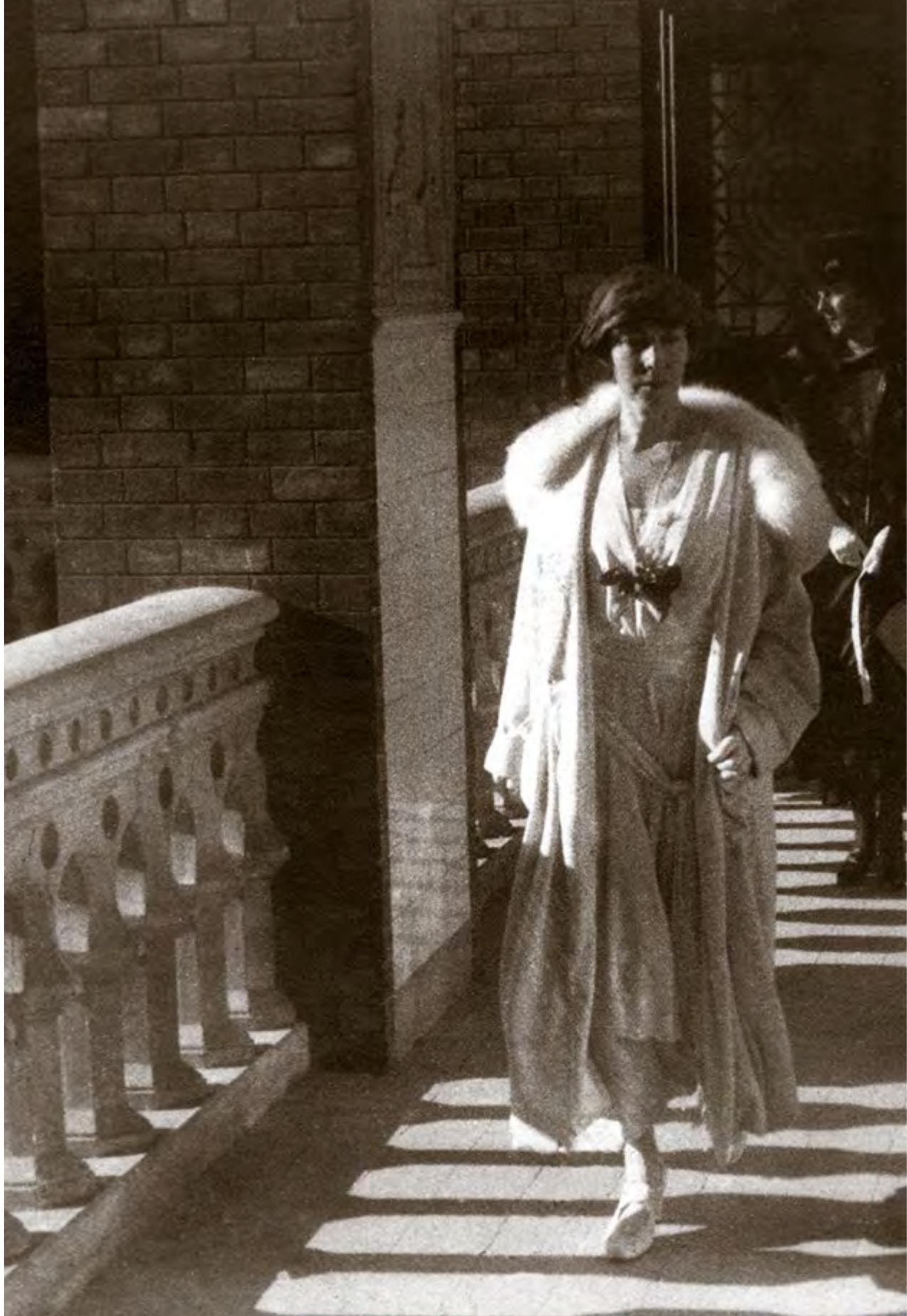


A rainha trocou idéias com o Dr. Carlos Chagas sobre a profilaxia da doença do 'barbeiro', e ficou bastante impressionada com as notícias das doenças rurais do país, procurando informar-se da organização sanitária que visa à respectiva profilaxia. $O$ diretor expôs-lhe em traços gerais o novo regulamento destinado ao combate das moléstias que dizimam a população dos nossos campos $e$, ao retirar-se a rainha, a quem fora oferecido um delicado 'lunch', S.S. fez-lhe oferta de um lindo ramalhete de cravos, presos por fitas com as cores brasileiras e belgas.

A Noite, 1920

The queen exchanged thoughts with Dr. Carlos Chagas on prevention of the "barber bug" disease, and was quite impressed by the news about the country's rural diseases; she sought to inform herself about the sanitary organization aimed at prophylaxis. The director gave her an overview of the new regulations intended to combat the sicknesses decimating the population in our countryside, and when the queen, who had been offered a light "lunch" [English in the original], took her leave, [Chagas] presented her with a beautiful bouquet of carnations, bound with ribbons in the colors of Brazil and Belgium. 
Chagas, com pesquisadores do Instituto Oswaldo Cruz, recepciona em Manguinhos Émile Marchoux, do Instituto Pasteur de Paris, década de 1920

1 - Antonio Eugenio de Arêa-Leão;

2 - José Gomes de Faria; 3 - José da Costa Cruz 4 - Henrique Aragão: 5 - César Pinto;

6 - Nicanor Botafogo

Gonçalves da Silva;

7 - Émile Marchoux; 8 - Leocádio Chaves; 9 - Carlos Chagas;

10 - Carlos Burle de Figueiredo

11 - Astrogildo Machado Foto J. Pinto

Acervo Casa de Oswaldo Cruz Chagas at Manguinhos with researchers from the Oswaldo Cruz Institute, receiving Émile Marchoux of the Pasteur Institute in Paris, 1920s

Photograph by J. Pinto

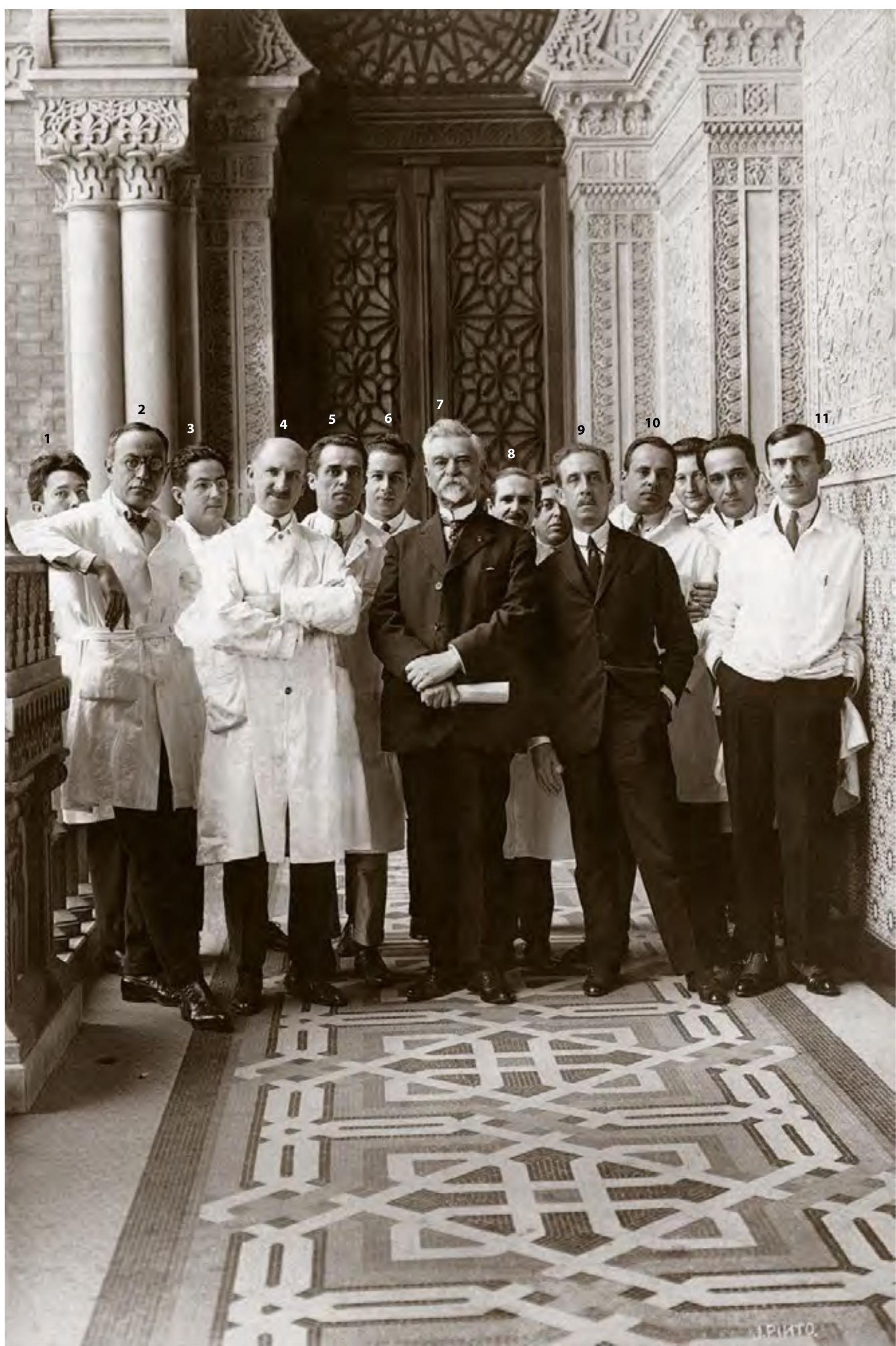




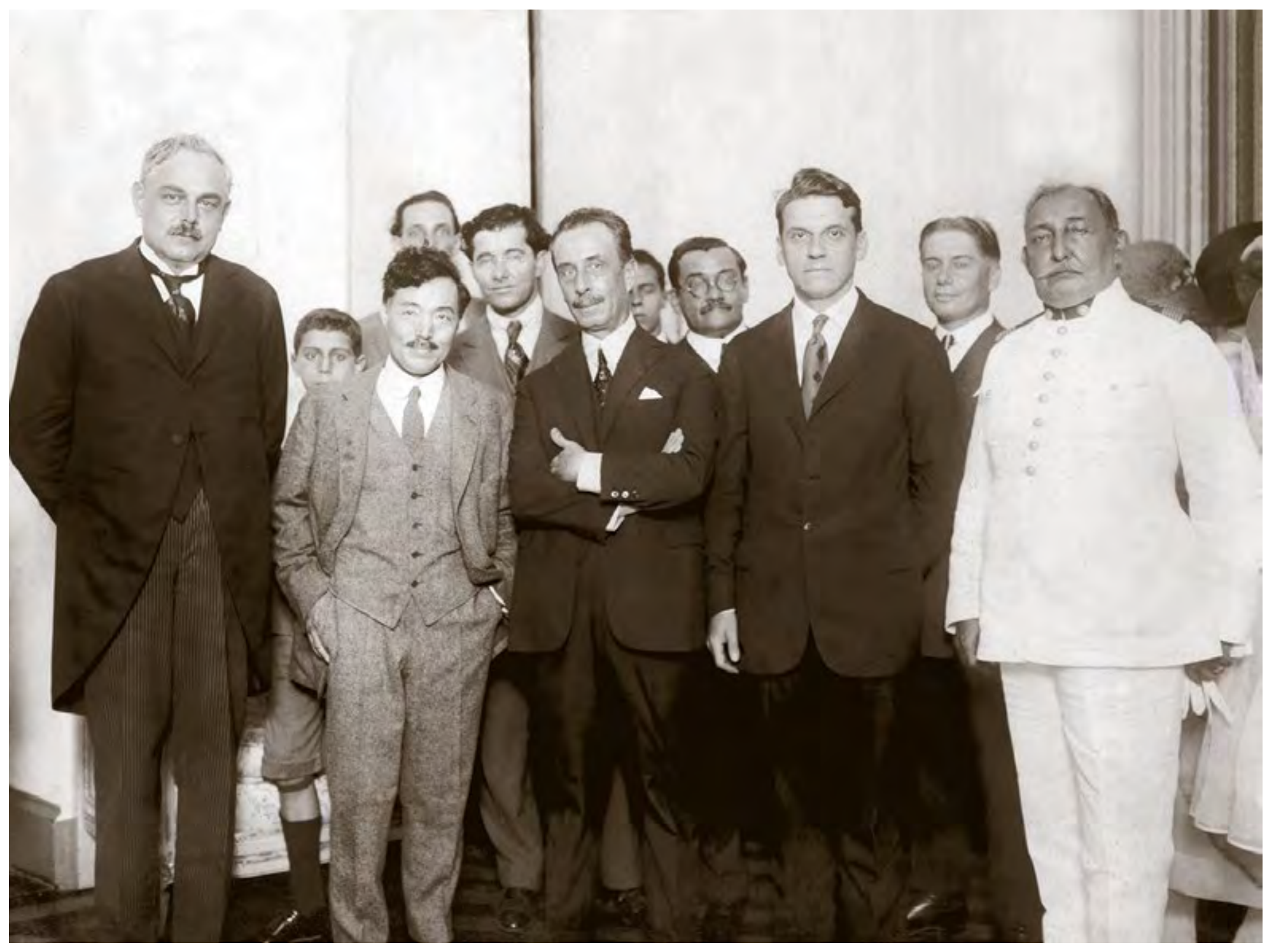

Carlos Chagas, por ocasião de sua posse como professor honorário da Faculdade de Medicina da Bahia, em encontro com Hideyo Noguchi ( $2^{\circ}$ a partir da esquerda) e Henry Miller $\left(4^{\circ}\right)$, pesquisadores da Fundação Rockefeller que trabalhavam no laboratório de pesquisas sobre a febre amarela. Salvador, BA, 1924 Acervo Casa de Oswaldo Cruz

Carlos Chagas, upon the occasion of his induction as an honorary professor of the Bahia School of Medicine, meeting Rockefeller Foundation investigators Hideyo Noguchi ( $2^{\text {nd }}$ from the left) and Henry Miller $\left(4^{\text {th }}\right)$, who worked at the yellow fever research laboratory.

Salvador, Bahia, 1924 
Carlos Chagas e Adolpho Lutz recebem em Manguinhos o pesquisador Marcel Eugène Émille Gley, fisiologista, professor do Collège de France e membro da Sociedade de Biologia de Paris, e Alexandre Conti, embaixador da França no Brasil. Década de 1920 Acervo Casa de Oswaldo Cruz Carlos Chagas and Adolpho Lutz at Manguinhos, receiving researcher Marcel Eugène Émille Gley, physiologist, professor at the Collège de France, and member of the Society of Biology in Paris, and Alexandre Conti, French Ambassador to Brazil, 1920 s

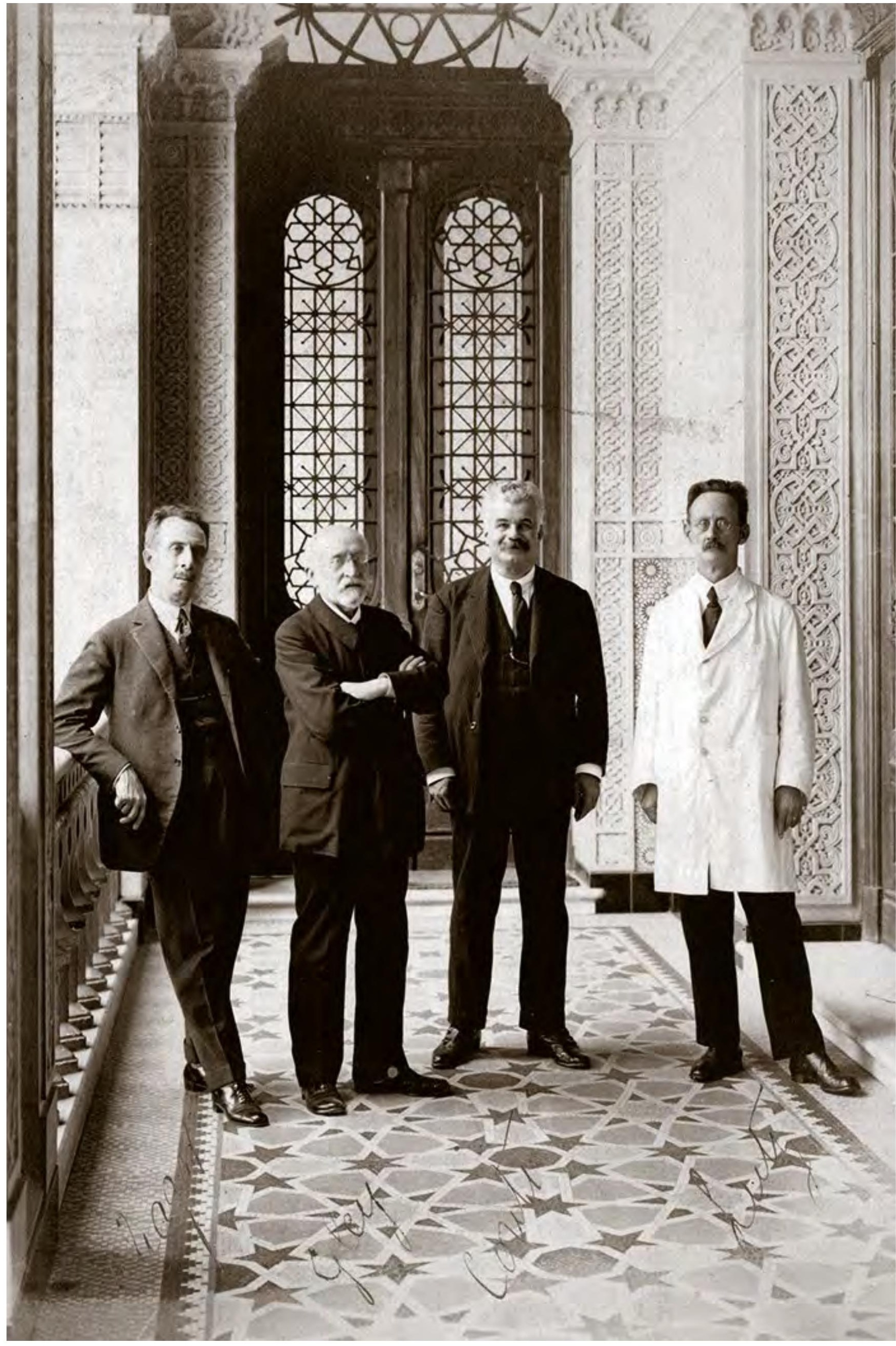




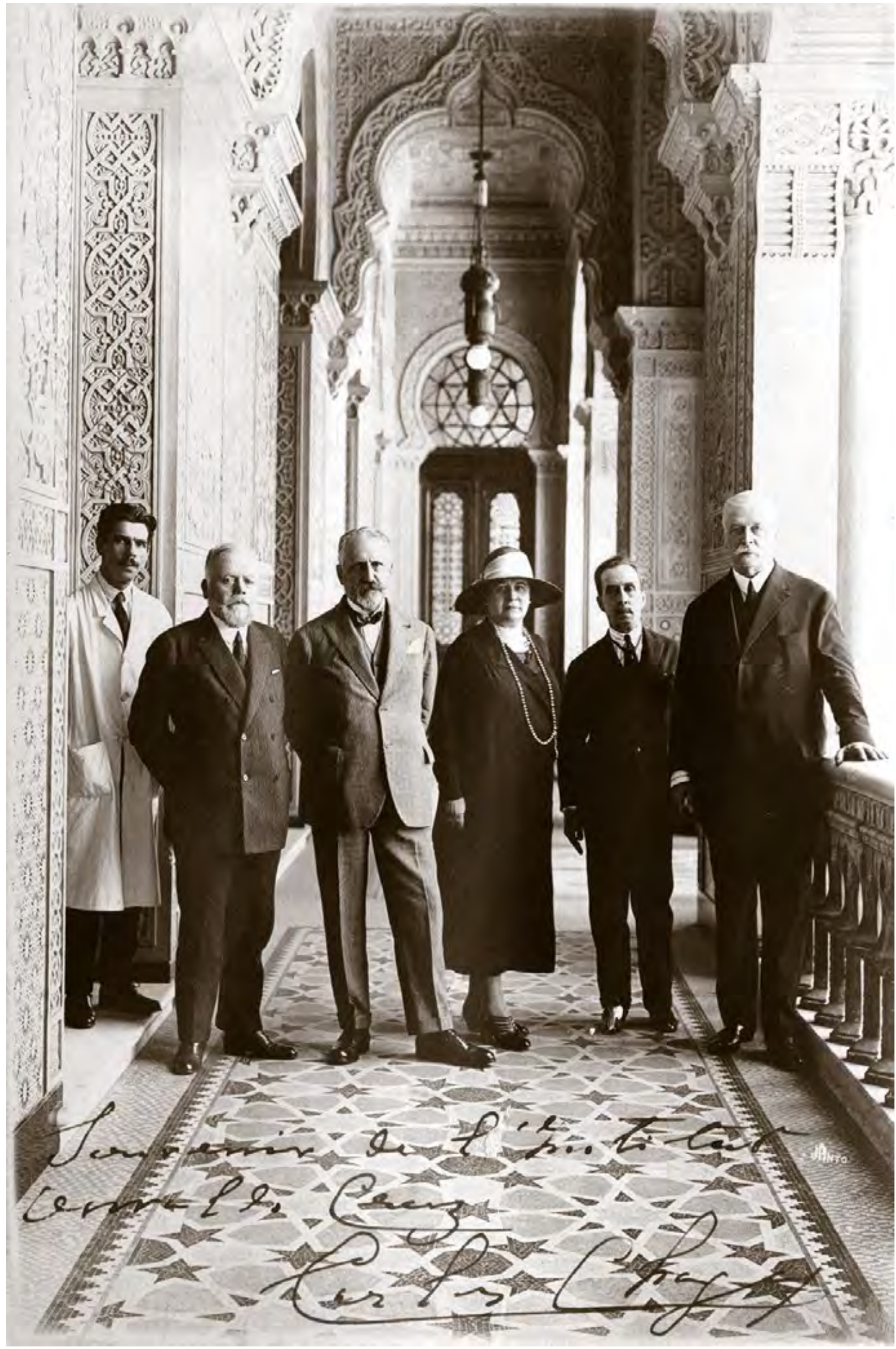

Eurico Villela, Louis Henri Vacquez, da Faculdade de Medicina de Paris, Leon Bernard, presidente do Comitê de Saúde da Liga das Nações, Carlos Chagas e Joseph Babinski, neurologista e professor da Universidade de Paris. Rio de Janeiro, 1925 Foto J. Pinto

Acervo Casa de Oswaldo Cruz Eurico Villela, Louis Henri Vacquez, from the Paris School of Medicine, Leon Bernard, president of the League of Nations' Health Committee, Carlos

Chagas and Joseph

Babinski neurologist and professor at Paris University.

Rio de Janeiro, 1925 Photograph by J. Pinto 
Carlos Chagas, com

pesquisadores do Instituto

Oswaldo Cruz, recepciona o

presidente da República

Washington Luiz e o ministro

da Justiça e Negócios

Interiores Augusto Vianna

Castelo. Rio de Janeiro,

1926-1930

Foto J. Pinto

Acervo Casa de Oswaldo Cruz.

1 - Julio Muniz;

2 - César Pinto

3 - Henrique Aragão;

4 - José Guilherme Lacorte;

5 - Carlos Chagas;

6 - Waldomiro de Andrade;

7 - Alcides Godoy;

8 - Lauro Travassos

9 - Washington Luiz;

10 - Nicanor Botafogo

Gonçalves da Silva;

11 - Antonio Cardoso Fontes

12 - Carlos Burle de

Figueiredo;

13 - Augusto Vianna Castelo; 14 - Antonio Eugenio de Arêa-Leão;

15 - Astrogildo Machado

Carlos Chagas with Oswaldo Cruz Institute researchers, receiving Brazilian president Washington Luiz and Justice and Interior Affairs Minister Augusto Vianna Castelo. Rio de Janeiro, 1926-1930

Photograph by J. Pinto

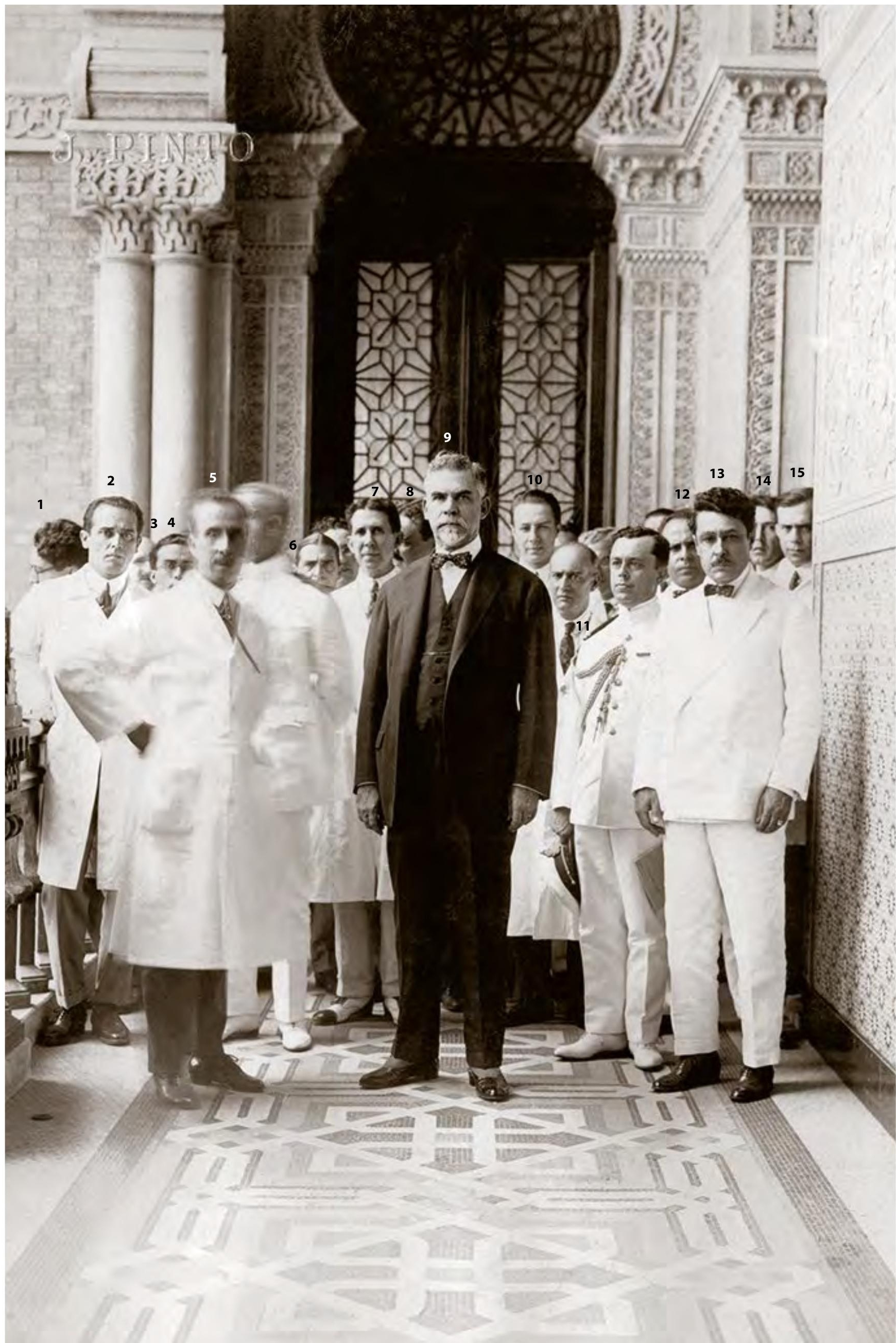



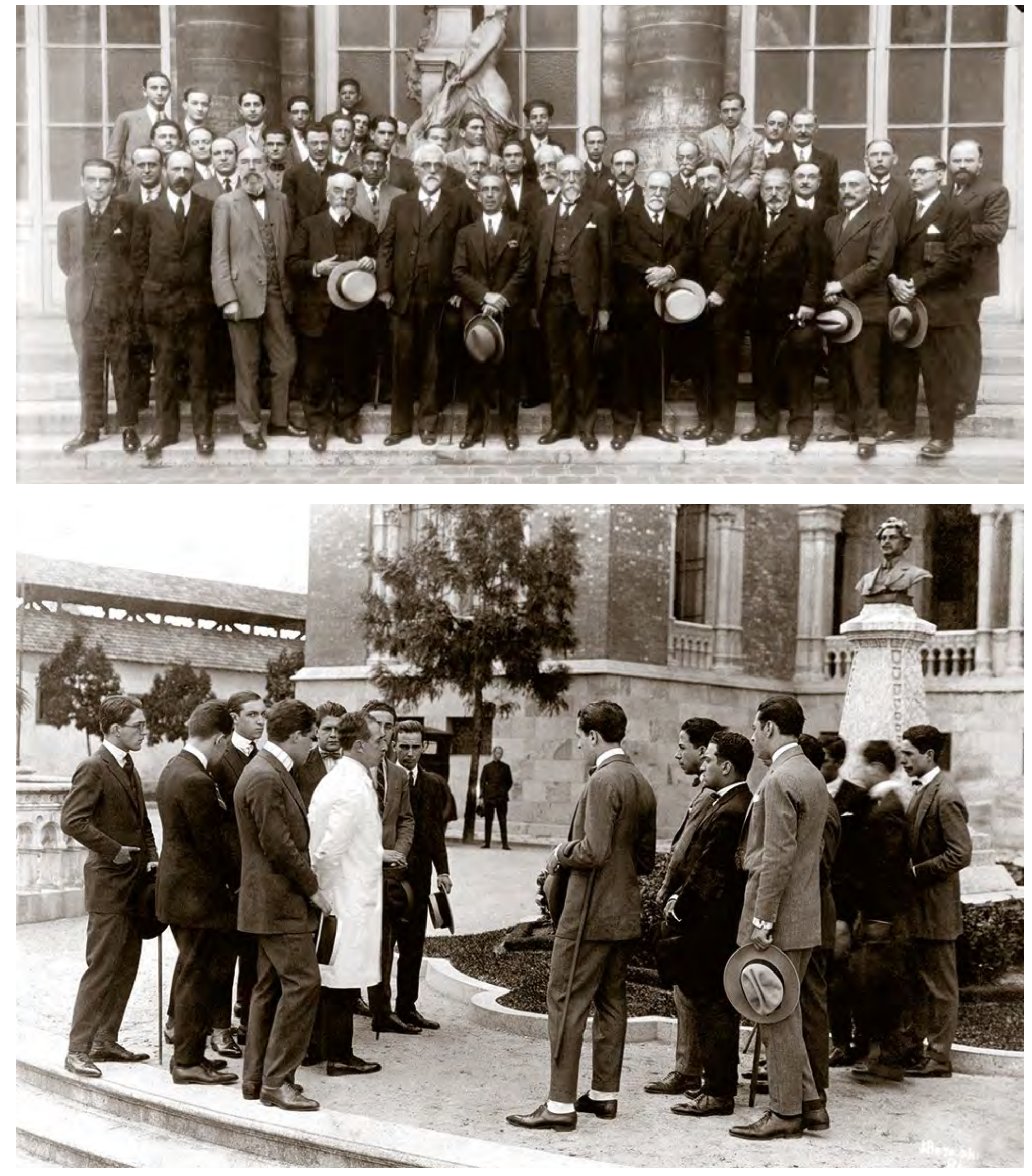

Carlos Chagas (ao centro) participa de Congresso de

Higiene na Sorbonne. Paris, 1929

Acervo Casa de Oswaldo Cruz

Carlos Chagas (center) attends the International

Hygiene Congress at the Sorbonne. Paris, 1929

Carlos Chagas com grupo de estudantes em

Manguinhos em frente ao busto de Oswaldo Cruz

Foto J. Pinto

Acervo Casa de Oswaldo Cruz

Carlos Chagas with a group of students at Manguinhos,

in front of the bust of Oswaldo Cruz

Photograph by J. Pinto 
Carlos Chagas recebe a visita de Albert Einstein no Instituto Oswaldo Cruz, em 9 de maio de 1925

1 - Carlos Burle de Figueiredo 2 - Antonio Eugenio de Arêa-Leão; 3 - Nicanor Botafogo Gonçalves da Silva

4 - Adolpho Lutz

5 - Alcides Godoy;

6 - Carlos Chagas;

7 - Astrogildo Machado;

8 - Albert Einstein;

9 - José da Costa Cruz;

10 - José Carneiro Felippe;

11 - Leocádio Chaves

Foto J. Pinto

Acervo Casa de Oswaldo Cruz

Carlos Chagas receiving Albert

Einstein on his visit to the Oswaldo

Cruz Institute on May 9, 1925

Photograph by J. Pinto

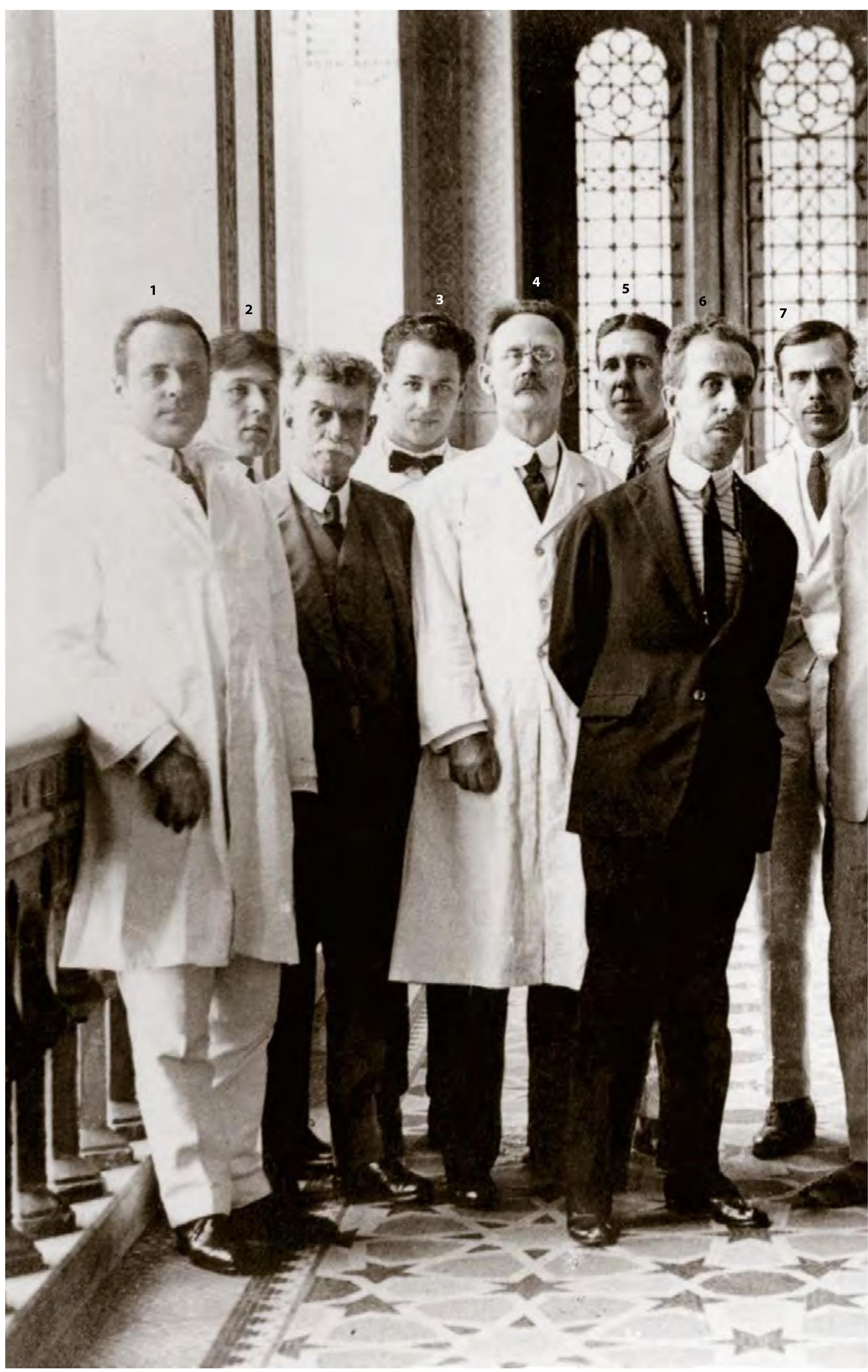




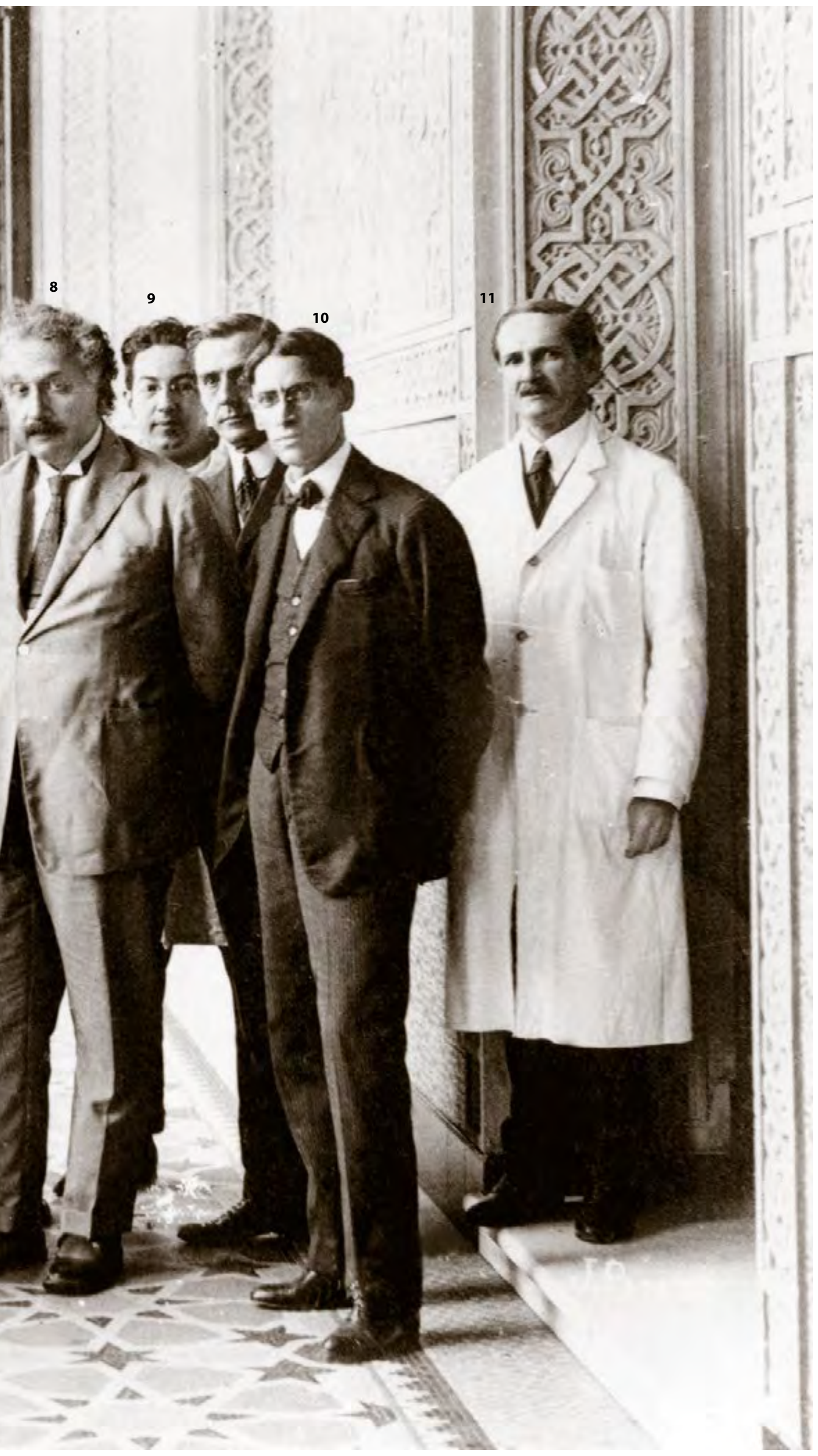

Foi, então, servida uma chícara de café ao visitante do Instituto, que aceitou a infusão da nossa rubiácea, mas gelada. Subindo ao terraço do grande edifício do Instituto, Einstein extasiou-se com os magníficos panoramas que daí se vêem, tendo, então, expressões de intenso entusiasmo. Descendo do terraço, percorreu vários laboratórios.

O Paiz, 1925

A cup of coffee was then served to the Institute's visitor, who accepted this infusion made from our Rubiaceae, but iced. Going up to the terrace of the Institute's great building, Einstein was enchanted by the splendid panoramas one sees from there and waxed most enthusiastic. Coming down from the terrace, he stopped by a number of laboratories.

O Paiz, 1925 
Carlos Chagas, com pesquisadores do Instituto Oswaldo Cruz, recebe a visita do interventor de

Pernambuco, Carlos de Lima Cavalcanti (1), do ministro da Educação e Saúde, Washington Pires (2), do ministro da

Agricultura, Juarez Távora (3), e do interventor do Distrito Federal, Pedro Ernesto (4), em 1933

Acervo Casa de Oswaldo Cruz

Carlos Chagas with Oswaldo Cruz Institute researchers, receiving the visit of

Pernambuco interventor Carlos de Lima Cavalcanti (1), Education and Health Minister Washington Pires (2)

Agriculture Minister Juarez Távora (3), and Federal District interventor Pedro Ernesto (4) in 1933
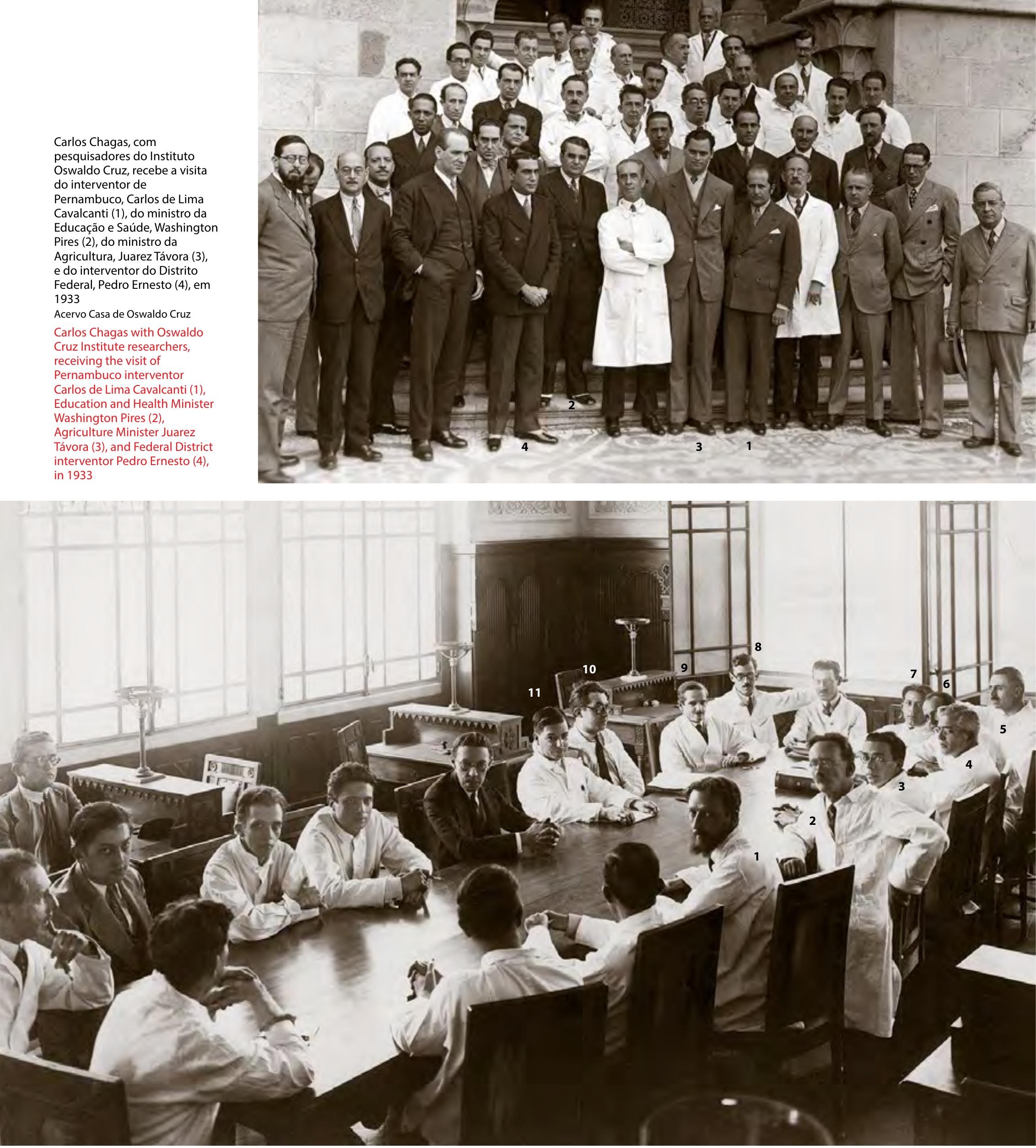

Carlos Chagas (à esquerda) preside sessão da Sociedade de Biologia do Rio de Janeiro, na biblioteca do Instituto Oswaldo Cruz em 1928.

1 - Miguel Osório de Almeida; 2 - Adolpho Lutz; 3 - José Guilherme Lacorte;

4 - Carlos Bastos de Magarinos Torres; 5 - Heráclides César de Souza-Araújo;

6 - Carlos Burle de Figueiredo; 7 - Antonio Eugenio de Arêa-Leão;

8 - João Carlos Nogueira Penido; 9 - Leocádio Chaves; 10 - Julio Muniz;

11 - Olympio da Fonseca Filho

Foto J. Pinto

Acervo Casa de Oswaldo Cruz

Carlos Chagas (left) presides over a session of Rio de Janeiro's Society of Biology at the Oswaldo Cruz Institute library in 1928.

Photograph by J. Pinto 


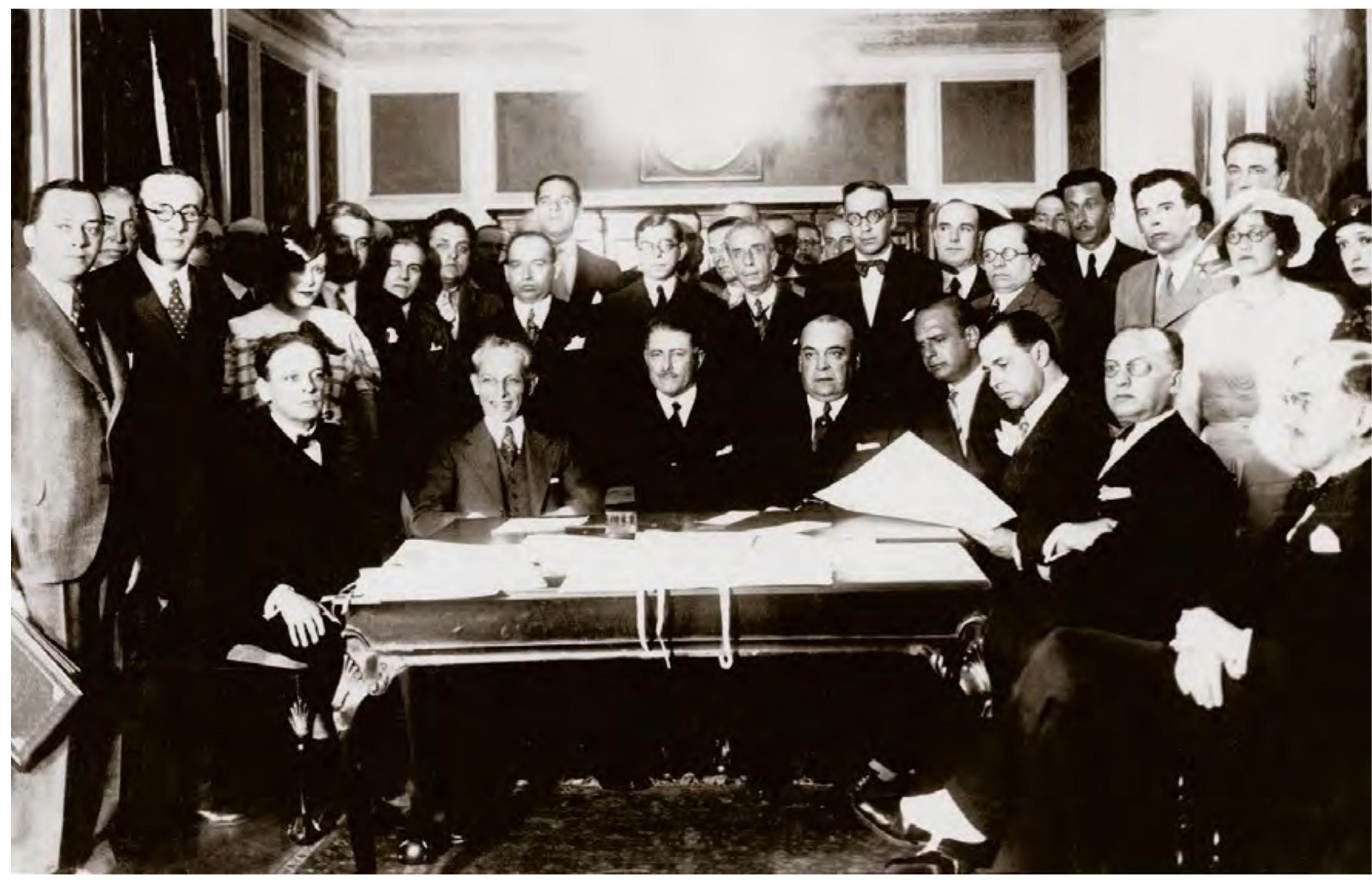

Carlos Chagas (ao centro) participa da VII Conferência Panamericana realizada em Montevidéu, Uruguai, em dezembro de 1933. A seu lado direito, Francisco Campos, consultor geral da República.

Da esquerda para a direita, sentado, Afrânio de Mello Franco ( $\left.2^{\circ}\right)$, ministro das Relações Exteriores e chefe da delegação brasileira Acervo Casa de Oswaldo Cruz

Carlos Chagas (center) attending the Seventh Pan-American Conference, held in Montevideo, Uruguay, in December 1933. To his right, Francisco Campos, the government's top legal adviser. Seated from left to right, Afrânio de Mello Franco $\left(2^{\text {nd }}\right)$, Minister of Foreign Affairs and head of the Brazilian delegation 


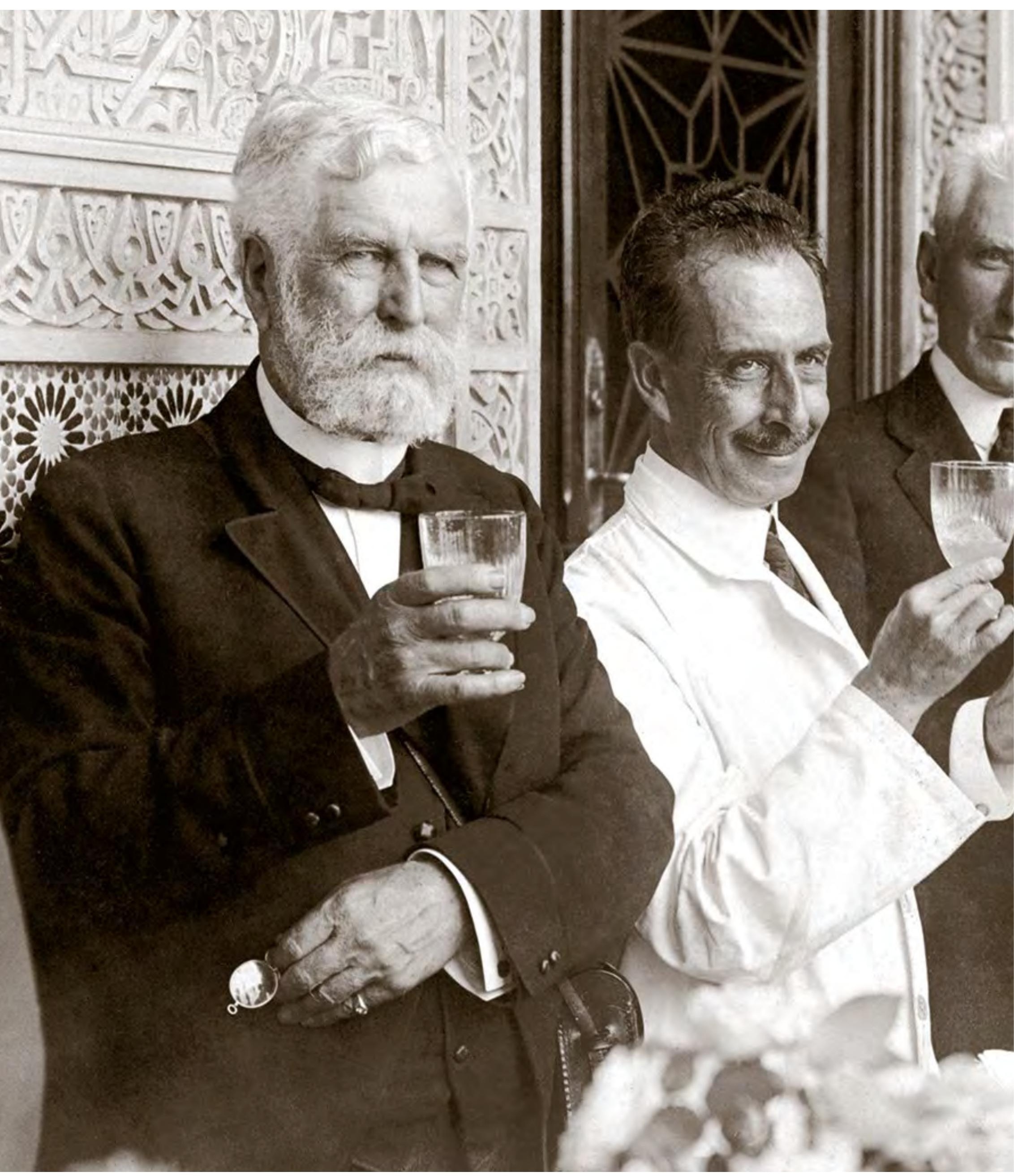

Carlos Chagas em recepção a grupo de cirurgiões americanos em Manguinhos, março de 1929 


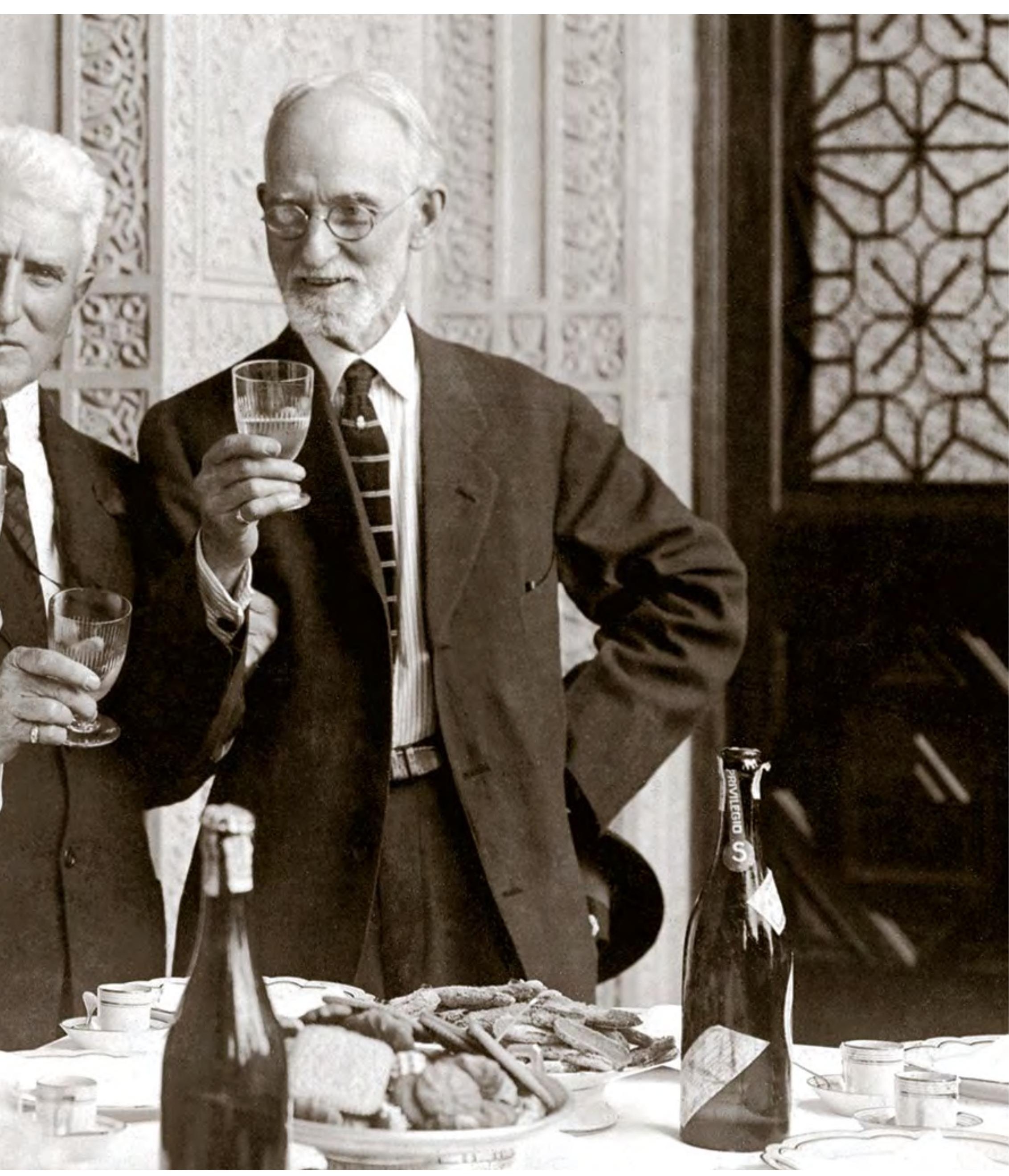



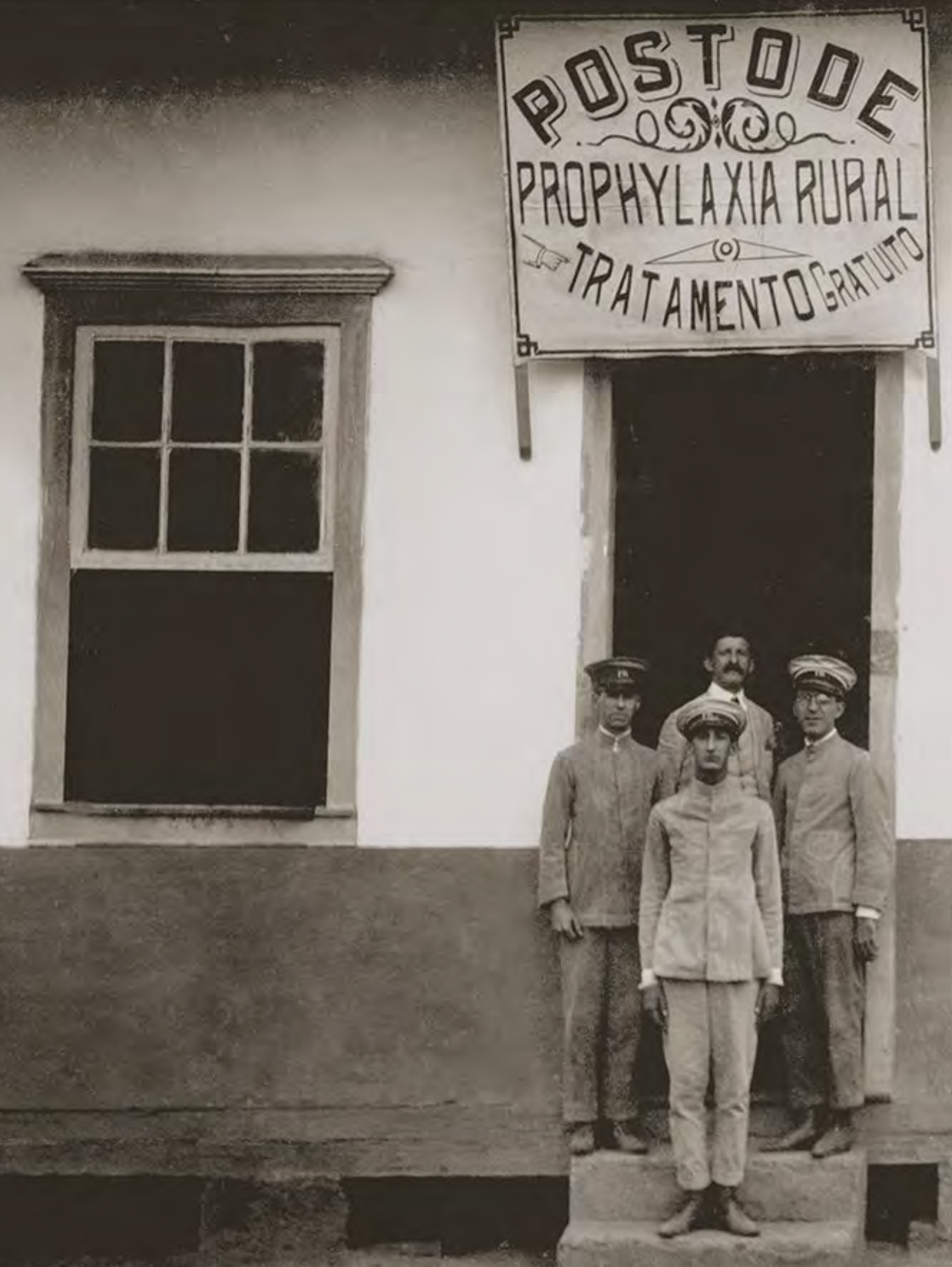

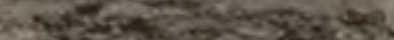



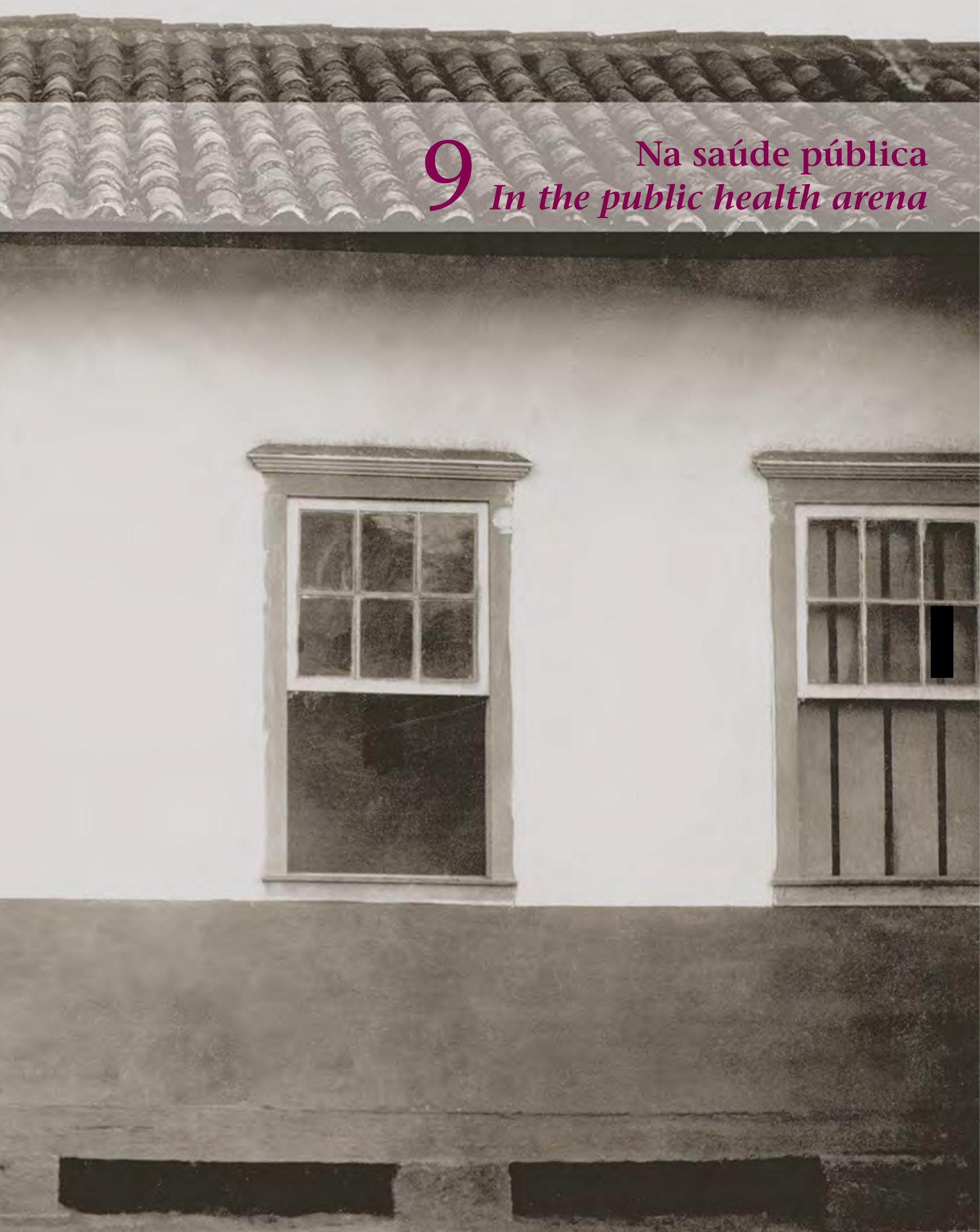
arlos Chagas teve atuação de destaque nos debates e nas ações sobre a saúde pública brasileira nas primeiras décadas do século XX.

Desde a descoberta da doença que leva seu nome, alertava sobre a importância das endemias rurais e a necessidade de combatê-las. Esta seria a bandeira principal do chamado movimento sanitarista que, entre 1916 e 1920, colocou no debate nacional o tema da saúde como elemento-chave para que o Brasil se tornasse efetivamente uma nação.

Em 1916, em discurso na Faculdade de Medicina do Rio de Janeiro, o médico e professor dessa escola Miguel Pereira denunciou as más condições de vida e de saúde no interior do país, assolado por endemias como a malária, a ancilostomíase e a doença de Chagas. Numa época de grande fervor nacionalista, declarou, em frase que se tornaria célebre e polêmica: "O Brasil é um imenso hospital". Suas palavras tiveram grande repercussão no debate político e intelectual sobre o país. Tal diagnóstico atualizava a denúncia de Euclides da Cunha (1866-1909) quanto ao isolamento e ao abandono dos sertões brasileiros.

O movimento sanitarista defendia a idéia de que o 'atraso' do Brasil não era resultado do clima tropical ou da composição racial de sua população, mas das doenças que afetavam as áreas rurais e da falta de ação do Estado diante dessa realidade. A campanha reivindicava que o governo federal aumentasse sua intervenção no campo da saúde pública e formalizou-se na Liga Pró-Saneamento do Brasil (1918-1920), criada e dirigida por Belisário Penna. Dela fizeram parte Chagas e muitos outros médicos, cientistas, intelectuais e políticos.

A denúncia do despreparo dos poderes públicos para enfrentar os problemas de saúde do país intensificouse nos últimos meses de 1918, quando chegou ao Brasil a devastadora pandemia de gripe espanhola. Para enfrentar a influenza no Rio de Janeiro, Chagas assumiu, a convite do presidente da República Wenceslau Braz, a responsabilidade de comandar a assistência médica à população. Providenciou a imediata instalação de hospitais emergenciais e postos de consulta em diferentes pontos da cidade e, por meio da publicação de anúncios nos principais jornais, buscou a colaboração de seus colegas de profissão para o enfrentamento da epidemia.

Ao tomar posse na presidência da República, Epitácio Pessoa (1865-1942) declarou que a reorganização dos serviços sanitários do país era uma prioridade nacional. Para comandá-la, nomeou Chagas, em outubro de 1919, para a Diretoria-Geral de Saúde Pública, que, em janeiro do ano seguinte, após intenso debate no Congresso Nacional, foi transformada em Departamento Nacional de Saúde Pública. Chagas assumiu sua direção, acumulando o cargo com suas funções à frente de Manguinhos.

O novo órgão fortaleceu a capacidade de intervenção e regulação do governo central na saúde pública. Chagas foi autor de um extenso Código Sanitário que modernizou a legislação sanitária brasileira. As ações de saúde, até então concentradas nas áreas urbanas, foram estendidas ao interior do país, sobretudo com a criação de postos de combate às endemias rurais. Para isso, foi decisiva a colaboração da Fundação Rockefeller, que atuava no país desde 1916 na profilaxia da ancilostomíase e da febre amarela. Os cuidados com a maternidade e a infância, a assistência hospitalar e o combate à tuberculose, sífilis e lepra foram também contemplados com serviços especializados.

Outra preocupação importante de Chagas à frente da saúde pública federal foi com a formação de profissionais especialmente destinados a essa área. Em 1922, com o apoio da Fundação Rockefeller, criou o Serviço de Enfermeiras, dirigido pela enfermeira norte-americana Ethel Parsons, a partir do qual fundou-se a Escola de Enfermagem Anna Nery. Ali seriam treinadas enfermeiras para atuar tanto no sistema hospitalar quanto no serviço de "enfermeiras visitadoras", visando a atender e orientar as famílias nos domicílios. Em 1926, organizou o Curso Especial de Higiene e Saúde Pública na Faculdade de Medicina da Universidade do Rio de Janeiro. Ministrado por pesquisadores de Manguinhos e sob a orientação de seu diretor, o curso garantia o acesso direto aos cargos da administração sanitária federal. Primeiro do gênero no país, foi um marco na institucionalização da carreira de sanitarista no Brasil.

Chagas deixou a direção do Departamento Nacional de Saúde Pública em 1926, ao final da conturbada presidência de Arthur Bernardes (1875-1955). O término de sua gestão foi marcado por fortes críticas: foi atacado na imprensa devido a um surto de varíola na capital e ao risco de uma epidemia de febre amarela. Seu sucessor no cargo foi Clementino Fraga (1880-1971).

No campo da saúde internacional, teve destacada atuação como representante brasileiro no Comitê de Saúde da Liga das Nações, a partir de 1922. No âmbito dessa associação, idealizou e dirigiu o Centro Internacional de Leprologia, inaugurado em 1934, com sede no Instituto de Manguinhos. 
arlos Chagas played a central role in Brazilian public health debates and initiatives during the early $\checkmark$ decades of the twentieth century.

After discovering the disease that carries his name, Chagas warned about the importance of rural endemic diseases and the need to fight them. This was the main plank of the so-called sanitation movement that made the issue of public health a matter of national debate from 1916 to 1920, as a key element of Brazilian nation-building.

In 1916, Miguel Pereira, physician and professor at the Rio de Janeiro School of Medicine, gave a speech at this institution in which he decried the poor living and health conditions in rural Brazil, beset by endemic diseases like malaria, ancylostomiasis, and Chagas disease. At a time of great nationalist zeal, he pronounced what would become a famous yet controversial phrase: "Brazil is an enormous hospital." His words had a major impact on the political and intellectual debate about Brazil. His diagnosis repeated the indictment by writer Euclides da Cunha (1866-1909), who had denounced the isolation and abandonment of the Brazilian hinterlands.

The sanitation movement defended the idea that Brazil's backwardness was not the product of its tropical climate or the racial make-up of its people but of the diseases afflicting its rural areas and the lack of government action in the face of this reality. The campaign called for the federal government to take firmer action in public health. It gave birth to the Pro-Sanitation League of Brazil (1918-1920), founded and directed by Belisário Penna. Chagas took part in it along with many other physicians, scientists, intellectuals, and politicians.

The accusation that the government was unprepared to deal with Brazil's public health problems grew louder in the closing months of 1918, when the devastating Spanish flu pandemic reached Brazil. At the invitation of the president of Brazil, Wenceslau Braz, Chagas was charged with the task of ensuring that the population received medical assistance when the flu hit Rio de Janeiro. He immediately had emergency hospitals and consultation posts set up around the city and, through announcements in major newspapers, encouraged his colleagues' collaboration in combating the epidemic.

When he took office, President Epitácio Pessoa (1865-1942) declared the reorganization of the country's sanitary services a national priority. To lead this effort, he appointed Chagas to head up the General Directorship of Public Health, in October 1919. After heated debate in Congress, the Directorship was transformed into the National Department of Public Health in January of the following year. Chagas was made director, while still holding his post as head of Manguinhos.

The new Department enhanced the central government's ability to take action in public health and to enact regulations. Chagas drafted a comprehensive Sanitary Code that modernized the nation's sanitary laws. Public health interventions that had previously been concentrated in urban areas were extended to the interior, particularly through the creation of sanitary posts for fighting rural endemic diseases. Decisive collaboration came from the Rockefeller Foundation, which had been working to prevent ancylostomiasis and yellow fever in Brazil since 1916. Mother and childhood care, hospital care, and the fight against tuberculosis, syphilis, and leprosy were also the subject of specialized services.

Another important concern of Chagas's during his tenure as head of the federal public health system was the training of specialized personnel. In 1922, with the support of the Rockefeller Foundation, he created the Nursing Service, directed by American nurse Ethel Parsons. This agency was the foundation for the Anna Nery School of Nursing. There, nurses were trained to work both in the hospital system and as visiting nurses who cared for and counseled families at home. In 1926, he organized the Special Course in Hygiene and Public Health at the University of Rio de Janeiro's School of Medicine. Run by Manguinhos researchers under the guidance of its director, the course guaranteed its graduates direct access to posts within the federal public health organization. The first of its type in the country, it was a landmark in the institutionalization of the career of sanitarian in Brazil.

Chagas left his position with the National Department of Public Health in 1926 at the close of President Arthur Bernardes' (1875-1955) troubled term in office. Chagas was the target of heavy criticism at the end of his administration, with the press coming down hard on him because of an outbreak of smallpox in Rio and the risk of a yellow fever epidemic. His successor was Clementino Fraga (1880-1971).

On the world stage, Chagas played a prominent role as the Brazilian delegate to the League of Nations' Health Committee, starting in 1922. Under the aegis of this institution, he conceptualized and directed the International Leprology Center, which opened its doors at the Manguinhos Institute in 1934. 


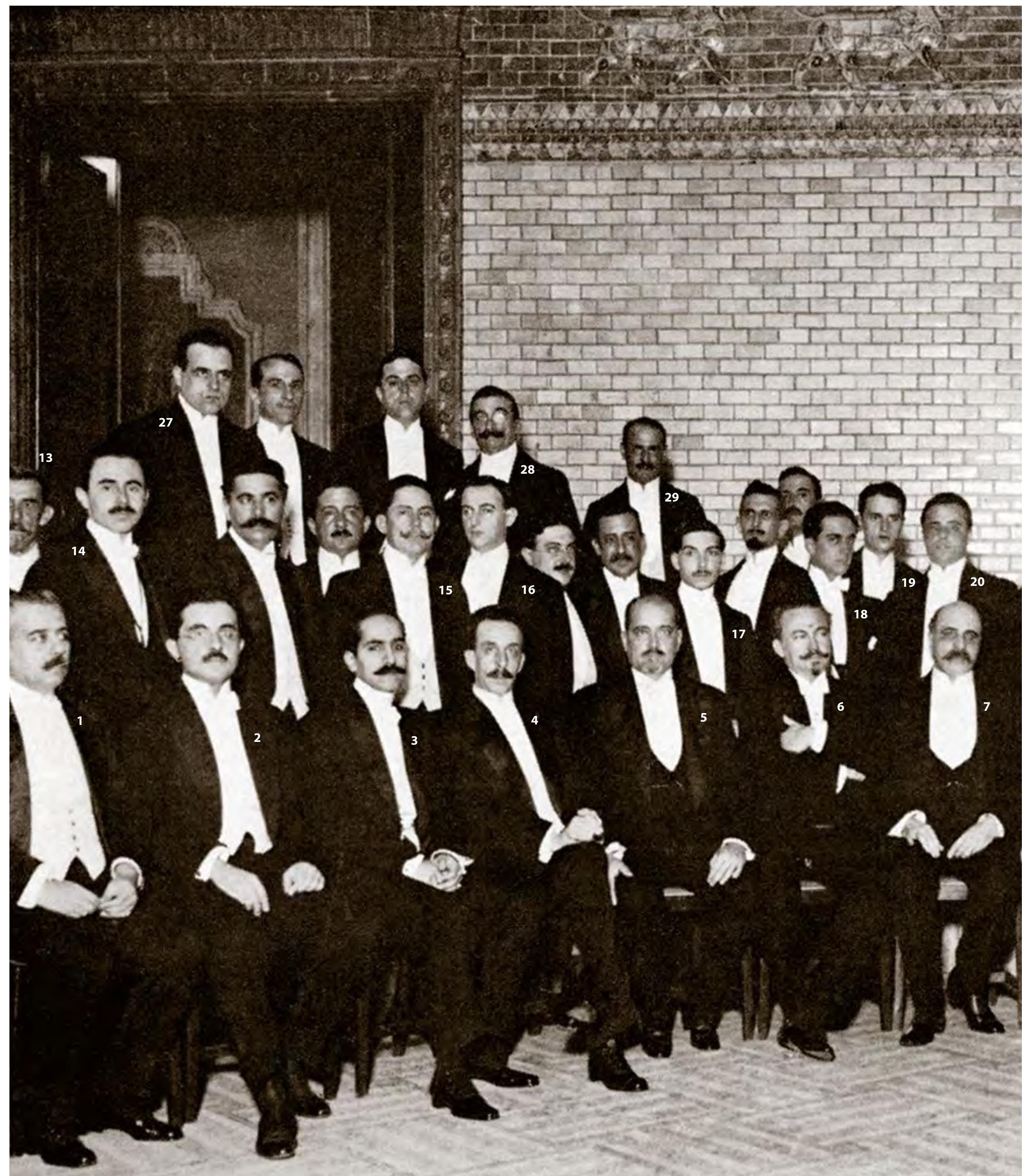




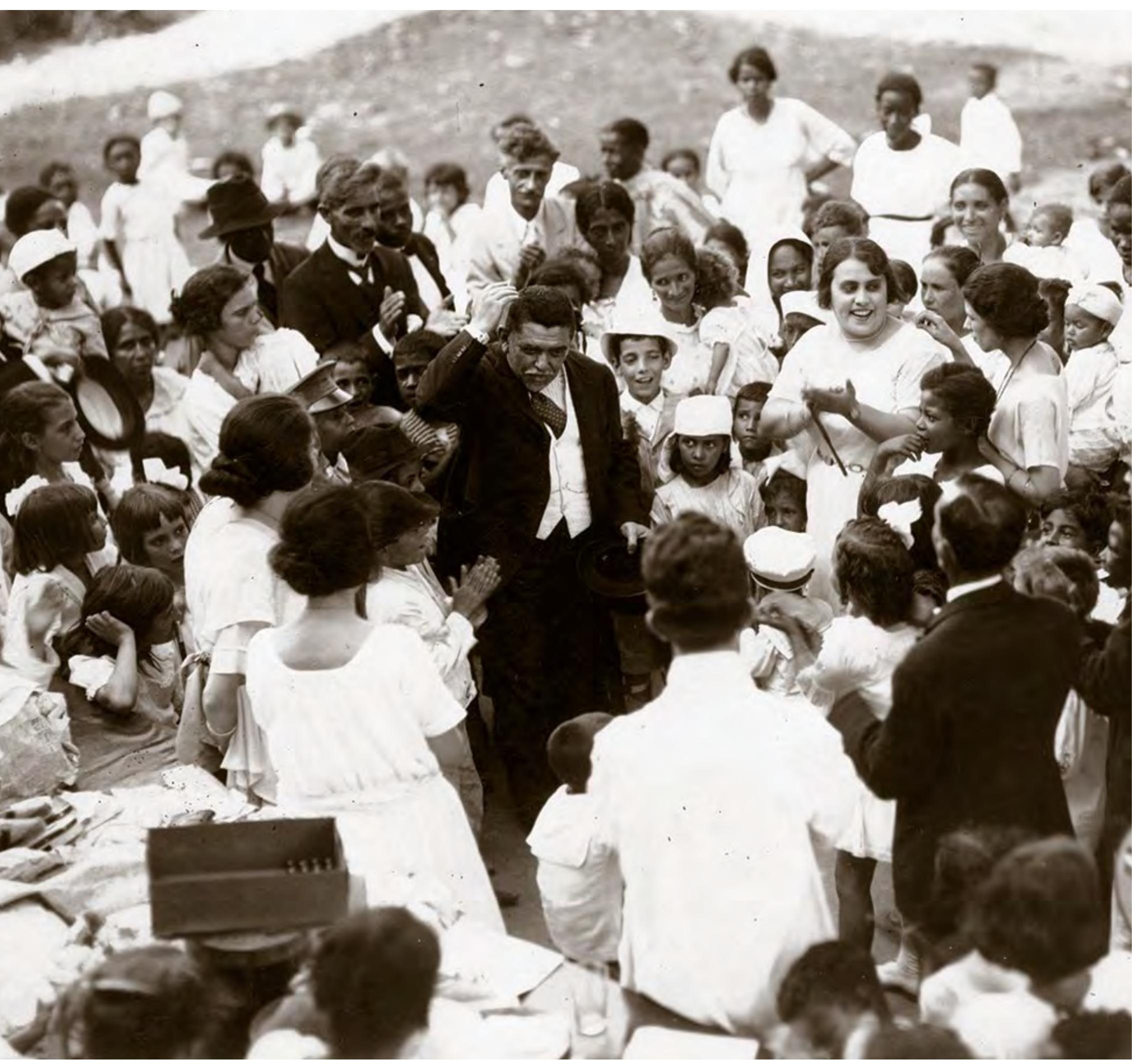

Belisário Penna, o autoproclamado "apóstolo do saneamento rural" e diretor da Liga Pró-

Saneamento do Brasil, discursa para moradores de Pilares, no Rio de Janeiro Acervo Casa de Oswaldo Cruz

Belisário Penna, self-proclaimed "apostle of

rural sanitation" and director of the Pro-

Sanitation League of Brazil, speaking before residents of Pilares, Rio de Janeiro 


\section{BELISARIO PENNA}

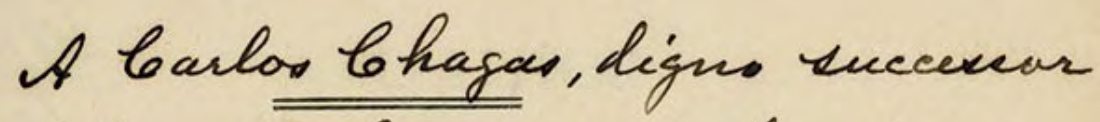 o Ouvals brux, con elevars ofreeco e frofunda ancisade $24-1-918$ s Selukaró Saneamento do Brasil}

Sanear o Brasil é povoal-o;

é enriquecel-o;é moralisal-o.

19. EDIÇก̃O
A saúde é a geratriz da alegria, do trabalho profícuo, da riqueza e do progresso. $A$ doença gera a tristeza, $o$ desânimo, a miséria e o atraso. Não há um só país culto e adiantado que não deva à higiene o seu progresso e a sua força.

Belisário Penna

Good health engenders happiness, productive work, wealth, and progress. Disease produces sorrow, despondency, poverty, and backwardness. There is not one single welleducated, advanced country that does not owe its progress and might to hygiene.

Belisário Penna

TYP. REVISTA DOS TRIBUNAES CARMO 55-RIO DE JANEIRO 1918 
Abaixo a bicharia que devora o brasileiro! Ter saúde é a grande qualidade de um povo. Tudo mais vem daí.

Jeca Tatu, personagem de Urupês, de Monteiro Lobato

Down with the hordes of bugs devouring the Brazilian people! Good health is a people's greatest asset. Everything else follows from it.

Jeca Tatu, character from Brazilian writer Monteiro Lobato's Urupês

\section{A CASA DO JECA ANTES DO SANEAMENTO}

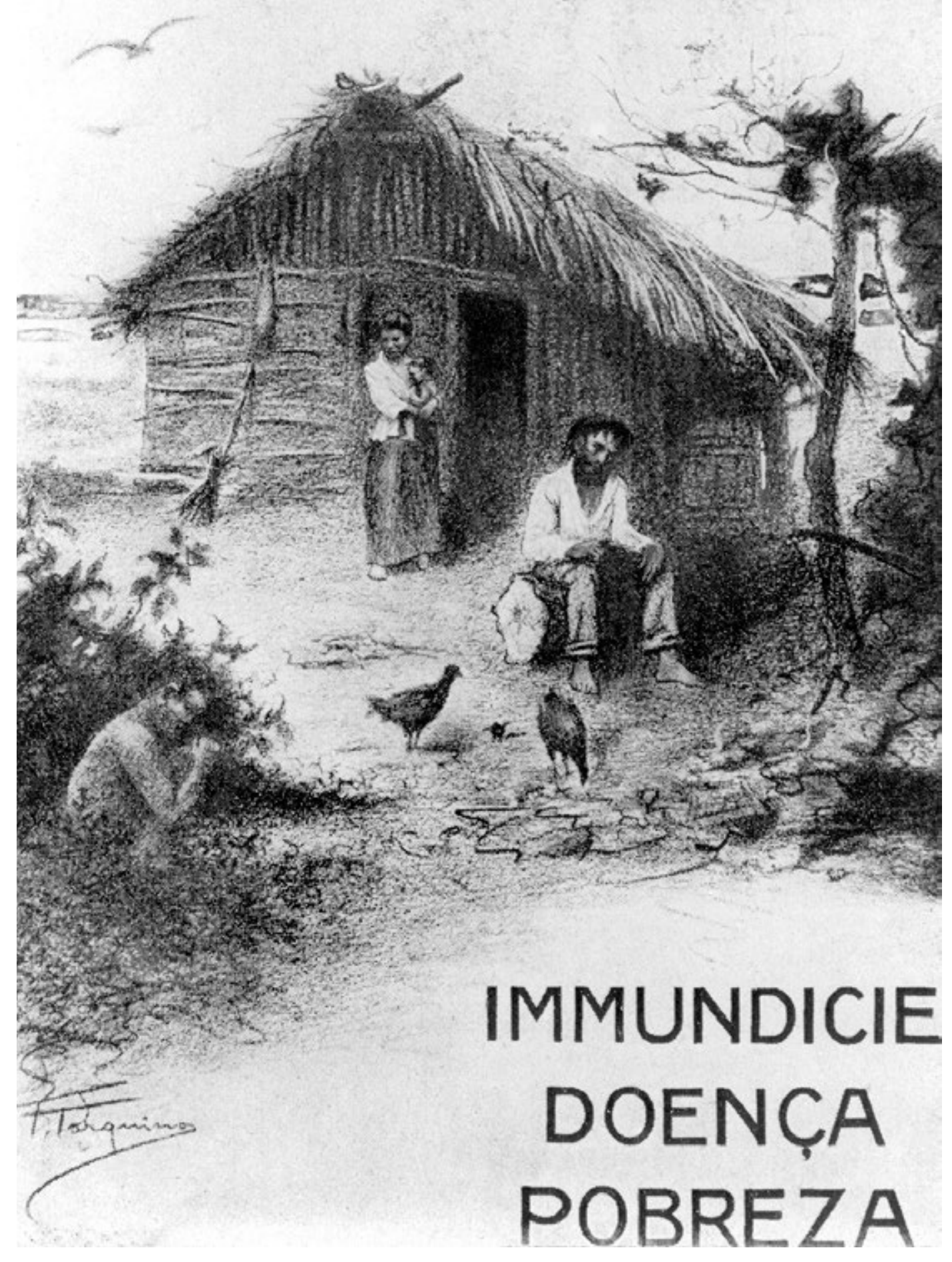




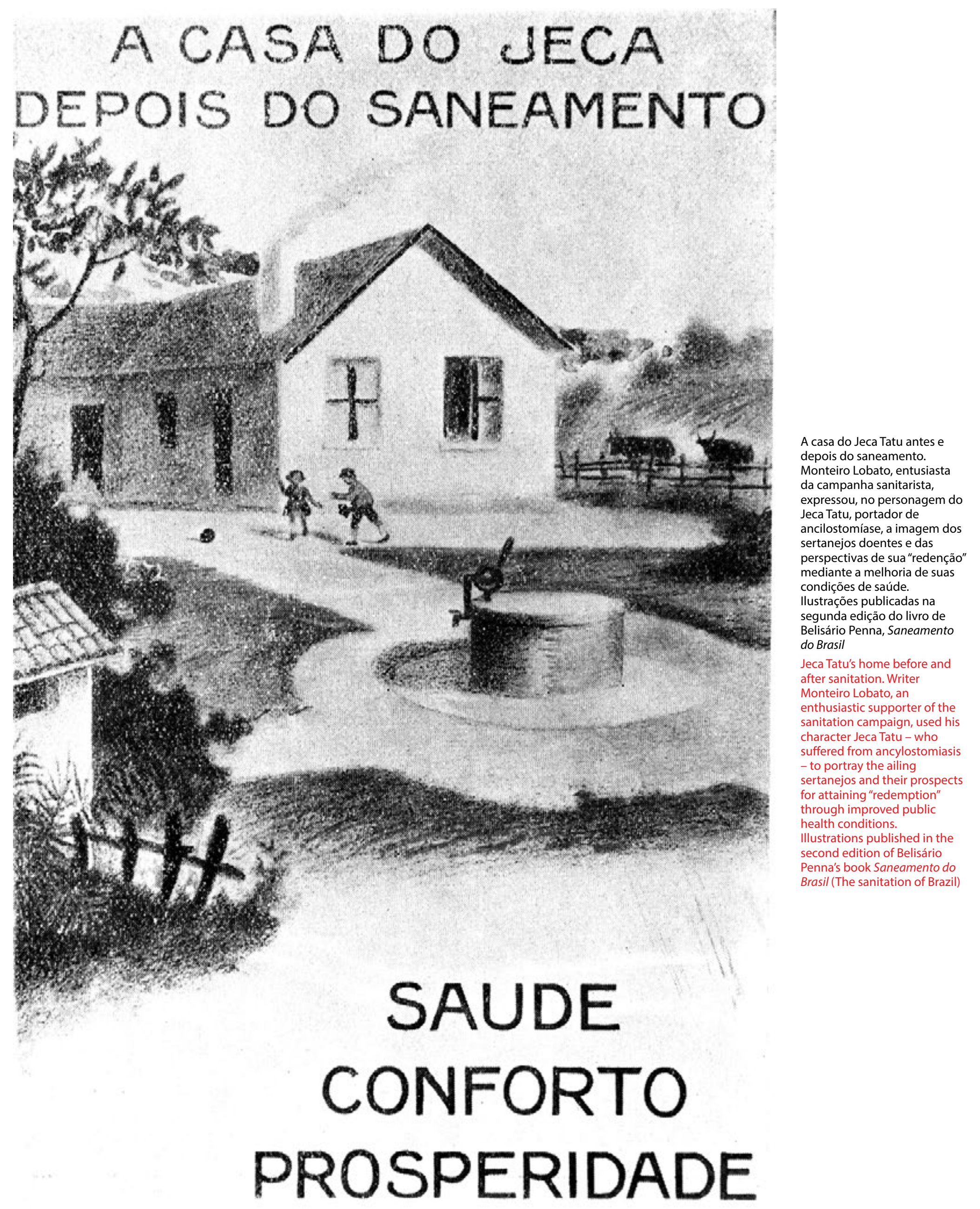




\section{MAATS UIMA ?}

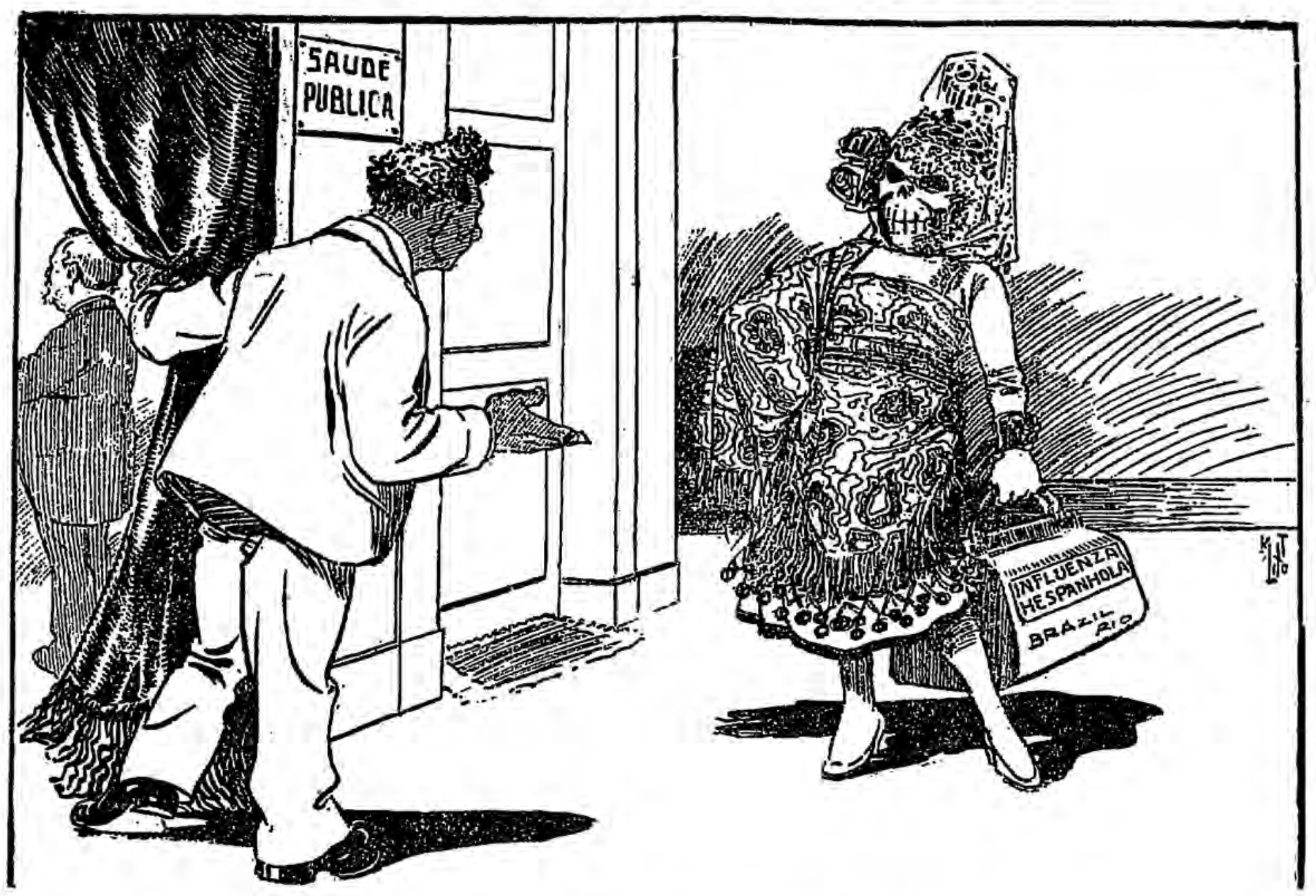

Ella - Hagn usted el favor de decir al airector yue estoy a sus orden is

Continuo - llas.. creio que nảo ha mais logar...

Fila - la como no, gi el doctor Seidl me dijo que yo aqui tenia la collocacion segurn? Esto es un cmbuste !...

Mais uma?

Gazeta de Noticias, 29 set. 1918

Acervo Fundação Biblioteca Nacional

"Another one?"

Gazeta de Noticias, Sep. 29, 1918 


\section{O presidente da Republica manda distri= buir caldo e pão á pobreza}

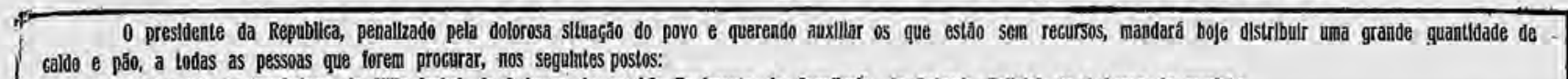

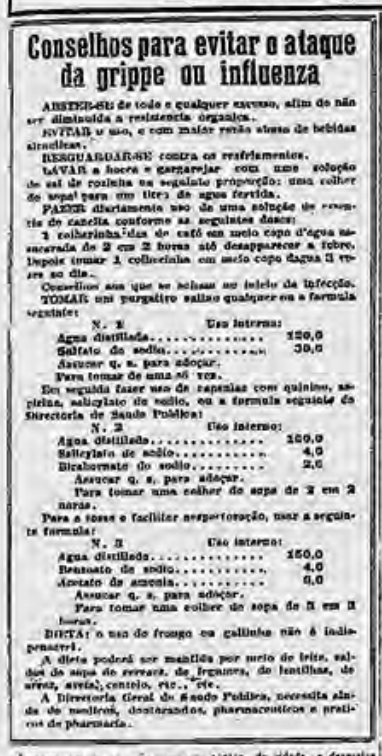

\section{O COMMERCIO PODE ABRIR \\ o prefeito belkoir ama circular declarando que, apesar dos dias feriados, as casas de commercio O prefeito balxon ama circular declarando que, apesar dos dias feria
poderüo abrir us portas e vender as mercadorias que o pablico reclamar,}

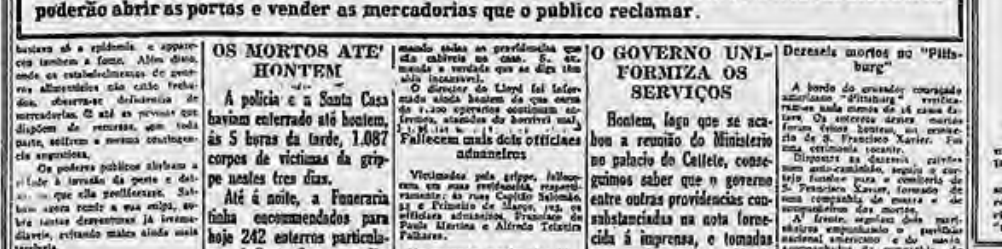

Os pastos de sacconro

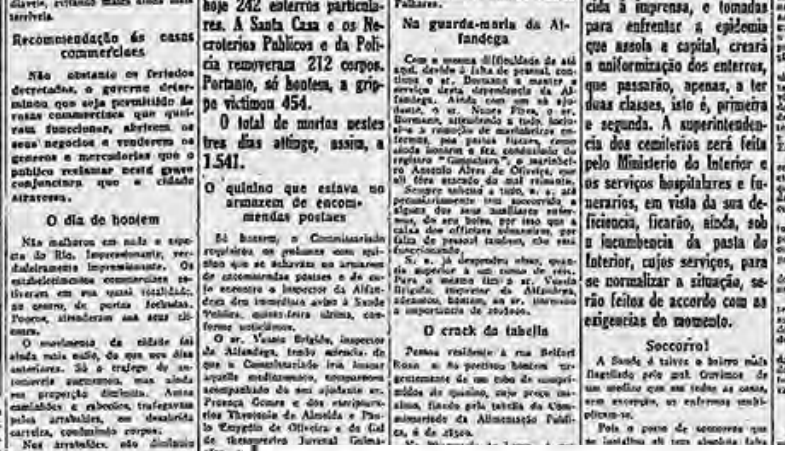

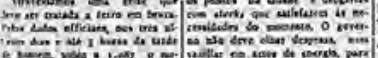
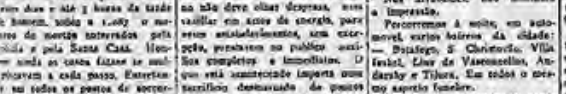

0 dr. Carlos Chagas encarregzdo de crear postos
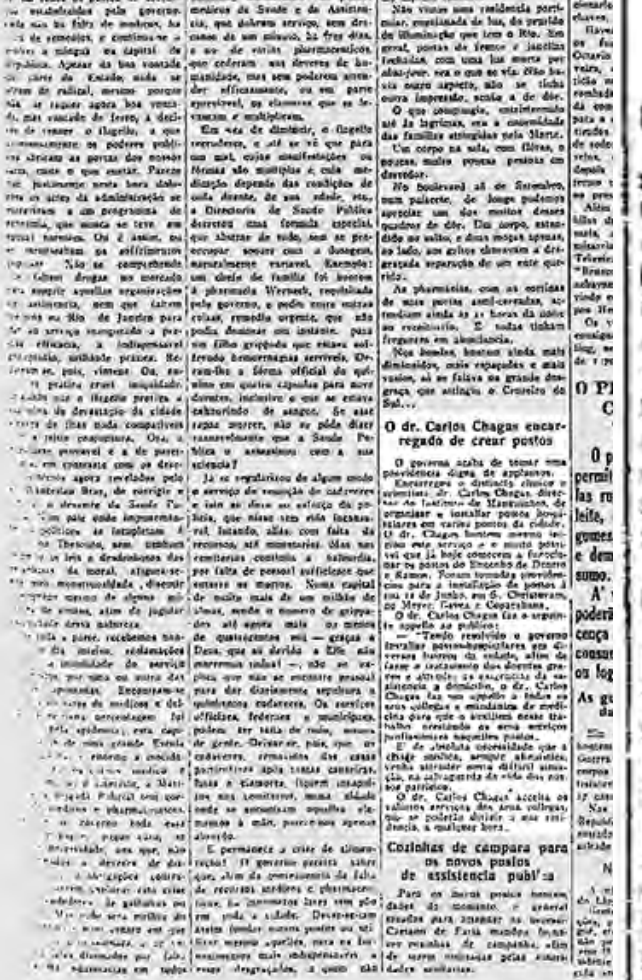

O poverno acsiba de tomar uma providencia dignz de applausos.

Encarregon o distincla clistico e scientist:, it. Carlos Chagas, dirteinr do Justittico de Mankuizhos. de organigar $z$ installar postos hosphtalares cm varios pontos da sidinde. 0 dr. Clages hantrm mesmo in:ciou este gerviça e é muto possisel que ji hoje comesem 2 furrecionar es postns do Engentio de Dentro c Ramos. Foram tomadas providemcias para a ingtallación de postos a

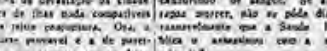
niza it de Jutnho, ens $\mathrm{S}$. Chrisiovam, ao Meyer. favera e Copjeabana.

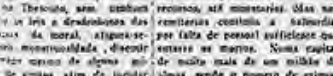
O Ur. Curlos Chagkas fat o seguinle appello no publico:

- Tendo resolvido a soverno installar postoshospit=lares em di. versos bairros da cillade, afím the fazer a trataulenlo dos doentea gra-

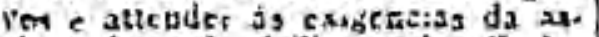
aistencia a donsicilio, o dr. Caslos Chagos fisz vim appeltin at toulas vo seus volleras e estudanteo de medicina para que o auxilien nesse tra. lasiho nrestando or setrs servicos jrofiskimace nayurellex rostos.

E' de abrolusa necessidade que a emine inediea. sempre alustistica, venhia attroter nesta difficil vimia.

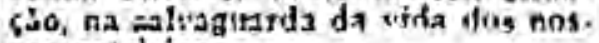
con patricion.

o dr. Curiog Clsianses atietica os

O presidente da Republica manda distribuir caldo e pão á pobreza Correio da Manhã, 22 out. 1918 Acervo Fundação Biblioteca Nacional valiosns acricos tina metic rallegal,

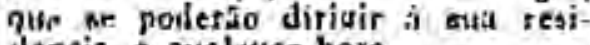
and soup distributed to the poor Correio da Manhã, Oct. 22, 1918 dencia, a nualiguer hora. 
Chagas e o presidente da República

Wenceslau Braz, em

posto de atendimento no Méier, bairro do Rio

de Janeiro, durante

a epidemia de gripe

espanhola

Careta, 9 nov. 1918

Acervo Fundação Biblioteca Nacional

Chagas and Brazilian president Wenceslau Braz, at a healthcare post in the Rio de Janeiro neighborhood of Méier during the Spanish flu epidemic Careta, Nov. 9, 1918

O Rio apavorado

O Malho, 26 out. 1918 Acervo Casa de Rui Barbosa

"A terrified Rio"

O Malho, Oct. 26, 1918

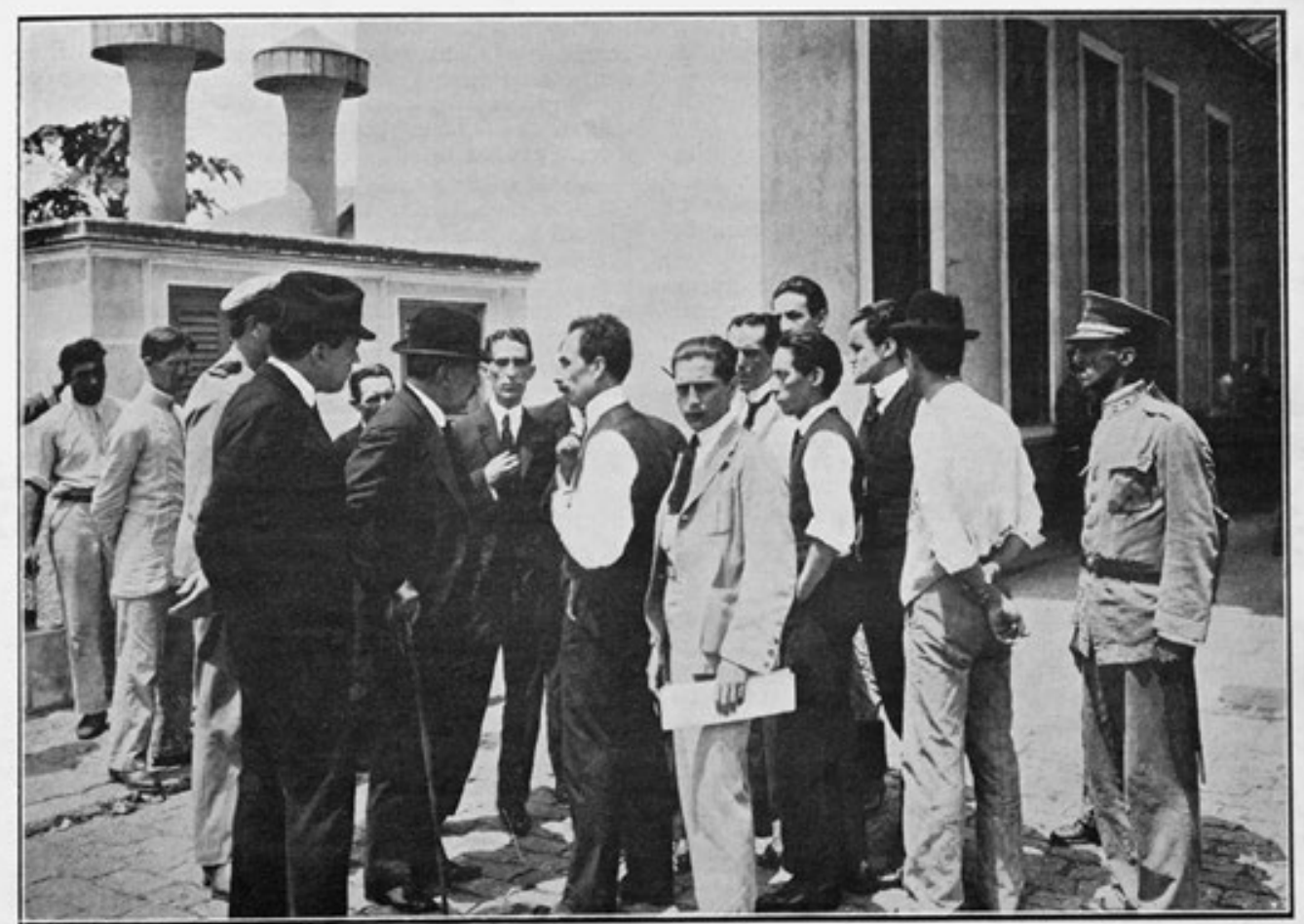

No Posto do Meyer, o dr. Carlos Chagas dá informaçies ao Chefe da Naçäo sobre ämarcha dá, epidemia. $\rightarrow-\infty$ $\rightarrow$

\section{OMALHO}

RIO DE JANEIRO, 26 DE OUTUBRO DE 1918:: NUMERO AVULSO, 100 Réis

(3) Rio apavorado

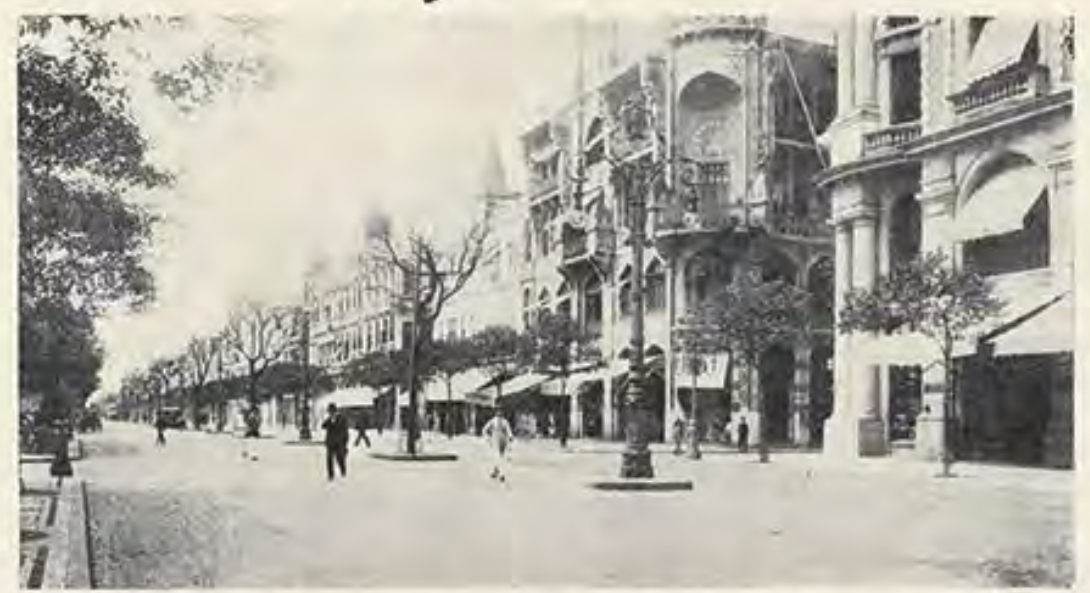

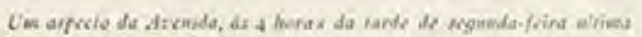

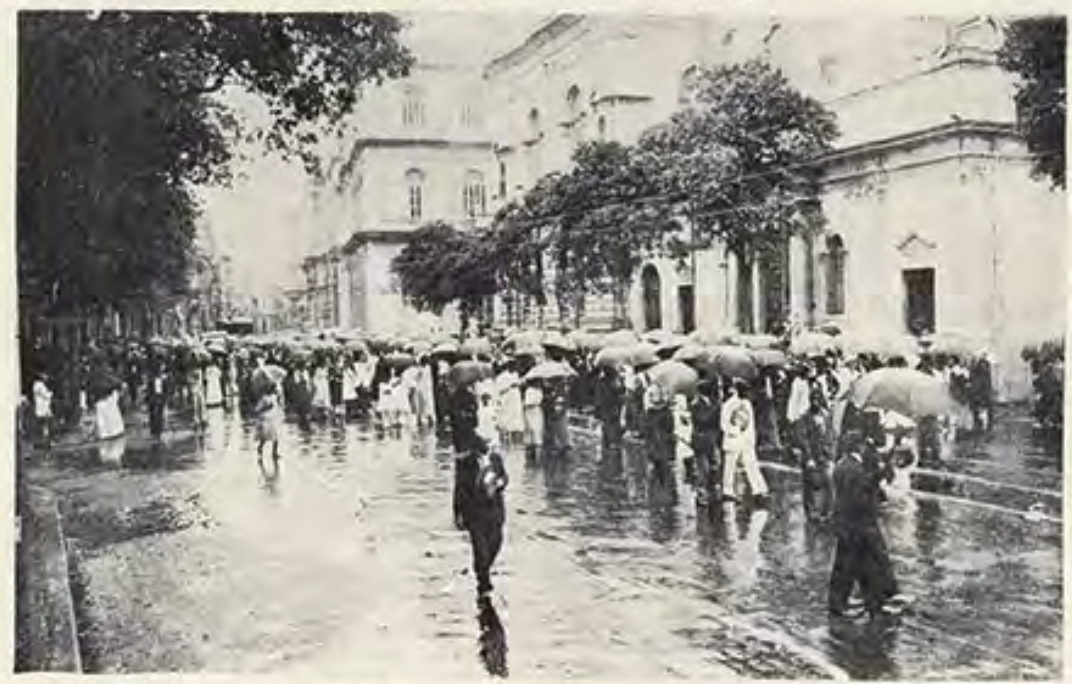

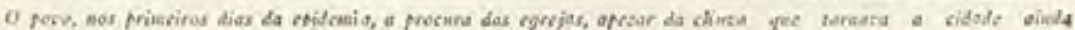
whit tivie 


\section{$=$ Correio da Manhã - ANINO XVIII- IV. 7.18 \\ O PRESTDENTR DA REPUBLIGA TRANQUULLLZA A POPULAGÃ̃}

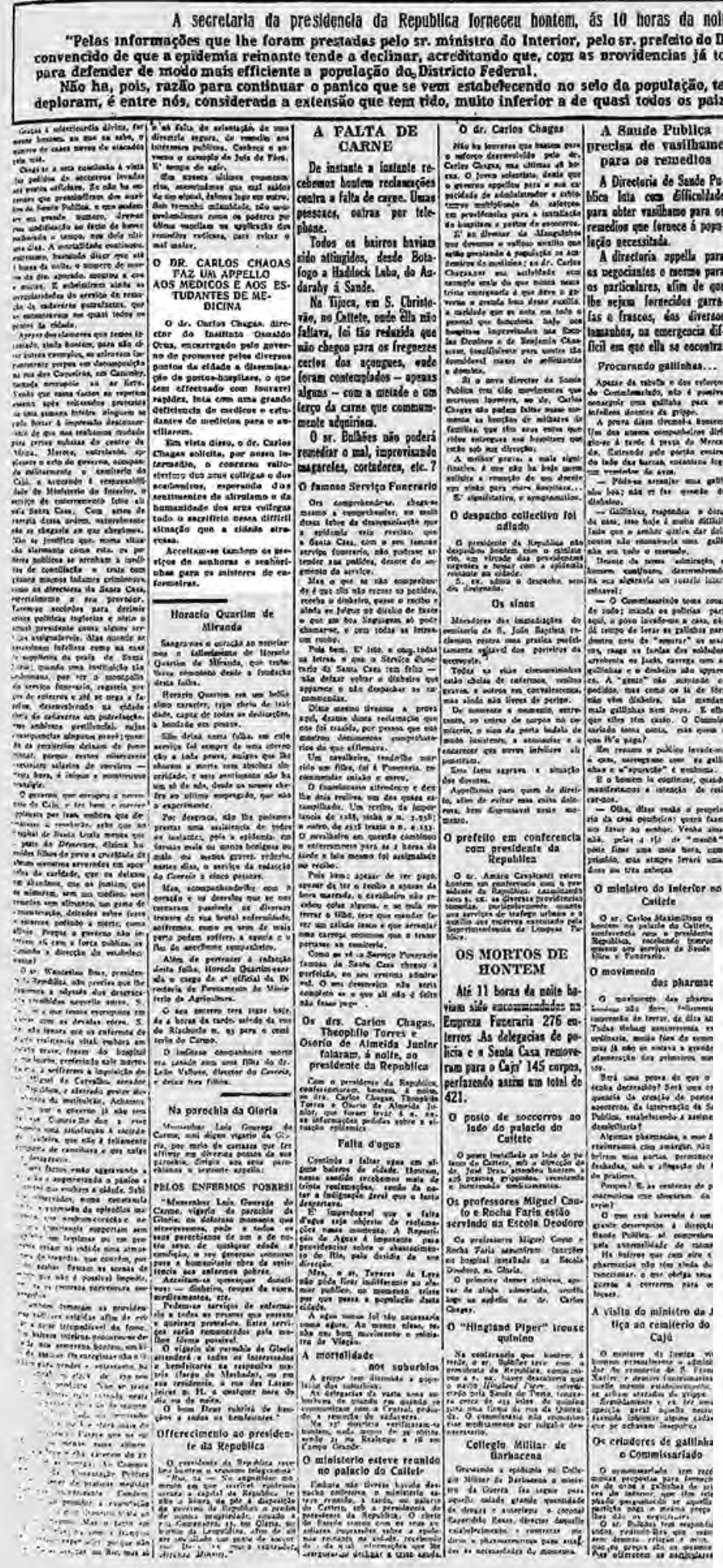

O presidente da Republica tranquilliza a população

Correio da Manhã, 24 out. 1918

Acervo Fundação Biblioteca Nacional

"President

Correio da Manhã, Oct. 24, 1918

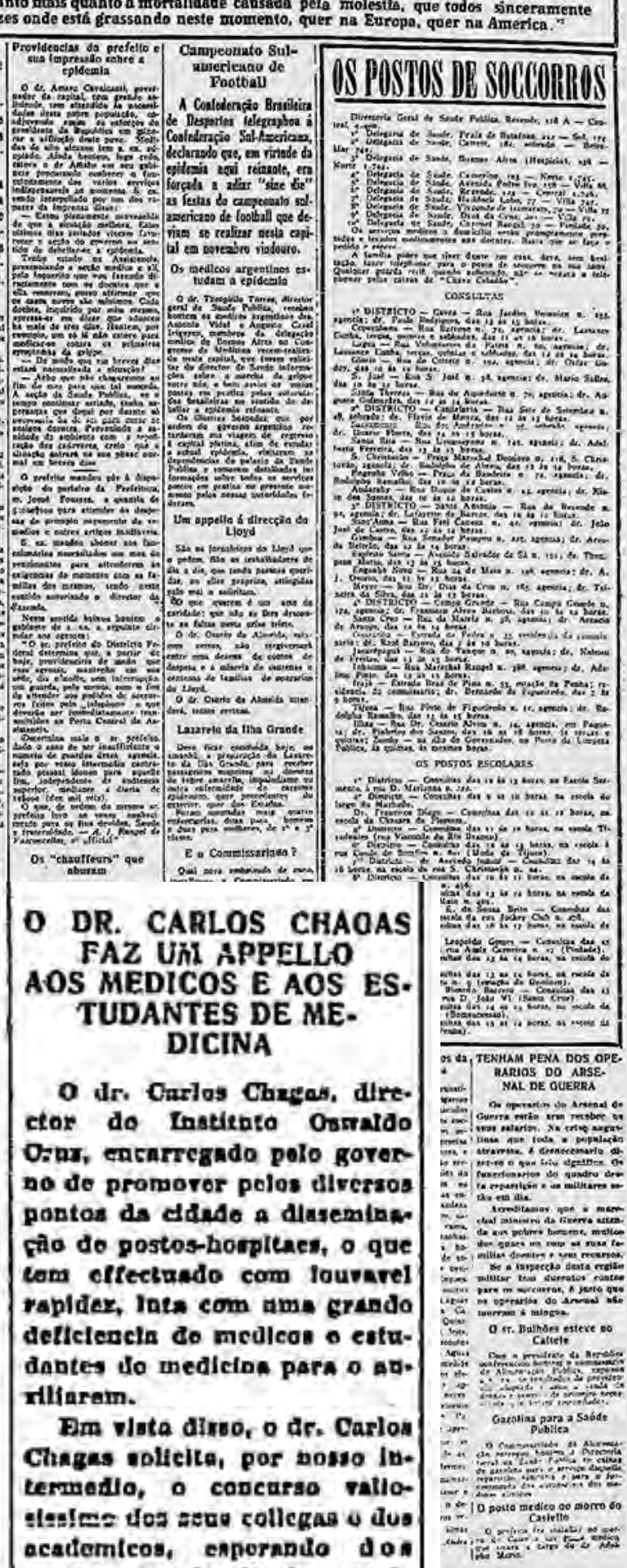
nentituentos de altraismo o da lramantdado dos sean collezas todo o sacriflela bessa alfficit stragito que a cliado atrareana.

Acceltam-ie tambera on kerricos do senhorag o sedhárluba para os misteres do eatormelras. 
No agudo da epidemia, num dia em que não havia mais jeito de transportar tanto morto, o Chefe de Polícia já dava o desespero quando a solução veio do Jamanta, $o$ célebre folião, figura de prol do Carnaval carioca. (...) Ele conhecia admiravelmente $o$ seu Rio de Janeiro e por um desses caprichos de boêmio aprendera, em passeatas noturnas, a dirigir bondes. Pediu e obteve dos seus superiores um bagageiro com dois taiobas e vasculhou com eles a cidade de norte a sul Fábrica de Chitas, Tijuca, Andaraí, Aldeia Campista, Vila Isabel, Méier, Engenho de Dentro, Piedade, Cascadura, Penha Circular, Benfica - apregoando que todos pusessem para fora seus mortos (Bring out your deads!). Bonde e reboques cheios de caixões empilhados e de amortalhados em lençóis, o motorneiro solitário batia para o Caju.

Descarregava. O dia já ia alto mas ele voltava a nove pontos, varejava Laranjeiras, Flamengo, Botafogo, Jardim Botânico, Ipanema, Copacabana - pegando mais defuntos. Lotava. Já noite, passava a sinistra composição como o Trem Fantasma ou o navio de Drácula - entupida de carga para o São João Batista. Fez isso uns dois ou três dias que marcaram para sempre sua lembrança.

Pedro Nava

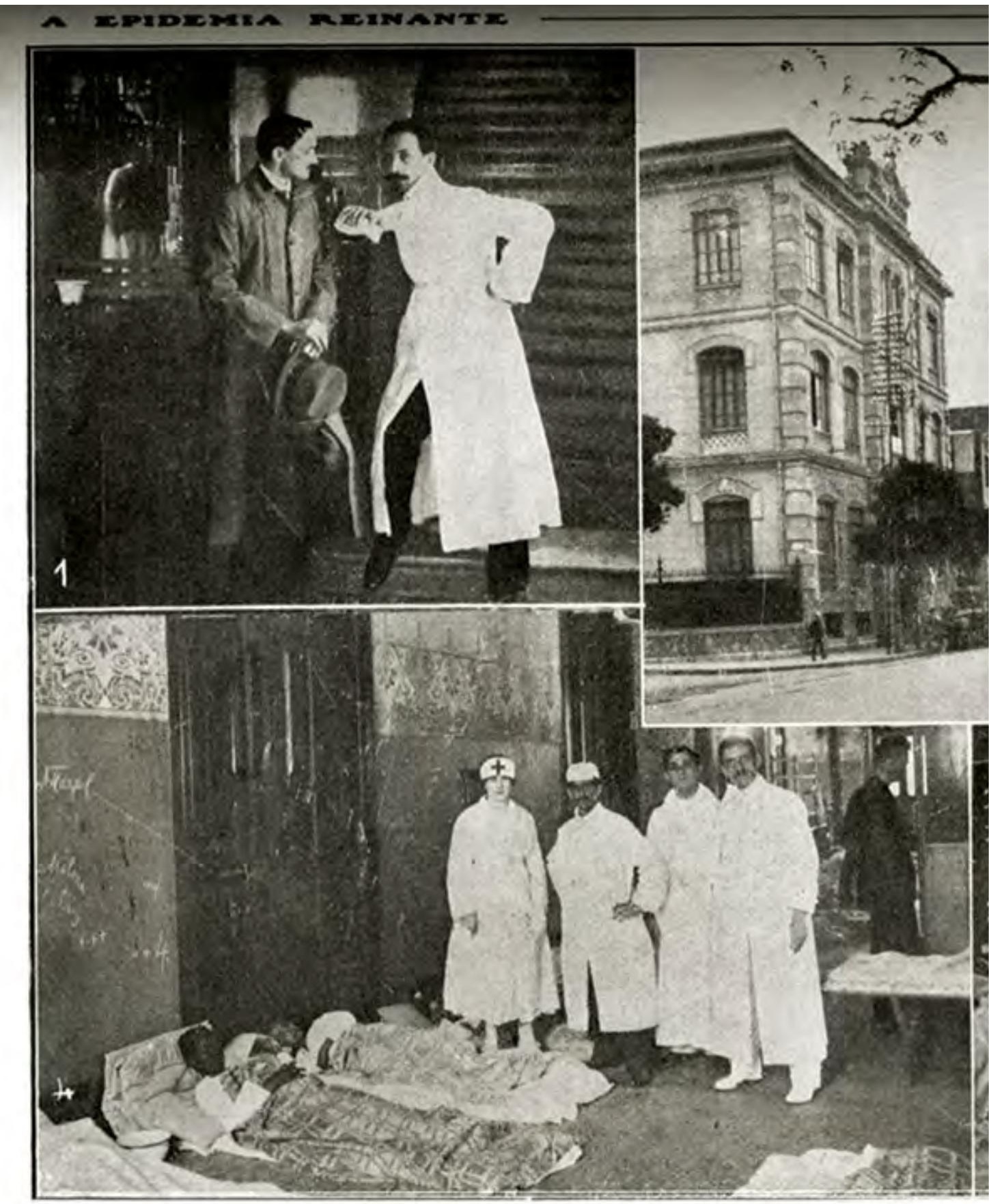

1 - O Dr. Carlos Chagas, á direita, director do Instituto Oswaldo Cruz.

2 - Ediïicio da Escola Deodoro, na Gloria, transformado em Posto de Assistencia.
Assim é que é! Viva a folia! Viva Momo - Viva a Troça! Não há tristeza que possa Suportar tanta alegria. Quem não morreu da Espanhola, Quem dela pôde escapar Não dá mais tratos à bola Toca a rir, toca a brincar...

Música de carnaval cantada no Club dos Democráticos Correio da Manhã 1919 


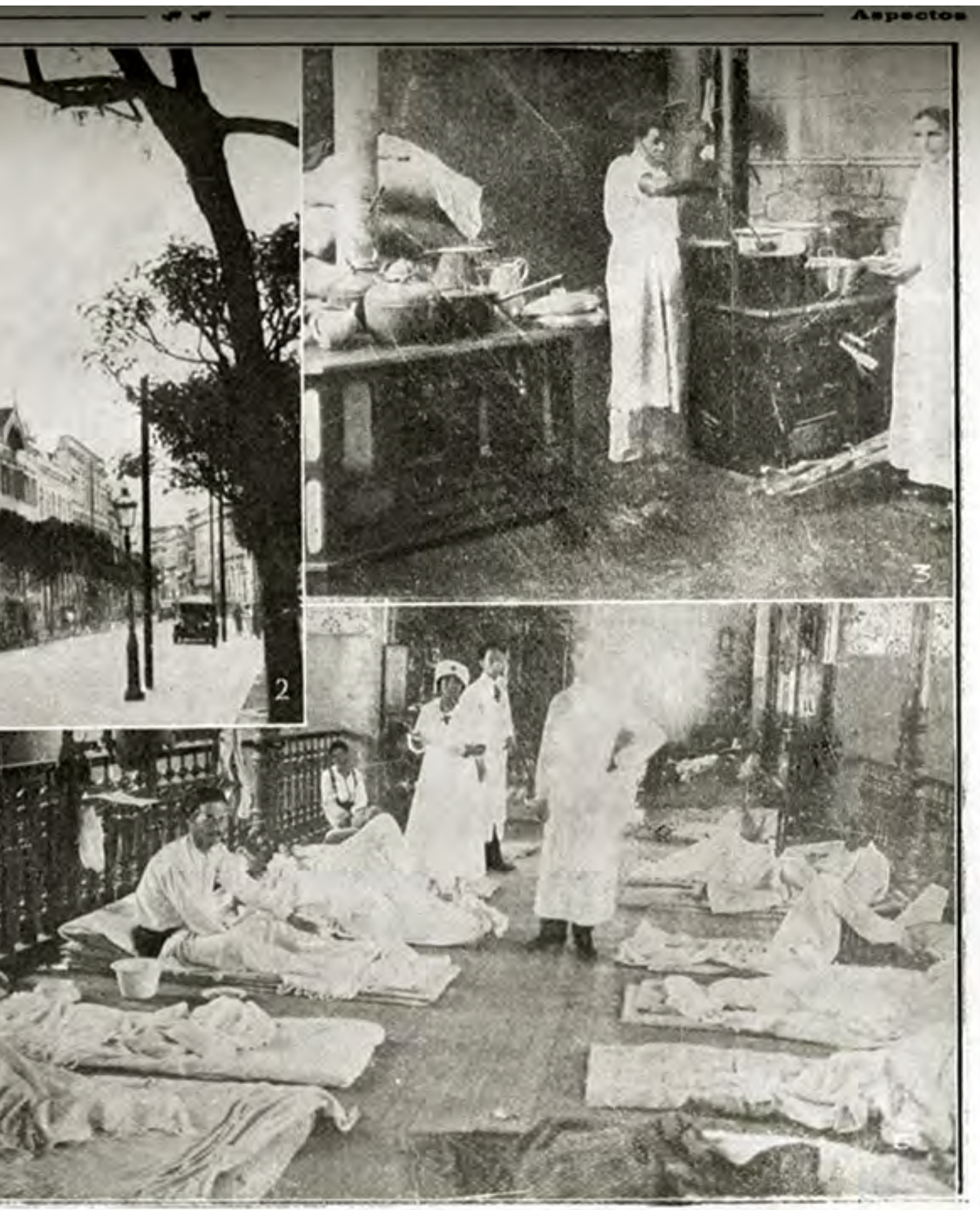

3- A cosinha do mesmo posto.

;-5 - Enfermarias na Escola Deodoro.
A epidemia reinante Fon-Fon, 2 nov. 1918 Acervo Casa de Rui Barbosa "The raging epidemic" Fon-Fon, Nov. 2, 1918

This is it! Viva merriment!

Viva the King of Carnival! Viva revelry!

Ain't no sorrow can resist

All this happiness.

If the Spanish flu didn't get you,

If it didn't kill you off,

Don't let it worry you no more.

Get back to the laughter, get back to the fun...

Carnival tune sung at the social organization known as the Democrats Club Correio da Manhã, 1919

At the height of the epidemic, one day when there was no way left to transport so many dead and the Chief of Police was at the end of his rope, the solution came from the famed reveler Jamanta, a notable figure from Rio de Janeiro's Carnival. (...) He knew his Rio de Janeiro remarkably well, and on some bohemian lark, during nighttime outings, had learned to drive trolleys. One of his superiors responded to his request for a carriage and two closed baggage cars and he used them to scour the city from north to south Fábrica de Chitas, Tijuca, Andaraí, Aldeia Campista, Vila Isabel, Méier, Engenho de Dentro, Piedade, Cascadura, Penha Circular, Benfica - urging everyone to put their dead outside (Bring out your deads! [English in the original]). Carriage and baggage cars piled high with caskets and shrouded corpses, the lone motorman would head to the cemetery in Caju. Unload. The day grew late but back he would go at top speed, combing Laranjeiras, Flamengo, Botafogo, Jardim Botânico, Ipanema, Copacabana, picking up more bodies. Filling up. Nighttime already, the ominous string of cars would pass by like the Ghost Train or Dracula's ship, crammed with cargo for São João Batista cemetery. He did this for two or three days that stuck in his memory forever. 

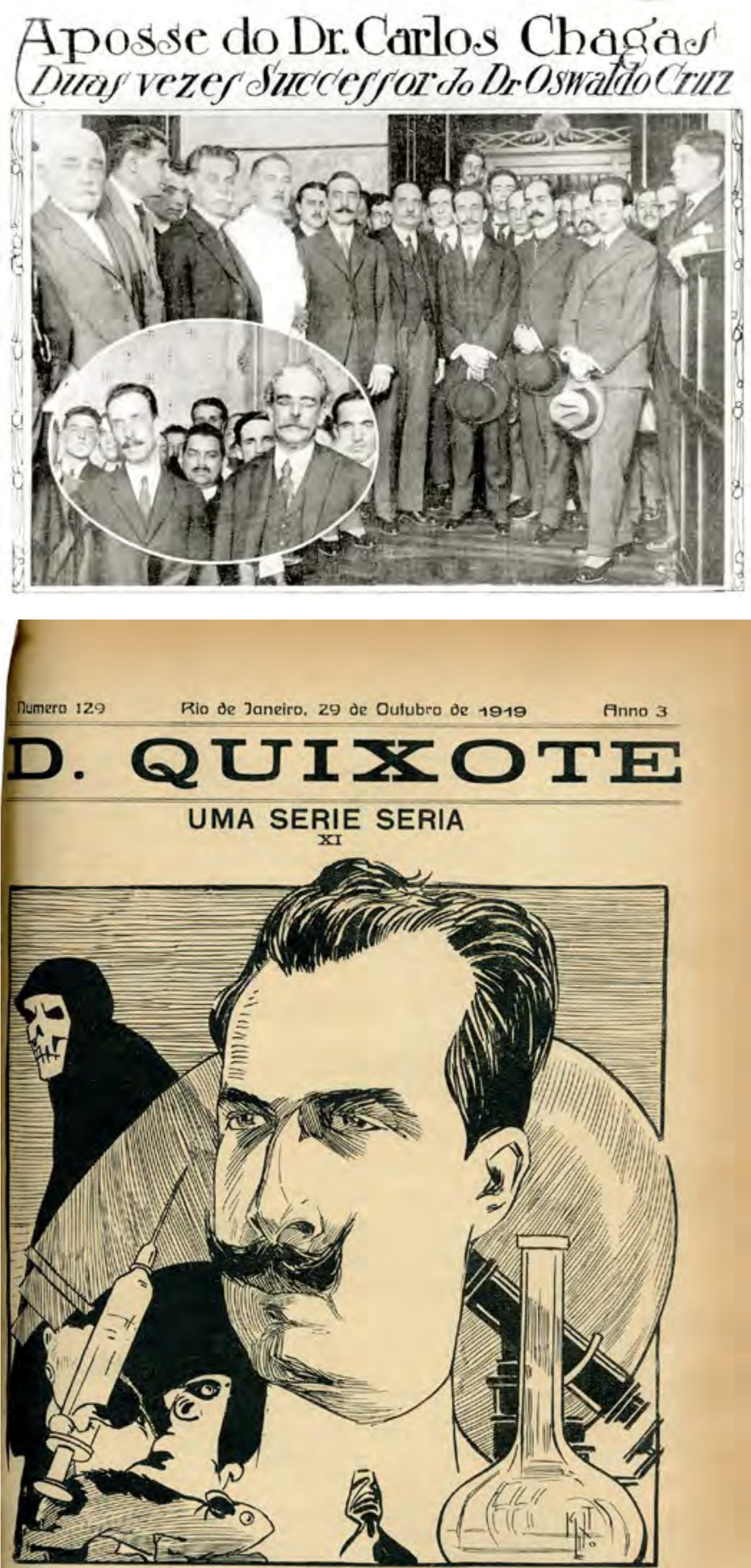

Tu gue tens virtudes magas,

Do Oswaldo as liç̧óes propagas,

Eua perda nos pagas

Carlos Chagas, Carlos Chagas !
Posse de Chagas na

Diretoria-Geral de Saúde Pública Revista da Semana,

11 out. 1919

Acervo Casa de Oswaldo Cruz

Chagas taking office at the

General Directorship of Public

Health

Revista da Semana, Oct. 11, 1919

Uma serie seria

D. Quixote, 29 out. 1920

Charge de Kalixto, por ocasião

da nomeação de Carlos Chagas

para a Diretoria-Geral de Saúde Pública

Acervo Casa de Oswaldo Cruz

"A serious series"

D. Quixote, Oct. 29, 1920

Cartoon by Kalixto published

when Carlos Chagas was

appointed to the General

Directorship of Public Health 


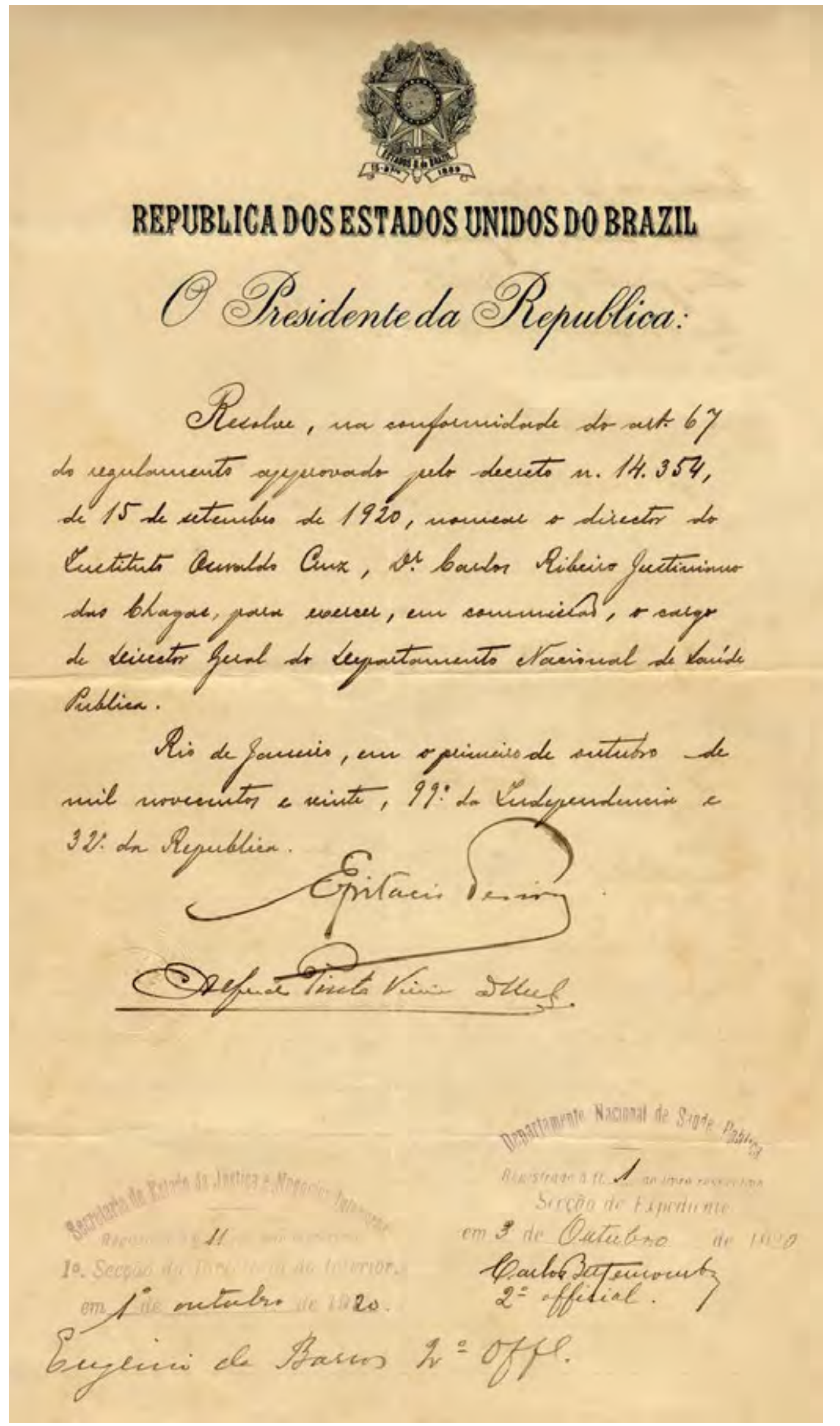

Ao assumir as funções do cargo de diretor-geral de saúde pública, não desconheço as dificuldades de seu desempenho, e sei apreciar bem alto as obrigações de trabalho que me são impostas pela confiança do governo.

Carlos Chagas

As I assume the duties of the office of director general of public health, I am not unaware of the challenges of this role, and I know full well how to appreciate the assignment with which the government has entrusted me. 

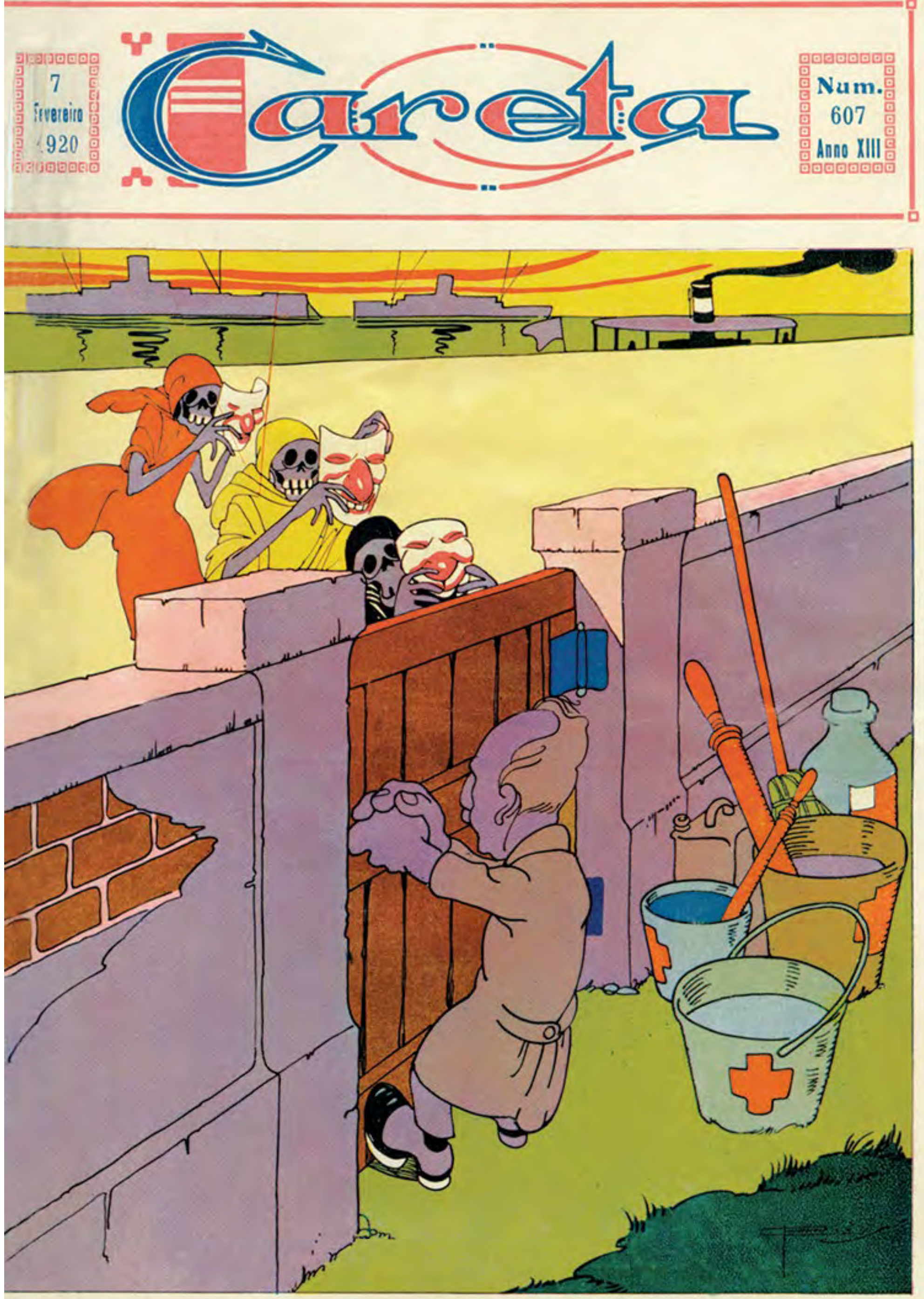

O PORTEIRO IMPLACAVEL.

Foi vedada a entrada aos primeiros mascarados. 


\section{COM A MÃ̃ NA MASSSA}

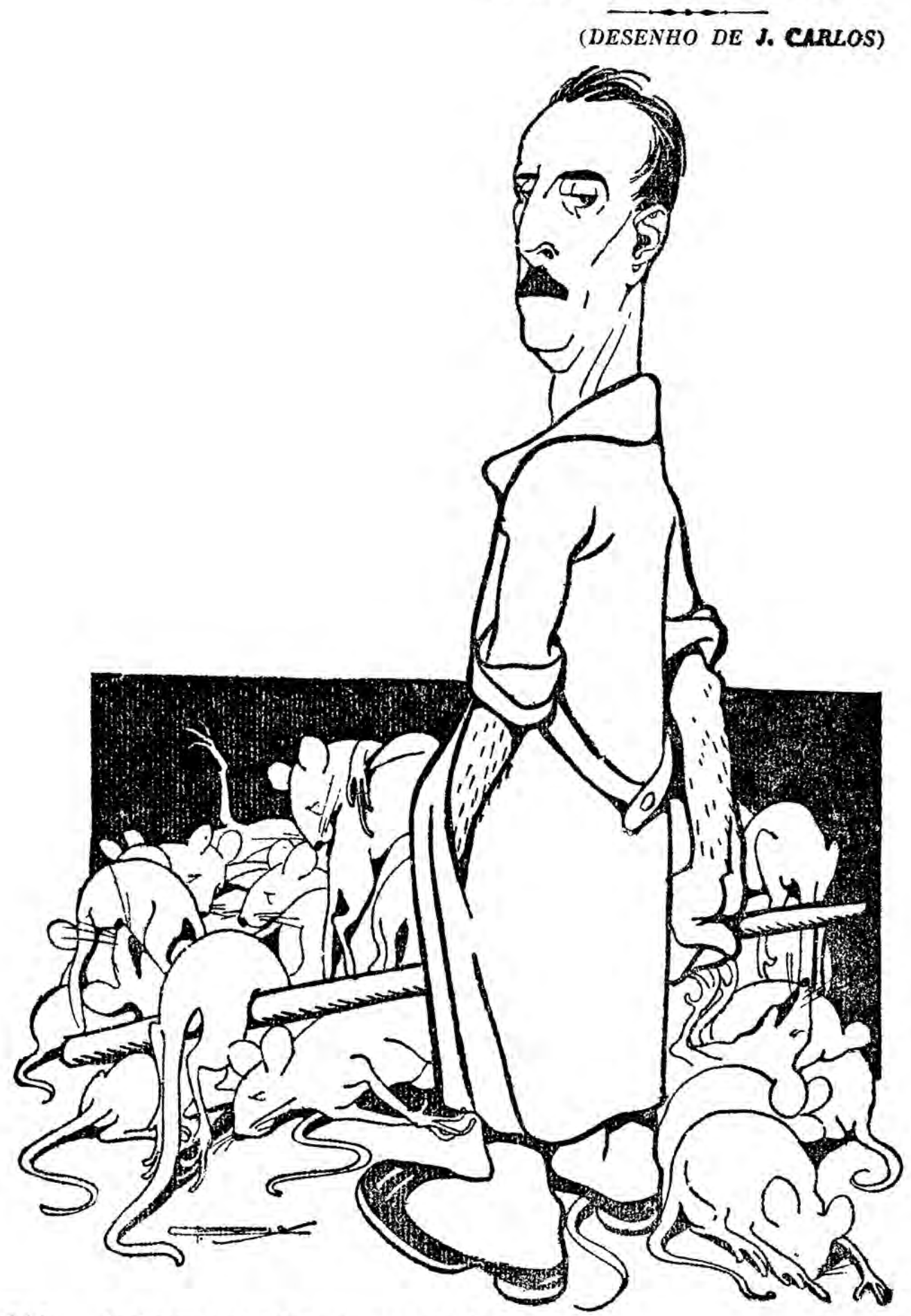

Cabcas - Acabarasos tambern com as "ratas".

$\begin{array}{ll}\text { O porteiro implacável } & \text { Com a mão na massa } \\ \text { Careta, 7 fev. 1920 } & \text { Charge de J. Carlos (José } \\ \text { Charge de J. Carlos } & \text { Carlos de Brito e Cunha, 1884- } \\ \text { (José Carlos } & \text { 1950) } \\ \text { de Brito e Cunha, } & \text { Acervo Casa de Oswaldo Cruz } \\ \text { 1884-1950) } & \text { "Getting one's hands dirty" } \\ \text { Acervo Casa de Oswaldo Cruz } & \text { Cartoon by J. Carlos } \\ \text { "The relentless doorman" } & \\ \text { Careta, Feb. 7, 1920 } & \\ \text { Cartoon by J. Carlos } & \end{array}$

Sob o ponto de vista

sanitário, não nos parece, de fato, que o festival de Momo seja, nas atuais circunstâncias, tão inócuo como as entrevistas fazem crer que pensa o Dr. Carlos Chagas. Mas S. Ex. éo principal responsável pela saúde pública, e, uma vez que a sua opinião parece inclinarse, no sentido de não ver inconveniente nos folguedos populares, não seremos nós que, mais realistas do que o rei, insistiremos em discutir a conveniência de adiar o entrudo, a poeira, a aglomeração e a fadiga dos dias heróicos do carnaval, para uma ocasião, em que mais afastada de nós estivesse a companhia da gripe.

O Paiz, 1920

From a sanitary standpoint, it does not actually seem to us that Carnival, under present circumstances, is as harmless as interviews lead us to believe Carlos Chagas thinks it is. But this gentleman bears primary responsibility for public health, and since his opinion seems to lean towards finding nothing inappropriate about popular revelry, far be it from us, more realistic than the king, to keep calling for discussions about the advisability of postponing the capers, the prancing, the crowds, and the fatigue of the heroic days of Carnival until an occasion when we are not in such close company with the flu.

O Paiz, 1920 


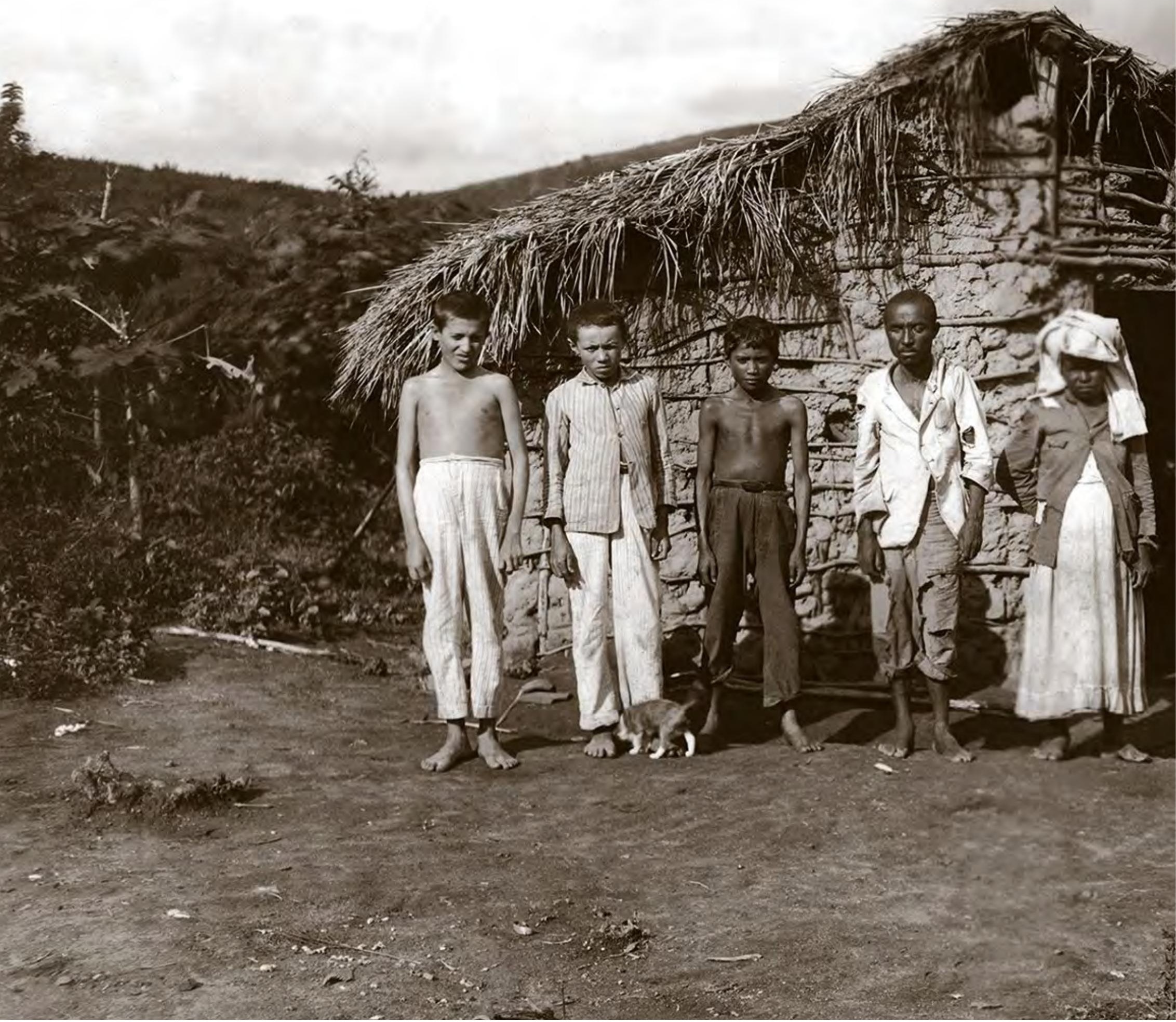

Moradores de Quebrangulo, AL 
Vivendo quatrocentos anos no litoral vastíssimo, em que palejam reflexos da vida civilizada, tivemos de improviso, como herança inesperada, a República. Ascendemos, de chofre, arrebatados na caudal dos ideais modernos, deixando na penumbra secular em que jazem, no âmago do país, um terço da nossa gente. Iludidos por uma civilização de empréstimo; respigando, em faina cega de copistas, tudo o que de melhor existe nos códigos orgânicos de outras nações, tornamos, revolucionariamente, fugindo ao transigir mais ligeiro com as exigências da nossa própria nacionalidade, mais fundo o contraste entre o nosso modo de viver e o daqueles rudes patrícios mais estrangeiros nesta terra do que os imigrantes da Europa. Porque não no-los separa um mar, separam-no-los três séculos...

Euclides da Cunha

After having lived for four hundred years on a vast stretch of seaboard, where we enjoyed the reflections of civilized life, we suddenly came into an unlooked-for inheritance in the form of the Republic. Caught up in the sweep of modern ideas, we abruptly mounted the ladder, leaving behind us in their centuriesold semidarkness a third of our people in the heart of our country. Deluded by a civilization which came to us second hand; rejecting, blind copyists that we were, all that was best in the organic codes of other nations, and shunning, in our revolutionary zeal, the slightest compromise with the exigencies of our own national interests, we merely succeeded in deepening the contrast between our mode of life and that of our rude native sons, who were more alien to us in this land of ours than were the immigrants who came from Europe. For it was not an ocean which separated us from them but three whole centuries... 
Vê-se, muitas vezes, confrangido e alarmado, nas nossas escolas públicas, crianças a bater os dentes com o calafrio das sezões. (...) E isto não nos confins do Brasil, aqui no Distrito Federal, em Guaratiba, Jacarepaguá, na Tijuca... Porque, não nos iludamos, o nosso sertão começa para os lados da Avenida.

Afrânio Peixoto

With distress and alarm, we very often see children's teeth chattering away from the chills of the ague in our public schools. (...) And this is not in the far reaches of Brazil but here in the Federal District, in Guaratiba, Jacarepaguá, Tijuca... For let us have no illusions, the Brazilian hinterlands begin somewhere around [Central] Avenue.

Afrânio Peixoto

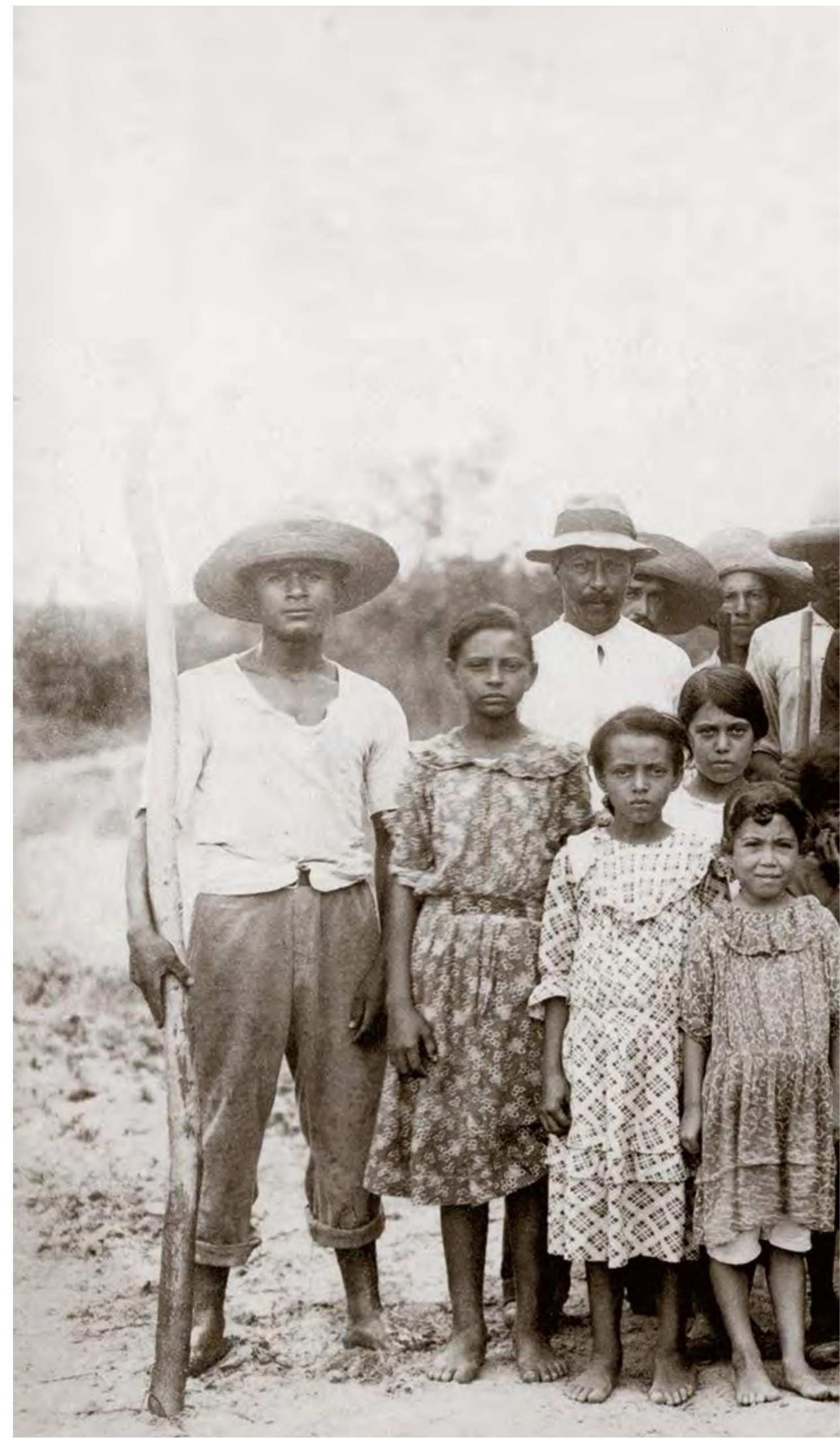

Moradores de área rural do estado do Rio de Janeiro

Foto A. Cerqueira

Acervo Casa de Oswaldo Cruz

Residents from rural Rio de Janeiro

Photograph by A. Cerqueira 


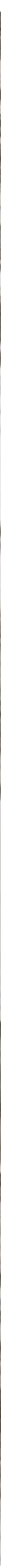



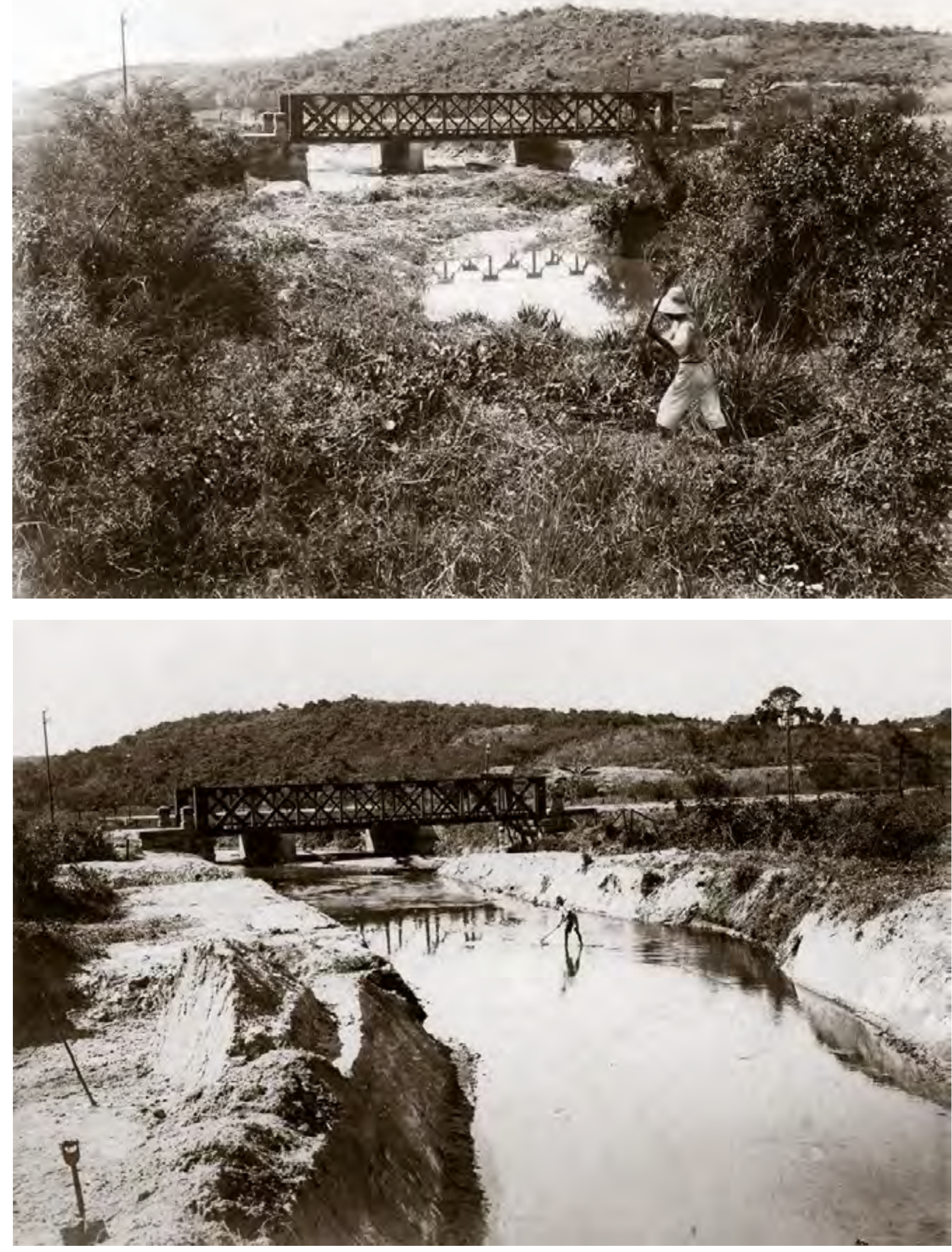

Obra de engenharia sanitária em Honório Gurgel, no Rio de Janeiro Acervo Casa de Oswaldo Cruz

Sanitary engineering works in the neighborhood of Honório Gurgel, Rio de Janeiro

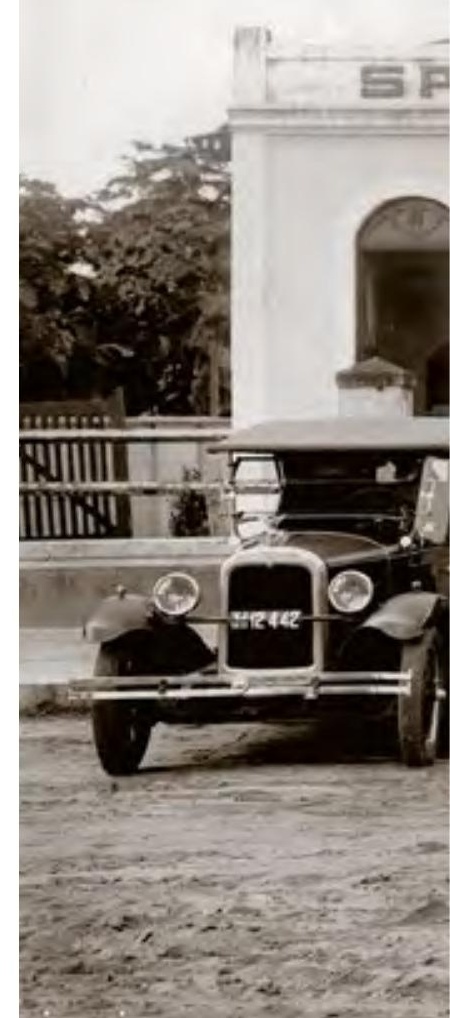



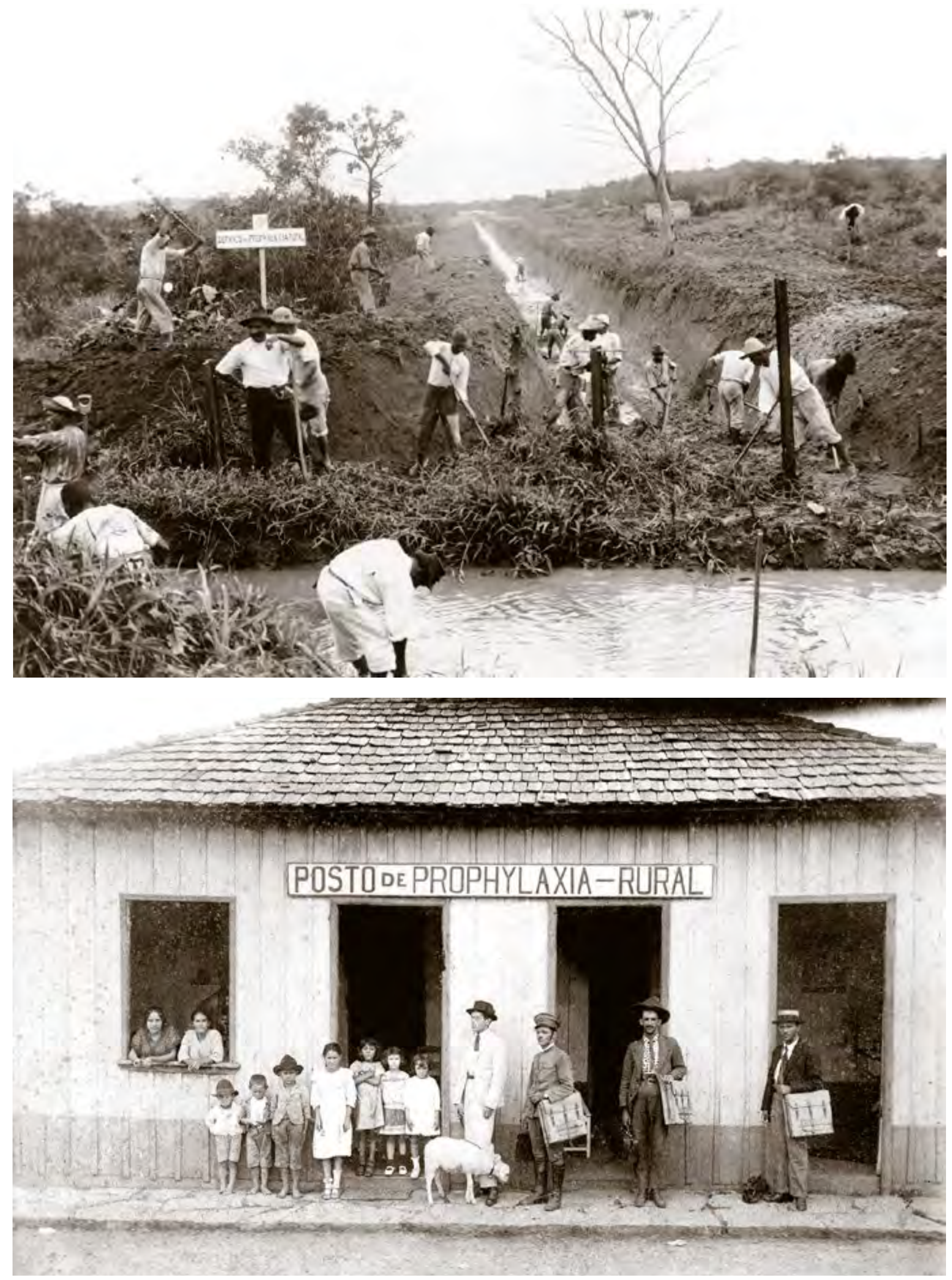

Obra de engenharia sanitária em Ribeirão Cachoeira.

Mesquita, RJ, 10 nov. 1922

Acervo Casa de Oswaldo Cruz

Sanitary engineering works in Ribeirão Cachoeira.

Mesquita, Rio de Janeiro, Nov. 10, 1922

Posto sanitário de Colônia Mineira, atual Siqueira

Campos, PR, 10 maio 1922

Acervo Casa de Oswaldo Cruz

Sanitary post in Colônia Mineira, now Siqueira Campos,

Paraná, May 10, 1922 

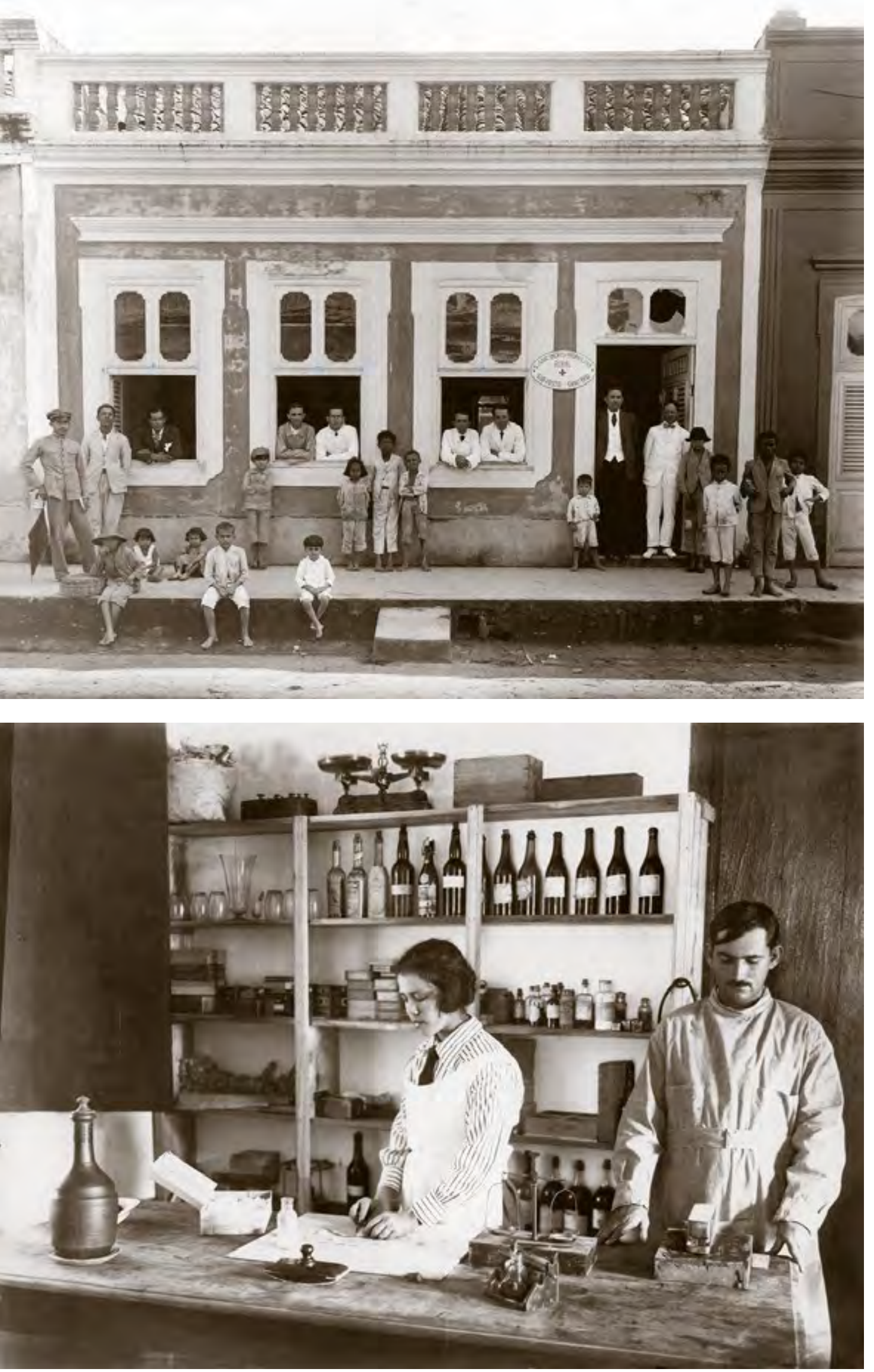

Subposto sanitário de Pilar, PB Acervo Casa de Oswaldo Cruz

Pilar sanitary sub-post, Paraíba

Com sincero regozijo e bem fundadas esperanças, hoje poderemos anunciar a organização de serviços sanitários rurais em onze Estados da União, de acordo com a nova lei federal. E temos a segurança de que algumas das unidades federadas, ainda excluídas desses serviços, embora realizando trabalhos de saneamento por iniciativa própria, ou auxiliados pela 'Rockefeller Foundation', não custarão em vir ao encontro de nossos intuitos e concorrerem para o êxito maior dessa obra de redenção sanitária do Brasil, que deve estender-se, com unidade de vistas e solidariedade de intuitos, a todo território nacional.

Carlos Chagas

With sincere rejoicing and justifiable hope, today we can announce the organization of rural sanitary services in eleven States of the Union, pursuant to new federal law. And we are certain that it will not be long before some states and other units of our federation as yet excluded from these services, albeit undertaking sanitation works at their own initiative or with the assistance of the Rockefeller Foundation, will not tardy in joining us in our purpose and contribute to the greater success of this endeavor to achieve the sanitary redemption of Brazil, which should extend throughout all our national territory, with a shared vision and unity of purpose.

Carlos Chagas

Farmácia do posto sanitário de Quebrangulo, AL Acervo Casa de Oswaldo Cruz

Quebrangulo sanitary post pharmacy, Alagoas 


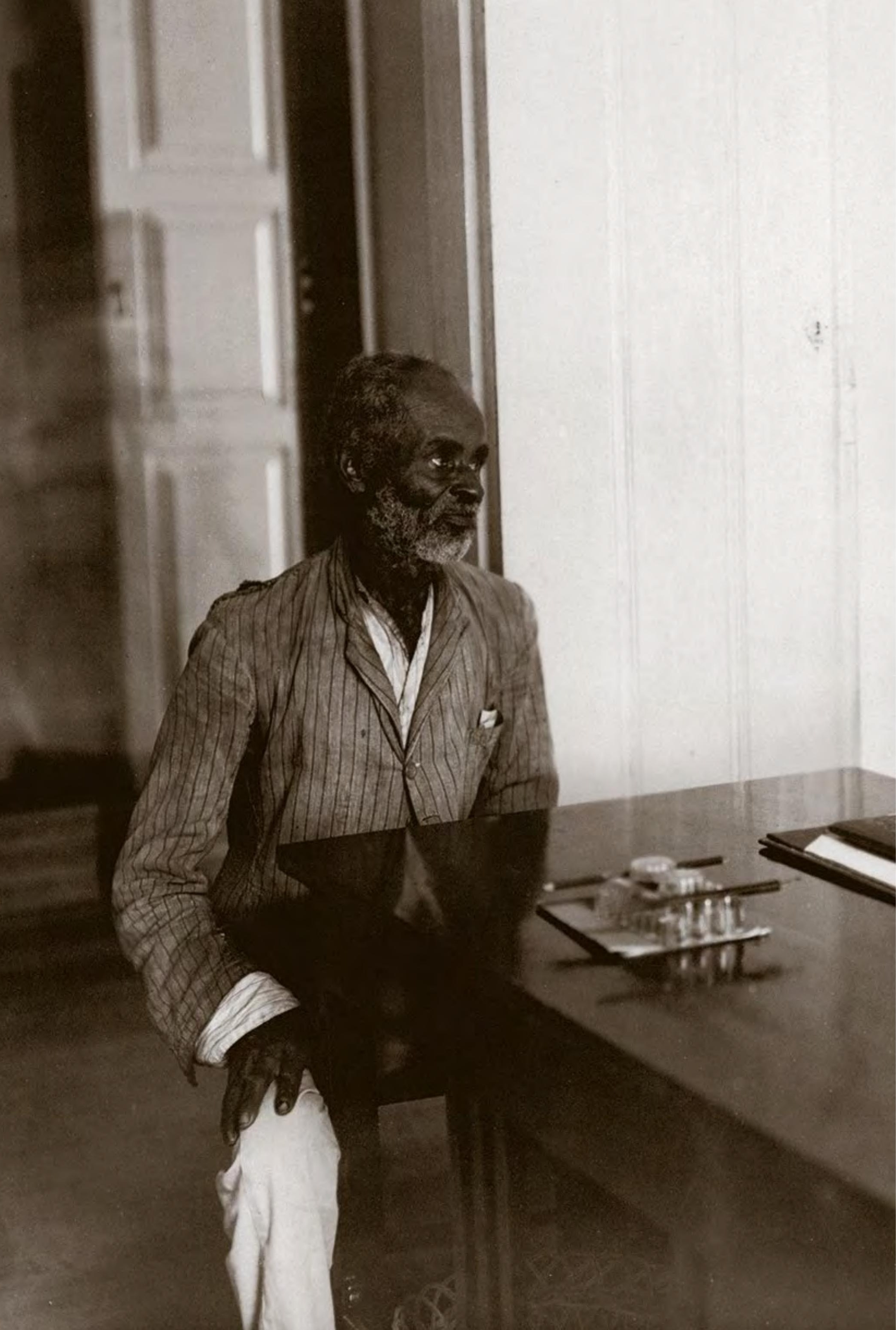


Atendimento médico no posto sanitário de Barra do Camaragibe, AL

Acervo Casa de Oswaldo Cruz

Health care at a sanitary

post in Barra do

Camaragibe, Alagoas 

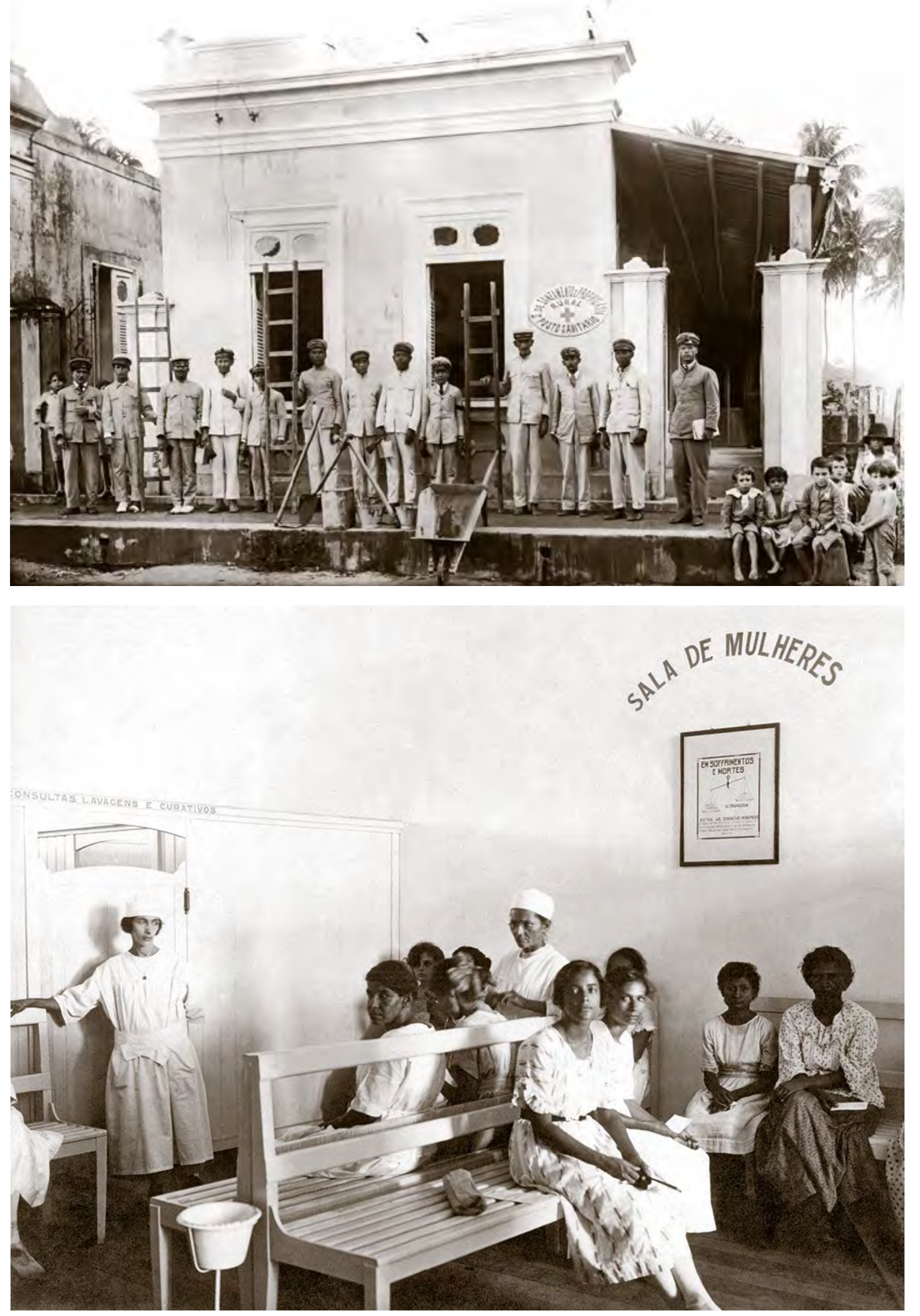

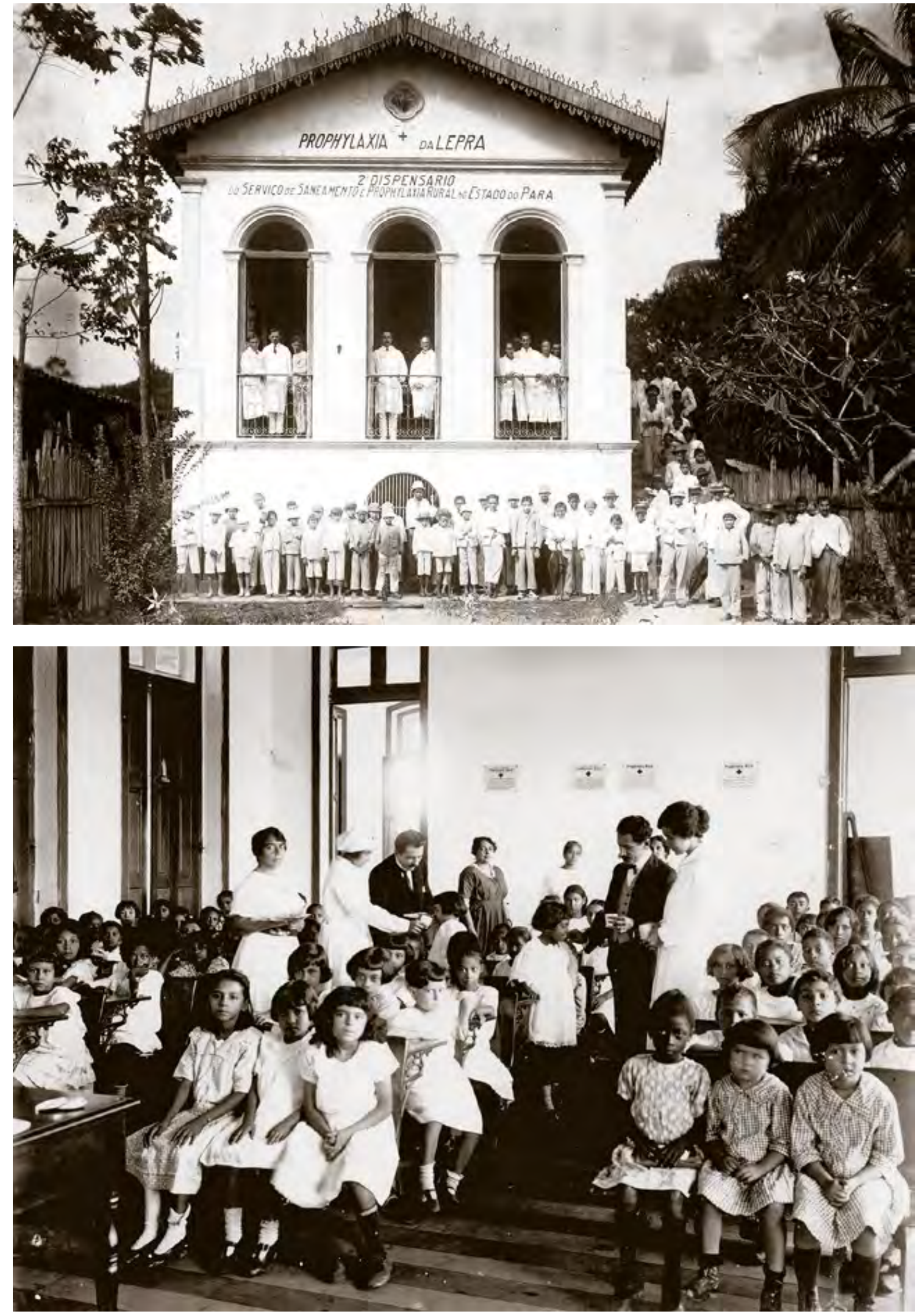

Dispensário do Serviço de Saneamento e

Profilaxia Rural do Pará Acervo Casa de Oswaldo Cruz

Dispensary at the state of Pará's Rural

Sanitation and

Prophylaxis Service

Administração de quinina a alunos de grupo escolar no

Amazonas. Ao fundo, de termo escuro, Samuel Uchôa, chefe do Serviço de

Saneamento e Profilaxia Rural do Amazonas

Acervo Casa de Oswaldo Cruz

Giving quinine to school students in Amazonas. In back, in a dark suit, Samuel Uchôa, head of the Rural Sanitation and Prophylaxis Service of Amazonas
Livreto de divulgação produzido pelo Departamento

Nacional de Saúde

Pública sobre

a formação de enfermeiras. Rio de

Janeiro, 1921

Acervo Casa de Oswaldo Cruz

Recruiting booklet about nursing

education, put out by the National

Department of Public Health. Rio de Janeiro, 1921 


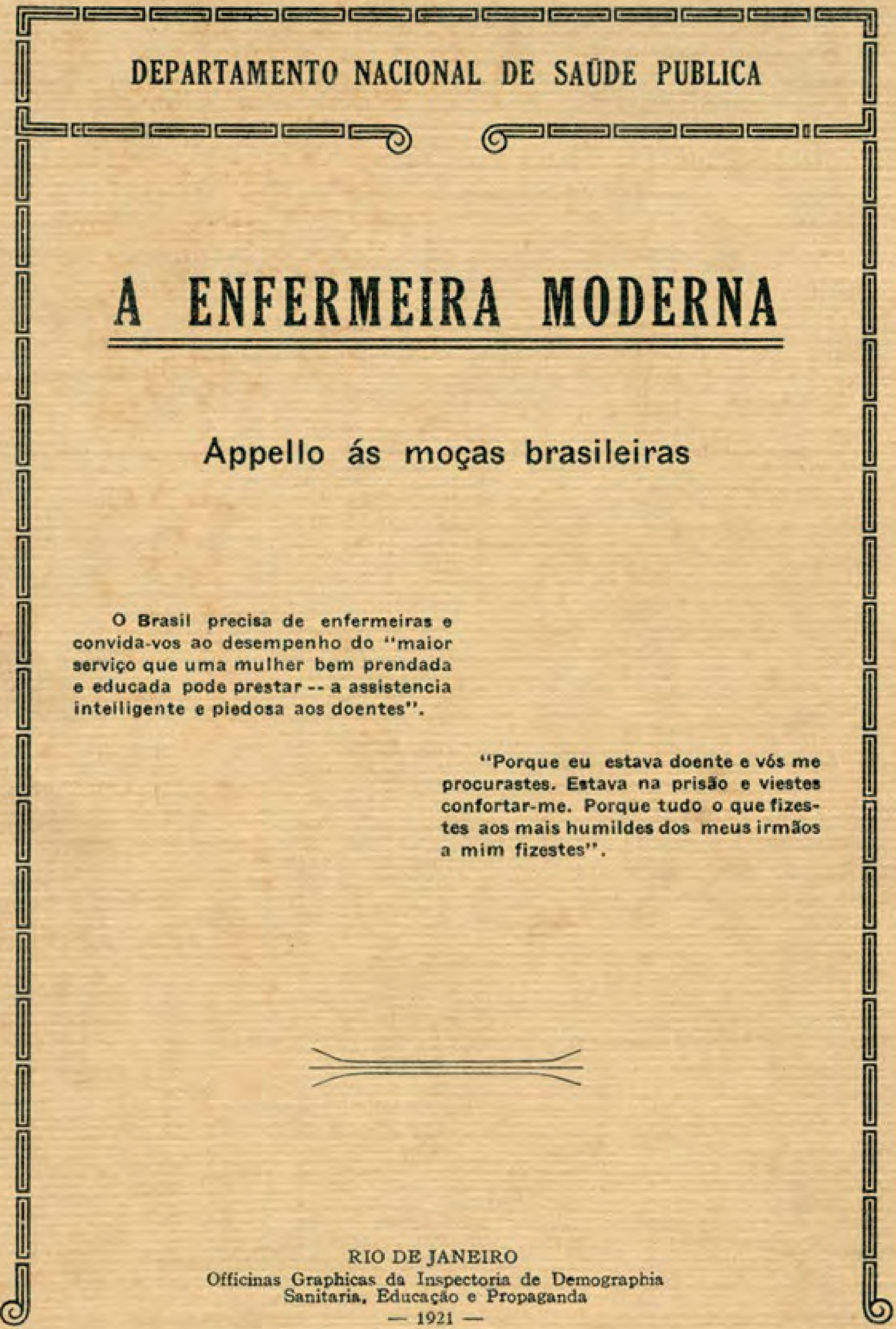




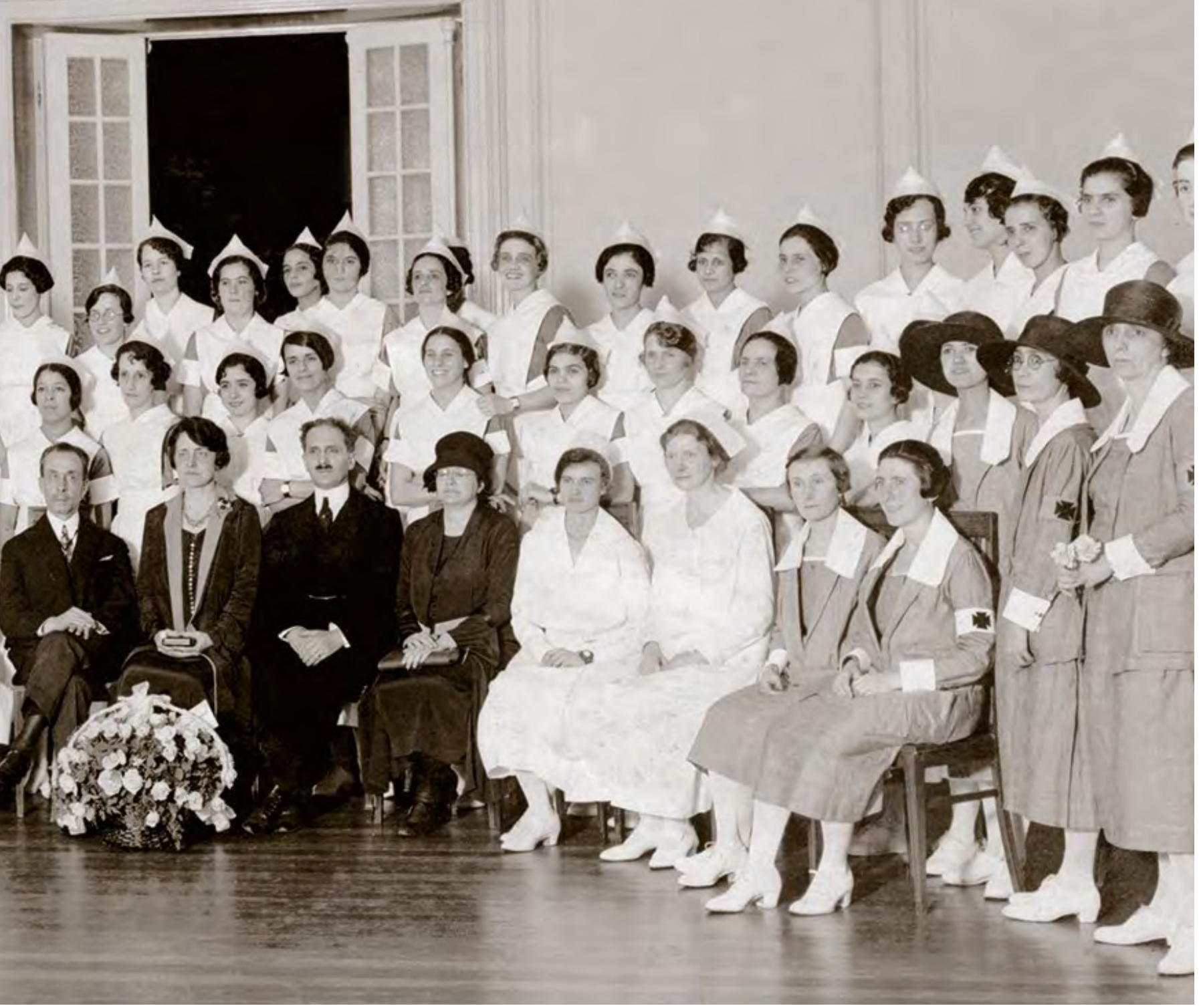

Chagas na inauguração do internato da Escola de Enfermagem Anna Nery. A sua esquerda, a

superintendente geral

do Serviço de

Enfermeiras do

Departamento Naciona

de Saúde Pública, a

norte-americana Ethel

Parsons, e Raul Leitão

da Cunha, professor da

Escola de Enfermagem.

Rio de Janeiro, 29 jul.

1926

Acervo Casa de Oswaldo

Cruz

Chagas at the

inauguration of the

Anna Nery Nursing

School student

dormitory. To his left,

Ethel Parsons (from the

U.S.), then

superintendent

general of the Nationa

Department of Public

Health's Nursing

Service, and Raul Leitão

da Cunha, professor at

the Nursing School. Rio

de Janeiro, Jul. 29, 1926

Alunas da Escola de

Enfermagem Anna Nery

em aula de microbiologia

Acervo Casa de Oswaldo Cruz

Students in a

microbiology class at

the Anna Nery Nursing

School

Alunas da Escola de

Enfermagem Anna Nery

realizam curativos em

paciente sob a

supervisão da

enfermeira chefe Miss

Murray

Acervo Escola de

Enfermagem Anna Nery

Students at the Ann

Nery Nursing School,

placing dressings on a

patient under the

supervision of chief

nurse "Miss Murray" 
Na profilaxia da tuberculose encontramos outro exemplo valioso da atividade das enfermeiras visitadoras. Aí, mais do que em qualquer outro ramo da administração sanitária, sua função é preponderante e

imprescindivel. São elas que levam aos tuberculosos toda a educação técnica necessária a impedir a difusão do contágio, cabendo-lhes no caso, a alta responsabilidade de evitar pelos ensinamentos acertados a contaminação das pessoas que assistem carinhosamente os tuberculosos, e às quais faltam as mais das vezes as noções mais elementares relativas ao contágio da peste branca.

O Jornal, 1922

We find another valuable example of the work of visiting nurses in tuberculosis prophylaxis. Here more than in any other branch of sanitary management, their role is crucial and indispensable. They are the ones who provide tuberculosis sufferers with all the technical education needed to keep the contagion from spreading, entrusted here with the immense responsibility of preventing, through proper teaching, the contamination of the people who tenderly care for tuberculosis patients, [people] who more often than not lack the most basic notions about the contagion of the white plague.

O Jornal, 1922

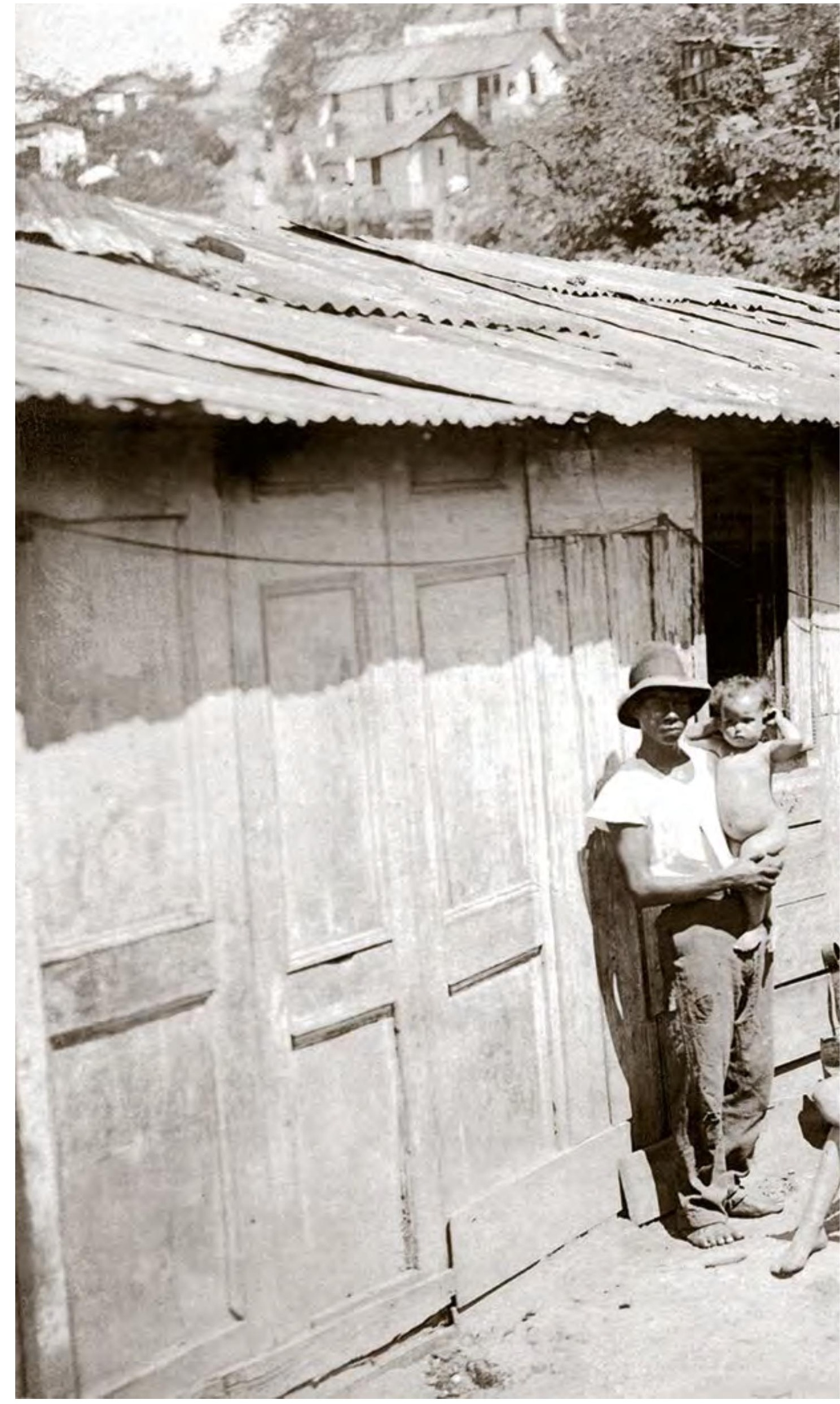

Enfermeira visitadora da Inspetoria de Profilaxia da Tuberculose em favela na cidade do Rio de Janeiro, final da década de 1920 Acervo Casa de Oswaldo Cruz

Visiting nurse from the Tuberculosis

Prophylaxis Inspectorship in a Rio de Janeiro slum, late 1920 s 


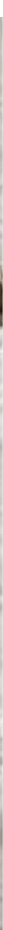

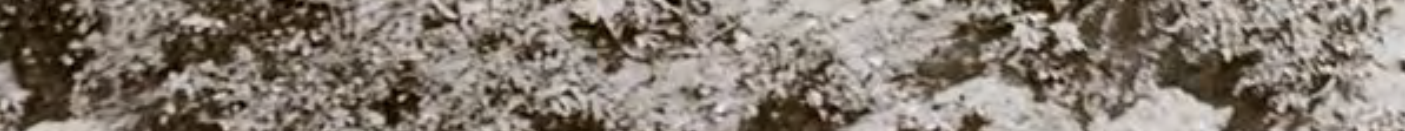

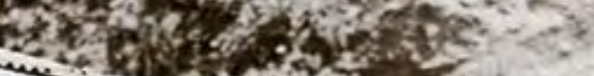

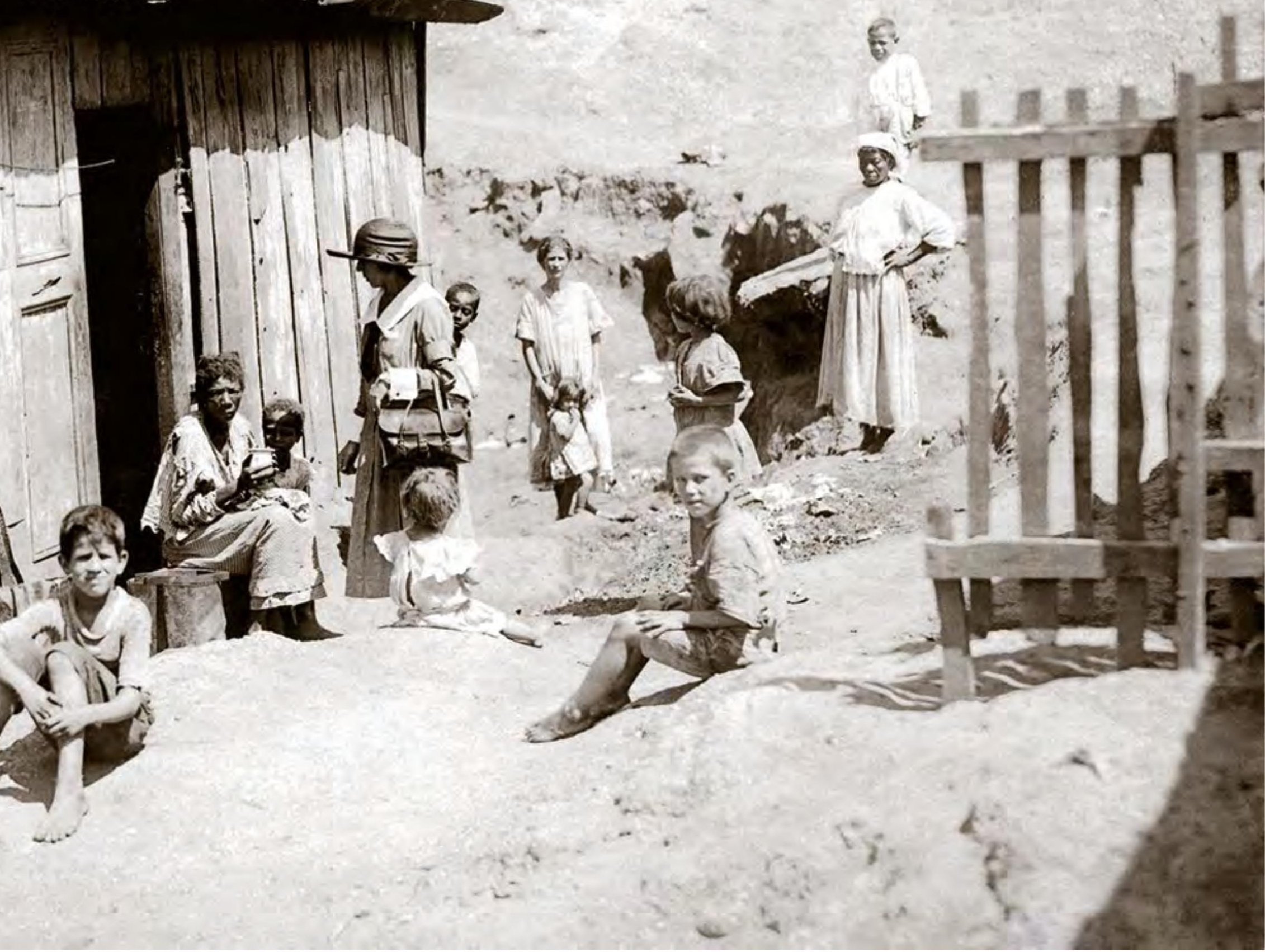




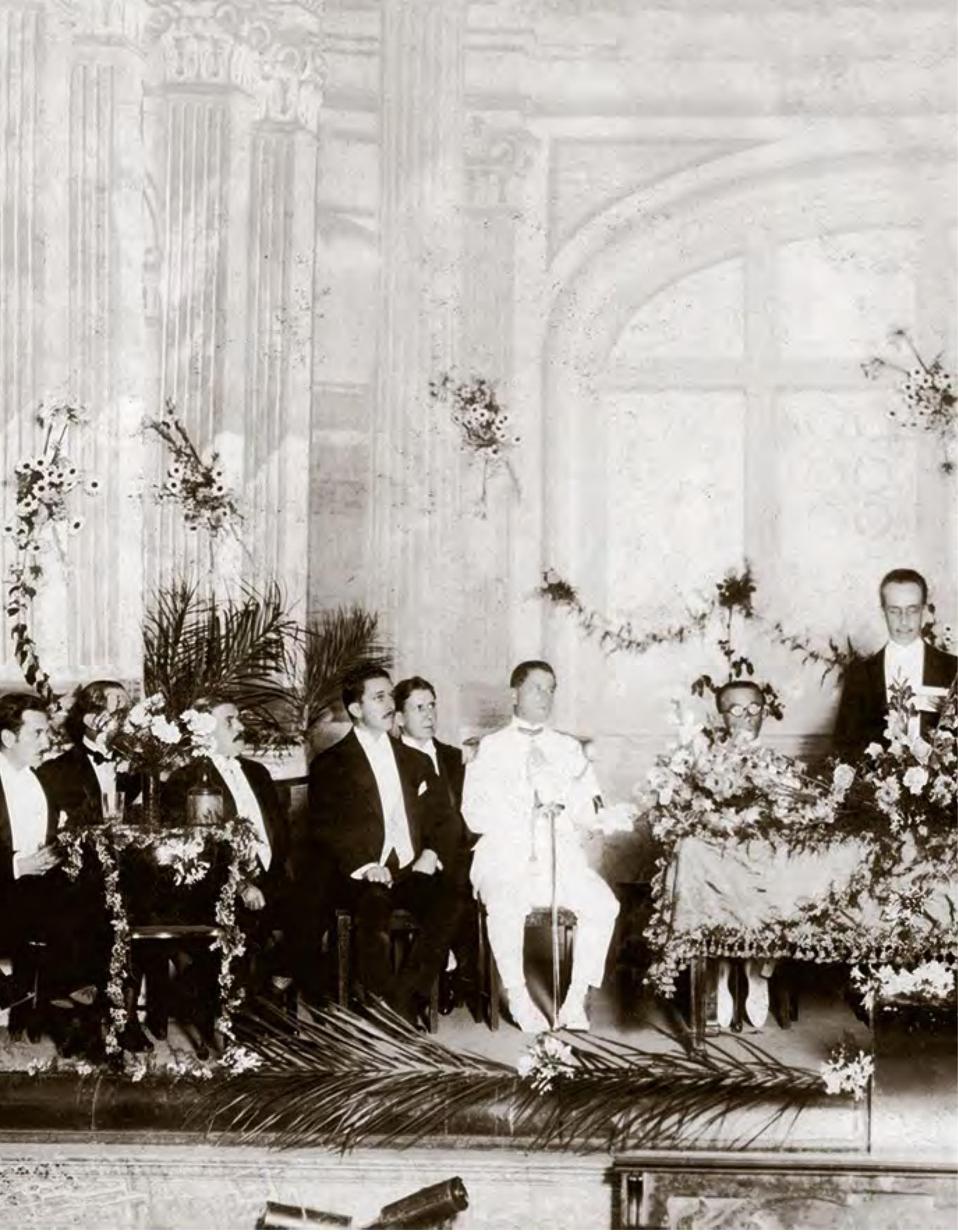




\section{E CHOVA ARROZ...}

A proposito da ficada do Dr. Carlos Chagas no D. N. S. P. :
Estará desmerecendo a fama de Manguinhos?

\section{Alastra-se a variola apezar da vaccina}

Ha medicos que reclamam contra a inefficacia daquelle recurso official

Mexa-se e fale, Sr. Dr. Carlos Chagas

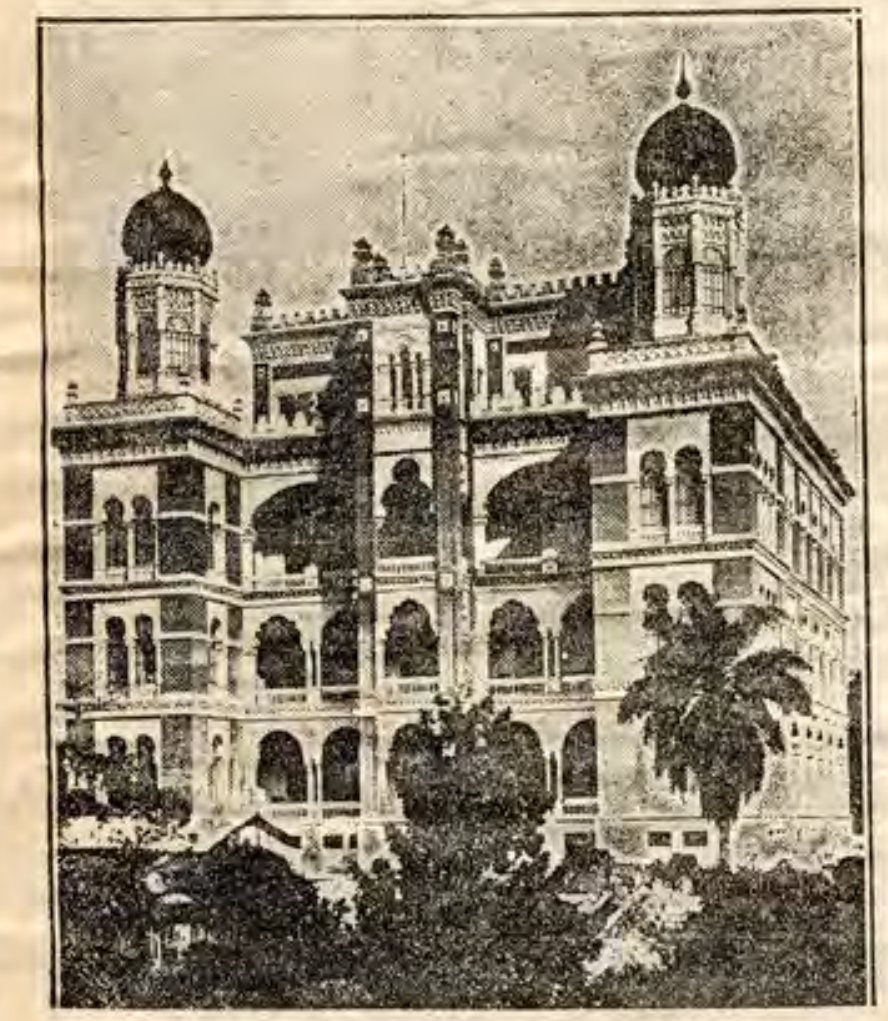

Instituto 0swaldo Cruz

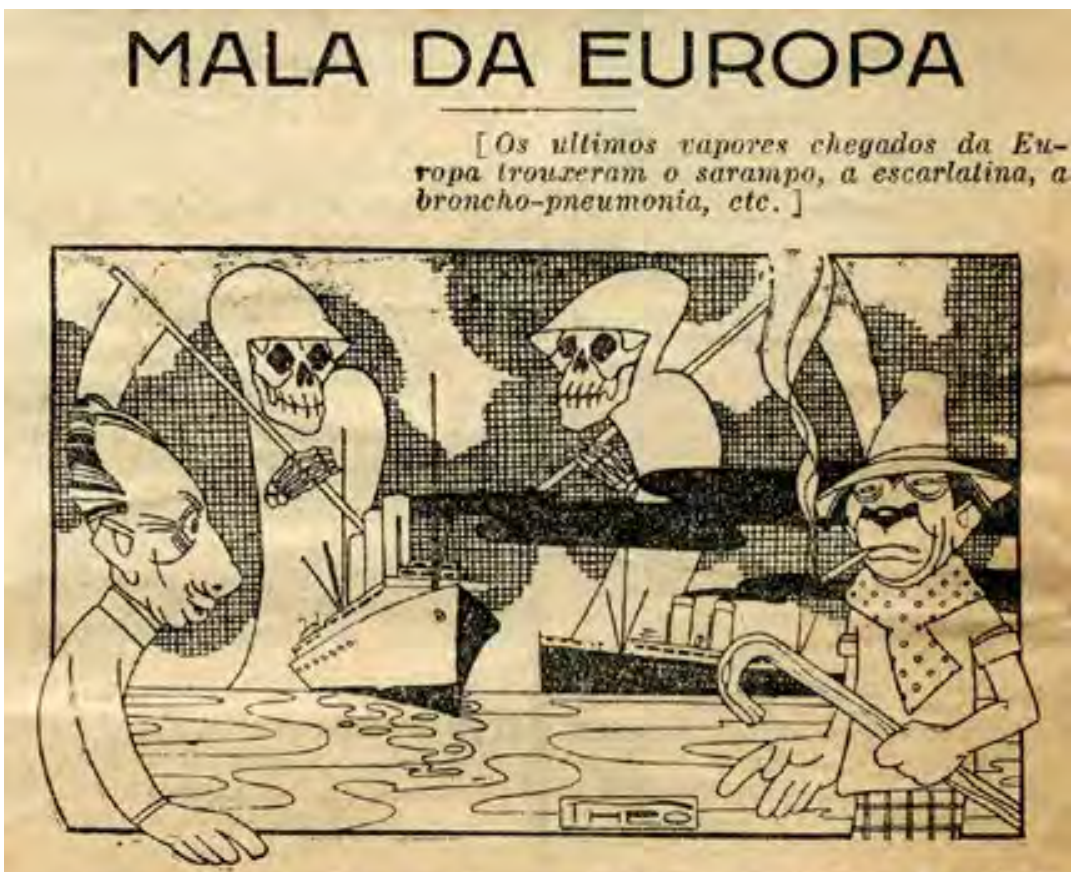

CHAGAS - Nāo vês aquelles navios? Trazem jornaes e revistas cheios de referencias ao men nome e aos mens titulos..

JEGA - Parece que trazem mais alguma cousa seo dinuto!...

Estará desmerecendo a fama de Manguinhos?

O Globo, 29 mar. 1926

Acervo Casa de Oswaldo Cruz

"Is Manguinhos's renown being disparaged?"

O Globo, Mar. 29, 1926

Mala da Europa

O Globo, 7 abr. 1926

Charge de Theo

Acervo Casa de Oswaldo Cruz

"Baggage from Europe"

O Globo, Apr. 7, 1926

Cartoon by Theo chova arroz...

OMalho, 24 nov. 1923

Charge alusiva ao

pedido de exoneração

do cargo de diretor do

Departamento Nacional

de Saúde Pública, feito

por Chagas em fevereiro de 1923, e recusado pelo presidente Arthur Bernardes

Charge de J. Carlos (José Carlos de Brito e Cunha, 1884-1950)

Acervo Fundação Biblioteca Nacional

"And it rains manna..."

O Malho, Nov. 24, 1923

Cartoon referring to

Chagas's request to step down as director of the

National Department of Public Health, lodged in

February 1923 and

rejected by Brazilian president Arthur Bernardes

Cartoon by J. Carlos 


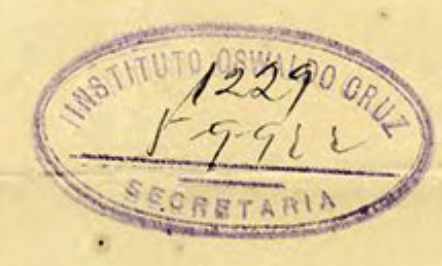

Sir,

I have the honour to inform you that the Council of the league of Nations, at the session recently held in Iond on, approved your nomination as member of the Health Committee. From the wires exchanged between you and the hedical Director, I am pleased to see that you have already expressed your wilingness to serve on the Committee.

hay I add that the next meeting of the Health Committee will take place on August 14th, when your colleagues will be pleased to welcome their new member.

I have the honour to be,

Sir,

Your obedient servant,

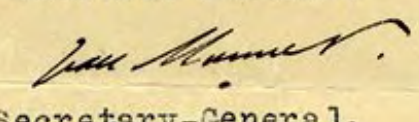

Deputy Secretary-General.

Dr. Carlos Chagas,

Director of the

Oswald Cruz Institute, RIO DE JANEIRO. 


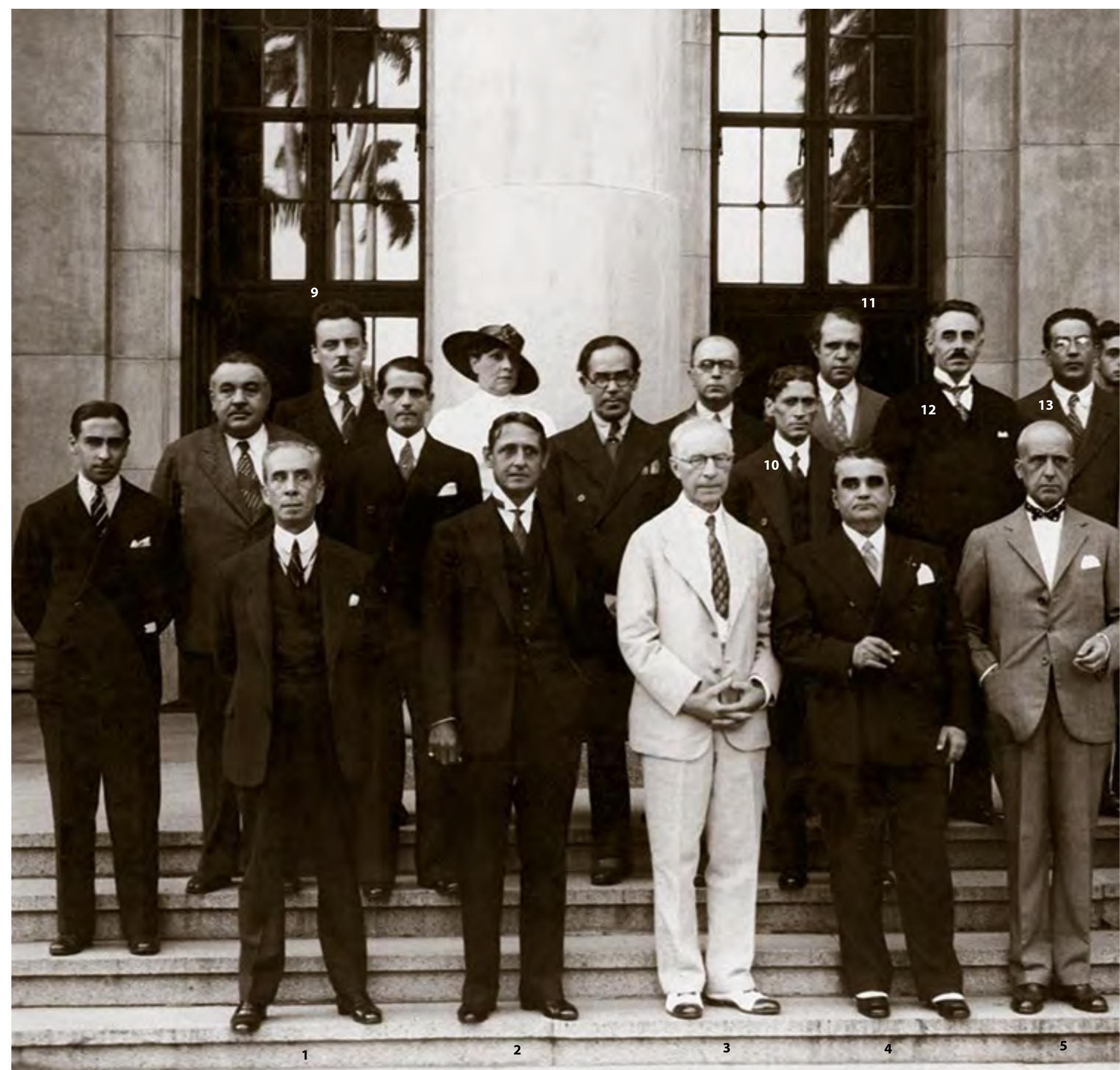

Inauguração do Centro Internacional de Leprologia

1 - Carlos Chagas; 2 - Guilherme Guinle; 3 - Etienne Burnet, representante da Sociedade das Nações; 4 - Washington Pires,

ministro da Educação e Saúde; 5 - Felix Barros Cavalcante de Lacerda, ministro das Relações Exteriores; 6 - Raul de Almeida

Magalhães; 7 - Eduardo Rabello; 8 - Oscar Silva de Araújo; 9 - Evandro Chagas; 10 - José Carneiro Felippe; 11 - Phocion Serpa;

12 - Heráclides César de Souza-Araújo; 13 - José da Costa Cruz; 14 - Clementino Fraga

Rio de Janeiro, 24 abr. 1934

Acervo Casa de Oswaldo Cruz

Inauguration of the International Leprology Center

1 - Carlos Chagas; 2 - Guilherme Guinle; 3 - Etienne Burnet, representing the Society of Nations; 4 - Education and Health

Minister Washington Pires; 5 - Foreign Affairs Minister Felix Barros Cavalcante de Lacerda; 6 - Raul de Almeida Magalhães;

7 - Eduardo Rabello; 8 - Oscar Silva de Araújo; 9 - Evandro Chagas; 10 - José Carneiro Felippe; 11 - Phocion Serpa; 12 - Heráclides

César de Souza-Araújo; 13 - José da Costa Cruz; 14 - Clementino Fraga

Rio de Janeiro, Apr. 24, 1934 


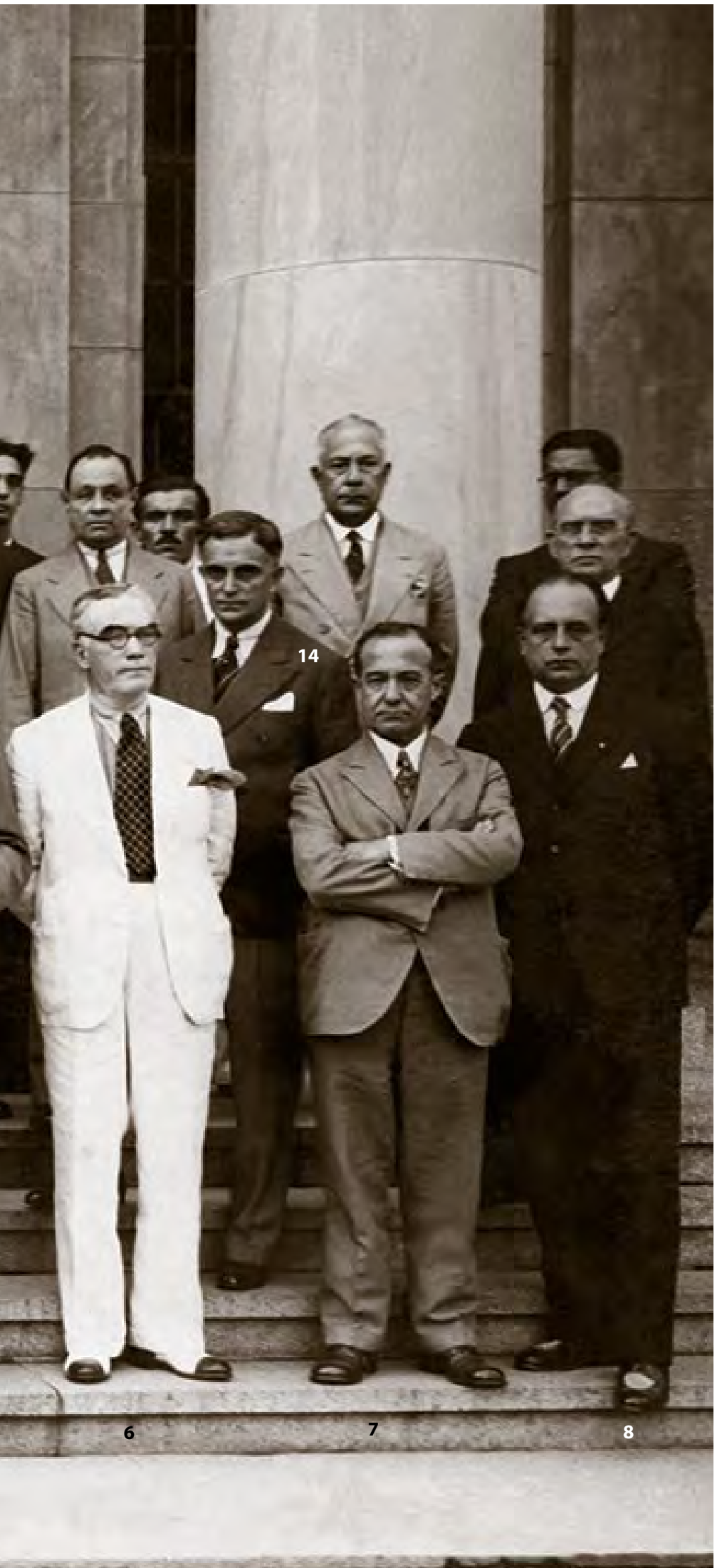

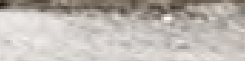

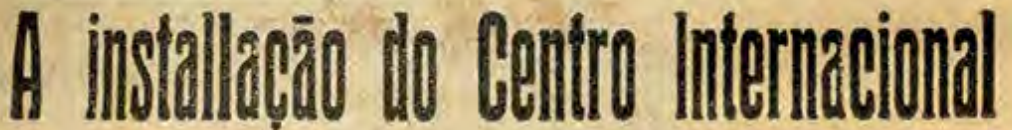 te bentobyja no Birsil \\ Fala á NOITE, sobre a missão desse instituto scientifico, o professor Carlos Chagas}

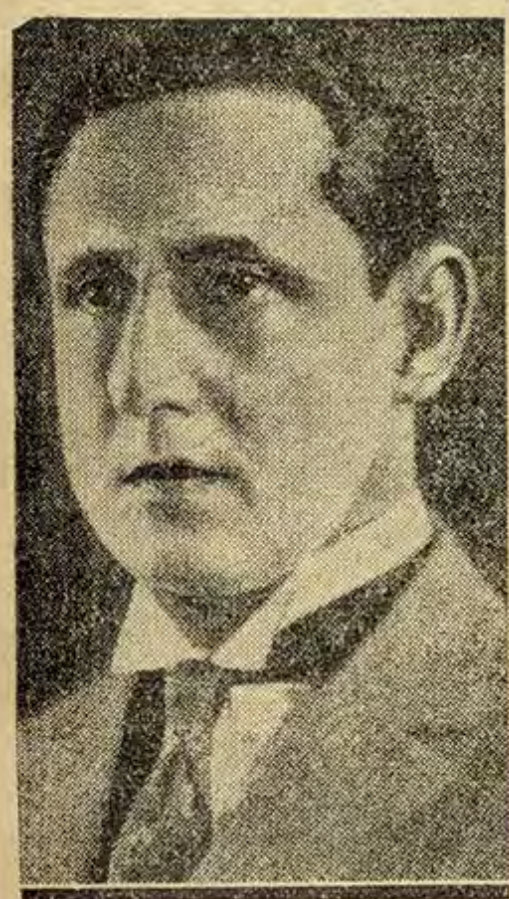

Sr. Guilherme Guinte

0 Centro Internacional de Lepro logia que vae ser installado em nosso paiz representa, inquestionavelmente, uma iniciativa de extraordinario relevo, cujos resultados interessam por egual a todos os povos. O problem da lepra tem constítuido, através do seculos, um problema gravissimo e uma preoccupaço permanente para o mundo scientifico. Pouco se tem conseguido, por emquanto, no sentido da repressáo ao mal de Hansen, dada precariedade dos processos preventidade continua desse, modo, a propagar-se de maneira impressionante. Emprehende-se, agora, um largo plaEmprehende-se, agora, um largo plano de estudos e pesquisas scientificas, como jamais fora antes levado a
effeito, com a creacåo do Centro Ineffeito, com a creaçăo do Centro Internacional de Leprologia, cuja direeção foi confiada, merceidamente, ao sabio brasileiro, professor Carlos Chagas. Figura eminente, enja palavra é acatada no mundo inteiro, tem - professor Carlos Chagas, na direeção do Instituto de Manguinhos, augmentado consideravelmente o patrimonio scientifico que Oswaldo Cruz nos legou, realisando uma obra notavel que honra eleva a cultura notavel que honra e eleva a cultura
medica brasileira. Ninguem melhor do que elle poderia, portanto, ser indicado para o alto posto que lhe confiou instituto de Genebra Ouvido per pela NOITE, o professor Carlos Chagas accentuou a importancia da funprologia o definiu os seus objectivos. A lepra no Brasil e no mundo

- 0 Centro Internacional de Leprologia - declara o entrovistado tem alta finalidade medico-social e autorisa, no programma de trabalhos que vae realisar, largas perspectivas de aperfeiçoamento technico nos dominios da medicina preventiva.

Duas razōes primordiaes fundamentam essa iniciativa e tornam digna de encomios a decisăo do governo brasileiro $\mathrm{Em}$ primeiro logar, a importancia maxima do problema da le pora, ño so para o nosso paiz, náo só pra, ná so para o nosso paiz, nắo só para o continente americano, senáo ainda para o mundo inteiro; $\mathrm{em}$ segundo logar, e como razá tambem ponderavel, as numerosas ineognitas que perduram nesse capitulo da pathologia humana, e difficuitam as providencias sanitarias e impossibilitam n exito definitivo do methodo prophylactico.

Nảo ficamos Iongo da verdade apreciando em 30 mil a cifrs de leprosos de Brasil e em 120.000 o numero desses infelizes, sb me continente sul-americano $B$ nas. Indias Inglezas existem mais de um millhão e 500 mil leprosos, no Japáo approximadamente 20 mì e Indias Hollandexas, nas colonias tropicaes de diversas naçóes da Europa, em vastas regióes do Extremo Oriente, é elevado o indice endemico. Mais ó que o contagio, embnra de modo iento, vae sempre se diffundindo, como $\&$ evidencia o ausmento prozressivo de enfermos, com o spparecimento de novos f $8 \mathrm{cos}$, entro nós, na Republica Argentina, na Colombia Republica Arcentina, na coutormbia em outros paizes. Por outro lado, aproveitados na lith contra esse dinença os processos actuaes de prevençáo. ermesmo applicatios com o maximo do conseguidos.

Os processos de combate

- O isolamento em leprosarios, ou n segrezacão de leprosos em colonias a segresaça de lejer sistencia medico-social, de accordo com as exigencias da technica moderua com os sentimentos de piedade, esse isolamento, de certo a medida de maior efficacia absolutamente indispensavel em qualquer paiz civilisado, onde (CONTINUA NOUTRO LOCAL) 

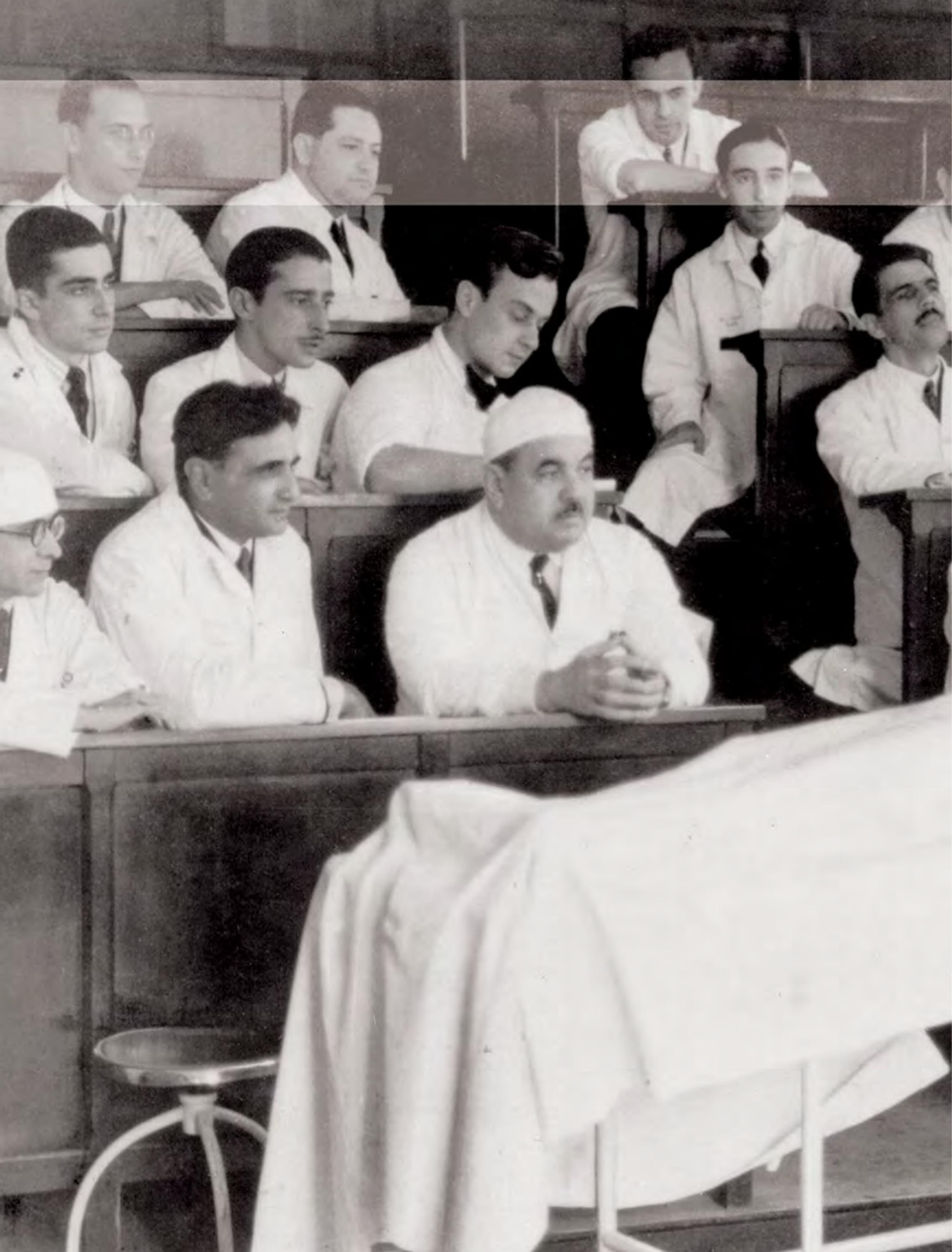


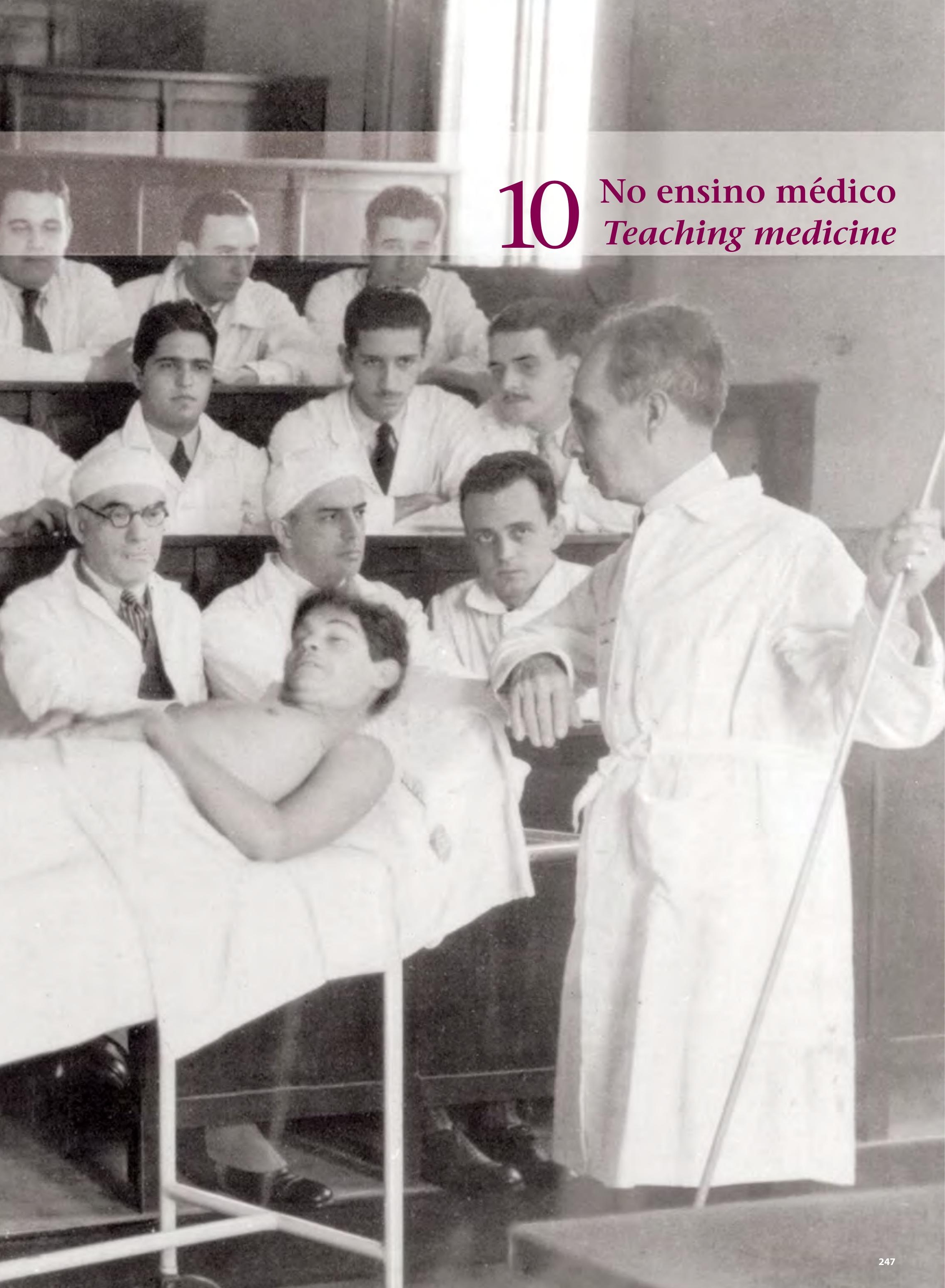


atuação de Carlos Chagas como professor teve início no Curso de Aplicação do Instituto Oswaldo A cruz, onde desde princípios da década de 1910 dava aulas de protozoologia.

Em 1925, ele foi nomeado primeiro titular da cátedra de medicina tropical da Faculdade de Medicina da Universidade do Rio de Janeiro, disciplina criada como parte da reforma do ensino superior implementada na ocasião. O curso era regido pela direção de Manguinhos, que decidia sobre a nomeação de professores, questões regimentais e conteúdos das aulas. Para abrigar a cátedra, foi construído, aos fundos do Hospital São Francisco de Assis, o Pavilhão de Doenças Tropicais (atual Pavilhão Carlos Chagas).

De acordo com Carlos Chagas Filho (1910-2000), as aulas de seu pai conjugavam a explanação teórica e a observação clínica de doentes, e eram subsidiadas por farto material expositivo trazido de Manguinhos. Ao seu término, os alunos percorriam as enfermarias, em companhia do professor, para aprofundar o aprendizado.

Chagas atuou no ensino médico também como membro eleito do Conselho Técnico-Científico da Faculdade. Em 1931, quando o ministro da Educação e Saúde Francisco Campos (1891-1968) deu início à reforma universitária que levaria, em 1935, à criação da Universidade do Brasil, ele formulou um projeto destinado a remodelar o ensino médico.

Chagas procurava mobilizar as futuras geraçoes para as bandeiras que defendia como cientista. Preconizava que o ensino médico deveria estar estreitamente associado à pesquisa científica. "Ensinar pesquisando e pesquisar ensinando", enfatizava em suas aulas. Além disso, afirmava que os estudantes deveriam prepararse para lidar não apenas com as doenças mais comuns nos consultórios das grandes cidades, mas também com "o mais relevante de nossos problemas médico-sociais": as enfermidades do interior.

Em sua aula inaugural de medicina tropical, em setembro de 1926, justificou a criação da especialidade à qual se haviam oposto muitos médicos desde o início do século XX - não apenas pela necessidade de se acompanhar os avanços nesse campo no cenário internacional. Tratava-se, sobretudo, de uma disciplina voltada para o estudo das "doenças do Brasil". 
arlos Chagas's first experience as a professor began in the 1910s, when he started teaching protozoology

at the Oswaldo Cruz Institute's program of specialization courses.

In 1925, he was named the first chair of the new tropical medicine course established at the University of Rio de Janeiro's School of Medicine as part of the higher education reform then taking place. It was administrated by the Manguinhos Institute, which made decisions regarding the appointment of professors, matters of guidelines and procedures, and class content. The course was housed in the Tropical Disease Pavilion, built behind São Francisco de Assis Hospital especially for this purpose and later renamed the Carlos Chagas Pavilion.

According to Carlos Chagas Filho (1910-2000), as a teacher his father combined theoretical explanations with clinical observations of patients, along with regular presentations of material from Manguinhos. At the end of the classes, students further broadened their learning by visiting infirmaries in the company of their professor.

Chagas was likewise involved in medical teaching as an elected member of the School's Technical and Scientific Council. In 1931, when Education and Health Minister Francisco Campos (1891-1968) rolled out the university reform that led to the 1935 creation of the University of Brazil, Chagas designed a project that was meant to reshape medical teaching.

Chagas endeavored to win future generations over to the ideas he defended as a scientist. He advocated a tight link between medical teaching and scientific research. In class he always emphasized: "Teach through research and research through teaching." Furthermore, he felt students should be prepared to deal not just with the most common illnesses encountered in their urban practices but also with Brazil's "foremost medical and social problems," that is, rural diseases.

In his inaugural lecture on tropical medicine, in September 1926, Chagas defended the establishment of the specialty, something many physicians had opposed since the early twentieth century. He not only wanted to keep step with international advances in the field but above all saw this discipline as focused on the study of the "diseases of Brazil." 


\section{E não vai demorar que} passemos adiante (...) o alto escopo de uma grande ciência, de uma grande e bela ciência, que se faz arte na defesa da vida.

Carlos Chagas

And it will not be long before we pass along (...) the vast scope of a great science, of a great and beautiful science, which becomes art in the defense of life.

Carlos Chagas

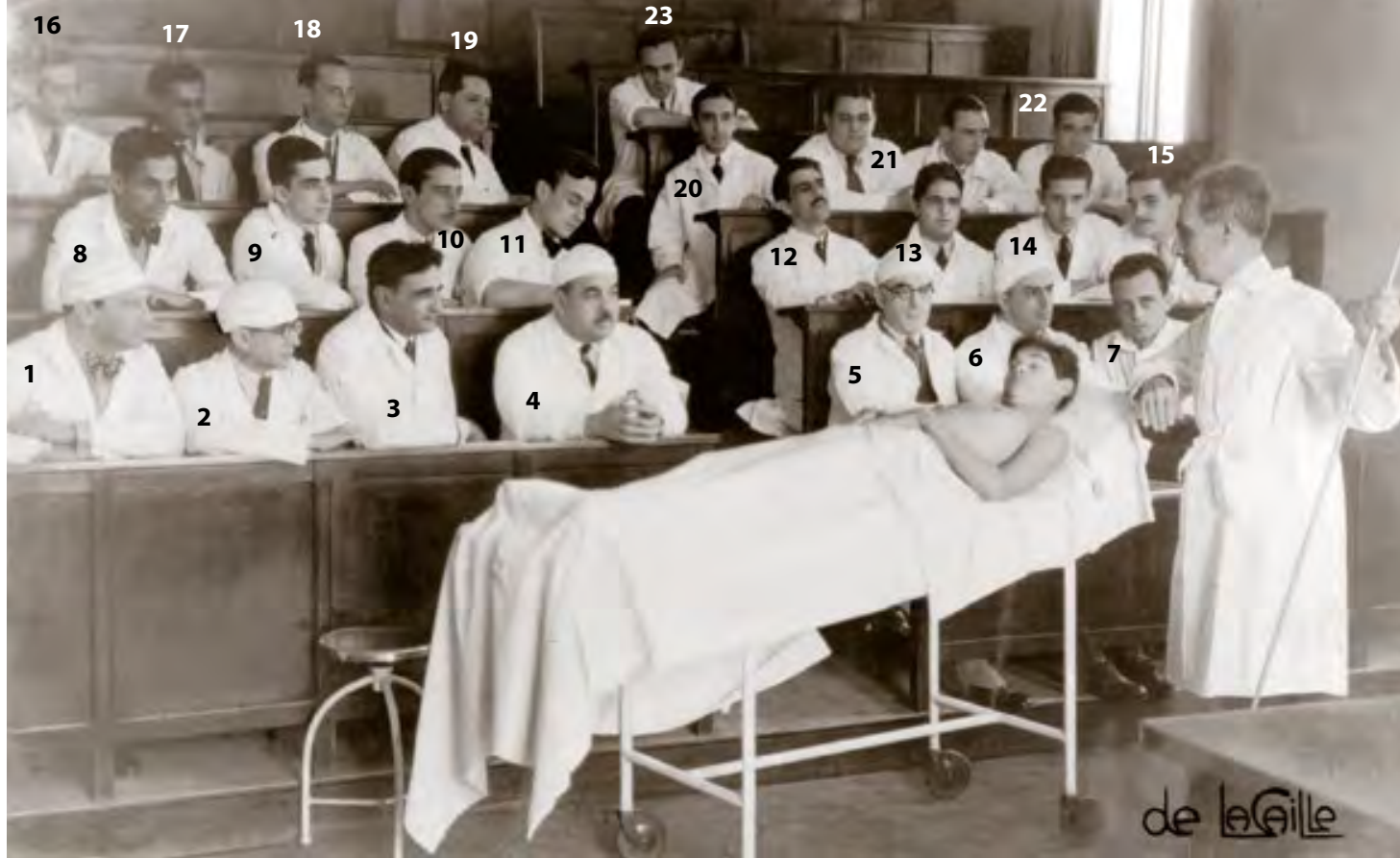

Imagem de abertura - Aula no Pavilhão de Doenças Tropicais da Faculdade de Medicina da Universidade do Rio de Janeiro, 1930

1 - Genserico de Souza Pinto; 2 - Thompson Motta; 3 - Lafayete de Freitas; 4 - Hebster Pereira;

5 - Raul de Almeida Magalhães; 6 - Carlos Bastos de Magarinos Torres; 7 - Evandro Chagas; 8 - Oswaldo Dias;

9 - Paulo César Azevedo; 10 - Aristides Paz de Almeida; 11 - Carlos Chagas Filho; 12 - Eurico Villela;

13 - Lincoln de Freitas Filho; 14 - Almir Castro; 15 - Alfredo Pereira Braga; 16 - Nelson Douat;

17 - Alfredo Norberto Bica; 18 - Pompeu Roças; 19 - Heraldo Maciel; 20 - José de Castro Teixeira;

21 - Maurício Hebster Pereira; 22 - Edmundo Martins; 23 - Vicente de Paulo Mellilo

Foto De Lacaille

Acervo Casa de Oswaldo Cruz

Opening image - Class at the Tropical Diseases Pavilion, University of Rio de Janeiro's School of Medicine, 1930

Photograph by De Lacaille

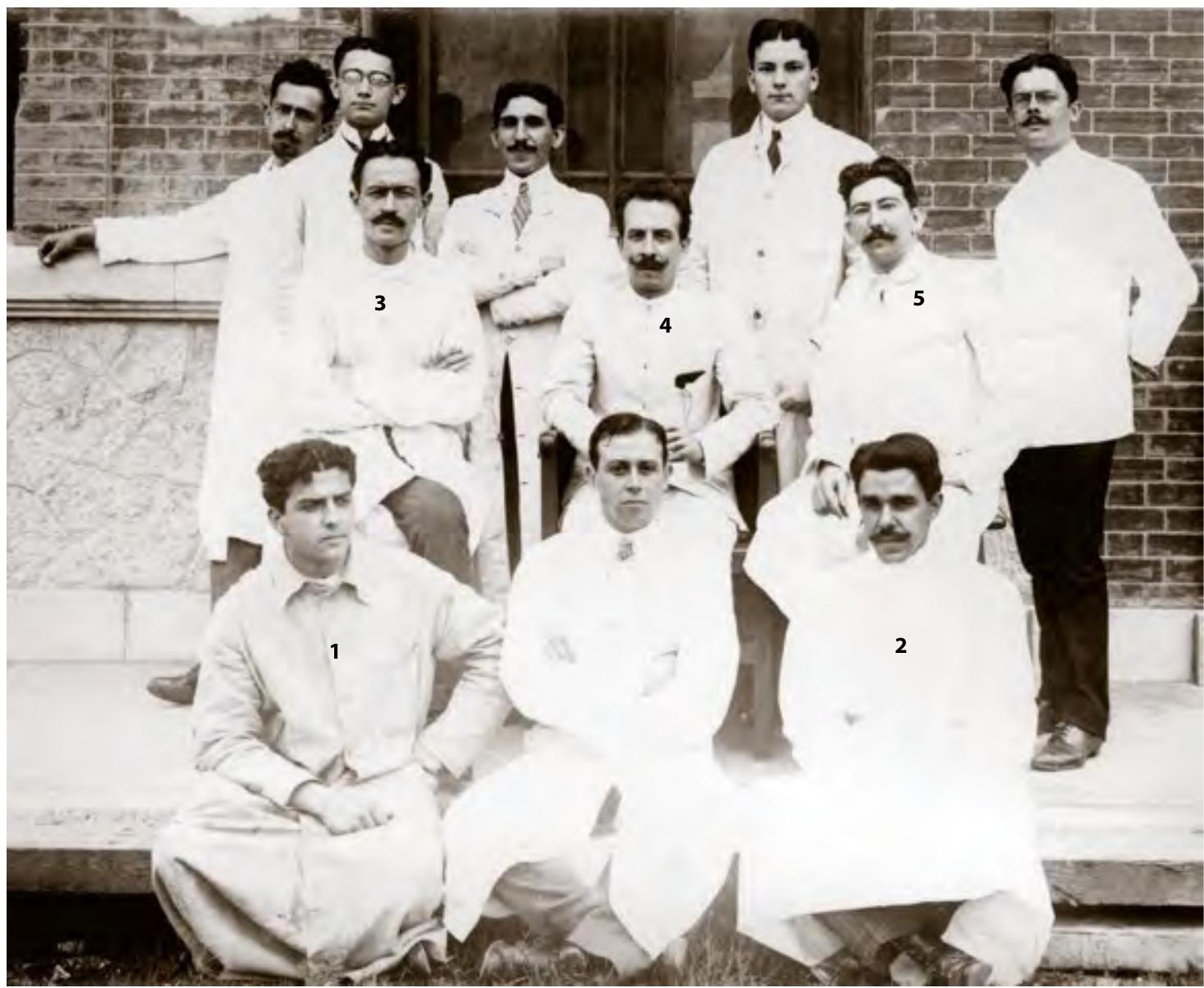

Chagas com alunos e professores do Curso de Aplicação do Instituto Oswaldo Cruz, em 1911

1 - Carlos Bastos de Magarinos Torres; 2 - Eurico Villela;

3 - José Gomes de Faria; 4 - Carlos Chagas; 5 - Paulo Parreiras Horta Acervo Casa de Oswaldo Cruz

Chagas with students and professors from the Oswaldo Cruz Institute's program of specialization courses in microbiology and medical zoology, 1911 

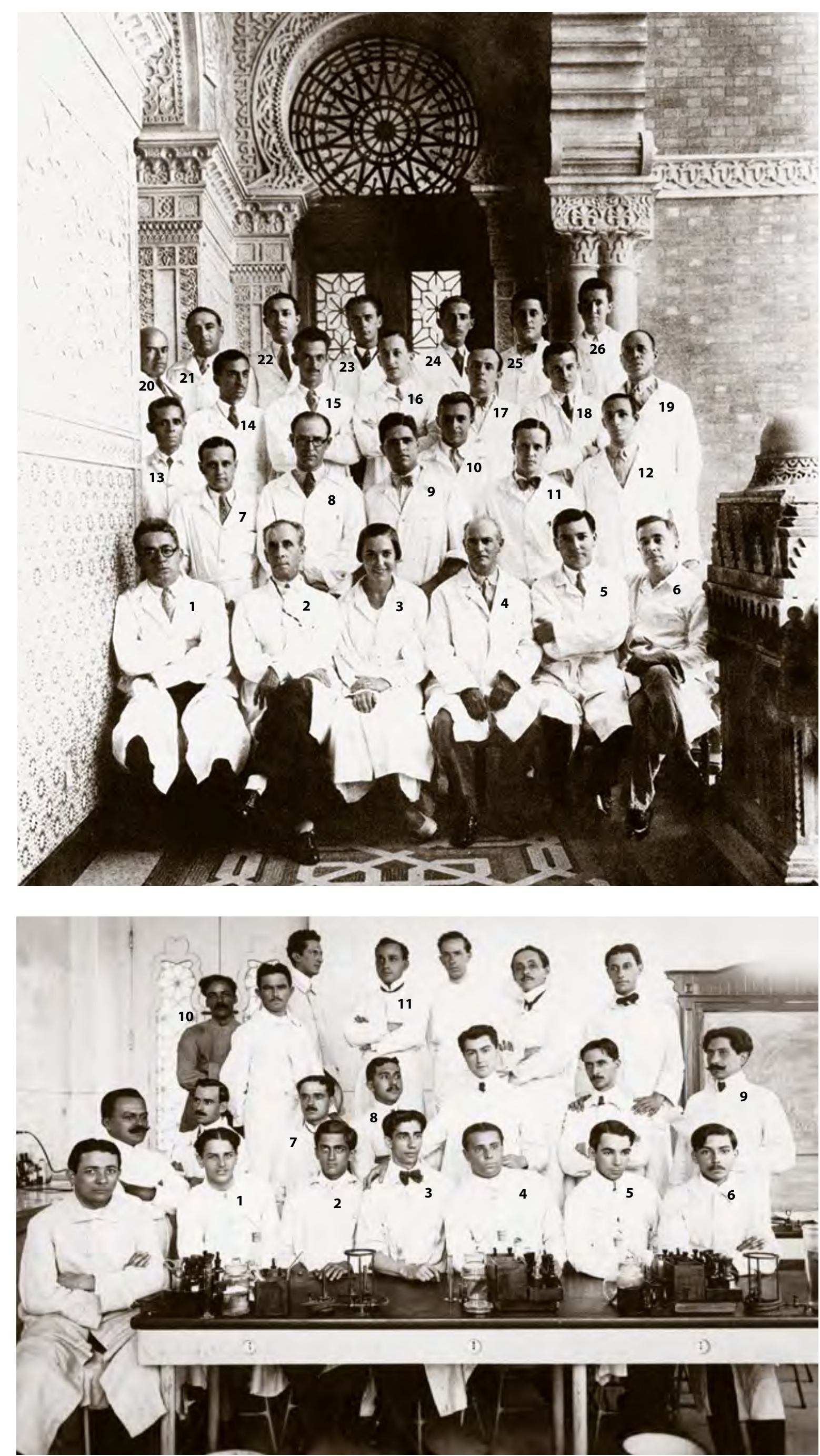

Chagas com a turma de 1932 do Curso de Aplicação do Instituto Oswaldo Cruz

1 - Julio Muniz;

2 - Carlos Chagas;

3 - Silvia Hasselmann;

4 - Antonio Cardoso Fontes:

5 - Olympio da Fonseca Filho;

6 - Angelo da Costa Lima;

7 - Renato Dias da Silva;

8 - Isaías Leite de Oliveira;

9 - Lincoln de Freitas Filho;

10 - Benedictus Mauro Mourão;

11 - Oswaldo Attino Doria;

12 - Alcides Figueiredo da Silva Jardim;

13 - Cecílio Silva;

14 - Walter Oswaldo Cruz;

15 - Emmanuel Dias;

16 - Herman Lent;

17 - Adalberto Severo

18 - Orlando Pena Ferreira;

19 - Aldemar Alves de Carvalho;

20 - Fábio Leone Werneck;

21 - Aulo Fiúza de Cerqueira;

22 - João Ferreira Teixeira;

23 - João Firmino Schons;

24 - Aristides Paz de Almeida;

25 - Humberto Monteiro;

26 - José Acylino de Lima Filho

Acervo Casa de Oswaldo Cruz

Chagas with the 1932 class of

the Oswaldo Cruz Institute's

specialization courses in microbiology and medical zoology
Alunos do Curso de Aplicação do Instituto Oswaldo Cruz, C. 1913

1 - Joaquim Vidal; 2 - Bento

Oswaldo Cruz; 3 - Antonio Luiz Cavalcante de Barros Barreto; 4 - Carlos Burle de Figueiredo; 5 - Cássio Miranda; 6 - Olympio da Fonseca Filho; 7 - Florêncio Gomes; 8 - Mário Dutra e Silva; 9 - João Tavares; 10 - Raymundo Paes; 11 - Pereira Filho Acervo Casa de Oswaldo Cruz Students from the Oswaldo Cruz Institute's specialization courses in microbiology and medical zoology, c. 1913 


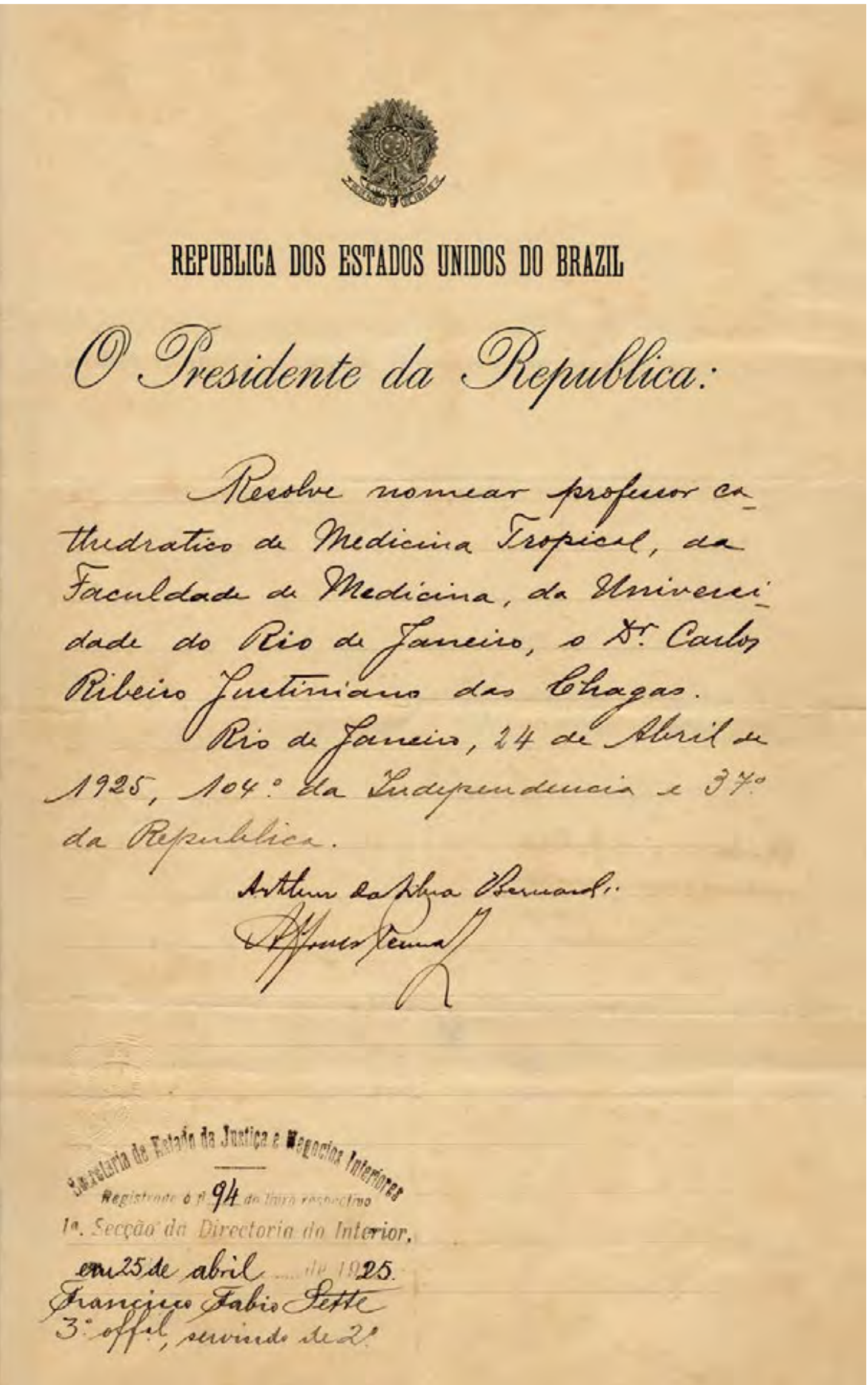

Nomeação para professor catedrático de medicina tropical da Faculdade de

Medicina da Universidade do Rio de

Janeiro, 24 abr. 1925

Acervo Casa de Oswaldo Cruz

Appointment as chair of tropical

medicine at the University of

Rio de Janeiro's School of Medicine,

Apr. 24, 1925 


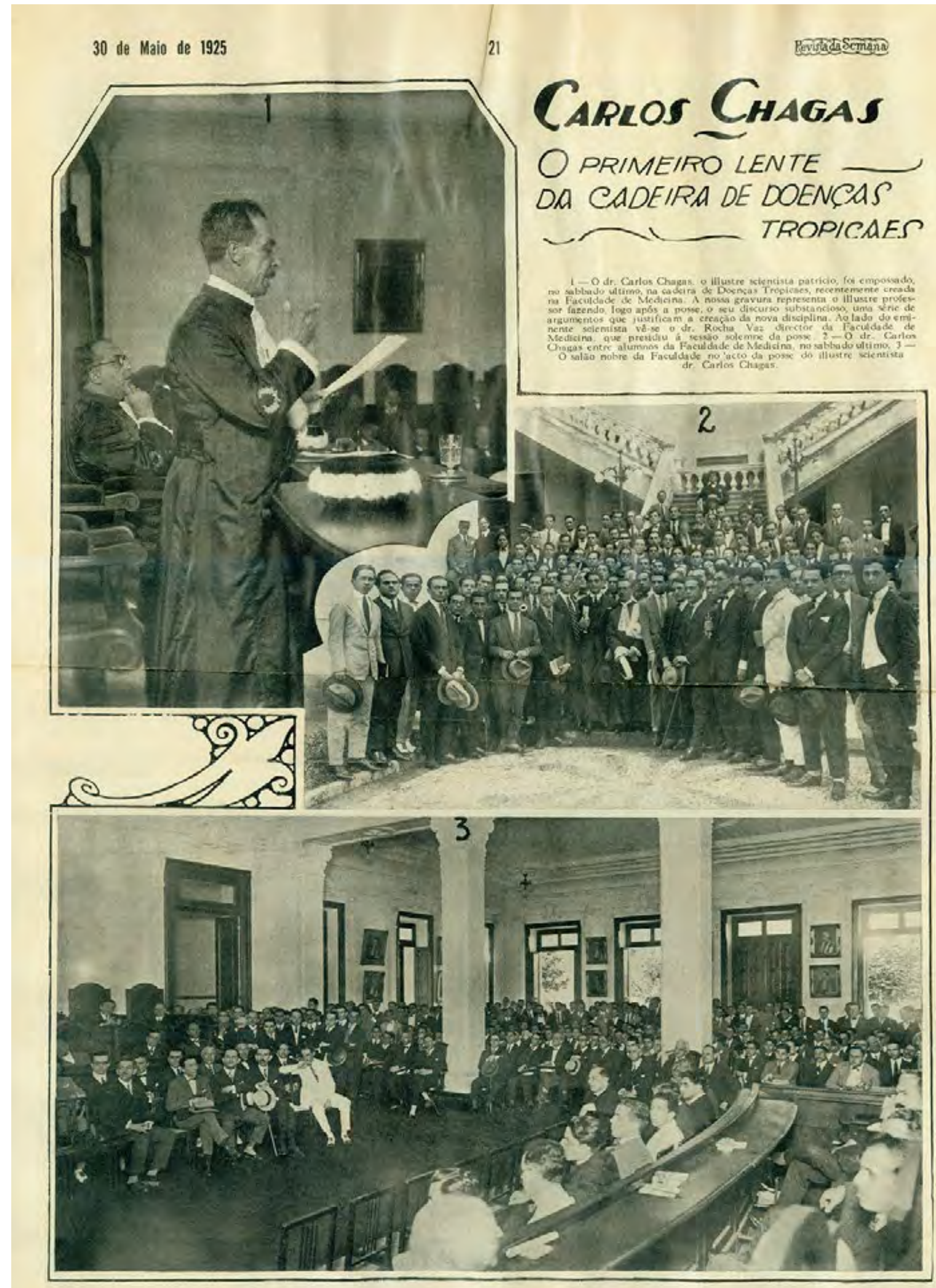

Carlos Chagas, o primeiro lente da

Acervo Casa de Oswaldo Cruz

"Carlos Chagas, first chair of tropical diseases"

Revista da Semana, May 30, 1925 


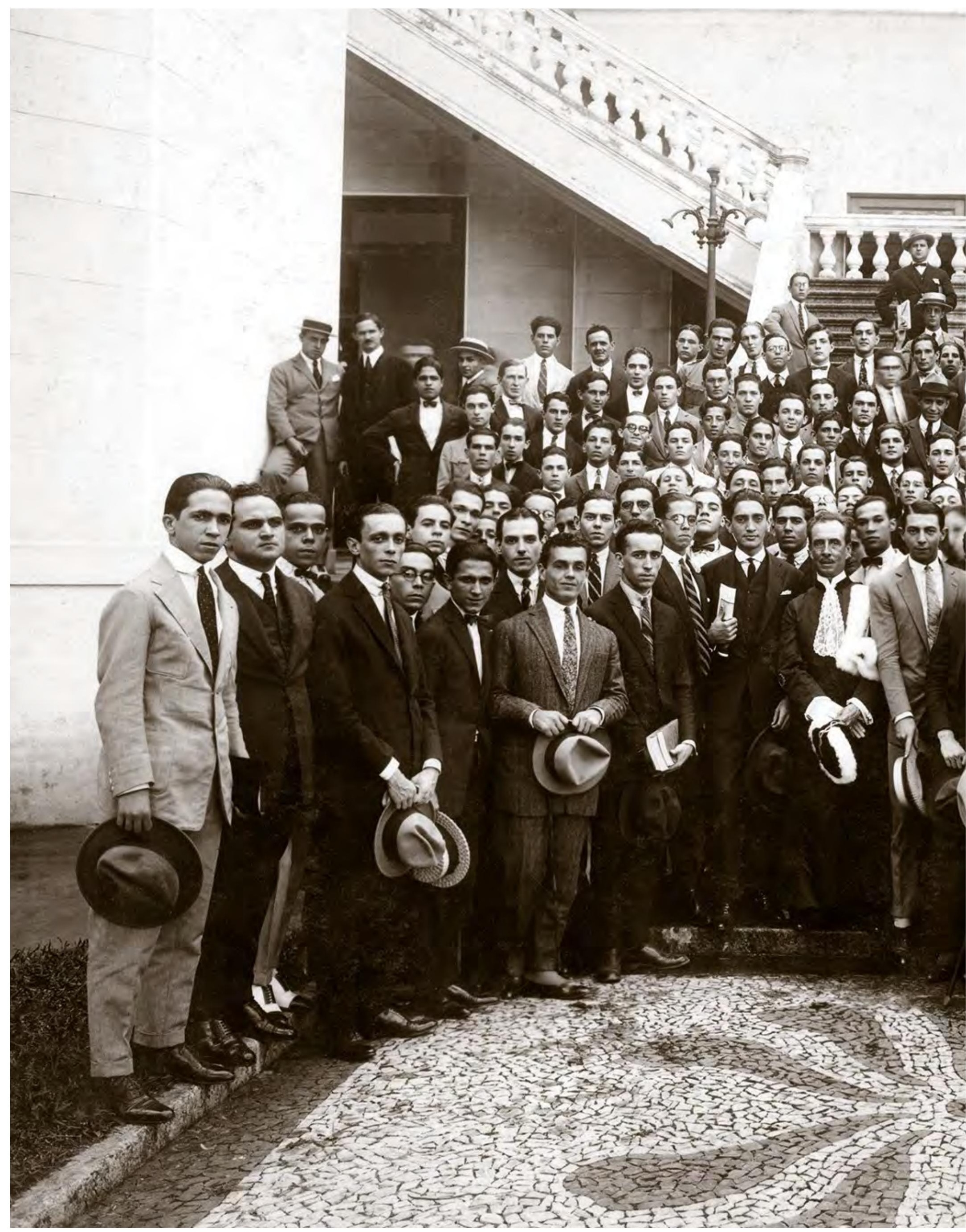




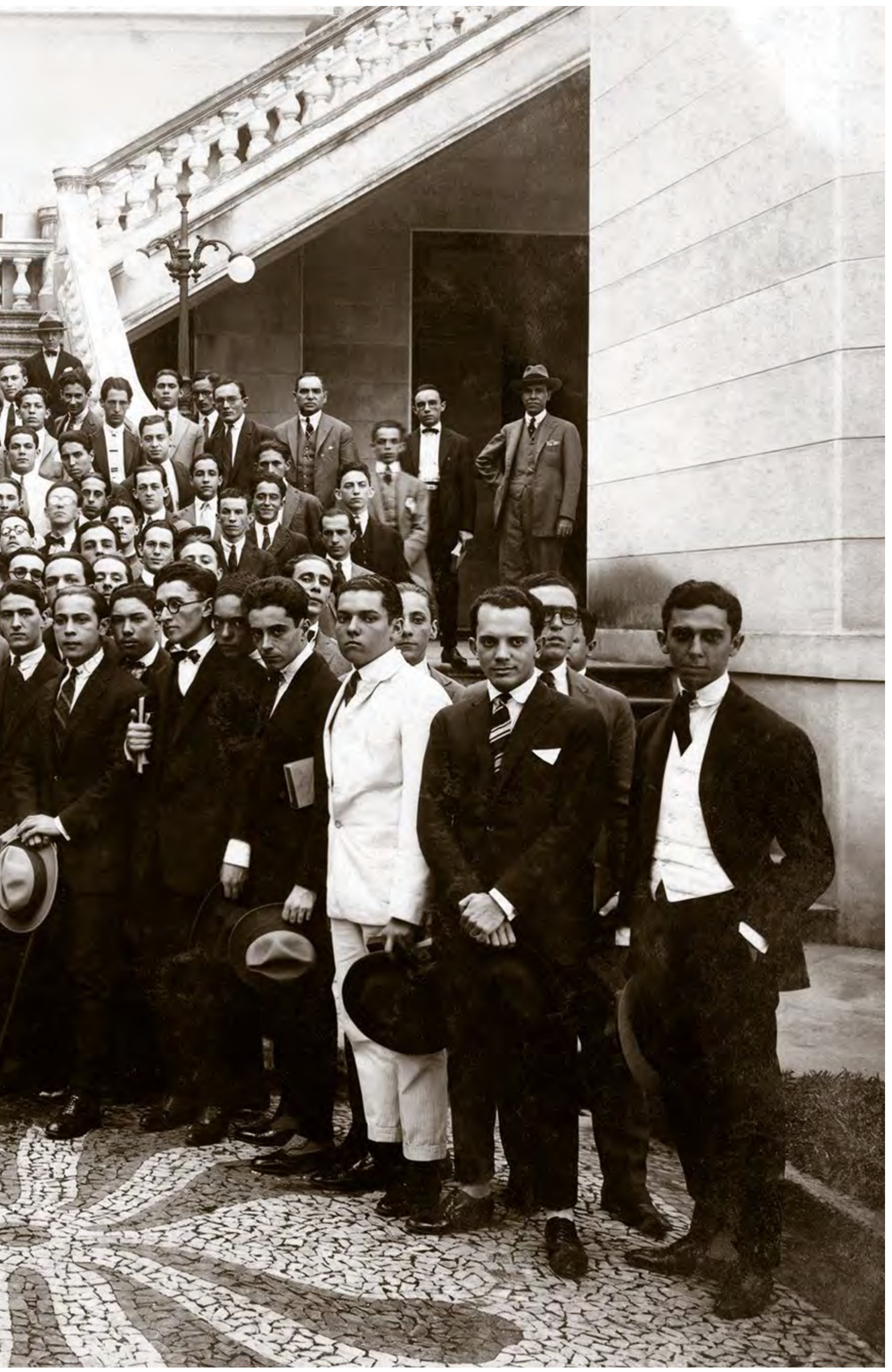

Chagas por ocasião de sua posse como professo catedrático

do curso de medicina tropical na Faculdade de Medicina. Rio de Janeiro, 23 maio 1925 Acervo Casa de Oswaldo Cruz Chagas takes office as chair of the tropical medicine course at the School of Medicine. Rio de Janeiro, May 23, 1925 
Vivemos, Srs. estudantes, num país de clima tropical e inter-tropical, e é por isso que os destinos de nossa Terra, a sua grandeza e a felicidade de sua gente não prescindem dos benefícios de vossa ação profissional, que se vai exercitar nesse vasto território sem limites, para povoá-lo e enriquecê-lo. Atentai bem nessa missão de patriotismo e estudai com esforço a doença do Brasil.

Carlos Chagas

Esteemed students, we live in a country with a tropical and intertropical climate, and this is why the fate of our Land, its grandeur, and the happiness of its people cannot forego the benefits of your professional action, which shall be put in practice across this vast, boundless territory in order to settle and enrich it. Pay utmost heed to this patriotic mission and study hard the diseases of Brazil.

Carlos Chagas

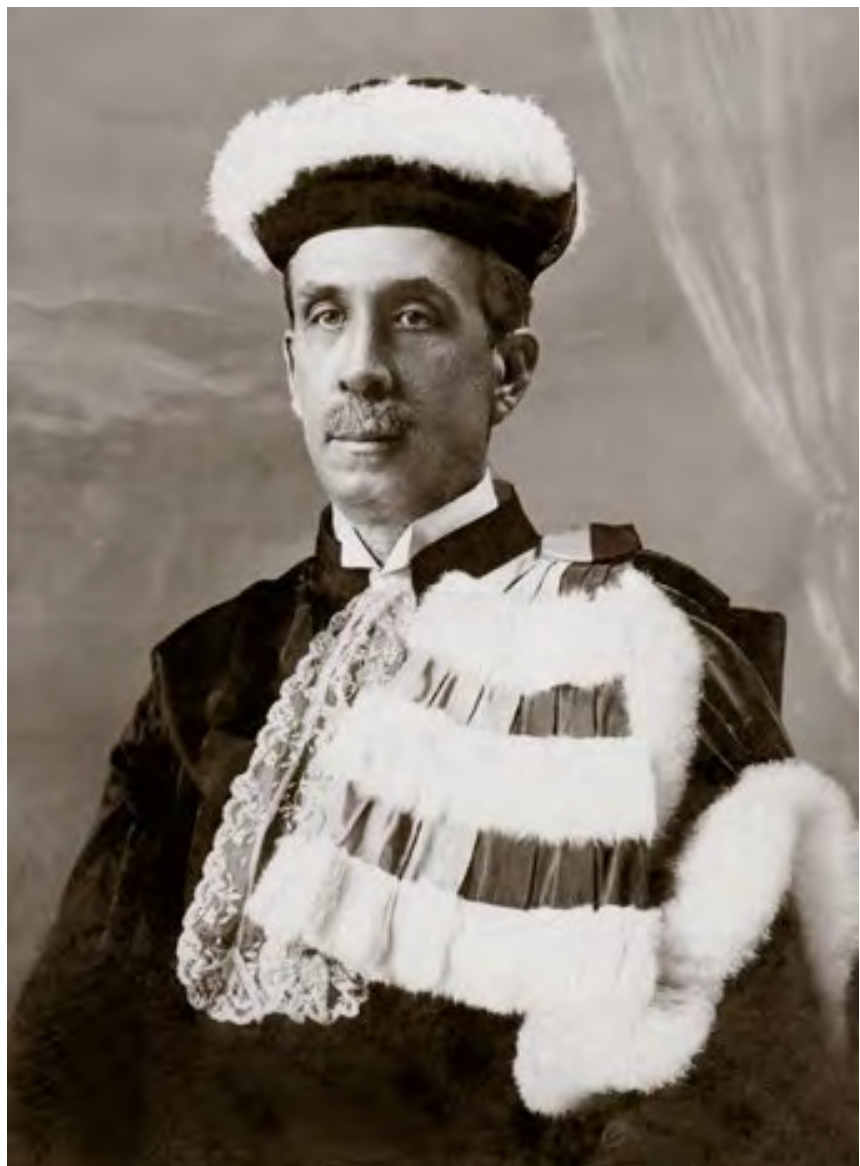

Com a beca de professor catedrático da Faculdade de Medicina da Universidade do Rio de Janeiro, em maio de 1925

Acervo Casa de Oswaldo Cruz

Wearing the toga of chair, niversity of Rio de Janeiro's

School of Medicine, May 1925

Publicação da aula inaugura da cadeira de medicina tropical na Faculdade de Medicina da Universidade do Rio de Janeiro em setembro de 1926 Acervo Casa de Oswaldo Cruz

Publication of Chagas's inaugural lecture as chair of tropical medicine at the University of Rio de Janeiro's School of Medicine in September 1926

\section{FACULDADE DE MEDICINA DO RIO DE JANEIRO}

C A D E IR A $-\mathrm{DE}-$

\section{Mealina Propical}

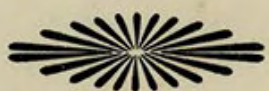

Aula inaugural do

Projessor Carlos Chagas, no Pavilhão

Miguel Couto,

a 14 de setembro de 1926. 


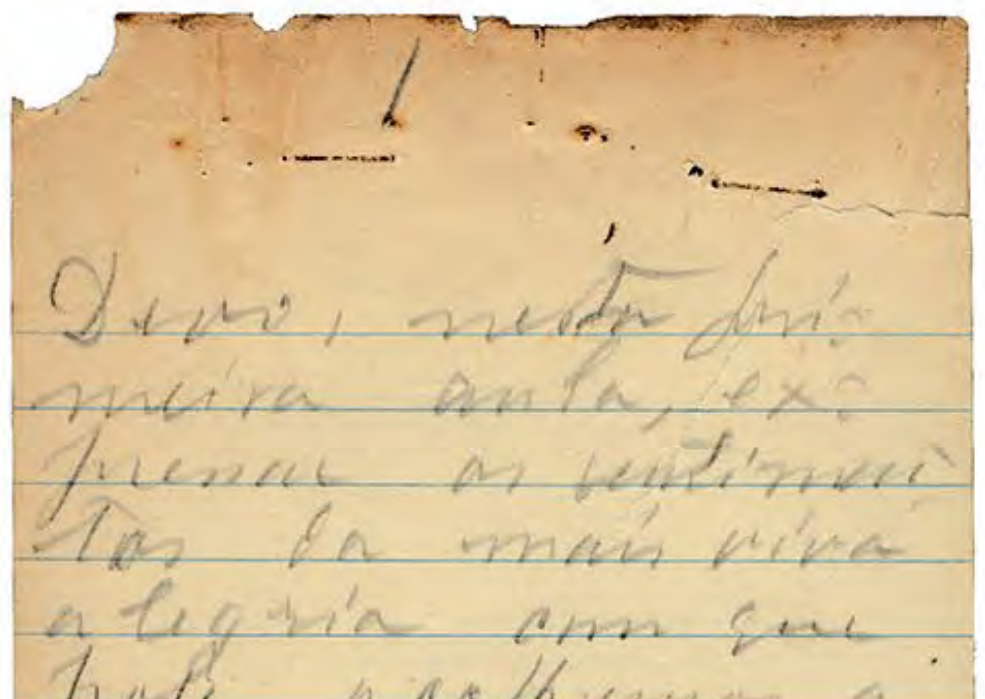

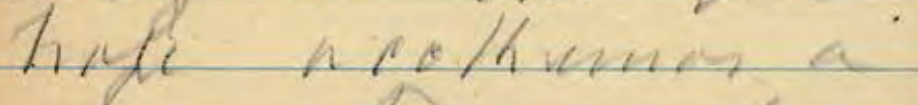

nurn Thime

alumas, chimen'

in pios, m mant

anvitimes e en, Ce

yon iver amplomes

Jin wivimin ko

जोik w nn amí

Giveferte nfores:

Rascunho de aula de Carlos Chagas

Acervo Casa de Oswaldo

Carlos Chagas's class

notes

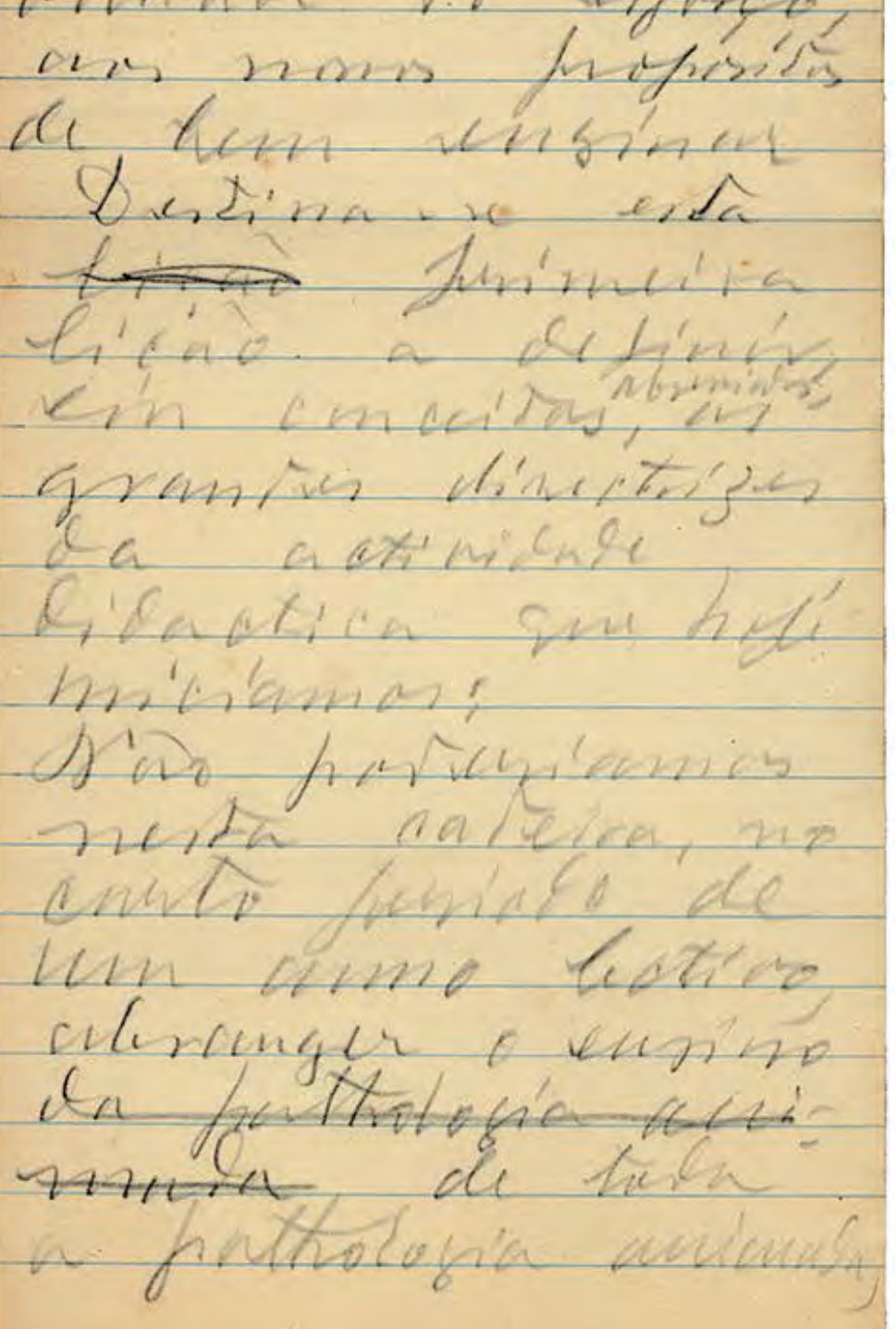

Meus senhores: as realizações práticas da higiene e da medicina tropicais vieram destruir o velho preconceito de uma fatalidade climática, que se traduzia na inadaptação das raças originárias dos países frios e temperados às regiões mais quentes da terra. O método científico vai dominando a doença nos trópicos, e assim desaparecem as restrições geográficas à vida sadia e à atividade humana, e desse modo se dilatam os domínios da civilização e do trabalho produtivo.

Carlos Chagas

Gentlemen: the practical achievements of tropical hygiene and medicine have done away with the old bias about climatic fatalism, which implied that races originating in cold and temperate countries could not adapt to the earth's warmest regions. Scientific method is conquering disease in the tropics, and so the geographic constraints on healthy living and human activity vanish, thereby expanding the realm of civilization and productive labor.

Carlos Chagas 


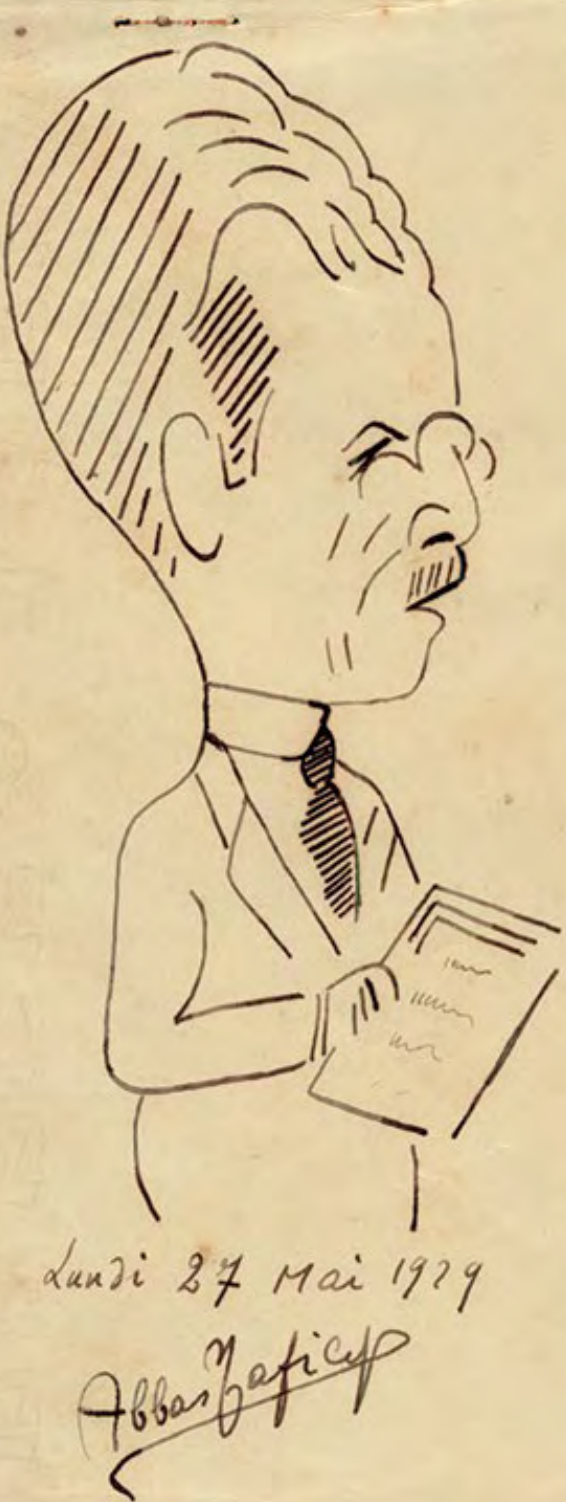

Caricatura de Chagas desenhada por

estudante iraniano durante conferência do cientista na Faculdade de Medicina de Paris em

27 de maio de 1929

Acervo Casa de Oswaldo Cruz

Caricature of Chagas drawn by an Iranian

student during the scientist's conference at

the Paris School of Medicine. May 27, 1929

Conselho Técnico da Faculdade de Medicina da Universidade do Rio de Janeiro, 1933

1 - Clementino Fraga; 2 - Fernando Magalhães;

3 - Miguel Couto; 4 - Carlos Chagas;

5 - Francisco Lafayette Rodrigues Pereira

6 - Eduardo Rabello; 7 - Martinho Guimarães;

8 - Raul Leitão da Cunha.

Acervo Casa de Oswaldo Cruz

Technical Council of the University of Rio de

Janeiro's School of Medicine, 1933

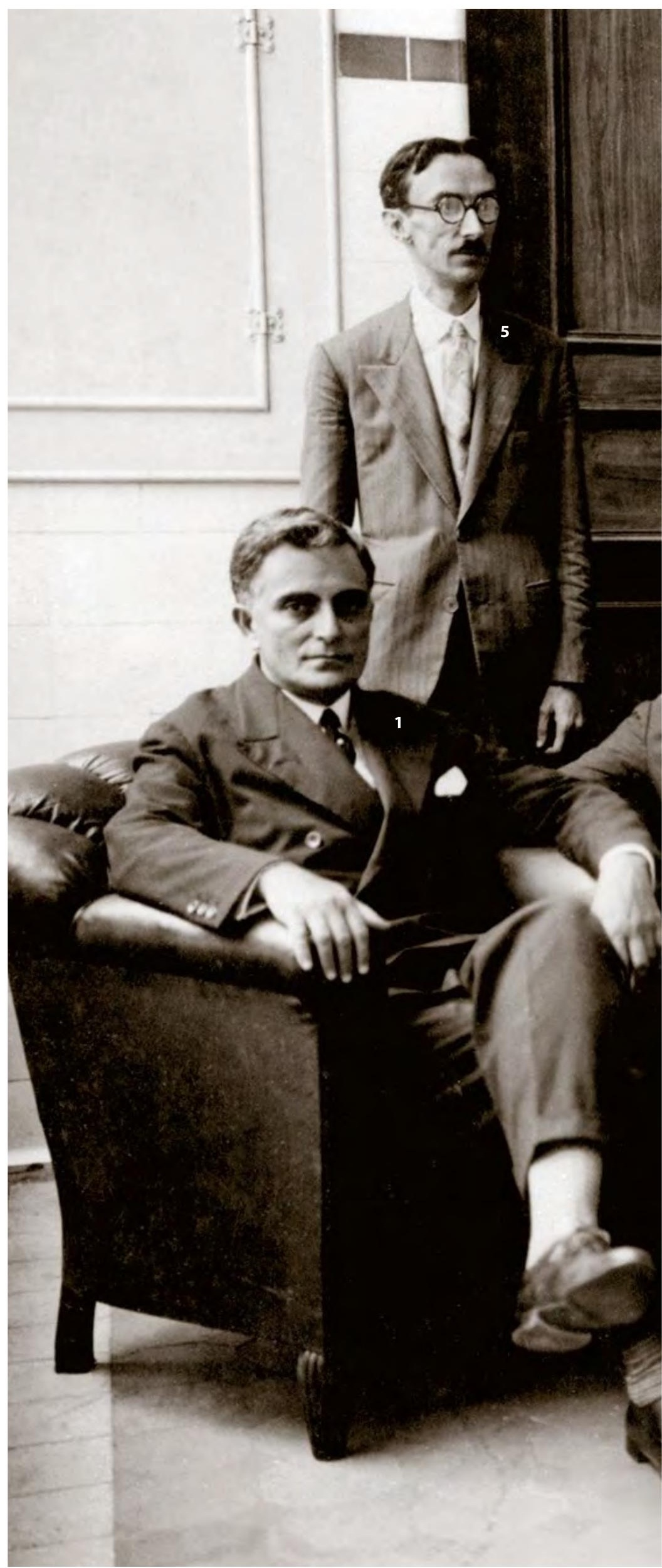




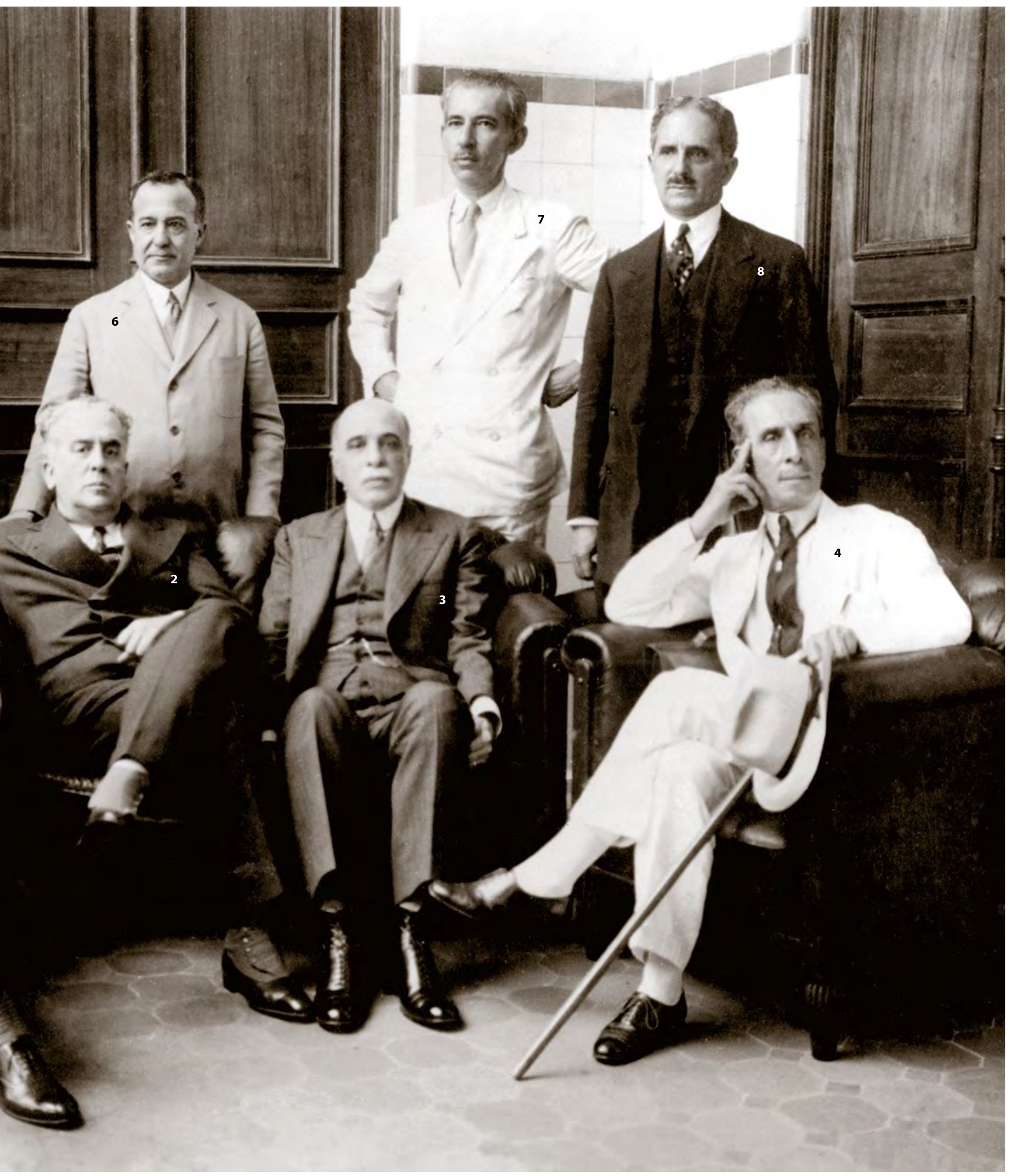




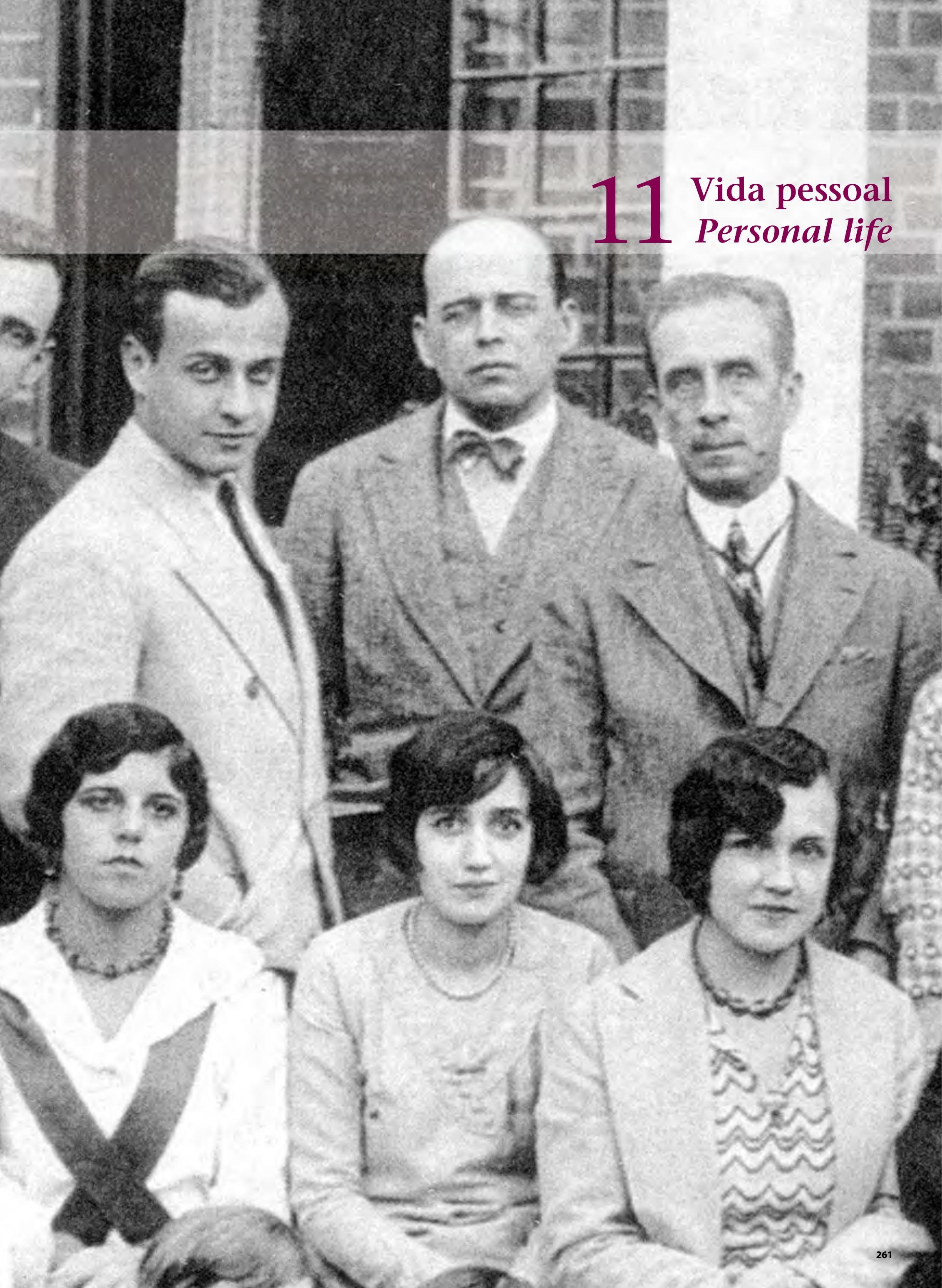


$\mathrm{C}$ arlos Chagas passou sua infância e adolescência dividido entre as fazendas de sua família em Oliveira e Juiz de Fora e as cidades onde realizou os seus estudos - Itu, São João del-Rei e Ouro Preto. Órfão de pai aos 4 anos, sua vida nesse período foi fortemente influenciada pela presença dos tios maternos e pela figura de sua mãe, Mariana Candida Ribeiro de Castro Chagas.

Em 1897, desembarcou no Rio de Janeiro para dar início ao curso na Faculdade de Medicina. Inicialmente foi morar em uma pensão na Tijuca, nas proximidades da casa de um primo, Augusto das Chagas, deputado federal por Minas Gerais. Dedicava praticamente todo o tempo aos estudos e ao trabalho com os professores nas enfermarias da Santa Casa de Misericórdia. Pouco saía de casa e mal conhecia os pontos turísticos da cidade. Essa rotina começaria, entretanto, a mudar no dia em que, levado por Miguel Couto a uma festa na casa do senador mineiro Fernando Lobo Leite Pereira, veio a conhecer aquela que seria sua futura esposa.

Iris Lobo, a mais velha entre muitos filhos, causou forte impressão no jovem estudante. Segundo relato do próprio Carlos Chagas, foi paixão à primeira vista. Os dois vieram a se casar no dia 23 de julho de 1904 e foram morar em uma pequena casa alugada na rua Voluntários da Pátria, em Botafogo. Aí nasceu Evandro Chagas, em 10 de agosto de 1905. Pouco tempo depois, a família mudou-se para uma residência mais ampla na avenida Izabel de Pinho, também em Botafogo. Nessa casa nasceu Carlos Chagas Filho, aos 12 de setembro de 1910. Maurício, o terceiro filho do casal, nascido em Juiz de Fora, morreria precocemente com apenas 1 mês de vida.

Da avenida Izabel de Pinho, Chagas transferiu-se para a rua Soares Cabral, em Laranjeiras, onde permaneceu por menos de um ano e meio. Foi então que adquiriu, em 1911, uma casa na rua Paissandu, bairro do Flamengo, onde viveria até a sua morte. Os tempos ali passados marcaram profundamente sua vida e a de toda a família.

Carlos Chagas gostava muito de música e promovia quase sempre animados saraus em sua casa. Era frequentador assíduo do Teatro Municipal, aonde ia assistir às óperas de sua predileção. Afora isso, não teve uma vida social muito intensa. Gostava de vestir-se elegantemente e tinha paixão pela caça, hábito provavelmente adquirido em Lassance. Interessava-se pelos debates ideológicos de seu tempo, mas nunca pretendeu ingressar na política. Manteve vivo, por certo, o gosto pela literatura e pelo estudo da língua portuguesa.

Chagas faleceu no dia 8 de novembro de 1934, aos 56 anos, vítima de problemas cardíacos. Chegou-se a especular na época que teria sido acometido pela forma cardíaca da tripanossomíase americana, o que não foi comprovado. Segundo Carlos Chagas Filho, o ritmo intenso de trabalho, acrescido do hábito de fumar, poderiam ter contribuído para fragilizar sua saúde. O cientista foi enterrado no Cemitério São João Batista, no Rio Janeiro, em meio a um cortejo que reuniu mais de mil pessoas, entre amigos, admiradores e anônimos. 
C arlos Chagas spent his childhood and teenage years on his family's farms in Oliveira and Juiz de Fora and in the cities where he studied - Itu, São João del-Rei, and Ouro Preto. After Chagas lost his father at the age of four, his life was greatly influenced by the presence of his maternal uncles and by his mother, Mariana Candida Ribeiro de Castro Chagas.

In 1897, he arrived in Rio de Janeiro to begin his studies at the School of Medicine. He first lived at a boardinghouse in Tijuca, near the home of his cousin Augusto das Chagas, a federal deputy for the state of Minas Gerais. He devoted almost all his time to his studies and to working with his professors at the Santa Casa de Misericórdia infirmaries. He went out little and barely saw any of the city's tourist attractions. But this routine started to change the day Miguel Couto took him to a party at the home of Minas Gerais Senator Fernando Lobo Leite Pereira, where he met the woman who would become his wife.

Iris Lobo, the oldest of a large family of children, made a marked impression on the young student. As Carlos Chagas himself used to tell it, it was love at first sight. They got married on July 23, 1904, and moved into a small rented house on Voluntários da Pátria Street in Botafogo. Then along came Evandro Chagas, born on August 10, 1905. A little while later, the family moved to a larger place, on Izabel de Pinho Avenue, likewise in Botafogo. Carlos Chagas Filho was born there on September 12, 1910. Maurício, the couple's third son, was born in Juiz de Fora but died when he was only one month old.

Chagas moved from Izabel de Pinho Avenue to Soares Cabral Street, in the neighborhood of Laranjeiras, where he stayed less than a year and a half. In 1911, he bought a house on Paissandu Street, in Flamengo, where he would live until his death. The days spent in this home left a deep mark on his life and his family's.

Carlos Chagas had a great appreciation for music and was always hosting lively evenings of music at his home. He could frequently be found in the audience at the Municipal Theater, where he would attend his favorite operas. Other than this, he did not lead a very busy social life. He enjoyed dressing elegantly and loved hunting, a taste he probably acquired in Lassance. He had an interest in the ideological debates of his time but never thought about going into politics. He always took pleasure in literature and the Portuguese language.

Chagas passed away from heart problems on November 8, 1934, at the age of 56 . There was some speculation back then that he had suffered from the cardiac form of American trypanosomiasis, but this was never proved. According to Carlos Chagas Filho, his father's heavy workload along with his smoking might have helped debilitate his health. The scientist's funeral at São João Batista Cemetery in Rio Janeiro was attended by over one thousand people, including friends, admirers, and the general public. 


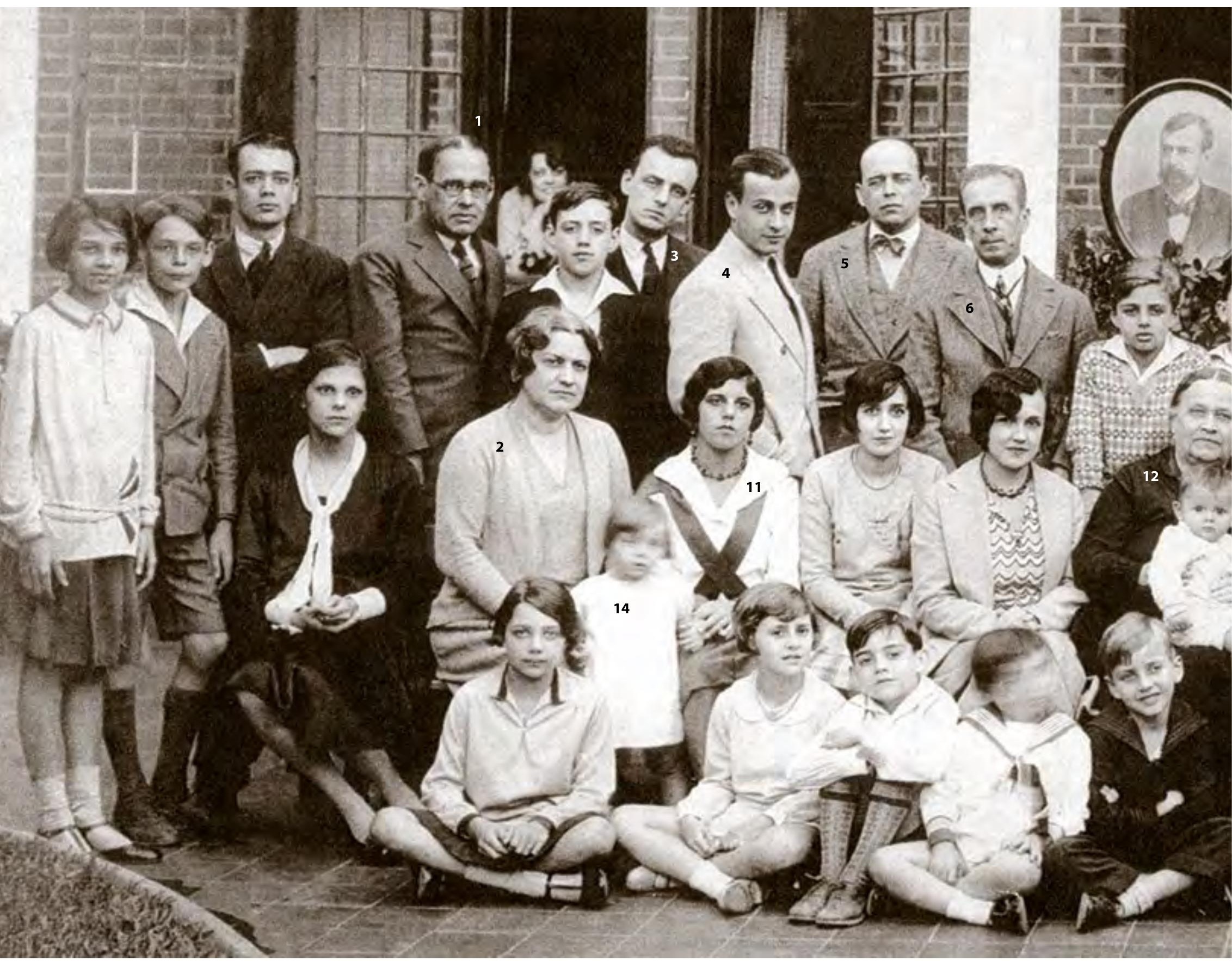

Família reunida em torno do retrato de Fernando Lobo Leite Pereira, sogro de Carlos Chagas, década de 1930. Entre os presentes, Asterio Lobo (1), irmão de Iris Lobo Chagas (2), esposa de Carlos Chagas; Evandro Chagas (3); Carlos Chagas Filho (4); Helio Lobo (5), irmão de Iris; Carlos Chagas (6); Fernando Lobo (7), irmão de Iris; Astrogildo Machado (8), pesquisador do Instituto Oswaldo Cruz e marido de Ruth Lobo (9), irmã de Iris; Orion Lobo (10), irmão de Iris; Maria da Graça F. Dutra (11), primeira esposa de Evandro Chagas; Maria Barroso (12), viúva de Fernando Lobo Leite Pereira; Aurora (13), irmã de Iris; Tatiana (14), filha de Evandro Chagas

Acervo Casa de Oswaldo Cruz

Family around a portrait of Fernando Lobo Leite Pereira, Carlos Chagas's father-in-law, 1930s. Among those present, Asterio Lobo (1), brother of Chagas's wife, Iris Lobo Chagas (2); Evandro Chagas (3); Carlos Chagas Filho (4); Iris's brother Helio Lobo (5); Carlos Chagas (6); Iris's brother Fernando Lobo (7); Astrogildo Machado (8), researcher at the Oswaldo Cruz Institute and husband to Iris's sister, Ruth Lobo (9); Iris's brother Orion Lobo (10); Maria da Graça F. Dutra (11), Evandro Chagas's first wife; Maria Barroso (12), widow of Fernando Lobo Leite Pereira; Iris's sister Aurora (13); Tatiana (14), Evandro Chagas's daughter

Casa na rua Voluntários da Pátria, 106, em Botafogo Acervo Casa de Oswaldo Cruz

House at 106 Voluntários da Pátria Street, in Botafogo

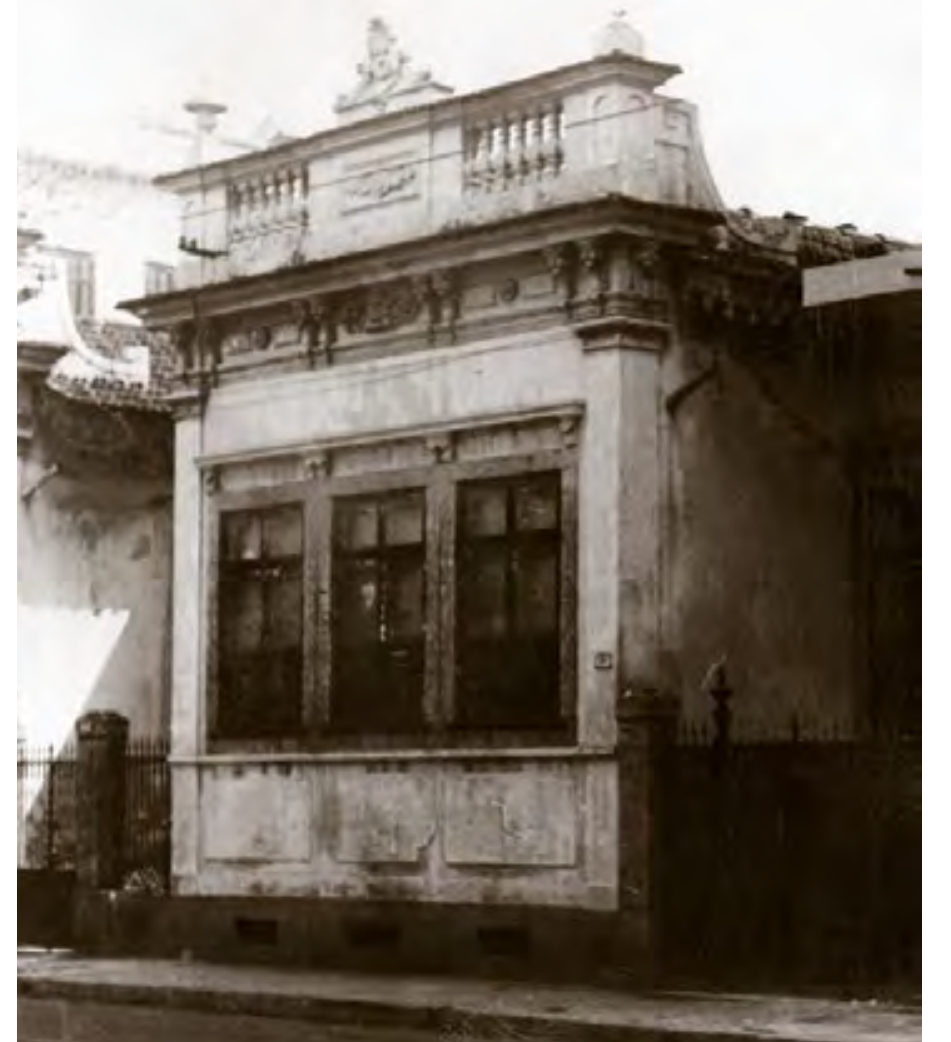



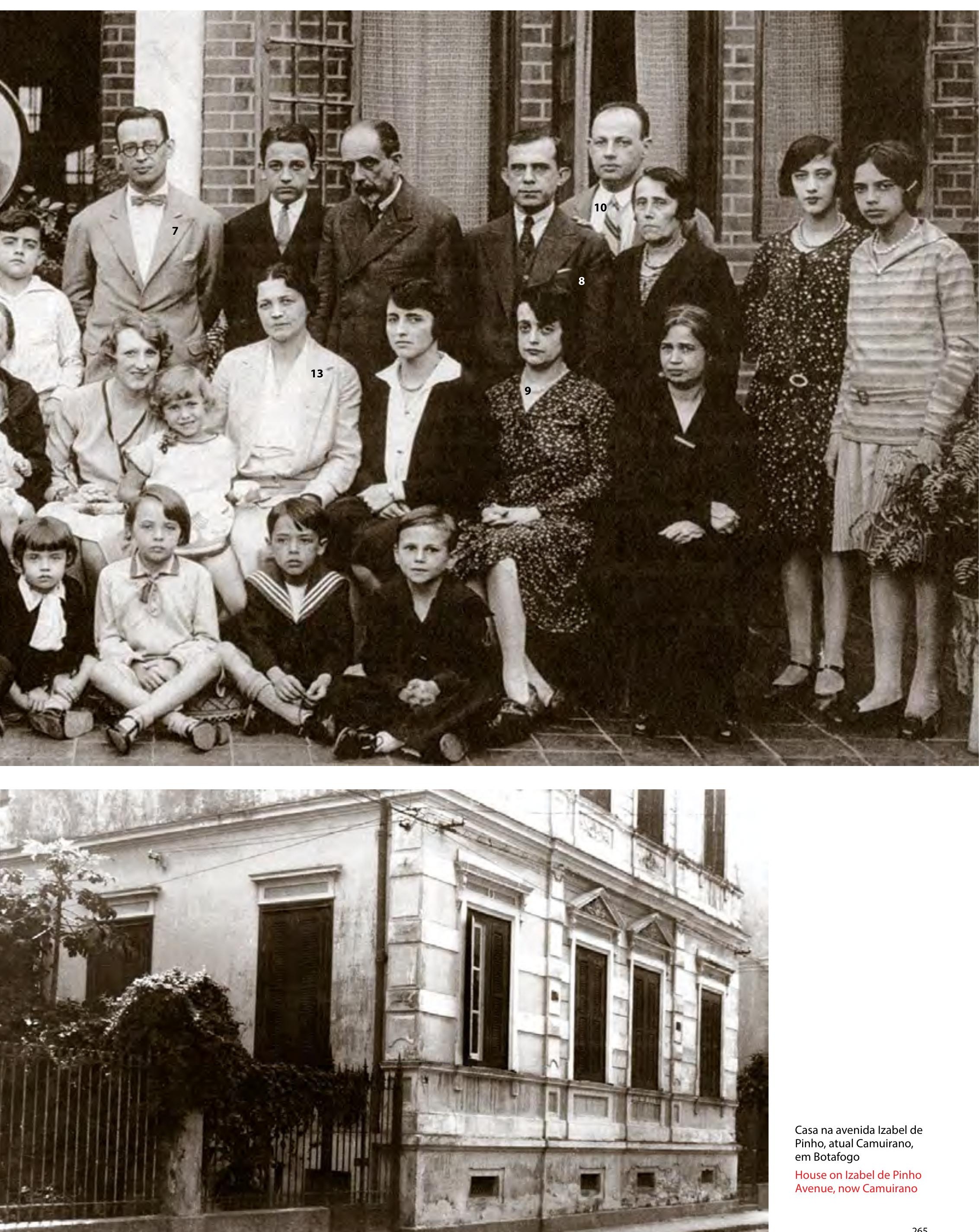

Casa na avenida Izabel de Pinho, atual Camuirano,

em Botafogo

House on Izabel de Pinho

Avenue, now Camuirano 
Paissandu 148! Como me lembro de todos os seus detalhes (...). Ouço ainda agora (...) os pregões e os sons então ouvidos, hoje substituídos pelas buzinas dos automóveis e o ranger dos pneumáticos sobre o asfalto. $O$ dia começava com o vendedor de leite. Vinham, depois, outros pregões matinais que iam pelo dia adentro. $O$ vozerio italianado do peixeiro, a voz pausada do mascate, sempre com uma pronúncia do Médio Oriente, o contínuo zunido do afiador de facas e tesouras, e assim por diante, até que, à noite, ouvia-se a campainha do sorveteiro avisando-nos da sua presença e dos seus sorvetes de frutas verdadeiras. Mais tarde, o apito do guarda-noturno, que anunciava a sua chegada.

Carlos Chagas Filho

148 Paissandu! How I remember all of its details (...). I can still hear (...) the street vendors' cries and the sounds heard back then, today replaced by car horns and tires squealing on the pavement. The day began with the milkman. Then came the shouts of other morning vendors, which continued through the day. The booming voice of the fishmonger with its traces of Italian, the rhythmic voice of the peddler, always with a Middle Eastern accent, the steady buzz of the man sharpening knives and scissors, and so on, until night, when you would hear the icecream man's bell, letting us know he was there, along with his ice-cream made from real fruit. Later on, the night watchman's whistle, announcing his arrival.

Carlos Chagas Filho

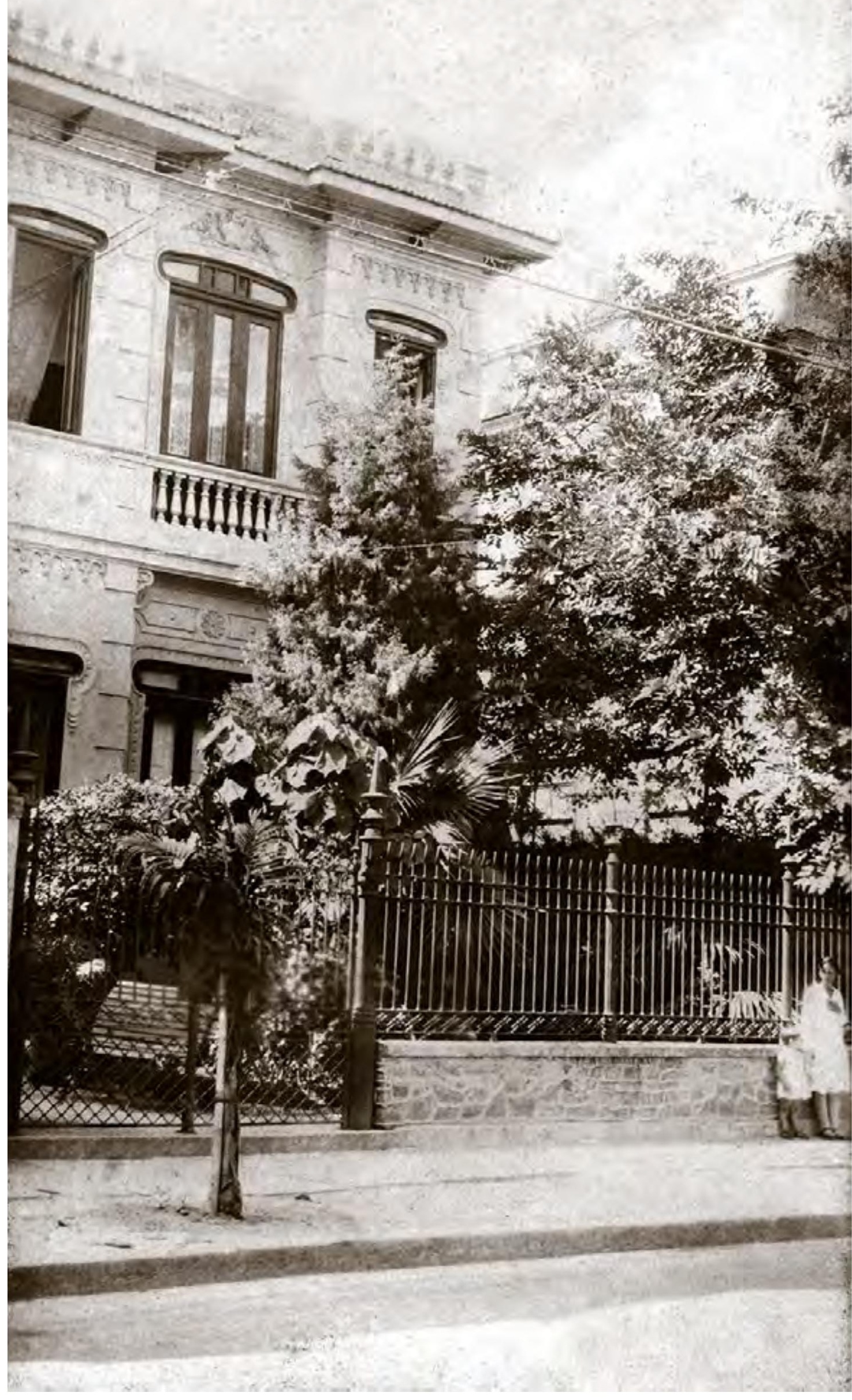

Casa na rua Paissandu, 148, no Flamengo Acervo Casa de Oswaldo Cruz

House at 148 Paissandu Street, in Flamengo 


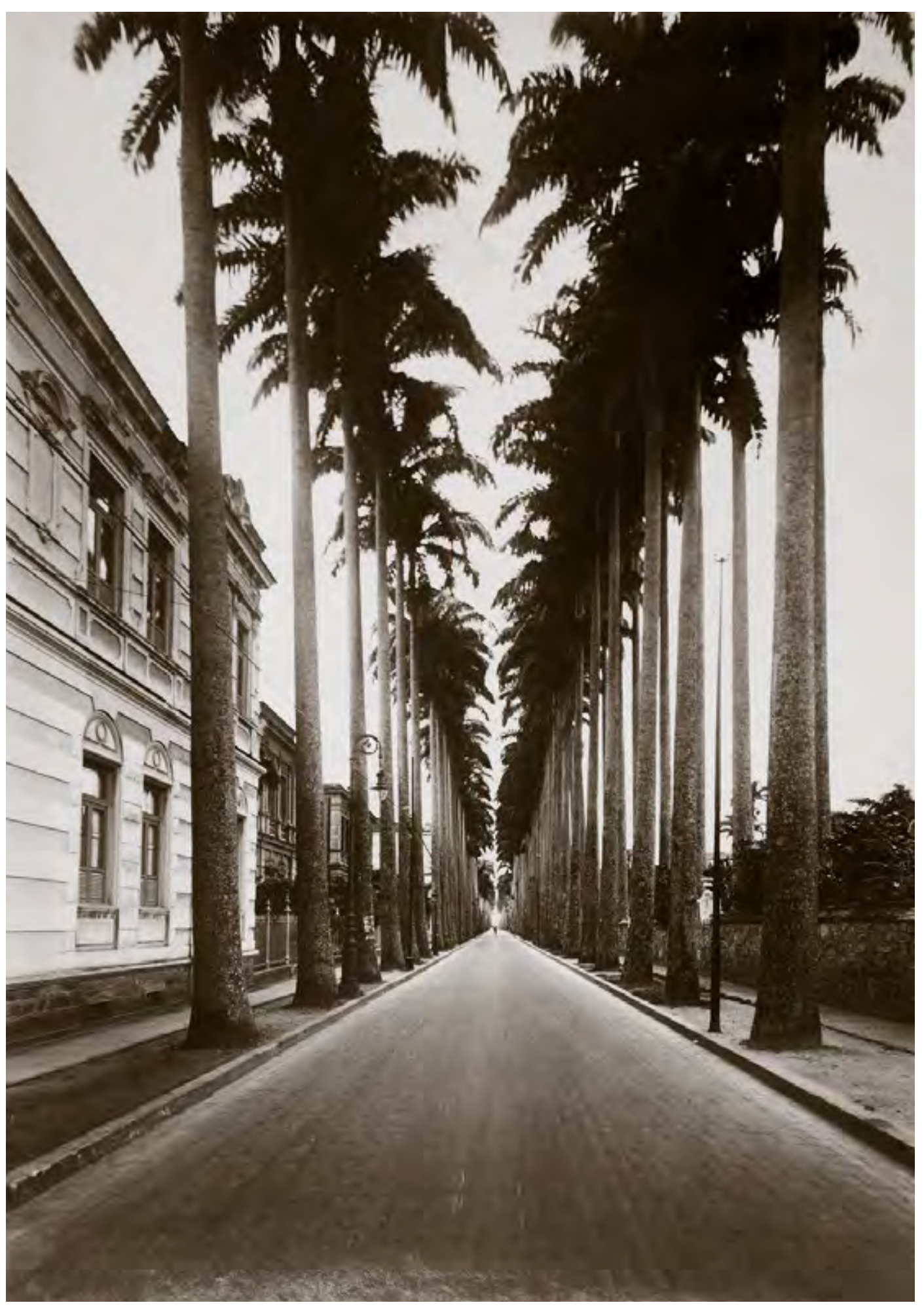

Rua Paissandu, bairro do

Flamengo, na década de 1920

Acervo Museu Histórico Nacional

Paissandu Street, in the

neighborhood of Flamengo, 1920s
Tudo se transforma, tudo varia - o amor, o ódio, o egoísmo. Hoje é mais amargo o riso, mais dolorosa a ironia. Os séculos passam, deslizam, levando as coisas fúteis e os acontecimentos notáveis. Só persiste e fica, legado das gerações cada vez maior, o amor da rua.

João do Rio

Everything transforms itself, everything changes - love, hate, egotism. Today laughter is more bitter, irony more painful. The centuries go by, slipping away, carrying off petty matters and remarkable events. The only thing that endures and remains, the ever greater legacy of generations, is the love of the streets.

João do Rio 
A alma da casa da rua Paissandu era minha mãe, para quem a casa era o espaço de sua vida. Ali viveu de 1911 a 1936: um quarto de século! Nela foi feliz.

Carlos Chagas Filho

The soul of the house on Paissandu street was my mother, for whom the house was where her life took place. She lived there from 1911 to 1936: a quarter of a century! She was happy in that home.

Carlos Chagas Filho

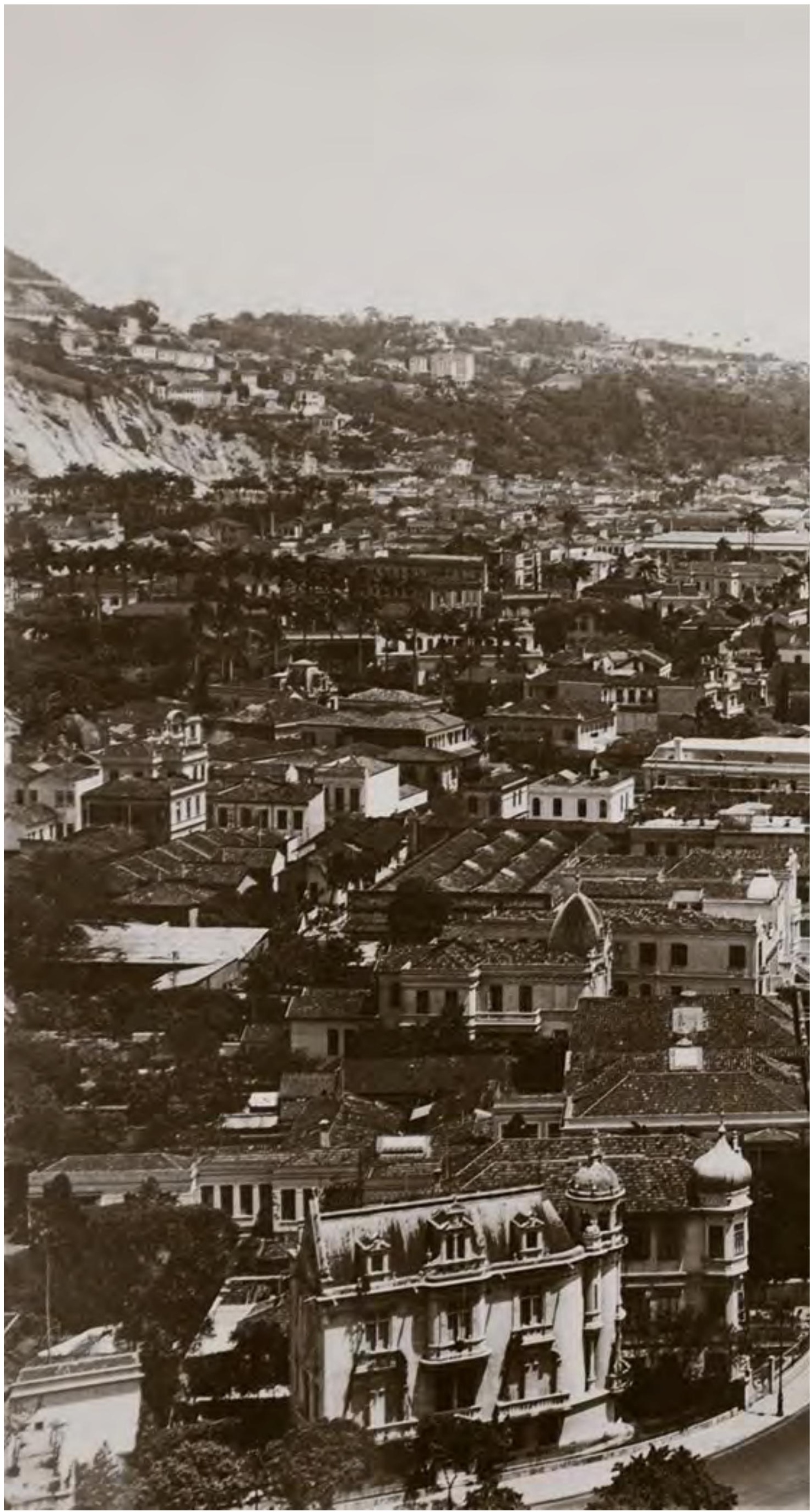




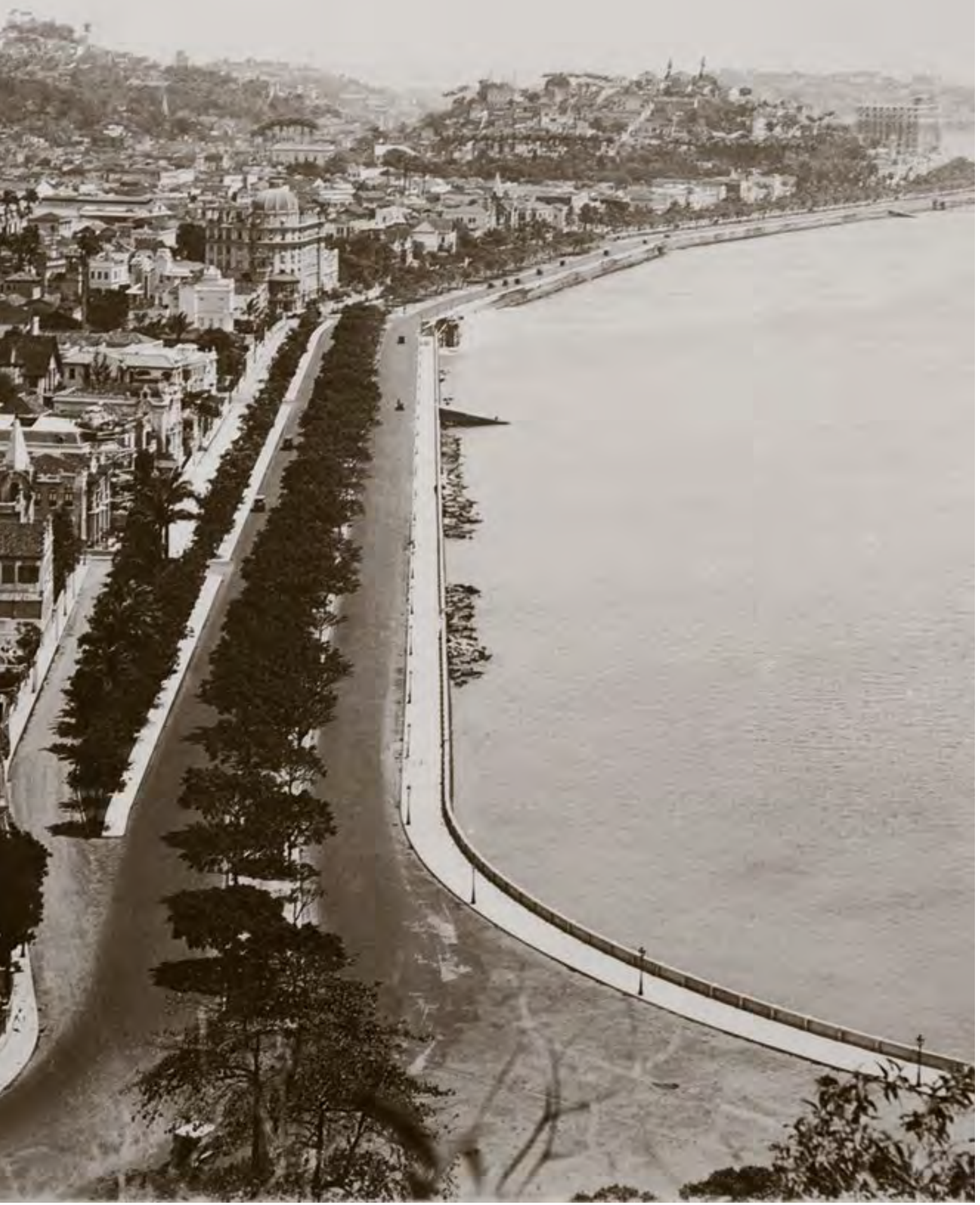

Bairro do Flamengo na década de 1920

Acervo Museu Histórico Nacional Neighborhood of Flamengo, 1920s 
A brancura de sua pele, os olhos e cabelos negros, atados em dois bandós, em um dos quais um cravo vermelho se destacava, davam à sua beleza traços andaluzes, indicativos de uma vaga hereditariedade castelhana. Seu vestido era lindo! Bemtalhado, de cor branca, enfeitado somente com rendas feitas à mão, combinava com a sua altura, mais do que mediana, e, sem dúvida, o negro do cabelo, com a alvura de sua roupa.

Carlos Chagas Filho

The whiteness of her skin, her black eyes and black hair, tied with two bands, a red carnation calling attention in one, lent hints of Andalusia to her beauty, indicating some vague Spanish ancestry. Her dress was beautiful! Well-cut, white in color, adorned only with handmade lace, it went well with her height, above average, and, without a doubt, the blackness of her hair went well with the whiteness of her clothing.

Carlos Chagas Filho

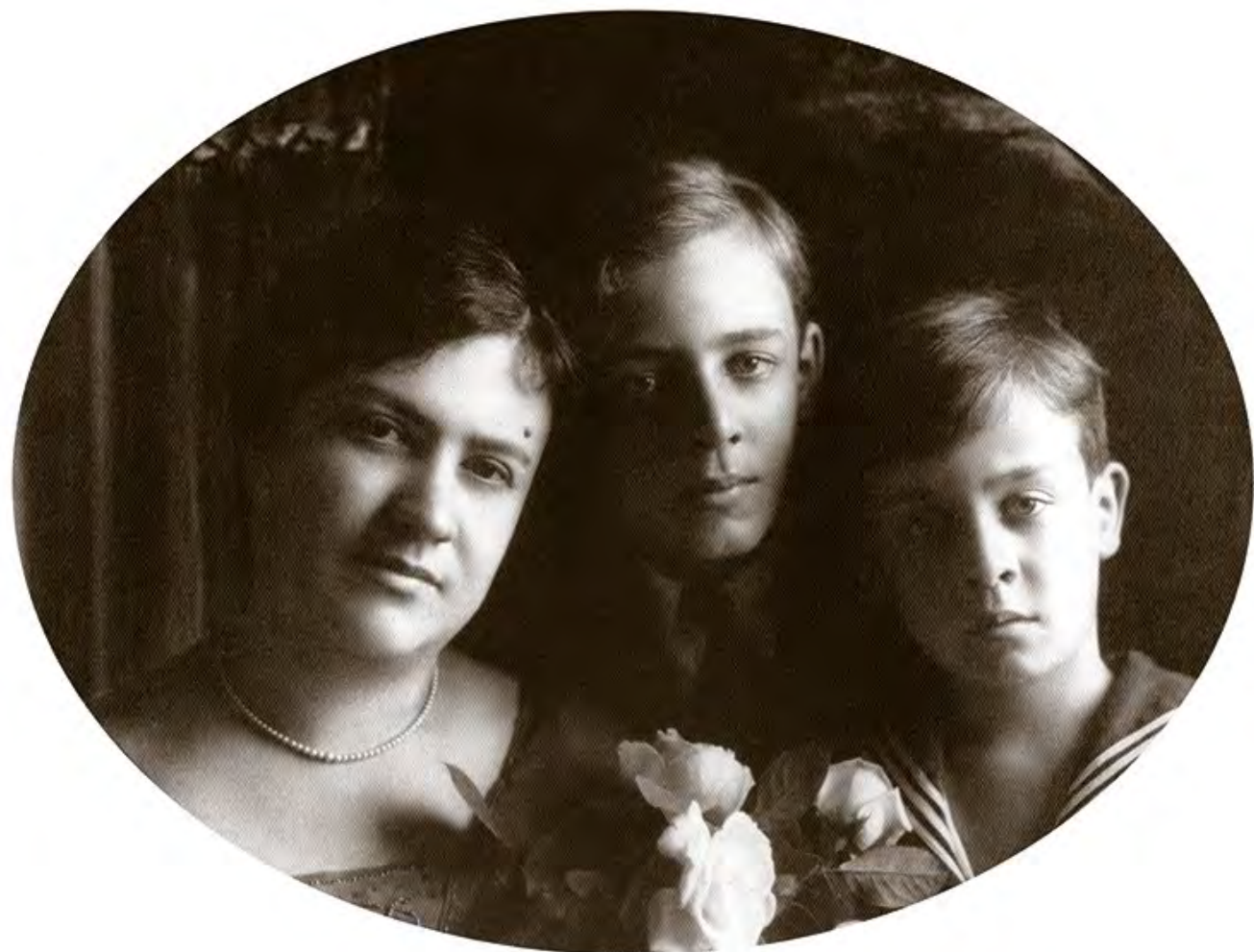

Iris Lobo Chagas com seus dois filhos, Evandro Chagas e Carlos Chagas Filho, c. 1914

Acervo Casa de Oswaldo Cruz

Iris Lobo Chagas with her two sons, Evandro Chagas and Carlos Chagas Filho, c. 1914

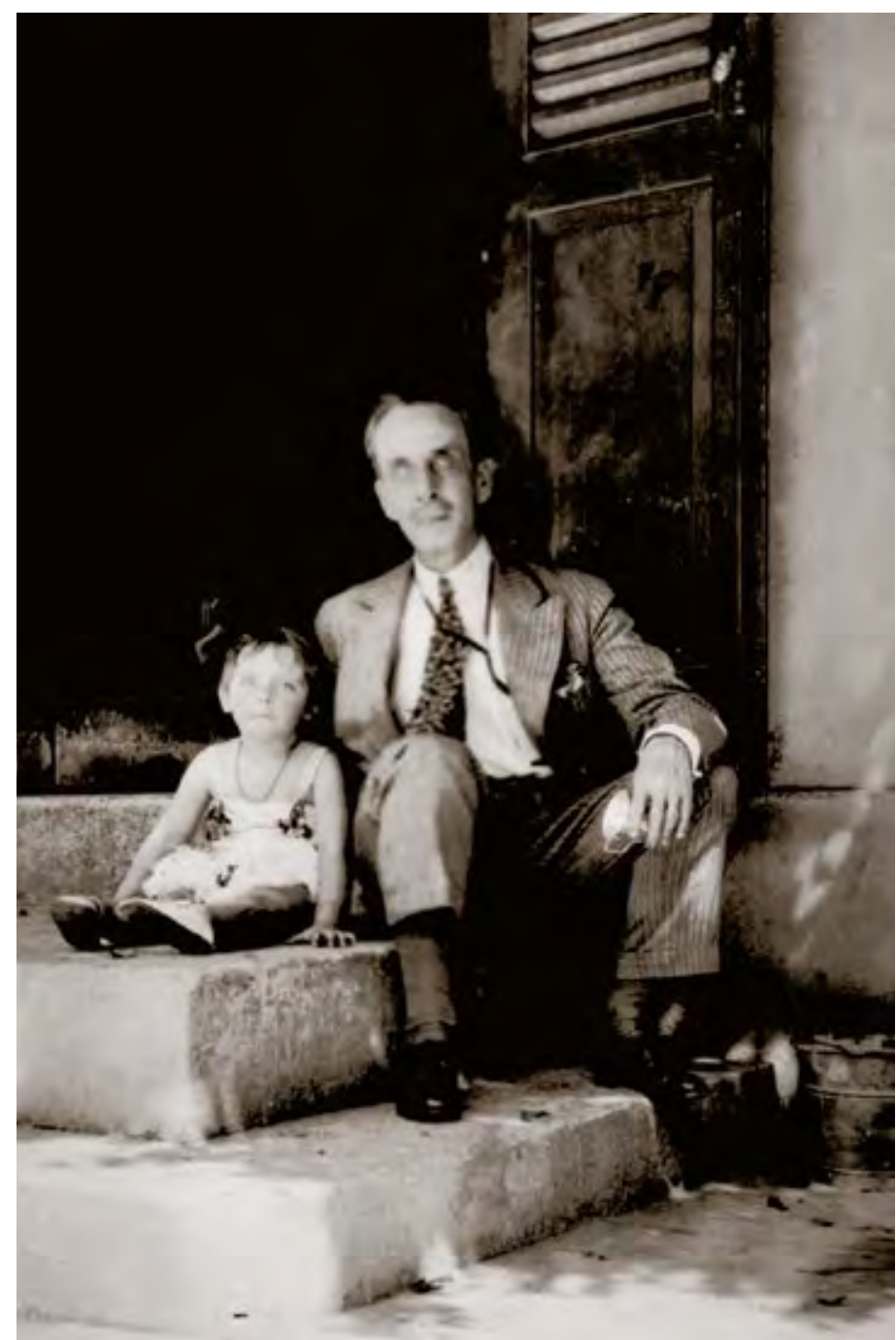

Carlos Chagas com Tatiana, filha de Evandro Chagas, única neta que conheceu Acervo Casa de Oswaldo Cruz

Carlos Chagas with Evandro Chagas's daughter Tatiana, the only granddaughter he ever knew 


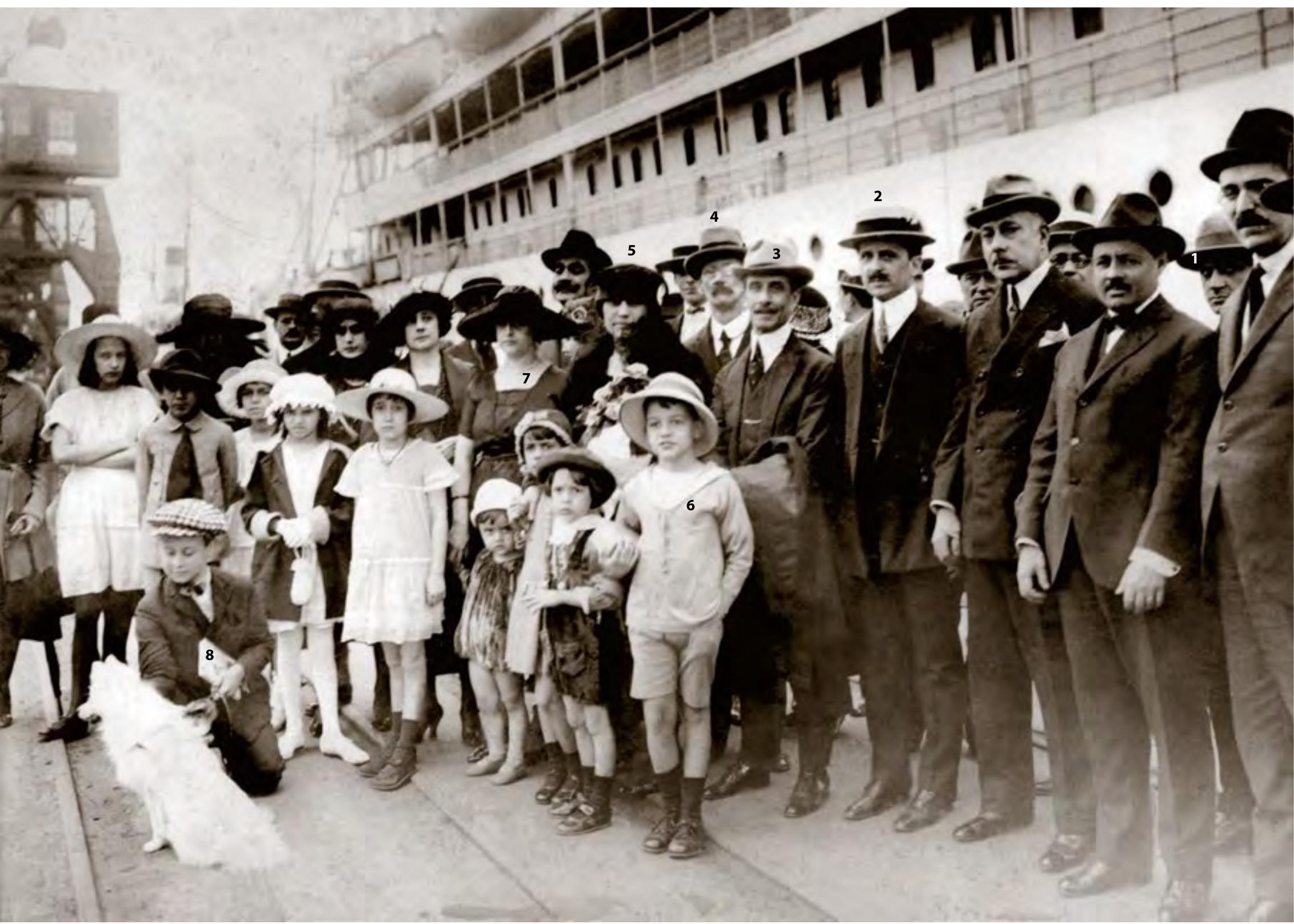

Desembarque da família Carlos Chagas no porto do Rio

de Janeiro após viagem aos Estados Unidos em 1921

1 - Bento Oswaldo Cruz; 2 - Raul Leitão da Cunha;

3 - Carlos Chagas; 4 - Adolpho Lutz; 5 - Iris Lobo Chagas;

6 - Fernando Luiz Lobo Barbosa Carneiro;

7 - Ruth Machado; 8 - Carlos Chagas Filho

Acervo Casa de Oswaldo Cruz

The Carlos Chagas family arriving at the port of Rio de

Janeiro following a trip to the United States in 1921

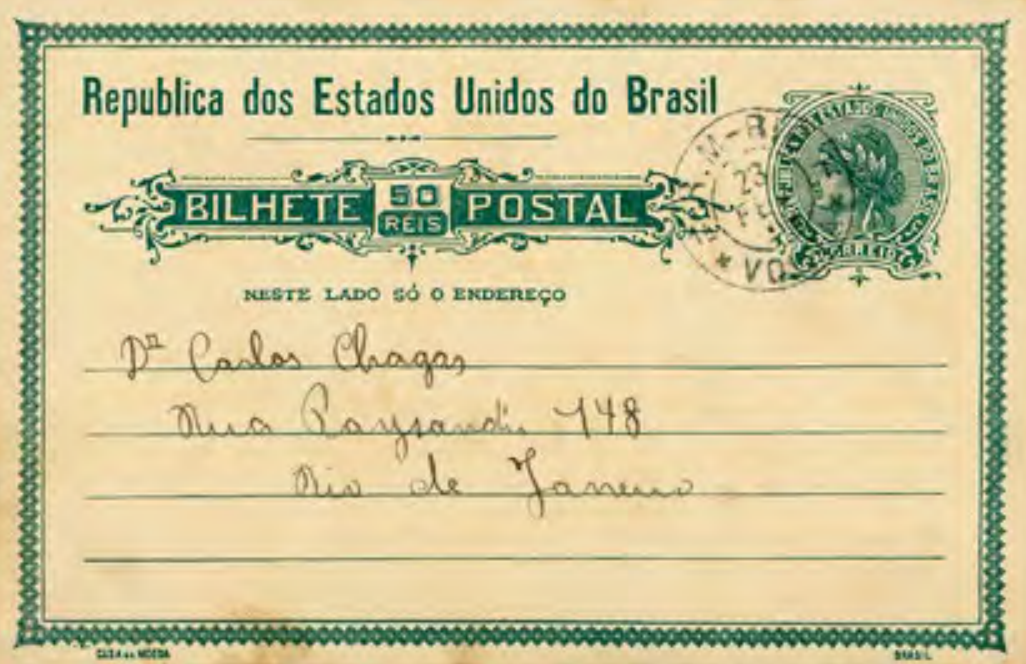

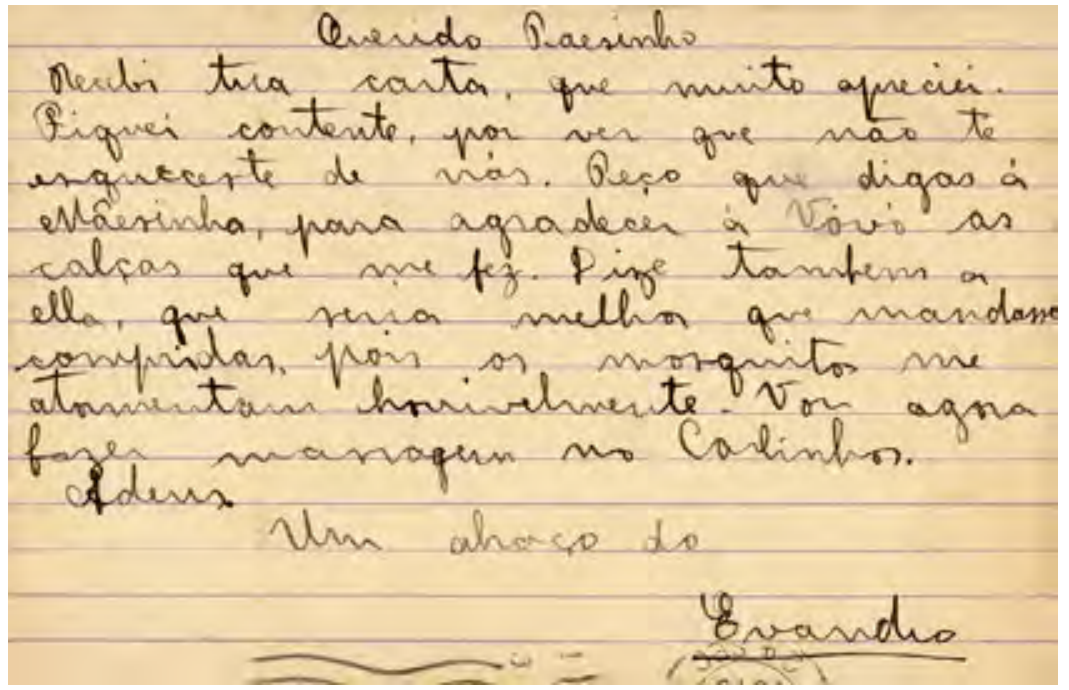

Carta de Evandro Chagas para seu pai

Acervo Casa de Oswaldo Cruz

Letter from Evandro Chagas to his father 


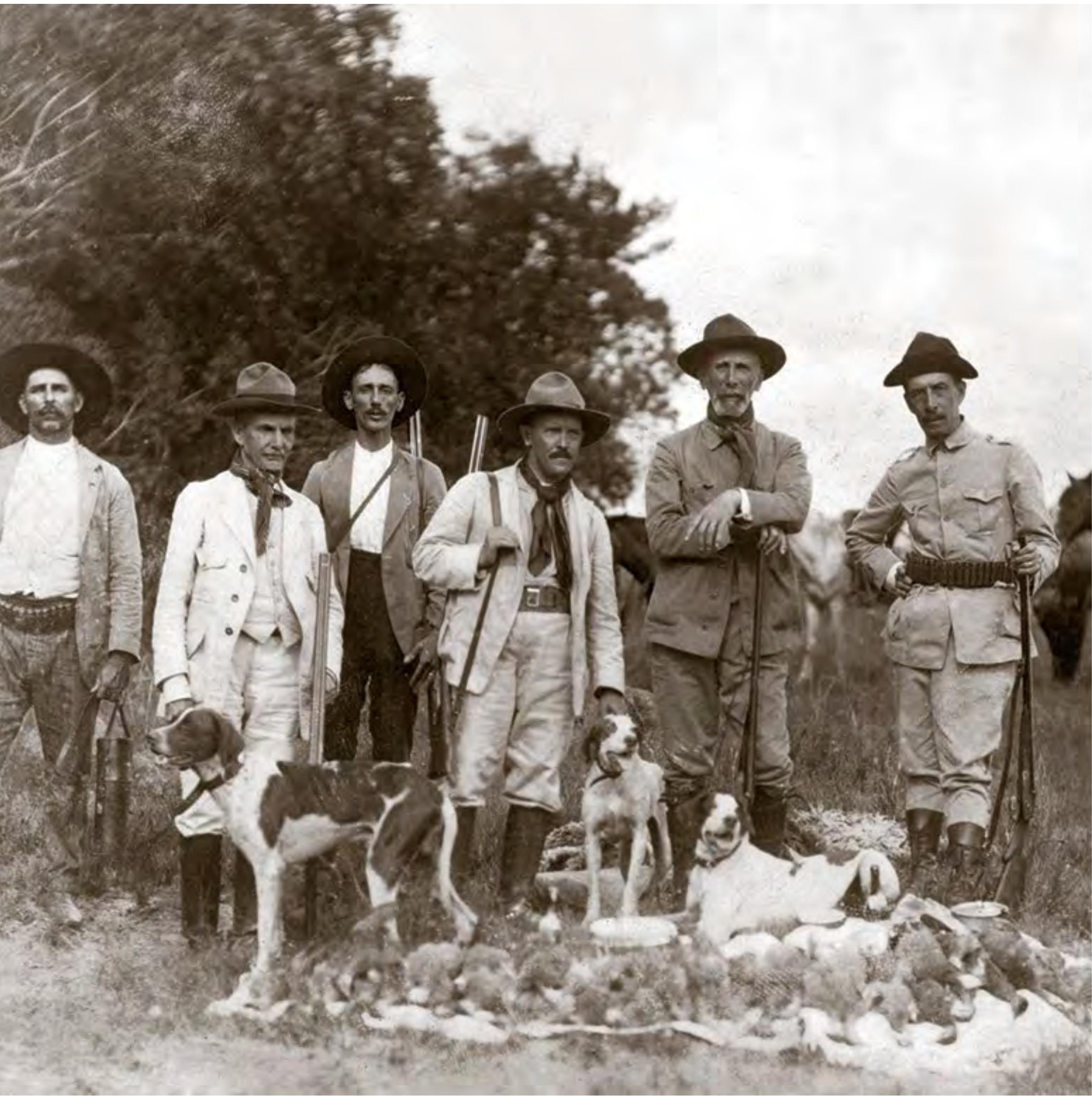

Carlos Chagas ( $1^{\circ}$ à direita), após caçada com

amigos. Ao seu lado, o deputado mineiro

João Penido, c. 1913

Acervo Casa de Oswaldo Cruz

Carlos Chagas ( $1^{\text {st }}$ on the right), after going

hunting with friends. Next to him, Minas

Gerais Deputy João Penido, c. 1913 


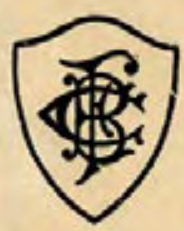

\section{Batalaga \\ Faatball Club}

NIO-OENERAL GEVERIANO \%7-CAIXA OSO-TEL, 49I-SUL

$2[0 ; 3$
Carta da diretoria do

Botafogo Football Club

comunicando a admissão

de Chagas como sócio

honorário. Rio de Janeiro,

23 abr. 1919

Acervo Casa de Oswaldo Cruz

Letter from the board of

directors of the Botafogo

Football Club, advising

that Chagas had been

made an honorary

member. Rio de Janeiro,

Apr. 23, 1919

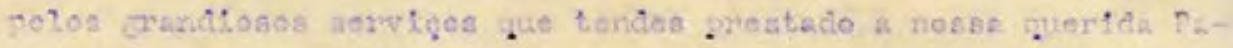

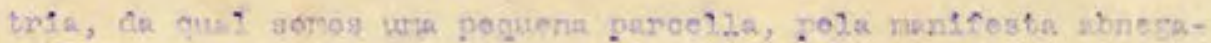
Qio com que soubestes ompregur todos os recursos de rezdrdetro

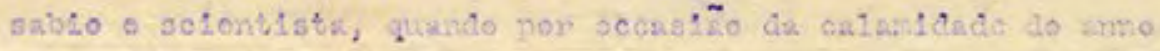
transacto.

$$
\text { Congraturandorms con o club, ger tiáo gusta o }
$$

merea1da prova de gretidho, aprovelto oste feliz ensojo priv apren.

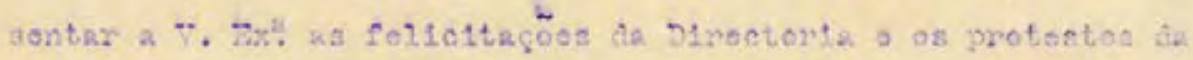

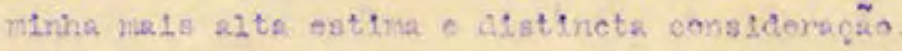

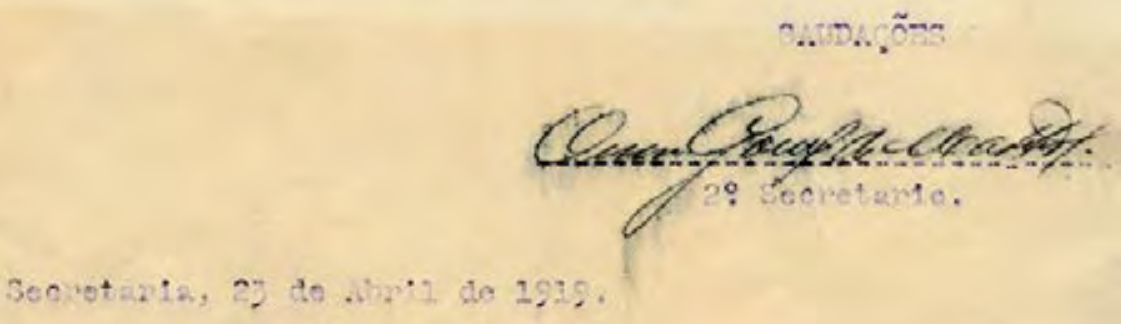


A impressão que sempre me deu foi a de um homem bom. (...) Desde pequeno tratou-me sempre com carinho inesquecivel e tenho plena consciência de que o menino da rua Paissandu era, as mais das vezes, pelo menos inoportuno. Nunca o vi ralhar nem comigo nem com Evandro (...). Que dizer, então, do seu desvelo e atenções com minha mãe!

Carlos Chagas Filho

The impression he always gave me was that he was a good man. (...) From the time I was little, he always treated me with unforgettable affection, and I am fully aware that the boy from Paissandu street was more often than not difficult, to say the least. I never saw him berate either me or Evandro (...). To say nothing of his devotion and consideration towards my mother!

Carlos Chagas Filho

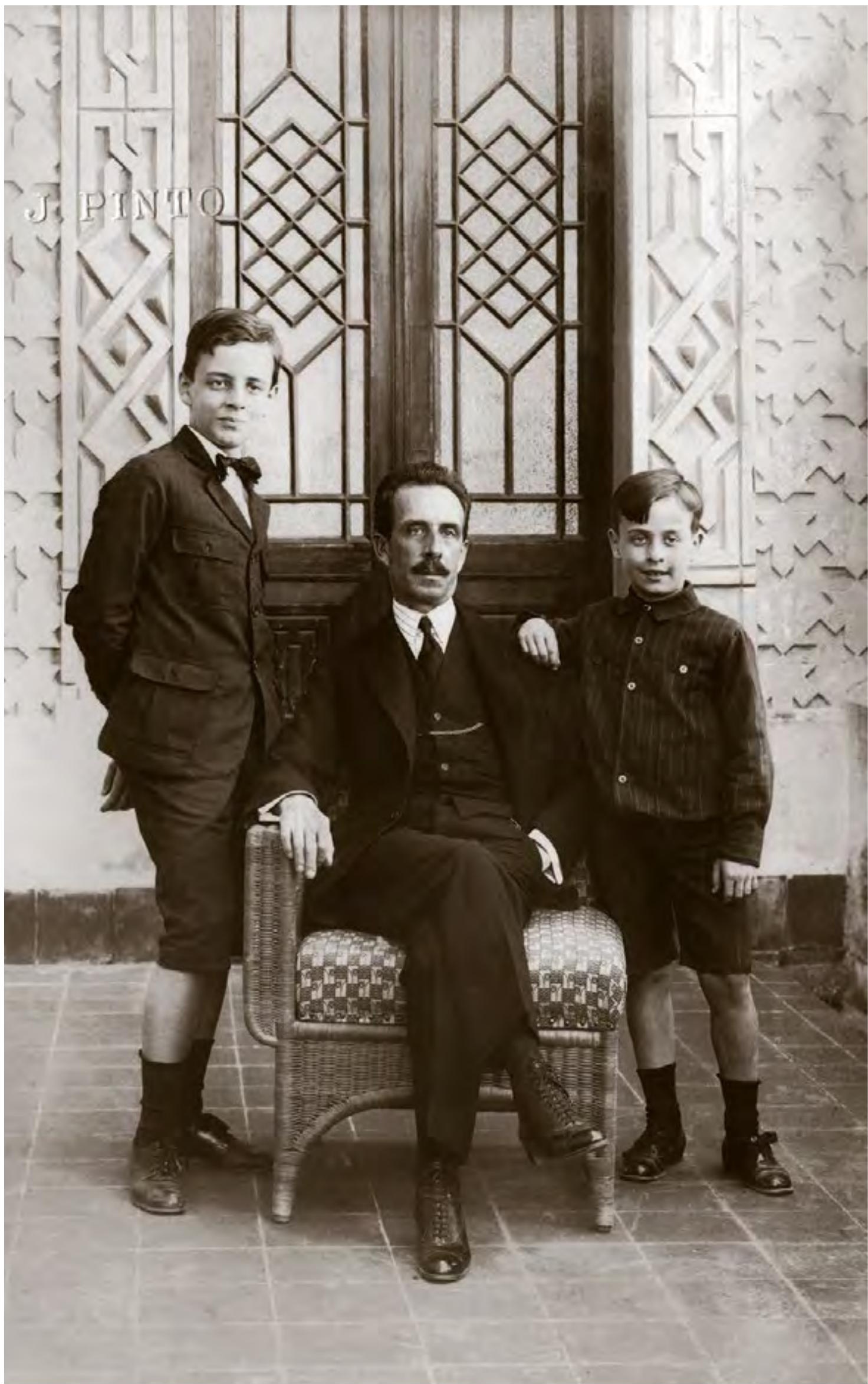

Carlos Chagas em uma das varandas

do castelo de Manguinhos, com os

filhos Evandro (à esquerda) e Carlos

(à direita), década de 1910

Foto J. Pinto

Acervo Casa de Oswaldo Cruz

Carlos Chagas on one of the

verandahs of the Manguinhos castle

with his sons, Evandro (left) and

Carlos (right), 1910s

Photograph by J. Pinto 


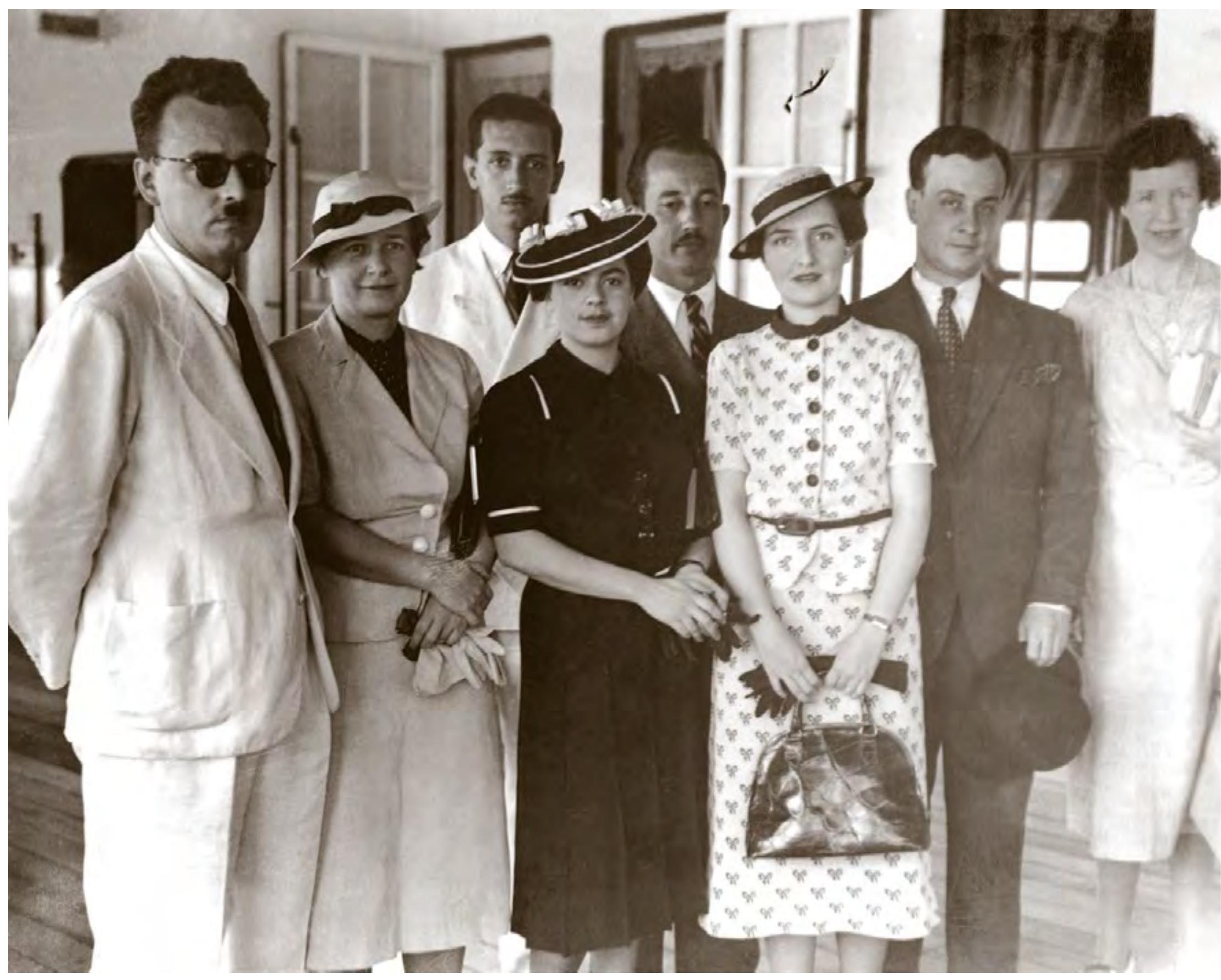

Evandro Chagas ( $10^{\circ}$ à esquerda), sua esposa

Agnes W. Chagas, Almir de Castro, Dora

Campos (filha de Francisco Campos, ministro

da Justiça), Virgílio Carneiro, Anna Leopoldina

de Mello Franco Chagas (esposa de Carlos

Chagas Filho), Carlos Chagas Filho e a

viscondessa Frances, 1938

Acervo Casa de Oswaldo Cruz

Evandro Chagas ( $1^{\text {st }}$ from left); his wife, Agnes

W. Chagas; Almir de Castro; Dora Campos

(daughter of Justice Minister Francisco

Campos); Virgílio Carneiro; Anna Leopoldina

de Mello Franco Chagas (Carlos Chagas Filho's

wife); Carlos Chagas Filho; and the viscountess

Frances, 1938 


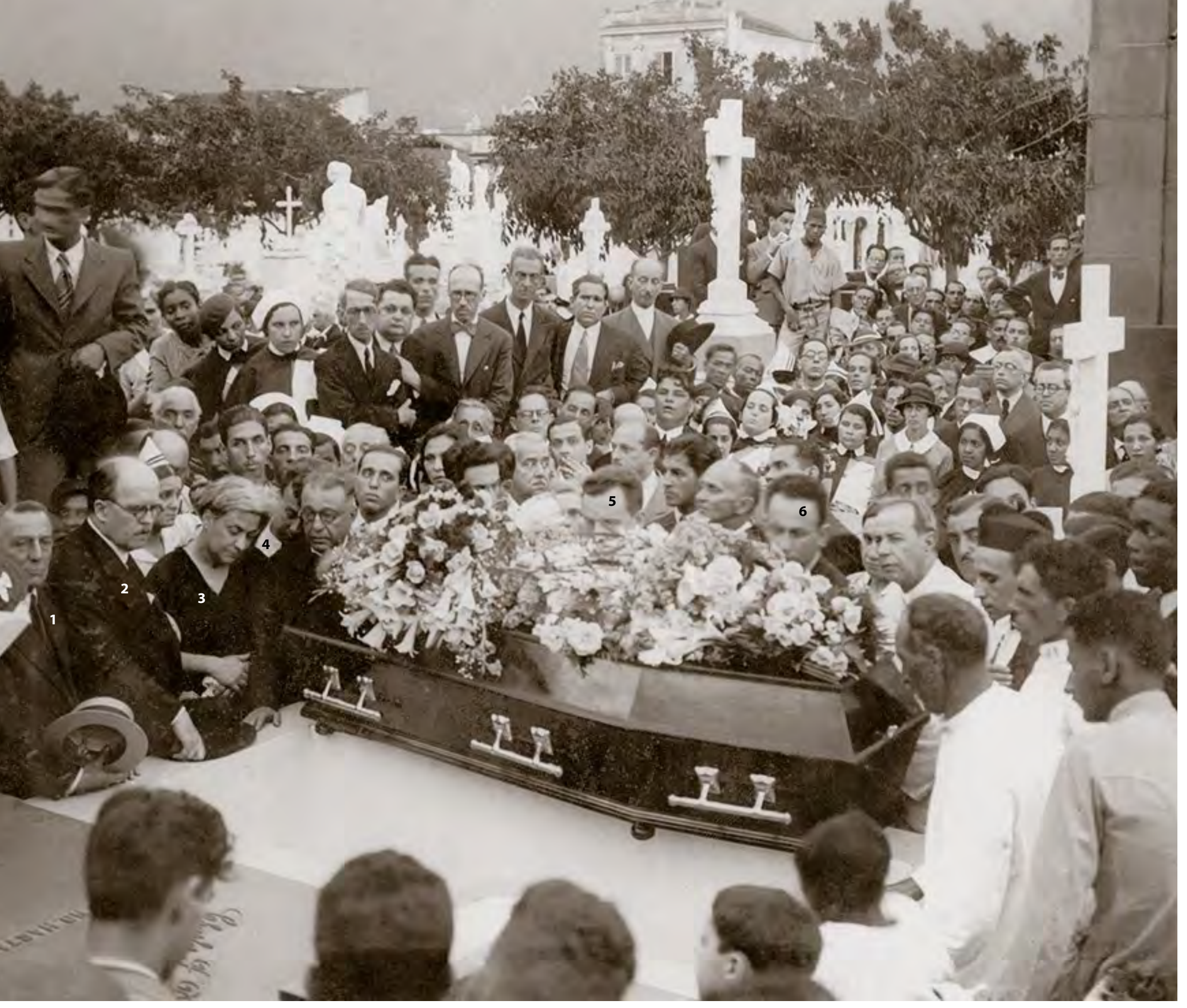

Enterro de Carlos Chagas no Cemitério

São João Batista, nov. 1934

1 - Alberto Cunha; 2 - Joaquim Moreira da Fonseca;

3 - Iris Lobo Chagas; 4 - Carlos Chagas Filho;

5 - Evandro Chagas; 6 - Jorge Jabour

Acervo Casa de Oswaldo Cruz

Carlos Chagas's burial at São João Batista cemetery, Nov. 1934 


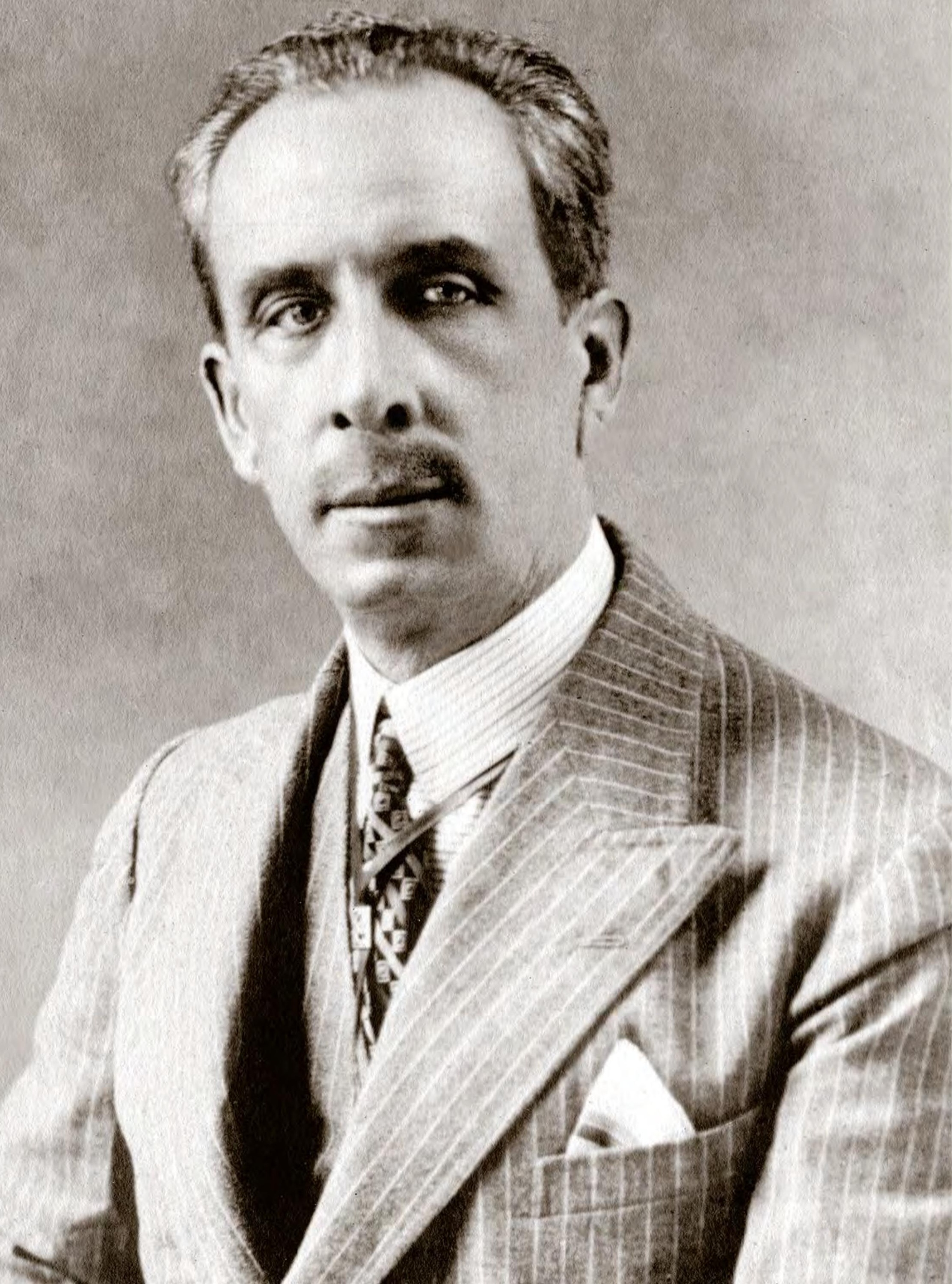




\section{HOMENAGEM A CARLOS \\ A REUNIÃO DE HONTEM,}

\section{CHAGAS} de pesado

O Brasil perde dois grandes viltos Griedes de Mello

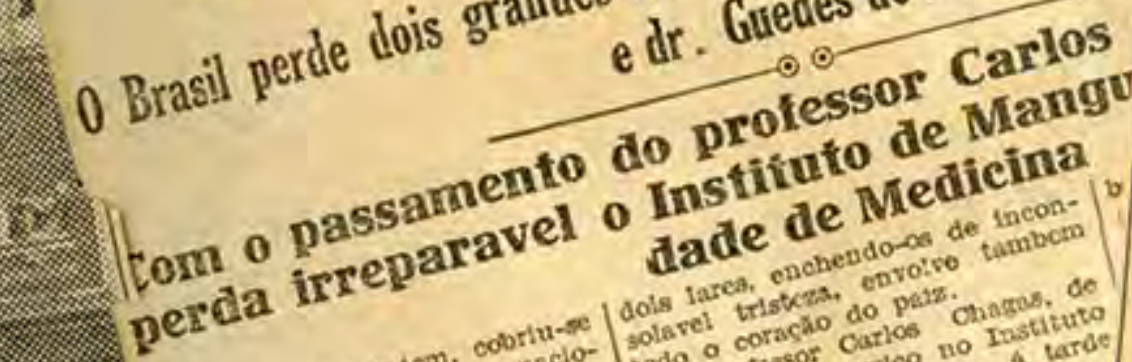
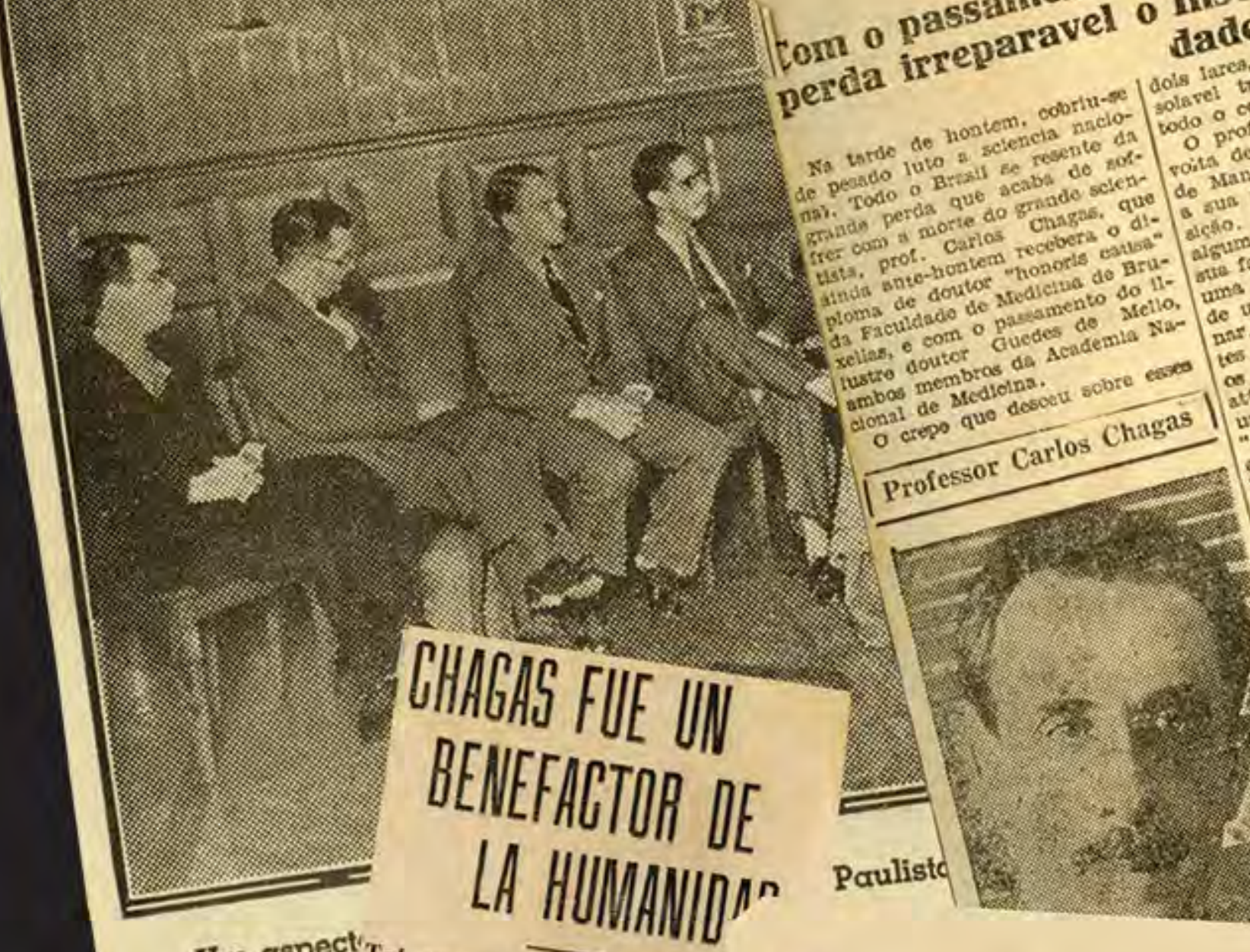

Um aspect'Tal expresa

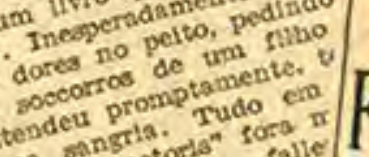

FALLL

Tma commiss Faculdade de Janetro convoge uma homenagas

turma. unitao do Ce mifacio Andracos Alres embajador follecime expresa o sulva, una José B minecimiento stas condo una nota

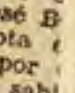

Factina 2

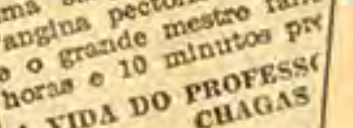

RIO

DR.

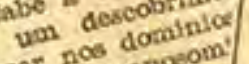

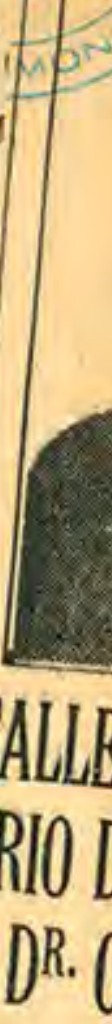




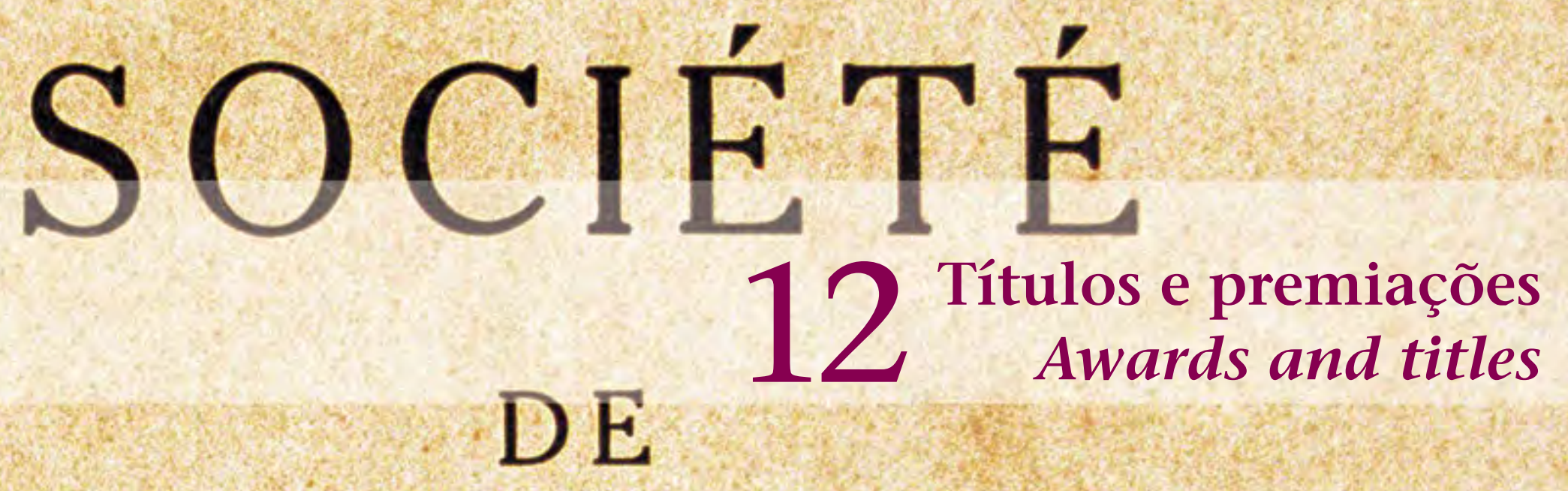

HOLOGIE EXOTIQUE

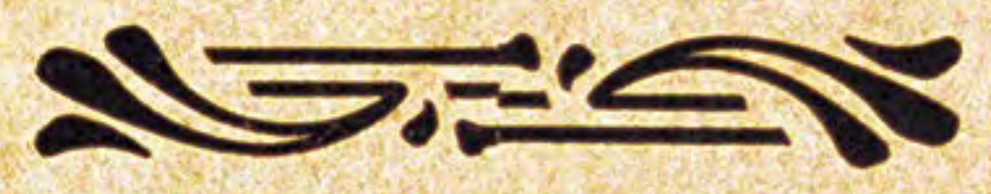

$\angle$.

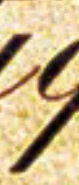
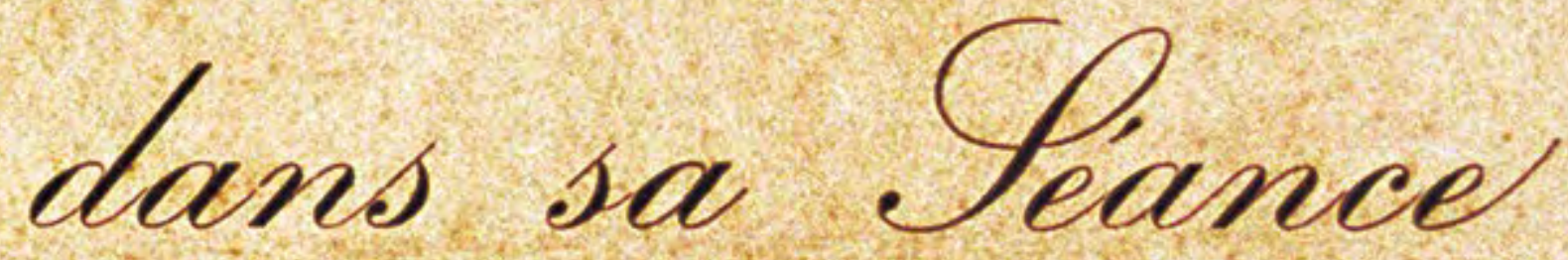

2 
C arlos Chagas alcançou grande prestígio durante sua trajetória como cientista e obteve amplo reconhecimento tanto no Brasil como no exterior. Tornou-se membro de algumas das mais importantes associações médico-científicas de sua época e foi agraciado com vários títulos e prêmios, conforme apresentamos a seguir.

\section{9}

Membro da Sociedade de Medicina da Bahia Membro da Sociedade de Medicina e Cirurgia do Rio de Janeiro

\section{0}

Membro honorário da Sociedade de Medicina e Cirurgia de São Paulo

Membro titular da Academia Nacional de Medicina Membro correspondente da Sociedade de Patologia Exótica de Paris

\section{1}

Membro honorário da Associação Médico-Cirúrgica de Minas Gerais

\section{2}

Prêmio Schaudinn, conferido pelo Instituto de Doenças Marítimas e Tropicais de Hamburgo

Professor honorário da Faculdade de Medicina de São Paulo

1913

Indicado ao Prêmio Nobel de Medicina

1916

Membro da Sociedade Brasileira de Ciências (Academia Brasileira de Ciências a partir de 1922)

Membro honorário da Sociedade Médica Argentina

\section{7}

Membro honorário da Sociedade de Medicina e

Cirurgia do Amazonas

Sócio honorário da Academia de Medicina da

Universidade Nacional de Buenos Aires

1919

Membro da Sociedade Americana de Medicina Tropical

1920

Membro do Conselho Médico da Liga das Sociedades

da Cruz Vermelha

Cavaleiro da Ordem da Coroa da Itália

\section{1}

Indicado pela segunda vez ao Prêmio Nobel de Medicina

Primeiro brasileiro a receber o título de doutor honoris causa da Universidade de Harvard

Membro honorário do Clube dos Médicos de Chicago

\section{2}

Membro correspondente da Academia Nacional de

Medicina do Peru

Membro associado da Sociedade Real de Ciências

Médicas e Naturais de Bruxelas

Doutor honoris causa da Universidade Nacional de Buenos Aires

\section{3}

Membro correspondente da Academia Real

de Medicina da Bélgica

Membro correspondente da Sociedade de Medicina de Montevidéu

Comendador da Ordem da Coroa da Bélgica

Primeiro presidente da Sociedade Brasileira de Higiene
Oficial da Ordem Nacional da Legião de Honra da França

Lecturer de medicina tropical da Escola Médica de Harvard

Prêmio hors-concours em congresso comemorativo do centenário de nascimento de Louis Pasteur, em Estrasburgo, França

1924

Professor honorário da Faculdade de Medicina da Bahia

Membro da Societas ad Artes Medicas in India Orientali Neerlandica

Membro correspondente da Academia Médica de Roma

\section{5}

Membro correspondente da Real Academia Nacional de Medicina da Espanha

Comendador da Ordem Civil de Alfonso XII, rei de Espanha

Prêmio Kümmel, conferido pela Faculdade de Medicina da Universidade de Hamburgo

\section{6}

Doutor honoris causa da Universidade de Paris Sócio correspondente da Sociedade Médico-Cirúrgica de Guayas, Equador

Comendador da Ordem de Isabel, a Católica, Espanha Membro da Academia Imperial Alemã de Pesquisas Naturais de Halle

Membro honorário da Academia de Medicina de Nova York

1928

Membro da Sociedade Real de Medicina Tropical e Higiene de Londres

1929

Doutor honoris causa da Faculdade de Medicina de Lima Cavaleiro da Ordem da Coroa da Romênia Membro honorário da Faculdade de Ciências da Universidade Nacional de Santo Agostinho de Arequipa, Peru

1930

Membro da Sociedade de Biologia de Buenos Aires

1931

Membro correspondente da Academia de Medicina de Paris

1932

Membro da Associação Médica Pan-Americana Membro da Associação Internacional da Lepra Comenda da Cruz Vermelha Alemã

\section{4}

Doutor honoris causa da Universidade Livre de Bruxelas Professor honorário da Escola de Farmácia e Odontologia de Juiz de Fora 

arlos Chagas achieved great prestige during his career as a scientist, earning wide recognition in Brazil and abroad. He became a member of some of the leading medical and scientific organizations of his day and garnered many titles and awards, as shown below.

\section{9}

Member of the Bahia Society of Medicine

Member of the Rio de Janeiro Society of Medicine and Surgery

1910

Honorary member of the São Paulo Society of Medicine and Surgery

Fellow of Brazil's National Academy of Medicine Corresponding member of the Society of Exotic Pathology of Paris

1911

Honorary member of the Minas Gerais Medical Surgical Association

1912

Schaudinn Prize, awarded by the Hamburg Institute for Maritime and Tropical Diseases

Honorary Professor from the São Paulo School of Medicine

1913

Nominated for the Nobel Prize in Medicine

1916

Member of the Brazilian Society of Sciences (Brazilian Academy of Sciences as of 1922)

Honorary member of the Medical Society of Argentina

1917

Honorary member of the Amazonas Society of Medicine and Surgery

Honorary member of the National University of Buenos Aires' Academy of Medicine

1919

Member of the American Society of Tropical

Medicine

1920

Member of the Medical Board of the League of Red Cross Societies

Knight of the Order of the Crown of Italy

1921

Second nomination for the Nobel Prize in Medicine First Brazilian to receive the title of Doctor Honoris Causa from Harvard University

Honorary member of the Physicians' Club of Chicago

1922

Corresponding member of Peru's National Academy of Medicine

Associate member of the Royal Society for Medical

Science and Natural Sciences of Brussels

Doctor Honoris Causa from the National University of Buenos Aires

\section{3}

Corresponding member of the Belgian Royal Academy of Medicine

Corresponding member of the Montevideo Society of Medicine

Commander of the Order of the Crown of Belgium First president of the Brazilian Hygiene Society
Officer of France's National Order of the Legion of

Honor

Lecturer of tropical medicine at Harvard Medical

School

Award hors-concours at the congress commemorating

the centennial of the birth of Louis Pasteur, in

Strasbourg, France

1924

Honorary professor of the Bahia School of Medicine Member of the Societas ad Artes Medicas in India Orientali Neerlandica

Corresponding member of the Medical Academy of Rome

1925

Corresponding member of Spain's Royal National Academy of Medicine

Commander of the Order of Alfonso XII, King of Spain

Kümmel Prize, awarded by the University of

Hamburg's School of Medicine

1926

Doctor Honoris Causa from Paris University

Corresponding member of the Medical Surgical

Association of Guayas, Ecuador

Commander of Spain's Order of Isabel the Catholic

Member of the German Imperial Academy of Natural

Sciences of Halle

Honorary member of the New York Academy of Medicine

1928

Fellow of London's Royal Society of Tropical

Medicine and Hygiene

1929

Doctor Honoris Causa from the Lima School of

Medicine

Knight of the Order of the Crown of Romania

Honorary member of the National University of St. Augustin of Arequipa's School of Sciences, Peru

1930

Member of the Buenos Aires Society of Biology

1931

Corresponding member of the Paris Academy of Medicine

1932

Member of the Pan American Medical Association Member of the International Leprosy Association Medal from the German Red Cross

1934

Doctor Honoris Causa from the Free University of Brussels

Honorary professor of the Juiz de Fora School of Pharmacy and Dentistry 
Diploma de membro correspondente da Sociedade de Patologia Exótica de Paris, 12 jan. 1910 Acervo Casa de Oswaldo Cruz Certificate of corresponding membership in the Society of Exotic Pathology of Paris, Jan. 12,1910

Diploma de nomeação como membro titular da Academia Nacional de Medicina. Rio de Janeiro, 26 out. 1910 Acervo Casa de Oswaldo Cruz Certificate naming Chagas a fellow of the National Academy of Medicine. Rio de Janeiro, Oct. 26, 1910
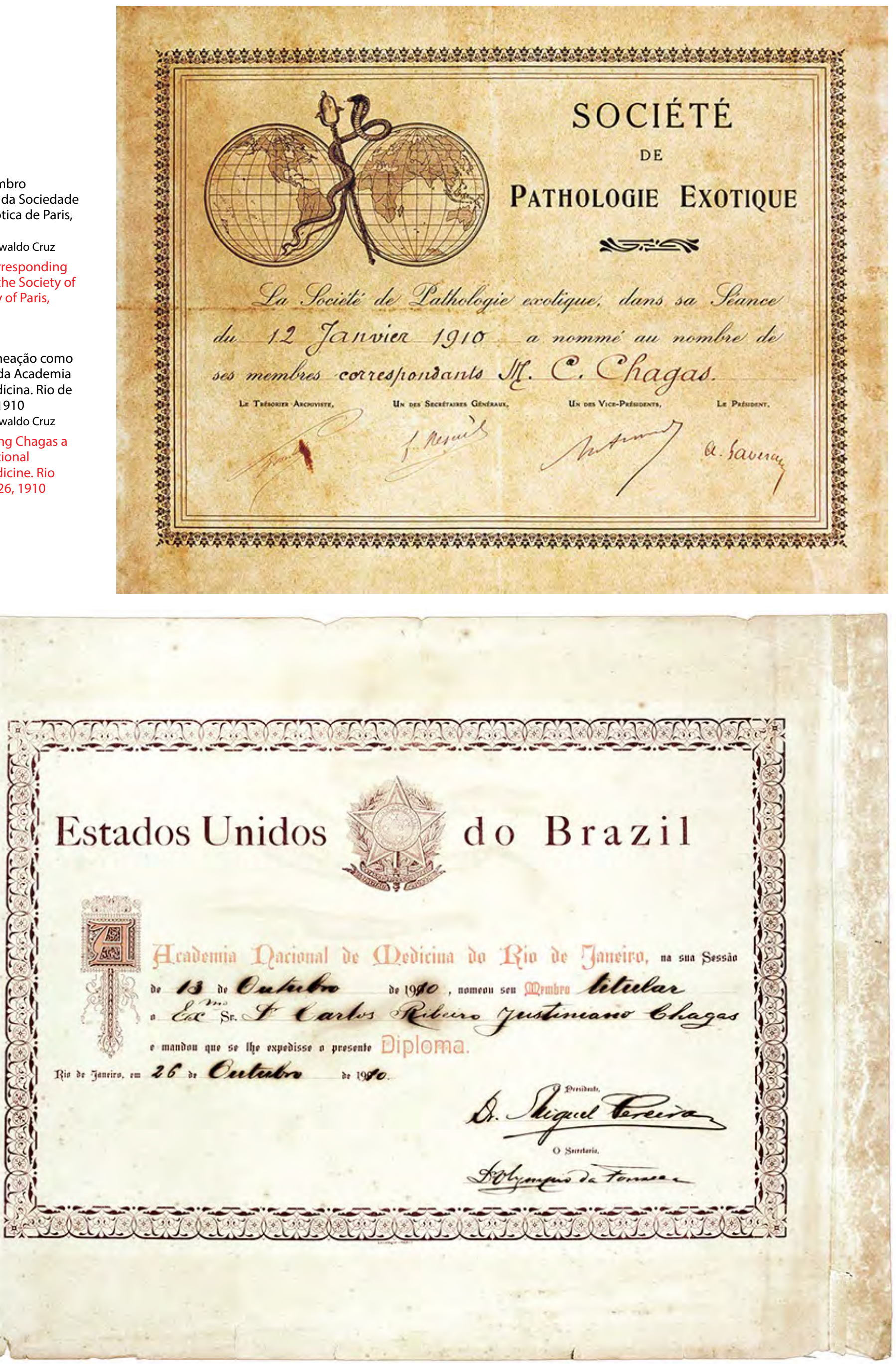

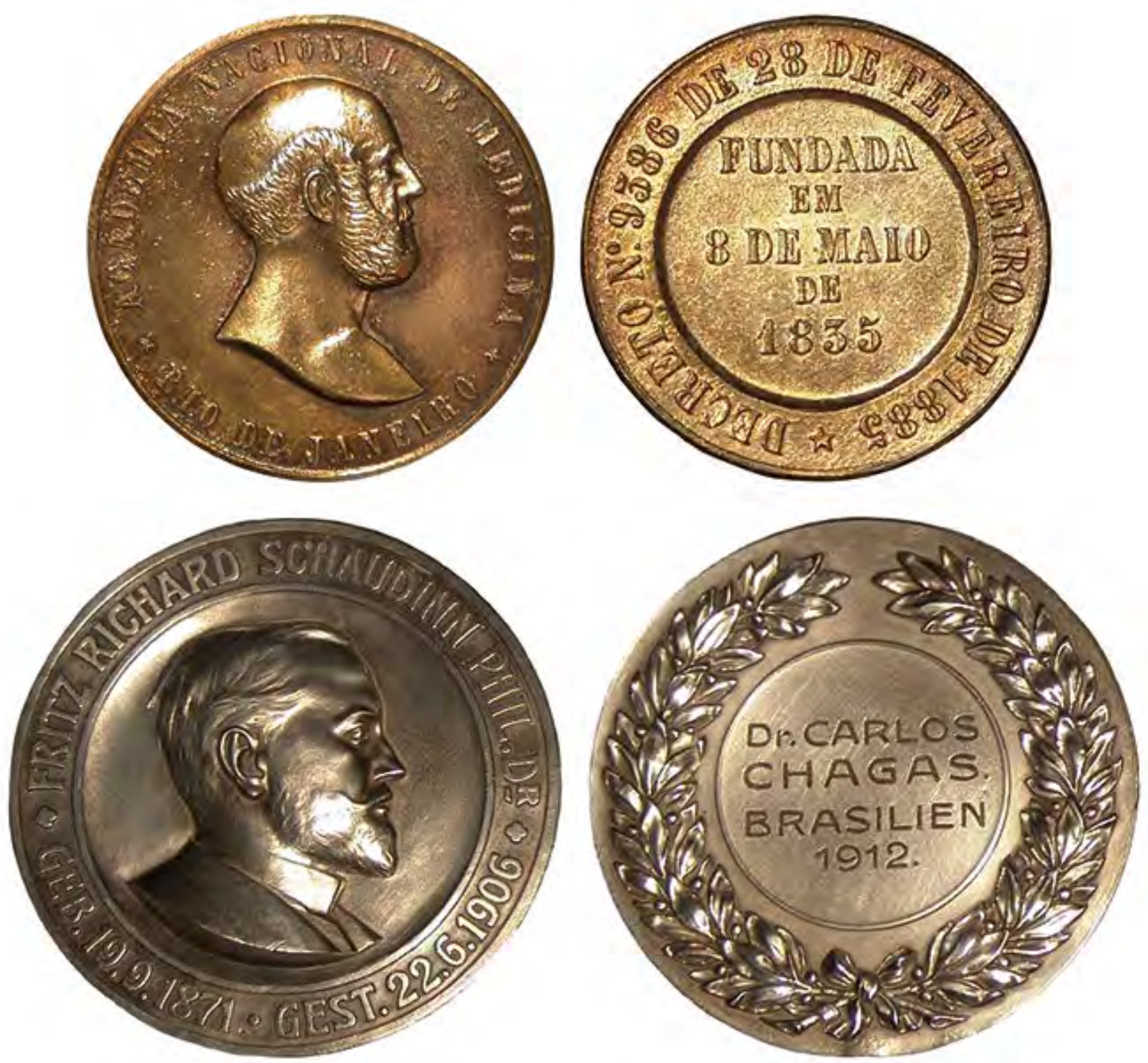

Medalha da Academia Nacional de Medicina Acervo Casa de Oswaldo Cruz

National Academy of Medicine medal

Medalha do Prêmio Schaudinn, concedido

pelo Instituto de Doenças Marítimas e

Tropicais de Hamburgo, Alemanha, 1912

Acervo Casa de Oswaldo Cruz

Schaudinn Prize medal, bestowed by the

Institute for Maritime and Tropical Diseases in

Hamburg, Germany, 1912 


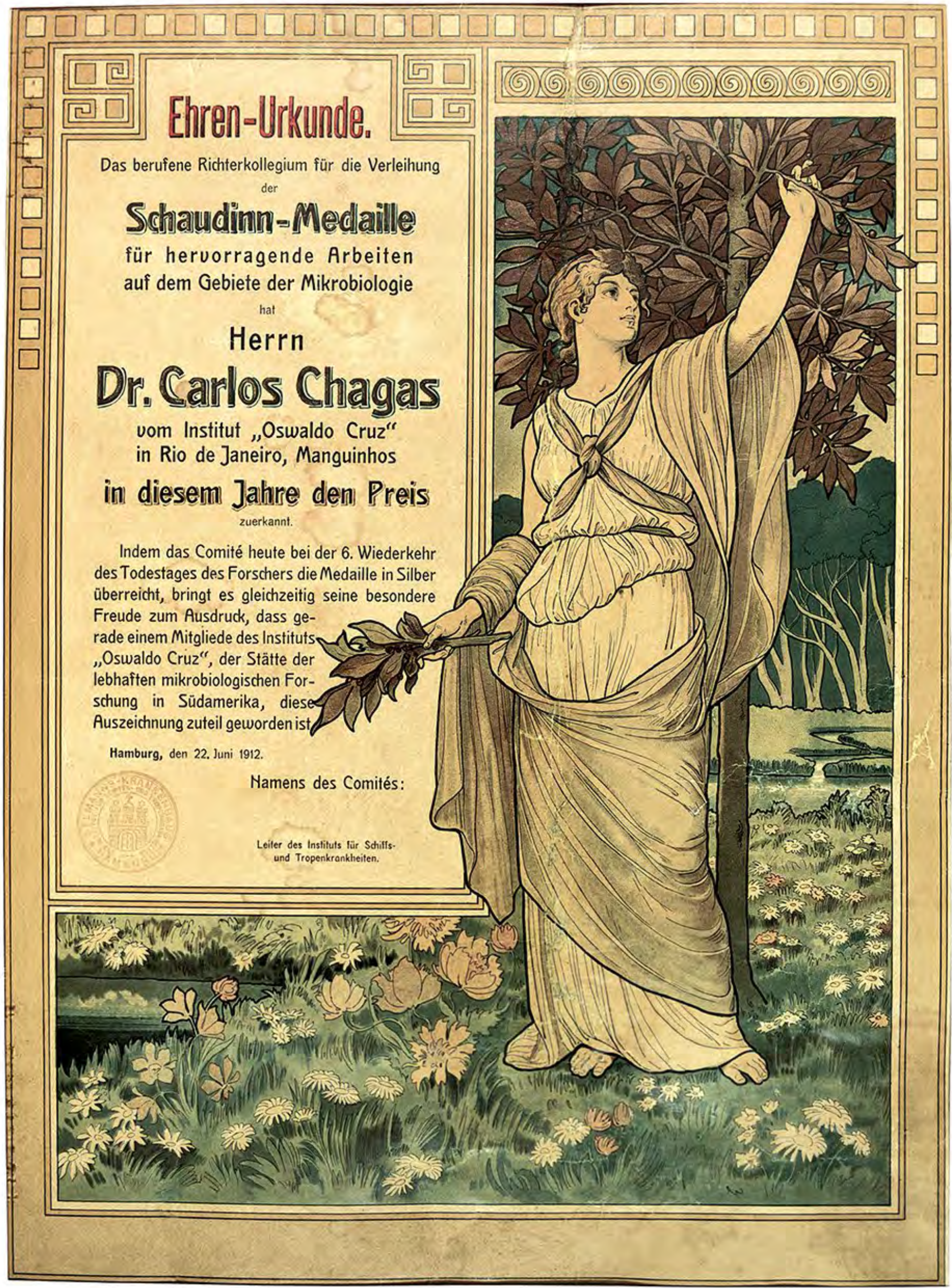

Diploma do Prêmio Schaudinn, conferido pelo Instituto de Doenças Marítimas e

Tropicais de Hamburgo, Alemanha, em

22 de junho de 1912

Acervo Casa de Oswaldo Cruz

Certificate of the Schaudinn Prize bestowed on Chagas by the Institute for Maritime and Tropical Diseases in Hamburg, Germany, on June 22, 1912 


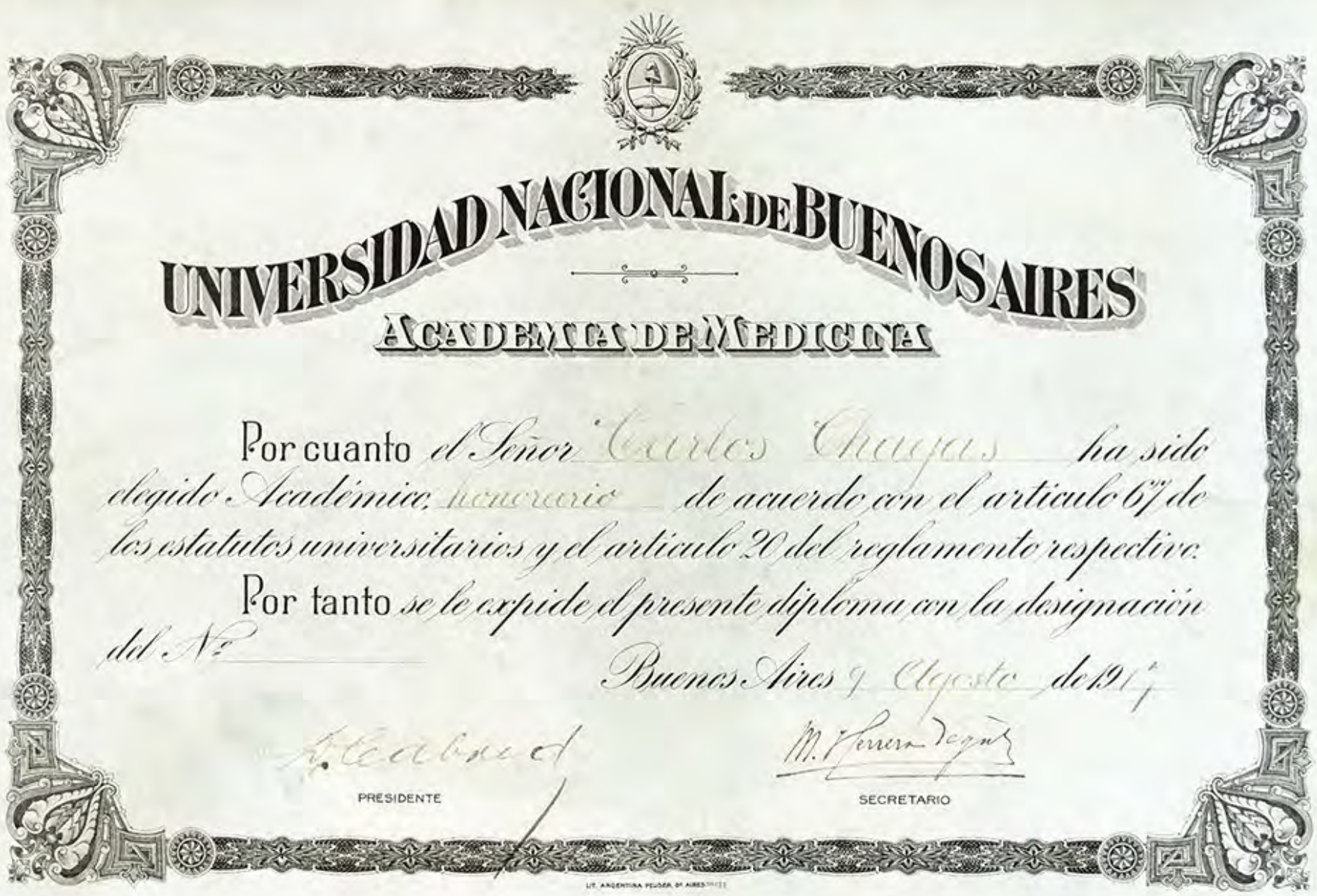

Diploma de sócio honorário da Academia de Medicina da Universidade Nacional de Buenos Aires, Argentina, 9 ago. 1917

Acervo Casa de Oswaldo Cruz Certificate of honorary membership in the National University of Buenos Aires' Academy of Medicine, Aug. 9, 1917

Diploma de doutor honoris causa da Universidade de Harvard, Estados Unidos, 23 jun. 1921. Chagas foi o primeiro pesquisador brasileiro a receber tal distinção

Acervo Casa de Oswaldo Cruz Diploma of Doctor Honoris Causa from Harvard

University, Jun. 23, 1921.

Chagas was the first Brazilian researcher to receive this distinction
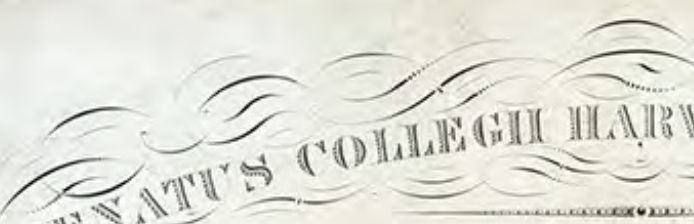

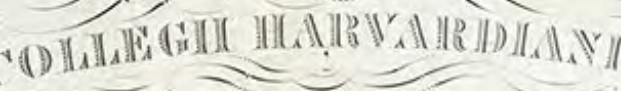

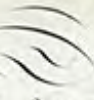

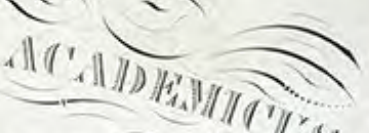

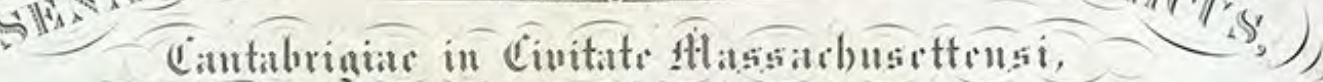

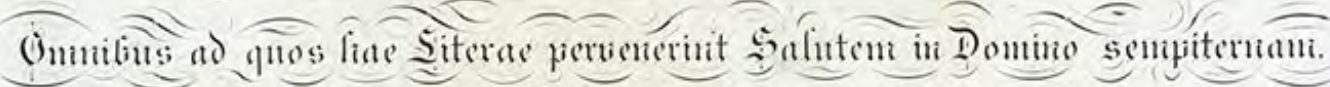

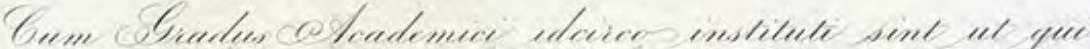

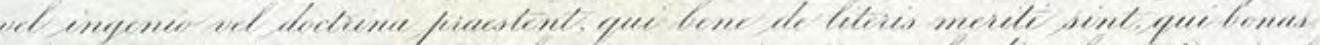

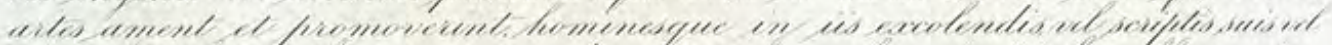

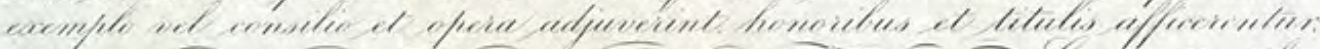

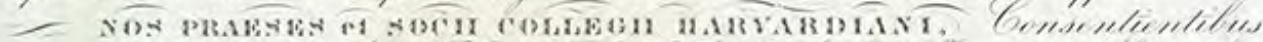

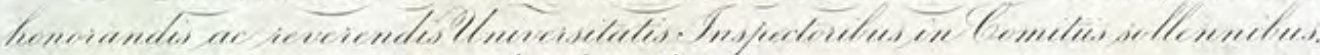
daralum ethayat

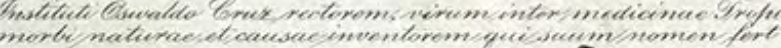

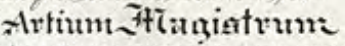

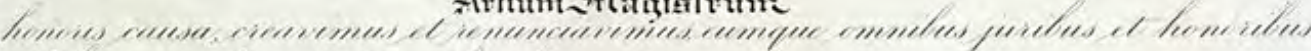

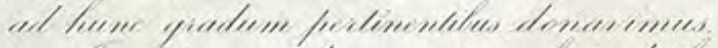

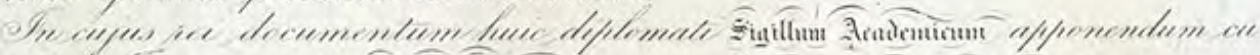

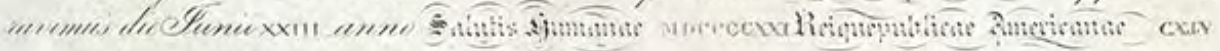
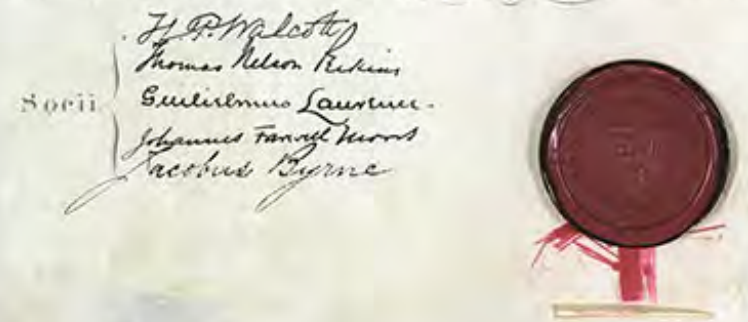

CAdecus Arrarii firatioctuas 


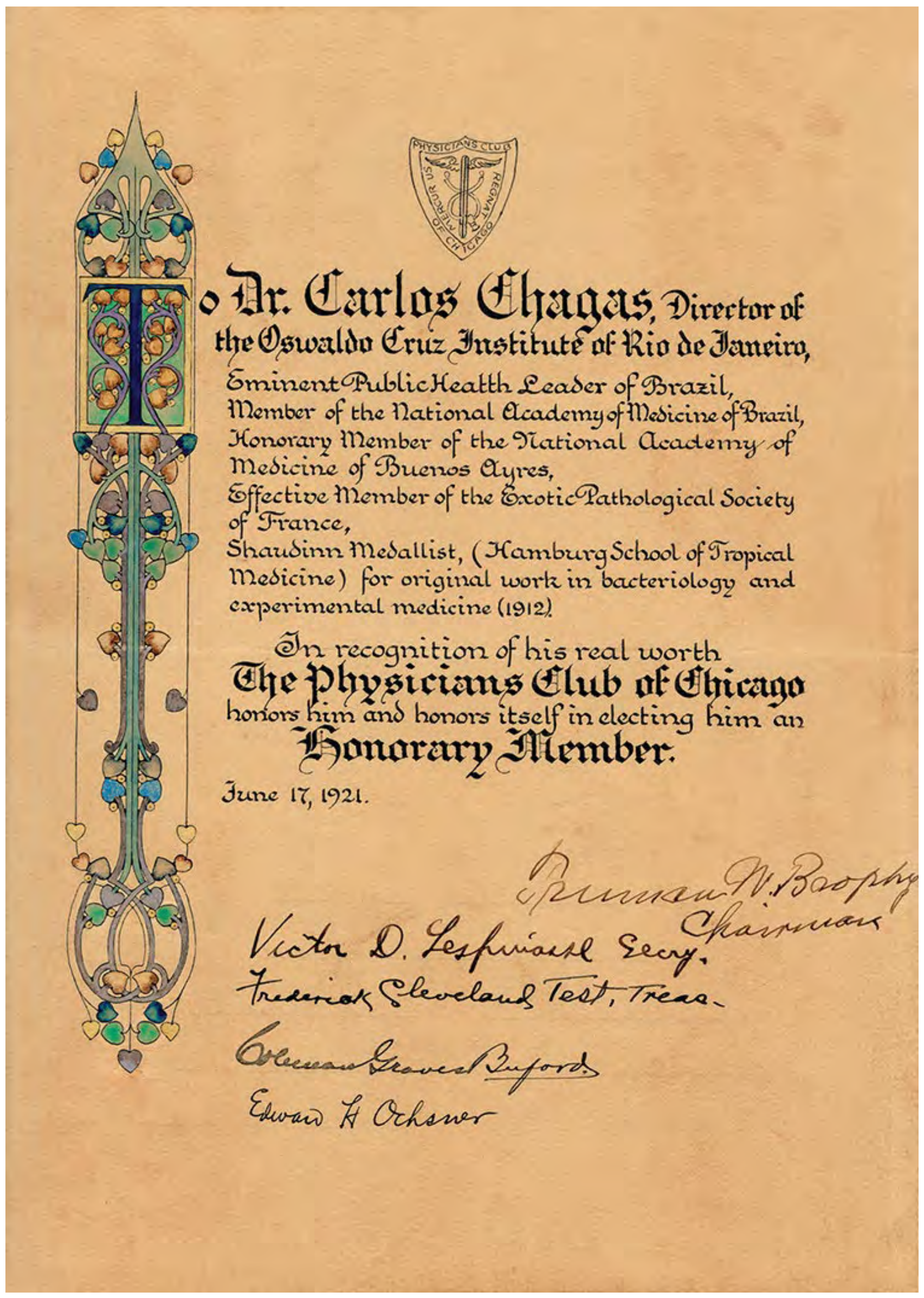

Diploma de membro honorário do

Acervo Casa de Oswaldo Cruz 

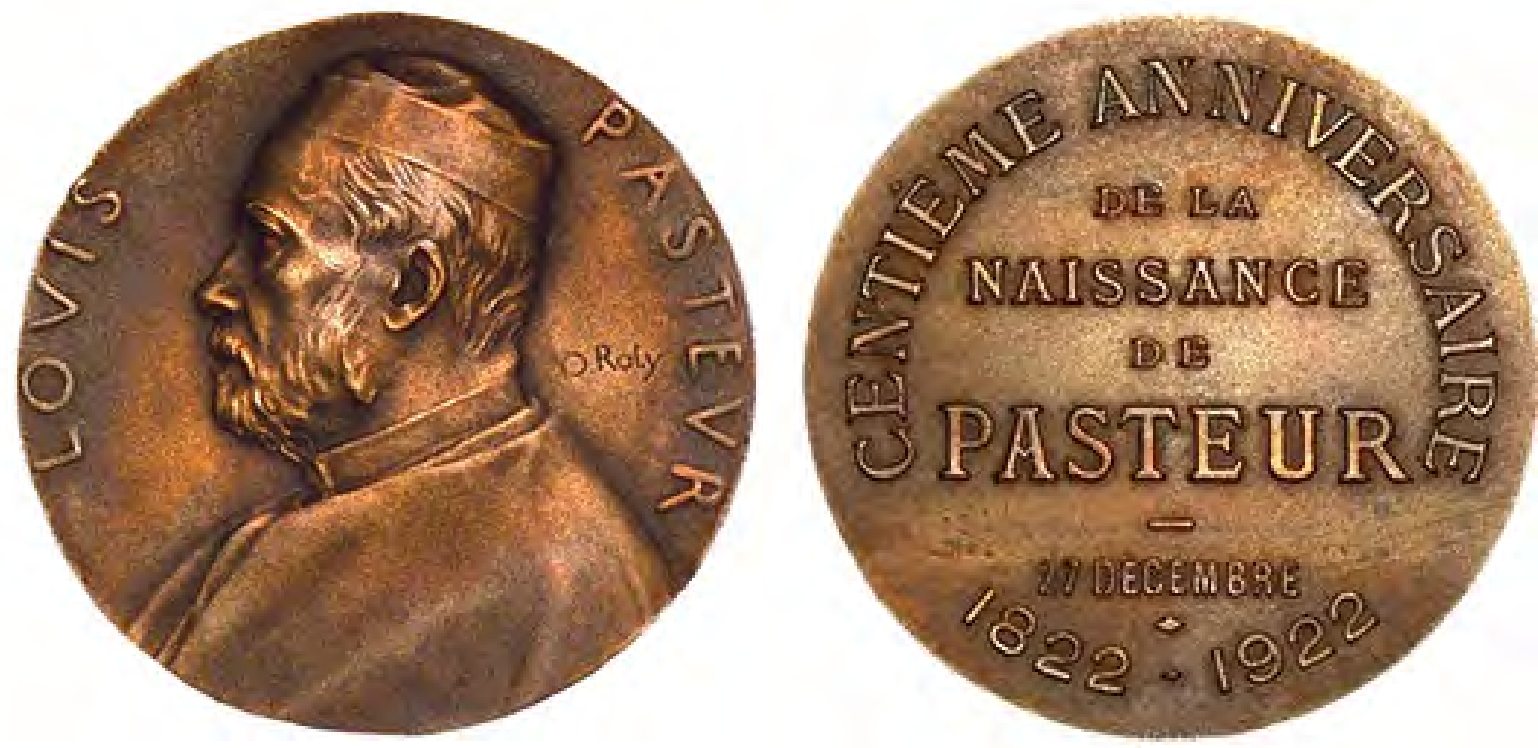

Medalha do centenário de

nascimento de Louis Pasteur,

comemorado em Estrasburgo,

França, em 1923

Acervo Casa de Oswaldo Cruz

Medal from the centennial of

Louis Pasteur's birth,

commemorated in Strasbourg,

France, 1923 

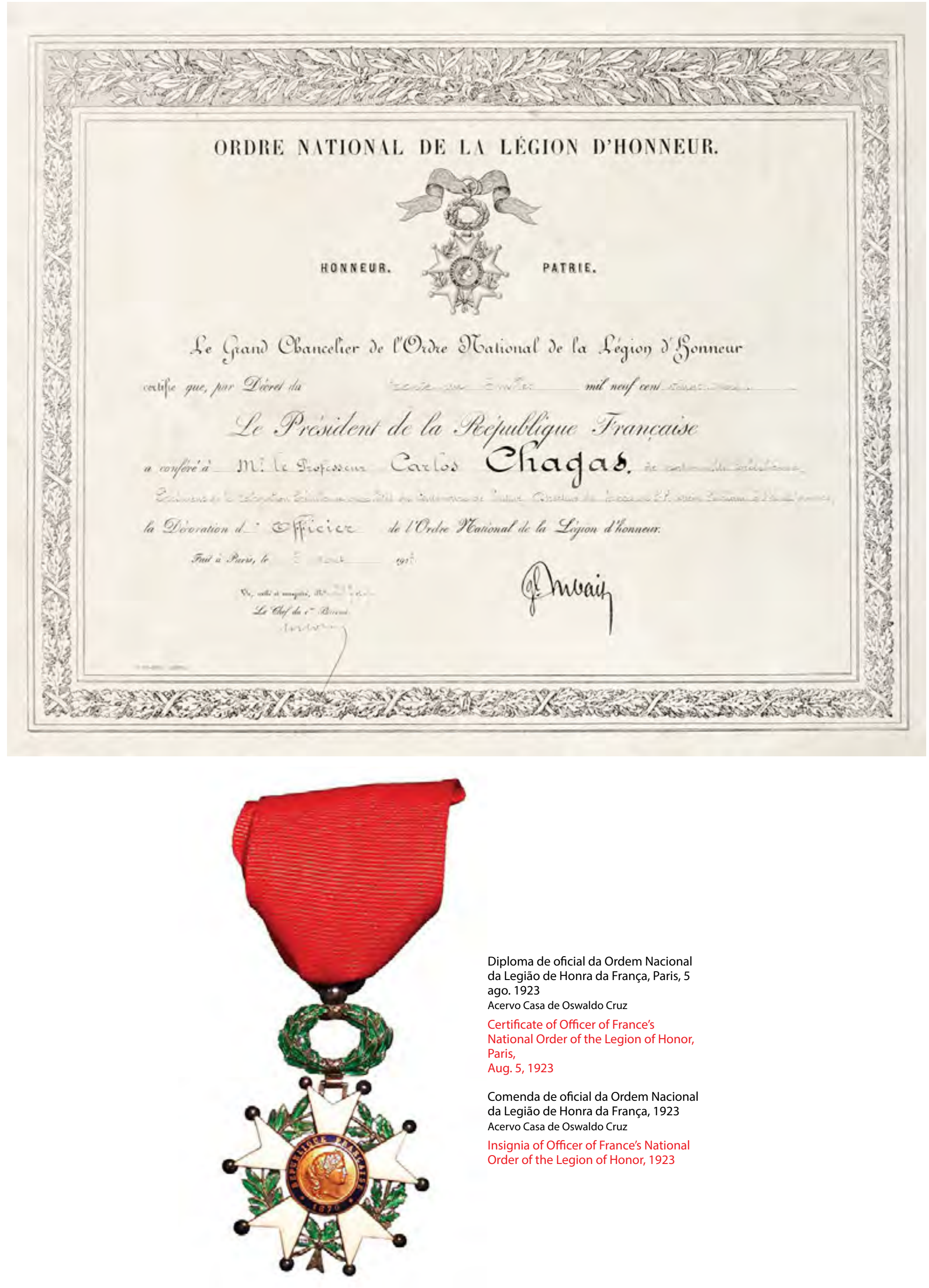

Diploma de oficial da Ordem Nacional da Legião de Honra da França, Paris, 5 ago. 1923

Acervo Casa de Oswaldo Cruz

Certificate of Officer of France's

National Order of the Legion of Honor Paris,

Aug. 5,1923

Comenda de oficial da Ordem Nacional da Legião de Honra da França, 1923 Acervo Casa de Oswaldo Cruz

Insignia of Officer of France's National Order of the Legion of Honor, 1923 


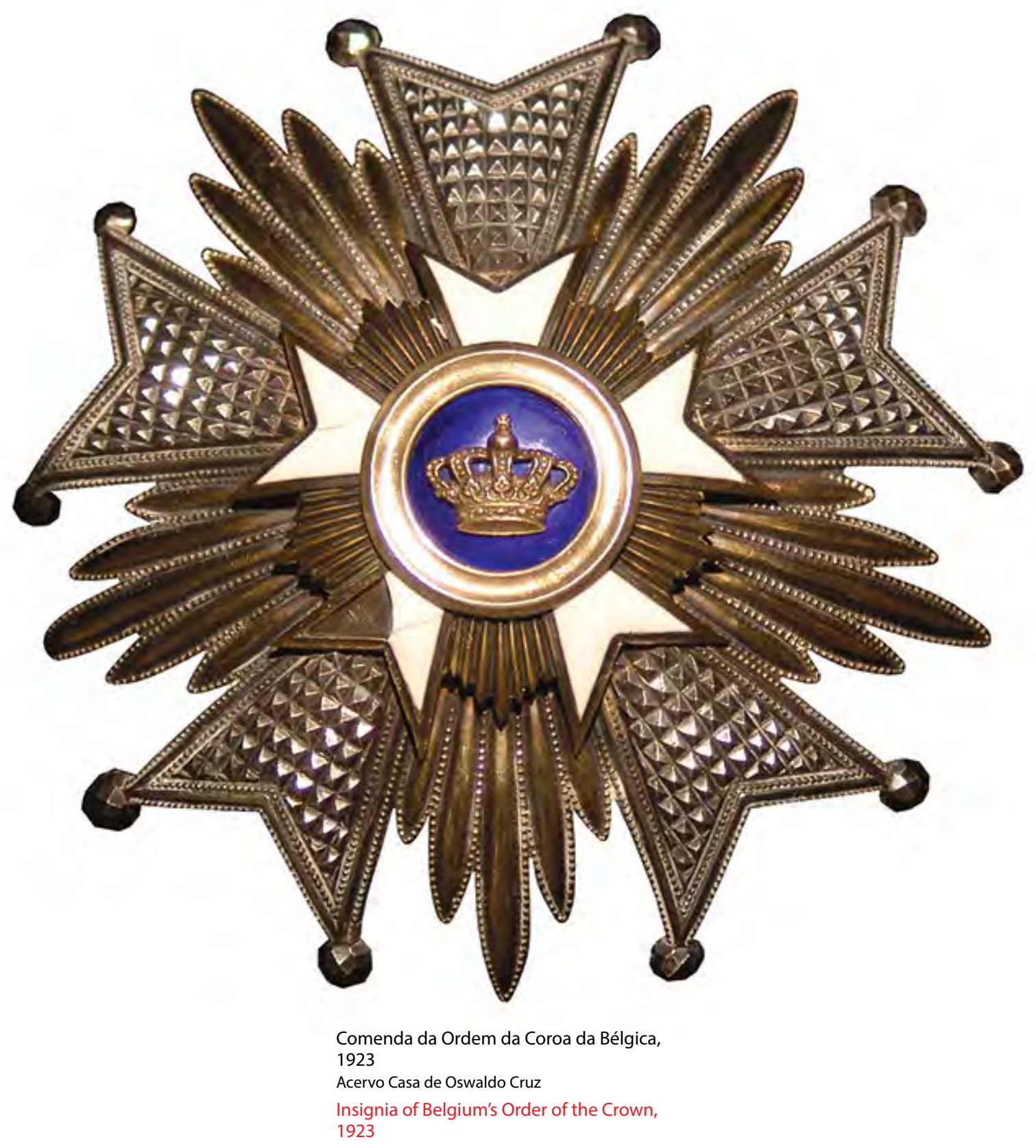




\section{Díemedizínísche rakultát der \\ tamburgíschen Uníversitất \\ verleíht díe goldene Ehrenmúnze der rakultät}

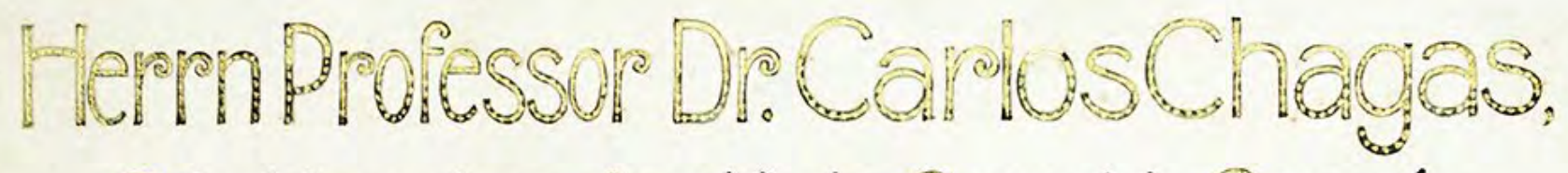

Dírektor des enstítuts oswaldo Cruz ín

Río de claneíro,

dem weltbekannten Erforscher der Tropenpathologíe Súdameríkas, dem Freunde deutscher Wissenschaft.

Zum Zeugnís dessen íst díese Lrkunde ausgestellt, mít dem Síegel der rakultất versehen undvom Dekan unterzeíchnetworden.

Hamburg, 5.November 1925.

Dr. Otho herkat

Dekan. 

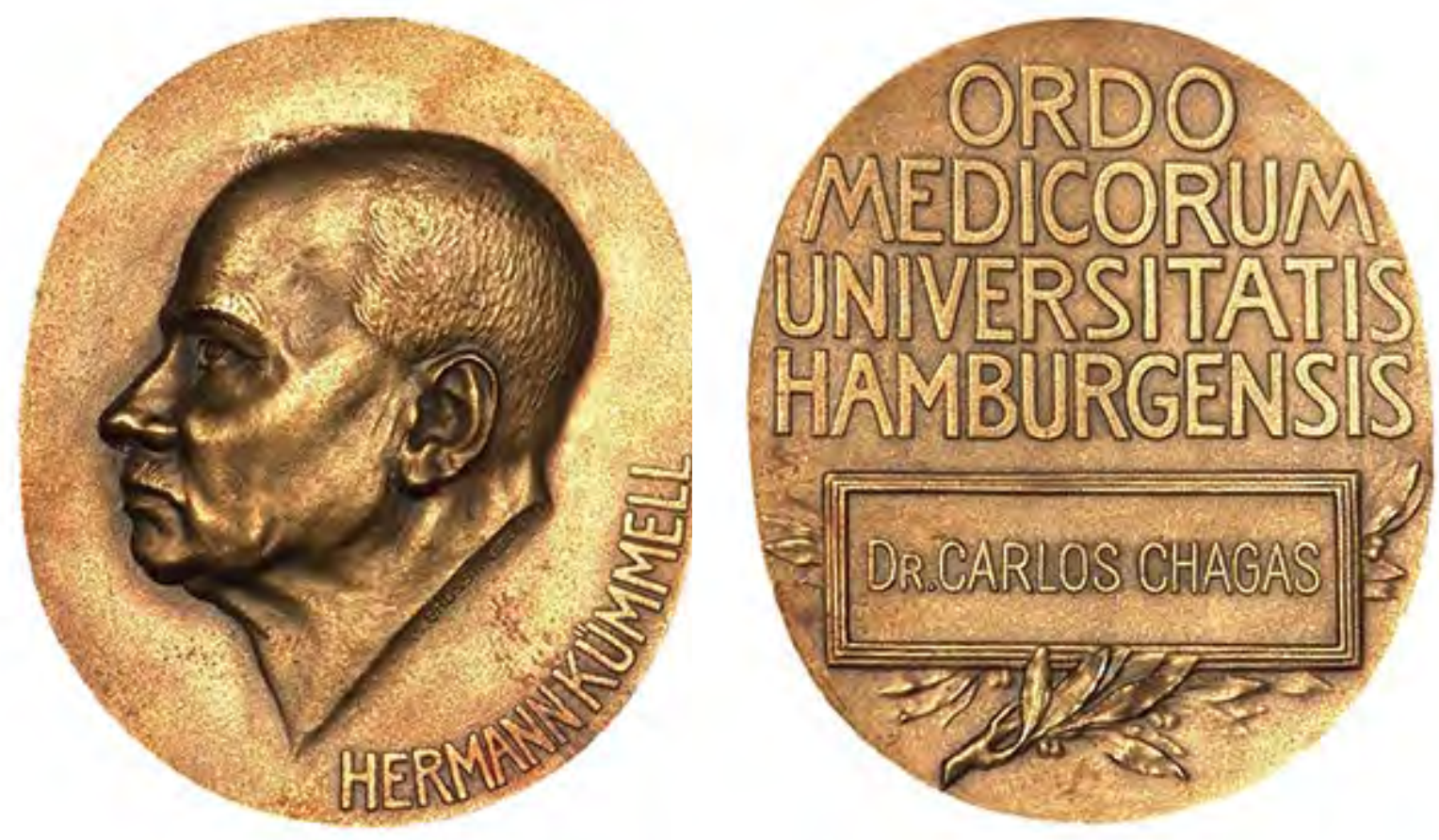

Medalha do Prêmio Kümmel concedida pela Faculdade de Medicina da Universidade de Hamburgo, Alemanha, 5 nov. 1925

Acervo Casa de Oswaldo Cruz

Kümmel Prize medal from the University of

Hamburg's School of Medicine, Germany,

Nov. 5, 1925 


\section{UNIVERSITE DE PARIS}

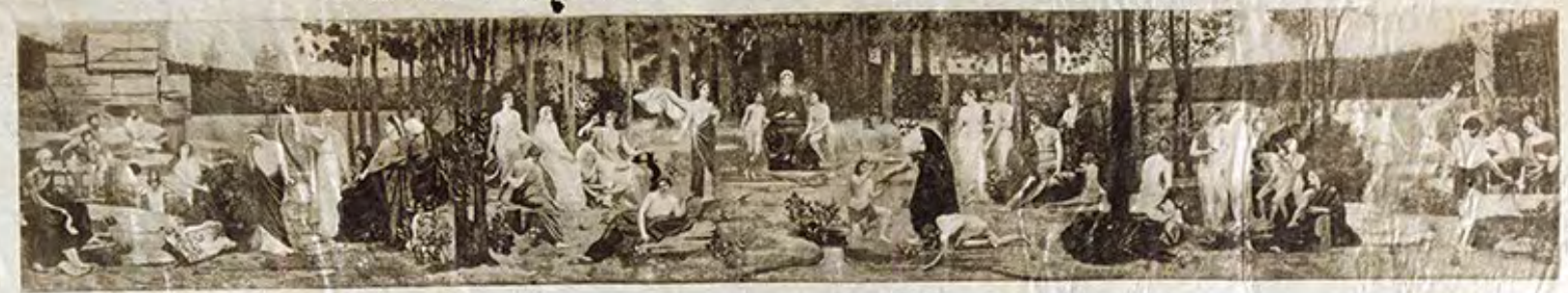

Nous, Président du Conseil de l'Université de Paris.

$V u$ le décret du 26 juin 1918 :

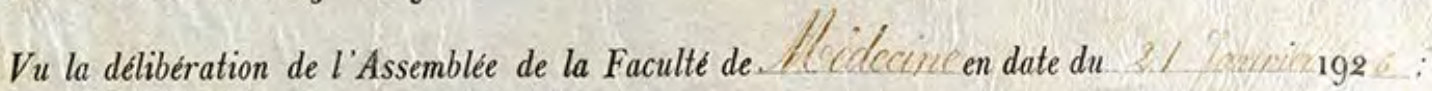

Vu la deliberation du Conseil de l Université de Paris en date du 192 :-

approuvé par le Ministre de l'Instruction publique le 23. (l (11.) 192 .

à Monsieur

Conférons par les présentes

le titre honorifique de Docteur de I Université de Paris.

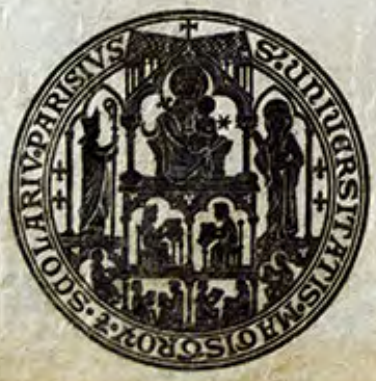

Fait en Sorbonne, sous le Sceau de l'Université,

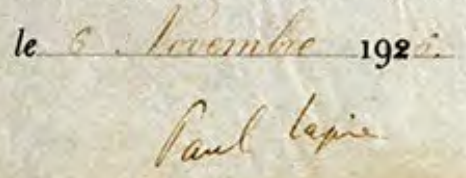

Diploma de doutor honoris causa da

Universidade de Paris, 5 nov. 1926

Acervo Casa de Oswaldo Cruz

Doctor Honoris Causa from Paris

University, Nov. 5, 1926 

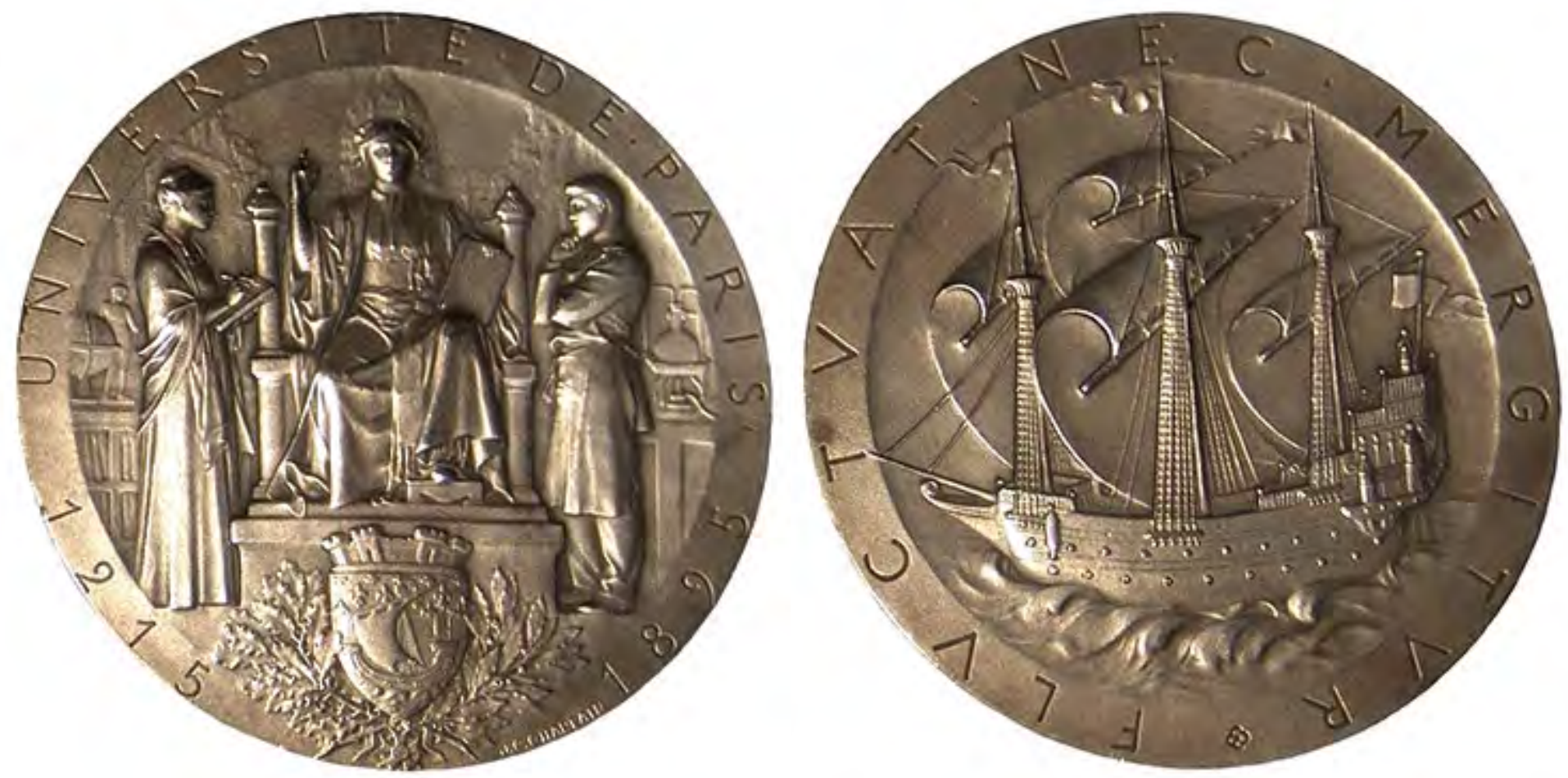

Medalha da Universidade de Paris,

1926

Acervo Casa de Oswaldo Cruz

Medal from Paris University, 1926 

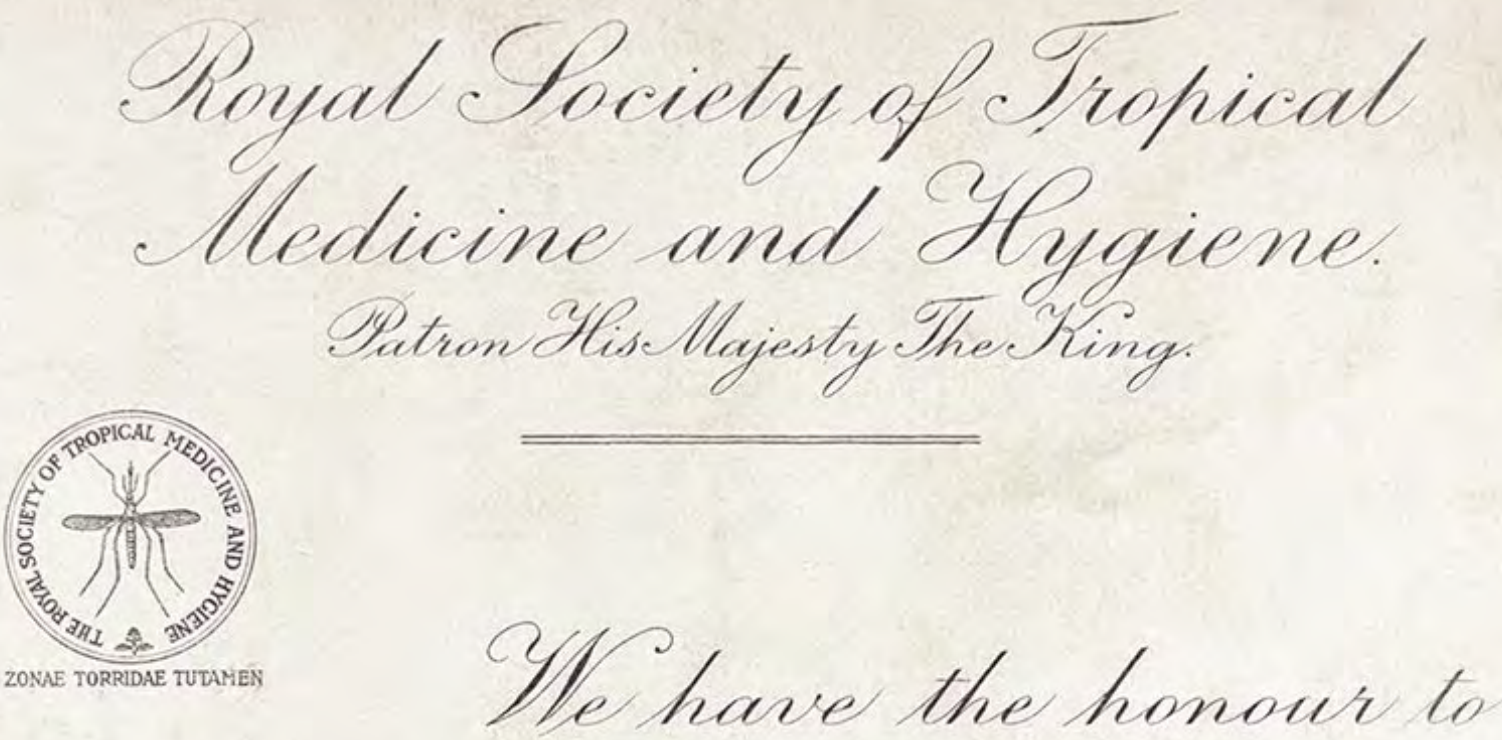
inform you that at the /leeting held on May3orh 1928 you were elected a Bellow of the Royal Society of Tropical olledicine and Mlygiene and that your name has bieen duly,

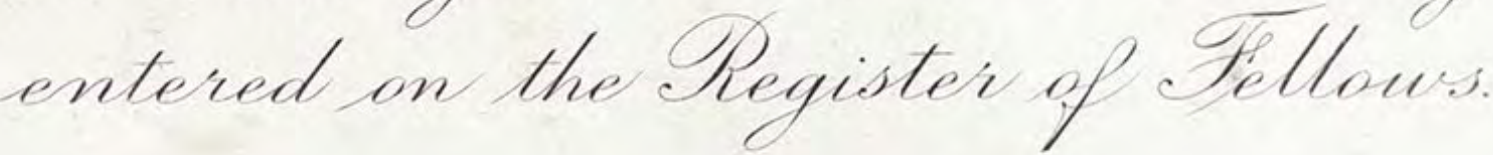

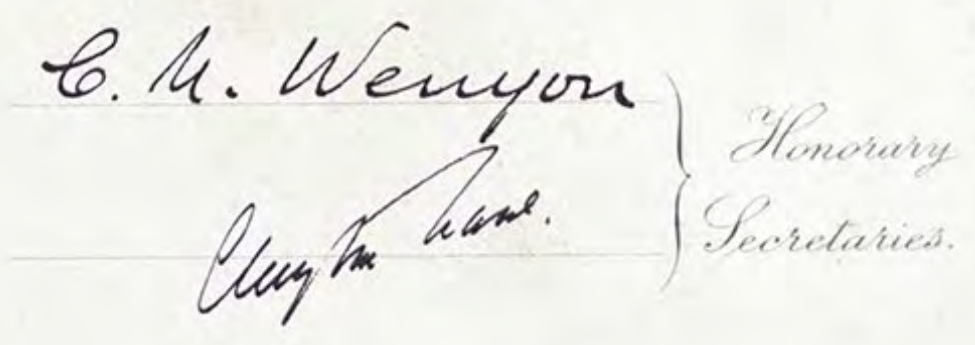

\section{Carlos Chagas}

\section{Numberom Mtayister, 2069 \\ Sondon. Auquet 128}

Diploma de membro da Sociedade Real de Medicina Tropical e Higiene de Londres, ago. 1928

Acervo Casa de Oswaldo Cruz

Certificate of fellow in the Royal

Society of Tropical Medicine and

Hygiene, London, Aug. 1928 

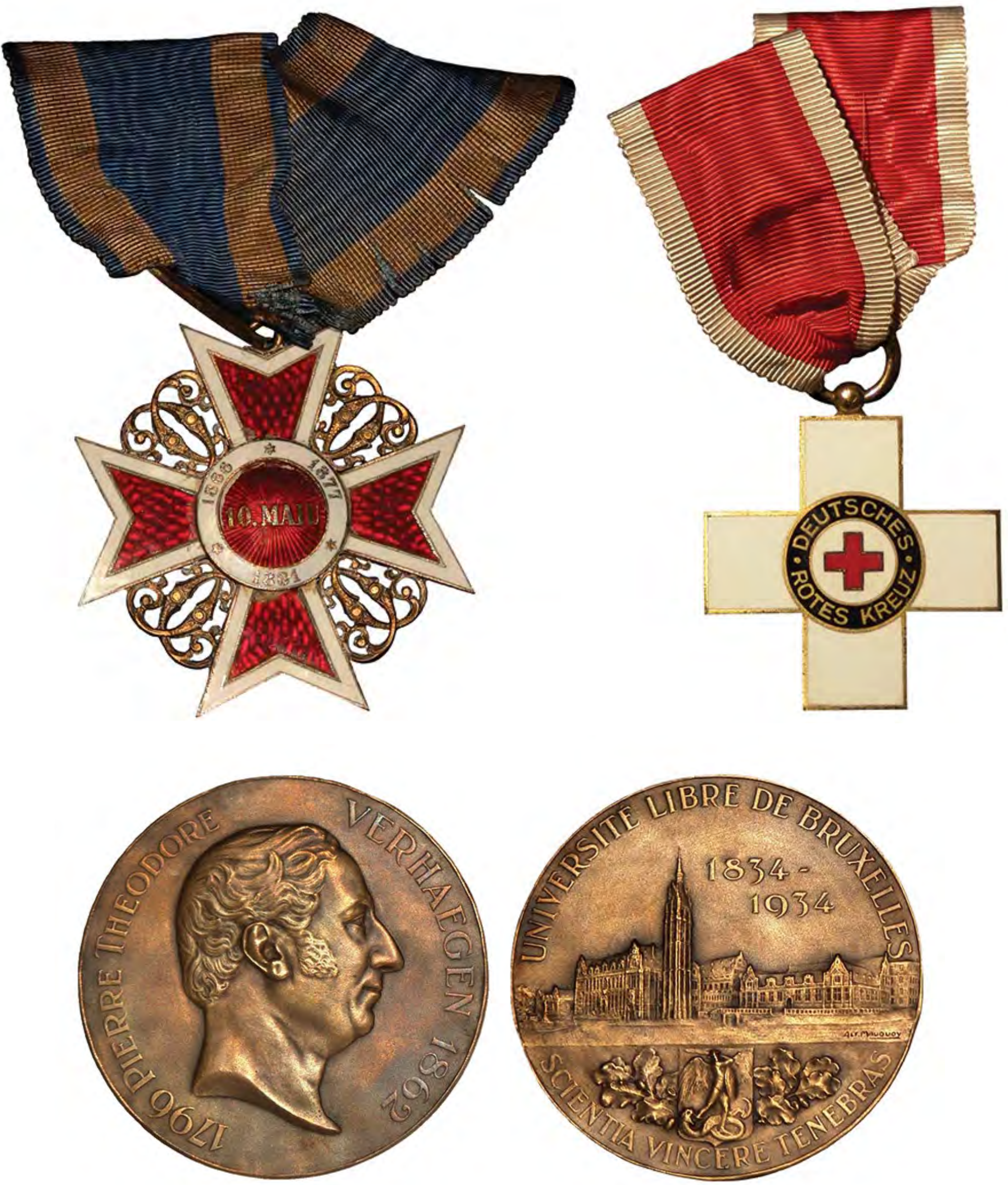

Comenda de cavaleiro da

Ordem da Romênia, 1929

Acervo Casa de Oswaldo Cruz

Insignia of Knight of the Order

of the Crown of Romania, 1929

Comenda da Cruz Vermelha Alemã, 1932

Acervo Casa de Oswaldo Cruz

Insignia from the German Red Cross, 1932

Medalha da Universidade Livre

de Bruxelas, 1934

Acervo Casa de Oswaldo Cruz

Medal from the Free University

of Brussels, 1934 
203

0.10 .40 .10

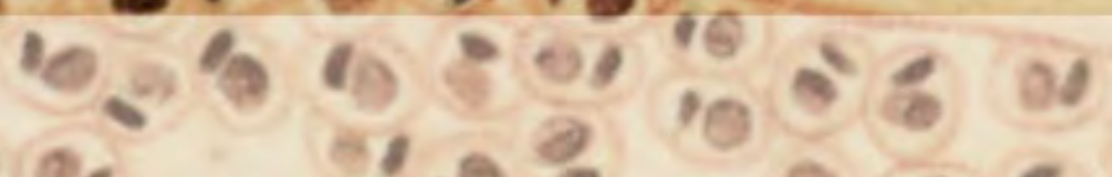

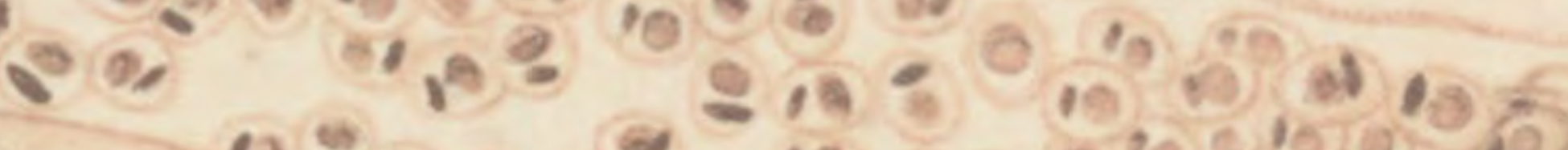

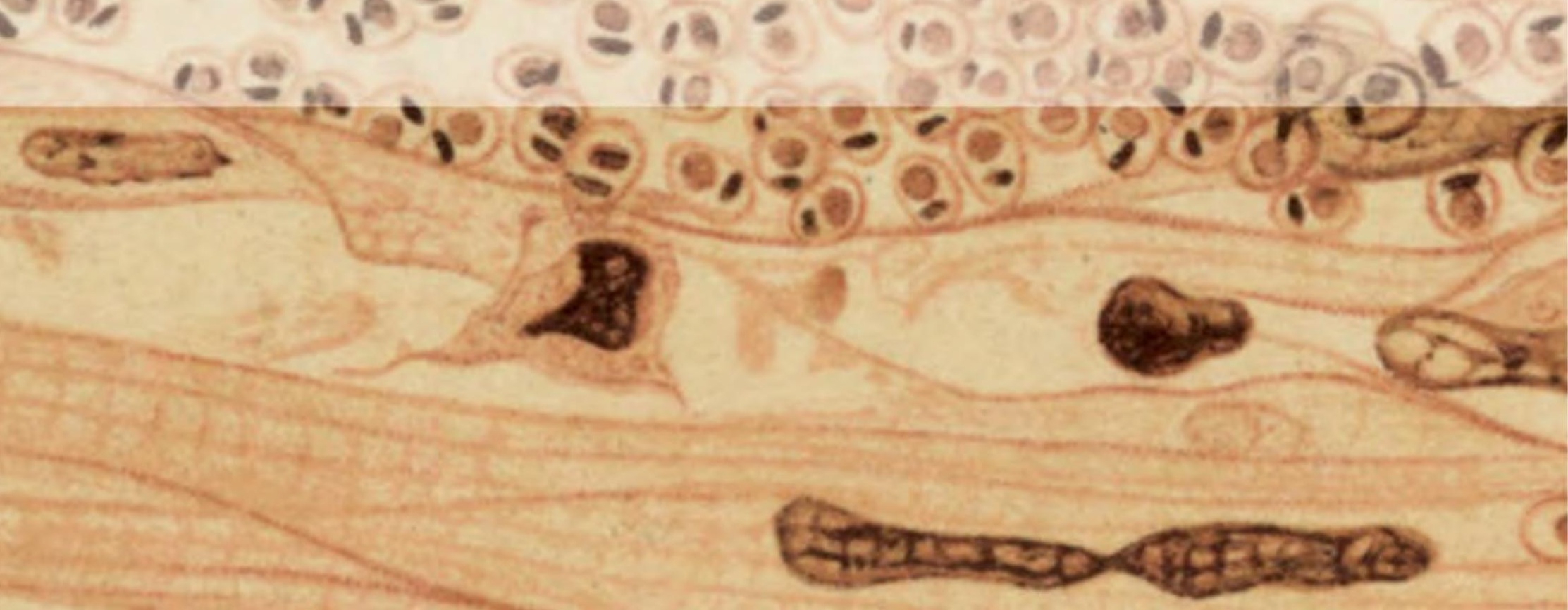
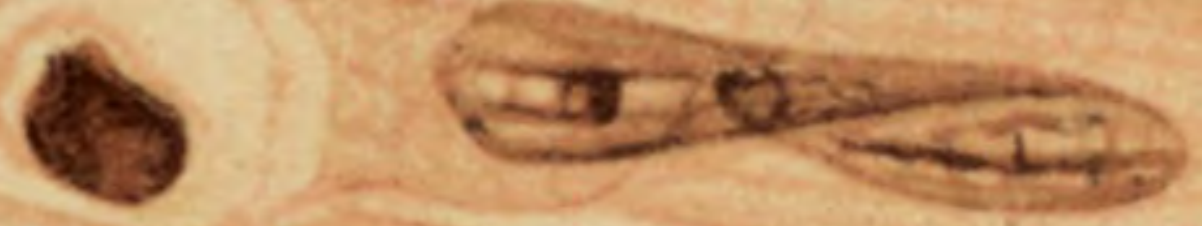

(अ92)

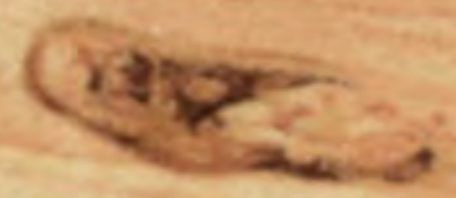

$$
\begin{aligned}
& 89 e^{4} \\
& 580^{\circ}
\end{aligned}
$$

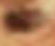
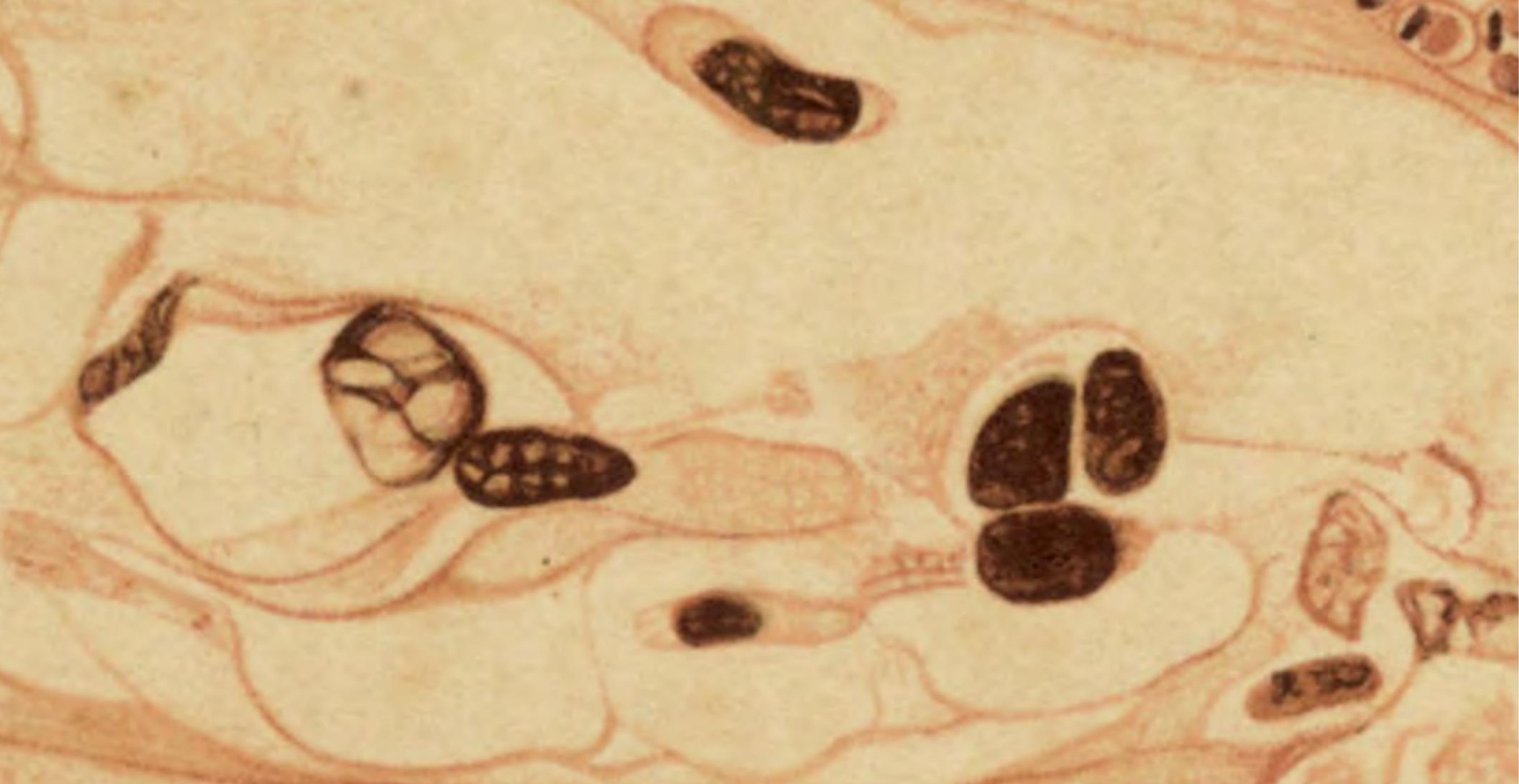


\section{Bibliografia/Bibliography}

A IMPRENSA. Um terrivel flagello que assola os sertões centraes do Brasil. Minas, Bahia, Goyaz, Mato-Grosso e parte de São Paulo presas do horrivel morbus. Entrevista com o dr. Carlos Chagas, o sabio descobridor do temivel microbio. A Imprensa, Rio de Janeiro, 6 ago. 1911, p. 1.

A NOITE. Os soberanos belgas no Brasil. A visita da rainha Elisabeth ao Instituto de Manguinhos. Foram optimas as impressões de $\mathrm{S}$. M., que pretende voltar a visita-lo. A Noite, Rio de Janeiro, 28 set. 1920, p. 2.

A NOITE. Os debates da sciencia. Outra vez em ordem do dia a 'Molestia de Chagas'. Precisando os termos da questão - primeiros depoimentos traquillos. A Noite, Rio de Janeiro, 11 dez. 1922, p. 1.

A NOITE. Turvando a sciencia. A Moléstia de Chagas e a attitude da Academia de Medicina. Deslocou-se a questão do seu verdadeiro plano. A Noite, Rio de Janeiro, 15 dez. 1922, p. 1.

A NOITE. A installação do Centro Internacional de Leprologia no Brasil. Fala à Noite, sobre a missão desse instituto scientifico, o professor Carlos Chagas. A Noite, Rio de Janeiro, 27 mar. 1934, p. 1.

ALMEIDA, M. O. de. Carlos Chagas. In: ALMEIDA, M. O. de. Ensaios, Críticas e Perfis. Rio de Janeiro: F. Brigueit \& Cia., 1938.

ARAGÃO, H. de B. Notícia histórica sobre a fundacão do Instituto Oswaldo Cruz (Instituto de Manguinhos). In: UNIVERSIDADE FEDERAL DO RIO DE JANEIRO Oswaldo Cruz no Julgamento dos Contemporâneos. Rio de Janeiro: Editora FGV, 1972.

ARQUIVO NACIONAL. Dicionário Brasileiro de Terminologia Arquivística. Rio de Janeiro: Arquivo Nacional, 2005.

ASSEMBLÉIA LEGISLATIVA DO ESTADO DE MINAS GERAIS. O estado: municípios mineiros - Lassance. Disponível em: <www.almg.gov.br/index.asp?grupo= estado\&diretorio $=$ munmg\&arquivo $=$ municipios $\&$ municipio=38104>. Acesso em: 10 mar. 2009.

ASSIS, M. Relíquias de casa velha. In: ASSIS, M. Obra Completa. Rio de Janeiro: Nova Aguilar, 1994. v. 2.

BACELLAR, R. C. Carlos Chagas. Medicina Universitária, 1(2): 3-13, 1938. (Separata).

BARBOSA, V. A. Dicionário Histórico-Geográfico de Minas Gerais. Belo Horizonte: Itatiaia, 1995.

BELLOTTO, H. L. Arquivos Permanentes: tratamento documental. 4. ed. Rio de Janeiro: Editora FGV, 2007.

BENCHIMOL, J. L. (Coord.) Manguinhos do Sonho à Vida: a ciência na Belle Époque. Rio de Janeiro: Casa de Oswaldo Cruz/Fiocruz, 1990.

BENCHIMOL, J. L. Dos Micróbios aos Mosquitos: febre amarela e a revolução pasteuriana no Brasil. Rio de Janeiro: Editora Fiocruz, Editora UFRJ, 1999.

BENCHIMOL, J. L. (Coord.) Febre Amarela: a doença e a vacina, uma história inacabada. Rio de Janeiro: Editora Fiocruz, Bio-Manguinhos, 2001.

BENCHIMOL, J. L. Reforma urbana e Revolta da Vacina na cidade do Rio de Janeiro. In: FERREIRA, J. \& DELGADO, L. A. N. (Orgs.) O Tempo do Liberalismo Excludente: da proclamação da República à Revolução de 1930. Rio de Janeiro: Civilização Brasileira, 2003. (O Brasil Republicano, 1)

BENCHIMOL, J. L. \& SÁ, M. R. Insetos, humanos e doenças: Adolpho Lutz e a medicina tropical. In: BENCHIMOL, J. L. \& SÁ, M. R. (Orgs.) Adolpho Lutz: obra completa. Rio de Janeiro: Editora Fiocruz, 2005. v. 2 , livro 1.

BENCHIMOL, J. L. \& SÁ, M. R. Adolpho Lutz e a entomologia médica no Brasil. In: BENCHIMOL, J. L. \& SÁ, M. R. (Orgs.) Adolpho Lutz: obra completa. Rio de Janeiro: Editora Fiocruz, 2006. v. 2, livro 3.

BENCHIMOL, J. L. \& SILVA, A. F. C. da. Ferrovias, doenças e medicina tropical no Brasil da Primeira República. História, Ciências, Saúde - Manguinhos, 15: 719-762, 2008.

BENCHIMOL, J. L. \& TEIXEIRA, L. A. Cobras, Lagartos \& Outros Bichos: uma história comparada dos institutos Oswaldo Cruz e Butantan. Rio de Janeiro: Editora UFRJ, 1993.

BIBLIOTECA VIRTUAL EM SAÚDE CARLOS CHAGAS. Site. Disponível em: <www.bvschagas.coc.fiocruz.br>.

BRAGA, T. (Org.). Álbum da cidade de S. João d'El Rei. [Rio de Janeiro]: Pimenta de Mello, 1913.

BRENER, Z. A descoberta (homenagem aos 80 anos da descoberta da doença de Chagas). Memórias do Instituto Oswaldo Cruz, 84, supl. II: 1-6, 1989.

BRITTO, N. Oswaldo Cruz: a construção de um mito na ciência brasileira. Rio de Janeiro: Editora Fiocruz, 1995.

BURTON, R. Explorations of the Highlands of the Brazil: with a full account of the gold and diamond mines, also canoeing down 1500 miles of the great river São Francisco, from Sabara to the sea. New York: Greenwood Press, 1969.

BURTON, R. Viagem de Canoa de Sabará ao Oceano Atlântico. Belo Horizonte, São Paulo: Itatiaia, Edusp, 1976.

BURTON, R. Viagens pelos Planaltos do Brasil. 2. ed. São Paulo, Brasília: Companhia Editora Nacional, Instituto Nacional do Livro, 1983. v. 1.

CAMARGO, A. M. A. \& GOULART, S. Tempo e Circunstância: a abordagem contextual dos arquivos pessoais - procedimentos metodológicos adotados na organização dos documentos de Fernando Henrique Cardoso. São Paulo: Instituto Fernando Henrique Cardoso, 2007.

CARETA. Dr. Carlos Chagas. Careta, Rio de Janeiro, 19 out. 1912.

CARETA. Sem título. Careta, Rio de Janeiro, 9 nov. 1918.

CARETA. O porteiro implacável. Careta, Rio de Janeiro, 7 fev. 1920.

CASTRO-SANTOS, L. A. O pensamento sanitarista na Primeira República: uma ideologia de construção da nacionalidade. Dados, 28 (2): 193-210, 1985.

CASTRO-SANTOS, L. A. Power, Ideology and Public Health in Brazil (1889-1930), 1987. PhD Thesis, Cambridge: Harvard University.

CASTRO-SANTOS, L. A. \& FARIA, L. O ensino de saúde pública no Brasil: os primeiros tempos no Rio de Janeiro. Trabalho, Educação e Saúde, 4(2): 291-324, 2006.

CHAGAS, C. Estudos Hematologicos no Impaludismo. Rio de Janeiro: Typographia da Papelaria União, 1903.

CHAGAS, C. Prophylaxia do Impaludismo. Rio de Janeiro: Typographia Besnard Frères, 1906.

CHAGAS, C. Nova especie morbida do homem, produzida por um trypanozoma (Trypanozoma Cruzi): nota previa. Brazil-Medico, 23(16): 161, 1909. 
CHAGAS, C. Nova tripanozomiase humana: estudos sobre a morfolojia e o ciclo evolutivo do Schizotrypanum cruzi $n$. gen., $n$. sp., ajente etiolojico de nova entidade morbida do homem. Memórias do Instituto Oswaldo Cruz, 1(2): 159-218, 1909.

CHAGAS, C. Relatório aprezentado pelo chefe da comissão medica ao sub-diretor da $6^{\mathrm{a}}$ divizão da E. F. Central do Brazil. In: REIS, A. Relatorio da Estrada de Ferro Central do Brazil Referente ao Ano de 1907 Apresentado ao Exmo. Sr. Dr. Miguel Calmon du Pin e Almeida, Ministro e Secretario d'Estado dos Negocios da Industria, Viação e Obras Publicas. Rio de Janeiro: Imprensa Nacional, 1909

CHAGAS, C. Aspecto clinico geral da nova entidade morbida produzida pelo Schizotrypanum cruzi: nota previa. Brazil-Medico, 24(27): 263-265, 1910

CHAGAS, C. Nova entidade morbida do homem. BrazilMedico, 24(43, 44, 45): 423-428, 433-437, 443-447, 1910.

CHAGAS, C. Sobre a etiologia do bocio endemico no estado de Minas Gerais: nota preliminar. BrazilMedico, 24(17): 163, 1910.

CHAGAS, C. Nova entidade morbida do homem: rezumo geral de estudos etiolojicos e clinicos. Memórias do Instituto Oswaldo Cruz, 3(2): 219-275, 1911.

CHAGAS, C. Discurso pronunciado pelo Dr. Carlos Chagas, Orador Official, na Sessão Solene do VII Congresso Brasileiro de Medicina e Cirurgia Realizado em Bello Horizonte em 21 de abril de 1912. Bello Horizonte: Imprensa Oficial, 1912.

CHAGAS, C. Notas sobre a epidemiologia do Amazonas. Brazil-Medico, 27(42): 450-456, 1913.

CHAGAS, C. Processos patojenicos da tripanozomiase americana. Memórias do Instituto Oswaldo Cruz, 8(2): 5-35, 1916.

CHAGAS, C. Descoberta do Trypanozoma Cruzi e verificação da tripanozomiase americana: retrospecto historico. Memórias do Instituto Oswaldo Cruz, 15(1): 67-76, 1922.

CHAGAS, C. Sessão de 6 de dezembro de 1923. Boletim da Academia Nacional de Medicina, 791-810, 1923.

CHAGAS, C. Estado actual da trypanosomiase americana. Revista de Biologia e Hygiene, 5(2): 58-64, 1934.

CHAGAS, C. Aula inaugural da cadeira de medicina tropical - 14 de setembro de 1926. In: CHAGAS, C. Discursos e Conferencias. Rio de Janeiro: A Noite, 1935.

CHAGAS, C. Lição de abertura dos cursos da Faculdade de Medicina do Rio de Janeiro - 1928. In: CHAGAS C. Discursos e Conferencias. Rio de Janeiro: A Noite, 1935.

CHAGAS, C. \& VILLELA, E. Forma cardiaca da trypanosomiase americana. Memórias do Instituto Oswaldo Cruz, 14(1): 5-61, 1922.

CHAGAS FILHO, C. Meu Pai. Rio de Janeiro: Casa de Oswaldo Cruz/Fiocruz, 1993.

CORREIO DA MANHÃ. A 'doença Carlos Chagas'. A sessão de hontem no hospital da Misericórdia. Correio da Manhã, Rio de Janeiro, 11 ago. 1911, p. 3.

CORREIO DA MANHÃ. O presidente da Republica manda distribuir caldo e pão à pobreza. Correio da Manhã, Rio de Janeiro, 22 out. 1918, p. 1.

CORREIO DA MANHÃ. O presidente da Republica tranquilliza a população. Correio da Manhã, 24 out. 1918 , p. 1.
CORREIO DA MANHÃ. Sem título. Correio da Manhã, Rio de Janeiro, 11 jan. 1919, p. 5.

CORREIO DA MANHÃ. Uma notavel sessão na Academia de Medicina. O Dr. Carlos Chagas, como estava annunciado, fez a sua defesa de modo brilhante. Correio da Manhã, Rio de Janeiro, 7 dez. 1923, p. 3.

COSTA FILHO, O. et al. Cozinha do Arco da Velha. Rio de Janeiro: Nova Fronteira, 1997.

COUTINHO, M. Ninety years of Chagas disease: a sucess story at the periphery. Social Studies of Science, 29(4): 519-549, 1999.

COUTINHO, M. Tropical medicine in Brazil: the case of Chagas disease. In: ARMUS, D. (Ed.) Disease in the History of Modern Latin America: from malaria to Aids. Durham, London: Duke University Press, 2003.

COUTINHO, M. \& DIAS, J. C. P. A reason to celebrate: the saga of Brazilian chagologists. Ciência e Cultura, 51(5/6): 394-410, 1999.

COUTINHO, M; FREIRE JR., O. \& DIAS, J. C. P. The Nobel enigma: Chagas nominations for the Nobel Prize. Memórias do Instituto Oswaldo Cruz, 94, supl. I: 123-129, 1999.

CRUZ, O. G. Algumas molestias produzidas por protozoarios. Conferencia feita na Bibliotheca Nacional pelo Dr. Oswaldo Cruz. Brazil-Medico, 29(44-45): 345-346, 353-356, 1915.

CUNHA, E. Os Sertões: campanha de Canudos. Rio de Janeiro: Laemmert, 1902.

CUNHA, E. Rebellion in the Backlands. Trad. Samuel Putnam. Chicago: University of Chicago Press, 1944.

D. QUIXOTE. Uma serie seria. D. Quixote, Rio de Janeiro, 29 out. 1920 , p. 1.

DIAS, E. C. Traços de Oswaldo Cruz. In: UNIVERSIDADE FEDERAL DO RIO DE JANEIRO. Oswaldo Cruz no Julgamento dos Contemporâneos. Rio de Janeiro: Editora FGV, 1972.

DIRETORIA GERAL DE SAÚDE PÚBLICA. Os Serviços de Saúde Pública no Brasil, Especialmente na Cidade do Rio de Janeiro de 1808 a 1907: esboço histórico e legislação. Rio de Janeiro: Imprensa Nacional, 1909.

EDLER, F. O debate em torno da medicina experimental no Segundo Reinado. História, Ciências, Saúde Manguinhos, 3(2): 284-299, 1996.

EDLER, F. A Constituição da Medicina Tropical no Brasil Oitocentista: da climatologia à parasitologia médica, 1999. Tese de Doutorado, Rio de Janeiro: Instituto de Medicina Social, Universidade do Estado do Rio de Janeiro.

EDLER, F. A institucionalização da medicina no Brasil Imperial. In: ANDRADE, A. M. R. (Org.). Ciência em Perspectiva: estudos, ensaios e debates. Rio de Janeiro: Museu de Astronomia e Ciências Afins, Sociedade Brasileira de História da Ciência, 2003.

EDWARDS, E. \& HART, J. (Eds.). Photographs Objects Histories: on the materiality of images. London, New York: Routledge, 2004.

ENCICLOPÉDIA dos Municípios Brasileiros. Rio de Janeiro: IBGE,1957-1958. v. 5.

ESCOLA ANATÔMICA, CIRÚRGICA E MÉDICA DO RIO DE JANEIRO. Dicionário Histórico-Biográfico das Ciências da Saúde no Brasil (1832-1930). Disponível em: <www.dichistoriasaude.coc.fiocruz.br>. Acesso em: 10 mar. 2006. 
FON-FON. A epidemia reinante. Fon-Fon, Rio de Janeiro, 2 nov. 1918.

FONSECA, L. G. História de Oliveira. Belo Horizonte: Bernardo Álvares, 1961.

FONSECA FILHO, O. A Escola de Manguinhos: contribuição para o estudo do desenvolvimento da medicina experimental no Brasil. São Paulo: Revista dos Tribunais, 1974. (Separata do Tomo II de 'Oswaldo Cruz monumenta histórica').

FRAGA, C. Nova entidade morbida do homem descoberta e estudada pelo Dr. Carlos Chagas. Brazil-Medico, 25(47): 473-478, 1911.

FRAGA, C. et al. Academia Nacional de Medicina, 13 de dezembro de 1934. Sessão conjunta das sociedades sábias em homenagem ao Prof. Carlos Chagas. O Hospital, 7(1): 77-82, 1935.

GAZETA DE NOTICIAS. Em Xerém: na captação das águas a febre palustre dizima. Gazeta de Noticias, Rio de Janeiro, 2 maio 1907, p. 3.

GAZETA DE NOTICIAS. Uma nova molestia. Na Academia Nacional de Medicina. Importante Communicação. A 'trypanozoma Cruzi'. Gazeta de Noticias, Rio de Janeiro, 23 abr. 1909, p. 1.

GAZETA DE NOTICIAS. Mais uma? Gazeta de Noticias, Rio de Janeiro, 29 set. 1918, p. 1.

GAZETA DE NOTICIAS. Academia Nacional de Medicina. O Dr. Carlos Chagas e os seus estudos sobre a trypanozomiase americana. Gazeta de Noticias, Rio de Janeiro, 13 nov. 1923, p. 3

GERODETTI, J. E. \& CORNEJO, C. As Ferrovias do Brasil nos Cartões-Postais e Álbuns de Lembranças. São Paulo: Solaris Edições Culturais, 2005.

GOULART, A. C. Revisitando a espanhola: a gripe pandêmica de 1918 no Rio de Janeiro. História, Ciências, Saúde - Manguinhos, 12(1): 101-142, 2005.

GUERRA, E. S. Oswaldo Cruz. Rio de Janeiro: Vecchi, 1940.

HOCHMAN, G. A Era do Saneamento: as bases da política de saúde pública no Brasil. São Paulo: Hucitec, Anpocs, 1998.

INSTITUTO BRASILEIRO DE GEOGRAFIA E ESTATÍSTICA (IBGE). Cidades: Lassance. Disponível em: <www.ibge.gov.br/cidadesat/topwindow.htm?1>. Acesso em: 10 mar. 2009.

INSTITUTO BRASILEIRO DE GEOGRAFIA E ESTATÍSTICA (IBGE). Lassance. Disponível em: <biblioteca.ibge.gov.br/visualizacao/dtbs/minasgerais/ lassance.pdf $>$. Acesso em: 10 mar. 2009.

INSTITUTO BRASILEIRO DE GEOGRAFIA E ESTATÍSTICA (IBGE). Pirapora. Disponível em: <biblioteca.ibge.gov.br/visualizacao/dtbs/minasgerais/ pirapora.pdf>. Acesso em: 10 mar. 2009.

JORNAL DO COMMERCIO. A manifestação dos acadêmicos ao professor Aloysio de Castro. Jornal do Commercio, Rio de Janeiro, 11 out. 1916, p. 4.

JORNAL DO COMMERCIO. Banquete ao dr. Carlos Chagas. Jornal do Commercio, Rio de Janeiro, 22 out. 1916, p. 3.

JORNAL DO COMMERCIO. Trypanosomiase americana. Uma rectificação do Sr. Dr. Carlos Chagas á conferencia do Dr. Figueiredo de Vasconcellos. Jornal do Commercio, Rio de Janeiro, 23 ago. 1919, p. 6-7.

JORNAL DO COMMERCIO. A nova orientação do serviço sanitario no Brasil. Conferencia do Dr. Carlos
Chagas. Jornal do Commercio, Rio de Janeiro, $11 \mathrm{fev}$. 1921, p. 4.

KALTMAN, H. Docas de Santos: uma empresa através dos séculos. Rio de Janeiro: Agir, 2000.

KRAUS, R. \& ROSENBUSCH, F. Bocio, cretinismo y enfermedad de Chagas. $2^{\mathrm{a}}$. comunicación. La Prensa Medica Argentina, 3(17): 177-180, 1916.

KRAUS, R.; MAGGIO, C. \& ROSENBUSCH, F. Bocio, cretinismo y enfermedad de Chagas. $1^{\text {a }}$. comunicación. La Prensa Medica Argentina, 2(1): 2-5, 1915.

KROPF, S. P. Carlos Chagas e os debates e controvérsias sobre a doença do Brasil (1909-1923). História, Ciências, Saúde - Manguinhos, 16, supl.: 205-227, 2009.

KROPF, S. P. Doença de Chagas, Doença do Brasil: ciência, saúde e nação (1909-1962). Rio de Janeiro: Editora Fiocruz, 2009.

KROPF, S. P.; AZEVEDO, N. \& FERREIRA, L. O. Doença de Chagas: a construção de um fato científico e de um problema de saúde pública no Brasil. Ciência e Saúde Coletiva, 5(2): 347-365, 2000.

KROPF, S. P.; AZEVEDO, N. \& FERREIRA, L. O. Biomedical research and public health in Brazil: the case of Chagas disease (1909-1950). Social History of Medicine, 16(1): 111-129, 2003.

KROPF, S. P. \& HOCHMAN, G. Chagas, Carlos Ribeiro Justiniano. In: BYNUM, W. F. \& BYNUM, H. (Eds.). Dictionary of Medical Biography. Connecticut, London: Greenwood Press, 2007. v. 1.

KROPF, S. P. \& SÁ, M. R. The discovery of Trypanosoma cruzi and Chagas disease (1908-1909): tropical medicine in Brazil. História, Ciências, Saúde Manguinhos, 16, supl. 1: 13-34, 2009.

LABRA, M. E. O Movimento Sanitarista nos Anos 20: da conexão sanitária internacional à especialização em saúde pública no Brasil, 1985. Dissertação de Mestrado, Rio de Janeiro: Escola Brasileira de Administração Pública, Fundação Getúlio Vargas.

LACERDA, A. L. Fotografia e valor documentário: o arquivo de Carlos Chagas. História, Ciências, Saúde Manguinhos, 16, supl.: 115-138, 1, 2009.

LASSANCE e sua história. In: Tribuna do Povo Online. Disponível em: < tribunadopovo.net/ tribuna_do_povo/lassance/festa1.htm $>$. Acesso em: 10 mar. 2009.

LIMA, N. T. Missões civilizatórias da República e interpretação do Brasil. História, Ciências, Saúde Manguinhos, 5, supl.: 163-193, 1998.

LIMA, N. T. Um Sertão Chamado Brasil: intelectuais e representação geográfica da identidade nacional. Rio de Janeiro: Revan, Iuperj, 1999.

LIMA, N. T. Viagem científica ao coração do Brasil: nota sobre o relatório da expedição de Arthur Neiva e Belisário Penna à Bahia, Pernambuco, Piauí e Goiás. Revista da Fundação Museu do Homem Americano, 1(3): 185-215, 2003.

LIMA, N. T. \& BRITTO, N. Salud y nación: propuesta para el saneamiento rural - un estudio de la revista Saúde (1918-1919). In: CUETO, M. (Ed.). Salud, Cultura y Sociedad en América Latina: nuevas perspectivas históricas. Lima: IEP, Organización Panamericana de la Salud, 1996.

LIMA, N. T. \& HOCHMAN, G. Condenado pela raça, absolvido pela medicina: o Brasil descoberto pelo movimento sanitarista da Primeira República. In: 
MAIO, M. \& SANTOS, R. V. (Orgs.). Raça, Ciência e Sociedade. Rio de Janeiro: Editora Fiocruz, Centro Cultural Centro do Brasil, 1996.

LIMA, N. T. \& HOCHMAN, G. Pouca saúde e muita saúva: sanitarismo, interpretações do país e ciências sociais. In: HOCHMAN, G. \& ARMUS, D. (Orgs.). Cuidar, Controlar, Curar: ensaios históricos sobre saúde e doença na América Latina. Rio de Janeiro: Editora Fiocruz, 2004.

LOBATO, M. Mr. Slang e o Brasil e Problema Vital. 7. ed. São Paulo: Brasiliense, 1956.

MAGALHÃES, O. Un Poco da la vida de Carlos Chagas. Mendoza: Best Hermanos, 1944.

MANSON, P. Tropical Diseases. London: Cassell, 1903.

MANSON-BAHR, F. H. Enfermedades Tropicales. Barcelona: Salvat, 1924.

MARCHOUX, E. Notice Nécrologique sur Carlos Chagas (de Rio de Janeiro) (1879-1934). Paris: Masson et Cie., 1934.

MARCHOUX, E. Carlos Chagas. A Folha Médica, 27(21): 313-314, 1936.

MAUAD, A. M. Através da imagem: fotografia e história interfaces. Tempo, 1(2): 73-98, 1996.

MELLO E SILVA, M. C. S. Avaliação de documentos de interesse para a história da ciência. In: ENCONTRO DE ARQUIVOS CIENTÍFICOS, 1, 20-21 out. 2003, Rio de Janeiro. Anais... Rio de Janeiro: Edições Casa de Rui Barbosa, 2006.

MENDONÇA, H. T. L. Memória Arquitetônica de Oliveira. Belo Horizonte: Imprensa Oficial, 1987.

MENESES, U. T. B. A fotografia como documento. Robert Capa e o miliciano abatido na Espanha: sugestões para um estudo histórico. Tempo (7)14: 131-151, 2003.

MENESES, U. T. B. Fontes visuais, cultura visual, história visual. Balanço provisório, propostas cautelares. Revista Brasileira de História, (23) 45: 11-36, 2003.

NAVA, P. Chão de Ferro. Rio de Janeiro: José Olympio, 1976.

NEIVA, A. Informações sobre a biolojia do Conorhinus megistus Burm. Memórias do Instituto Oswaldo Cruz, 2(2): 206-212, 1910.

NEIVA, A. \& PENNA, B. Viajem cientifica pelo norte da Bahia, sudoeste de Pernambuco, sul do Piauhí e de norte a sul de Goiaz. Memórias do Instituto Oswaldo Cruz, 8(3): 74-224, 1916.

O BRASIL. Trepanosoma e... ciumadas... O Brasil, Rio de Janeiro, 18 nov. 1923.

O GLOBO. Estará desmerecendo a fama de Manguinhos? Alastra-se a variola apezar da vaccina. Ha medicos que reclamam contra a inefficacia daquelle recurso official. Mexa-se e fale, Sr. Dr. Carlos Chagas. O Globo, Rio de Janeiro, 29 mar. 1926, p. 1.

O GLOBO. Mala da Europa. O Globo, Rio de Janeiro, 7 abr. 1926, p. 1.

O IMPARCIAL. O novo director do Instituto Oswaldo Cruz. Foi nomeado hontem o dr. Carlos Chagas. Uma entrevista com o eminente scientista. O Imparcial, Rio de Janeiro, 15 fev. 1917, p. 5.

O IMPARCIAL. Memoravel sessão da Academia Nacional de Medicina. O Dr. Carlos Chagas expõe serenamente, á luz da verdade scientifica, os seus estudos sobre a trypanosomiase americana. O Imparcial, Rio de Janeiro, 7 dez. 1923, p. 1.

O JORNAL. Os serviços do Departamento Nacional de Saude Publica. Vae abrir-se a Escola de Enfermeiras. Nenhuma administração sanitaria moderna pode prescindir do concurso valioso desse orgão de acção. O que nos disse o Dr. Chagas. O Jornal, Rio de Janeiro, 7 abr. 1922, p. 3.

O JORNAL. A doença de Cruz e Chagas. O Jornal, Rio de Janeiro, 17 dez. 1922, p. 6.

O MALHO. Saneamento da baixada do Rio. O Malho, Rio de Janeiro, 3 set. 1910.

O MALHO. Moléstia 'Carlos Chagas'. O Malho, Rio de Janeiro, 12 ago. 1911.

O MALHO. O Rio apavorado. O Malho, Rio de Janeiro, 23 out. 1918 .

O MALHO. O mal do Chagas. O Malho, Rio de Janeiro, 2 jun. 1923.

O MALHO. E chova arroz... O Malho, Rio de Janeiro, 24 nov. 1923.

O PAIZ. Estrada de Ferro Central. O Paiz, Rio de Janeiro, 6 jun. 1907, p. 1.

O PAIZ. A doença de Carlos Chagas. Uma sessão memorável na Academia Nacional de Medicina. O Paiz, Rio de Janeiro, 31 out. 1910, p. 6.

O PAIZ. O estado sanitario. O Paiz, Rio de Janeiro, 12 fev. 1920 , p. 3.

O PAIZ. Como correu o dia de Einstein. O sabio teutoisraelita visitou o Instituto Oswaldo Cruz e a Escola Politecnica e á noite será recebido pela colônia alemã. O Paiz, 8 maio 1925.

O PORVIR. O progresso do Norte. O Porvir, Curvelo, 29 jun. 1904, p. 2.

OLIVEIRA, B. T.; COSTA, R. G. R. \& PESSOA, A. J. S. Um Lugar para a Ciência: a formação do campus de Manguinhos. 1. ed. Rio de Janeiro: Editora Fiocruz, 2003.

PEIXOTO, A. Discurso pronunciado no banquete oferecido ao prof. Miguel Pereira, em 18 de maio de 1918. In: LEÃO, P. et al (Eds.). Afranio versus Afranio. Niterói: Typ. Jerônimo Silva, 1922.

PEIXOTO, A. Sessão de 6 de dezembro de 1923. Boletim da Academia Nacional de Medicina, 787-789, 1923.

PENNA, B. Discurso na academia. Discurso proferido pelo titular na Academia Nacional de Medicina por ocasião de sua posse como membro honorário. Fundo Belisário Penna, série Trajetória Profissional; 19210915, p. 10-11. (Casa de Oswaldo Cruz/ Fundação Oswaldo Cruz). Rio de Janeiro, 1921.

PENNA, B. Saneamento do Brasil. 2. ed. Rio de Janeiro: Ribeiro dos Santos, 1923.

PEREIRA, M. Sessão ordinária em 13 de outubro de 1910. Anais da Academia de Medicina, (76): 191-197, 1910.

PROGRAMA INTEGRADO DE DOENÇA DE CHAGAS DA FIOCRUZ. Portal Doença de Chagas. Rio de Janeiro: Fundação Oswaldo Cruz, 2007. Disponível em: <www.fiocruz.br/chagas >.

REVISTA DA SEMANA. Sem título. Revista da Semana, Rio de Janeiro, 26 maio 1907.

REVISTA DA SEMANA. A posse do Dr. Carlos Chagas. Duas vezes successor do Dr. Oswaldo Cruz. Revista da Semana, Rio de Janeiro, 11 out. 1919. 
REVISTA DA SEMANA. Uma questão que empolga do mundo medico. Revista da Semana, Rio de Janeiro, 15 dez. 1923.

REVISTA DA SEMANA. Carlos Chagas, o primeiro lente da cadeira de doenças tropicaes. Revista da Semana, Rio de Janeiro, 30 maio 1925.

REZENDE, J. M. Carlos Chagas. Revista Goiana de Medicina, 5(4): 285-302, 1959.

RIO, J. A Alma Encantadora das Ruas. São Paulo: Companhia das Letras, 1997.

ROCHA, I. A doença de Carlos Chagas. Uma sessão memoravel na Academia Nacional de Medicina. O País, Rio de Janeiro, 31 out. 1910, p. 6.

ROUILLÉ, A. La Photographie: entre document et art contemporaine. Paris: Éditions Gallimard, 2005.

SÁ, D. M. A voz do Brasil: Miguel Pereira e o discurso sobre o 'imenso hospital'. História, Ciências, Saúde Manguinhos, 16, supl. 1: 333-348, 2009.

SÁ, M. R. The history of tropical medicine in Brazil: the discovery of Trypanosoma cruzi by Carlos Chagas and the German school of protozoology. Parassitologia, 47(3-4): 309-317, 2005

SAINT-HILAIRE, A. Viagem às Nascentes do Rio São Francisco e pela Província de Goiás. São Paulo: Companhia Editora Nacional, 1944.

SALGADO, J. A. O centenário de Carlos Chagas e a menina Berenice. Memórias do Instituto Oswaldo Cruz, 75 (1-2): 193-195, 1980.

SANTOS, P. R. E. Arquivos de Cientistas: gênese documental e procedimentos de organização. São Paulo: Associação de Arquivistas de São Paulo, 2005.

SANTOS, P. R. E. Entre o Laboratório, o Campo e Outros Lugares: gênese documental e tratamento técnico em arquivos de cientistas, 2002. São Paulo: Dissertação de Mestrado, Faculdade de Filosofia, Letras e Ciências Humanas, Universidade de São Paulo.

SCHWEICKARDT, J. C. \& LIMA, N. T. Os cientistas brasileiros visitam a Amazônia: as viagens científicas de Oswaldo Cruz e Carlos Chagas (1910-1913). História, Ciências, Saúde - Manguinhos, 14, supl.: 15-50, 2007.

SIMPÓSIO INTERNACIONAL DA DESCOBERTA DA DOENÇA DE CHAGAS. Sítio Oficial. Rio de Janeiro: Fundação Oswaldo Cruz, 2009. Disponível em: $<$ www.chagas2009.com.br>.

STEPAN, N. L. Beginnings of Brazilian Science: Oswaldo Cruz, medical research and policy, 1890-1920. New York: Science History Publications, 1976.

STEPAN, N. L. Picturing Tropical Nature. London: Reaktion Books, 2001.

THIELEN, E. V. et al. A Ciência a Caminho da Roça: imagens das expedições científicas do Instituto Oswaldo Cruz ao interior do Brasil entre 1911 e 1913. Rio de Janeiro: Casa de Oswaldo Cruz/Fiocruz, 1991.

VASCONCELLOS, H. F. Molestia de Cruz e Chagas. A conferencia do Dr. Figueiredo de Vasconcellos. Jornal do Commercio, Rio de Janeiro, 21 ago. 1919, p. 6.

VASCONCELLOS, H. F. Molestia de Cruz e Chagas. Conferencia do Dr. Figueiredo de Vasconcellos na Sociedade de Medicina e Cirurgia. Jornal do Commercio, Rio de Janeiro, 23 ago. 1919, p. 6.

VIANNA, G. Contribuição para o estudo da anatomia patolojica da 'Molestia de Carlos Chagas' (esquizotripanoze ou tireoidite parazitaria). Memórias do Instituto Oswaldo Cruz, 3(2): 276-294, 1911.

VIEIRA NETO, M. Lassance: o berço histórico do Dr. Carlos Chagas. Várzea da Palma: s.n., 2003. 


\section{Acervos /Holdings}

Academia Brasileira de Letras (Rio de Janeiro, RJ)

Academia Nacional de Medicina (Rio de Janeiro, RJ)

Arquivo Público Mineiro (Belo Horizonte, MG)

Associação dos Antigos Alunos da Companhia de Jesus (São Paulo, SP)

Biblioteca Pública Estadual Luiz de Bessa (Belo Horizonte, MG)

Casa de Oswaldo Cruz/Fundação Oswaldo Cruz (Rio de Janeiro, RJ)

Coleção Entomológica do Instituto Oswaldo Cruz/Fundação Oswaldo Cruz (Rio de Janeiro, RJ)

Escola de Enfermagem Anna Nery/Universidade Federal do Rio de Janeiro (Rio de Janeiro, RJ)

Família Paula Machado (Rio de Janeiro, RJ)

Fundação Biblioteca Nacional (Rio de Janeiro, RJ)

Fundação Casa de Cultura Carlos Chagas (Oliveira, MG)

Fundação Casa de Rui Barbosa (Rio de Janeiro, RJ)

Instituto Moreira Salles/Coleção Gilberto Ferrez (Rio de Janeiro, RJ)

Museu Histórico Nacional/Instituto do Patrimônio Histórico e Artístico Nacional/Ministério da Cultura (Rio de Janeiro, RJ)

Universidade Federal de São João del-Rei (São João del-Rei, MG) 


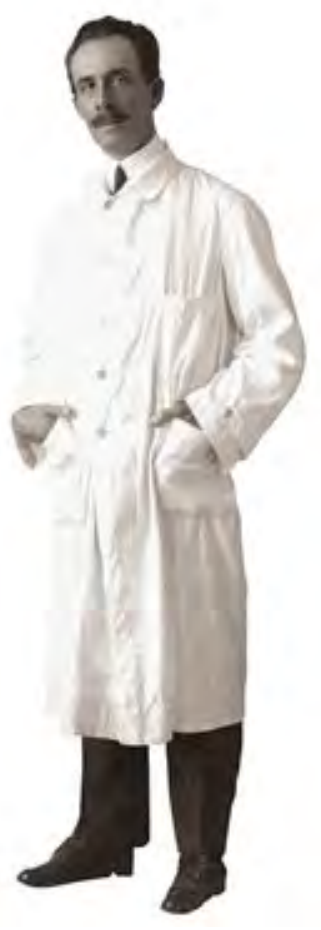




\section{Formato: \\ $31,5 \times 23 \mathrm{~cm}$ \\ Tipologia: \\ miolo/ capa \\ Myriad Pro \\ Stone Serif}

Papel:

Couche fosco $115 \mathrm{~g} / \mathrm{m}^{2}$ (miolo)

Capa:

Couche fosco $170 \mathrm{~g} / \mathrm{m}^{2}$

Cartão Paraná 18

CTP, Impressão e acabamento:

Imprinta Express Gráfica e Editora Ltda

Rio de Janeiro, dezembro de 2009.

Não encontrando nossos títulos em livrarias,

contactar a EDITORA FIOCRUZ:

Av. Brasil, $4036-1^{\circ}$ andar - sala 112 - Manguinhos

21041-361 - Rio de Janeiro - RJ

Tel.: (21) 3882-9039 e 3882-9041

Telefax: (21) 3882-9006

http://www.fiocruz.br/editora

e-mail: editora@fiocruz.br 

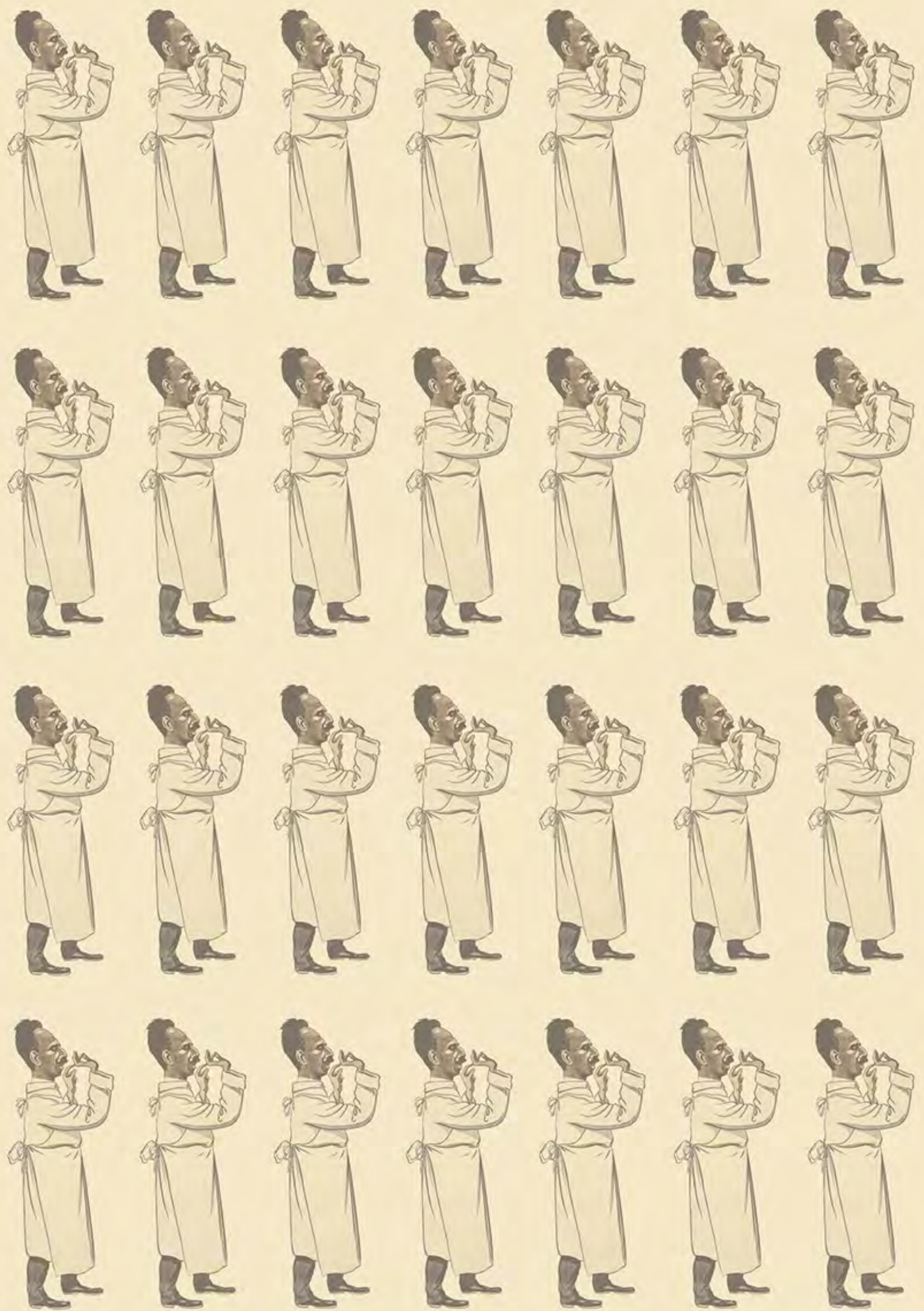

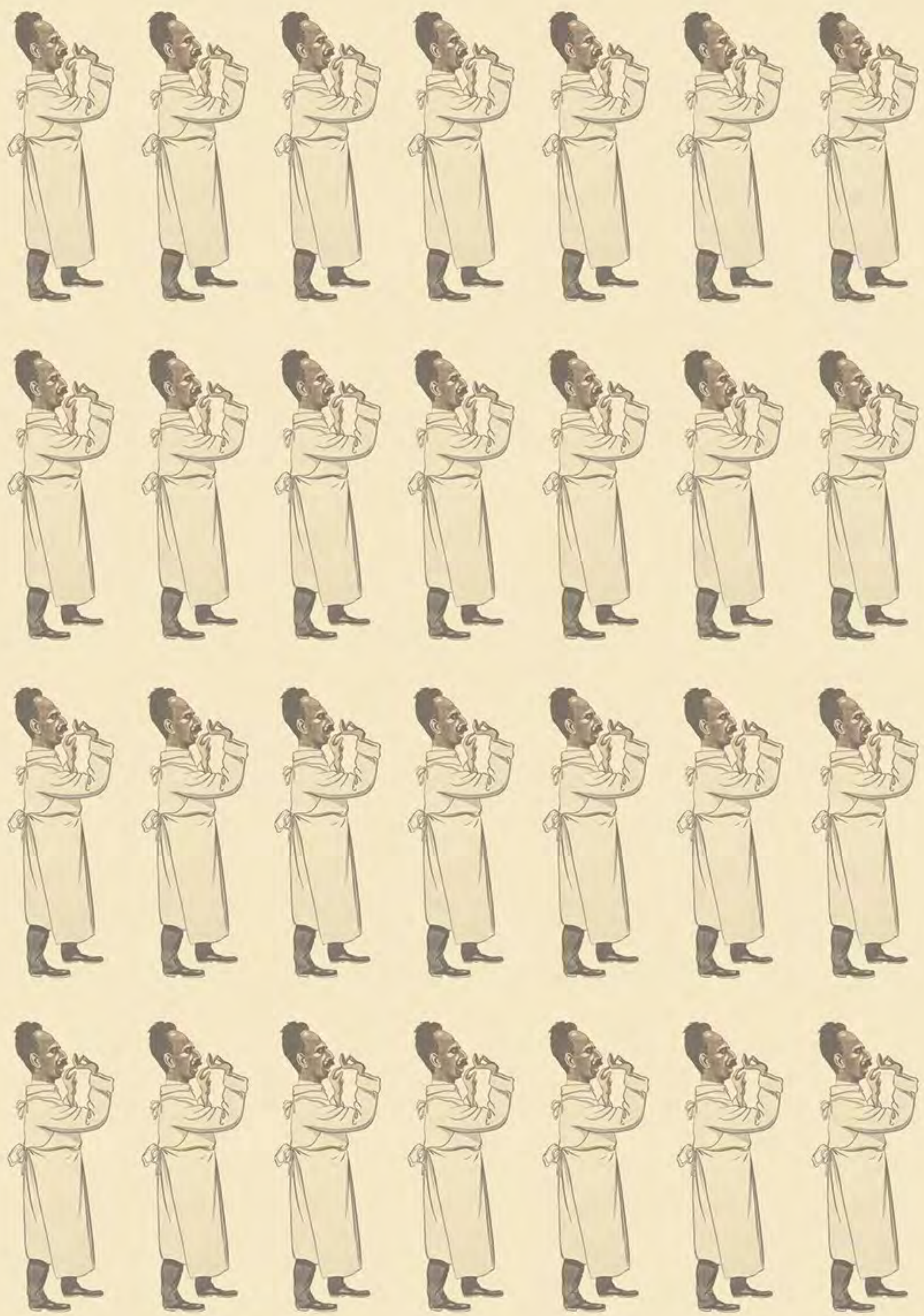

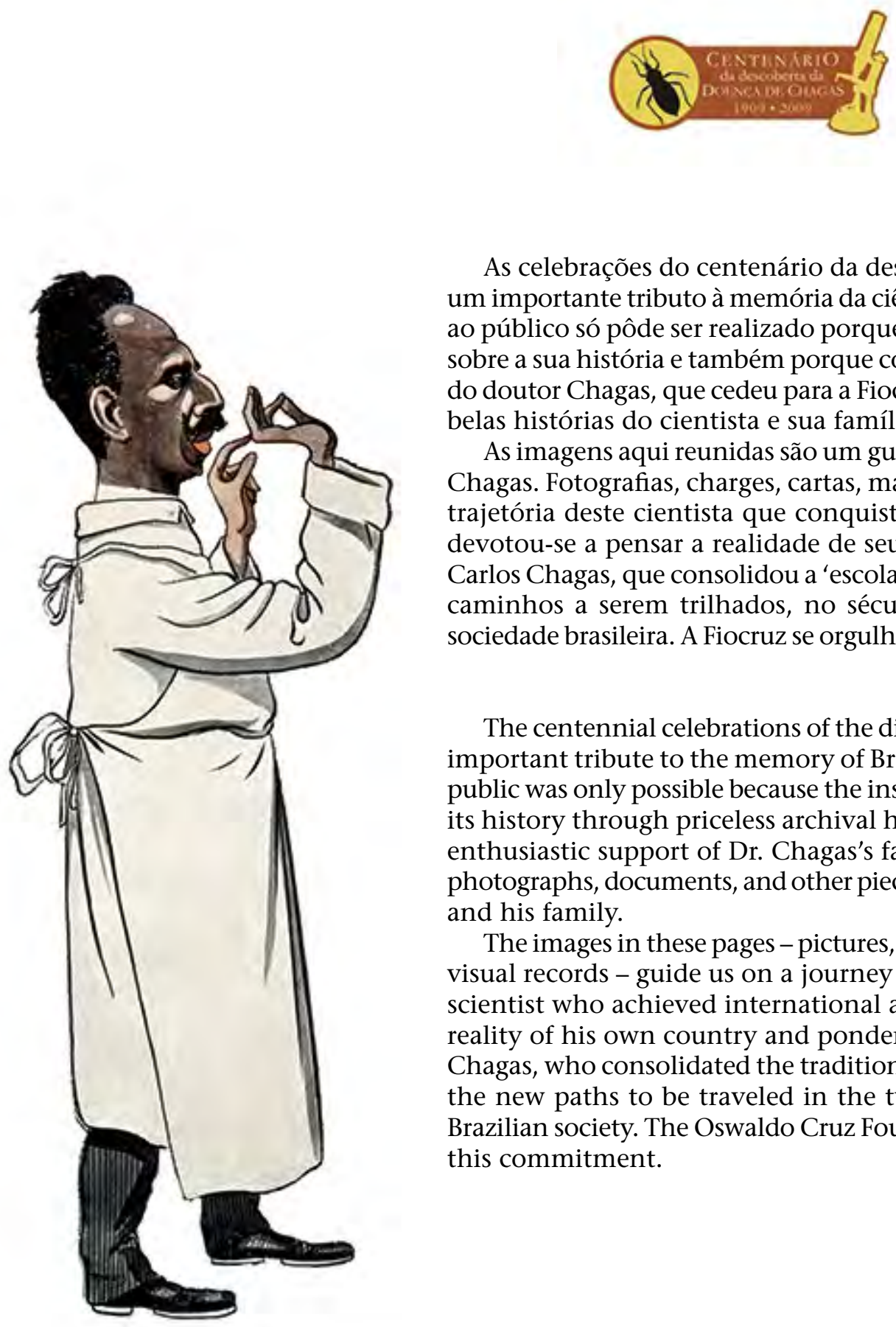

As celebrações do centenário da descoberta da doença de Chagas têm neste álbum um importante tributo à memória da ciência brasileira. O trabalho que agora entregamos ao público só pôde ser realizado porque Manguinhos preservou um acervo inestimável sobre a sua história e também porque contamos com a cumplicidade calorosa da família do doutor Chagas, que cedeu para a Fiocruz fotografias, documentos e peças que contam belas histórias do cientista e sua família.

As imagens aqui reunidas são um guia para acompanharmos a vida e a obra de Carlos Chagas. Fotografias, charges, cartas, matérias de jornal e outros registros visuais sobre a trajetória deste cientista que conquistou renome internacional e, ao mesmo tempo, devotou-se a pensar a realidade de seu país e os meios de transformá-la. O legado de Carlos Chagas, que consolidou a 'escola' de Oswaldo Cruz, nos faz refletir sobre os novos caminhos a serem trilhados, no século 21, por uma ciência comprometida com a sociedade brasileira. A Fiocruz se orgulha de ser parte dessa história e desse compromisso.

The centennial celebrations of the discovery of Chagas disease stand enriched by this important tribute to the memory of Brazilian science. The book we now present to the public was only possible because the institute long known as Manguinhos has preserved its history through priceless archival holdings and because this endeavor enjoyed the enthusiastic support of Dr. Chagas's family, who gave the Oswaldo Cruz Foundation photographs, documents, and other pieces which tell wonderful stories about the scientist and his family.

The images in these pages - pictures, cartoons, letters, newspaper clippings, and other visual records - guide us on a journey through the life and career of Carlos Chagas, a scientist who achieved international acclaim while devoting himself to studying the reality of his own country and pondering ways to transform it. The legacy of Carlos Chagas, who consolidated the tradition forged by Oswaldo Cruz, sets us to reflecting on the new paths to be traveled in the twenty-first century by a science committed to Brazilian society. The Oswaldo Cruz Foundation is proud to be part of this history and of this commitment.

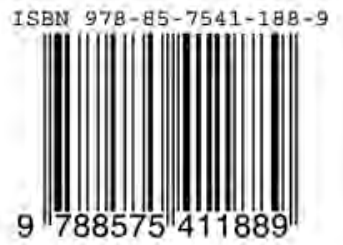

